NIST NCSTAR 1-5G

Federal Building and Fire Safety Investigation of the World Trade Center Disaster

\title{
Fire Structure Interface and Thermal Response of World Trade Center Towers
}

Kuldeep Prasad

Howard Baum 

NIST NCSTAR 1-5G

Federal Building and Fire Safety Investigation of the World Trade Center Disaster

\section{Fire Structure Interface and Thermal Response of the World Trade Center Towers}

Kuldeep Prasad

Howard Baum

Building and Fire Research Laboratory

National Institute of Standards and Technology

September 2005

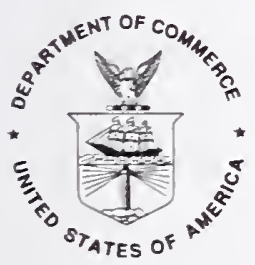

U.S. Department of Commerce

Carlos M. Gutierrez, Secretary

Technology Administration

Michelle O'Neill, Acting Under Secretary for Technology

National Institute of Standards and Technology

William Jeffrey, Director 


\title{
Disclaimer No. 1
}

Certain commercial entities, equipment, products, or materials are identified in this document in order to describe a procedure or concept adequately or to trace the history of the procedures and practices used. Such identification is not intended to imply recommendation, endorsement, or implication that the entities, products, materials, or equipment are necessarily the best available for the purpose. Nor does such identification imply a finding of fault or negligence by the National Institute of Standards and Technology.

\section{Disclaimer No. 2}

The policy of NIST is to use the International System of Units (metric units) in all publications. In this document, however, units are presented in metric units or the inch-pound system, whichever is prevalent in the discipline.

\section{Disclaimer No. 3}

Pursuant to section 7 of the National Construction Safety Team Act, the NIST Director has determined that certain evidence received by NIST in the course of this Investigation is "voluntarily provided safety-related information" that is "not directly related to the building failure being investigated" and that "disclosure of that information would inhibit the voluntary provision of that type of information" (15 USC 7306c).

In addition, a substantial portion of the evidence collected by NIST in the course of the Investigation has been provided to NIST under nondisclosure agreements.

\section{Disclaimer No. 4}

NIST takes no position as to whether the design or construction of a WTC building was compliant with any code since, due to the destruction of the WTC buildings, NIST could not verify the actual (or as-built) construction, the properties and condition of the materials used, or changes to the original construction made over the life of the buildings. In addition, NIST could not verify the interpretations of codes used by applicable authorities in determining compliance when implementing building codes. Where an Investigation report states whether a system was designed or installed as required by a code provision, NIST has documentary or anecdotal evidence indicating whether the requirement was met, or NIST has independently conducted tests or analyses indicating whether the requirement was met.

\section{$\underline{\text { Use in Legal Proceedings }}$}

No part of any report resulting from a NIST investigation into a structural failure or from an investigation under the National Construction Safety Team Act may be used in any suit or action for damages arising out of any matter mentioned in such report (15 USC 281a; as amended by P.L. 107-231).

National Institute of Standards and Technology National Construction Safety Team Act Report 1-5G Natl. Inst. Stand. Technol. Natl. Constr. Sfty. Tm. Act Rpt. 1-5G, 338 pages (September 2005) CODEN: NSPUE2

\author{
U.S. GOVERNMENT PRINTING OFFICE \\ WASHINGTON: 2005
}

For sale by the Superintendent of Documents, U.S. Government Printing Office

Internet: bookstore.gpo.gov — Phone: (202) 512-1800 — Fax: (202) 512-2250

Mail: Stop SSOP, Washington, DC 20402-0001 
The collapse of the World Trade Center (WTC) towers on September 11, 2001, resulting from a combination of aircraft impact damage and subsequent fires, was studied as part of the Federal Building and Fire Safety Investigation of the WTC Disaster. This report documents the evolving thermal state of the structure on the focus floors of each tower. A methodology was developed to couple the thermal response of the towers to the fire dynamic simulations. Heat transfer to sub-grid scale structural elements was computed using a simple radiative transport model that assumes the compartment can be locally divided into a hot, sooty upper layer and a cool relatively clear lower layer. Properties of the two layers were extracted from temporal averages of the results of the fire simulations. The model predictions were found to compare favorably with measurements from a series of large-scale experiments. Exploratory studies were conducted to estimate the role of fireproofing thickness and sensitivity of the results to input parameters. The methodology was subsequently used extensively in National Institute of Standards and Technology's (NIST's) WTC Investigation to predict the thermally induced structural response to spatially and temporally developing fires. Finite element models were constructed for the steel structural elements and the fireproofing that covers the floor trusses, core beams, perimeter and core columns as well as the concrete slab on floors 92-99 of the North Tower and floors 78-83 of the South Tower. Structural and fireproofing damage due to aircraft impact on the various floors of each tower was incorporated into the models. The three dimensional time dependent thermal response of the structural elements was generated in a format that is consistent with the structural models and the finite element analysis software. Four global simulations, two each for WTC 1 and WTC 2 are reported for prediction of thermally induced structural response and collapse of the towers. Based on the results of the global simulations, fireproofing thickness and fireproofing damage due to aircraft impact was identified as the single most important parameter that had the largest effect on steel temperature and on the thermally induced structural response.

Keywords: Fire Structure Interface, fireproofing thickness, radiative heat transfer, World Trade Center. 
This page intentionally left blank. 


\section{TABLE OF CONTENTS}

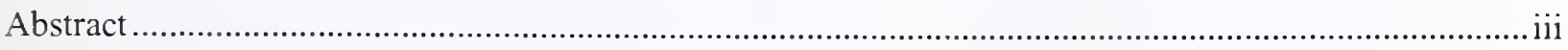

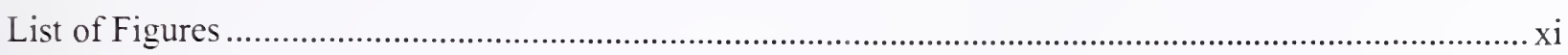

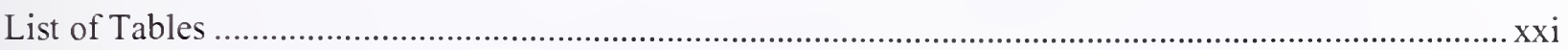

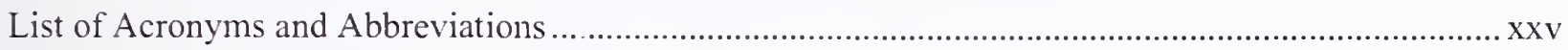

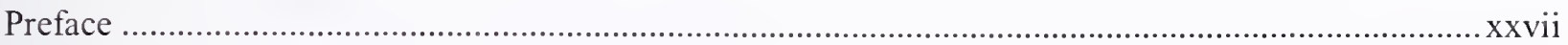

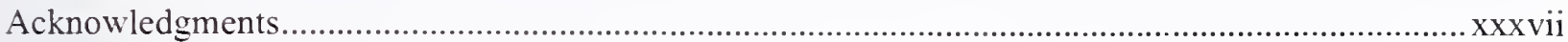

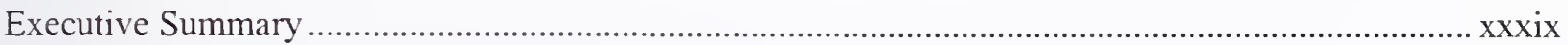

\section{Chapter 1}

Sub-Grid Scale Model for Radiative Heat Transfer ......................................................... 1

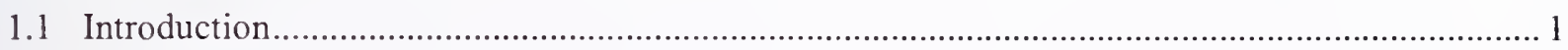

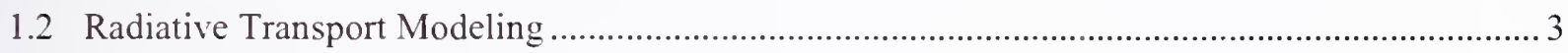

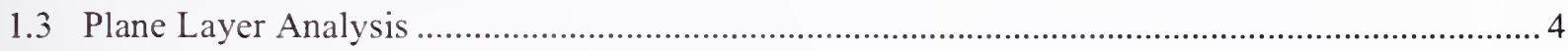

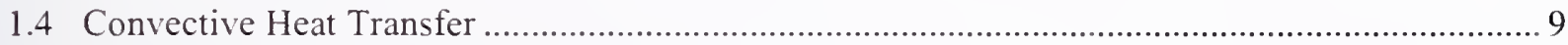

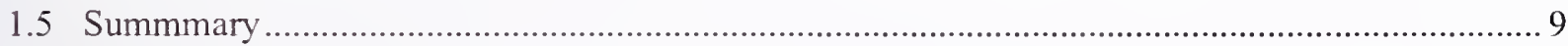

\section{Chapter 2}

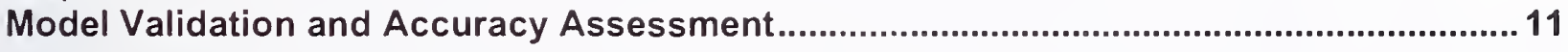

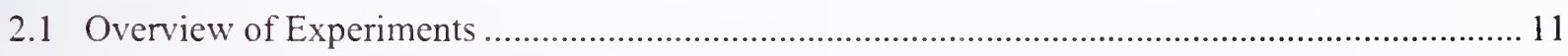

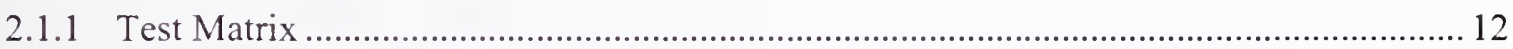

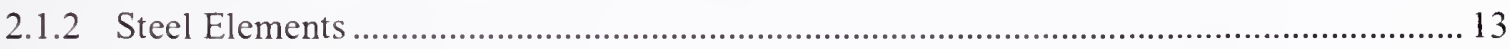

2.1.3 Sprayed Coating of the Steel ........................................................................... 13

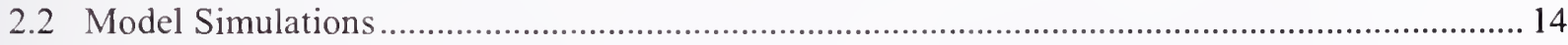

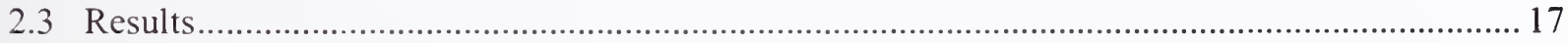

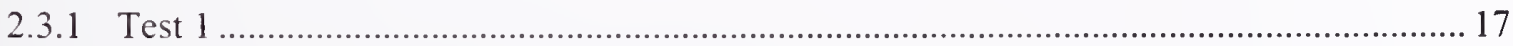

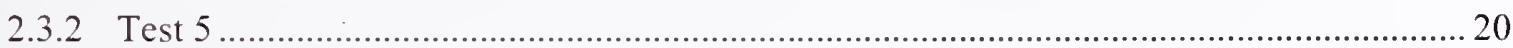

2.3.3 Quantification of Agreement between Models and Measurements................................ 24

2.3.4 Experimental Uncertainty and Model Sensitivity of the Steel Temperatures ................... 25

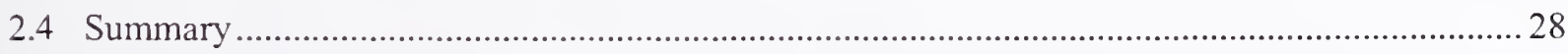

\section{Chapter 3}

Exploratory Studies on Thermal Response of Structural Elements .................................29

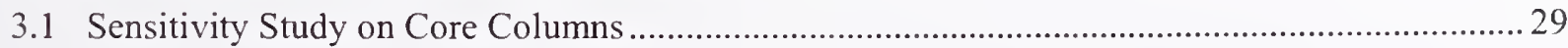


3.1.1 Light Box Shape Core Columns ............................................................................. 29

3.1.2 Heavy Box Shape Core Columns ....................................................................... 33

3.2 Statistical Variability in Fireproofing Thickness .................................................................. 34

3.3 Selective Fireproofing Damage on One Face of the Column ................................................. 35

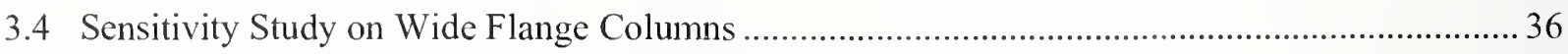

3.5 Sensitivity of Thermal Response to Fireproofing Geometry ................................................ 37

\section{Chapter 4}

Perimeter Columns ................................................................................................55

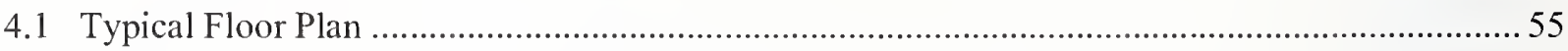

4.2 Finite Element Models of the Perimeter Column and Fireproofing ......................................... 55

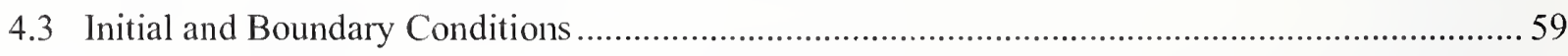

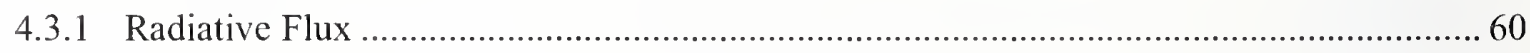

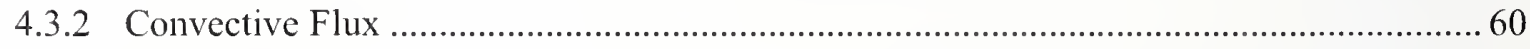

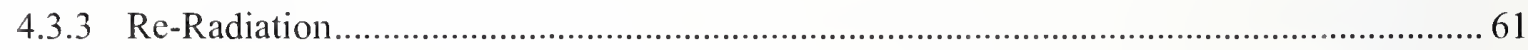

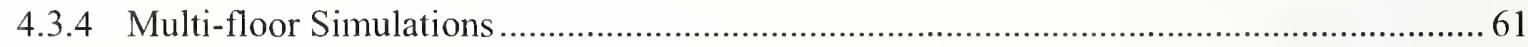

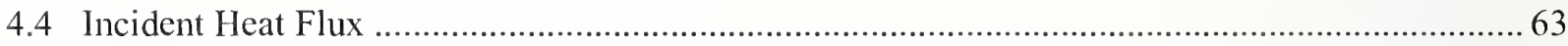

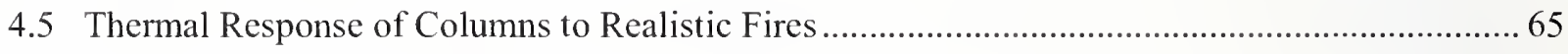

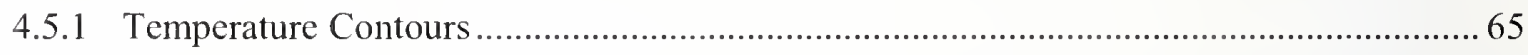

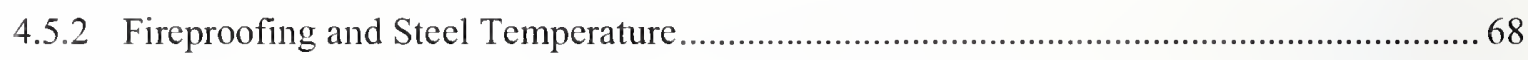

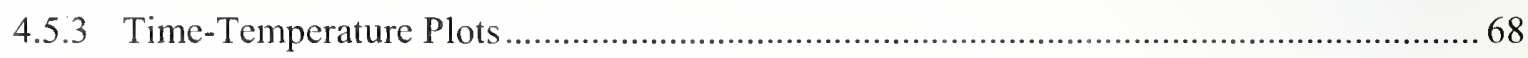

4.6 Modeling Fireproofing and Structural Damage on Perimeter Columns ................................... 71

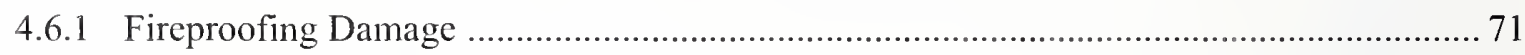

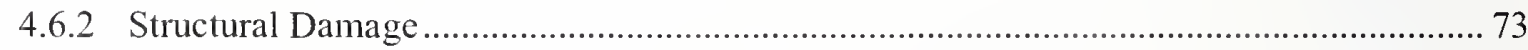

4.7 Interface between Thermal and Structural Models........................................................... 74

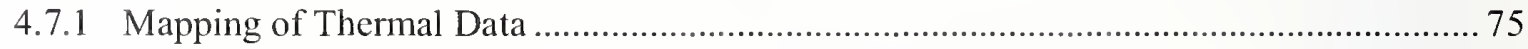

4.7.2 Procedure for Mapping Thermal Data onto the Structural Model................................. 76

4.7.3 Full Floor and Multiple Floor Mapping of Thermal Data ......................................... 78

\section{Chapter 5}

Floor Trusses and Core Beams ......................................................................................... 81

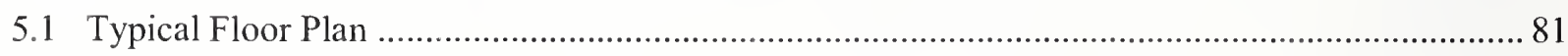

5.2 Finite Element Model of the Floor Truss......................................................................... 82

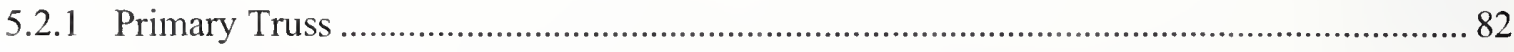

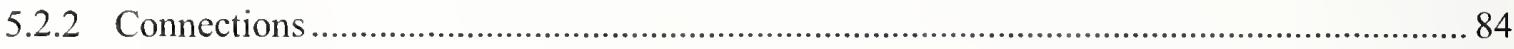

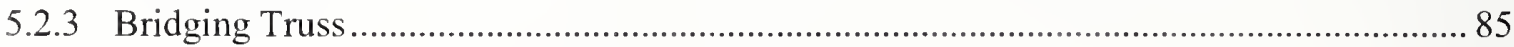




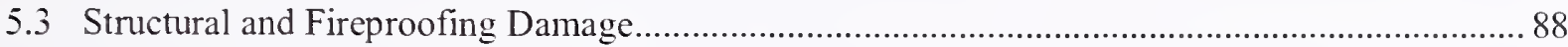

5.3.1 Incorporating Structural Damage on Floor Trusses or Core Beams................................. 88

5.3.2 Incorporating Fireproofing Damage on Trusses or Core Beams.................................... 88

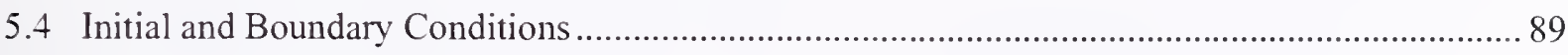

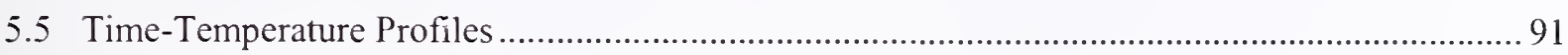

5.6 Interface between Thermal and Structural Models ............................................................. 92

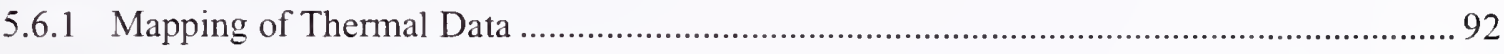

5.6.2 Procedure for Mapping Thermal Data....................................................................... 93

\section{Chapter 6}

Concrete Slabs

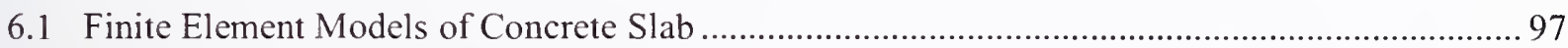

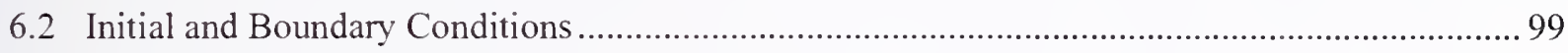

6.3 Temperature and Temperature Gradient in Concrete Slab ............................................... 103

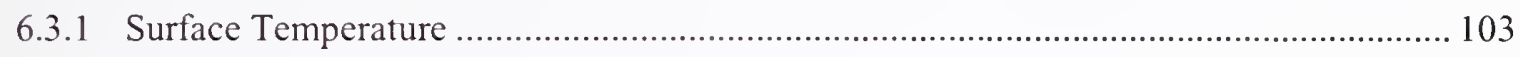

6.3.2 Temperature Profiles through the Concrete Slab ...................................................... 104

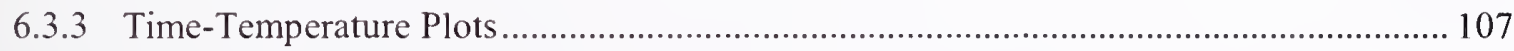

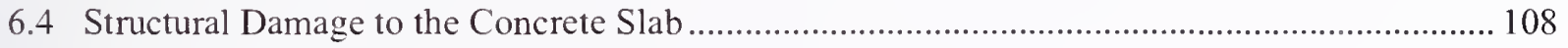

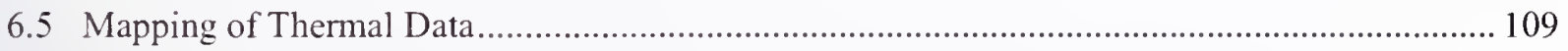

\section{Chapter 7}

Core Columns

7.1 Finite Element Model for Core Columns...................................................................... 111

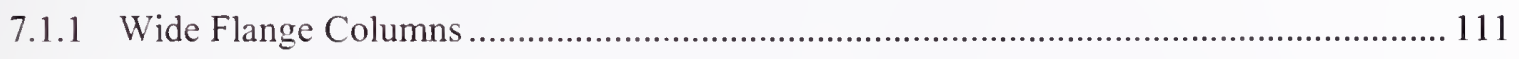

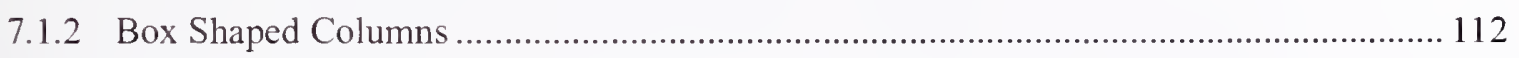

7.1.3 Fireproofing Thickness for Core Columns ............................................................ 113

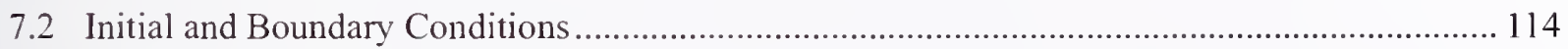

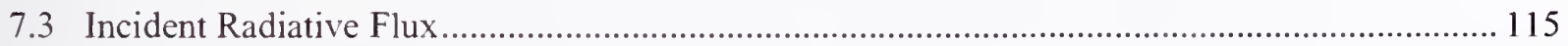

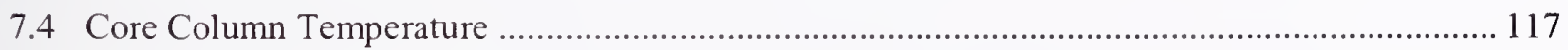

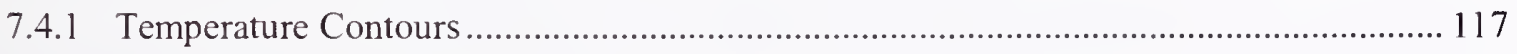

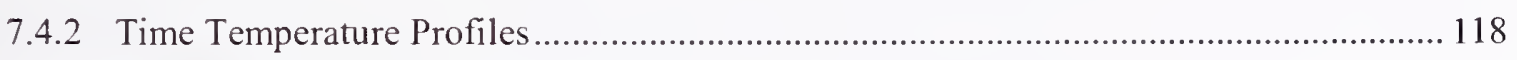

7.5 Fireproofing and Structural Damage on Core Columns ................................................ 123

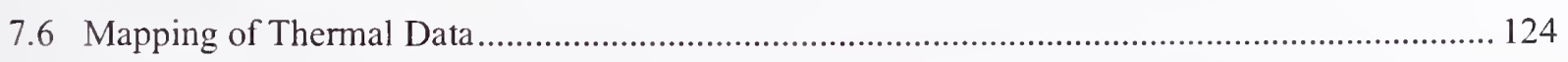

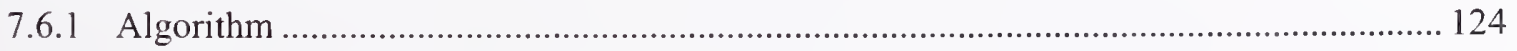

7.6.2 Full Floor Mapping of Thermal Data ................................................................... 124 


\section{Chapter 8}

Global Thermal Response of WTC 1: Case A.

8.1 Overview

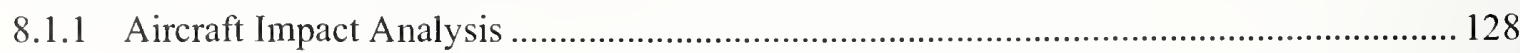

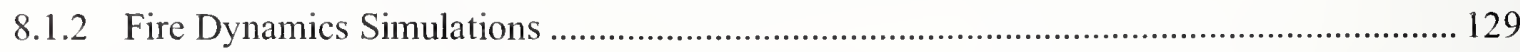

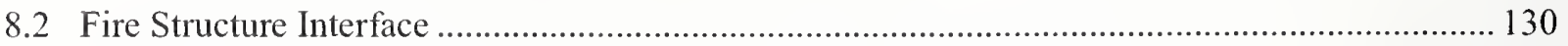

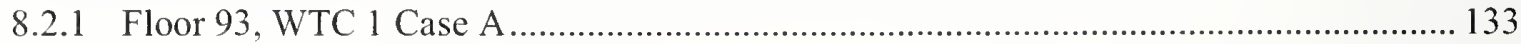

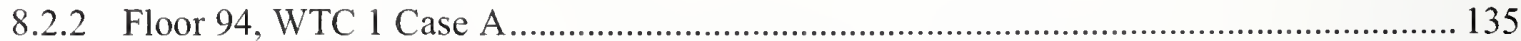

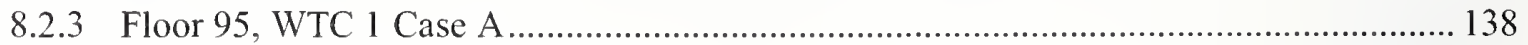

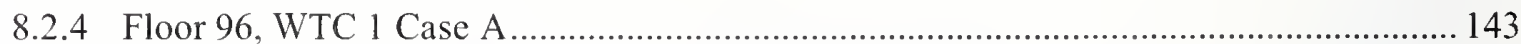

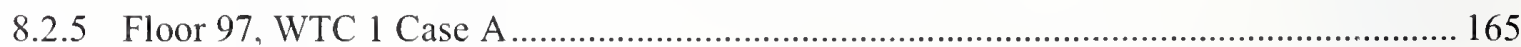

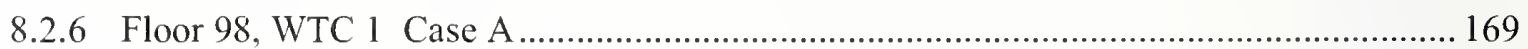

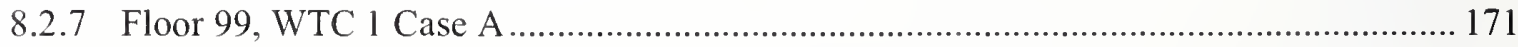

8.3 Data Transfer for Structural Analysis .................................................................................... 171

\section{Chapter 9}

Global Thermal Response of WTC 1: Case B......................................................................179

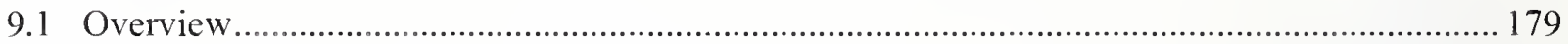

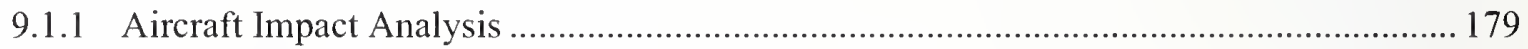

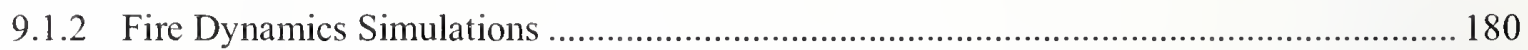

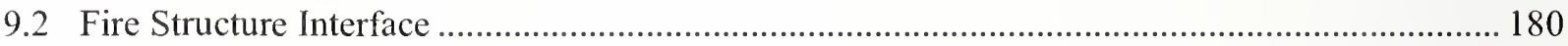

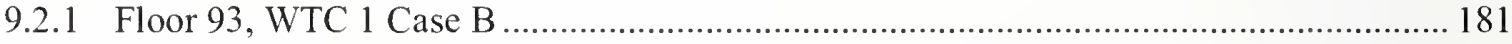

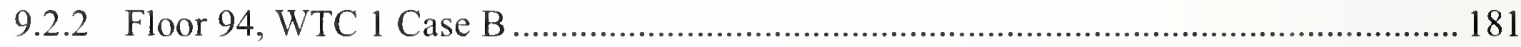

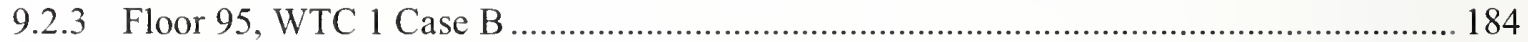

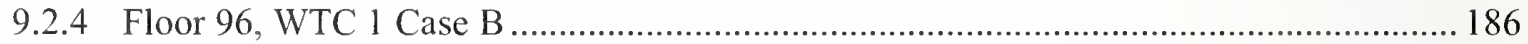

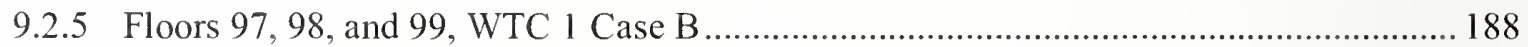

9.3 Data Transfer for Structural Analysis ................................................................................ 189

\section{Chapter 10}

Global Thermal Response of WTC 2 : Case C.................................................................... 199

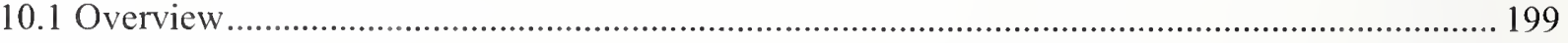

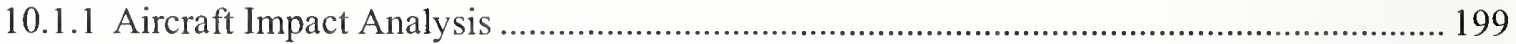

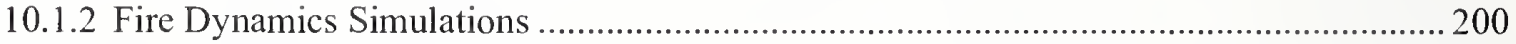

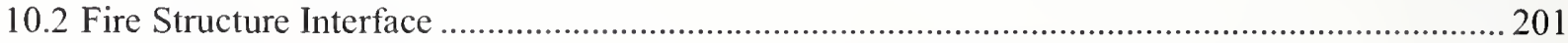

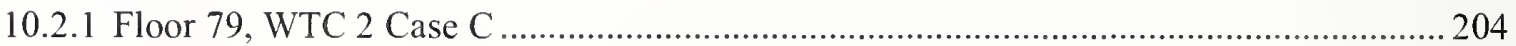

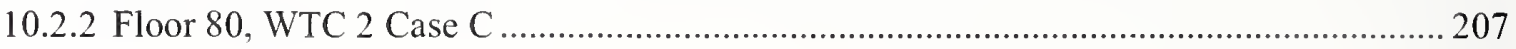


10.2.3 Floor 81, WTC 2 Case C ...................................................................................... 210

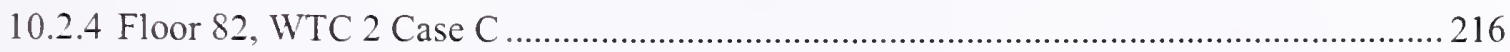

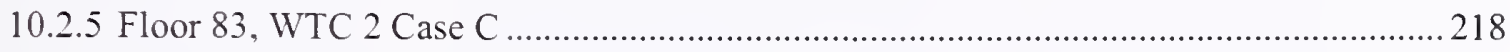

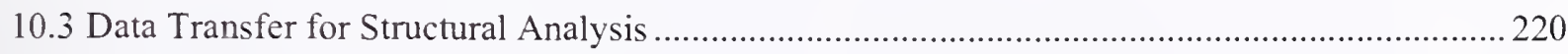

\section{Chapter 11}

Global Thermal Response of WTC 2 : Case D................................................................2229

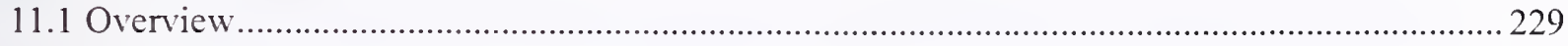

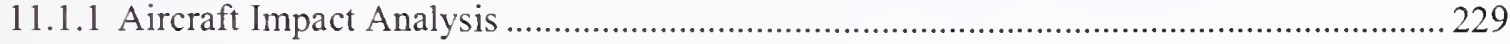

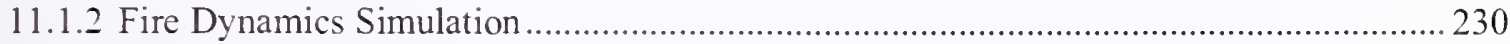

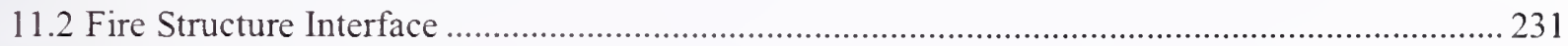

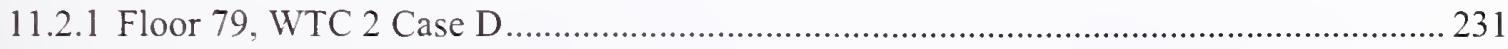

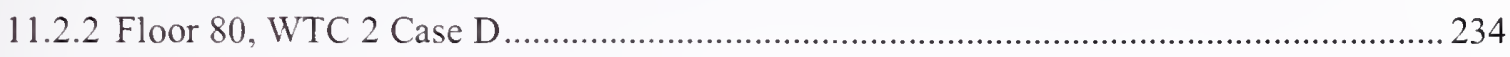

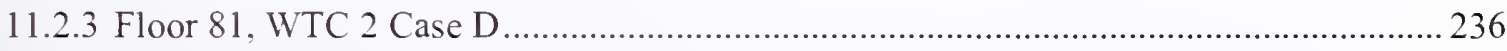

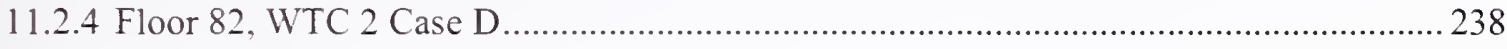

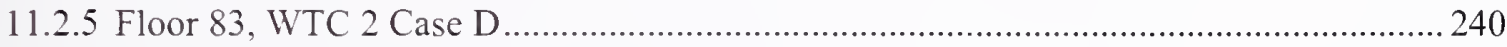

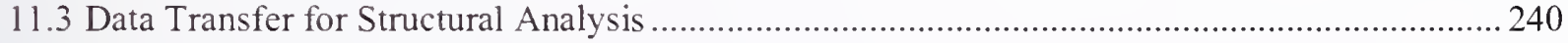

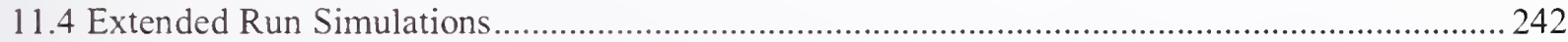

\section{Chapter 12}

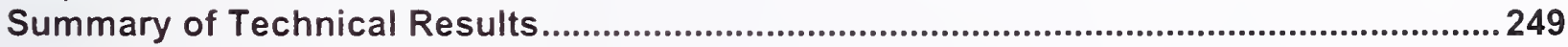

12.1 Global Thermal Response of the World Trade Center Towers..............................................2250

12.2 Global Thermal Response of WTC 1 : Comparison of Case A and Case B ............................252

12.3 Global Thermal Response of WTC 2 : Comparison of Case C and Case D ............................261

\section{Chapter 13}

References.

\section{Appendix A}

Thermo-physical Properties

\section{Appendix B}

Column Schedule. 
This page intentionally left blank. 


\section{LIST OF FIGURES}

Figure P-1. The eight projects in the federal building and fire safety investigation of the WTC disaster. xxix

Figure 1-1. Computed upper layer temperatures as predicted from an FDS simulation for World Trade Center Tower 1, Floor 96. The temperature contours (in degree C) are shown at 1,000 seconds after the impact of the airplane.

Figure 1-2. Schematic of a two-layer model of a fire environment showing a hot layer at temperature $T_{H}$ and absorption coefficient $\kappa_{H}$

Figure 1-3. Dimensionless heat fluxes, Q, showing profiles as a function of dimensionless height, $Z$, for a downward facing surface (bottom curve) and upward facing surface (top curve).

Figure 1-4. Dimensionless heat fluxes showing profiles as a function of dimensionless hcight, Z. The flux profiles correspond to values of dimensionless optical depth.

Figure 2-1. Schematic drawing of compartment contents.

Figure 2-2. Finite element model for the $3.05 \mathrm{~m}(10.0 \mathrm{ft})$ long steel bar, showing the elements distributed uniformly along the length of the bar. Figure on the right exhibits a crosssectional view of the bar showing mesh density.

Figure 2-3. Finite element representation of the insulated steel truss (blue), the SFRM (violet), and the ceiling (red) used in the thermal analysis of Test 5.

Figure 2-4. Top view of the finite element model of the steel column with SFRM. 16

Figure 2-5. Snapshot of the numerical simulation showing the fire and a contour plot of the gas temperature along the compartment centerline, looking toward the north wall.

Figure 2-6. Comparison of numerical simulations with measurements for the steel surface temperature at four locations on Bar $\mathrm{A}$ in Test 1.

Figure 2-7. Comparison of numerical simulations with measurements for the stecl surface temperature at four locations $3.70 \mathrm{~m}$ above the floor on Truss A in Test 1.

Figure 2-8. Comparison of numerical simulations with measurements for the steel surface tcmperature at four locations $3.69 \mathrm{~m}$ above the floor on the column in Test 1

Figure 2-9. Comparison of numerical simulations with measurements for the steel surface temperature at four locations $2.13 \mathrm{~m}$ above the floor on the column in Test 1.

Figure 2-10. Comparison of numerical simulations with measurements for the temperature of the SFRM surface at four locations on the insulated bar in Test 5.

Figure 2-11. Comparison of numerical simulations with measurements for the temperature of the steel surface at four locations on the insulated bar in Test 5 . 
Figure 2-12. Comparison of numerical simulations with measurements for the temperature of the SFRM surface at four locations, $3.69 \mathrm{~m}$ above the floor on the insulated steel column in Test 5 .

Figure 2-13. Comparison of numerical simulations with measurements for the temperature of the steel surface at four locations, $3.69 \mathrm{~m}$ above the floor on the insulated steel column in Test 5 .

Figure 2-14. Comparison of numerical simulations with measurements for the temperature of the steel surface at four locations $3.70 \mathrm{~m}$ above the floor on Truss A in Test 5.

Figure 2-15. Comparison of numerical simulations with measurements for the temperature of the steel surface at four locations $3.70 \mathrm{~m}$ above the floor on Truss A in Test 5 .

Figure 3-1. Finite element model of light box shape core column (left) and temperature contours (Kelvin) at one instant in time.

Figure 3-2. Non-dimensional yield strength as a function of temperature for typical steel used in WTC tower (NIST NCSTAR 1-3)

Figure 3-3. Finite element model of heavy box shape core column (left) and temperature contours (Kelvin) at one instant in time.

Figure 3-4. Effect of statistical variability in fireproofing thickness on steel temperature Temperature contours have been shown in Kelvin.

Figure 3-5. Effect of fireproofing damage on one face of a heavy core column. Temperature contours have been shown in Kelvin.

Figure 3-6. Example of variability in fireproofing thickness and "gap" in fireproofing on diagonal member of a bridging floor truss

Figure 3-7. Model used to study effects of fireproofing thickness and variability of thickness on steel temperature: a) physical model used in analyses (points 1-5 are sensor locations where temperature are monitored); b) finite element mesh used to represent physical model.

Figure 3-8. Finite element model to represent thickness of fireproofing (purple). The elements in red represent a material that provides no resistance to heat flow (very high thermal conductivity and very low thermal inertia).

Figure 3-9. Variation of steel temperature at Sensor Location \#1 with time for different average thickness of fireproofing (shown as numbers on the curves). The fireproofing thickness is uniform over the entire length.

Figure 3-10. Finite element model for studying the effect of gap in fireproofing thickness a) location of the gap on the plate b) temperature contours at one instant in time.

Figure 3-11. Temperature at Sensor Location \#1 plotted as a function of time for various insulation thickness, standard deviation and gap size.

Figure 3-12. Temperature at Sensor Location \#2 plotted as a function of time for various insulation thickness, standard deviation and gap size.

Figure 3-13. Temperature at Sensor Location \#3 plotted as a function of time for various insulation thickness, standard deviation and gap size. 
Figure 3-14. Temperature at Sensor Location \#4 plotted as a function of timc for various insulation thickness, standard deviation and gap size.

Figure 3-15. Temperature at Sensor Location \#5 plotted as a function of time for various insulation thickness, standard deviation and gap size.

Figure 3-16. Temperature as function of length along the bar for various insulation thickncss.

Results are shown at 30 min after application of radiative flux.

Figure 3-17. Temperature as function of length along the bar for various insulation thickness.

Results are shown at $60 \mathrm{~min}$ after application of radiative flux

Figure 3-18. Temperature as function of length along the bar for various insulation thickness.

Results are shown at $90 \mathrm{~min}$ after application of radiative flux 52

Figure 3-19. Temperature as function of length along the bar for various insulation thickness. Results are shown at $120 \mathrm{~min}$ after application of radiative flux.

Figure 3-20. Sensitivity of results to various input parameters.

Figure 4-1. Representative floor plan of the exterior wall and column layout for WTC 1 and WTC 2

Figure 4-2. Finite element model of a box shape perimeter column (Column Type 120) showing the exterior faces. Cyan colored elements have material attributes of steel, while the violet colored elements have material attributes of fireproofing (BLAZE-SHIELD DC/F).

Figure 4-3. Finite element model of box shape perimeter column (Column Type 120) showing the interior faces. Cyan colored elements have material attributes of steel, violet colored elements have material attributes of fireproofing (BLAZE-SHIELD DC/F) and pink colored elements have material attributes of Vermiculite plaster. 58

Figure 4-4. Finite element mesh used to model a typical perimeter column. Figure shows the density of the mesh elements in the column and spandrel beam.

Figure 4-5. Finite element mesh used to model a typical perimeter column. Figure shows the density of the mesh elements in the column.

Figure 4-6. Heat flux boundary conditions were applied on the interior faces of the pcrimeter column as indicated by the arrows. The intensity of the incident flux varies with time and space.

Figure 4-7. Convective flux boundary conditions indicated by arrows were applied to all the exposed faces of the perimeter column.

Figure 4-8. Arrows indicate the surfaces used for modeling re-radiation within the cavity of a perimeter column.

Figure 4-9. Boundary conditions on a typical perimeter column

Figure 4-10. Heat flux incident on the inner faces of a perimeter column as a function of time. Plots are shown for Column 145 on floor 96, WTC 1 at 1,000, 2,000, 3,000, 4,000 5,000 and $6,000 \mathrm{~s}$ after impact.

Figure 4-11. Incident heat flux at 6,000 s after impact for perimeter columns 145, 230, 330 and 430 on floor 96 (WTC 1). Partial results from one fire simulation have been used to illustrate the nature of the coupling process 
Figure 4-12. Temperature Contours (Kelvin) on perimeter column number 145 on floor 96 (WTC 1). The contours are shown at five different instants in time ranging from $10 \mathrm{~min}$ to $50 \mathrm{~min}$ at $10 \mathrm{~min}$ intervals. The contour scale ranges from $273 \mathrm{~K}$ to $948 \mathrm{~K}$ $\left(0^{\circ} \mathrm{C}\right.$ to $\left.675^{\circ} \mathrm{C}\right)$.

Figure 4-13. Temperature Contours (Kelvin) on perimeter column number 145 on floor 96 (WTC 1). The contours are shown at five different instants in time ranging from $60 \mathrm{~min}$ to $100 \mathrm{~min}$ at $10 \mathrm{~min}$ intervals. These contour plots supplement those shown in Figure 4-12. The contour scale ranges from $273 \mathrm{~K}$ to $948 \mathrm{~K}\left(0^{\circ} \mathrm{C}\right.$ to $\left.675 \mathrm{C}\right)$.

Figure 4-14. Temperature contours (Kelvin) through the cross-section of a perimeter column, showing the temperature gradient between the interior and exterior faces.

Figure 4-15. Time-temperature plot for perimeter Column 145, floor 96, WTC 1.

Figure 4-16. Time-temperature plot for perimeter Column 230, floor 96, WTC 1.

Figure 4-17. Time-temperature plot for perimeter Column 330, floor 96, WTC 1.

Figure 4-18. Time temperature plot for perimeter Column 430, floor 96, WTC 1.

Figure 4-19. Incorporating fireproofing damage on the interior faces of a perimeter column.

Figure on the left shows fireproofing damage on a part of the column below the column under consideration. Figure on the right shows fireproofing damage on part of the column above the column under consideration, while the figure in the middle shows fireproofing damage on the column of interest.

Figure 4-20. Incorporating fireproofing damage on the interior and exterior faces of a perimeter column. Material attributes of the fireproofing elements were changed to model damage to fireproofing.

Figure 4-21. Incorporating structural damage caused by the aircraft impact on the steel columns. The plot on the left shows damage to the steel column below the column under consideration, while the figure on the right shows damage to the steel column above and below the column under consideration.

Figure 4-22. Mapping between the thermal models (left) and the structural model (right) for a typical perimeter column. Both temperature and temperature gradient information was transferred from the thermal model to the structural model for predicting the thermally induced response of the column.....

Figure 4-23. Time temperature plot for perimeter column 145, floor 96, WTC1, indicating the frequency at which the thermal data is plotted (small symbols) and the frequency at which it is transferred into the structural models (large symbols).

Figure 4-24. Perimeter columns on floor 82 of WTC 2. The perimeter columns on the south face are damaged due to the impact of the aircraft, while many columns on the north and east faces exhibit fireproofing damage.

Figure 4-25. Visualization of the temperatures and temperature gradient information transferred to the WTC 1 structural model (floor 92-99) at $6000 \mathrm{~s}$ after impact. The thermal data is provided as a body load file.

Figure 5-1. Isometric view of a finite element model of a portion of the main truss. 82

Figure 5-2. End view of the truss model showing upper and lower steel flanges (cyan colored) covered with fireproofing (violet colored). 


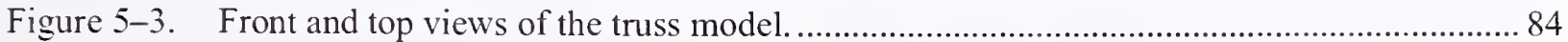

Figure 5-4. Finite element model of a primary truss showing truss construction details. 84

Figure 5-5. Replications of the basic element of the truss model to create a 60 ' long truss. The ends of the truss were modified to properly account for the connections to the core columns and perimeter columns.

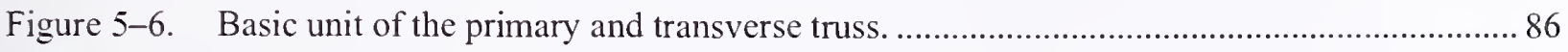

Figure 5-7. Replication of the basic truss unit to cover a small portion of the floor slab.................... 87

Figure 5-8. Finite element model of the entire truss assembly (steel only) that supports the concrete slab on floor 96 of WTC 1

Figure 5-9. Incorporating structural damage due to aircraft impact on the truss model 88

Figure 5-10. Incorporating structural and fireproofing damage on the truss assembly.

Figure 5-11. Radiative flux boundary conditions on truss elements.

Figure 5-12. Radiative fluxes coupled with realistic fire simulations are applied as surface loads on a truss model.

Figure 5-13. Temperature profile as a function of time at four different locations on the steel truss. Sub-plot $\mathrm{a}$ and $\mathrm{b}$ are for locations on the north face, while sub-plots $\mathrm{c}$ and $\mathrm{d}$ are for locations on the south face of WTC 1 , floor 96.

Figure 5-14. Time temperature plot on the steel truss (north face, floor 96 WTC 1) indicating the frequency at which the thermal data is plotted (small symbols) as well as the frequency at which it is transferred into the structural models (large symbols).

Figure 5-15. Mapping of the thermal data between the thcrmal models and the structural models showing element density.

Figure 5-16. Mapping of the thermal data between the thermal modcls and the structural models showing nodal density.....

Figure 5-17. Mapping of the thermal data for floor 96, WTC 1 onto the structural models. Thermal data is provided as a body load file for the structural model. In this picture results are shown at $6000 \mathrm{~s}$ after impact.

Figure 6-1. Finite element model of a concrete slab (top view) showing element density 98

Figure 6-2. Finite element model of a concrete slab indicating element density through the thickness of the slab.

Figure 6-3. Variation of radiative heat flux incident on the surfacc of a concrete slab representing the $96^{\text {th }}$ floor of the WTC 1 . Arrows pointing downwards indicate flux incident on the floor from a fire on top of the concrete slab, while arrows pointing upwards indicate flux incident on the ceiling of the concrete slab from a fire below.

Figure 6-4. Radiative heat flux $\left(\mathrm{W} / \mathrm{m}^{2}\right)$ incident on the top of the $96^{\text {th }}$ floor concrete slab (due to fires on the $96^{\text {th }}$ floor).

Figure 6-5. Radiative heat flux $\left(\mathrm{W} / \mathrm{m}^{2}\right)$ incident on the bottom of the $96^{\text {th }}$ floor concrete slab (due to fires on the $95^{\text {th }}$ floor). 
Figure 6-6. Typical temperature contours (Kelvin) on the top and bottom faces of the concrete slab $\left(96^{\text {th }}\right.$ floor, WTC 1$)$ at $6000 \mathrm{~s}$ after impact. A portion of the concrete slab on the north face (top) was damaged by the impact of the aircraft.

Figure 6-7. Temperature contours through the thickness of the concrete slab at two different instants in time ( $1,000 \mathrm{~s}$ and $3,000 \mathrm{~s}$ after impact). The range of temperature contours is the same as shown in Figure 6-6.

Figure 6-8. Location of the four nodes on the concrete slab where temperature profiles through the slab thickness have been plotted in Figure 6-9 through Figure 6-12 .

Figure 6-9. Temperature profiles through the slab thickness at Location 1. The temperature profiles have been plotted at six different instants in time at $1,000 \mathrm{~s}$ intervals.

Figure 6-10. Temperature profiles through the slab thickness at Location 2. The temperature profiles have been plotted at six diffcrent instants in time at $1,000 \mathrm{~s}$ intervals.

Figure 6-11. Temperature profiles through the slab thickness at Location 3. The temperature profiles have been plotted at six different instants in time at $1,000 \mathrm{~s}$ intervals......... 106

Figure 6-12. Temperature profiles through the slab thickness at Location 4 . The temperature profiles have been plotted at six different instants in time at $1,000 \mathrm{~s}$ intervals.

Figure 6-13. Temperature is plotted as a function of time at four different locations (top and bottom surfaces) on a concrete slab representing the $96^{\text {th }}$ floor of WTC 1 . These rcsults clearly demonstrate the transient nature of fire growth through the floors.

Figure 6-14. Mapping of thermal data (tempcrature and temperature gradient) from the thermal models to the structural model.

Figure 6-15. Mapping of the thermal data (temperature and temperature gradient) from the thermal models to the structural model.

Figure 7-1. Finite element models of wide flange core columns, including insulation developed for thermal analysis of the World Trade Center Towers. Steel elements are colored cyan and fireproofing elements violet.

Figure 7-2. Finite element models of box columns including insulation used for thermal analysis in the World Trade Center towers. Steel elements are colored cyan, and fireproofing elements are violet.

Figure 7-3. Isometric view of finite element models of the core columns showing mesh density and column construction. The elements are color coded with material attributes. Cyan colored elements have material attributes of steel while violet colored elements have material attributes of fireproofing.

Figure 7-4. Radiative flux and convective flux boundary conditions (indicated by arrows) imposed on wide flange and box shaped core columns.

Figure 7-5. Radiative heat flux incident on column 501 at floor 96 (WTC 1, Case B) at six different instants in time. (1,000-6,000 $\mathrm{s}$ at 1,000 $\mathrm{s}$ interval)

Figure 7-6. Temperature contours (Kelvin) for core columns in the World Trade Center towers. Both steel and fireproofing elements have been shown.

Figure 7-7. Temperature contours (Kelvin) in the steel (Column 501, floor 96, WTC 1) as a function of time. Figure shows the temperature gradient in the steel and variability in temperature along the length of the columns. 
Figure 7-8. Core column temperature for columns 501 through 508 on floor 96 of WTC 1 as a function of time.

Figure 7-9. Core column temperature for columns 601 through 608 on floor 96 of WTC 1 as a function of time.

Figure 7-10. Core column temperature for columns 701 through 708 on floor 96 of WTC 1 as a function of time.

Figure 7-11. Core column temperature for columns 801 through 807 on floor 96 of WTC 1 as a function of time.

Figure 7-12. Core column temperature for columns 901 through 908 on floor 96 of WTC 1 as a function of time.

Figure 7-13. Core column temperature for columns 1001 through 1008 on floor 96 of WTC 1 as a function of time.

Figure 7-14. Incorporating the effect of fireproofing damage on columns by selectively changing the material attributes of the underlying elements.

Figure 7-15. Mapping of the thermal data from thermal models of the core column to the structural models.

Figure 7-16. Mapping of the thermal data for the core columns onto the structural model for the $96^{\text {th }}$ floor of WTC 1 at $6,000 \mathrm{~s}$ after impact. The temperature data is provided as a body load and is generated in a format that is consistent with the structural model.

Figure 7-17. Core column temperature for columns 501 through 508 on floor 96 of WTC 1, as a function of time indicating the frequency at which the thermal data is plotted (small symbols) and the frequency at which data is transferred into the structural modcls (large symbols).

Figure 8-1. Sample plot of temperature contours superimposed on the steel structure showing the core beams and floor trusses that support a concrete slab. Perimeter and core columns extend to the floor above and below the floor under consideration. The concrete slab is included in the analysis, but has not been shown here for clarity.

Figure 8-2. Thermal response of floor 93, WTC 1 Case A at different instants in time 134

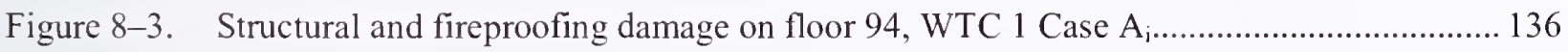

Figure 8-4. Thermal response of floor 94, WTC 1 Case A at different instants in time..................... 137

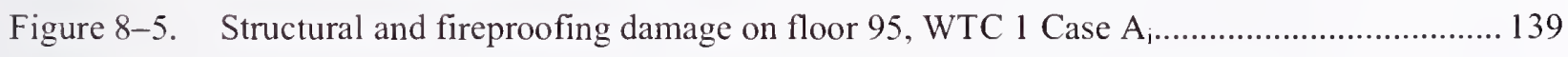

Figure 8-6. Upper layer temperature predicted by fire dynamics simulation for floor 95, WTC 1

Case A

Figure 8-7. Thermal response of floor 95, WTC 1 Case A at different instants in time, grid view. ... 141

Figure 8-8. Thermal response of floor 95, WTC 1 Case A at different instants in time. 142

Figure 8-9. Structural and fireproofing damage on floor 96, WTC 1 Case $\mathrm{A}_{\mathrm{i}} \ldots \ldots \ldots \ldots \ldots \ldots \ldots \ldots \ldots \ldots \ldots . . . . . . . . . . . . . .144$

Figure 8-10. Thermal response of floor 96, WTC 1 Case A at $600 \mathrm{~s}$ after impact............................. 145

Figure 8-11. Thermal response of floor 96, WTC 1 Case A at $1200 \mathrm{~s}$ after impact........................... 146

Figure 8-12. Thermal response of floor 96, WTC 1 Case A at $1800 \mathrm{~s}$ after impact........................... 147 
Figure 8-13. Thermal response of floor 96, WTC 1 Case A at $2400 \mathrm{~s}$ after impact.......................... 148

Figure 8-14. Thermal response of floor 96, WTC 1 Case A at $3000 \mathrm{~s}$ after impact........................... 149

Figure 8-15. Thermal response of floor 96, WTC 1 Case A at $3600 \mathrm{~s}$ after impact............................ 150

Figure 8-16. Thermal response of floor 96, WTC 1 Case A at $4200 \mathrm{~s}$ after impact........................... 151

Figure 8-17. Thermal response of floor 96, WTC 1 Case A at $4800 \mathrm{~s}$ after impact.......................... 152

Figure 8-18. Thermal response of floor 96, WTC 1 Case A at $5400 \mathrm{~s}$ after impact........................... 153

Figure 8-19. Thermal response of floor 96, WTC 1 Case A at $6000 \mathrm{~s}$ after impact.......................... 154

Figure 8-20. Thermal response of floor 96, WTC 1 Case A (slab and columns) at $600 \mathrm{~s}$ after

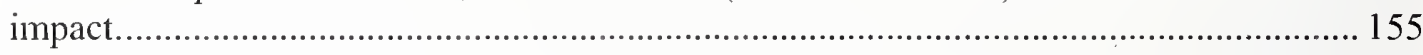

Figure 8-21. Thermal response of floor 96, WTC 1 Case A (slab and columns) at $1200 \mathrm{~s}$ after

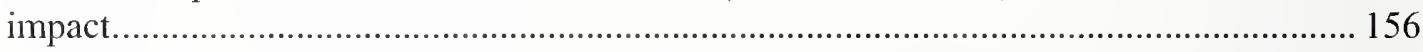

Figure 8-22. Thermal response of floor 96, WTC 1 Case A (slab and columns) at $1800 \mathrm{~s}$ after impact.

Figure 8-23. Thermal response of floor 96, WTC 1 Case A (slab and columns) at $2400 \mathrm{~s}$ after impact.

Figure 8-24. Thermal response of floor 96, WTC 1 Case A (slab and columns) at $3000 \mathrm{~s}$ after impact.

Figure 8-25. Thermal response of floor 96, WTC 1 Case A (slab and columns) at $3600 \mathrm{~s}$ after impact.

Figure 8-26. Thermal response of floor 96, WTC 1 Case A (slab and columns) at $4200 \mathrm{~s}$ after impact.

Figure 8-27. Thermal response of floor 96, WTC 1 Case A (slab and columns) at $4800 \mathrm{~s}$ after impact.

Figure 8-28. Thermal response of floor 96, WTC 1 Case A (slab and columns) at $5400 \mathrm{~s}$ after impact.

Figure 8-29. Thermal response of floor 96, WTC 1 Case A (slab and columns) at $6000 \mathrm{~s}$ after impact. 164

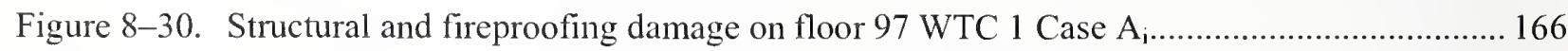

Figure 8-31. Thermal response of floor 97, WTC 1 Case A at different instants in time, grid view. ... 167

Figure 8-32. Thermal response of floor 97, WTC 1 Case A at different instants in time.................... 168

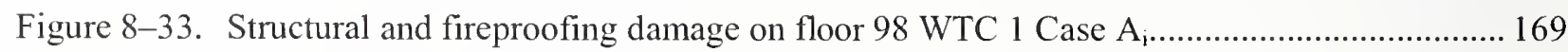

Figure 8-34. Thermal response of floor 98, WTC 1 Case A at different instants in time..................... 170

Figure 8-35. Thermal response of floor 99, WTC 1 Case A at different instants in time.................... 172

Figure 9-1. Thermal response of floor 93, WTC 1 Case B at different instants in time.................... 182

Figure 9-2. Thermal response of floor 94, WTC 1 Case B at different instants in time.................... 183

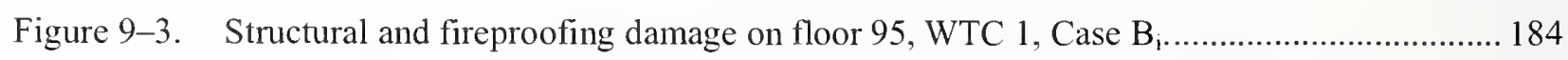

Figure 9-4. Thermal response of floor 95, WTC 1 Case B at different instants in time.................... 185 


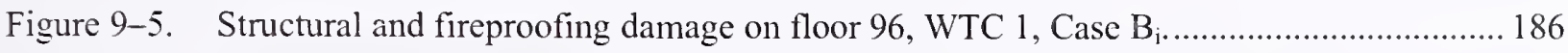

Figure 9-6. Thermal response of floor 96, WTC 1 Case B at different instants in time................... 187

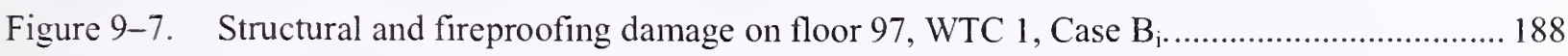

Figure 9-8. Structural and fireproofing damage on floor 98, WTC 1, Case $\mathrm{B}_{\mathrm{i}} \ldots \ldots \ldots \ldots \ldots \ldots \ldots \ldots \ldots \ldots$

Figure 9-9. Thermal response of floor 97, WTC 1 Case B at different instants in time.................... 190

Figure 9-10. Thermal response of floor 98, WTC 1 Case B at different instants in time.................... 191

Figure 9-11. Thermal response of floor 99, WTC 1 Case B at different instants in time................... 192

Figure 10-1. Sample plot of temperature contours superimposed on the steel structure showing core beams and floor trusses that support a concrete slab of a typical floor in WTC 2. Perimeter and core columns extend to the floor above and below the floor under consideration. The concrete slab is included in the analysis, but has not been shown here for clarity. 203

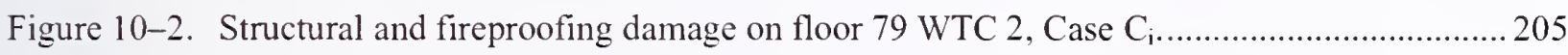

Figure 10-3. Thermal response of floor 79 WTC 2 Case $\mathrm{C}$ at six different instants in time. ............... 206

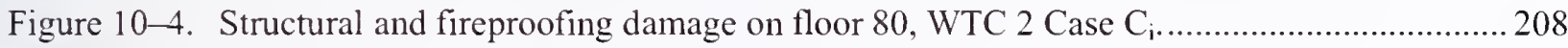

Figure 10-5. Thermal response of floor 80, WTC 2 at different instants in time, Case C....................209

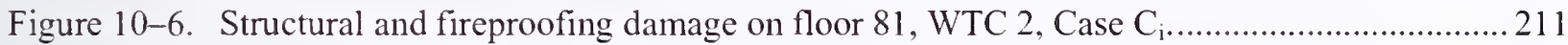

Figure 10-7. Thermal response of floor 81, WTC 2 Case $\mathrm{C}$ at $600 \mathrm{~s}$ after impact. ...........................2 211

Figure 10-8. Thermal response of floor 81, WTC 2 Case $\mathrm{C}$ at $1,200 \mathrm{~s}$ after impact....................... 212

Figure 10-9. Thermal response of floor 81, WTC 2 Case $\mathrm{C}$ at $1,800 \mathrm{~s}$ after impact........................2 212

Figure 10-10. Thermal response of floor 81, WTC 2 Case $\mathrm{C}$ at 2,400 s after impact........................213

Figure 10-11. Thermal response of floor 81, WTC 2 Case $\mathrm{C}$ at 3,000 s after impact..........................213

Figure 10-12. Thermal response of floor 81, WTC 2 Case $\mathrm{C}$ at 3,600 s after impact.........................2 214

Figure 10-13. Thermal response of floor 81, WTC 2 Case C (concrete slab and columns) at

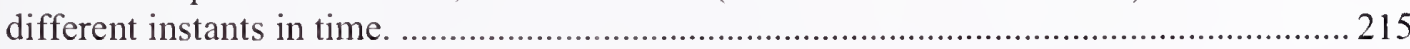

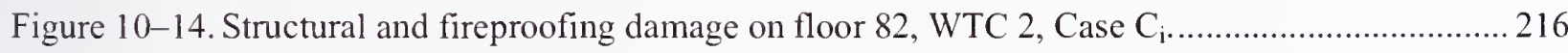

Figure 10-15. Thermal response of floor 82, WTC 2 Case $\mathrm{C}$ at different instants in time.................... 217

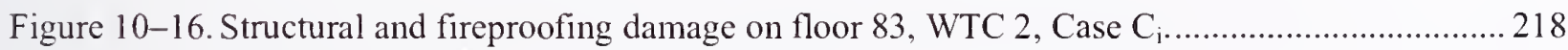

Figure 10-17. Thermal response of floor 83, WTC 2 Case C, at different instants in time.................... 219

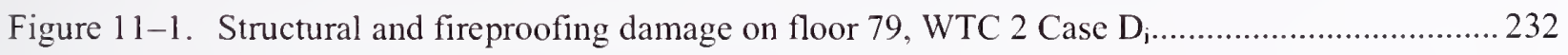

Figure 11-2. Thermal response of floor 79, WTC 2 Case D at different instants in time....................233

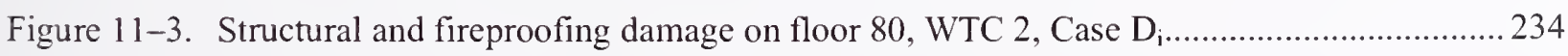

Figure 11-4. Thermal response of floor 80, WTC 2 Case D at different instants in time...................2235

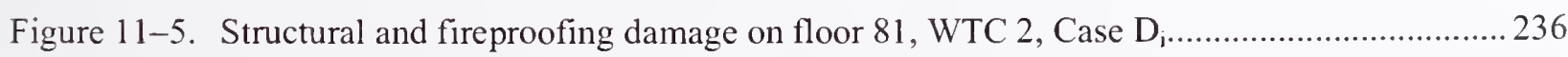


Figure 11-6. Thermal response of floor 81, WTC 2 Case D at different instants in time....................237

Figure 11-7. Structural and fireproofing damage on floor 82, WTC 2, Case $\mathrm{D}_{\mathrm{i}} \ldots \ldots \ldots \ldots \ldots \ldots \ldots \ldots \ldots \ldots . . . . . . . . . . . . . .238$

Figure 11-8. Thermal response of floor 82, WTC 2 Case D at different instants in time....................239

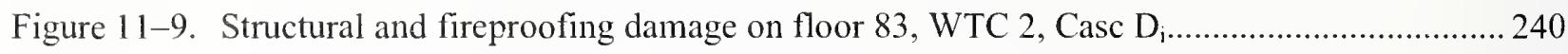

Figure 11-10. Thermal response of floor 83, WTC 2 Case D, at different instants in time................... 241

Figure 11-11. Thermal response of floor trusses that support the concrete slab on floor 82, WTC 2 at $6,000 \mathrm{~s}$ after impact (extended simulation for Case D)........................................... 242

Figure 11-12. Typical time-temperature plot for floor trusses on the west side for the extended run, indicating rapid heating at $6000 \mathrm{~s}$ after impact followed by gradual cooling. 243

Figure 12-1. Global thermal response of WTC 1, Case A.............................................................. 255

Figure 12-2. Global thermal response of WTC 1, Case B............................................................ 256

Figure 12-3. Comparison of the final thermal state of perimeter columns for WTC 1, Case A, with

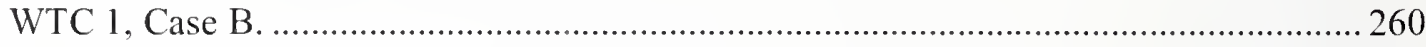

Figure 12-4. Global thermal response of WTC 2, Case C ........................................................... 263

Figure 12-5. Global thermal response of WTC 2, Case D........................................................... 264

Figure 12-6. Comparison of the final thermal state of perimeter columns for WTC 2, Case C with WTC 2, Case D. 


\section{LIST OF TABLES}

Table P-1. Federal building and fire safety investigation of the WTC disaster............................xxviii

Table P-2. Public meetings and briefings of the WTC Investigation. ........................................... Xxxi

Table 2-1. Test Matrix for comparison with numerical simulations. ........................................... 12

Table 2-2. Percentage difference between peak values of the measured and the simulated steel surface temperatures at the hottest and coolest locations on various un-insulated components in Test 1 .

Table 2-3. Percentage difference between peak values of the measured and the simulated steel temperatures for the hottest and coolest locations for various components with SFRM in Test 5.

Table 2-4. Percentage difference in the peak value of temperatures between the baseline simulations and those with a 10 percent higher heat release rate at the hottest and coolest locations on the steel surface of various un-insulated components in Test 1.

Table 3-1. Time (in seconds) to reach critical temperature for light box shape core columns............. 31

Table 3-2. Time (in seconds) to reach critical temperature for heavy box shape core columns.......... 34

Table 3-3. Time (in seconds) to reach critical temperature for wide flange column 12WF133.......... 37

Table 3-4. Time (in seconds) to reach critical temperature for wide flange column 14WF730.......... 37

Table 8-1. Input parameters for WTC 1 global impact analyses (Base Case)................................. 129

Table 8-2. Values of WTC1 Case A fire simulation variables...................................................... 129

Table 8-3. Input for global thermal response of WTC 1, Case A ................................................... 130

Table 8-4. Perimeter column damage status for WTC 1, Case A. .............................................. 173

Table 8-5. Core column damage status for WTC 1, Case A ......................................................... 176

Table 9-1. Input parameters for WTC 1 global impact analyses (More Severe)............................ 180

Table 9-2. Values of WTC fire simulation variables.......................................................... 180

Table 9-3. Input for global thermal response of WTC 1, Case B............................................. 181

Table 9-4. Perimeter column damage status for WTC 1, Case B................................................ 193

Table 9-5. Core dolumn damage status for WTC 1, Case B........................................................ 196

Table 10-1. Input parameters for WTC 2 global impact analyses (Base Case)................................2200

Table 10-2. Values of WTC fire simulation variables............................................................ 201 
Table 10-3. Input for global thermal response of WTC 2 ....................................................... 202

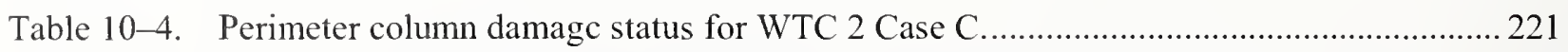

Table 10-5. Core column fireproofing damage status for WTC 2, Case C. ..................................... 224

Table 10-6. Core column structural damage status for WTC 2, Case C. ......................................... 226

Table 11-1. Input parameters for WTC 2 global impact analyses (more severe)............................ 229

Table 11-2. Values of WTC fire simulation variables................................................................. 230

Table 1 1-3. Input for global thermal response of WTC 2 ........................................................... 231

Table 11-4. Perimeter Column Damage Status for WTC 2 Case D. .............................................. 244

Table 11-5. Core Column Damage Status for WTC 2, Case D..................................................... 247

Table 12-1. Input parameters for WTC 1 global impact analyses................................................250

Table 12-2. Input parameters for WTC 2 global impact analyses..............................................2 251

Table 12-3. Values of WTC fire simulation variables...............................................................251

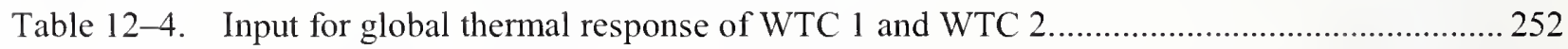

Table 12-5. Temperature range $\left({ }^{\circ} \mathrm{C}\right)$ for perimeter columns on various floors at five instants in time, WTC 1, Case A.

Table 12-6. Temperature range $\left({ }^{\circ} \mathrm{C}\right)$ for perimeter columns on various floors at five instants in time, WTC 1, Case B.

Table 12-7. Temperature range $\left({ }^{\circ} \mathrm{C}\right)$ for core columns on various floors at five instants in time,

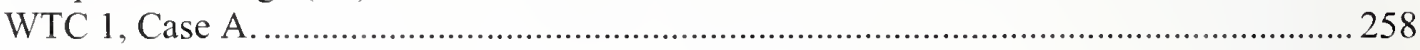

Table 12-8. Temperature range $\left({ }^{\circ} \mathrm{C}\right)$ for core columns on various floors at five instants in time, WTC 1, Case B.

Table 12-9. Temperature range $\left({ }^{\circ} \mathrm{C}\right)$ for floor trusses on various floors at five instants in time, WTC 1, Case A.

Table 12-10. Temperature range $\left({ }^{\circ} \mathrm{C}\right)$ for floor trusses on various floors at five instants in time, WTC 1, Case B. .

Table 12-11. Temperature range $\left({ }^{\circ} \mathrm{C}\right)$ for perimeter columns on various floors at six instants in time, WTC 2, Case C.

Table 12-12. Temperature range $\left({ }^{\circ} \mathrm{C}\right)$ for perimeter columns on various floors at six instants in time, WTC 2, Case D.

Table 12-13. Temperature range $\left({ }^{\circ} \mathrm{C}\right)$ for core columns on various floors at six instants in time, WTC 2, Case C.

Table 12-14. Temperature range $\left({ }^{\circ} \mathrm{C}\right)$ for core columns on various floors at six instants in time, WTC 2, Case D.

Table 12-15. Temperature range $\left({ }^{\circ} \mathrm{C}\right)$ for floor trusses on various floors at six instants in time, WTC 2, Case C. 
Table 12-16. Temperature range $\left({ }^{\circ} \mathrm{C}\right)$ for floor trusses on various floors at six instants in time, WTC 2, Case D. 
This page intentionally left blank. 


\section{LIST OF ACRONYMS AND ABBREVIATIONS}

Acronyms

BPS Building Performance Study

FEMA Federal Emergency Management Agency

NIST National Institute of Standards and Technology

PANYNJ Port Authority of New York and New Jersey

SEAoNY Structural Engineers Association of New York

USC United States Code

WTC World Trade Center

\section{Abbreviations}

$\begin{array}{ll}{ }^{\circ} \mathrm{C} & \text { degrees Celsius } \\ { }^{\circ} \mathrm{F} & \text { degrees Fahrenheit } \\ \mathrm{ft} & \text { feet } \\ \text { in. } & \text { inch } \\ \mathrm{h} & \text { hour } \\ \mathrm{L} & \text { liter } \\ \mathrm{K} & \text { Kelvin } \\ \mathrm{m} & \text { meter } \\ \mu \mathrm{m} & \text { micrometer } \\ \mathrm{min} & \text { minute } \\ \mathrm{s} & \text { second }\end{array}$


This page intentionally left blank. 


\section{Preface}

\section{Genesis of This Investigation}

Immediately following the terrorist attack on the World Trade Center (WTC) on September 11, 2001, the Federal Emergency Management Agency (FEMA) and the American Society of Civil Engineers began planning a building performance study of the disaster. The week of October 7, as soon as the rescue and search efforts ceased, the Building Performance Study Team went to the site and began its assessment. This was to be a brief effort, as the study team consisted of experts who largely volunteered their time away from their other professional commitments. The Building Performance Study Team issued its report in May 2002, fulfilling its goal "to determine probable failure mechanisms and to identify areas of future investigation that could lead to practical measures for improving the damage resistance of buildings against such unforeseen events."

On August 21, 2002, with funding from the U.S. Congress through FEMA, the National Institute of Standards and Technology (NIST) announced its building and fire safety investigation of the WTC disaster. On October 1, 2002, the National Construction Safety Team Act (Public Law 107-231), was signed into law. The NIST WTC Investigation was conducted under the authority of the National Construction Safety Team Act.

The goals of the investigation of the WTC disaster were:

- To investigate the building construction, the materials used, and the technical conditions that contributed to the outcome of the WTC disaster.

- To serve as the basis for:

- Improvements in the way buildings are designed, constructed, maintained, and used;

- Improved tools and guidance for industry and safety officials;

- Recommended revisions to current codes, standards, and practices; and

- Improved public safety.

The specific objectives were:

1. Determine why and how WTC 1 and WTC 2 collapsed following the initial impacts of the aircraft and why and how WTC 7 collapsed;

2. Determine why the injuries and fatalities were so high or low depending on location, including all technical aspects of fire protection, occupant behavior, evacuation, and emergency response;

3. Determine what procedures and practices were used in the design, construction, operation, and maintenance of WTC 1,2, and 7; and

4. Identify, as specifically as possible, areas in current building and fire codes, standards, and practices that warrant revision. 
NIST is a nonregulatory agency of the U.S. Department of Commerce's Technology Administration. The purpose of NIST investigations is to improve the safety and structural integrity of buildings in the United States, and the focus is on fact finding. NIST investigative teams are authorized to assess building performance and emergency response and evacuation procedures in the wake of any building failure that has resulted in substantial loss of life or that posed significant potential of substantial loss of lifc. NIST does not have the statutory authority to make findings of fault nor negligence by individuals or organizations. Further, no part of any report resulting from a NIST investigation into a building failure or from an investigation under the National Construction Safety Team Act may be used in any suit or action for damages arising out of any matter mentioned in such report (15 USC 281a, as amended by Public Law 107-231).

\section{Organization of the Investigation}

The National Construction Safety Team for this Investigation, appointed by the then NIST Director, Dr. Arden L. Bement, Jr., was led by Dr. S. Shyam Sunder. Dr. William L. Grosshandler served as Associate Lead Investigator, Mr. Stephen A. Cauffman served as Program Manager for Administration, and Mr. Harold E. Nelson served on the team as a private sector expert. The Investigation included eight interdependent projects whose leaders comprised the remainder of the team. A detailed description of each of these eight projects is available at http:/wtc.nist.gov. The purpose of each project is summarized in Table $\mathrm{P}-1$, and the key interdependencies among the projects are illustrated in Fig. $\mathrm{P}-1$.

Table P-1. Federal building and fire safety investigation of the WTC disaster.

\begin{tabular}{|c|c|}
\hline Area and Project Leader & \\
\hline $\begin{array}{l}\text { Analysis of Building and Fire Codes and } \\
\text { Practices; Project Leaders: Dr. H. S. Lew } \\
\text { and Mr. Richard W. Bukowski }\end{array}$ & $\begin{array}{l}\text { Document and analyze the code provisions, procedures, and } \\
\text { practices used in the design, construction, operation, and } \\
\text { maintenance of the structural, passive fire protection, and } \\
\text { emergency access and evacuation systems of WTC } 1,2 \text {, and } 7 \text {. }\end{array}$ \\
\hline $\begin{array}{l}\text { Baseline Structural Performance and } \\
\text { Aircraft Impact Damage Analysis; Project } \\
\text { Leader: Dr. Fahim H. Sadek }\end{array}$ & $\begin{array}{l}\text { Analyze the baseline performance of WTC } 1 \text { and WTC } 2 \text { under } \\
\text { design, service, and abnormal loads, and aircraft impact damage on } \\
\text { the structural, fire protection, and egress systems. }\end{array}$ \\
\hline $\begin{array}{l}\text { Mechanical and Metallurgical Analysis of } \\
\text { Structural Steel; Project Leader: Dr. Frank } \\
\text { W. Gayle }\end{array}$ & $\begin{array}{l}\text { Determine and analyze the mechanical and metallurgical properties } \\
\text { and quality of steel, weldments, and connections from steel } \\
\text { recovered from WTC } 1,2 \text {, and } 7 \text {. }\end{array}$ \\
\hline $\begin{array}{l}\text { Investig. } \\
\text { Systems } \\
\text { D. Evan }\end{array}$ & $\begin{array}{l}\text { Investigate the performance of the active fire protection systems in } \\
\text { WTC } 1,2 \text {, and } 7 \text { and their role in fire control, emergency response, } \\
\text { and fate of occupants and responders. }\end{array}$ \\
\hline $\begin{array}{l}\text { Reconstruction of Thermal and Tenability } \\
\text { Environment; Project Leader: Dr. Richard } \\
\text { G. Gann }\end{array}$ & $\begin{array}{l}\text { Reconstruct the time-evolving temperature, thermal environment, } \\
\text { and smoke movement in WTC } 1,2 \text {, and } 7 \text { for use in evaluating the } \\
\text { structural performance of the buildings and behavior and fate of } \\
\text { occupants and responders. }\end{array}$ \\
\hline $\begin{array}{l}\text { Fire Response and Collapse } \\
\text { roject Leaders: Dr. John } \\
\text { ad Dr. Therese P. McAllister }\end{array}$ & $\begin{array}{l}\text { Analyze the response of the WTC towers to fires with and without } \\
\text { aircraft damage, the response of WTC } 7 \text { in fires, the performance } \\
\text { of composite steel-trussed floor systems, and determine the most } \\
\text { probable structural collapse sequence for WTC } 1,2 \text {, and } 7 \text {. }\end{array}$ \\
\hline $\begin{array}{l}\text { Occupant Behavior, Egress, and Emergency } \\
\text { Communications; Project Leader: Mr. Jason } \\
\text { D. Averill }\end{array}$ & $\begin{array}{l}\text { Analyze the behavior and fate of occupants and responders, both } \\
\text { those who survived and those who did not, and the performance of } \\
\text { the evacuation system. }\end{array}$ \\
\hline $\begin{array}{l}\text { Emergency Response Technologies and } \\
\text { Guidelines; Project Leader: Mr. J. Randall } \\
\text { Lawson }\end{array}$ & $\begin{array}{l}\text { Document the activities of the emergency responders from the time } \\
\text { of the terrorist attacks on WTC } 1 \text { and WTC } 2 \text { until the collapse of } \\
\text { WTC 7, including practices followed and technologies used. }\end{array}$ \\
\hline
\end{tabular}




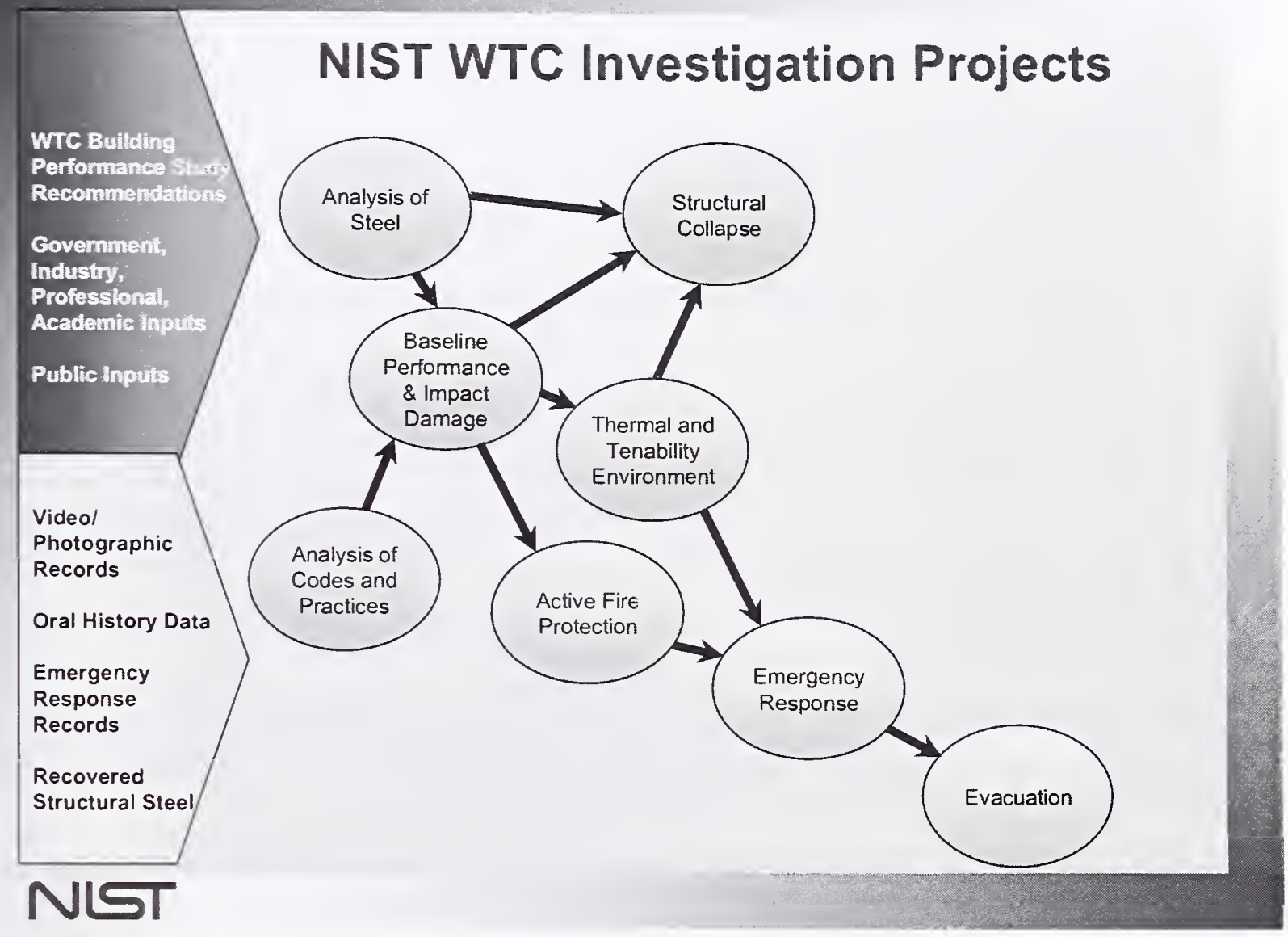

Figure P-1. The eight projects in the federal building and fire safety investigation of the WTC disaster.

\section{National Construction Safety Team Advisory Committee}

The NIST Director also established an advisory committee as mandated under the National Construction Safety Team Act. The initial members of the committee were appointed following a public solicitation. These were:

- Paul Fitzgerald, Executive Vice President (retired) FM Global, National Construction Safety Team Advisory Committee Chair

- John Barsom, President, Barsom Consulting, Ltd.

- John Bryan, Professor Emeritus, University of Maryland

- David Collins, President, The Preview Group, Inc.

- Glenn Corbett, Professor, John Jay College of Criminal Justice

- Philip DiNenno, President, Hughes Associates, Inc. 
- Robert Hanson, Professor Emeritus, University of Michigan

- Charles Thornton, Co-Chairman and Managing Principal, The Thornton-Tomasetti Group, Inc.

- Kathleen Tierney, Director, Natural Hazards Research and Applications Information Center, University of Colorado at Boulder

- Forman Williams, Director, Center for Energy Research, University of California at San Diego

This National Construction Safety Team Advisory Committee provided technical advice during the Investigation and commentary on drafts of the Investigation reports prior to their public release. NIST has benefited from the work of many people in the preparation of these reports, including the National Construction Safety Team Advisory Committee. The content of the reports and recommendations, however, are solely the responsibility of NIST.

\section{Public Outreach}

During the course of this Investigation, NIST held public briefings and meetings (listed in Table P-2) to solicit input from the public, present preliminary findings, and obtain comments on the direction and progress of the Investigation from the public and the Advisory Committee.

NIST maintained a publicly accessible Web site during this Investigation at http://wtc.nist.gov. The site contained extensive information on the background and progress of the Investigation.

\section{NIST's WTC Public-Private Response Plan}

The collapse of the WTC buildings has led to broad reexamination of how tall buildings are designed, constructed, maintained, and used, especially with regard to major events such as fires, natural disasters, and terrorist attacks. Reflecting the enhanced interest in effecting necessary change, NIST, with support from Congress and the Administration, has put in place a program, the goal of which is to develop and implement the standards, technology, and practices needed for cost-effective improvements to the safety and security of buildings and building occupants, including evacuation, emergency response procedures, and threat mitigation.

The strategy to meet this goal is a three-part NIST-led public-private response program that includes:

- A federal building and fire safety investigation to study the most probable factors that contributed to post-aircraft impact collapse of the WTC towers and the 47-story WTC 7 building, and the associated evacuation and emergency response experience.

- A research and development (R\&D) program to (a) facilitate the implementation of recommendations resulting from the WTC Investigation, and (b) provide the technical basis for cost-effective improvements to national building and fire codes, standards, and practices that enhance the safety of buildings, their occupants, and emergency responders. 
Table P-2. Public meetings and briefings of the WTC Investigation.

\begin{tabular}{|c|c|c|}
\hline Date & Location & Principal Agenda \\
\hline June 24,2002 & New York City, NY & $\begin{array}{l}\text { Public meeting: Public comments on the Draft Plan for the } \\
\text { pending WTC Investigation. }\end{array}$ \\
\hline August 21.2002 & Gaithersburg, MD & Media briefing announcing the formal start of the Investigation. \\
\hline December 9,2002 & Washington, DC & $\begin{array}{l}\text { Media briefing on release of the Public Update and NIST request } \\
\text { for photographs and videos. }\end{array}$ \\
\hline April 8.2003 & New York City, NY & $\begin{array}{l}\text { Joint public forum with Columbia University on first-person } \\
\text { interviews. }\end{array}$ \\
\hline April 29-30,2003 & Gaithersburg, MD & $\begin{array}{l}\text { NCST Advisory Committee meeting on plan for and progress on } \\
\text { WTC Investigation with a public comment session. }\end{array}$ \\
\hline May 7,2003 & New York City, NY & Media briefing on release of May 2003 Progress Report. \\
\hline August 26-27.2003 & Gaithersburg, MD & $\begin{array}{l}\text { NCST Advisory Committee meeting on status of the WTC } \\
\text { investigation with a public comment session. }\end{array}$ \\
\hline September 17,2003 & New York City, NY & $\begin{array}{l}\text { Media and public briefing on initiation of first-person data } \\
\text { collection projects. }\end{array}$ \\
\hline December $2-3,2003$ & Gaithersburg, MD & $\begin{array}{l}\text { NCST Advisory Committee meeting on status and initial results } \\
\text { and release of the Public Update with a public comment session. }\end{array}$ \\
\hline February 12, 2004 & New York City. NY & $\begin{array}{l}\text { Public meeting on progress and preliminary findings with public } \\
\text { comments on issues to be considered in formulating final } \\
\text { recommendations. }\end{array}$ \\
\hline June 18,2004 & New York City, NY & Media/public briefing on release of June 2004 Progress Report. \\
\hline June $22-23.2004$ & Gaithersburg, $M D$ & $\begin{array}{l}\text { NCST Advisory Committee meeting on the status of and } \\
\text { preliminary findings from the WTC Investigation with a public } \\
\text { comment session. }\end{array}$ \\
\hline August 24, 2004 & Northbrook, IL & $\begin{array}{l}\text { Public viewing of standard fire resistance test of WTC floor } \\
\text { system at Underwriters Laboratories, Inc. }\end{array}$ \\
\hline October 19-20, 2004 & Gaithersburg, MD & $\begin{array}{l}\text { NCST Advisory Committee meeting on status and near complete } \\
\text { set of preliminary findings with a public comment session. }\end{array}$ \\
\hline November 22, 2004 & Gaithersburg. MD & $\begin{array}{l}\text { NCST Advisory Committee discussion on draft annual report to } \\
\text { Congress, a public comment session, and a closed session to } \\
\text { discuss pre-draft recommendations for WTC Investigation. }\end{array}$ \\
\hline April 5, 2005 & New York City, NY & $\begin{array}{l}\text { Media and public briefing on release of the probable collapse } \\
\text { sequence for the WTC towers and draft reports for the projects on } \\
\text { codes and practices, evacuation, and emergency response. }\end{array}$ \\
\hline June 23,2005 & New York City, NY & $\begin{array}{l}\text { Media and public briefing on release of all draft reports for the } \\
\text { WTC towers and draft recommendations for public comment. }\end{array}$ \\
\hline $\begin{array}{l}\text { September 12-I3, } \\
2005\end{array}$ & Gaithersburg, MD & $\begin{array}{l}\text { NCST Advisory Committee meeting on disposition of public } \\
\text { comments and update to draft reports for the WTC towers. }\end{array}$ \\
\hline $\begin{array}{l}\text { September } 13-15 \text {, } \\
2005\end{array}$ & Gaithersburg, MD & $\begin{array}{l}\text { WTC Technical Conference for stakeholders and technical } \\
\text { community for dissemination of findings and recommendations } \\
\text { and opportunity for public to make technical comments. }\end{array}$ \\
\hline
\end{tabular}

- A dissemination and technical assistance program (DTAP) to (a) engage leaders of the construction and building community in ensuring timely adoption and widespread use of proposed changes to practices, standards, and codes resulting from the WTC Investigation and the R\&D program, and (b) provide practical guidance and tools to better prepare facility owners, contractors, architects, engineers, emergency responders, and regulatory authorities to respond to future disasters.

The desired outcomes are to make buildings, occupants, and first responders safer in future disaster events. 


\section{National Construction Safety Team Reports on the WTC Investigation}

A final report on the collapse of the WTC towers is being issued as NIST NCSTAR 1. A companion report on the collapse of WTC 7 is being issued as NIST NCSTAR 1A. The present report is one of a set that provides more detailed documentation of the Investigation findings and the means by which these technical results were achieved. As such, it is part of the archival record of this Investigation. The titles of the full set of Investigation publications are:

NIST (National Institute of Standards and Technology). 2005. Federal Building and Fire Safety Investigation of the World Trade Center Disaster: Final Report on the Collapse of the World Trade Center Towers. NIST NCSTAR 1. Gaithersburg, MD, September.

NIST (National Institute of Standards and Technology). 2006. Federal Building and Fire Safety Investigation of the World Trade Center Disaster: Final Report on the Collapse of World Trade Center 7. NIST NCSTAR 1A. Gaithersburg, MD.

Lew, H. S., R. W. Bukowski, and N. J. Carino. 2005. Federal Building and Fire Safety Investigation of the World Trade Center Disaster: Design, Construction, and Maintenance of Structural and Life Safety Systems. NJST NCSTAR 1-1. National Institute of Standards and Technology. Gaithersburg, MD, September.

Fanella, D. A., A. T. Derecho, and S. K. Ghosh. 2005. Federal Building and Fire Safety Investigation of the World Trade Center Disaster: Design and Construction of Structural Systems. NIST NCSTAR 1-1 A. National Institute of Standards and Technology. Gaithersburg, MD, September.

Ghosh, S. K., and X. Liang. 2005. Federal Building and Fire Safety Investigation of the World Trade Center Disaster: Comparison of Building Code Structural Requirements. NIST

NCSTAR 1-1B. National Institute of Standards and Technology. Gaithersburg, MD, September.

Fanella, D. A., A. T. Derecho, and S. K. Ghosh. 2005. Federal Building and Fire Safety Investigation of the World Trade Center Disaster: Maintenance and Modifications to Structural Systems. NIST NCSTAR 1-1C. National Institute of Standards and Technology. Gaithersburg, MD, September.

Grill, R. A., and D. A. Johnson. 2005. Federal Building and Fire Safety Investigation of the World Trade Center Disaster: Fire Protection and Life Safety Provisions Applied to the Design and Construction of World Trade Center 1, 2, and 7 and Post-Construction Provisions Applied after Occupancy. NIST NCSTAR 1-1D. National Institute of Standards and Technology. Gaithersburg, MD, September.

Razza, J. C., and R. A. Grill. 2005. Federal Building and Fire Safety Investigation of the World Trade Center Disaster: Comparison of Codes, Standards, and Practices in Use at the Time of the Design and Construction of World Trade Center 1, 2, and 7. NIST NCSTAR 1-1E. National Institute of Standards and Technology. Gaithersburg, MD, September.

Grill, R. A., D. A. Johnson, and D. A. Fanella. 2005. Federal Building and Fire Safety

Investigation of the World Trade Center Disaster: Comparison of the 1968 and Current (2003) New 
York City Building Code Provisions. NIST NCSTAR 1-1F. National Institute of Standards and Technology. Gaithersburg, MD, September.

Grill, R. A., and D. A. Johnson. 2005. Federal Building and Fire Safety Investigation of the World Trade Center Disaster: Amendments to the Fire Protection and Life Safety Provisions of the New York City Building Code by Local Laws Adopted While World Trade Center 1, 2, and 7 Were in Use. NIST NCSTAR 1-1G. National Institute of Standards and Technology. Gaithersburg, MD, September.

Grill, R. A., and D. A. Johnson. 2005. Federal Building and Fire Safety Investigation of the World Trade Center Disaster: Post-Construction Modifications to Fire Protection and Life Safety Systems of World Trade Center 1 and 2. NIST NCSTAR 1-1H. National Institute of Standards and Technology. Gaithersburg, MD, September.

Grill, R. A., D. A. Johnson, and D. A. Fanella. 2005. Federal Building and Fire Safety Investigation of the World Trade Center Disaster: Post-Construction Modifications to Fire Protection, Life Safety, and Structural Systems of World Trade Center 7. NIST NCSTAR 1-1I. National Institute of Standards and Technology. Gaithersburg, MD, September.

Grill, R. A., and D. A. Johnson. 2005. Federal Building and Fire Safety Investigation of the World Trade Center Disaster: Design, Installation, and Operation of Fuel System for Emergency Power in World Trade Center 7. NIST NCSTAR 1-1J. National Institute of Standards and Technology. Gaithersburg, MD, September.

Sadek, F. 2005. Federal Building and Fire Safety Investigation of the World Trade Center Disaster: Baseline Structural Performance and Aircraft Impact Damage Analysis of the World Trade Center Towers. NIST NCSTAR 1-2. National Institute of Standards and Technology. Gaithersburg, MD, September.

Faschan, W. J., and R. B. Garlock. 2005. Federal Building and Fire Safety Investigation of the World Trade Center Disaster: Reference Structural Models and Baselime Performance Analysis of the World Trade Center Towers. NIST NCSTAR 1-2A. National Institute of Standards and Technology. Gaithersburg, MD, September.

Kirkpatrick, S. W., R. T. Bocchieri, F. Sadek, R. A. MacNeill, S. Holmes, B. D. Peterson, R. W. Cilke, C. Navarro. 2005. Federal Building and Fire Safety Investigation of the World Trade Center Disaster: Analysis of Aircraft Impacts into the World Trade Center Towers, NIST

NCSTAR 1-2B. National Institute of Standards and Technology. Gaithersburg, MD, September.

Gayle, F. W., R. J. Fields, W. E. Luecke, S. W. Banovic, T. Foecke, C. N. McCowan, T. A. Siewcrt, and J. D. McColskey. 2005. Federal Building and Fire Safety Investigation of the World Trade Center Disaster: Mechanical and Metallurgical Analysis of Structural Steel. NIST NCSTAR 1-3. National Institute of Standards and Technology. Gaithersburg, MD, September.

Luecke, W. E., T. A. Siewert, and F. W. Gayle. 2005. Federal Building and Fire Safety Investigation of the World Trade Center Disaster: Contemporaneous Structural Steel Specifications. NIST Special Publication 1-3A. National Institute of Standards and Technology. Gaithersburg, MD, September. 
Banovic, S. W. 2005. Federal Building and Fire Safety Investigation of the World Trade Center Disaster: Steel Inventory and Identification. NIST NCSTAR 1-3B. National Institute of Standards and Technology. Gaithersburg, MD, September.

Banovic, S. W., and T. Foecke. 2005. Federal Building and Fire Safety Investigation of the World Trade Center Disaster: Danlage and Failure Modes of Structural Steel Components. NIST NCSTAR 1-3C. National Institute of Standards and Technology. Gaithersburg, MD, September.

Luecke, W. E., J. D. McColskey, C. N. McCowan, S. W. Banovic, R. J. Fields, T. Foecke, T. A. Siewert, and F. W. Gayle. 2005. Federal Building and Fire Safety Investigation of the World Trade Center Disaster: Meclranical Properties of Structural Steels. NIST NCSTAR 1-3D.

National Institute of Standards and Technology. Gaithersburg, MD, September.

Banovic, S. W., C. N. McCowan, and W. E. Luecke. 2005. Federal Building and Fire Safety Investigation of the World Trade Center Disaster: Physical Properties of Structural Steels. NIST NCSTAR 1-3E. National Institute of Standards and Technology. Gaithersburg, MD, September.

Evans, D. D., R. D. Peacock, E. D. Kuligowski, W. S. Dols, and W. L. Grosshandler. 2005. Federal Building and Fire Safety Investigation of the World Trade Center Disaster: Active Fire Protection Systems. NIST NCSTAR 1-4. National Institute of Standards and Technology. Gaithersburg, MD, September.

Kuligowski, E. D., D. D. Evans, and R. D. Peacock. 2005. Federal Building and Fire Safety Itvestigation of the World Trade Center Disaster: Post-Construction Fires Prior to September 11, 2001. NIST NCSTAR 1-4A. National Institute of Standards and Technology. Gaithersburg, MD, September.

Hopkins, M., J. Schoenrock, and E. Budnick. 2005. Federal Building and Fire Safety Investigation of the World Trade Center Disaster: Fire Suppression Systems. NIST NCSTAR 1-4B. National Institute of Standards and Technology. Gaithersburg, MD, September.

Keough, R. J., and R. A. Grill. 2005. Federal Building and Fire Safety Investigation of the World Trade Center Disaster: Fire Alarm Systems. NIST NCSTAR 1-4C. National Institute of Standards and Technology. Gaithersburg, MD, September.

Ferreira, M. J., and S. M. Strege. 2005. Federal Building and Fire Safety Investigation of the World Trade Center Disaster: Smoke Management Systems. NIST NCSTAR 1-4D. National Institute of Standards and Technology. Gaithersburg, MD, September.

Gann, R. G., A. Hamins, K. B. McGrattan, G. W. Mulholland, H. E. Nelson, T. J. Ohlemiller, W. M. Pitts, and K. R. Prasad. 2005. Federal Building and Fire Safety Investigation of the World Trade Center Disaster: Reconstruction of the Fires in the World Trade Center Towers. NIST NCSTAR 1-5. National Institute of Standards and Technology. Gaithersburg, MD, September.

Pitts, W. M., K. M. Butler, and V. Junker. 2005. Federal Building and Fire Safety Investigation of the World Trade Center Disaster: Visual Evidence, Damage Estimates, and Timeline Analysis. NIST NCSTAR 1-5A. National Institute of Standards and Technology. Gaithersburg, MD, September. 
Hamins, A., A. Maranghides, K. B. McGrattan, E. Johnsson, T. J. Ohlemiller, M. Donnelly, J. Yang, G. Mulholland, K. R. Prasad, S. Kukuck, R. Anleitner and T. McAllister. 2005. Federal Building and Fire Safety Investigation of the World Trade Center Disaster: Experinents and Modeling of Structural Steel Elements Exposed to Fire. NIST NCSTAR 1-5B. National Institute of Standards and Technology. Gaithersburg, MD, September.

Ohlemiller, T. J., G. W. Mulholland, A. Maranghides, J. J. Filliben, and R. G. Gann. 2005. Federal Building and Fire Safety Investigation of the World Trade Center Disaster: Fire Tests of Single Office Workstations. NIST NCSTAR 1-5C. National Institute of Standards and Technology. Gaithersburg, MD, September.

Gann, R. G., M. A. Riley, J. M. Repp, A. S. Whittaker, A. M. Reinhorn, and P. A. Hough. 2005. Federal Building and Fire Safety Investigation of the World Trade Center Disaster: Reaction of Ceiling Tile Systems to Shocks. NIST NCSTAR 1-5D. National Institute of Standards and Technology. Gaithersburg, MD, September.

Hamins, A., A. Maranghides, K. B. McGrattan, T. J. Ohlemiller, and R. Anleitner. 2005. Federal Building and Fire Safety Investigation of the World Trade Center Disaster: Experiments and Modeling of Multiple Workstations Burning in a Compartment. NIST NCSTAR 1-5E. National Institute of Standards and Technology. Gaithersburg, MD, September.

McGrattan, K. B., C. Bouldin, and G. Forney. 2005. Federal Building and Fire Safety Investigation of the World Trade Center Disaster: Computer Simmlation of the Fires in the World Trade Center Towers. NIST NCSTAR 1-5F. National Institute of Standards and Technology. Gaithersburg, MD, September.

Prasad, K. R., and H. R. Baum. 2005. Federal Building and Fire Safety Investigation of the World Trade Center Disaster: Fire Structure Interface and Thermal Response of the World Trade Center Towers. NIST NCSTAR 1-5G. National Institute of Standards and Technology. Gaithersburg, MD, September.

Gross, J. L., and T. McAllister. 2005. Federal Building and Fire Safety Investigation of the World Trade Center Disaster: Structural Fire Response and Probable Collapse Sequence of the World Trade Center Towers. NIST NCSTAR 1-6. National Institute of Standards and Technology. Gaithersburg, MD, September.

Carino, N. J., M. A. Stames, J. L. Gross, J. C. Yang, S. Kukuck, K. R. Prasad, and R. W. Bukowski. 2005. Federal Building and Fire Safety Investigation of the World Trade Center Disaster: Passive Fire Protection. NIST NCSTAR 1-6A. National Institute of Standards and Technology. Gaithersburg, MD, September.

Gross, J., F. Hervey, M. Izydorek, J. Mammoser, and J. Treadway. 2005. Federal Building and Fire Safety Investigation of the World Trade Center Disaster: Fire Resistance Tests of Floor Truss Systems. NIST NCSTAR 1-6B. National Institute of Standards and Technology. Gaithersburg, MD, September.

Zarghamee, M. S., S. Bolourchi, D. W. Eggers, Ö. O. Erbay, F. W. Kan, Y. Kitane, A. A. Liepins, M. Mudlock, W. I. Naguib, R. P. Ojdrovic, A. T. Sarawit, P. R Barrett, J. L. Gross, and 
T. P. McAllister. 2005. Federal Building and Fire Safety Imestigation of the World Trade Center Disaster: Component, Connection, and Subsystem Structural Analysis. NIST NCSTAR 1-6C. National Institute of Standards and Technology. Gaithersburg, MD, September.

Zarghamee, M. S., Y. Kitane, Ö. O. Erbay, T. P. McAllister, and J. L. Gross. 2005. Federal Building and Fire Safety Investigation of the World Trade Center Disaster: Global Structural Analysis of the Response of the World Trade Center Towers to Impact Damage and Fire. NIST NCSTAR 1-6D. National Institute of Standards and Technology. Gaithersburg, MD, September.

McAllister, T., R. W. Bukowski, R. G. Gann, J. L. Gross, K. B. McGrattan, H. E. Nelson, L. Phan, W. M. Pitts, K. R. Prasad, F. Sadek. 2006. Federal Building and Fire Safety Investigation of the World Trade Center Disaster: Structmral Fire Response and Probable Collapse Sequence of World Trade Center 7. (Provisional). NIST NCSTAR 1-6E. National Institute of Standards and Technology. Gaithersburg, MD.

Gilsanz, R., V. Arbitrio, C. Anders, D. Chlebus, K. Ezzeldin, W. Guo, P. Moloney, A. Montalva, J. Oh, K. Rubenacker. 2006. Federal Building and Fire Safety Investigation of the World Trade Center Disaster: Structmral Analysis of the Response of World Trade Center 7 to Debris Damage and Fire. (Provisional). NIST NCSTAR 1-6F. National Institute of Standards and Technology. Gaithersburg, MD.

Kim, W. 2006. Federal Building and Fire Safety Investigation of the World Trade Center Disaster: Analysis of September 11, 2001, Seisnogram Data. (Provisional). NIST NCSTAR 1-6G. National Institute of Standards and Technology. Gaithersburg, MD.

Nelson, K. 2006. Federal Building and Fire Safety Investigation of the World Trade Center Disaster: The Con Ed Substation in World Trade Center 7. (Provisional). NIST NCSTAR 1-6H. National Institute of Standards and Technology. Gaithersburg, MD.

Averill, J. D., D. S. Mileti, R. D. Peacock, E. D. Kuligowski, N. Groner, G. Proulx, P. A. Reneke, and H. E. Nelson. 2005. Federal Brilding and Fire Safety Investigation of the World Trade Center Disaster: Occmpant Behavior, Egress, and Emergency Communication. NIST NCSTAR 1-7. National Institute of Standards and Technology. Gaithersburg, MD, September.

Fahy, R., and G. Proulx. 2005. Federal Building and Fire Safety Investigation of the World Trade Center Disaster: Analysis of Published Accounts of the World Trade Center Evacuation. NIST NCSTAR 1-7A. National Institute of Standards and Technology. Gaithersburg, MD, September.

Zmud, J. 2005. Federal Building and Fire Safety Investigation of the World Trade Center Disaster: Technical Documentation for Smvey Administration. NIST NCSTAR 1-7B. National Institute of Standards and Technology. Gaithersburg, MD, September.

Lawson, J. R., and R. L. Vettori. 2005. Federal Building and Fire Safety Investigation of the World Trade Center Disaster: The Emergency Response Operations. NIST NCSTAR 1-8. National Institute of Standards and Technology. Gaithersburg, MD, September. 


\section{ACKNOWLEDGMENTS}

We thank the following individuals for their support and assistance during the development of the Fire Structure Interface:

James Filliben developed orthogonal design techniques for estimating model sensitivity.

Richard Gann helped during the review of FSI global simulation results and arranged for additional software licenses during the compute intensive stages of the investigation.

Frank Gayle, Richard Fields, Bill Luecke and Tim Foecke performed tests on thermo-physical properties of steel.

John Gross and Monica Starnes provided data on shape and size of the structural components and reviewed the models for accuracy.

William Grosshandler for technical discussions on thermal analysis.

Anthony Hamins, Alexander Maranghides and the entire staff at the NIST Large Fire Facility performed experiments for FSI model validation and uncertainty analysis.

Steven Kirkpatrick from Applied Research Associates, Albuquerue, New Mexico, and his team performed simulations of aircraft impact and estimated probable damage to structural systems.

Therese McAllister and Fahim Sadek estimated the fireproofing damage due to debris field generated by the aircraft impact on the towers.

Kevin McGrattan and Glenn Forney conducted FDS / Smokeview fire simulations for WTC 1 and WTC 2.

Harold Nelson advised on fireproofing codes and standards and provided a link between modeling effort and current practice.

William Pitts provided information on structural damage to perimeter columns for WTC 1 and WTC 2.

Ronald Rehm conducted preliminary studies on fire spread in the towers and reviewed the final report.

Cheri Sawyer, John Eichner, Walter Soverow and Sydel Cavanaugh from SAIC, Gaithersburg, MD provided administrative support and assistance with transferring the equations into a Word document.

Emil Simiu, Dat Duthinh, Long Phan and Michael Riley collaborated in the field of fire-thermalstructural engineering. Long Phan also provided the thermo-physical property data for concrete.

Dan Williams, Supervisor at the Critical Structures Building Inspections Section, Department of Public Works \& Environmental Services, Fairfax, VA, provided assistance in examining and measuring fireproofing thickness in new and old construction buildings in Fairfax County. 
Jiann Yang and Dale Bentz provided thermo-physical properties of fireproofing material.

Mehdi Zarghamee, Atis Liepins and Frank Kan from Simpson Gumpertz and Heger Inc., Boston, MA provided the structural models for transfer of thermal data. 


\section{EXECUTIVE SUMmARY}

The collapse of the World Trade Center (WTC) towers on September 11, 2001, left only limited direct evidence to explain the collapse of each tower. In contrast, visual evidence, photographs, and videos, of the damage initially inflicted by each aircraft, and the subsequent insult to each structure caused by the fires, was probably more extensive than for any other disaster. Consequently, the National Institute of Standards and Technology (NIST) investigation relied heavily on computer simulations, constrained by the visual evidence, to try to explain the events of that morning.

The collapse of the WTC towers sparked an active debate on what was the maximum steel temperature reached in each tower. Some speculated that the temperatures were high enough to melt the steel columns. The fire protection engineering community considered the differences in fireproofing thickness in WTC 1 and WTC 2 and its effect on steel temperature. Lack of information on damage caused by the aircraft impact complicated any analysis. Software tools that could simulate the thermally induced structural response to spatially and temporally developing fires, over one or more floors of a WTC tower damaged by the impact of the aircraft were needed to carry out the investigation. This report describes a methodology to couple the fire simulations with structural response for each tower. This methodology, termed the Fire Structure Interface (FSI), uses the output of a fire simulation performed using the NIST Fire Dynamics Simulator (FDS) together with aircraft impact analysis results to predict the thermal state of each tower. The temperature distribution is subsequently mapped in a form suitable for use in stress analysis of the load bearing structure.

Traditionally, structural response to extreme fires is estimated by subjecting the structure to a prescribed time-temperature curve. This approach de-couples the stress analysis in the load bearing structure from the fire simulations that predict growth and spread of fires in a building. Direct coupling of the NIST FDS with an appropriate structural analysis package (ANSYS) is an extremely difficult task. Enormous differences in spatial and temporal length scales, differences in numerical techniques and complexity of the software packages (both FDS and ANSYS) precludes a direct coupling of these codes at this time. The FSI, developed during NIST's Investigation into the collapse of the WTC Towers, couples the fire simulations with a thermal analysis suitable for complex building geometries. The development of a methodology for predicting radiative fluxes from spatially evolving fires, to sub-grid scale structural elements (described in Chapter 1) is a critical element of the coupling process. FSI also links the thermal analysis and structural analysis by creating thermal loading data files in a format that is consistent with the structural models.

FSI was used extensively during NIST's Investigation into the collapse of the WTC towers. The Investigation relied heavily on four major modeling efforts. The first was a detailed simulation of the impact of an aircraft on WTC 1 and WTC 2, to predict structural and fireproofing damage in the towers (NIST NCSTAR 1-2).' Next, fire simulations were performed to predict the post-impact spread of fires on multiple floors of each tower (NIST NCSTAR 1-5F). FSI (third of four modeling tasks) couples the results of fire simulations and aircraft impact with thermal analysis of a damaged structure and maps the

1 This reference is to one of the companion documents from this Investigation. A list of these documents appears in the Preface to this report. 
resulting temporally and spatially varying temperatures on to the structural models. Finally, global structural analysis (NIST NCSTAR 1-6) of the towers was performed to predict the thermally induced structural response and to identify the most probable collapse mechanism for each building.

The development of any computer model requires a complementary experimental program to furnish large-scale test data with which to compare model predictions. A set of experiments with liquid hydrocarbon fuel fires ( $2 \mathrm{MW}$ and $3 \mathrm{MW}$ ) in a compartment with various structural components such as columns, trusses and bars was performed at the Large Fire Facility at NIST (NIST NCSTAR 1-5B). The structural components were insulated in some tests and un-insulated in other tests to study the role of fireproofing. Experimental results were compared with model predictions to assess the accuracy of the models and their sensitivity to changes in various input parameters. These experiments and model predictions are summarized in Chapter 2.

Most of the structural steel in the WTC towers was "fireproofed" with sprayed fire-resistive material (SFRM). The insulation presents some special problems that must be considered. The temperatures reached in the steel in any fire simulation are extremely sensitive to the amount and spatial distribution of the insulation. However, the amount of insulation sprayed on the trusses during construction is uncertain. Moreover, it is impossible to spray insulation uniformly on complex surfaces like the truss system. Finally, any analysis of the thermal loading of the towers must consider the possibility of insulation damage caused by the aircraft impact. Thus, any plausible model of the insulation must account for random variations in the thickness of the insulation, and the sensitivity of the results to variations caused by insulation damage must be established. Exploratory studies described in Chapter 3 were performed to assess the role of fireproofing thickness and variability on the thermal response of structural elements. Fireproofing thickness and fireproofing danage due to aircraft impact is identified as the single niost important parameter in these simnlations that has a direct impact on the thermally indinced structnral response.

The exploratory studies, experimental data, photographic evidence (NIST NCSTAR 1-5A) as well as published literature, helped guide the development of models for various structural components (perimeter and core columns, floor trusses, core beams and concrete slabs). A detailed thermal analysis (coupled with a realistic fire) of each structural component is described in Chapter 4 through Chapter 7. A sampling of the calculated results is shown to illustrate how the large-scale temperature distributions in the steel and concrete change with time. One of the most striking observations that emerge from these results is the wide variation of "time - temperature" curves that hold at different points in the structure of each tower. Equally striking is the lack of resemblance of these curves to the "standard" time temperature curves used in furnace tests of structural elements.

The component models were developed such that they could be readily replicated to cover an entire floor or extend to multiple floors of the WTC towers. Construction of the global models was guided by the need to adequately resolve the underlying physics without resulting in computationally prohibitive simulations. During the course of this Investigation, hundreds of full floor simulations wcre performed to understand the nature of the thermal insult. Four global simulations, two each for WTC 1 and WTC 2, are reported for prediction of thermally induced structural response and collapse of the towers. Each global thermal simulation is coupled with a corresponding fire simulation and includes the aircraft impact damage estimates. The simulations described in Chapter 8 through Chapter 11 represent an application of FSI to simulate the global thermal response of WTC 1 and WTC 2. Results for the four cases are 
compared and contrasted in Chapter 12. The figures included in these chapters are visual representations of the thermal state of the towers at specific instants in time. 
This page intentionally left blank. 


\section{Chapter 1 \\ SUB-GRID SCALE MODEL FOR RADIATIVE HEAT TRANSFER}

Simulation of the effects of severe fires on the structural integrity of buildings requires a close coupling between the gas phase energy release and transport phenomena and the stress analysis in the load bearing materials. The connection between the two is established primarily through the interaction of the radiative heat transfer between the solid and gas phases with the conduction of heat through the structural elements. This process is made difficult in large, geometrically complex buildings by the wide disparity in length and time scales that must be accounted for in the simulations. A procedure for overcoming these difficulties. used in the analysis of the collapse of the World Trade Center (WTC) towers, is presented in this chapter. The large-scale temperature and other thermo-physical properties in the gas phase are predicted using the National Institute of Standards and Technology (NIST) Fire Dynamics Simulator (FDS). Heat transfer to sub-grid scale structural elements is calculated using a simple radiative transport model that assumes the compartment is locally divided into a hot, soot laden upper layer and a cool, relatively clear lower layer. The properties of the two layers are extracted from temporal averages of the results obtained from the FDS. Explicit formulae for the heat flux are obtained as a function of temperature, hot layer depth, soot concentration, and orientation of each structural element. These formulae are used to generate realistic thermal boundary conditions for a coupled transient threedimensional finite element code. This code is used to generate solutions for the heating of complex structural assemblies.

\section{$1.1 \quad$ INTRODUCTION}

The coupling between fire dynamics and structural analysis in building fires is largely due to radiative heat transfer from combustion products to structural elements. A common assumption used in the thermal analysis of structures is that the radiant heat flux, $q$, incident upon the surface of the element is related to the local gas temperature, by the formula $q=\sigma T^{4}$. Here, $\sigma$ is the Stefan-Boltzmann constant $\left(5.67 \times 10^{-8} \mathrm{~W} / \mathrm{m}^{2} \mathrm{~K}^{4}\right)$. Thus, given a spatially uniform enclosure temperature and a "time-temperature curve" the thermal environment of the enclosure is specified, and attention can be confined to the calculation of the temperature and stress distribution in the structural elements.

However, this is tantamount to assuming that the radiation field is in local equilibrium with the gas, an unlikely scenario in most fires. In general, the radiation field must be determined from solutions of the radiative transport equation, which relates the incident flux to the spatial distribution of temperature and combustion products (most particularly the distribution of soot particulate) as well as the enclosure geometry. Such calculations are typically performed as part of a computational fluid dynamics (CFD) based simulation of the fire dynamics. However, the ability to couple such codes as the NIST FDS (McGrattan et. al 2002) directly to a suitable structural analysis code does not yet exist. The enormous differences in spatial and temporal length scales, differences in numerical techniques, and the complexity of the computer codes makes the development of an efficient coupled analysis of fire-structure interactions a daunting task. CFD codes like FDS assume that the radiative transport to a surface and the thermal response of that structural element can be calculated as if the surface is locally one dimensional. However, important elements of the WTC structure (e.g., trusses and perimeter columns) are inherently 
three dimensional. Moreover, many of the critical segments of these structures lie below the resolution limits of any CFD calculation that attempts to simulate the fire dynamics over the entire floor or multiple floors of the WTC towers. Finally, the computed temperature distribution in the structure must be in a format accessible to the code used to perform structural analysis.

An interim approach to the calculation of the coupled heat transfer problem is presented here. It takes advantage of the fact that the horizontal dimensions of each floor of the WTC towers are much greater than the height of an individual floor. The ratio of these lengths, the geometric aspect ratio of the floor, is quite large. Each floor is about $63 \mathrm{~m}$ on a side and $4 \mathrm{~m}$ high. Thus, any floor can be thought of as a large aspect ratio compartment with relatively few interior obstacles. A fire in a compartment configured in this manner tends to produce a stratified spatial distribution of temperature and soot particulate. The temperature and soot concentration changes quite rapidly in the vertical direction, but much more slowly in the two horizontal directions. Under these circumstances, the compartment can be thought of as containing a hot, sooty upper layer and a cool, relatively clear lower layer. The thickness, soot content, and average temperature of each layer vary slowly in the horizontal directions. This idealization is very similar to that used in "zone models" (Quintiere, 1989) of fire dynamics, which ignore any variation of thermal properties in the horizontal directions.

The local spatial and temporal averages needed to define the properties of the layers are taken from the output of simulations generated by FDS (Figure 1-1). Spatial averaging is defined by the grid size used in the FDS simulation. (For the WTC Investigation, the FDS resolution is $50 \mathrm{~cm}$, and therefore, the spatial averaging is performed over a $50 \mathrm{~cm}$ square area). The time intervals needed to generate the averages used are chosen to be comparable to the time required for heat to diffuse through the smallest structural members of interest. The spatial averages replace the detailed vertical temperature and soot profiles with an effective "zone model" profile. It is important to note that the quantities averaged are $T^{4}$ and the absorption coefficient, since these are the variables needed to define the radiative transport problem. The result of this simplification is that the radiative transport equation takes the same form that it would have in a plane layer geometry.

For this simplified geometry, the radiative transport equation can be solved exactly and explicit formulae for the heat flux obtained as functions of the temperatures, hot layer depth, soot concentration, and orientation of the structural element. The basic analysis is quite well known in the heat transfer community (Siegel and Howell, 1992). These formulae can be used directly as input into finite element computer codes widely used for time dependent three dimensional structural analysis. The output of such codes yields the temperature distribution required for computing the thermal strains / stresses induced in the structural assembly when exposed to a fire. The higher temperature induced in the solid can also degrade the strength of the material (yield strength) and affect the elastic-plastic stress strain relationship. Thus, an approximate methodology capable of dealing with the heat transfer to realistic models of a building structure can be developed.

The objective of this chapter is to demonstrate how this approach can be applied to study the heating of a complex building structural geometry that is an idealization of an entire floor of the one of the World Trade Center towers. The general solutions to the radiative transport equation and explicit results for radiative heat flux to vertical and horizontal planar surfaces are summarized in the next section. 


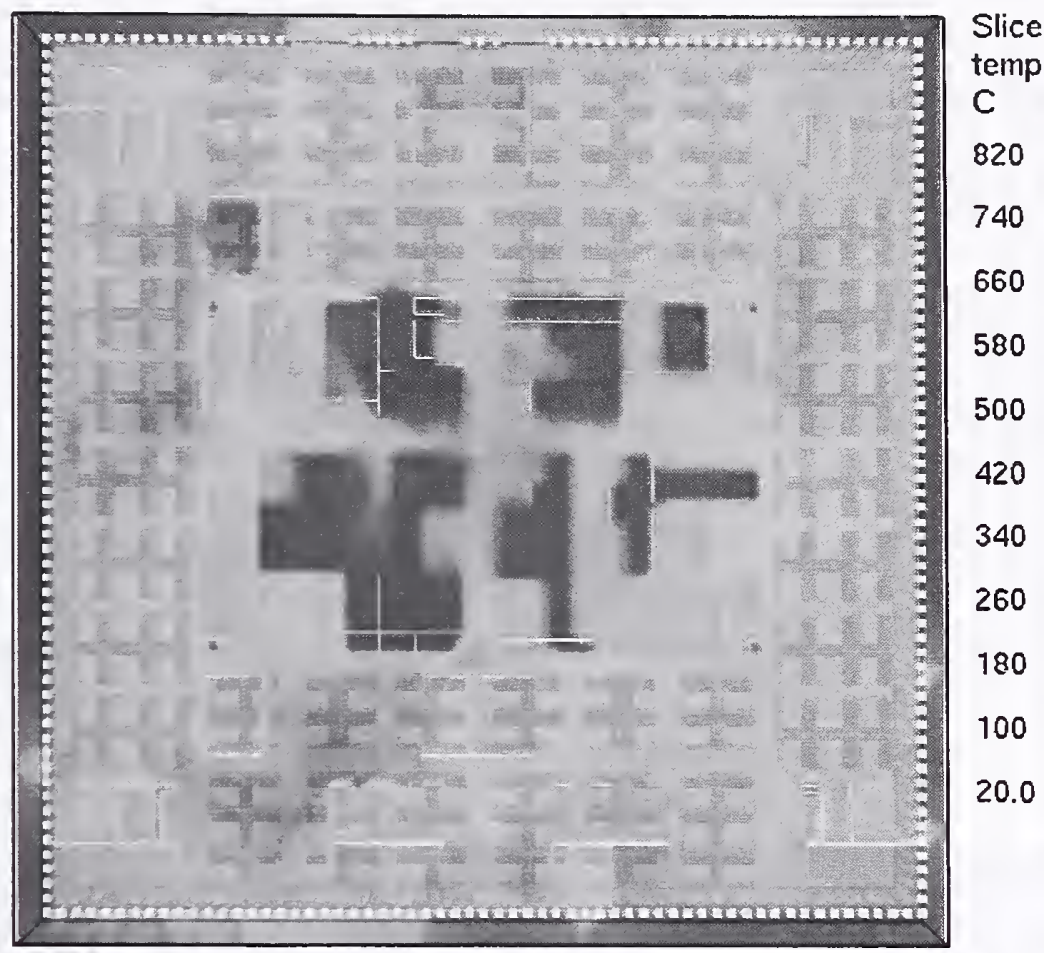

Slice

temp

C

820

740

660

580

500

420

340

260

180

100

20.0

Figure 1-1. Computed upper layer temperatures as predicted from an FDS simulation for World Trade Center Tower 1, Floor 96. The temperature contours (in degree C) are shown at 1,000 seconds after the impact of the airplane.

\subsection{RADIATIVE TRANSPORT MODELING}

Two major simplifications are introduced so that incident radiative fluxes that apply surface loads for thermal analysis of structures are obtained. First, we employ the concept of a grey gas, whose properties are independent of frequency. If the spectral absorption coefficient, $\kappa_{v}$, is replaced by some average value to be defined later, then the radiative transport equation can be expressed in terms of the integrated intensity, $I(\vec{r}, \vec{\Omega})$.

$$
\begin{gathered}
\vec{\Omega} \cdot \nabla I=\kappa\left(\frac{\sigma T^{4}}{\pi}-I\right) \\
I(\vec{r}, \vec{\Omega})=\int_{0}^{\infty} I_{v} d v
\end{gathered}
$$

The utility of this approximation depends strongly on the properties of the absorbing medium. For the problems of interest here, soot particulate is the dominant absorber and emitter of thermal radiation. The typical soot size distribution and temperature range are such that the spectral dependence of the soot 
varies slowly compared with that of the Planck distribution. The result is that the soot absorption coefficient can be approximated as follows:

$$
\kappa=(\text { const }) f_{v} T \quad(\mathrm{~cm})^{-1}
$$

Here $f_{v}$ is the soot volume fraction. Formulae of this type, with some variation in the numerical coefficient, are widely used in the combustion and fire research literature (Quintiere, 1989). The quantity $(\kappa)^{-1}$ based on representative values for the enclosure in question is the optical depth of the soot laden gas.

The second simplification is that the enclosure geometry induces a vertically stratified distribution of temperature and combustion products. Specifically, it is assumed that the vertical dimensions of each part of the enclosure that can be considered as a separate entity are much smaller than either of the horizontal dimensions. As a fire develops in such an enclosure, the hot layer that forms has spatial variations in these properties that vary much more rapidly in the vertical than in the horizontal directions (Fig. 2). If $d$ denotes the depth of a hot layer of roughly uniform thermal properties, and $L$ denotes any of the horizontal directions, then the analysis of the radiation field as a vertically stratified layer is internally consistent if $\kappa L \gg 1$ Physically, this means that the thermal radiation from remote points of the hot layer cannot penetrate to affect the local radiation fields. In a typical commercial building environment with ceiling heights of a few meters, we are intercsted in situations in which $\kappa d \approx 1$. If $\kappa d \gg 1$, then the radiation is in equilibrium with the matter at the local temperature, $T$, and the local heat flux is $\sigma T^{4}$. If $\kappa d \ll 1$, then the gas is locally transparent to thermal radiation.

The quantity of most interest in the analysis to follow is the heat flux incident on a material surface. Let $\vec{n}$ denote the unit normal pointing outward from an element of surface. Then the radiation heat flux to that surface, $q_{n}$, is determined by the formula:

$$
q_{n}=-\int_{\vec{\Omega} \cdot \vec{n} \leq 0} I(\vec{\Omega}, \vec{r}) \vec{\Omega} \cdot \vec{n} d \vec{\Omega}
$$

Clearly, the orientation of the surface, as well as the radiation field in the gas, plays a role in the analysis. We will be particularly concerned with both vertically oriented (columns) and horizontally oriented (floors, ceilings, trusses) surfaces.

\section{$1.3 \quad$ PLANE LAYER ANALYSIS}

Now consider the analysis of a plane heated layer of depth $d$. We define a Cartesian coordinate system $\vec{r}=x \vec{i}+y \vec{j}+z \vec{k}$ such that $(x, y)$ are the horizontal coordinates and $z$ is the vertical coordinate with $z=0$ at the bottom of the hot layer. If the hot layer extends down to the floor, then the origin is at the floor. However, we always have $0 \leq z \leq d$ no matter how deep the layer is (Figure 1-2). The absorption coefficient $\kappa=\kappa(z)$; similarly the temperature $T=T(z)$. The unit vector $\vec{\Omega}$ can be represented in terms of a spherical polar coordinate system oriented so that the polar angle $\theta$ is measured from the positive $z$ axis.

$$
\vec{\Omega}=\sin \theta \cos \phi \vec{i}+\sin \theta \sin \phi \vec{j}+\cos \theta \vec{k}
$$


In this system of coordinates, the integrated intensity, $I$, depends only on $z$ and $\cos \theta$. The radiative transport equation becomes:

$$
\cos \theta \frac{\partial I}{\partial z}=\kappa(z)\left(\frac{\sigma T^{4}(z)}{\pi}-I\right)
$$

Considered as a function of $z$ eq. (6), is in fact two equations. For values of $\cos \theta \geq 0$ the radiation emerges from the bottom of the hot layer. We denote the intensity of this radiation as $I^{+}$. For values of $\cos \theta \leq 0$; the radiation emerges from the ceiling. Let this radiant intensity be $I$. Boundary conditions for $I^{+}$and $I$ are obtained by assuming that radiation entering the hot layer from below is in equilibrium with a "cool" floor at "ambient" temperature $T_{a}$, while radiation emitted by the "hot" ceiling is in equilibrium with the ceiling temperature $T_{c}$.

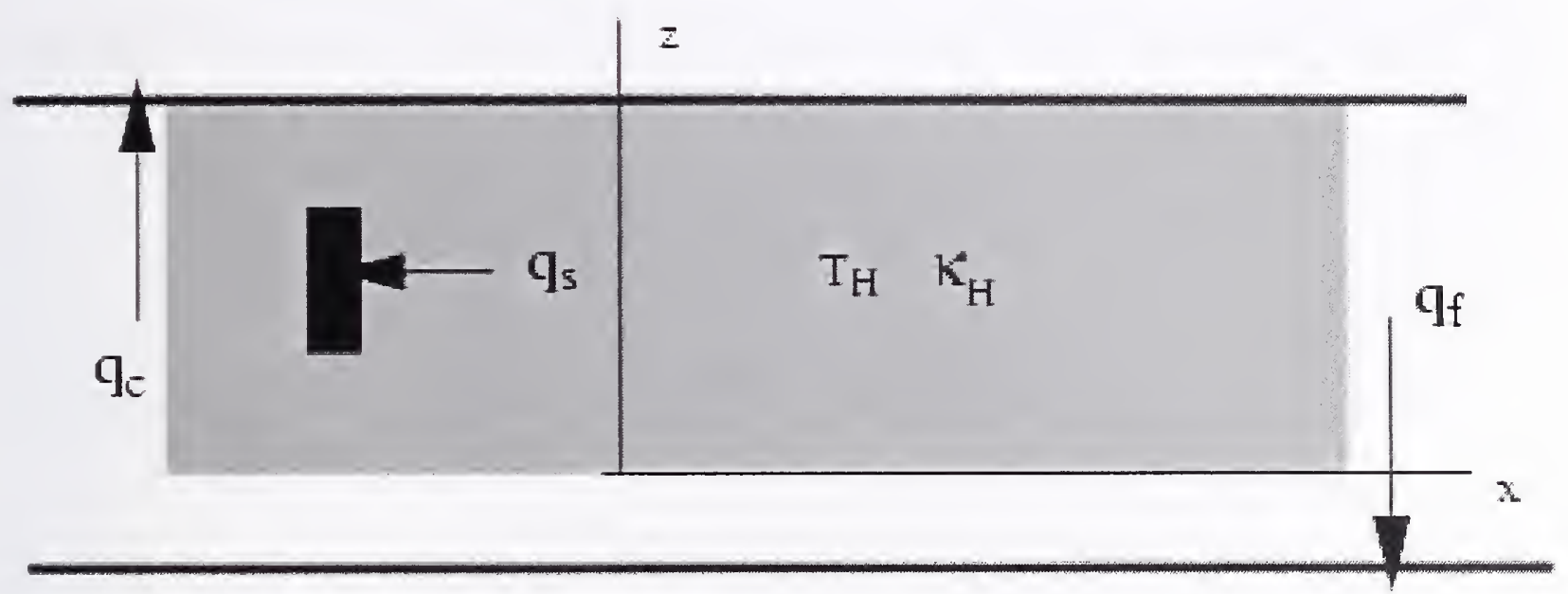

Figure 1-2. Schematic of a two-layer model of a fire environment showing a hot layer at temperature $T_{H}$ and absorption coefficient $\kappa_{H}$.

The result of these assumptions is that eq. (6) must be solved subject to the following boundary conditions:

$$
I^{+}(z=0)=\frac{\sigma T_{a}^{4}}{\pi} \quad I^{-}(z=d)=\frac{\sigma T_{c}^{4}}{\pi}
$$

The solutions can now be readily obtained in terms of local optical depths $r^{+}(z)$ and $r^{-}(z)$ defined as follows:

$$
\tau^{+}(z)=\int_{0}^{z} \kappa(z) d z \quad \tau^{-}(z)=\int_{z}^{d} \kappa(z) d z
$$


We are now in a position to evaluate the heat flux to a target surface. If the enclosure is completely unobstructed, then only the heat flux to the floor and ceiling need be considered, and no further assumptions are necessary. These results are well known, and will emerge as part of the analysis to follow. However, in order to calculate the heat flux to structural elements it is necessary to assume that each surface is unobstructed by others for the purpose of calculating the incident flux.

This is a reasonable assumption if the cross-sectional area of each element is small compared with the unobstructed area in each plane normal to the axis of each of the elements. For example, the projected floor area of a room containing several columns must be much larger than the cross-sectional area of all the columns. Similarly, a vertical plane crossing the enclosure should have an area much larger than that of all the trusses that penetrate the plane.

First consider horizontal surfaces. There are two possibilities: a ceiling-like or downward facing surface, corresponding to $\vec{n}=-\vec{k}$, and a floor-like or upward facing surface, corresponding to $\vec{n}=\vec{k}$. The lower surface of a truss would be an example of a downward facing surface, while the upper surface would be an upward facing surface. Let $q_{c}(z)$ be the heat flux to a downward facing surface located at a height, $z$, and $q_{f}(z)$ be the corresponding flux to an upward facing surface. If we further assume that the upper layer temperature, $T$, takes on the constant value $T=T_{H}$ and that the absorption coefficient $\kappa=\kappa_{H}$ is also constant, the following explicit results are obtained:

$$
\begin{gathered}
\tau^{+}=\kappa_{H} z \quad \tau^{-}=\kappa_{H}(d-z) \\
q_{c}(z)=2 \sigma T_{a}^{4} E_{3}\left(\tau^{+}\right)+\sigma T_{H}^{4}\left(1-2 E_{3}\left(\tau^{+}\right)\right) \\
q_{f}(z)=2 \sigma T_{c}^{4} E_{3}\left(\tau^{-}\right)+\sigma T_{H}^{4}\left(1-2 E_{3}\left(\tau^{-}\right)\right)
\end{gathered}
$$

Here, $E_{n}(z)$ is the Exponential Integral as defined in (Abramowitz and Stegun, 1964).

The flux to a downward facing surface (Figure 1-3) starts out from very low values because at the bottom of the hot layer the surface only "sees" radiation from the "cold" lower surface. As the downward facing surface is moved upward through the hot layer, the surface sees more and more of the hot layer radiation, and eventually reaches a value corresponding to equilibrium radiation from an infinitely thick layer. The flux to an upward facing surface typically starts from a somewhat higher value near the ceiling, since the ceiling temperature is usually much hotter than the floor temperature. As the upward facing surface moves down through the hot layer, it also sees more and more radiation from the layer and ultimately the flux again reaches a value corresponding to radiative equilibrium in the layer. In both cases, however, a substantial fraction of the layer is far from radiative equilibrium with much lower fluxes to the surfaces. 


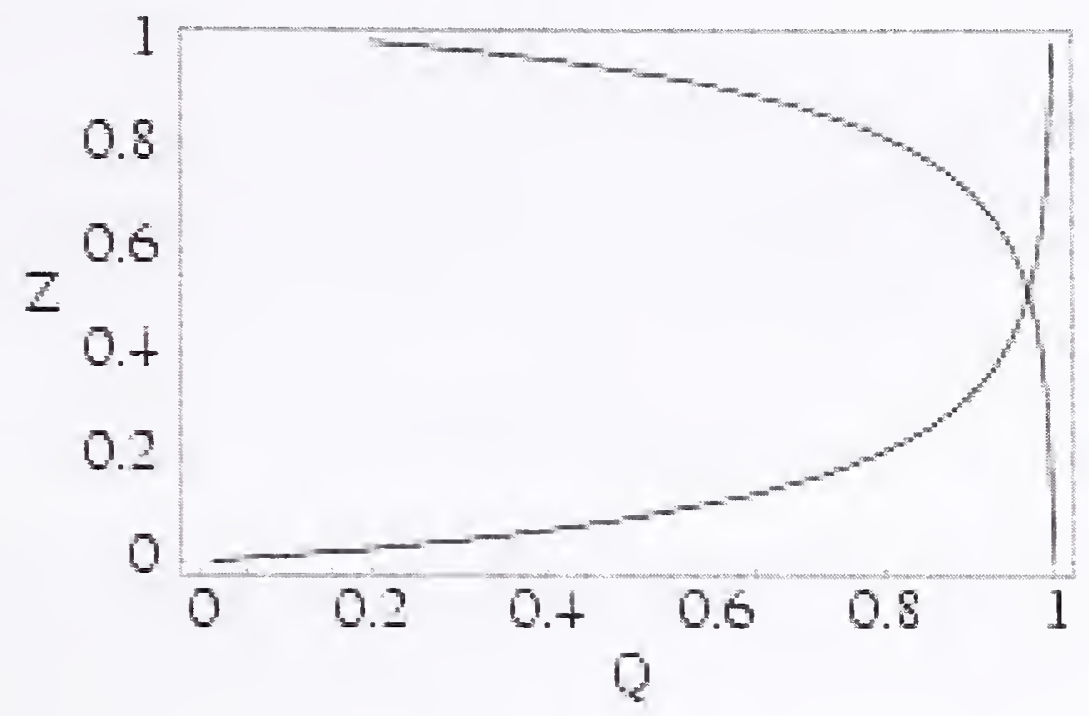

Figure 1-3. Dimensionless heat fluxes, $Q$, showing profiles as a function of dimensionless height, $Z$, for a downward facing surface (bottom curve) and upward facing surface (top curve).

The heat flux to a vertical surface is not usually calculated within the context of the plane layer problem. While the analysis is not difficult, it does not seem to be readily available. We consider this case next. Let the direction of the outward pointing normal to the surface be $\vec{n}=-\vec{i}$. Since the radiant intensity is independent of the azimuthal angle, $\phi$, any horizontal direction could be chosen, and this choice is convenient for the analysis. Under these circumstances, $\vec{\Omega} \cdot \vec{n}=-\sin \theta \cos \phi$. Thus, we need to evaluate equation (4) over the domain $0 \leq \theta \leq \pi,-\pi / 2 \leq \phi \leq \pi / 2$. Denoting the heat flux to the vertical surface by $q_{s}(z)$, we have:

$$
q_{s}(z)=2\left(\int_{0}^{\pi / 2} I^{+} \sin ^{2} \theta d \theta+\int_{\pi / 2}^{\pi} I^{-} \sin ^{2} \theta d \theta\right)
$$

Equation (12) shows that the solution is a sum of two terms involving $I^{+}$and $\Gamma$ respectively.

Denote the respective contributions of these terms as $q_{s}^{+}$and $q_{s}^{-}$respectively. Then:

$$
q_{s}(z)=q_{s}^{+}(z)+q_{s}^{-}(z) .
$$

Again, letting the upper layer temperature and absorption coefficient be constant, the necessary integrations can be carried out to yield:

$$
q_{s}^{+}(z)=\frac{2}{\pi} \sigma T_{a}^{4} f\left(\tau^{+}\right)+\frac{2}{\pi} \sigma T_{H}^{4} g\left(\tau^{+}\right)
$$




$$
\begin{gathered}
q_{s}^{-}(z)=\frac{2}{\pi} \sigma T_{c}^{4} f\left(\tau^{-}\right)+\frac{2}{\pi} \sigma T_{H}^{4} g\left(\tau^{-}\right) \\
f(z)=K i_{1}(z)-K i_{3}(z) \\
g(z)=\frac{\pi}{4}-K i_{1}(z)-K i_{3}(z)
\end{gathered}
$$

Here, $K i_{r}(z)$ is the $r^{\text {th }}$ integrated integral of the Modified Bessel function, $K_{0}(z)$ (Abramowitz and Stegun, 1964a).

These results are illustrated in Figure 1-4, which shows profiles of radiative flux to a vertical surface as a function of the dimensionless optical depth, $\kappa_{H} d$. The floor and ceiling temperature ratios are respectively, $T_{a} / T_{H}=1 / 3$ and $T_{c} / T_{H}=2 / 3$. The most important observation is the extreme sensitivity of the results to the optical depth of the hot layer. In the present example, the flux corresponding to radiative equilibrium is not reached anywhere for any of the profiles. The maximum value of the flux is reached near the center of the hot layer, since both the upward and downward moving radiation have had some chance to be absorbed and re-emitted at the higher temperatures. However, unless the layer is either much thicker or sootier than is the case for the present example, the equilibrium flux cannot be achieved.

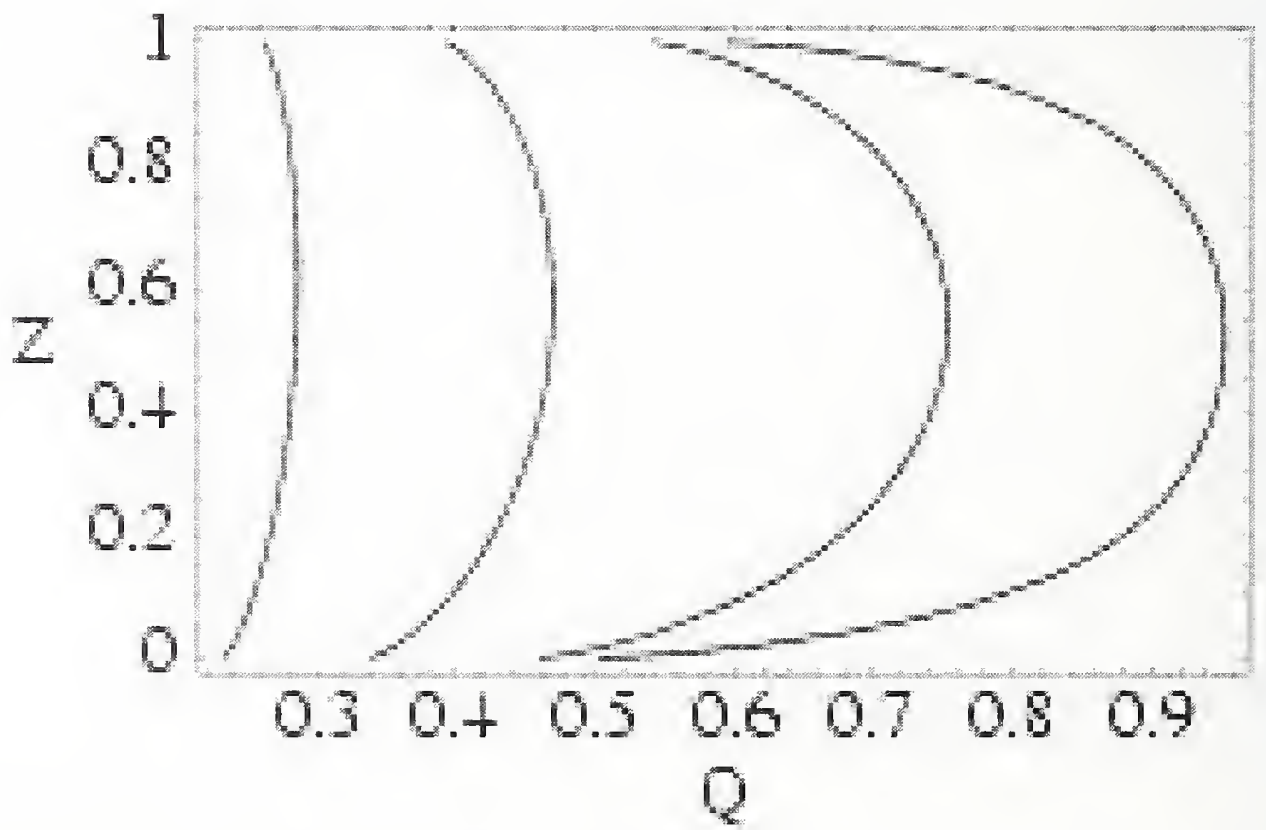

Figure 1-4. Dimensionless heat fluxes showing profiles as a function of dimensionless height, $Z$. The flux profiles correspond to values of dimensionless optical depth. 


\subsection{CONVECTIVE HEAT TRANSFER}

Structural elements can heat up or cool down due to convective heating or cooling from the gas that surrounds the structure. Radiative heat transfer described in the earlier sections is the dominant mode of heat transfer at high temperatures, while convective heat transfer is dominant at relative low temperatures. The overall effect of convection is included through Newton`s law of cooling:

$$
\mathrm{q}=\mathrm{hA}\left(\mathrm{T}_{\mathrm{w}}-T_{\infty}\right)
$$

Here, the heat-transfer rate, $q$, is related to the overall temperature difference between the wall and fluid and the surface area $\mathrm{A}$. The quantity, $\mathrm{h}$, is called the convection heat transfer coefficient and is a function of the velocity of the fluid and its thermo-physical properties. The fluid temperature, $T_{\infty}$, of the ambient air is obtained from the results of the FDS simulations and is a function of the location of the structural element relative to the hot layer.

\subsection{SUMMMARY}

The coupling between fire dynamics and structural analysis due to radiative and convective heat transfer from the hot combustion products to the structural elements is studied. A simple radiative transport model is developed, that permits the prediction of radiative flux incident on the surface as a function of the orientation of the structural element, temperature, hot layer depth, and soot concentration. The model is used to study radiative and convective heat transfer to structural elements of the WTC tower. Chapter 2 through Chapter 7 describe the results of this analysis at the component level, while Chapter 8 through Chapter 11 present results of the global tower analysis. 
This page intentionally left blank. 


\section{Chapter 2 \\ MODEL VALIDATION AND ACCURACY ASSESSMENT}

Chapter 1 of this report described a methodology for coupling fire simulations with the thermal response of structural elements. This methodology was used extensively in National Institute of Standards and Technology's (NIST's) World Trade Center (WTC) Investigation to predict the thermally induced structural response to spatially and temporally developing fires. To test the accuracy of the methodology, a series of large-scale fire experiments was conducted in the NIST Large Fire Laboratory from March 13 to March 26, 2003. The experiments established a data set, which was used to test that the models were accurately capturing the thermal response of the structural elements.

In this chapter, an application of Fire Structure Interface (FSI) to simulate these large-scale experiments will be discussed. Model predictions were found to compare favorably with experimental results. The accuracy of the FSI results and its sensitivity to changes in various input parameters is assessed. Differences between numerical predictions and experimental data were attributed to uncertainty in physical input parameters, the most important of which was the variability in fireproofing thickness on a structural component and to a lesser extent the heat release rate in fire simulations.

\section{$2.1 \quad$ OVERVIEW OF EXPERIMENTS}

A steel-frame compartment ( $3.60 \mathrm{~m}$ by $7.04 \mathrm{~m}$ by $3.82 \mathrm{~m}$ high) lined with $25 \mathrm{~mm}$ thick calcium silicate board (referred to as Marinite, manufactured by BNZ Materials, Inc.) was constructed. Several steel components (two trusses, one thin-walled tubular column, and a simple rod) were placed in this compartment. The components wcre either left bare or had a fibrous sprayed firc-resistive material (SFRM) applied in two nominal thicknesses (17 $\mathrm{mm}$ and $34 \mathrm{~mm})$.

The fire was generated using liquid hydrocarbon fuels introduced by a two-nozzle spray burner onto a $1 \mathrm{~m}$ by $2 \mathrm{~m}$ pan $(0.1 \mathrm{~m}$ deep). The fire sizes tested were between $1.9 \mathrm{MW}$ and $3.4 \mathrm{MW}$ to assure that the structural components were immersed in flames and hot gases. The fire pan was located on the floor of the enclosure, $3.5 \mathrm{~m}$ from the front of the compartment (west side). Two fuels were used. A blend of heptane isomers ("heptane") was selected as the baseline fuel. A mixture composed of 60 percent heptane and 40 percent toluene by mass was selected as the second fuel, as it is representative of fires that yield elevated amounts of soot.

Figure 2-1 is a schematic drawing of the compartment and its contents. The compartment was equipped with eight openings. There was no forced ventilation in the compartment, and the ventilation was solely induced by the fire. The openings through which fresh air entered were located $1 \mathrm{~m}$ above the floor on the west wall of the compartment. The openings through which heat and combustion products were emitted were located $2 \mathrm{~m}$ above the floor on the other end of the enclosure. The compartment was located so that the exhaust vents were under the $6 \mathrm{~m}$ by $6 \mathrm{~m}$ exhaust hood. Fire products flowed into a large exhaust hood for measurement of the heat release rate and were then exhausted from the building. A vertical 
baffle $1 \mathrm{~m}$ high, $2 \mathrm{~m}$ wide, and $0.15 \mathrm{~m}$ deep, was placed $2 \mathrm{~m}$ from the west wall of the compartment to limit flame tilt. The experiments are described in detail in NIST NCSTAR 1-5B. ${ }^{2}$

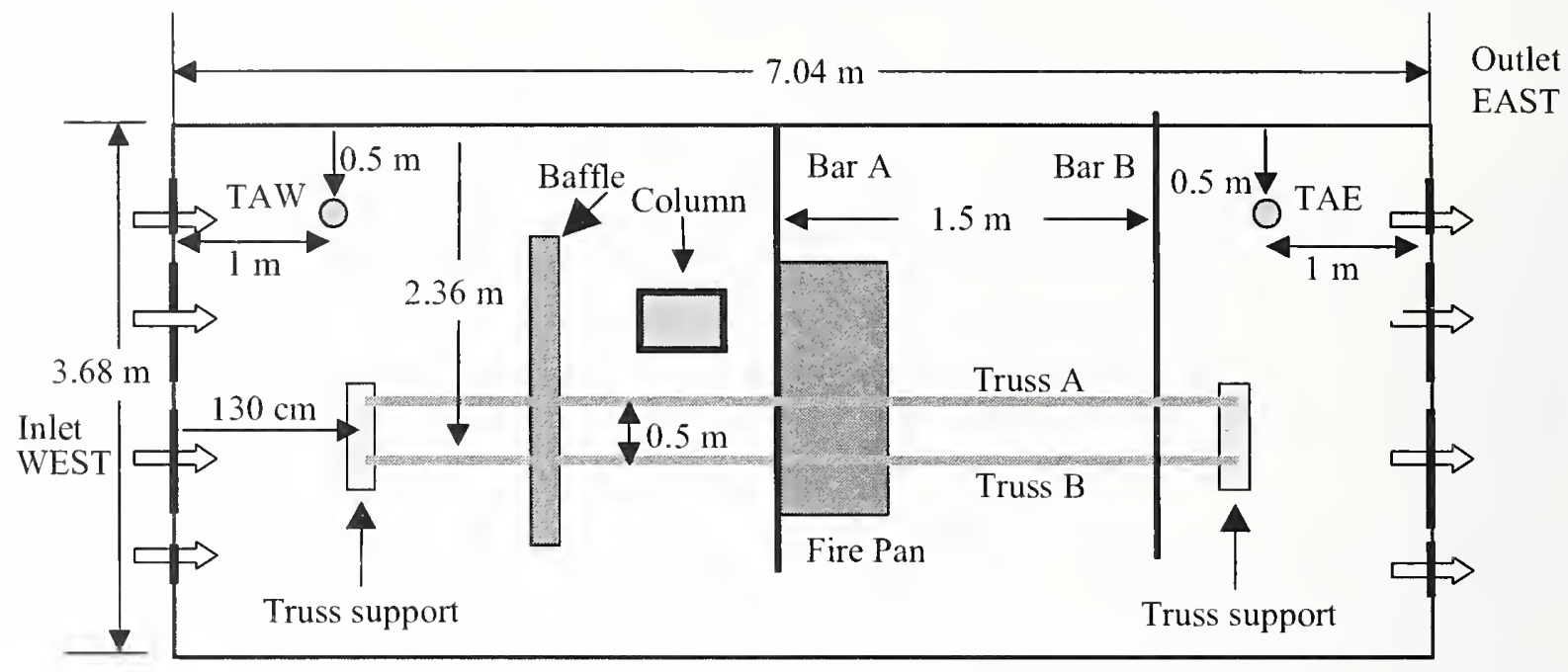

Figure 2-1. Schematic drawing of compartment contents.

\subsubsection{Test Matrix}

The test matrix for which FSI simulations were performed and the experimental conditions for each test are presented in Table 2-1. The table lists the test number, the date the test was conducted, the nominal fire heat release rate $(\dot{Q})$, the fuel type, the nominal thickness of the SFRM on the steel, and the approximate test duration.

Table 2-1. Test Matrix for comparison with numerical simulations.

\begin{tabular}{|c|c|c|c|c|c|}
\hline Test & Date & $\begin{array}{c}\text { Nominal } \dot{Q} \\
(\mathbf{M W})\end{array}$ & Fuel & $\begin{array}{c}\text { SFRM } \\
\text { Thickness (mm) }\end{array}$ & $\begin{array}{c}\text { Nominal Duration } \\
\text { (min) }\end{array}$ \\
\hline 1 & $3 / 13 / 03$ & 2.0 & Heptane & None & 14.3 \\
\hline 5 & $3 / 24 / 03$ & 3.0 & Heptane & 17,34 & 51.2 \\
\hline
\end{tabular}

More than 350 channels of data were acquired for each of the experiments. Measurements were made of the fuel flow, steel temperatures, heat release rate, local radiative and total heat flux to steel and SFRM, gas phase temperature and location of upper and lower layers. Thermocouples were placed on the surface of the walls and ceiling, within the walls, on the surface of the steel components, and at the surface of the SFRM. Heat flux gauges were placed strategically around the compartment to measure the transport of radiant energy. Bare-bead Type $\mathrm{K} 30$-gauge thermocouples were used to measure the temperature histories at the steel and SFRM surfaces. Thermocouple beads were spot welded to the bare steel surfaces.

In this report we will present FSI results for a few representative cases in Test 1 (un-insulated components) and Test 5 (insulated components). A complete description of all the results, including the

2 This reference is to one of the companion documents from this Investigation. A list of these documents appears in the Preface to this report. 
instrumentation. measurement techniques, locations, and uncertainty associated with each measurement has been presented in NIST NCSTAR 1-5B.

\subsubsection{Steel Elements}

The time varying temperatures of the steel components were measured to determine the thermal response of structural steel components to quasi-steady controlled room fire conditions, including flame immersion. and to establish a data set to validate predictions of the temperature rise of insulated and uninsulated structural steel components. The components were tested in an un-insulated state in Test 1 and with an insulating coating of fireproofing or fibrous SFRM in Test 5. Steel components were selected to meet several criteria. including the following:

- Components were sized to be similar to those in WTC 1 and WTC 2.

- A bar was included as a simple reference case for analysis purposes.

- Various types of structural components were selected to measure the heating effect of fires on horizontal and vertical steel components.

- The cross sectional thicknesses of the steel and the SFRM were selected based on representative values used in the WTC towers.

Three types of steel components were selected for study: two bars, a hollow steel tubular column, and two bar-joist trusses. The bars were nominally $3 \mathrm{~m}$ long and $25 \mathrm{~mm}$ in diameter. The columns were $0.26 \mathrm{~m}$ by $0.36 \mathrm{~m}$ tubular steel sections with a nominal $6 \mathrm{~mm}$ wall thickness. The trusses were $4.6 \mathrm{~m}$ long and $0.8 \mathrm{~m}$ deep with $64 \mathrm{~mm}$ to $76 \mathrm{~mm}$ double angles for the top and bottom chords. The top and bottom chords of the truss were $0.84 \mathrm{~m}$ apart and were bound by three web bars ( $25.6 \mathrm{~mm}$ thick), emanating from a single location on the bottom chord every $1.53 \mathrm{~m}$. The top surface of the truss chords was located $15 \mathrm{~cm}$ from the ceiling. Detailed drawings are given in NIST NCSTAR 1-5B. The steel components were constructed of A572 steel, and the density was taken as $7860 \mathrm{~kg} / \mathrm{m}^{3}$; its specific heat was $450 \mathrm{~J} / \mathrm{kg} \cdot \mathrm{K}$ (McColskey and Leucke 2005).

\subsubsection{Sprayed Coating of the Steel}

The SFRM product used in the WTC towers and these experiments was BLAZE-SHIELD DC/F, which was manufactured and supplied by Isolatek International. BLAZE-SHIELD DC/F is a spray applied single-package factory controlled premix, based on a mixture of mineral wool fibers and cement binders. The manufacturer reported average density is $208 \mathrm{~kg} / \mathrm{m}^{3}$ (minimum), and its thermal conductivity is 0.042 $\mathrm{W} / \mathrm{m}-\mathrm{K}$ at $24^{\circ} \mathrm{C}$. The SFRM was applied by an experienced applicator from Isolatek. A nominal SFRM thickness was specified for each steel component, either $17 \mathrm{~mm}$ or $34 \mathrm{~mm}$. The applicator took considerable care to apply an even coating of the specified thickness of SFRM to the steel components. The first coating adhered to the bare steel, and the second coating was applied the following day to obtain the required thickness. The SFRM was dried in place for four weeks, as required by the manufacturer, before proceeding with thickness measurements, placement of thermocouple beads just under the SFRM surface, and verifying the thermocouple locations and function prior to testing. 
A pin thickness gauge specifically designed for SFRM products was used to measure the applied coating. The gauge can measure to the nearest $1 \mathrm{~mm}$; its measurement accuracy is $0.5 \mathrm{~mm}$. A significant variation in the thickness of the sprayed fire protective coating applied to the steel components was measured. The SFRM mean thickness, $\mu$, was greater than the specified nominal thickness by 20 percent to 35 percent typically, but ranged in value from 5 percent to 42 percent greater. The standard deviation, $\sigma$, assuming a normal distribution of thicknesses, ranged from $0.30 \mathrm{~cm}$ to $0.82 \mathrm{~cm}$. The standard deviation was influenced by the shape of the structural element as well as by the lumpy nature of the SFRM. A smooth surface cannot be obtained when the product is spray applied. The coefficient of variation (COV), where $\mathrm{COV}=\sigma / \mu$, ranged from 0.17 to 0.27 for the bars, columns, and trusses, with the exception of the column in Test 5 which had a COV=0.07. This lower COV occurred for the condition in which a thicker SFRM coat was applied to a smooth steel surface. Lower COV values were measured for the columns; the higher COV values occurred for the bars and angles.

We next describe the application of FSI and the methodology described in Chapter 1 for coupling the fire simulations with thermal response of structural elements and for simulating the experiments described in this chapter. The experimental measurements are compared with model predictions for bare and insulated steel components. Results are analyzed in terms of measurement uncertainty and model sensitivity.

\section{$2.2 \quad$ MODEL SIMULATIONS}

The methodology for coupling fire dynamics with thermal response of structural components, described in detail in Chapter 1 of this report, was employed to simulate the experiments and to predict the thermal response of structural components placed in the compartment and subjected to realistic fires. The methodology used here was analogous to that for the global analysis of the WTC towers and is discussed extensively in Chapter 8 through Chapter 11.

Finite element models of the structural components were developed using the ANSYS parametric design language (Franssen, 1995) and coupled with fire simulations to predict their thermal response. Figure 2-2 is a finite element representation of the $3.05 \mathrm{~m}$ long steel bar. The bar was divided into 30 uniform divisions along its length. The sub-figure on the right in Figure 2-2 shows the components through a cross-section of the steel bar and SFRM. The bar diameter was $2.54 \mathrm{~cm}$. The thickness of the SFRM on the various components tested in the experiments was reported in NIST NCSTAR 1-5B. In Test 5, the SFRM had a mean thickness of $2.30 \mathrm{~cm} \pm 0.55 \mathrm{~cm}$. In the calculations, the SFRM thickness was assumed to be uniform over the entire length of the component. A sensitivity analysis, presented below, was performed to assess the validity of this assumption.

Figure 2-3 shows a finite element representation of the steel truss, the insulation, and the ceiling. The elements have been color coded with the components in blue representing the steel and those in violet representing the fire protective coating. Simulations were performed with approximately six to ten elements through the thickness of the fire resistive coating. Surface elements were used to model the reradiation back to the ambient atmosphere, as well as to apply convective flux boundary conditions to the structural components.

Figure 2-4 shows a top view of the finite element model of the steel column with SFRM. The crosssectional view shows the steel column with a uniform SFRM wrapped around it. A portion of the ceiling 
and floor were also included in the model in an effort to capture the radiative exchange between the column and these elements. Accuracy of the predicted thermal response of the structural steel components is discussed below in terms of an analysis of model sensitivity.
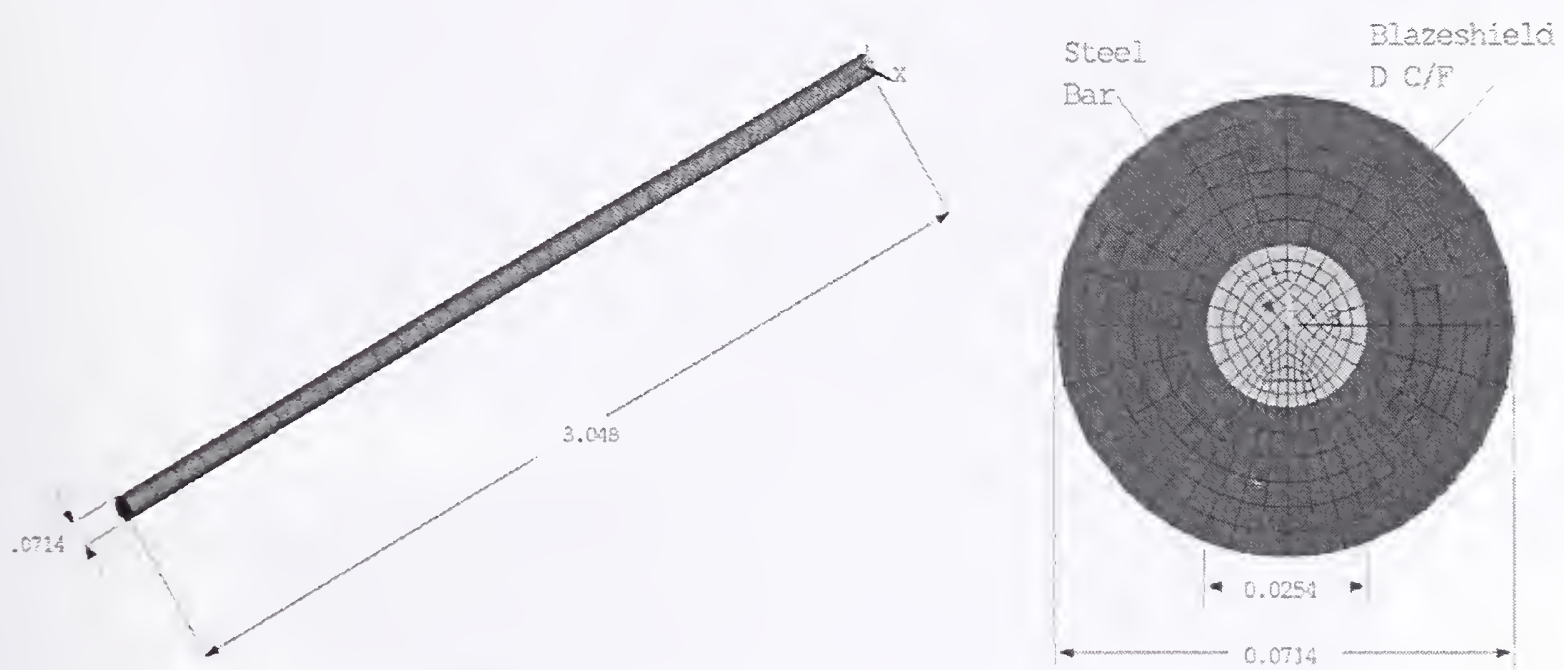

Figure 2-2. Finite element model for the $3.05 \mathrm{~m}(10.0 \mathrm{ft})$ long steel bar, showing the elements distributed uniformly along the length of the bar. Figure on the right exhibits a cross-sectional view of the bar showing mesh density.

The compartment fire was modeled using the NIST FDS (McGrattan 2004). The geometry and dimensions of the compartment conformed to a simple rectilinear grid. A uniform numerical grid whose cells were $10 \mathrm{~cm}$ on a side was chosen based on a grid resolution study. Figure 2-5 is a snapshot of a simulation showing the isometric surface of stoichiometric mixture fraction, which is an adequate representation of the fire. The major geometric features of the compartment as seen from the south wall looking toward the north are seen in the figure, as are the inlets on the left (west) and the outlets on the right (east). Figure 2-5 also shows the temperature profile through the centerline plane for one of the simulations as seen from the south wall looking north.

The fire heat release rate and the yields of the major combustion products were prescribed in the simulation. No attempt was made to model the spray burner, and the distribution of the heat release rate was assumed to be uniform over a $1 \mathrm{~m}$ by $1 \mathrm{~m}$ area in the fuel pan, which was consistent with observations of the hydrocarbon spray fire. A uniform numerical grid, with cells $10 \mathrm{~cm}$ on a side was chosen based on a grid resolution study. The large-scale temperature and other thermo-physical properties in the gas phase predicted using the CFD fire model were subsequently used in the finite element analysis to apply a radiative flux on the surface of the structural elements and to predict the three-dimensional time dependent thermal response (Prasad and Baum 2004).

Thermo-physical properties of steel and SFRM as a function of temperature, were needed for analysis. These properties include density, specific heat, and thermal conductivity. Steel components were constructed of A572 steel, which has thermo-physical properties very similar to A242 steel (McCloskey and Fields 2005). Properties for BLAZE-SHIELD DC/F were estimate by Harmathy (1983). The . thermo-physical properties measured as part of the NIST Investigation were not available at the time when these calculations were performed, hence the use of the data from Harmathy (1983). The Harmathy 
data for thermo-physical properties of fireproofing was, in general, comparable to the one measured as part of the NIST Investigation (NIST NCSTAR 1-6A). The Harmathy data, however, shows a slightly lower thermal conductivity at high temperatures compared to the NIST data. Lower thermal conductivity can result in lower predicted steel temperatures. Thermo-physical properties for Marinite were obtained from Taylor et al. (2003).

A detailed description of the application of initial and boundary conditions and the methodology for performed the analysis is presented in Chapter 4 through Chapter 7.

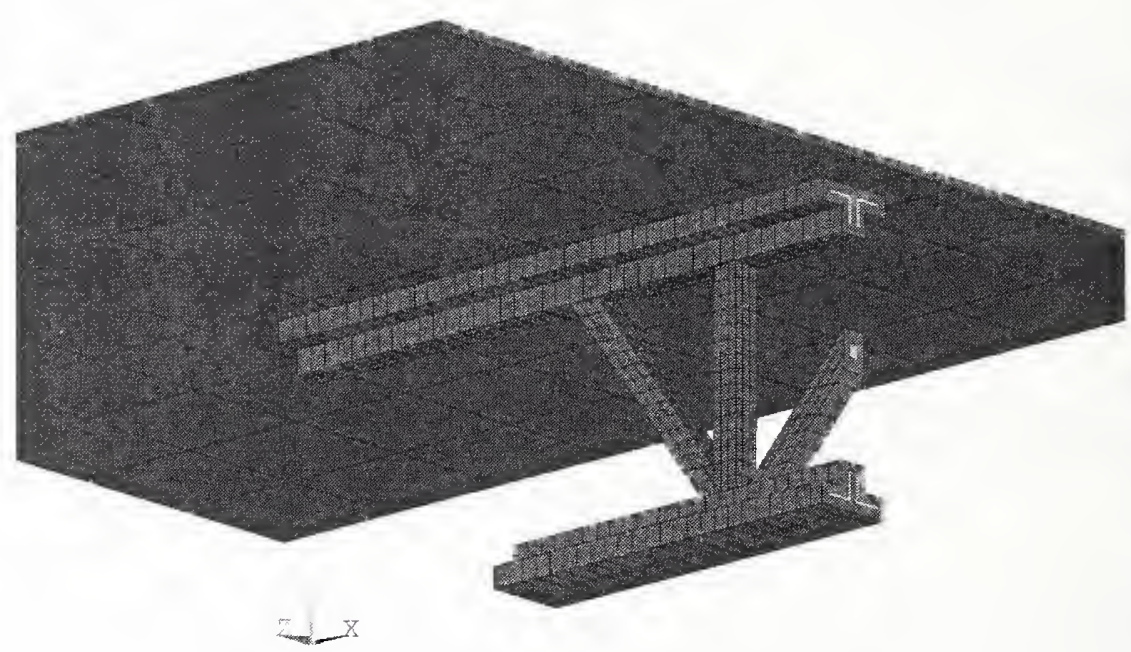

Figure 2-3. Finite element representation of the insulated steel truss (blue), the SFRM (violet), and the ceiling (red) used in the thermal analysis of Test 5.

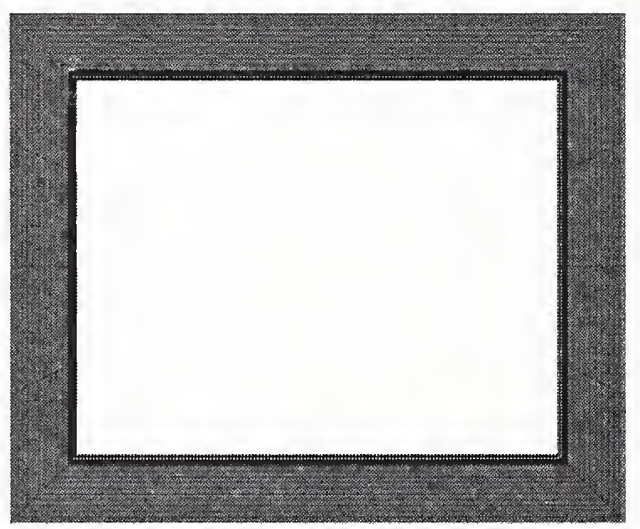

Figure 2-4. Top view of the finite element model of the steel column with SFRM. 


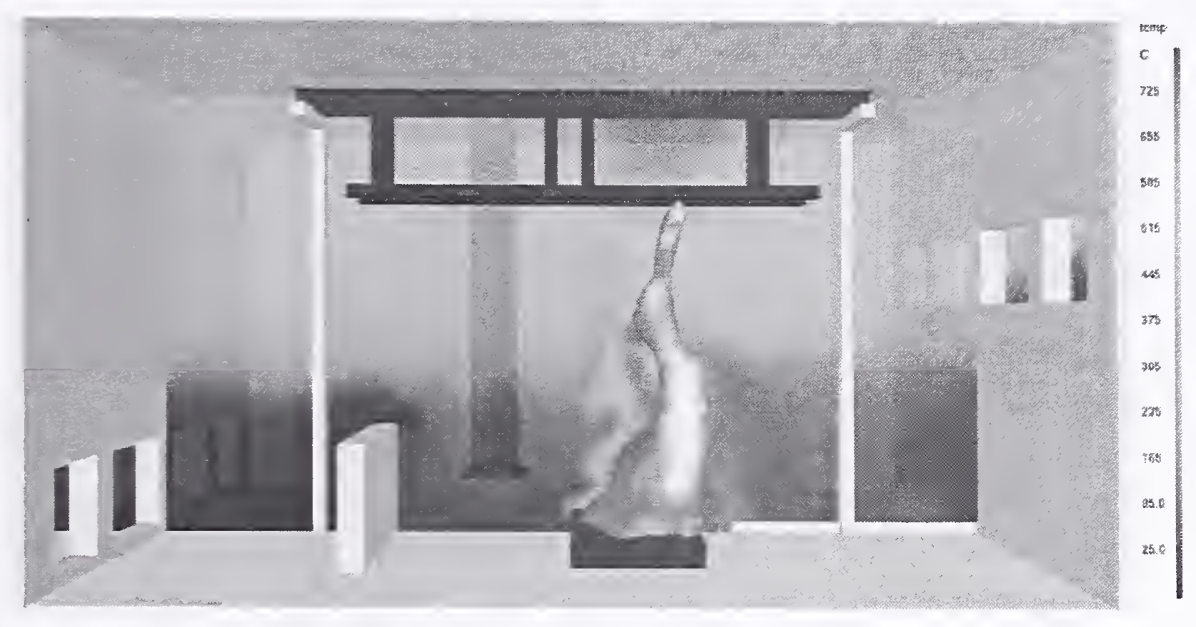

Figure 2-5. Snapshot of the numerical simulation showing the fire and a contour plot of the gas temperature along the compartment centerline, looking toward the north wall.

\section{$2.3 \quad$ RESULTS}

In this Section, the experimental measurements and the numerical simulations of the steel temperatures are presented. Comparisons of the simulation results with the measurements are considered in terms of measurement uncertainty and a sensitivity analysis of the model results.

The simulation of the temperature of the steel was considered for Test 1 and Test 5, which were two representative experiments. Test 1 was a $2 \mathrm{MW}$ heptane fire with a $15 \mathrm{~min}$ duration in which the steel components were bare (uncoated). Test 5 was a $3 \mathrm{MW}$ heptane fire with a 50 min duration in which the steel components were insulated with various thicknesses of SFRM.

\subsubsection{Test 1}

Figure 2-6 compares the numerical simulations (symbols) with the measured steel surface temperatures (solid lines) at four locations on Bar A during Test 1. The location of the origin was taken as the north end of the bar (at the top of the bar in the figures). The difference between predicted results and experimental data is $-9{ }^{\circ} \mathrm{C}$ on the low side and $+1{ }^{\circ} \mathrm{C}$ on the high side. The shape of the simulated timetemperature results was similar to the measurements. Both curves increased in a monotonic fashion from ambient values at time equal to zero, to finite values, which obtained a maximum when the fuel was stopped, and subsequently decreased, also in a monotonic manner. The general character of these results was representative of all of the tests. For most locations, the absolute difference between the numerical predictions and the experimental data was less than $20^{\circ} \mathrm{C}$ at any time. Temperature measurements and the model simulations differed along the bar at some locations because the asymmetry of the fire plume was not predicted in the FDS simulations.

Figure 2-7 compares the numerical simulations and the temperature measurements at various locations on the uppermost surface $3.70 \mathrm{~m}$ above the floor on Truss A during Test 1 . The numerical results match the trends of the measurement profiles reasonably well. For most locations, the maximum difference between the measurements and the simulations was less than 10 percent. The maximum temperatures on the steel occurred approximately when the fuel flow was stopped, which was at $860 \mathrm{~s}$. 
Figure 2-8 and Figure 2-9 compare the numerical simulations with measurements for the steel surface temperature for locations on the north, south, east and west faces of the bare column during Test 1 at heights of $3.69 \mathrm{~m}$ and $2.13 \mathrm{~m}$ above the floor, respectively. The location of the column relative to the compartment is shown in Figure 2-1. In Figure 2-8 and Figure 2-9, both the numerical predictions and the experimental measurements have been color coded for the four faces of the column. (The west face of the column faced the compartment inlet.) The highest predicted and measured temperatures occurred on the south face of the column. At one location on the south face ( $3.69 \mathrm{~m}$ above the floor), the largest difference between the simulations and measurements was immediately after the start of the test, when the temperatures were still relatively low, but the rate of temperature change was large. The largest temperature difference generally occurred just before the fuel flow was stopped. In Test 1, this was $900 \mathrm{~s}$ after ignition. For most locations, the relative differences between the peak measured and simulated temperatures was less than 5 percent, whereas for some locations the differences were as large as 10 percent.

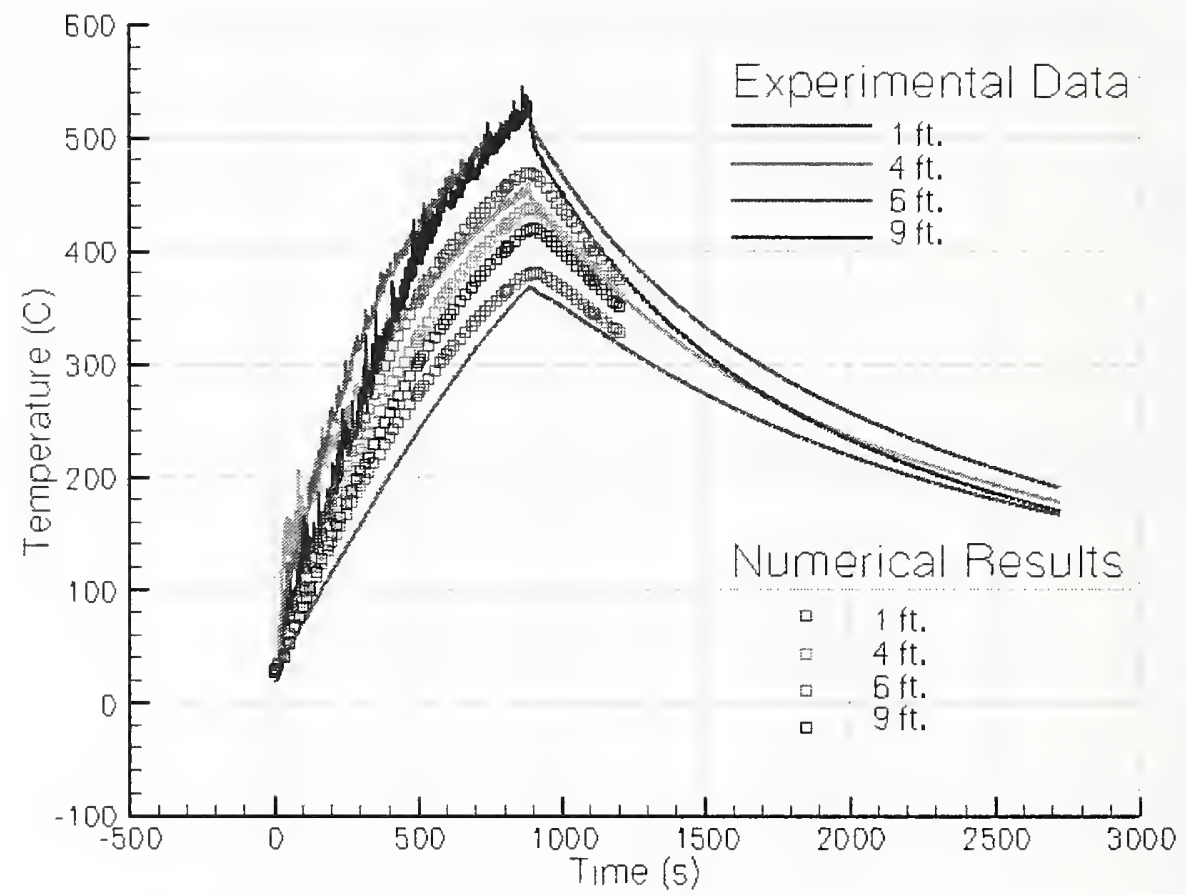

Figure 2-6. Comparison of numerical simulations with measurements for the steel surface temperature at four locations on Bar A in Test 1. 


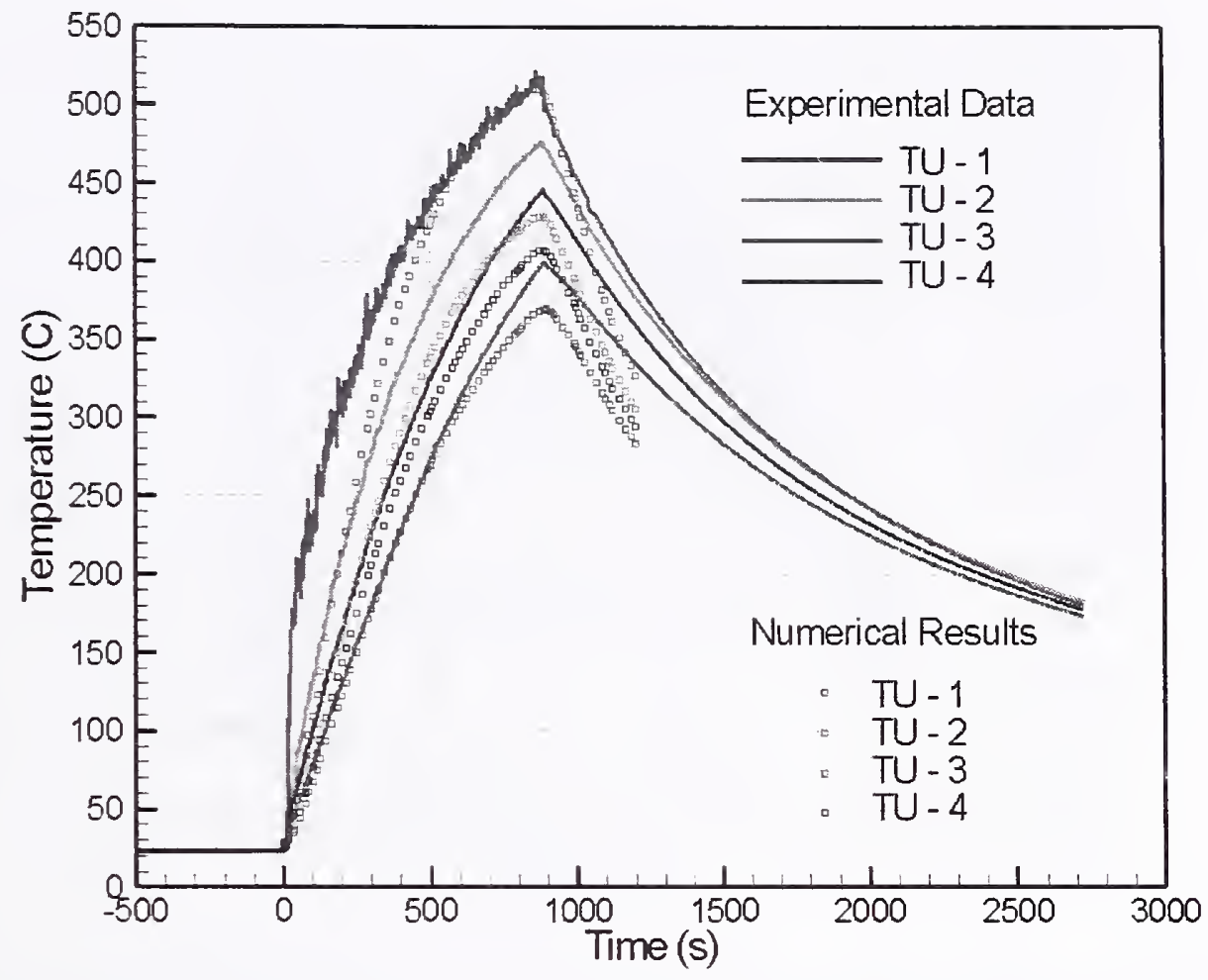

Figure 2-7. Comparison of numerical simulations with measurements for the steel surface temperature at four locations $3.70 \mathrm{~m}$ above the floor on Truss $A$ in Test 1.

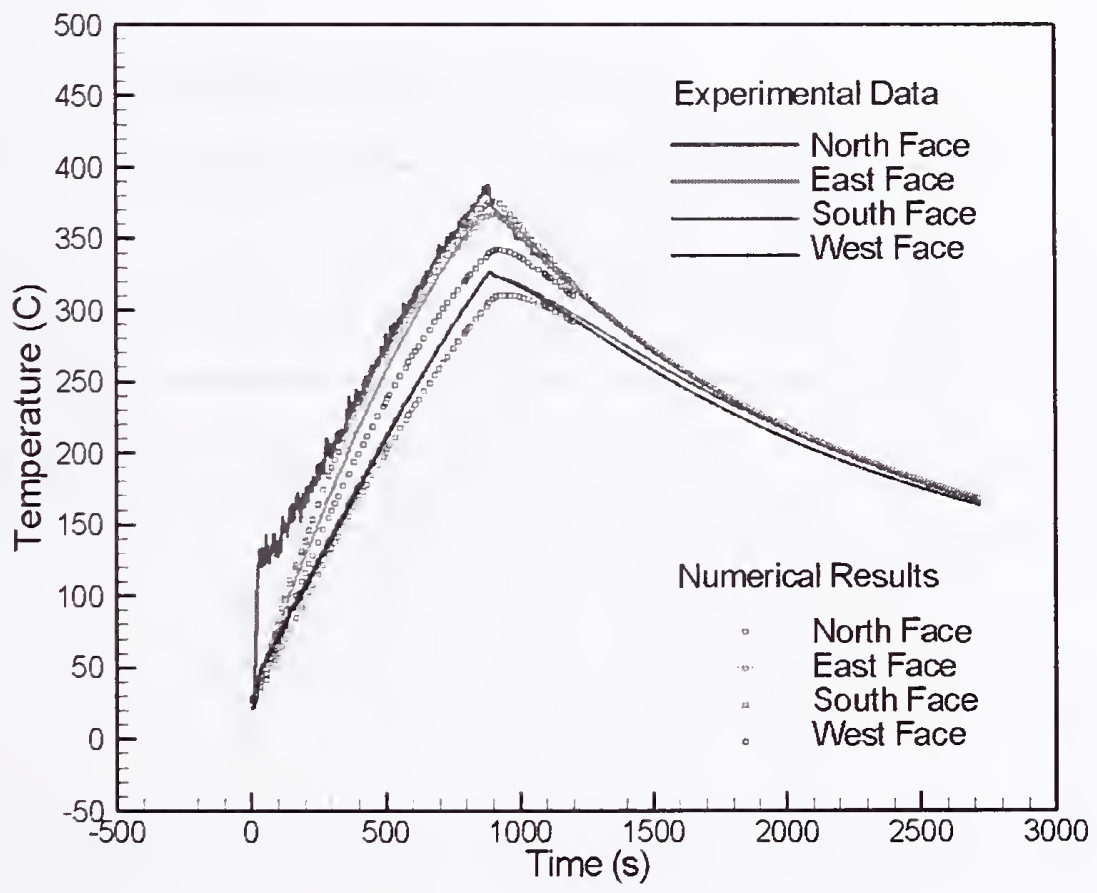

Figure 2-8. Comparison of numerical simulations with measurements for the steel surface temperature at four locations $3.69 \mathrm{~m}$ above the floor on the column in Test 1 . 


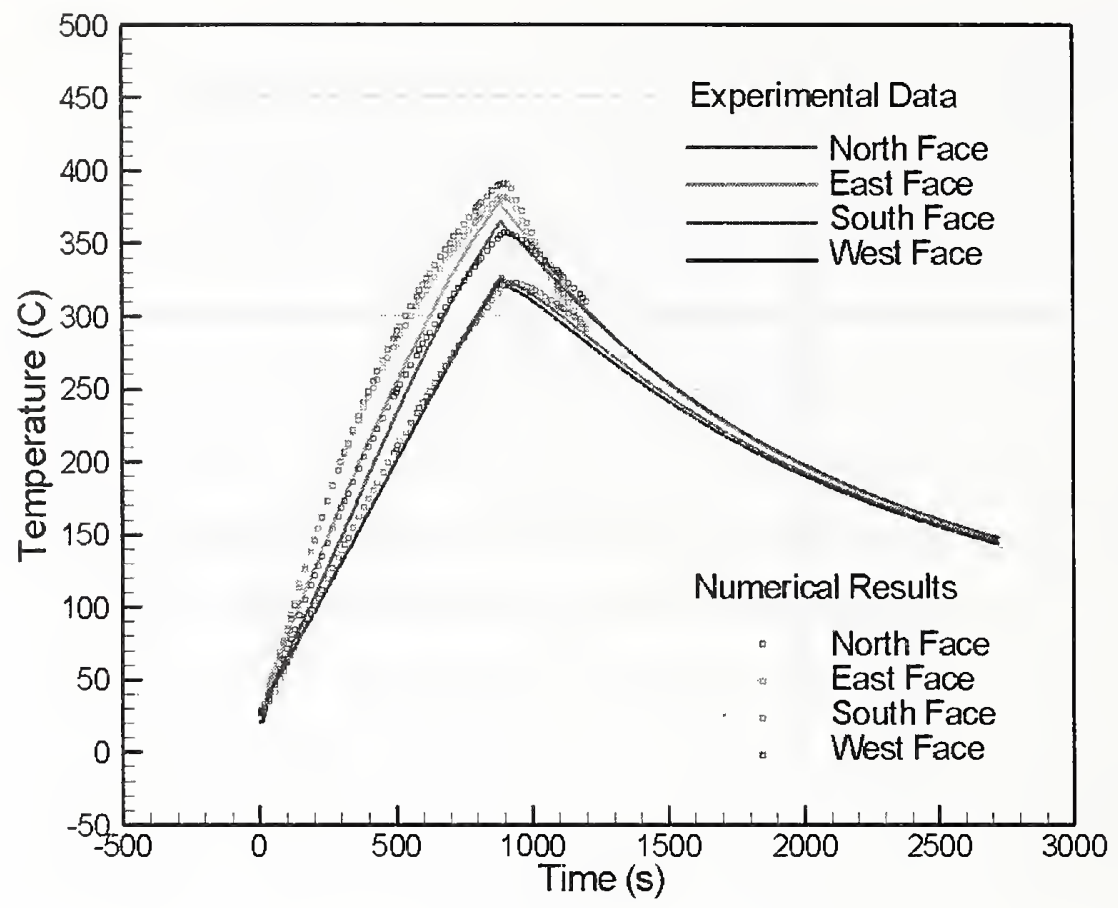

Figure 2-9. Comparison of numerical simulations with measurements for the steel surface temperature at four locations $2.13 \mathrm{~m}$ above the floor on the column in Test 1 .

\subsubsection{Test 5}

Figure 2-10 through Figure 2-15 compare the simulations with measurements at locations on the steel surface and SFRM surface for the bar, column, and truss in Test 5. For the bar and the column, the maximum difference between the measurements and the simulations was less than 15 percent, which generally occurred shortly after the fuel flow was stopped. For Truss A, the maximum difference between the measurements and the simulations was typically less than 20 percent. At one location, however, the temperature difference was as large as approximately 30 percent. The reason for the magnitude of this difference appears to be variability in fireproofing thickness, thermo-physical properties of fireproofing, and heat release rate associated with FDS simulations. Other reasons for the differences between numerical simulations and temperature measurements are discussed below in terms of uncertainty in the measurements and a sensitivity analysis of the model. 


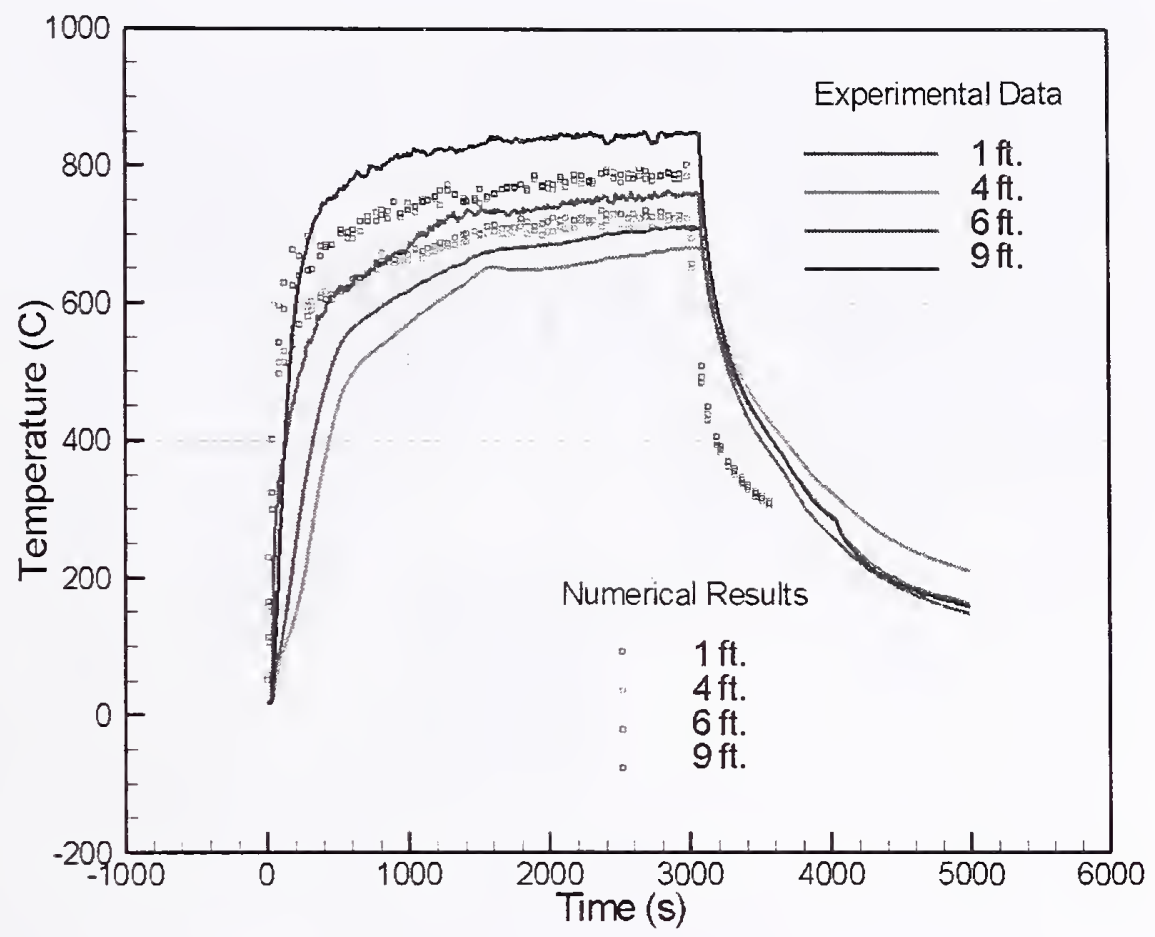

Figure 2-10. Comparison of numerical simulations with measurements for the temperature of the SFRM surface at four locations on the insulated bar in Test 5.

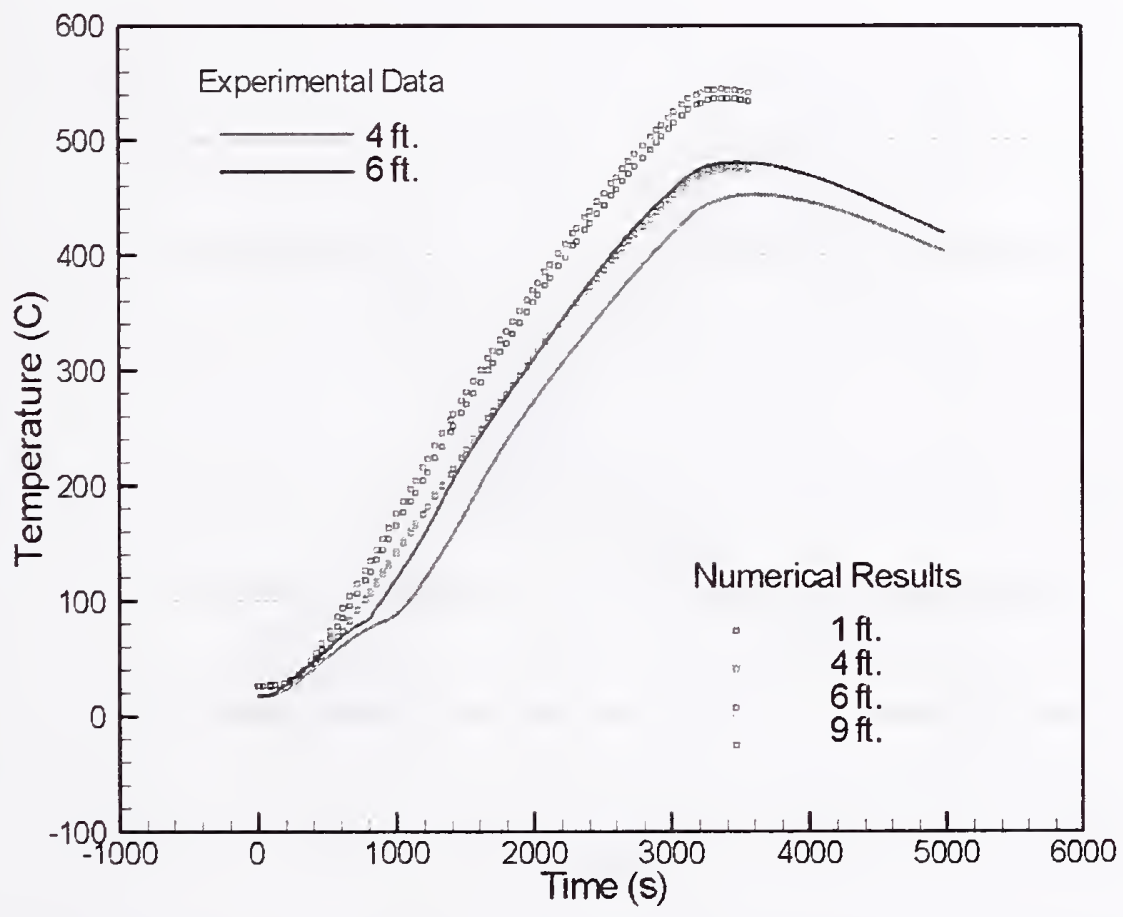

Figure 2-11. Comparis on of numerical simulations with measurements for the temperature of the steel surface at four locations on the insulated bar in Test 5. 


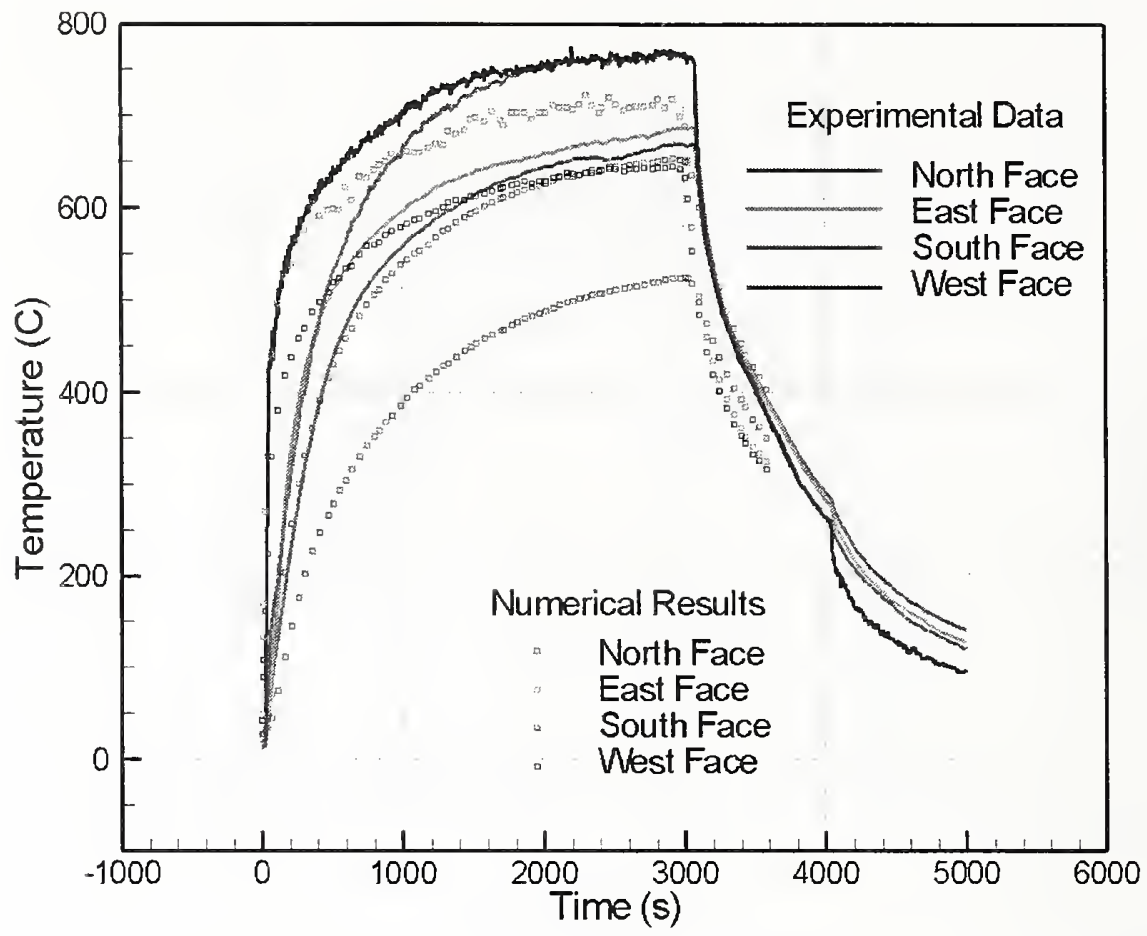

Figure 2-12. Comparison of numerical simulations with measurements for the temperature of the SFRM surface at four locations, $3.69 \mathrm{~m}$ above the floor on the insulated steel column in Test 5.

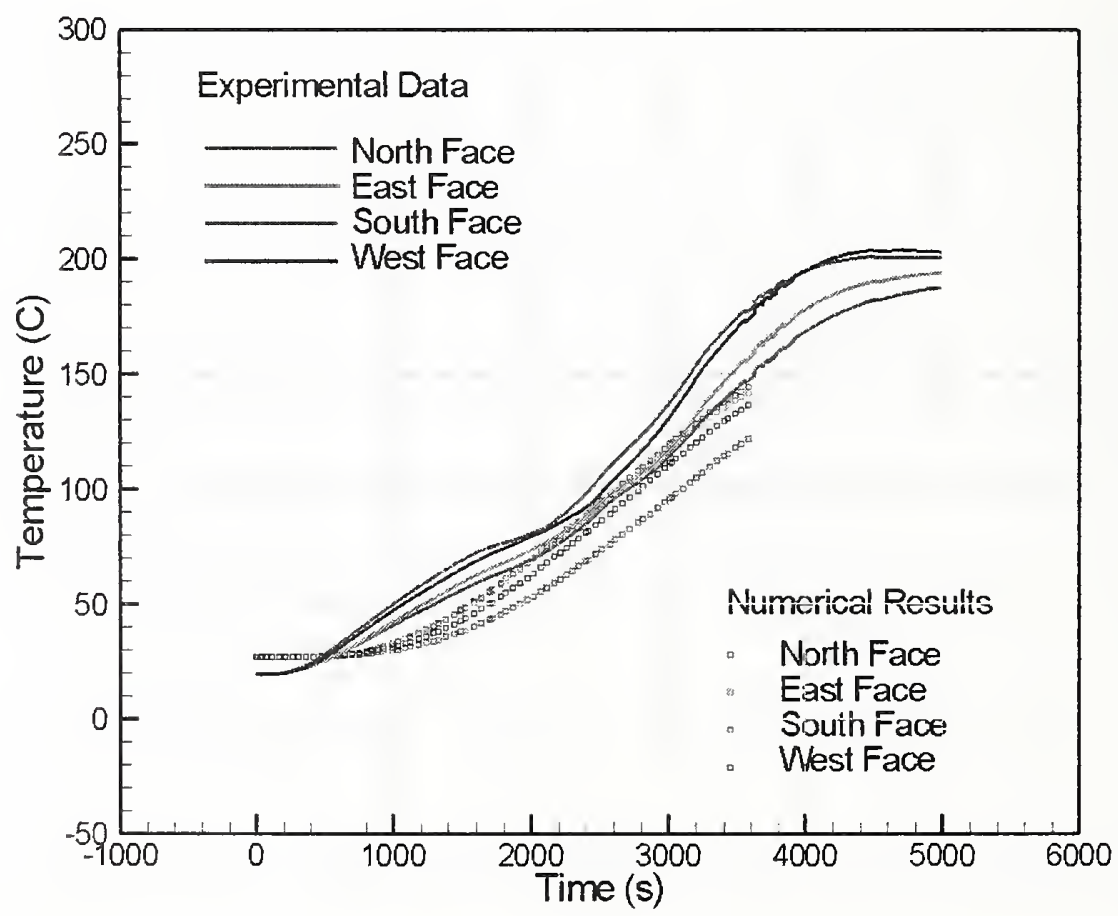

Figure 2-13. Comparison of numerical simulations with measurements for the temperature of the steel surface at four locations, $3.69 \mathrm{~m}$ above the floor on the insulated steel column in Test 5. 


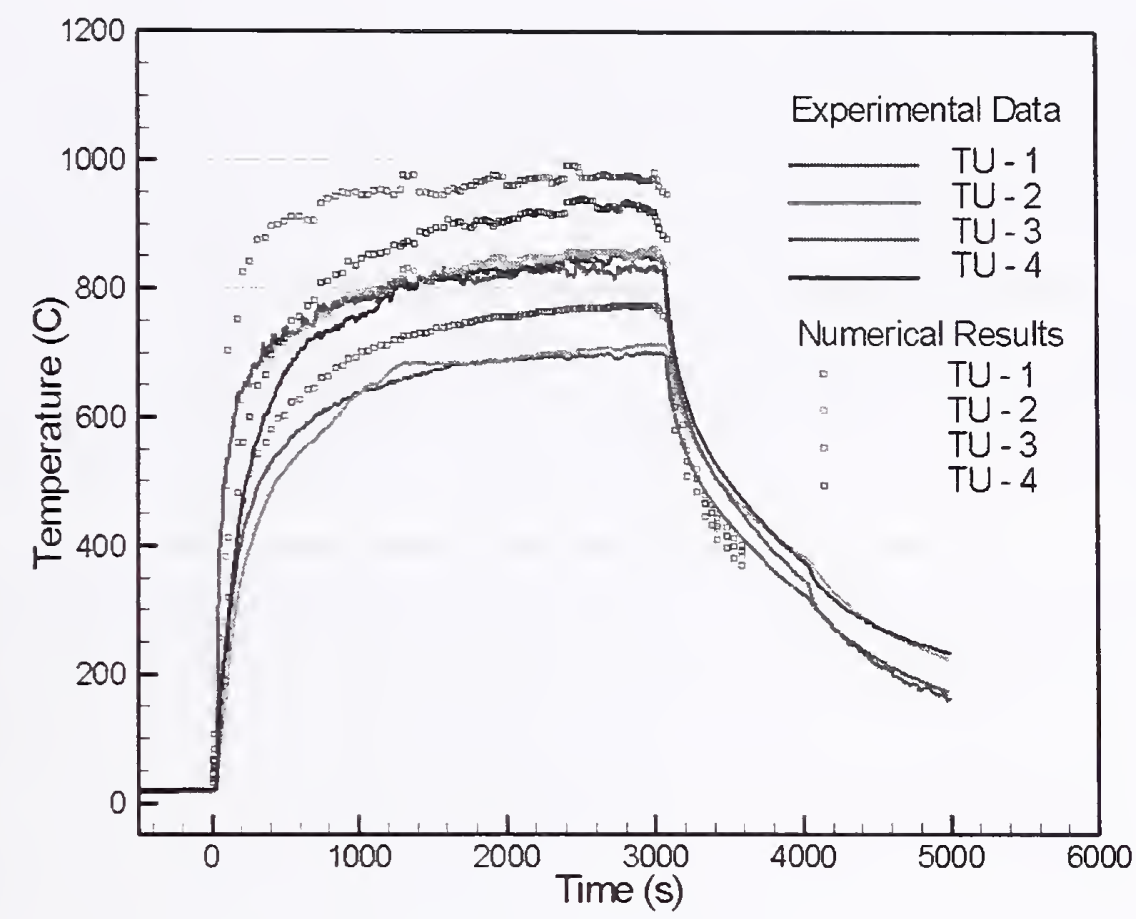

Figure 2-14. Comparison of numerical simulations with measurements for the temperature of the steel surface at four locations $3.70 \mathrm{~m}$ above the floor on Truss A in Test 5.

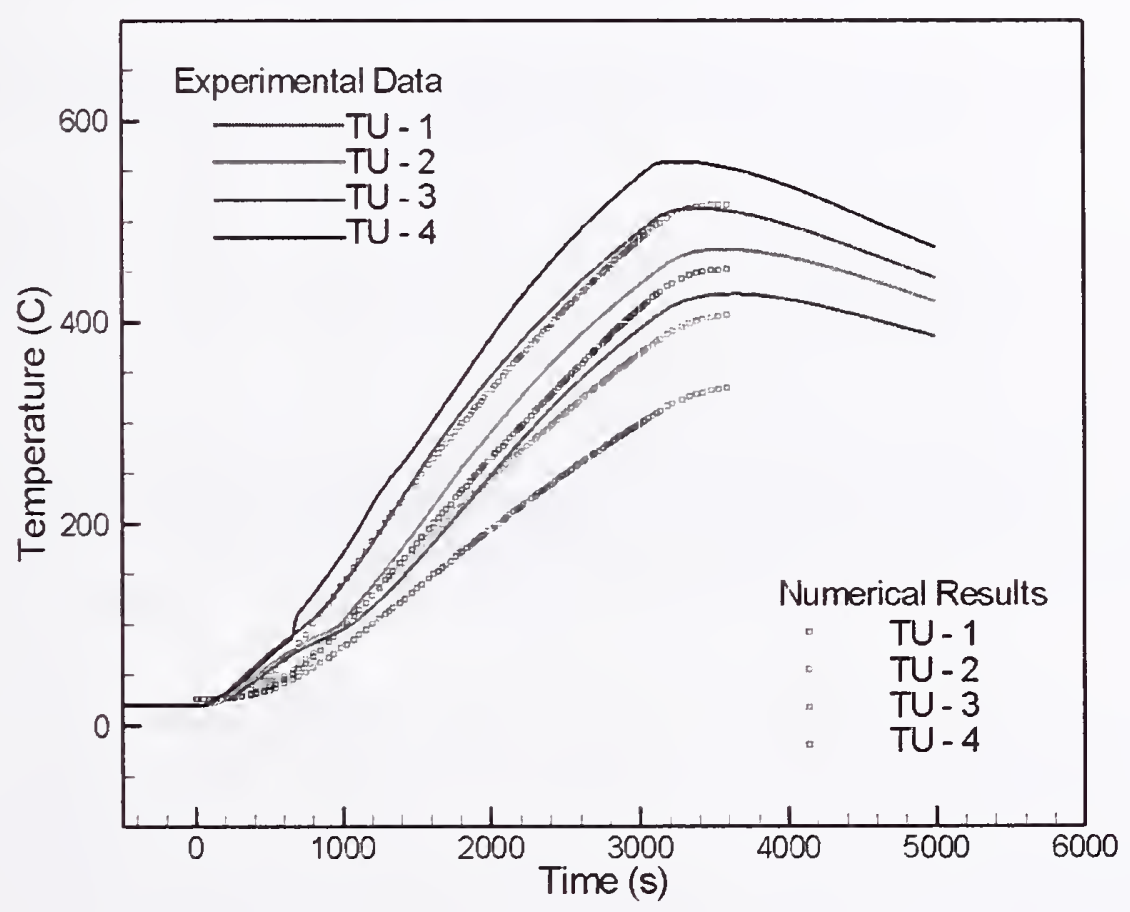

Figure 2-15. Comparison of numerical simulations with measurements for the temperature of the steel surface at four locations $3.70 \mathrm{~m}$ above the floor on Truss $A$ in Test 5. 


\subsubsection{Quantification of Agreement between Models and Measurements}

The level of agreement between the calculated and the measured values of the peak temperature for the various steel components are summarized in Table 2-2 and Table 2-3 for Tests 1 and 5, respectively. The tables list the difference, for each location, between the peak values of the measured and the stimulated steel surface temperatures, normalized by the average of those temperatures, with results listed for the hottest and the coolest temperature locations on each element. A negative percentage in the tables indicates that the numerical simulation was less than the measured value, whereas a positive percentage indicates that the simulation was greater than the measured value. The average of the absolute values of the percentages is given at the bottom of each table and the average of the percentages are shown in parenthesis.

Table 2-2 shows that the values were negative for Test 1 in most cases, indicating that the numerical predictions consistently under predicted the measurements by a finite, but small percentage. The average of the absolute value of the differences was less than 5 percent, although some individual differences were as large as 10 percent for some locations on some of the elements. Similar results were found in Test 5, although the agreement between models and simulations was somewhat less. Table $2-3$ shows that the values were also generally negative for Test 5 , indicating that the numerical predictions consistently under predicted the measurements. The average of the absolute value of the differences was less than 20 percent, although some individual differences were as large as 33 percent for some of the locations on some of the elements.

The major difference between Test 1 and Test 5 is the presence of fireproofing on the structural components. The methodology for measuring temperature and for performing the FSI simulations did not change between Test 1 and Test 5. Agreement between model predictions and experimental data is somewhat less because of uncertainty associated with fireproofing thickness (variability in fireproofing thickness along the length of the structural component) and its thermo-physical properties.

The uncertainty associated with a type $\mathrm{K}$ thermocouple measurement for near steady conditions is about $2{ }^{\circ} \mathrm{C}$ [Omega, 2000]. Because the magnitude of the disagreement shown in Table 2-2 and Table 2-3 could not be explained solely by uncertainty in this measurement, further analysis was necessary and is described below.

Table 2-2. Percentage difference between peak values of the measured and the simulated steel surface temperatures at the hottest and coolest locations on various uninsulated components in Test 1.

\begin{tabular}{|l|c|c|}
\hline \multicolumn{1}{|c|}{ Element (Vertical Position) } & Hottest Location & Coolest Location \\
\hline Bar A & $-10 \%$ & $3 \%$ \\
\hline Bar B & $8 \%$ & $-2 \%$ \\
\hline Column (2.13 m above floor) & $2 \%$ & $-2 \%$ \\
\hline Column (3.69 m above floor) & $-3 \%$ & $-6 \%$ \\
\hline Truss A (2.89 m above floor) & $-4 \%$ & $2 \%$ \\
\hline Truss A (3.29 m above floor) & $-6 \%$ & $-8 \%$ \\
\hline Truss A (3.70 m above floor) & $1 \%$ & $-10 \%$ \\
\hline Absolute Value of Average (Average) & $4.9 \%(-1.7 \%)$ & $4.7 \%(-3.3 \%)$ \\
\hline
\end{tabular}


Table 2-3. Percentage difference between peak values of the measured and the simulated steel temperatures for the hottest and coolest locations for various components with SFRM in Test 5.

\begin{tabular}{|l|c|c|}
\hline \multicolumn{1}{|c|}{ Element } & Hottest Location & Coolest Location \\
\hline Bar $^{2}$ & $8 \%$ & $3 \%$ \\
\hline Column $(0.77 \mathrm{~m}$ above floor $)$ & $-20 \%$ & $3 \%$ \\
\hline Column (2.13 m above floor) & $-11 \%$ & $-13 \%$ \\
\hline Column (3.69 m above floor) & $-30 \%$ & $25 \%$ \\
\hline Truss A (2.89 m above floor) & $15 \%$ & $-15 \%$ \\
\hline Truss A (3.29 m above floor) & $-15 \%$ & $-33 \%$ \\
\hline Truss A (3.70 m above floor) & $-10 \%$ & $-30 \%$ \\
\hline Absolute Value of Average (Average) & $16 \%(-9 \%)$ & $20 \%(-11 \%)$ \\
\hline a. Only one bar was used in Test 5. & & \\
\hline
\end{tabular}

\subsubsection{Experimental Uncertainty and Model Sensitivity of the Steel Temperatures}

Model sensitivity was considered in an effort to understand the effect of uncertainty of the various input parameters used in the NIST FSI models on the calculated thermal response of the structural steel components. This information is useful for understanding the differences between the simulated and measured temperature behavior of the steel members in the experiments. The sensitivity study focused on the effect of variability in fireproofing thickness, the gas phase heat release rate, and the FDS grid on steel temperature.

\section{Sensitivity to the Thickness of the Sprayed Fire-Resistive Material (SFRM)}

A major factor that influenced the thermal response of steel was fireproofing thickness and its variability along the length and perimeter of the structural components. The SFRM thickness was not uniform about a structural element, even a simple symmetric element such as a bar. On the bars, for example, the SFRM thickness was not uniform about all sides of the bar - even at a single location along the axis of the bar. The non-uniform thickness led to three-dimensional effects that impacted the thermal behavior of the SFRM, effectively increasing the uncertainty in the simulated steel temperature underneath the SFRM. The importance of this effect can be characterized by the coefficient of variation (COV) of the SFRM thickness (the ratio of the standard deviation to the mean thickness) and is bounded by the maximum and minimum values of the SFRM thickness. The coefficient of variation ranged from 0.17 to 0.27 for the bars, columns, and trusses.

The SFRM thickness in the calculations presented here was based on the mean value, which was assumed to be uniform over the entire length of the bar. In Test 5 for example, the mean thickness of the SFRM on the bars was measured as $2.31 \mathrm{~cm}$, and the COV was 0.24 . Numerical simulation of the steel surface temperature for Bar A in Test 5, assuming a 25 percent decrease in the thickness of the SFRM, led to a temperature increase of approximately 10 percent as compared to the baseline results. Locally, the SFRM thickness on some sections of the bars was smaller than the mean by as much as 45 percent. This indicates that the variation in the calculated steel surface temperature was as much as 20 percent simply from 
uncertainty in the SFRM thickness. Sensitivity of results to fireproofing thickness will be discussed in a systematic manner in Chapter 3 of this report.

The difference between Test 1 and Test 5 is the presence of fireproofing on the structural components. The methodology for measuring temperature and for performing the FSI simulations did not change between Test 1 and Test 5. Comparison between model predictions and experimental data is somewhat less because of uncertainty associated with fireproofing thickness (variability in fireproofing thickness along the length of the structural component) and its thermo-physical properties.

\section{Sensitivity of the Steel Temperature to Thermo-physical Properties}

Thermo-physical properties of steel and SFRM (used in this study) may have also had an influence on the predicted steel temperature. The effect of uncertainty in the thermal conductivity of the SFRM will also play a role in the computations performed using the finite element procedure. Typical uncertainty in the determination of thermal conductivity using the ASTM standard method is not better than \pm 6 percent (ASTM 2000). For insulation materials like BLAZE-SHIELD DC/F SFRM, the measurement uncertainty may be considerably larger, although it has not been quantified. According to the manufacturer, the thermal conductivity for BLAZE-SHIELD DC/F was $0.042 \mathrm{~W} / \mathrm{m}-\mathrm{K}$ at $24{ }^{\circ} \mathrm{C}$, which was quite different from Harmathy's data (Harmathy, 1983), which was used in the baseline calculations reported here. The Harmathy data exhibits slightly lower thermal conductivity at high temperature as compared with the NIST data (NIST NCSTAR 1-6A).

The sensitivity of the calculation results to the thermo-physical properties was investigated by considering an idealized situation where a $2.5 \mathrm{~cm}$ bar with $2.5 \mathrm{~cm}$ of insulation was exposed to a constant source of heat flux. The results showed a 7 percent lower steel temperature for the calculations that used the Harmathy data as compared to the calculations that used the NIST data. Lower thermal conductivity for SFRM can result in lower steel temperatures. The sensitivity of FSI to the thermo-physical properties of the SFRM analysis increased uncertainty in the simulation.

BLAZE-SHIELD DC/F has a significant amount of moisture that can evaporate under fire conditions. The role of moisture was not accounted for in the simulations described in this chapter. However, the role of moisture was included in the simulations described in Chapter 4 through Chapter 11 by incorporating the heat of evaporation in an enthalpy formulation.

The optical properties of the steel and the SFRM likely did not play an important role, as soot rapidly coated the steel components upon ignition of the fire.

\section{Sensitivity of the Steel Temperature to Heat Release Rate}

The temperature of the steel elements in Test 1 were calculated using the methodology described in this report with heat release rate 10 percent higher than the baseline value (in the fire simulations). The computed transient steel temperatures for the higher heat release rate fire were similar in shape to those computed using the baseline heat release rate, but the rate of the temperature increase was always larger. This led to simulated temperatures that were 5 percent to 21 percent higher than values in the baseline case, depending on location, which either improved or worsened agreement with the measurements. 
The predicted steel surface temperature at two different heights on the column in Test 1 for a 10 percent higher heat release rate than that used in the baseline simulations were paradoxically lower for the increased gas phase heat release rate. Analysis showed that this occurred because the flame tended to bend away from the column for the simulated fire with the higher heat release rate. The simulated steel surface temperature on Truss A in Test 1 for a 10 percent higher heat release rate than that used in the baseline calculations showed that the temperature of the steel on Truss A increased 4 percent to 29 percent for the higher heat release rate, depending on the exact location. Table $2-4$ summarizes the FSI simulation results for the various steel elements. The table lists the percentage difference in the peak value of the simulated temperature profiles between the baseline simulations and those with a 10 percent higher heat release rate at the hottest and coolest locations on the steel surface of various un-insulated components in Test 1. The increased heat release rate and upper layer temperature led to changes in the simulated steel surface temperature of 21 percent on average at the hottest locations on each of the components, with a range from -38 percent to +29 percent. Table $2-4$ shows that the percentage change at the hottest locations was smaller on average than at the coolest locations.

Table 2-4. Percentage difference in the peak value of temperatures between the baseline simulations and those with a 10 percent higher heat release rate at the hottest and coolest locations on the steel surface of various un-insulated components in Test 1.

\begin{tabular}{|l|c|c|}
\hline \multicolumn{1}{|c|}{ Element (Vertical Position) } & Hottest Location & Coolest Location \\
\hline Bar A & $5 \%$ & $5 \%$ \\
\hline Bar B & $21 \%$ & $14 \%$ \\
\hline Column (3.69 $\mathrm{m}$ above floor) & $-33 \%$ & $-22 \%$ \\
\hline Column (2.13 $\mathrm{m}$ above floor) & $-38 \%$ & $-26 \%$ \\
\hline Truss A (2.89 $\mathrm{m}$ above floor) & $20 \%$ & $5 \%$ \\
\hline Truss A (3.29 $\mathrm{m}$ above floor) & $29 \%$ & $8 \%$ \\
\hline Truss A (3.70 $\mathrm{m}$ above floor) & $4 \%$ & $4 \%$ \\
\hline Absolute Value of Average & $21 \%$ & $12 \%$ \\
\hline
\end{tabular}

The increase in the maximum calculated steel temperatures for locations on the bars, column, and truss should be compared with the change in the upper layer gas temperatures calculated by FDS, which increased by 9 percent on average for the 10 percent increase in the heat release rate above baseline. The change in the simulated steel surface temperature did not change linearly with the upper layer gas temperature. The difference in the temperature increases on the steel can be attributed to changes in the character of the simulated fire (captured by the FSI results), including its physical location, its size, and its extent, all of which impacted the calculated flux onto the structural steel components and, subsequently, the calculated temperature distribution in the steel components.

\section{Sensitivity to Grid Size}

The predicted steel temperature for Bars A and B in Test 1 using coarse grid fire simulations were of interest because the WTC calculations must be completed using a coarse grid due to large CPU time required to completed the simulations. The computed steel temperatures using the coarse mesh were similar in shape to those computed using the finer mesh, but the maximum calculated temperatures were shifted by approximately 10 percent, to either larger or smaller values. The coarse mesh fire simulations 
resulted in uniform temperatures along the length of the bar, which was in contrast to the fine mesh calculations, which led to finite temperature differences ( 5 percent) along the length of the bar. The calculations show that FDS grid resolution has a finite effect on the structural analysis, aithough it is not greater than the effect of model sensitivity to various model input parameters.

The difference between the measured and predicted steel surface temperatures (sce Table 2-2) can be explained through consideration of FSI model sensitivity to uncertainty in physical input parameters, the most important of which was the variability in fireproofing thickness on a structural component and to a lesser extent the heat release rate in fire simulations.

\subsection{SUMMARY}

A series of experiments was conducted to assess the models that were developed to predict the temperature rise of structural components within a compartment fire. The well-controlled large-scale experiments described here were designed specifically to validate the NIST FSI, used to couple fire simulations with thermal behavior of structural components as applied to the investigation of the WTC towers. Measurements were conducted to assess the accuracy of the model calculations.

On average, the numerical predictions of the steel surface temperature were within 5 percent of the experimental measurements for the case of bare steel and within 20 percent for the steel components with SFRM. For the bare steel, a series of calculations showed that these differences could be attributed to model sensitivity to the heat release rate in the fire model. For the insulated steel, the differences could be attributed to model sensitivity to the variability in the SFRM coating thickness and thermo-physical properties of fireproofing in addition to the unccrtainties in fire modeling.

In conclusion, FSI couples the fires dynamics simulations with the thermal response of structural elements with an uncertainty that is small compared to the uncertainty in the measurements and the FDS simulations. The study provides confidence in the application of the modeling methodology to the investigation of the WTC disaster. 


\section{Chapter 3 \\ EXPLORATORY STUDIES ON THERMAL RESPONSE OF STRUCTURAL ELEMENTS}

Modeling the global thermal response of World Trade Center (WTC) towers coupled with realistic fire simulations was a daunting task. Global analysis of each tower resulted in models that were computationally intensive and required large memory for efficient calculations. At the same time, results of the global simulations were sometimes difficult to understand because of simultaneous variation in a number of parameters. Exploratory studies, that are computationally inexpensive, were performed during the initial stages of the Investigation to understand the role of the important parameters on numerical predictions. The objective of this chapter is to present these exploratory studies and to discuss the sensitivity of the results to model parameters.

A large number of preliminary studies were conducted, to develop an understanding of how typical structural elements behave under furnace conditions. Exploratory studies were limited to 2-D or axisymmetric representation of structural elements to help reduce computational costs. No attempt was made to couple the analysis with fire simulations. Instead, the response of structural elements to a constant radiative flux or gas temperature was simulated. The 2-D models allow the flexibility to conduct a large number of parametric studies to estimate the time to reach a critical temperature under different fireproofing scenarios and gas temperatures. The results of these exploratory studies have guided the development of the component models (presented in Chapter 4 through Chapter 7) and the global analysis discussed in Chapter 8 through Chapter 11 .

\subsection{SENSITIVITY STUDY ON CORE COLUMNS}

The core columns were considered a critical structural element throughout the Investigation, and sensitivity studies were conducted to predict the time required to reach a critical temperature under different fireproofing thickness and damage scenarios as well as different incident flux (gas temperature). Sensitivity studies on two box shape core columns are discussed in this section. The box columns were chosen so that the predicted rcsponse for these two columns would cover the entire spectrum of responses that are expected for the various core columns (each box shape core column in the affected floors of the WTC tower was unique in its cross-sectional area and dimensions). The first of these two columns is a light box shape core column, while the second core column is a heavy column.

\subsubsection{Light Box Shape Core Columns}

Figure 3-1 shows a finite element model of light box shape core column ( 15 by 17 by $13 / 16$ in.) developed using the ANSYS structural analysis package finite element software. The steel is covered with $11 / 8$ in. of fireproofing (BLAZE-SHIELD DC/F). The thermo-physical properties for fireproofing (used in the exploratory studies only and not in the main Investigation) were obtained from Harmathy 1983. In Figure 3-1, the elements have been color coded with the material attributes. Cyan colored elements have material attributes of steel, while violet colored elements have attributes of fireproofing. As 
mentioned earlier, exploratory studies were performed with 2-D models of core columns. It was assumed that the flux was constant over the entire length of the column. Heat conduction along the length of the columns was neglected in this analysis.

Sensitivity studies described in this chapter de-couple the thermal analysis from fire simulations. Thermal response of core columns was predicted by subjecting the columns to a constant radiative flux over their entire perimeter and for the duration of the simulation. There was no ramping of the incident flux. The radiative flux $q$ was related to gas temperature $T$ by using the formula $q=\sigma T^{4}$, where, $\sigma$ is the StefanBoltzmann constant $\left(5.67 \times 10^{-8} \mathrm{~W} / \mathrm{m}^{2} K^{4}\right)$. The column was not subjected to any convective flux from the gases in these preliminary studies. (Convective heat transfer was included in the more detailed studies presented in Chapter 4 through Chapter 11.) Radiation is the dominant mode of heat transfer at high temperatures $\left(1,100^{\circ} \mathrm{C}\right.$ gas temperature). Re-radiation to the ambient atmosphere and in the cavity formed by the four plates of the box column was modeled.

The finite element mesh in the steel and fireproofing has been shown with white lines superimposed on the model shown in Figure 3-1. Because of the 2-D nature of the model, computational time (CPU time) was no longer a deciding factor, and the mesh density was varied to study its effect on the analysis. The sub-figure on the right in Figure 3-1 shows typical temperature contours (Kelvin) through the steel and fireproofing at one instant in time, ranging from 300 to 1,400 Kelvin. High surface temperature on the surface of the fireproofing is predicted, and the energy gradually diffuses into the steel.
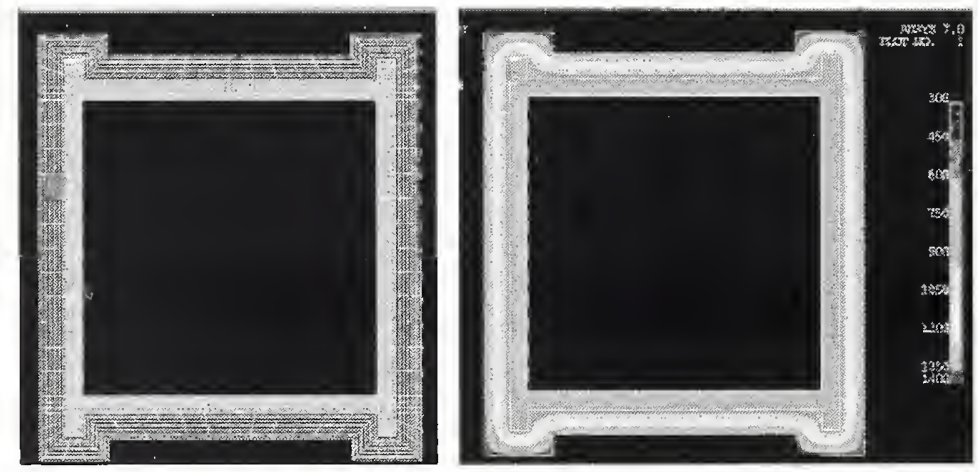

\section{Figure 3-1. Finite element model of light box shape core column (left) and temperature contours (Kelvin) at one instant in time.}

Simulations were performed with different fireproofing thickness and gas temperatures to estimate the time to reach a critical temperature. These results have been shown in Table 3-1. Fireproofing thickness was set at $0,1 / 2$ and $11 / 8 \mathrm{in}$. The first row shows gas temperature and critical temperature of the steel column. The first box for example shows that the gas temperature was set to $700{ }^{\circ} \mathrm{C}$, and the critical temperature of steel was $573{ }^{\circ} \mathrm{C}$. Gas temperature ranges from $700{ }^{\circ} \mathrm{C}$ to $1,100{ }^{\circ} \mathrm{C}$. The boxes to the right of fireproofing thickness show the time in seconds for the steel to reach the specified critical temperature. For the conditions that are being simulated, we do not observe any significant temperature gradient in steel (see right sub-figure in Figure 3-1).

Table 3-1 shows that it would take approximately $16,750 \mathrm{~s}$ (4.6 hours) for this light box shape core column (covered with 1 1/8 in. thick fireproofing) to reach a critical temperature of $700{ }^{\circ} \mathrm{C}$ when subjected to a gas temperature of $1,100{ }^{\circ} \mathrm{C}$ (radiative flux of approximately $200 \mathrm{~kW} / \mathrm{m}^{2}$ ). As the critical 
temperature reduced from $700{ }^{\circ} \mathrm{C}$ to $538^{\circ} \mathrm{C}$, the time to reach the critical temperature also reduced to 2.9 hours.

The choice of critical temperature was based on the strength of material as a function of temperature. Given enough time, any structural element, irrespective of its size, shape, and fireproofing thickness will reach the gas temperature. One measure of the critical temperature, thus, can be the gas temperature itself. Steel, however, loses a large fraction of its strength before it reaches the gas temperature. Figure 3-2 shows non-dimensional yield strength of typical steel (NIST NCSTAR 1-3) as a function of temperature. The figure shows that steel has only 10 percent of its strength at $700{ }^{\circ} \mathrm{C}$, and that there is a rapid drop in strength in the $500-600^{\circ} \mathrm{C}$ range. The choice of critical temperature in the $500-700{ }^{\circ} \mathrm{C}$ range was dictated by this degradation in mechanical strength of steel.

Table 3-1. Time (in seconds) to reach critical temperature for light box shape core columns.

\begin{tabular}{|l|c|c|c|c|c|c|c|c|}
\hline & \multicolumn{7}{|c|}{ Gas Temperature / Critical Temperature $\left({ }^{\circ} \mathrm{C}\right)$} \\
\hline & $700 / 538$ & $700 / 650$ & $900 / 538$ & $900 / 600$ & $900 / 700$ & $1100 / 538$ & $1100 / 600$ & $1100 / 700$ \\
\hline Bare & 1100 & 2000 & 450 & 510 & 700 & 201 & 255 & 350 \\
\hline $\begin{array}{l}\text { Thickness } \\
1 / 2 \text { inch }\end{array}$ & 11750 & 21700 & 6550 & 8100 & 11545 & 4450 & 5300 & 7250 \\
\hline $\begin{array}{l}\text { Thickness } \\
11 / 8 \text { inch }\end{array}$ & 26424 & 36000 & 15191 & 18691 & 26691 & 10593 & 12593 & 16750 \\
\hline $\begin{array}{l}20 \% \\
\text { damage- } \\
\begin{array}{l}\text { Hottest } \\
\text { location }\end{array}\end{array}$ & 12148 & 23648 & 7000 & 8750 & 12800 & 4800 & 6000 & 7850 \\
\hline $\begin{array}{l}\text { 20\% damage } \\
\text {-Coolest } \\
\text { location }\end{array}$ & 15000 & 28000 & 9312 & 11400 & 16300 & 5800 & 6900 & 9138 \\
\hline
\end{tabular}

As expected, the time to reach critical temperature increases if the gas temperature reduces. If the gas temperature is $900{ }^{\circ} \mathrm{C}$, then it takes the steel column $26,691 \mathrm{~s} \mathrm{(7.4} \mathrm{hours)} \mathrm{to} \mathrm{reach} \mathrm{a} \mathrm{critical} \mathrm{temperature} \mathrm{of}$ $700{ }^{\circ} \mathrm{C}$. If the gas temperature is $700{ }^{\circ} \mathrm{C}$, then it would take 10 hours to reach a critical temperature of $650{ }^{\circ} \mathrm{C}$. Realistic fire simulations (NIST NCSTAR 1-5F) show that the fire moves from one location to another at 15-20 min intervals, depending on how quickly the combustibles are consumed. It is highly unlikely that any column would see a continuous heat flux at the specified intensity for the duration of the simulation. 


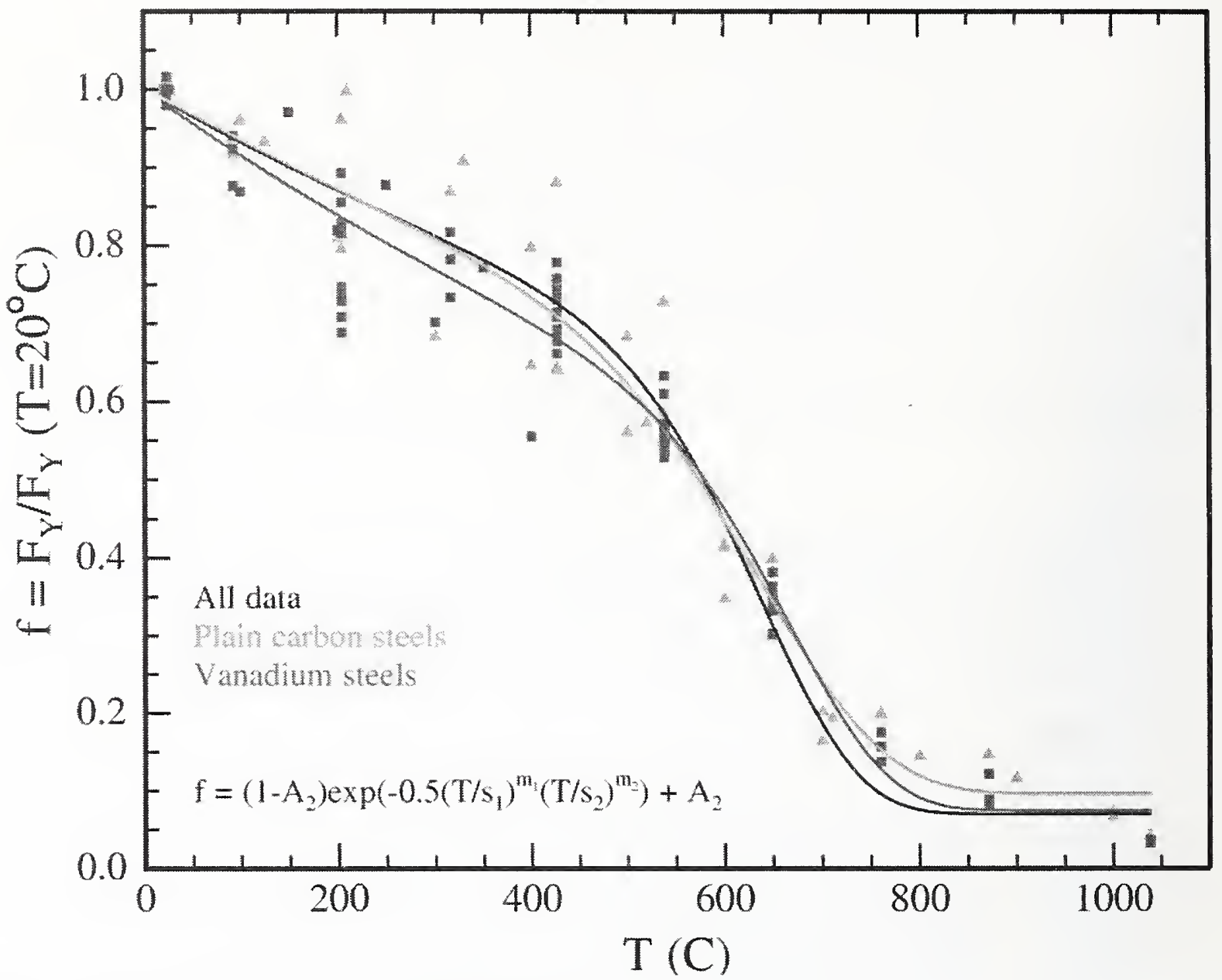

Figure 3-2. Non-dimensional yield strength as a function of temperature for typical steel used in WTC tower (NIST NCSTAR 1-3)

As the insulation thickness decreases from $11 / 8$ in. to $1 / 2$ in., the columns heats up quicker when subjected to a constant radiative flux. At $1 / 2 \mathrm{in}$. the column takes approximately $7,250 \mathrm{~s}$ ( 2 hours) to reach a critical temperature of $700{ }^{\circ} \mathrm{C}$ with a specified gas temperature of $1,100{ }^{\circ} \mathrm{C}$. If the column is completely bare (no fireproofing) then its temperature increases very rapidly, and the critical temperature is reached within $350 \mathrm{~s}$. For a bare column, the time to reach a critical temperature of $700{ }^{\circ} \mathrm{C}$ ranges between 350 to $2,000 \mathrm{~s}$.

It is noted that the time to reach critical temperature for bare columns is less than one hour, the period during which the buildings withstood intense fires. Core columns (similar to the one studied in this section) that have their fireproofing intact can not reach a critical temperature of $600{ }^{\circ} \mathrm{C}$ during the 1 or $1 \frac{1}{2}$ hour period. (Note that WTC 1 collapsed in approximately $1 \frac{1}{2}$ hour, while WTC 2 collapsed in approximately 1 hour). This implies that if these core columns played any role in the final collapse, some fireproofing damage, would be required to result in thermal degradation of it strength. 


\subsubsection{Heavy Box Shape Core Columns}

The corner columns of the core of the WTC towers had a heavy box shape construction. These columns were studied in a manner similar to the one for light box shape columns. Figure 3-3 shows a similar finite element model of a heavy box column ( 22 by 22 by 3 by $215 / 16$ in.). The sub-figure on the right shows predicted temperature contours at one instant in time. Element density in the steel plates of heavy box shaped core columns was varied to resolve any temperature gradient in the plates.

Table 3-2 shows time to reach critical temperature for heavy box shaped core columns for various fireproofing thicknesses and gas temperatures. Results indicate that a heavy box column would take approximately 14 hours to reach a critical temperature of $700{ }^{\circ} \mathrm{C}$, when exposed to gas temperature of $1,100{ }^{\circ} \mathrm{C}$. Reducing the fireproofing thickness to $0.5 \mathrm{in}$., results in more than 50 percent reduction in time to reach a specified critical temperature. The heavy box core columns take a lot longer to heat up as compared with light box columns because of the larger heat capacity associated with the thick section. The trends with changing fireproofing thickness or gas temperature are similar to those for light box columns.
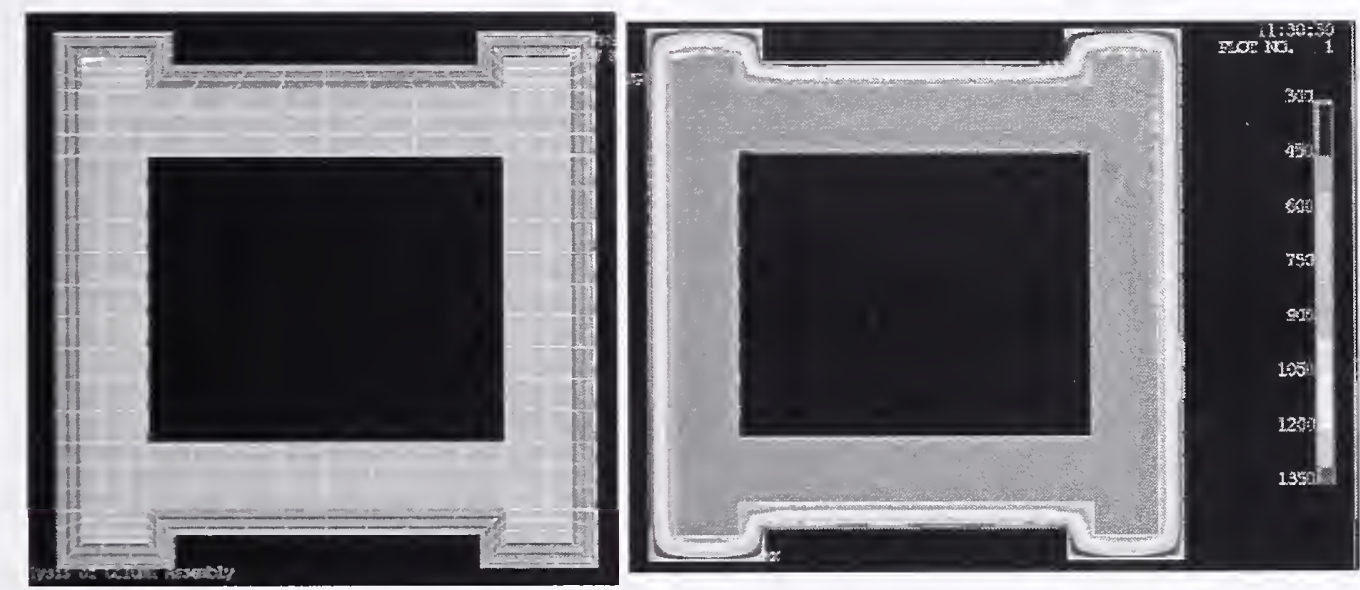

Figure 3-3. Finite element model of heavy box shape core column (left) and temperature contours (Kelvin) at one instant in time.

For bare columns, the time to reach a critical temperature of $700{ }^{\circ} \mathrm{C}$ is approximately $950 \mathrm{~s}$ when exposed to a gas temperature of $1,100{ }^{\circ} \mathrm{C}$ for the entire duration. We conclude, that significant thermally induced degradation of strength in such core columns would have been possible only if they had been bare, or if there was significant damage to the fireproofing on these columns. 
Table 3-2. Time (in seconds) to reach critical temperature for heavy box shape core columns.

\begin{tabular}{|l||c|c|c|c|c|c|c|c|}
\hline & \multicolumn{7}{|c|}{ Gas Temperature / Critical Temperature $\left({ }^{\circ} \mathrm{C}\right)$} \\
\hline & $700 / 538$ & $700 / 650$ & $900 / 538$ & $900 / 600$ & $900 / 700$ & $1100 / 538$ & $1100 / 600$ & $1100 / 700$ \\
\hline Bare & 3200 & 5580 & 1250 & 1500 & 2100 & 550 & 800 & 950 \\
\hline $\begin{array}{l}\text { Thickness } \\
1 / 2 \text { inch }\end{array}$ & $>36000$ & $>36000$ & 20550 & 25500 & 37000 & 14000 & 17000 & 23000 \\
\hline $\begin{array}{l}\text { Thickness } \\
11 / 8 \text { inch }\end{array}$ & $>72000$ & $>72000$ & 46000 & 57000 & 84000 & 32040 & 38000 & 51040 \\
\hline $\begin{array}{l}20 \% \\
\text { damage- } \\
\begin{array}{l}\text { Hottest } \\
\text { location }\end{array}\end{array}$ & $>36000$ & $>36000$ & 22900 & 28401 & 42000 & 17500 & 21370 & 28972 \\
\hline $\begin{array}{l}20 \% \text { damage } \\
\text { - Coolest } \\
\text { location }\end{array}$ & $>36000$ & $>36000$ & 25901 & 31901 & 46000 & 17972 & 21472 & 28990 \\
\hline
\end{tabular}

\subsection{STATISTICAL VARIABILITY IN FIREPROOFING THICKNESS}

The fireproofing was sprayed on to the various structural elements, and it is conceivable that the fireproofing thickness varies from one location on the column to another. Variability in fireproofing thickness for the World Trade Center Towers has been recorded in NIST NCSTAR 1-6A. The experiments conducted at the large fire facility to study the response of insulated structural elements to 2$3 \mathrm{MW}$ fires also recorded a variability in fireproofing thickness (NIST NCSTAR 1-5B).

Statistical variability in fireproofing thickness was incorporated in the finite element model through a scheme based on the use of a random number generator. The random number generation scheme identified a subset of elements (with material attributes of fireproofing). The material attributes of the selected elements were modified, such that those elements offered no resistance to heat transfer.

Figure 3-4 shows a finite element model of a thick box column with statistical variability in fireproofing thickness. The fireproofing elements for which the material attributes were modified are shown in red. Because of the randomness of fireproofing damage the effective thickness of fireproofing becomes smaller, which results in faster heating up of the column.

Table 3-1 and Table 3-2 show the effect of 20 percent random damage to fireproofing on the time to reach a certain critical temperature. Because of the variability in fireproofing thickness, small temperature gradients can set up in the column. Two sets of number are recorded in Table 3-1 for the hottest and coolest location on the column. The initial thickness of fireproofing was assumed to be the specified thickness of $11 / 8$ in., and 20 percent damage was subsequently included in the model, resulting 
in a smaller equivalent thickness. These results indicate that the time to reach a critical temperature of $700{ }^{\circ} \mathrm{C}$ is approximately $7,850 \mathrm{~s}$ when subjected to a gas temperature of $1,100^{\circ} \mathrm{C}$. As compared to the time of $16,750 \mathrm{~s}$ for an un-damaged structure, statistical variability in fireproofing thickness has resulted in 50 percent reduction in heat up time. This is due to a combination of the reduction in equivalent thickness and the variability in fireproofing thickness.
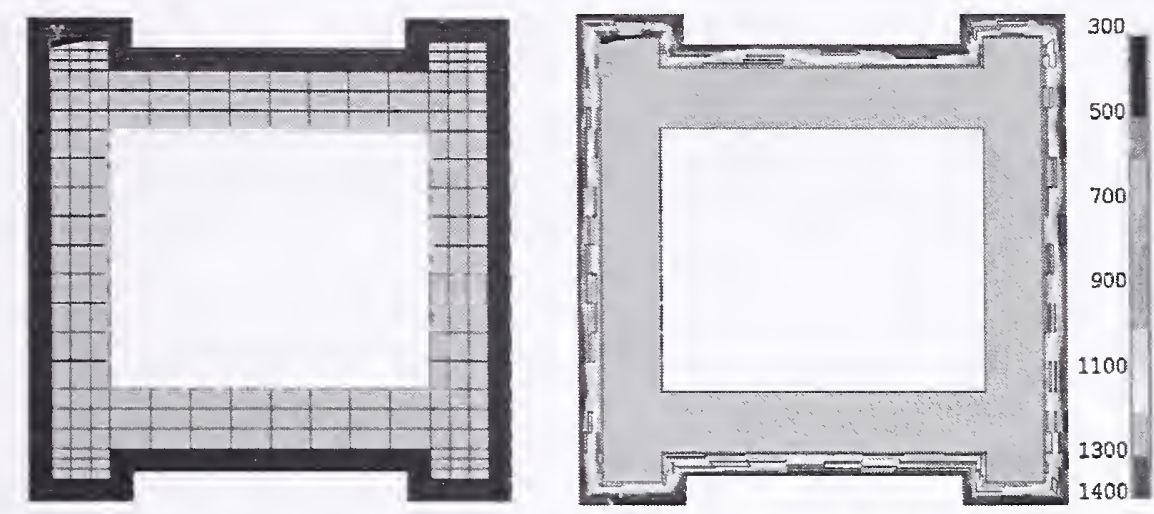

Figure 3-4. Effect of statistical variability in fireproofing thickness on steel temperature. Temperature contours have been shown in Kelvin.

\subsection{SELECTIVE FIREPROOFING DAMAGE ON ONE FACE OF THE COLUMN}

One of the objectives of this Investigation was to simulate the thermally induced response of a structure that has been damaged by aircraft impact. The aircraft impact can knock fireproofing from the columns. In the previous section, the effect of complete fireproofing damage (no fireproofing over the entire perimeter of the column) was studied. In this section we discuss the effect of selectively damaging portions of the fireproofing on a column.

Figure 3-5 shows fireproofing damage on one face of a heavy core column (indicated by missing fireproofing on the right side). The column is subjected to radiative flux on all its exposed faces. Temperature contours (Kelvin) shown in Figure 3-5 at 7,200 s after the application of radiative heating indicate that the right side of the column heats up very quickly, while the left side stays relative cool, resulting in a severe temperature gradient through the cross-section of the column. Temperature gradients through a core column can result in differential thermal expansion and bowing of the column. 

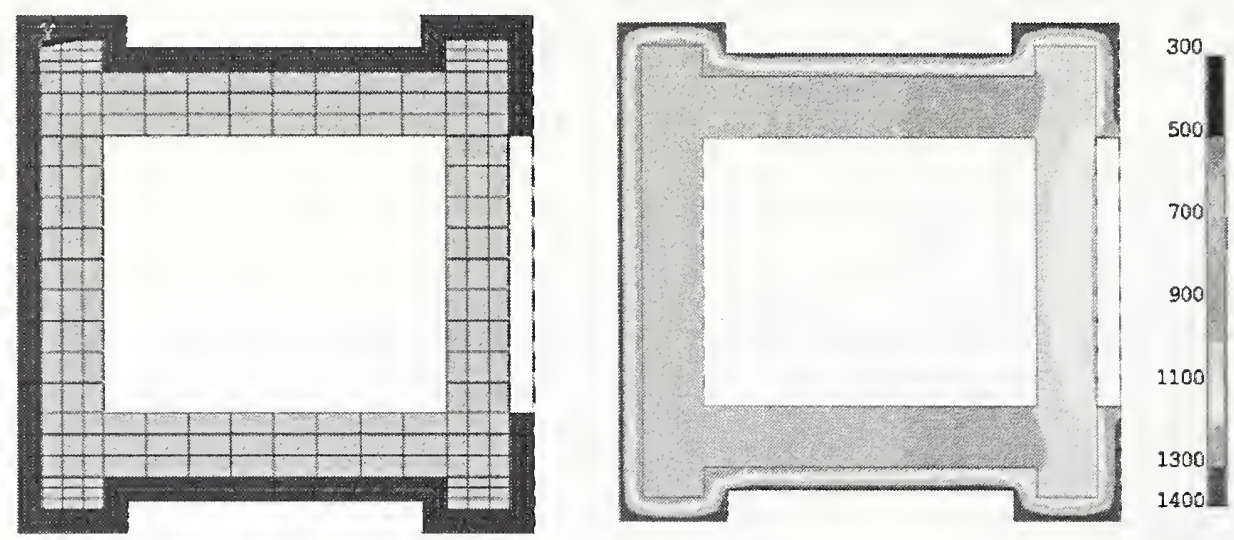

Figure 3-5. Effect of fireproofing damage on one face of a heavy core column. Temperature contours have been shown in Kelvin.

Selective fireproofing damage on one or two faces can exist on core columns that are in the debris path of an aircraft. This can result in a potentially severe thermal loading condition on the column. Although fireproofing damage due to aircraft impact was incorporated in the global analysis (presented in Chapter 8 through Chapter 11), it was assumed that fireproofing was either completely damaged or fully intact. Selective fireproofing damage on one or two faces of any column was not accounted for in the main investigation, due to lack of accurate techniques to estimate the extent of damage. These results are presented here to illustrate awareness of the extreme loading that can occur on the structure due to selective fireproofing damage and of its impact on thermally induced structural response.

\subsection{SENSITIVITY STUDY ON WIDE FLANGE COLUMNS}

A sensitivity study was conducted for wide flange columns in a manner identical to that for box columns described in the earlier section. Two wide flange columns, one (12WF133) with a relatively light crosssection, and other (14WF730) with a heavy cross-section were selected for analysis. Table 3-3 and Table 3-4 summarize the time to reach critical temperature for wide flange columns 12 WF 133 and 14WF730, respectively. Results are presented for bare columns, columns with specified fireproofing thickness of $23 / 16$ in., columns with a 20 percent statistical variability in fireproofing, and columns with one face bare. 
Table 3-3. Time (in seconds) to reach critical temperature for wide flange column 12WF133.

\begin{tabular}{|l|c|c|c|c|c|c|c|c|}
\hline & \multicolumn{7}{|c|}{ Gas Temperature / Critical Temperature $\left({ }^{\circ} \mathrm{C}\right)$} \\
& $700 / 500$ & $700 / 600$ & $900 / 500$ & $900 / 600$ & $900 / 700$ & $1100 / 500$ & $1100 / 600$ & $1100 / 700$ \\
\hline Bare & 580 & 900 & 220 & 320 & 450 & 100 & 150 & 180 \\
\hline $\begin{array}{l}\text { Thickness } \\
23 / 16 \text { inch }\end{array}$ & $>14400$ & $>14400$ & $>14400$ & $>14400$ & $>14400$ & 10200 & 12900 & $>14400$ \\
\hline $\begin{array}{l}20 \% \text { random } \\
\text { damage }\end{array}$ & $>14400$ & $>14400$ & 8200 & 10800 & $>14400$ & 4700 & 5900 & 7400 \\
\hline $\begin{array}{l}\text { One face } \\
\text { bare }\end{array}$ & 5000 & 8300 & 2650 & 3800 & 5900 & 1700 & 2500 & 3300 \\
\hline
\end{tabular}

Table 3-4. Time (in seconds) to reach critical temperature for wide flange column 14WF730.

\begin{tabular}{|l|l|l|l|l|l|l|l|l|}
\hline & \multicolumn{7}{|c|}{ Gas Temperature / Critical Temperature $\left({ }^{\circ} \mathrm{C}\right)$} \\
\hline & $700 / 500$ & $700 / 600$ & $900 / 500$ & $900 / 600$ & $900 / 700$ & $1100 / 500$ & $1100 / 600$ & $1100 / 700$ \\
\hline \begin{tabular}{l} 
Bare \\
\hline $\begin{array}{l}\text { Thickness } \\
\text { 3/16 inch }\end{array}$
\end{tabular} & $>14400$ & $>14400$ & $>14400$ & $>14400$ & $>14400$ & $>14400$ & $>14400$ & $>14400$ \\
\hline $\begin{array}{l}20 \% \text { random } \\
\text { damage }\end{array}$ & $>14400$ & $>14400$ & 14000 & $>14400$ & $>14400$ & 7200 & 9500 & 12200 \\
\hline $\begin{array}{l}\text { One face } \\
\text { bare }\end{array}$ & 11500 & $>14400$ & 5800 & 8400 & 12200 & 3500 & 500 & 5000 \\
\hline
\end{tabular}

\subsection{SENSITIVITY OF THERMAL RESPONSE TO FIREPROOFING GEOMETRY}

The fireproofing thickness has a great effect on the thermal response of the structural elements for a given fire condition. While others have considered the effect of thickness of fireproofing, the role of variation of thickness along the length of a member or fireproofing damage (gap in fireproofing) in a portion of the member, is not well known. A sensitivity study is described to investigate the effect of fireproofing thickness, fireproofing damage, and variability in fireproofing thickness on thermal response of structural members. 
Figure 3-6 shows a bridging truss of the WTC towers floor system. The picture shows the upper and lower flange of the truss and the web diagonals that form the " $M$ " shaped pattern. Fireproofing thickness varies along the length of web diagonal. The web diagonal on the far left of the picture, shows very thick fireproofing at the bottom and less fireproofing on the top. This picture shows that fireproofing was not applied evenly and that its thickness varied along the length of the diagonal. Fireproofing thickness also varied from one diagonal to another.

The third diagonal from the left in Figure 3-6 shows fireproofing damage (gap in fireproofing). This diagonal has fireproofing intact at the top and bottom, and fireproofing is completely missing in the middle. Also note that fireproofing at the top and bottom of the diagonal has variability in thickness. In this section, the effect of variability in fireproofing thickness and gap size (as observed in Figure 3-6) on thermal response of structural member is presented.

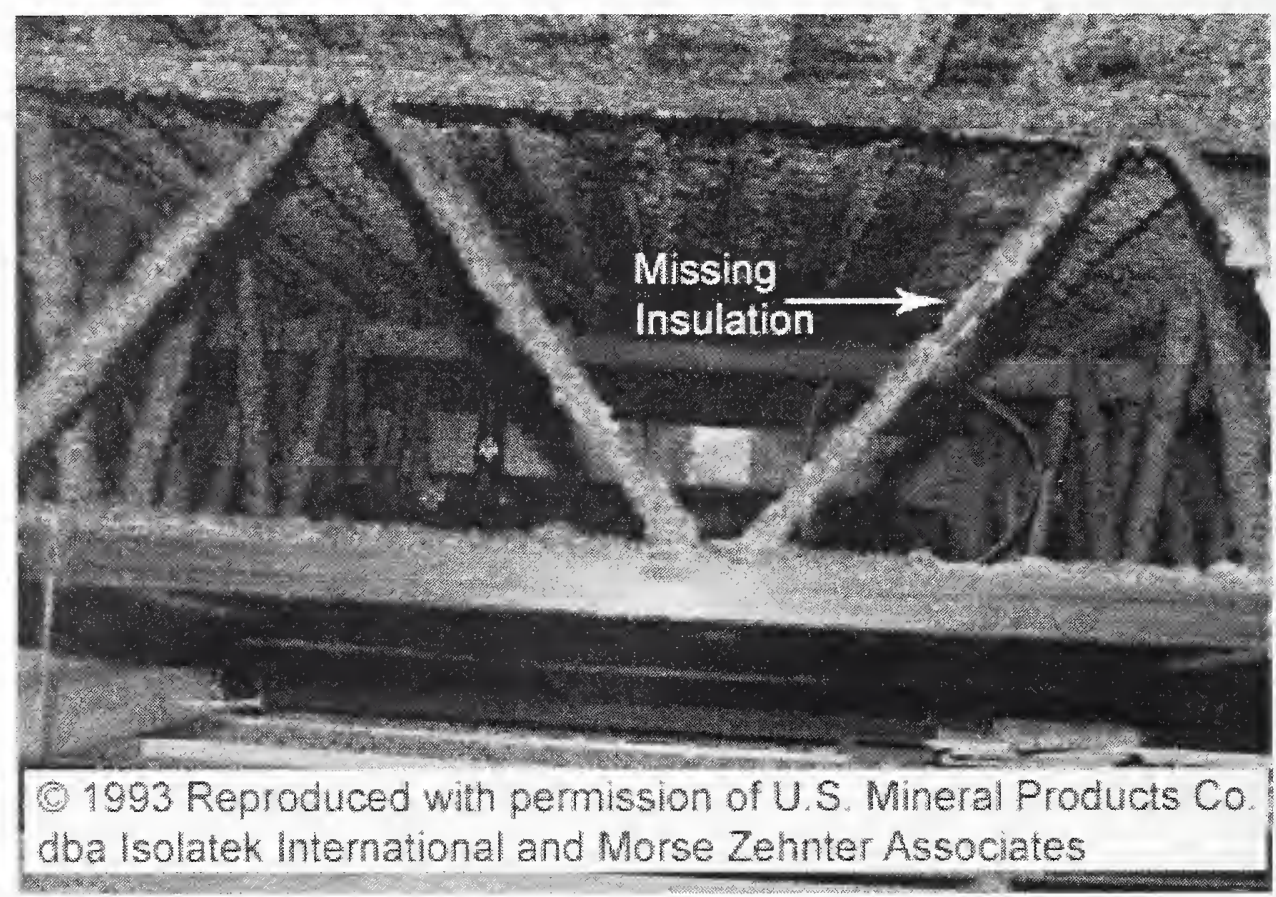

\section{Figure 3-6. Example of variability in fireproofing thickness and "gap" in fireproofing on diagonal member of a bridging floor truss.}

The simplified model that was used is shown in Figure 3-7 (a). A 1 in. thick, 60 in. long steel plate (cyan color) was coated with fireproofing material (purple color) and subjected to the uniform radiative flux arising from a $1,100^{\circ} \mathrm{C}$ fire. In this figure the fireproofing thickness is 2 in., but this thickness can change from one simulation to another simulation. A two-dimensional model using the ANSYS finite element software was developed to study the heat transfer in such a geometry. Figure 3-7 (b) shows the finite element mesh on a blown up view of a portion of the steel plate and fireproofing. As shown in Figure 3-7 (b), the fireproofing is modeled with a layer of finite elements $(0.125 \mathrm{in}$. thick and $0.6 \mathrm{in}$. long) having the thermal properties of fireproofing (purple). The steel plate is meshed with 10 elements through its thickness, each element is $0.6 \mathrm{in}$. long.

A parametric study was conducted with average thickness of fireproofing varying from 0 in. to 2 in. in increments of $1 / 4 \mathrm{in}$. The effect of variability in thickness was modeled by imposing a normal probability 
distribution to the fireproofing thickness along the length of the steel plate. The assumed standard deviation varied from $0 \mathrm{in}$. (uniform thickness) to $1 \mathrm{in.}$ A psuedo random number generator was employed to determine the thickness at each cross section based on the assumed average thickness and standard deviation. The randomness in fireproofing thickness was incorporated in a finite element model by first constructing a model where fireproofing thickness was twice the average thickness and was meshed with 2-D finite elements. At any given location, the random number generator predicted a certain thickness. Finite elements at that location, which lie above the predicted thickness were assigned a new material attribute. The material attribute was chosen such that the elements did not provide any resistance to the flow of heat. Finite elements that lie below the predicted thickness were assigned the material attributes of fireproofing. Figure 3-8(a) shows an example of variable thickness fireproofing; in this case the average thickness is $1 \mathrm{in}$. and the standard deviation is $3 / 8 \mathrm{in}$.

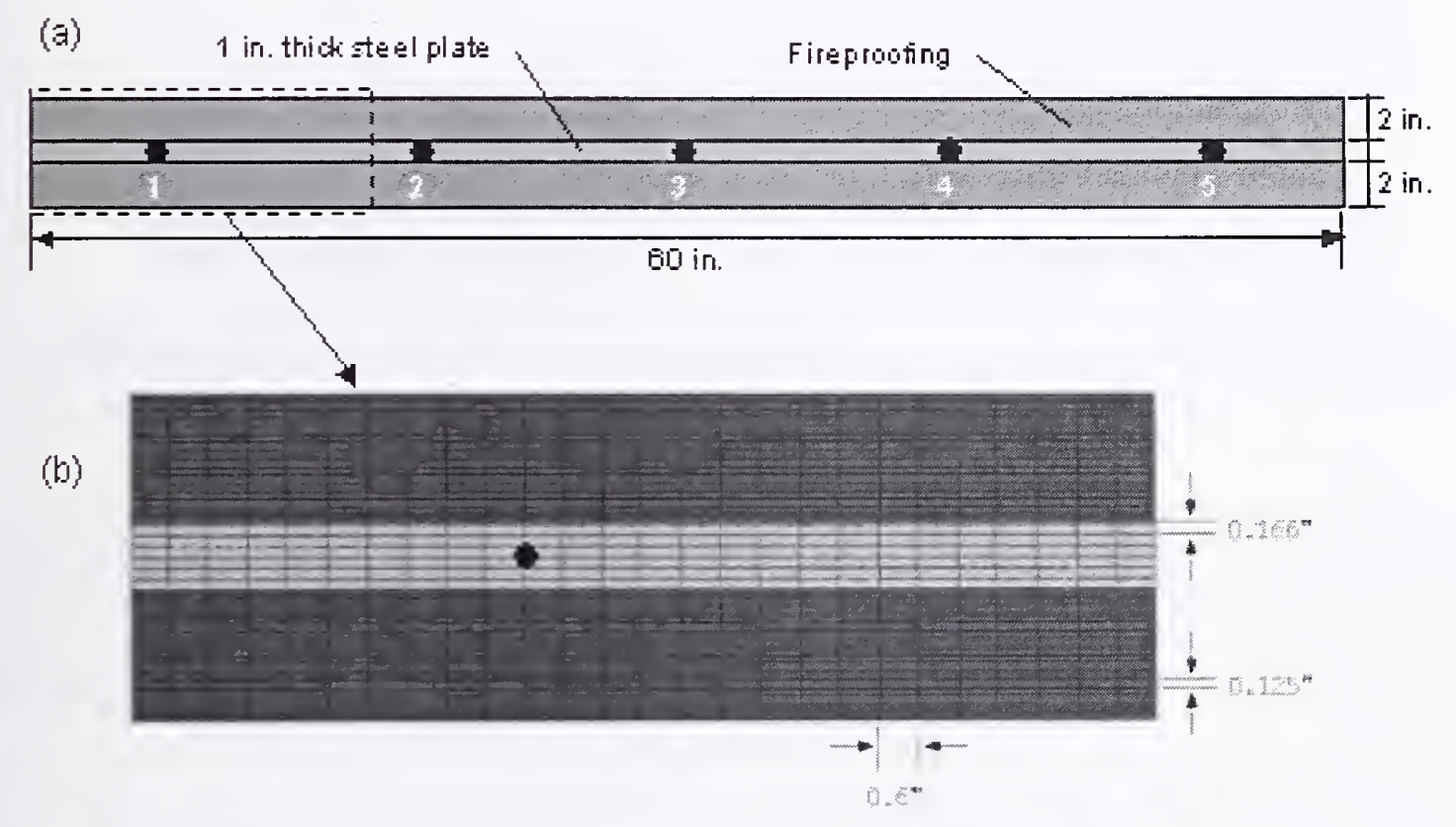

Figure 3-7. Model used to study effects of fireproofing thickness and variability of thickness on steel temperature: a) physical model used in analyses (points 1-5 are sensor locations where temperature are monitored); b) finite element mesh used to represent physical model.

When the model in Figure 3-7 is exposed to the thermal flux representing an 1,100 ${ }^{\circ} \mathrm{C}$ fire, the surface of the insulation heats up quickly to the gas temperature. Numerical simulation was performed over a $2 \mathrm{~h}$ period, and the steel temperature at five sensor locations were recorded at 30,60,90, and 120 min of exposure. The temperature locations are $6 \mathrm{in}$. from each end and at $12 \mathrm{in.} \mathrm{intervals,} \mathrm{which} \mathrm{are} \mathrm{shown} \mathrm{as}$ numbers 1 to 5 in Figure 3-7 (a). The initial temperature of the model is $27^{\circ} \mathrm{C}$. 
a)
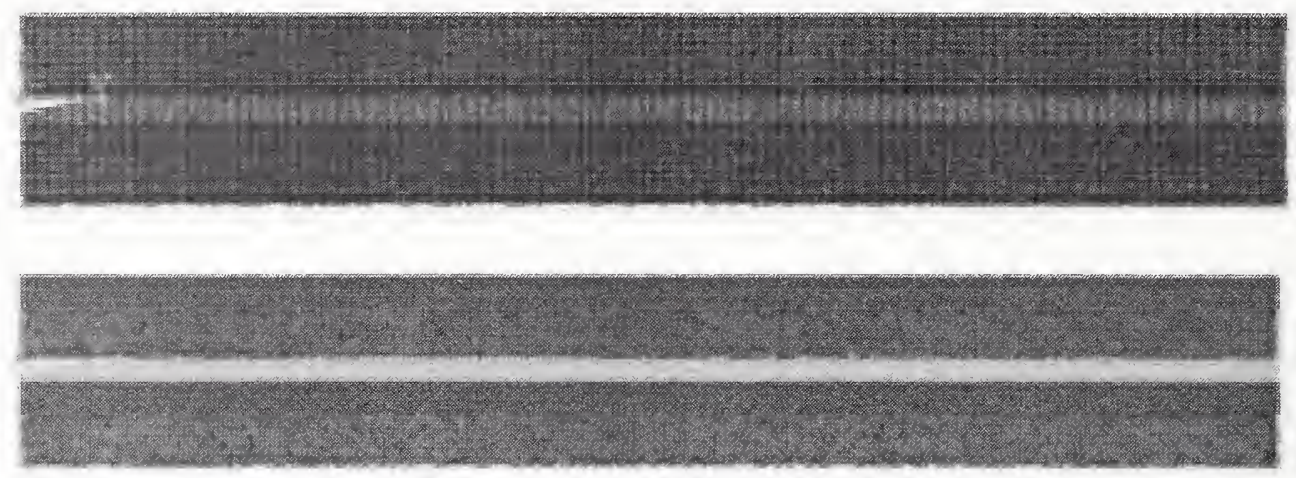

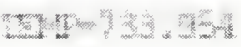

b)
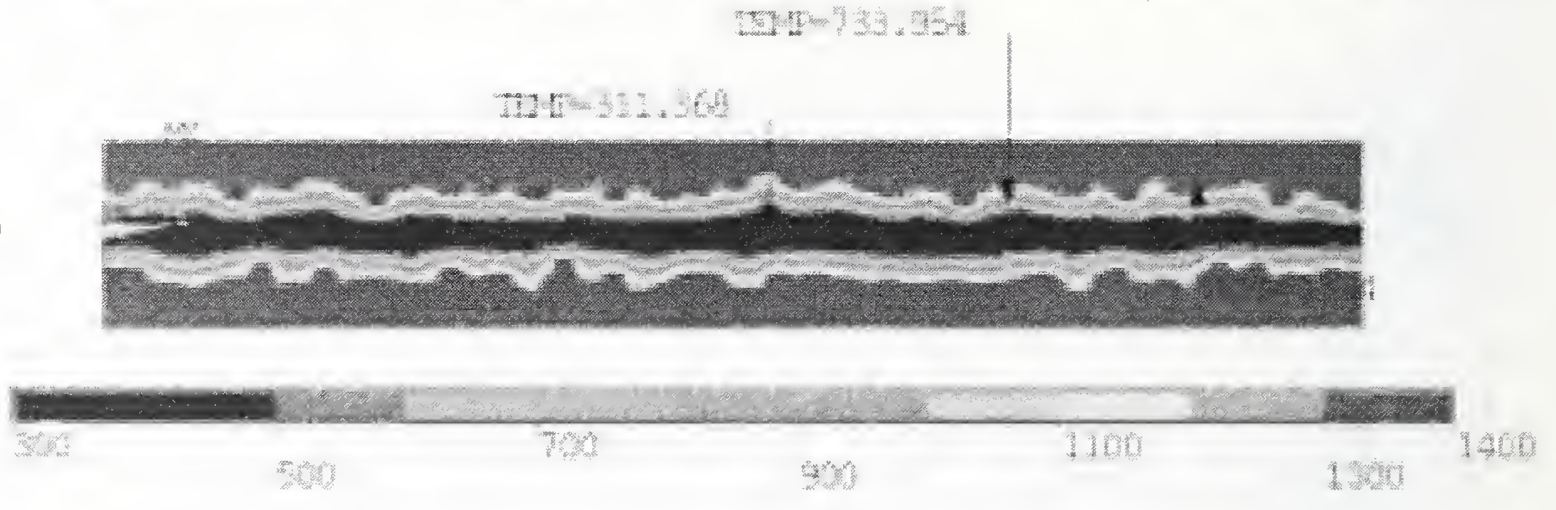

Figure 3-8. Finite element model to represent thickness of fireproofing (purple). The elements in red represent a material that provides no resistance to heat flow (very high thermal conductivity and very low thermal inertia).

Figure 3-8 shows temperature contours (Kelvin) through the fireproofing and steel at 60 min after initial exposure for the model shown in Figure 3-7 (a). The fireproofing surface temperature is close to the gas temperature of $1,373 \mathrm{~K}$, while the steel temperature is $311 \mathrm{~K}$. If the fireproofing were of uniform thickness, the isotherms would be a series of lines parallel to the plate (since the flux is uniform over the entire plate). It is seen that, when the thickness of fireproofing is variable the isotherms follow the shape of the fireproofing surface contour. Thus, the temperature history at any point in the steel depends on the local thickness of the fireproofing. We also observe that, if the fireproofing thickness is very small at any location, then steel in that region heats up very quickly.

Figure 3-9 shows the steel temperature at the far sensor \#1 (6 in. from the end) as a function of time for various insulation thicknesses ranging from 0 in. to $2 \mathrm{in}$. (the thickness is indicated by the numbers on the curves). For the case in Figure 3-9 (a), the fireproofing is of uniform thickness, and for the cases in Figure 3-9 (b), the thickness varies with a standard deviation of 1 in. The time to reach a temperature of $600{ }^{\circ} \mathrm{C}$ is used as a measure of relative performance. It is seen that the presence of high variability in thickness has a detrimental effect on the protection provided by fireproofing. For example, for a uniform thickness of $0.5 \mathrm{in}$., it takes about $60 \mathrm{~min}$ for the steel at point $\# 1$ to reach $600{ }^{\circ} \mathrm{C}$; but when the standard deviation of the thickness is $1 \mathrm{in}$., the average thickness has to be $1.75 \mathrm{in}$. for the same level of thermal protection. 


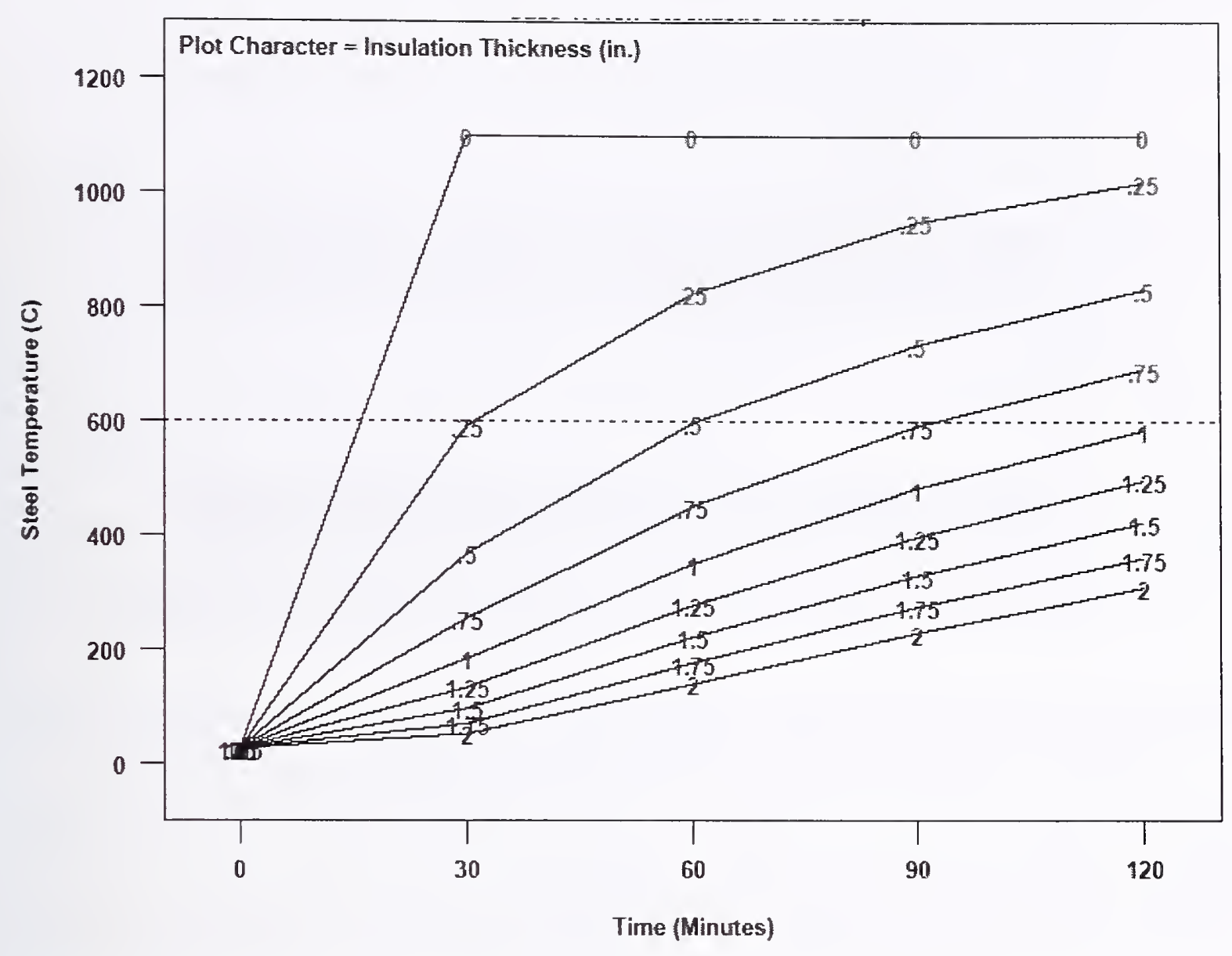

Figure 3-9. Variation of steel temperature at Sensor Location \#1 with time for different average thickness of fireproofing (shown as numbers on the curves). The fireproofing thickness is uniform over the entire length.

In addition to the effect of variation in thickness, it is important to understand the effect of missing fireproofing over a portion of a member (Chang, Buchanan and Moss, 2005). As an example, Figure 3-10 models missing fireproofing from a diagonal of a bridging truss of the WTC towers floor system. Figure 3-10 (a) shows an example of a numerical model with missing fireproofing. In this case, there are 12 in. of missing fireproofing on the steel plate, which is otherwise protected by 2 in. of uniform thickness fireproofing. Figure 3-10 (b) shows isotherms in the steel and fireproofing. As expected, the bare steel at the missing fireproofing is at the gas temperature. but more importantly the "gap" in fireproofing leads to a "leakage" of heat into the steel plate. 
a)

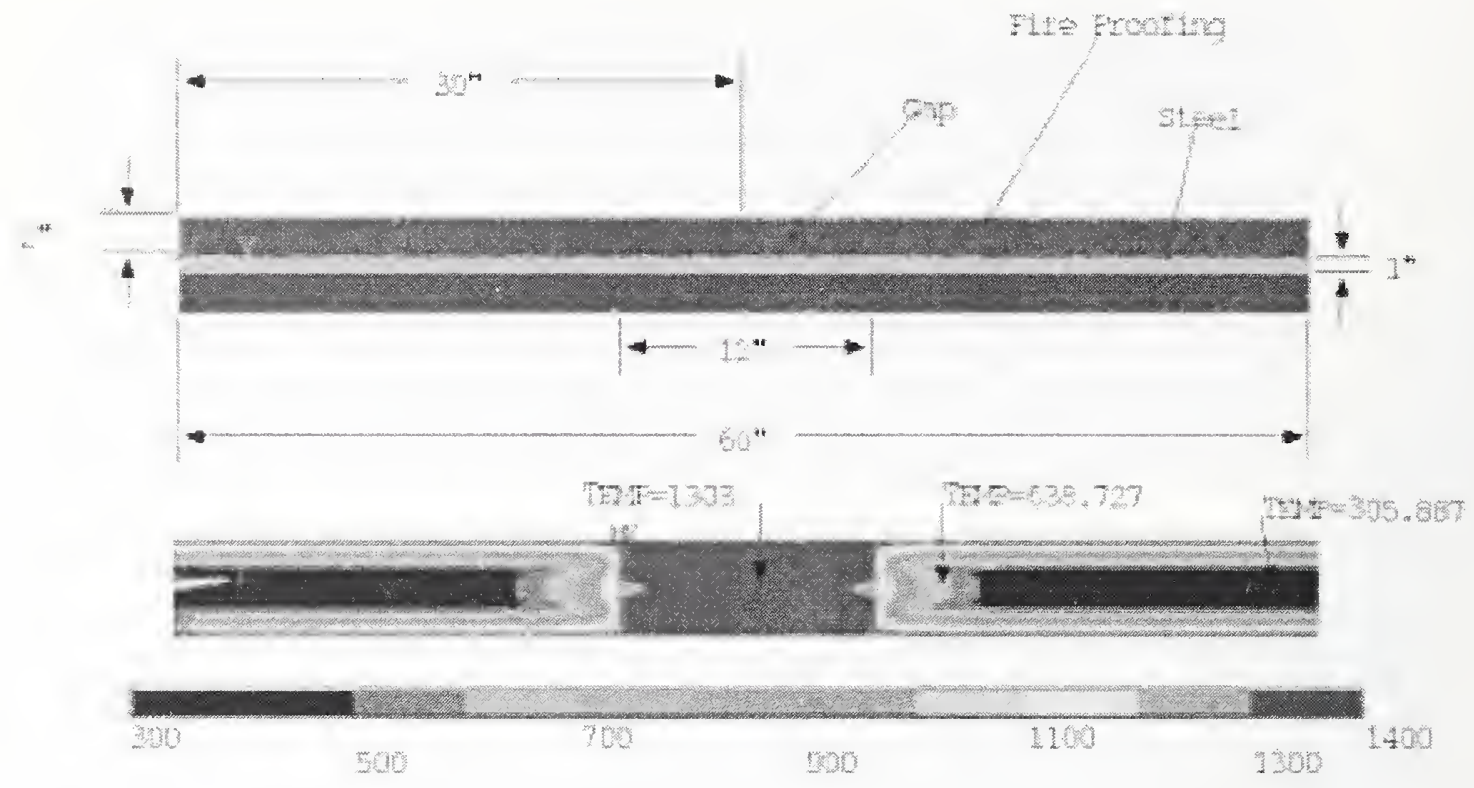

Figure 3-10. Finite element model for studying the effect of gap in fireproofing thickness a) location of the gap on the plate b) temperature contours at one instant in time.

The combined effects of variation in thickness of the fireproofing and length of missing fireproofing were examined in a full factorial study with the following factors:

- Average thickness of fireproofing varying from 0 in. to 2.0 in. in $1 / 4$ in. increments;

- Standard deviation of fireproofing thickness of $0 \mathrm{in} ., 0.25 \mathrm{in} ., 0.5 \mathrm{in} ., 0.75 \mathrm{in}$., and $1.0 \mathrm{in}$; and

- Length of missing fireproofing varying from 0 in. to $30 \mathrm{in.,} \mathrm{in} 6 \mathrm{in.} \mathrm{increments.}$

The results of the sensitivity study can be summarized in a series of plot matrices as shown in Figure 3-11 through Figure 3-15 for sensor location \# 1 through sensor location \#5, respectively. Each figure shows the time history of steel temperature for different combinations of gap length and variability in fireproofing thickness. For example, Figure 3-11 shows the plot matrix (consisting of $25 \mathrm{x}-\mathrm{y}$ plots) for temperature history at sensor location \#1 (6 in. from the end of the plate). Each $x-y$ plot contains a series of curves representing different average thickness of fireproofing, as in Figure 3-9. Each column of $x-y$ plots represents a constant value of thickness variability (defined by standard deviation), and each row represents a constant gap length. The plot in the upper left corner represents the case of uniform thickness of fireproofing and no gap, which is the same plot as Figure 3-9 (a). (Note that for the case of uniform thickness and no gap, the steel temperature at any point in a cross section is the same along the length of the plate. The upper left corner plots in Figure 3-11 through Figure 3-15 are the same as one shown in Figure 3-9 (a).)

For gaps of $24 \mathrm{in.}$ and $30 \mathrm{in}$., the temperature at sensor location \#1 rises rapidly because there is no fireproofing on the plate at that location. This explains the shapes of the curves in the two lower rows. It should be noted that for each $x-y$ plot, data at five instants in time $(0 \mathrm{~min}, 30 \mathrm{~min}, 60 \mathrm{~min}, 90 \mathrm{~min}$ and 120 
min after the application of radiative flux) has been plotted. The data points have been connected with straight lines. In reality the profile between any two points can be highly non-linear.

Moving from left to right in one of the top four rows, shows that as variability of thickness increases, the time histories shift upward, thereby reducing the time to reach $600{ }^{\circ} \mathrm{C}$. Moving from the top to the bottom in any column shows the effect of increasing gap length. The effect of gap length depends, of course, on where the steel temperature is measured. Temperature rises quickly on points on the steel plate that are bare. At points within the steel that are surrounded with fireproofing, the gap provides a path for heat flow, as shown in Figure 3-9. As a result, points in the steel within the vicinity of the missing fireproofing will experience higher temperatures, as indicated by the rising trend of the curves in going downwards from the top of a column in Figure 3-11.

Figure 3-12 shows a matrix of plots similar to Figure 3-11, plotted at sensor location \#2. Sensor location \#2 is shown in Figure 3-7 and is located 18 in. from the left end of the plate. Since this location is closer to the center of the plate, the effect of gap size will have a bigger effect on the predicted steel temperature at this location. The plots for a gap size of $24 \mathrm{in.} \mathrm{or} 30 \mathrm{in}$. with no variability in fireproofing thickness shows a very rapid increase in steel temperature to a value close to the gas temperature.

Figure 3-14 shows a plot matrix at sensor location \#4. Sensor location \#2 and \#4 are placed equidistance from the center line. Note that the gap in fireproofing is always centered on the plate. The plot matrix for sensor locations \#2 and \#4 are not identical in general. The random number generator introduces variability in the fireproofing thickness distribution, and as a result there are visible differences in the $x-y$ plots shown in Figure 3-12 and Figure 3-14, especially for large values of standard deviation. Similarly plots for sensor location \#1 are in general different from those for sensor location \#5. The only exception is plots where the standard deviation is zero (no variability in fireproofing thickness). The first column of plots in Figure 3-12 and Figure 3-14 are similar since there is no variability in thickness for this column. 


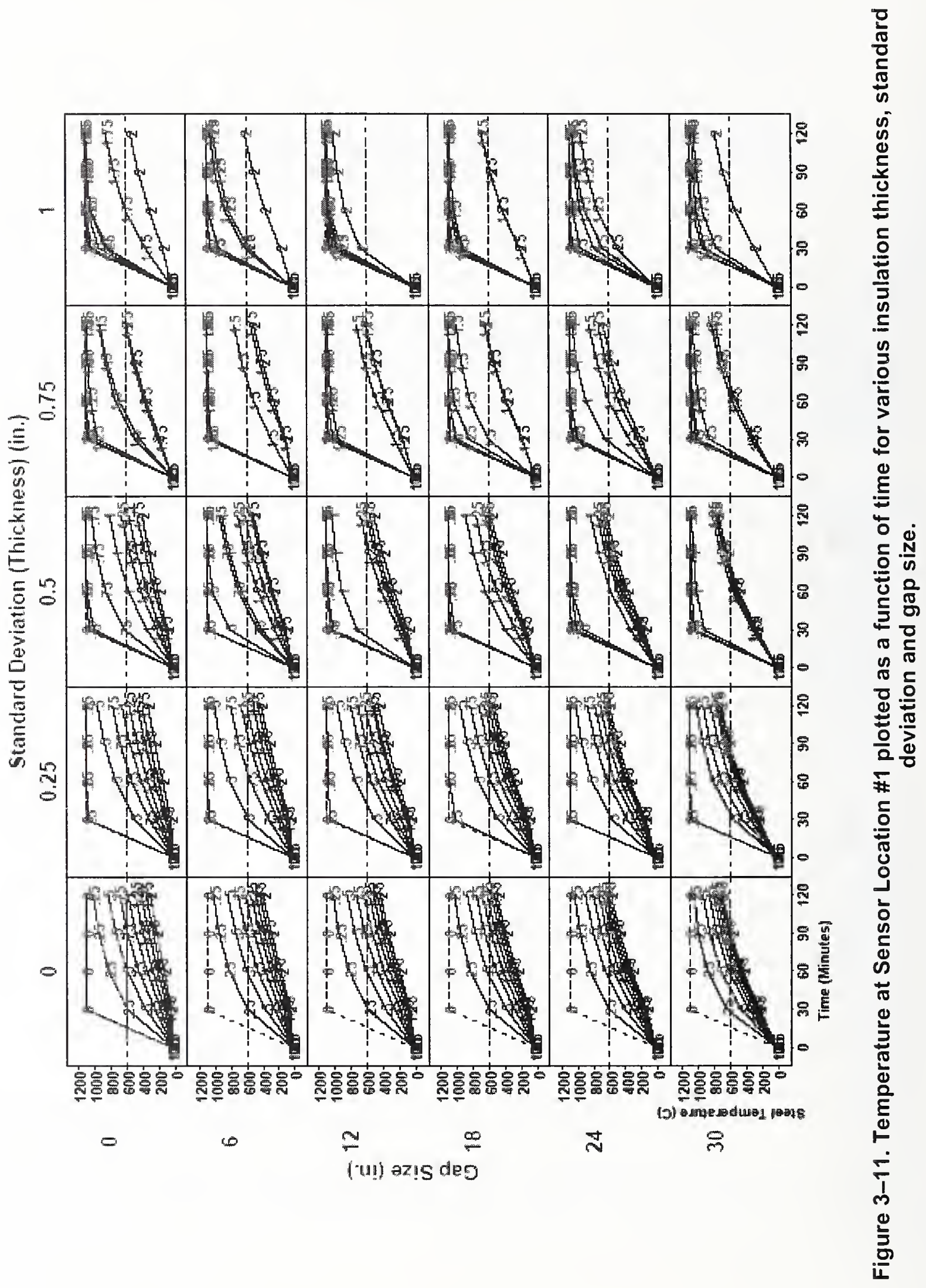




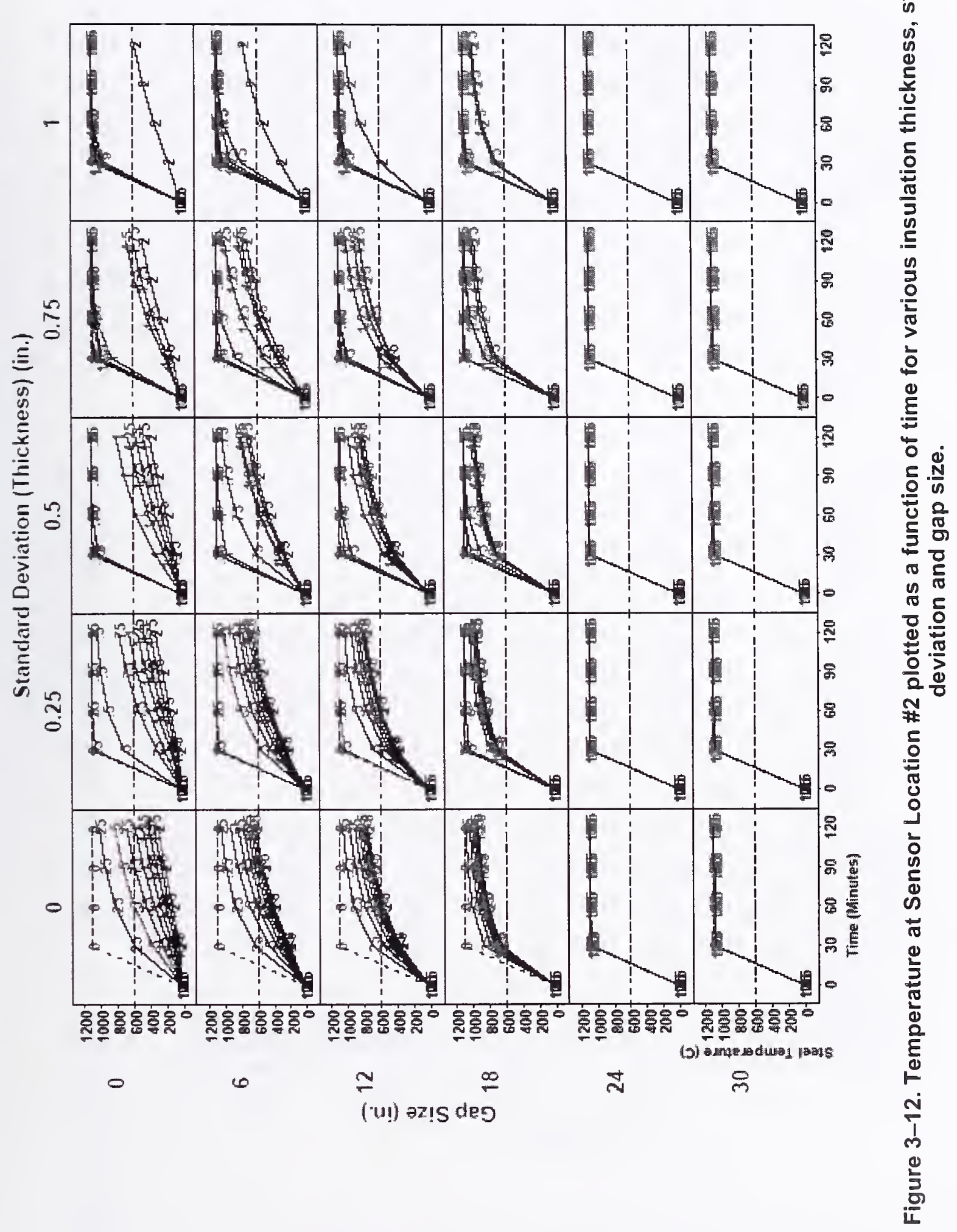




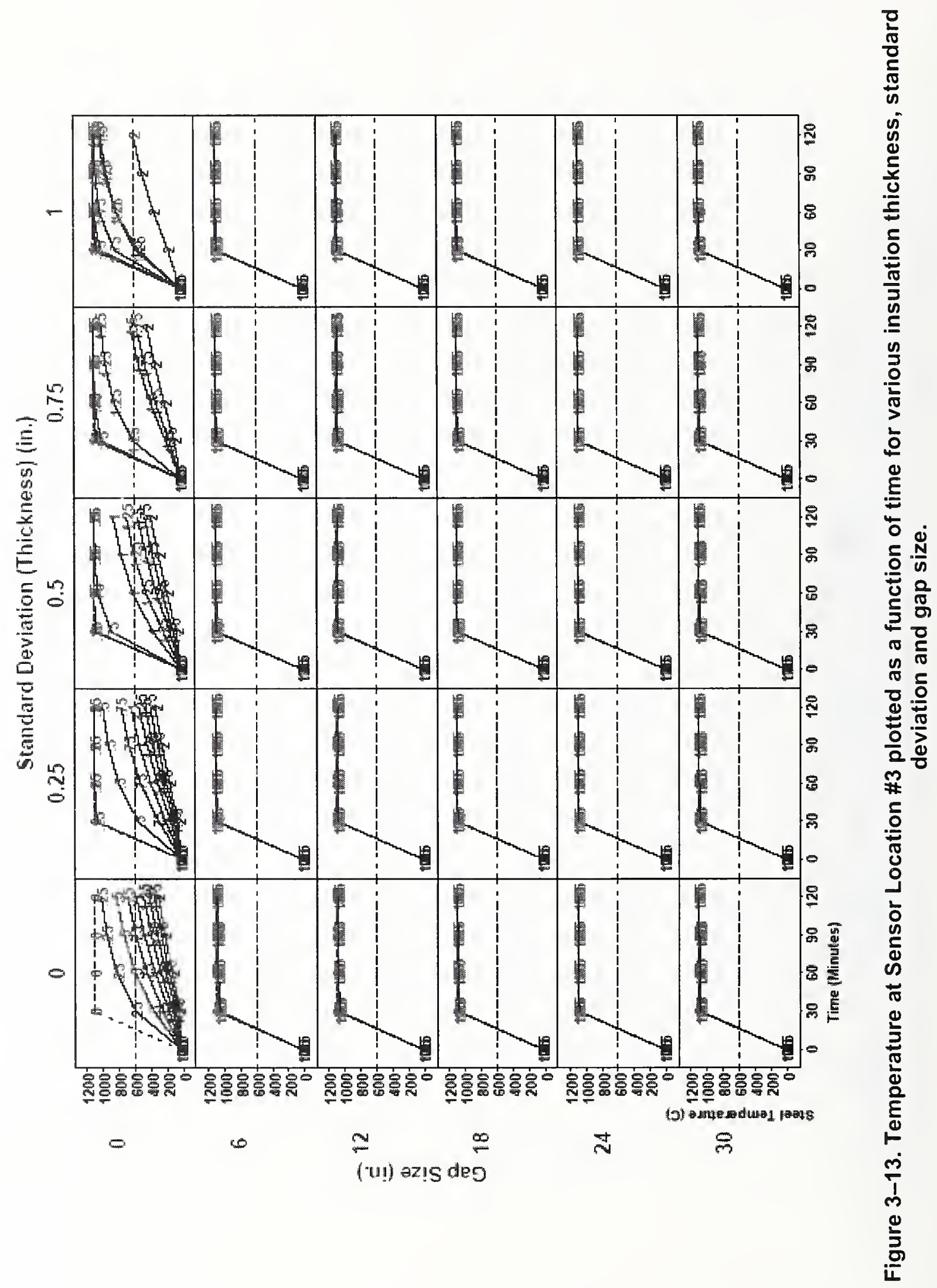




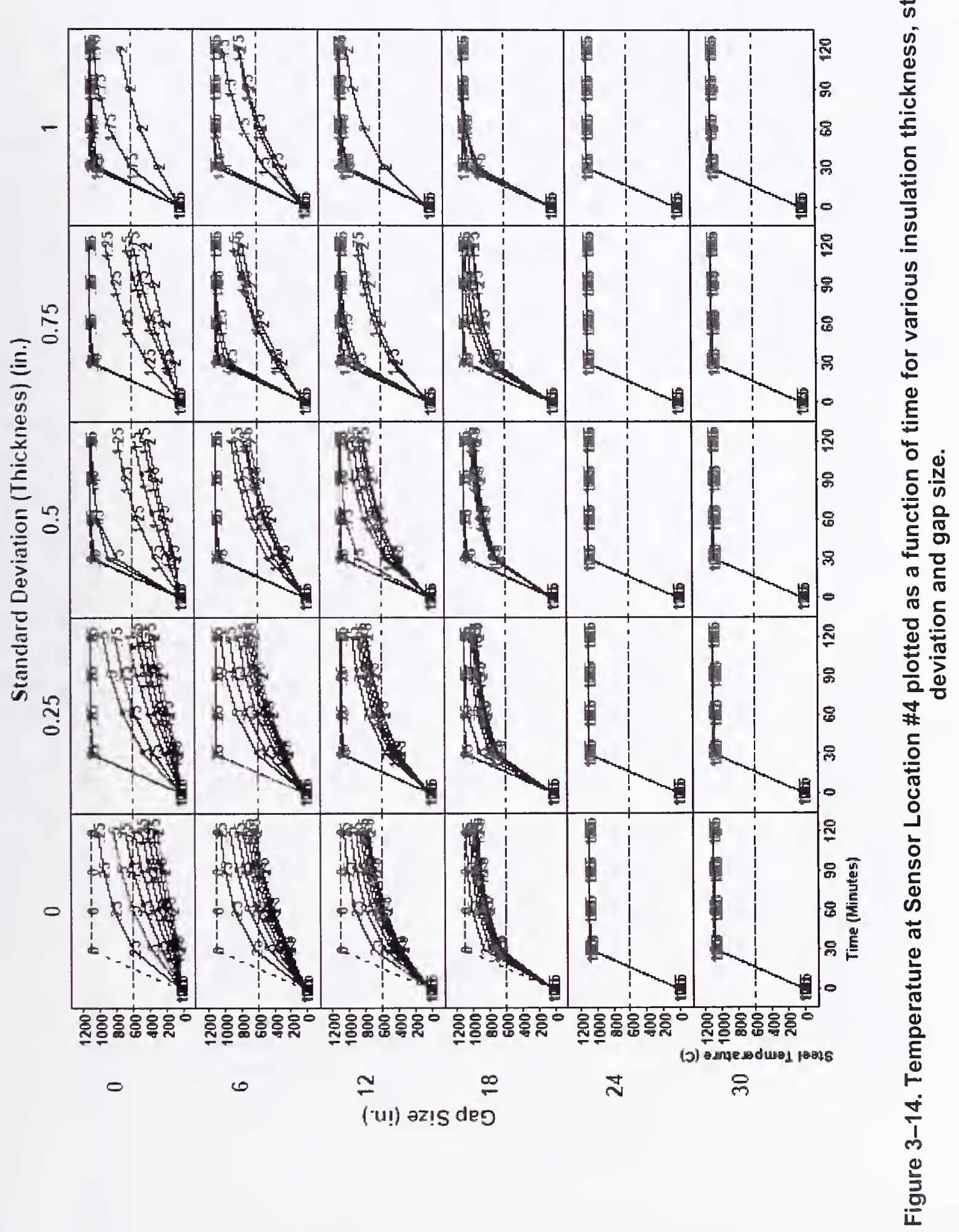




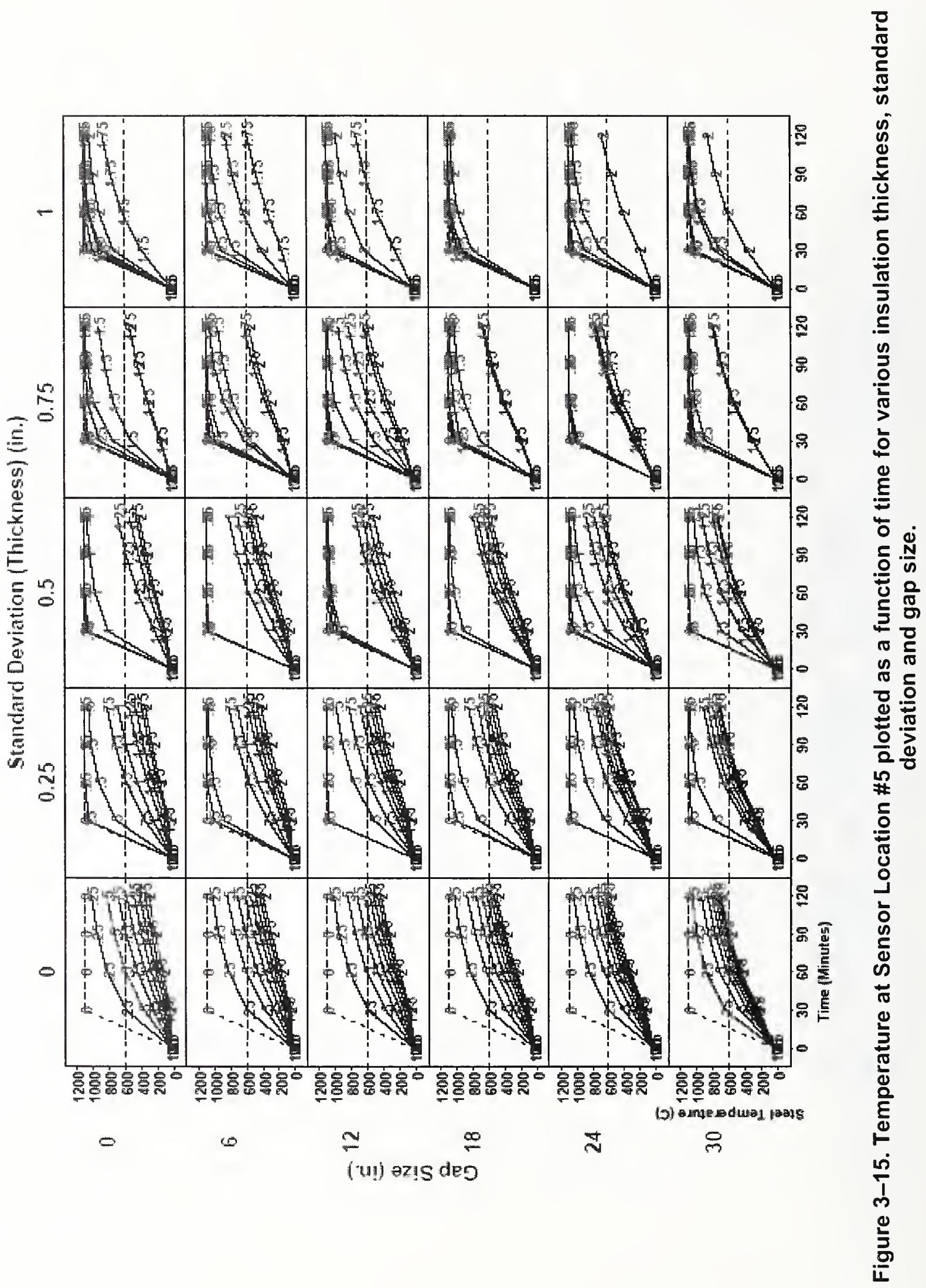


When the standard deviation is zero, the steel temperature at any given time increases as the fireproofing thickness decreases, but as the variability in fireproofing thickness increases, this trend does not always hold true. The first row of plots in Figure 3-15 shows that for a standard deviation of 1 in. and zero gap thickness, the profile for 1.75 in. mean thickness shows lower temperature as compared to 2 in. thick fireproofing. This is again due to the randomness of number generator. It is possible that if the experiment is carried out with a different initial seed value of the random generator, then the trend at this location would reverse.

Figure 3-16 through Figure 3-20 show this effect in a clearer manner. Each figure shows a matrix of $x-y$ plots showing the steel temperature along the length of the steel plate for different combinations of gap length and variability in fireproofing thickness. The matrix in Figure 3-16 is for steel temperature at 30 min after application of radiative flux. Results have been shown at 30 min intervals in Figure 3-16 through Figure 3-20. When there is no variability in fireproofing thickness or gap in fireproofing, the profiles are flat, indicating constant temperature along the length of the plate (no temperature gradient). As the standard deviation increases, temperature profiles along the length of the plate indicate a temperature gradient. The temperature profiles do not indicate a monotonic increase in temperature as the fireproofing thickness decreases (due to the randomness in fireproofing thickness).

Figure 3-20 summarizes all the results shown in Figure 3-11 through Figure 3-19 by plotting the sensitivity of various input parameters on steel temperature. Results indicate that steel temperature reduces with increasing thickness, as one would have expected. Variability in fireproofing thickness results in higher steel temperature (higher standard deviation means higher temperature). Variability in fireproofing thickness reduces the local effective thickness of fireproofing and the results. Figure 3-20 shows that steel temperature increases with gap length and with time (duration of application of incident radiative flux). 


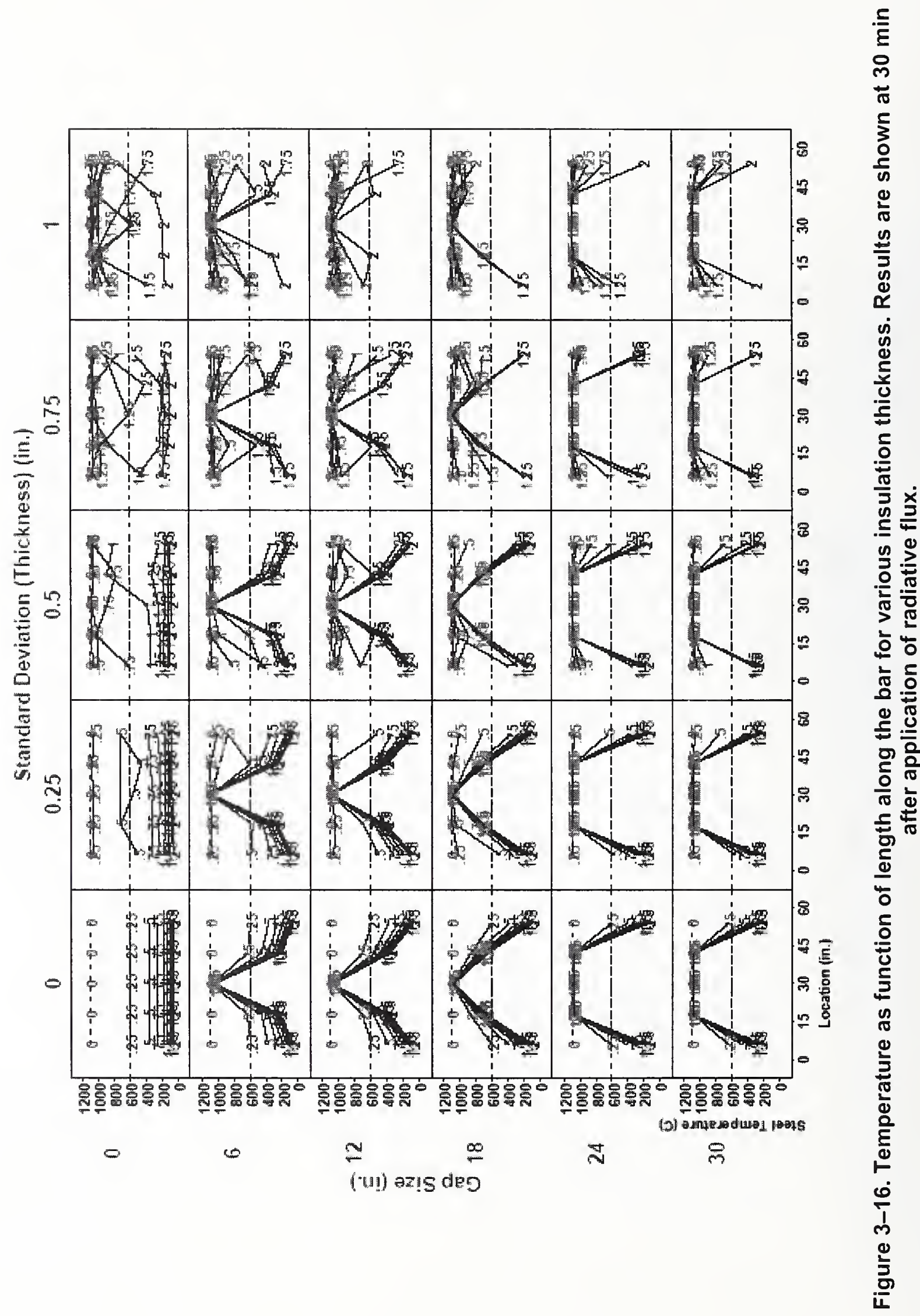




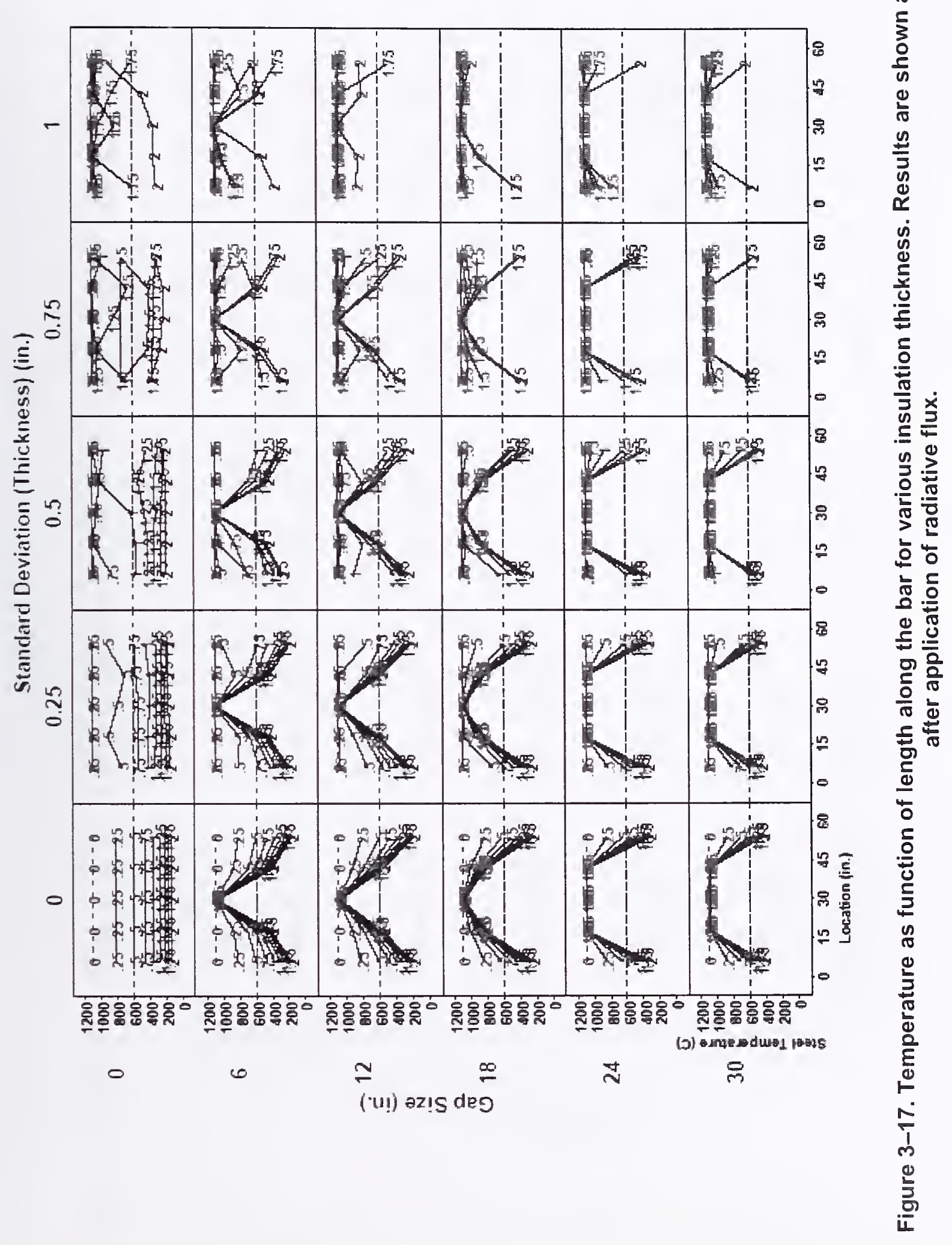




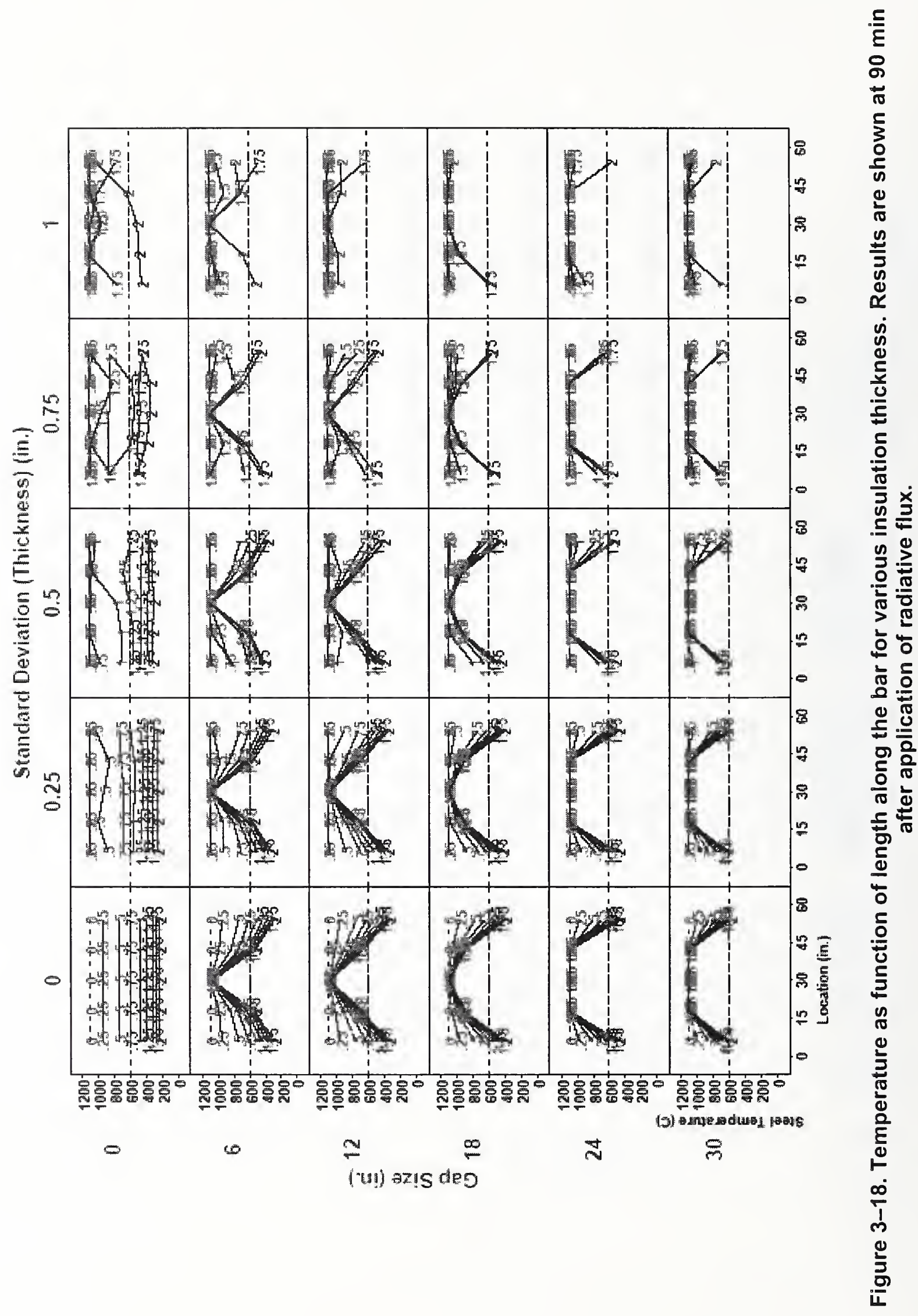




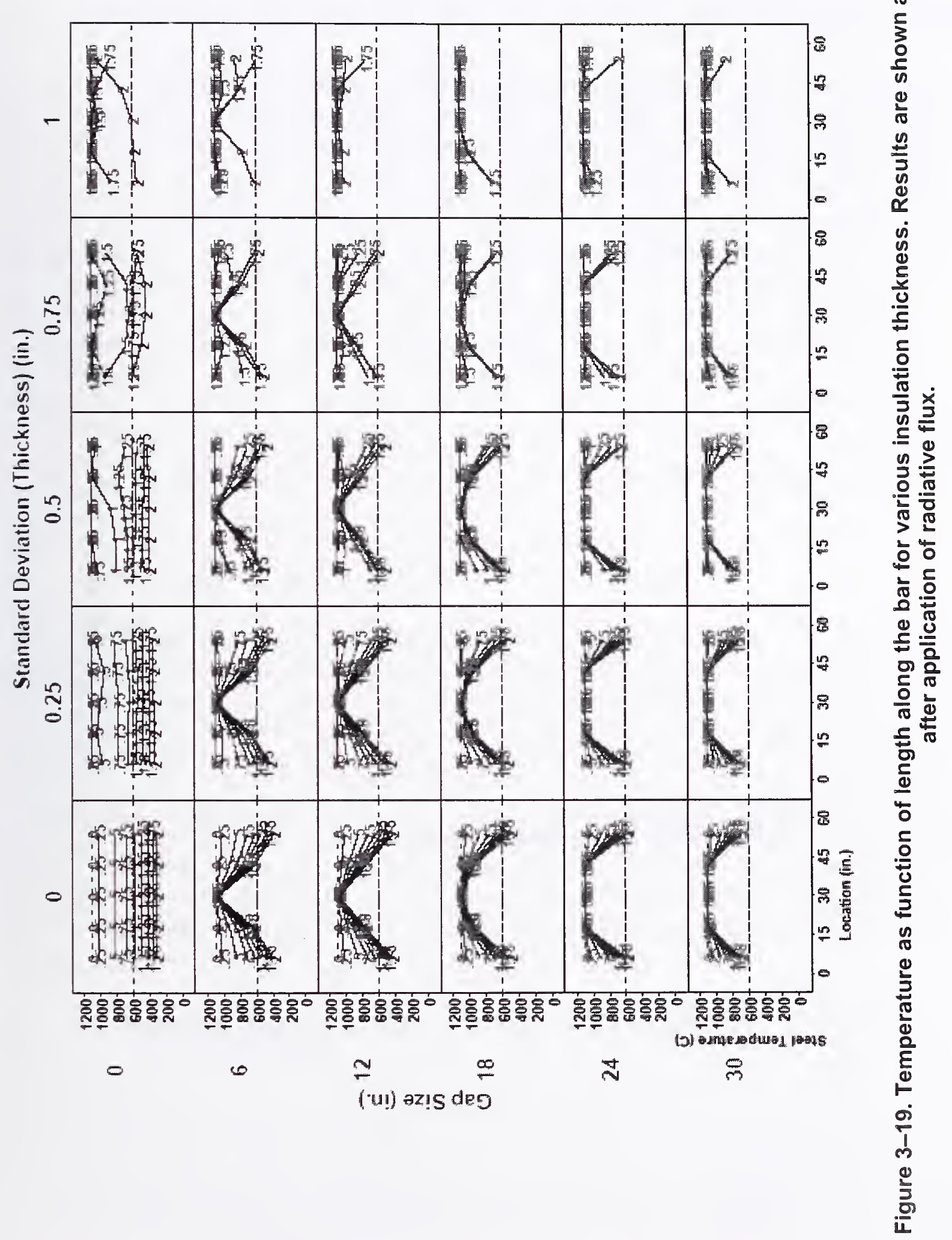




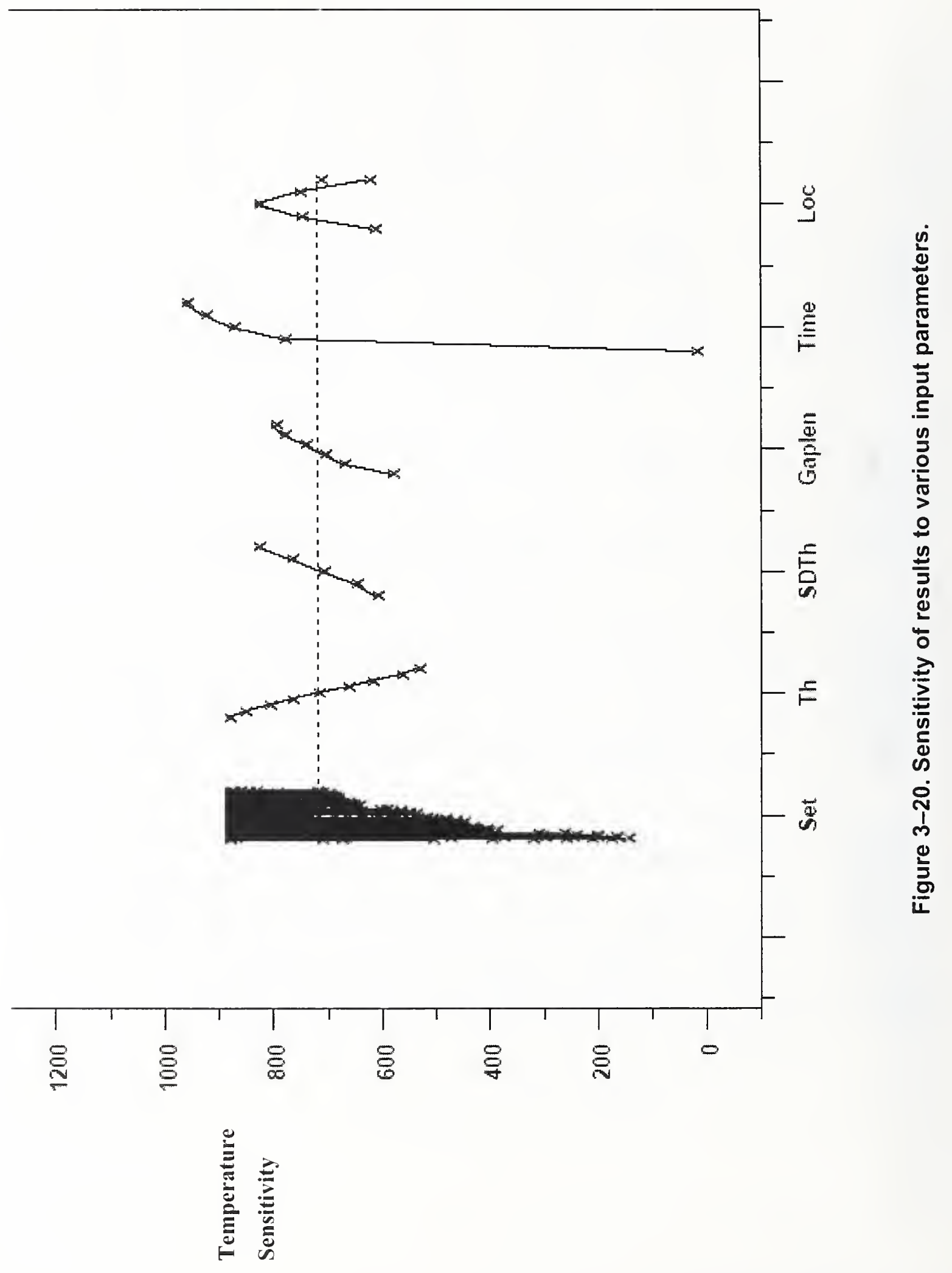




\section{Chapter 4 \\ Perimeter Columns}

In Chapter 3, an exploratory study was presented for understanding the thermal response of 2-D or axisymmetric models of various structural components to furnace conditions that do not change with time. This chapter is the first of four chapters that details how the major structural components (along with the fireproofing) in the World Trade Center (WTC) towers were represented with three-dimensional finite element models and also how the thermal response of these components was coupled to temporally and spatially evolving realistic fires. The focus of this chapter is on perimeter columns. Starting with the basic building block for a column, this chapter outlines a procedure for developing models that cover a single floor or multiple floors. For each structural component. the approach for including fireproofing and structural damage is outlined. Typical radiative fluxes incident on a perimeter column and their dependence on fire growth and spread has been presented. Temperature contours on the structure are shows to help gain insight into the structural response of the column. Time-temperature profiles are discussed for various perimeter columns to help understand the spatial and temporal nature of the thermal insult. The description applies to the fire floors, floors 92 through 99 in WTC 1, and floors 78 through 83 in WTC 2. We have used results from one of the fire simulations to understand the coupled fire-thermal response in this chapter. A full delineation of all the cases will be presented in Chapter 8 through Chapter 11 .

\section{$4.1 \quad$ TYPICAL FLOOR PLAN}

An architectural design feature (NIST NCSTAR 1-1, NIST NCSTAR 1-1A, NIST NCSTAR 1-1B) of each World Trade Center tower was a series of closely spaced built-up box columns. At typical floors, a total of 59 of these perimeter columns were present along each of the flat faces of the building. These columns were built up by welding four plates together to form an approximately $14 \mathrm{in}$. square section, spaced at $3 \mathrm{ft} 4 \mathrm{in}$. on center. Adjacent perimeter columns were interconnected at each floor level by deep spandrel plates, typically $52 \mathrm{in}$. in depth. In alternate storics, an additional column was present at the center of each of the chamfered building corners. The perimeter columns form an important structural component of the World Trade Center tower. This chapter describes a finite element analysis for studying thermal response of a box column to the fires evolving on the various floors of the tower and for transferring the thermal data as body loads on to the structural models. The application of the ANSYS finite element software (ANSYS 2005) to develop models for perimeter columns is discussed in this chapter.

\subsection{FINITE ELEMENT MODELS OF THE PERIMETER COLUMN AND FIREPROOFING}

This section describes the development of finite element models to analyze the basic building block of a perimeter column. The model represents not only the stcel but also the fireproofing that protects the steel from thermal exposure. The finite element model was developed using the ANSYS parametric design language to quickly and easily obtain a range of models with different thickness and dimensions. Finally, we provide a brief explanation of the choice of elements and mesh density used in the thermal models. 
Figure 4-1 shows a typical layout of a perimeter column on floor 96 of the WTC 1. Each perimeter column was a box shape column, for which the plate thickness varied from one column to another. Each perimeter column was identified as a spccific column type (e.g. column type $120,121, \ldots 132)$. The column types forWTC 1 (floors 92-99) are listed in Table B-1. Similarly the column types for WTC 2 (floors 78-83) are listed in Table B-2. As seen in these tables, the column type changed between floors, and also between columns on the same floor. The plate dimensions (in meters) for the various column types are shown in Table B-3. Here thickness $t 1$ refers to the flange plate thickness, $t 2$ refers to the web plate thickness and thickness $\mathrm{t} 3$ refers to the thickness of the spandrel plate (NIST NCSTAR 1-1, NIST NCSTAR 1-2).

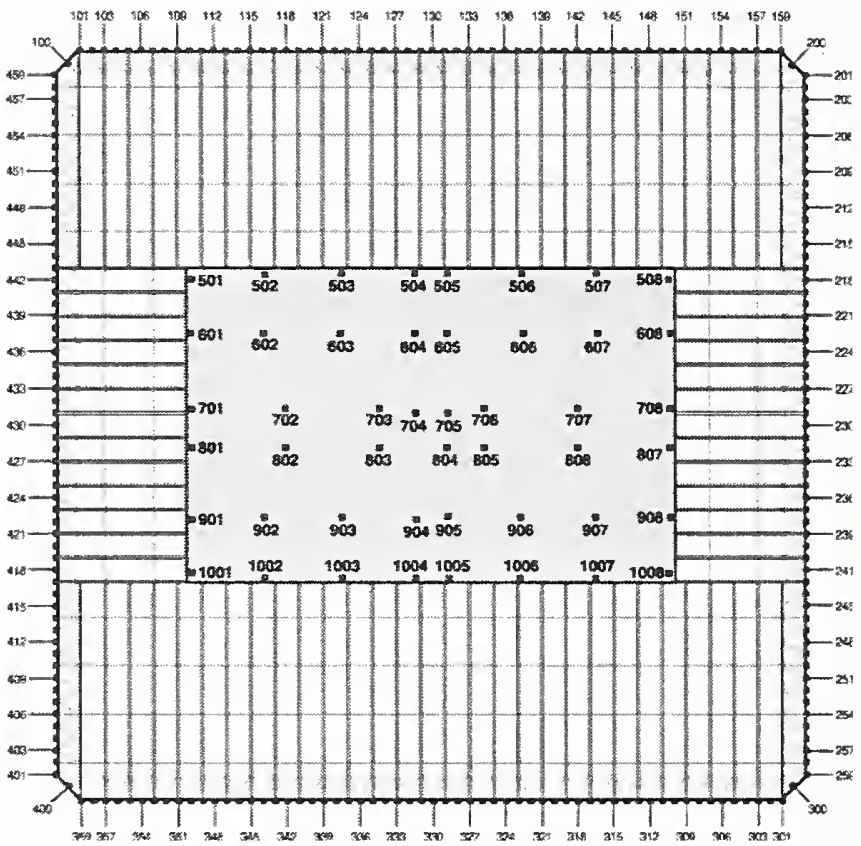

Figure 4-1. Representative floor plan of the exterior wall and column layout for WTC 1 and WTC 2 .

The fireproofing that covers the perimeters columns plays a very important role in the thermal response of the perimeter columns. In this model, the fireproofing on the exterior faces of the columns has a thermally equivalent thickness of $13 / 16$ in. while the thickness on the exterior face of the spandrel plate was $0.5 \mathrm{in}$. The fireproofing material was identified as BLAZE-SHIELD DC/F (NIST NCSTAR 1-6A). The interior faces of the perimeter columns were covered with a vermiculite aggregate. The thickness (thermally equivalent) of the vermiculite aggregate on the interior faces of the columns was $7 / 8 \mathrm{in}$. while that on the spandrel beams was set to $1 / 2$ in. The thermo-physical properties of all the materials are discussed in Appendix A.

ANSYS parametric design language (ANSYS 2005) was used to construct finite element models of the various perimeter columns. Figure 4-2 through Figure 4-5 each shows a solid finite element model of the steel and the fireproofing that covers a typical perimeter column. Figure 4-2 shows the exterior faces of a perimeter column (Column type 120), while Figure 4-3 shows the interior face. Only the portion of the perimeter column that lies in between two concrete slabs has been shown in Figure 4-2 and Figure 4-3. Figure 4-4 shows the cross-sectional view of perimeter column type 120 along with the spandrel plate, while Figure 4-5 shows the cross-sectional view of the column only (without the spandrel plate). The 
elements are color coded with their assigned material attributes. Cyan colored elements have material attributes of steel, violet colored elements have material attributes of fireproofing (BLAZE-

SHIELD DC/F) and pink colored elements have material attributes of Vermiculite plaster (See Figure 4-2 and Figure 4-3).

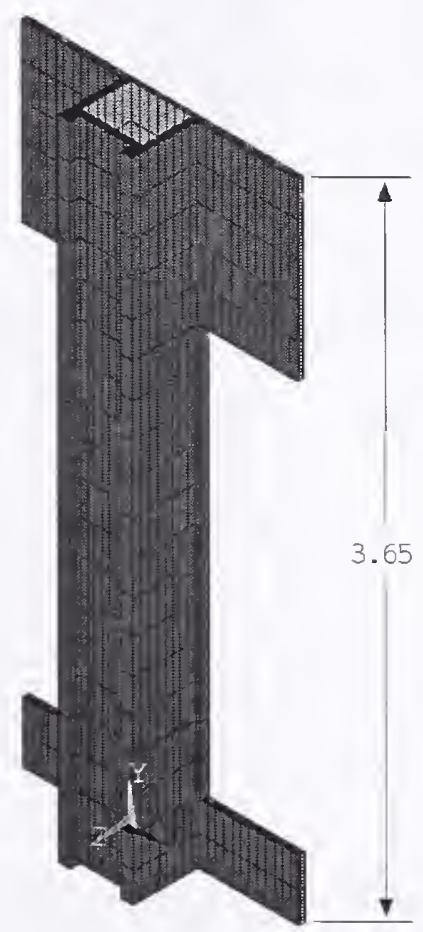

Figure 4-2. Finite element model of a box shape perimeter column (Column Type 120) showing the exterior faces. Cyan colored elements have material attributes of steel, while the violet colored elements have material attributes of fireproofing

(BLAZE-SHIELD DC/F). 


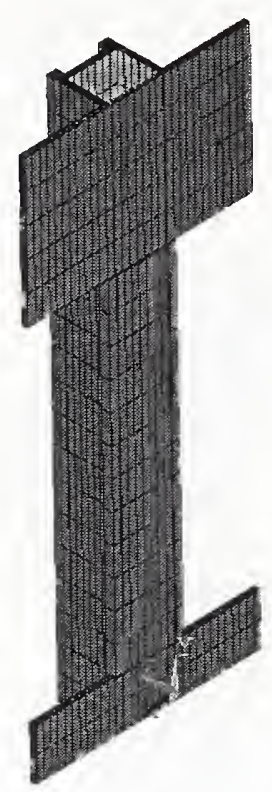

Figure 4-3. Finite element model of box shape perimeter column (Column Type 120) showing the interior faces. Cyan colored elements have material attributes of steel, violet colored elements have material attributes of fireproofing (BLAZE-SHIELD DC/F) and pink colored elements have material attributes of Vermiculite plaster.

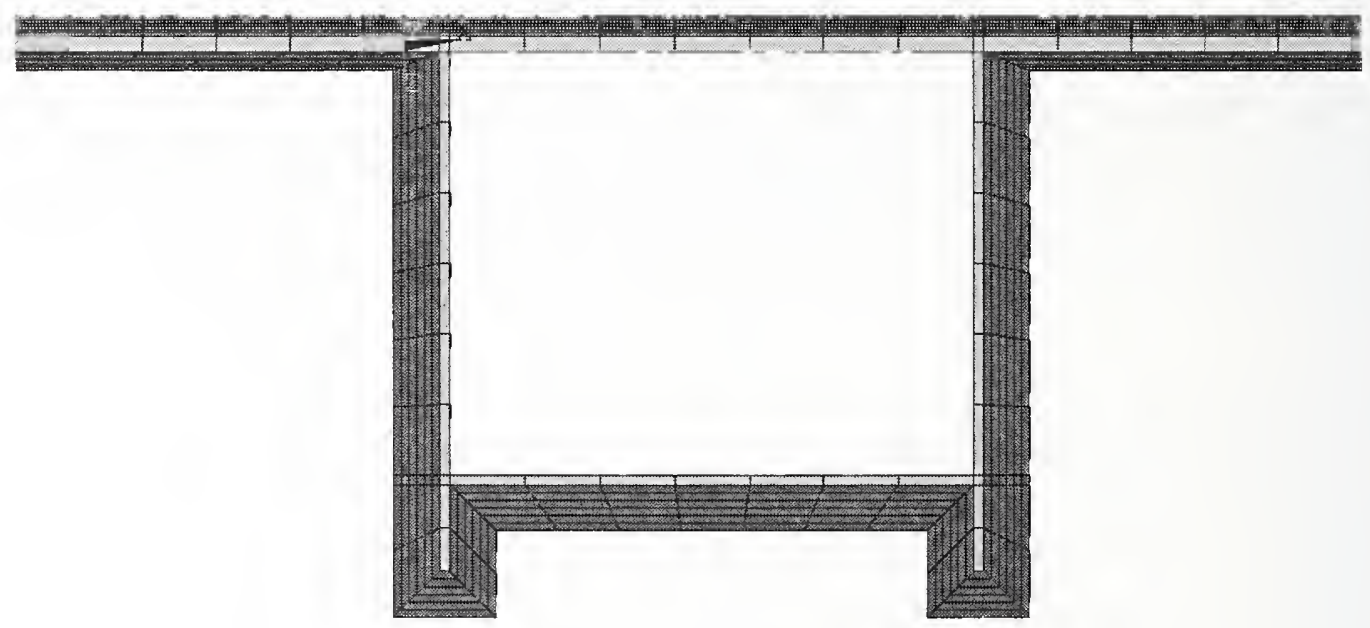

Figure 4-4. Finite element mesh used to model a typical perimeter column. Figure shows the density of the mesh elements in the column and spandrel beam. 


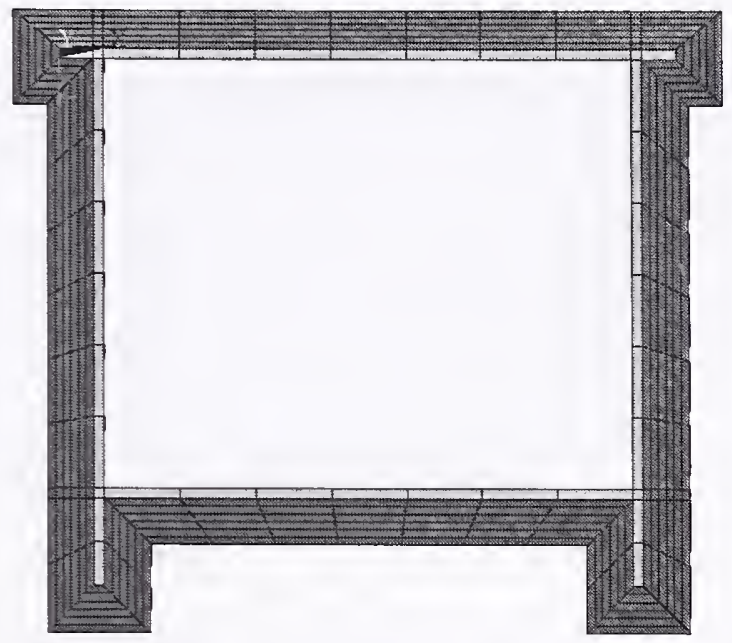

Figure 4-5. Finite element mesh used to model a typical perimeter column. Figure shows the density of the mesh elements in the column.

Brick elements with 3-D thermal conduction capability were used to mesh the steel and fireproofing of each perimeter column. The specific ANSYS element that was used for analysis is called "SOLID70". The element has eight nodes with a single degree of freedom, temperature, at each node. The element is applicable to a 3-D, steady state or transient thermal analysis. Surface effect elements were superimposed on the brick elements to model convective and radiative heat transfer to the perimeter column. The mesh density was dictated by the need to adequately resolve the physical processes of interest in this problem. The radiative flux incident on the column can vary quite substantially over the length of the column (Prasad and Baum 2004). It was found that dividing the length of the column into 20 equal increments could capture the variation in the incident flux on a column without drastically increasing the computational time of doing a global analysis (Chapter 8 through Chapter 11). Typical simulations of the perimeter columns were performed with approximately 20 elements (Figure 4-2) along the length of the column (the part between two concrete slabs). Sensitivity studies were performed by doubling the number of elements (40 elements), and it was found to have a very small effect on steel temperature. Along the circumference of the column, elements were placed roughly at $5 \mathrm{~cm}$ intervals (Figure 4-4). Usually, the mesh density was controlled so that there were six elements through the thickness of the fireproofing. This was based on the need to adequately capture the propagation of the thermal wave through the fireproofing. Again, sensitivity studies performed with a more refined finite element mesh did not result in any significant change in the steel temperature. Once a finite element model of a perimeter column was constructed, the next task was to apply appropriate initial and boundary conditions on the column and to couple the fire dynamics with the incident flux on the column.

\subsection{INITIAL AND BOUNDARY CONDITIONS}

The thermal response of the perimeter columns to spatially and temporally varying fires was simulated by imposing a specific set of initial and boundary conditions. The initial temperature of the perimeter column (steel and fireproofing) was set at room temperature $\left(27^{\circ} \mathrm{C}\right.$ ). 


\subsubsection{Radiative Flux}

Heat flux (Prasad and Baum 2004) boundary conditions (surface loads predicted from a plane layer analysis) were applied to the inner web plates of the columns and the inner portion of the spandrel plates. The flux is incident normally on the fireproofing (if the fireproofing is intact) or on the steel (if the fireproofing is considered to bc damaged). The flux varies as a function of space and timc, depending on the location of the perimeter column relative to the fire. Figure 4-6 shows the flux boundary conditions on a typical perimeter column. The radiative flux incident on the inner plates of the column varies along the height of the column and changes with time. The incident flux is strongly coupled with the fire growth and spread through the various floors of the World Trade Center towers as it is a function of the instantaneous hot laycr thickness, absorption coefficients, hot layer temperature, and ambient temperature as predicted by the fire simulations.

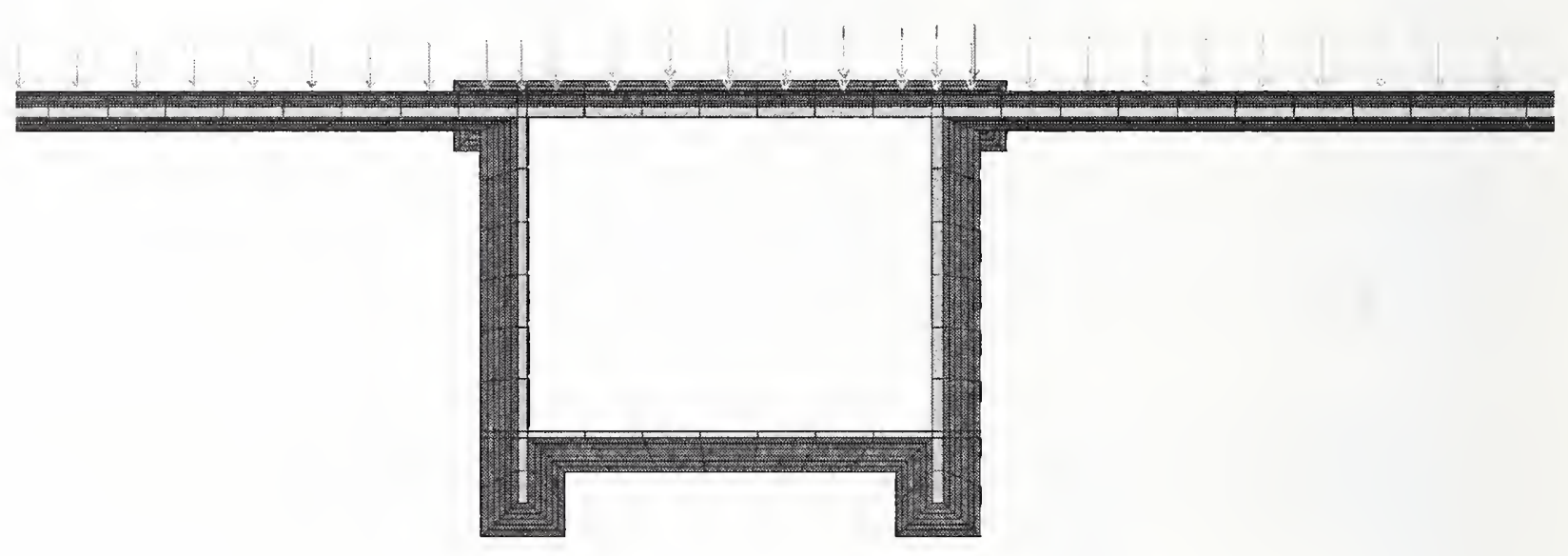

Figure 4-6. Heat flux boundary conditions were applied on the interior faces of the perimeter column as indicated by the arrows. The intensity of the incident flux varies with time and space.

\subsubsection{Convective Flux}

Convective flux boundary conditions were applied on all the interior and exterior faces of the column and spandrel plates as discussed in Chapter 1. The heat transfer coefficient in general depcnds on the viscosity and velocity of the local instantaneous flow field established in the vicinity of the columns. A convective heat transfer coefficicnt value of $25 \mathrm{~W} / \mathrm{m}^{2}-\mathrm{K}$ was assumed for computing the convective fluxes (NIST NCSTAR 1-5F, Hollman et al.). Structural elements in the hot layer were subject to convective fluxes with bulk temperature values equal to the local instantaneous value of the temperature in the hot layer. Structural elements below the hot layer were subject to convective fluxes with bulk temperature equal to the local instantaneous value of the ambient temperature. The exterior faces of the column and spandrel plate were subjected to convective fluxes with bulk temperature values equal to the room temperature (27 ${ }^{\circ} \mathrm{C}$ ). The arrows in Figure 4-7 show the surfaces on which the convective flux boundary conditions were applied for thermal analysis. The size and color of the arrows is proportional to the bulk temperature of the surrounding gases. The small blue colored arrows on the exterior faces of the column represent a bulk temperature value of $27^{\circ} \mathrm{C}$, while the red arrows on the interior faces indicate higher bulk temperature. 


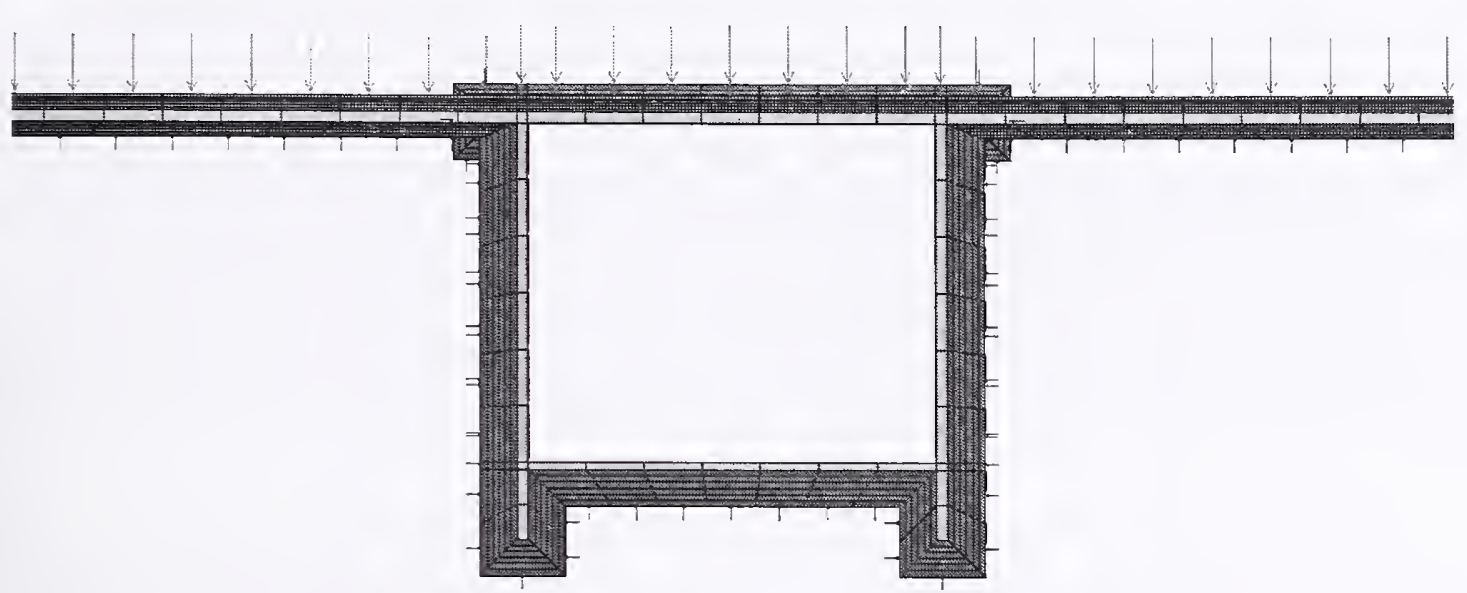

Figure 4-7. Convective flux boundary conditions indicated by arrows were applied to all the exposed faces of the perimeter column.

\subsubsection{Re-Radiation}

In order to model re-radiation from the surface of the perimeter column to the ambient atmosphere, the perimeter columns were covered with surface effect elements (ANSYS 2005). An emissivity value of 0.95 was used based on fire simulations (NIST NCSTAR 1-5F).

Radiative heat transfer within the cavity formed by the four plates of the box shaped perimeter column is also modeled, as shown in Figure 4-8, to allow for heat exchange between the four plates. Re-radiation between the four plates will help to equilibrate the temperature of the four plates as described in the results section. It is assumed that the effect of natural convection within the cavity is much less than the radiative exchange.

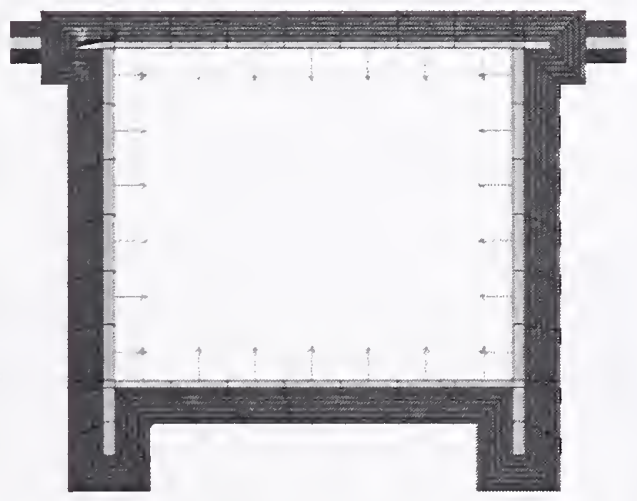

Figure 4-8. Arrows indicate the surfaces used for modeling re-radiation within the cavity of a perimeter column.

\subsubsection{Multi-floor Simulations}

Specifying boundary conditions at the top and bottom of a perimeter column is a challenging task. Since the column extends all the way up to the $110^{\text {th }}$ floor, one could construct finite element models of 
perimeter columns that are 110 floors tall. From a computational point of view, it would have been prohibitive to solve such a model. In the present Investigation, the length of the column was extended half a floor above and half a floor below the floor under consideration to account for the effect of multiple floor fires. As an example, consider a part of the column that lies between floor 96 and floor 97 as the column under study (See Figure 4-9). The part of the column between floor 96 and floor 97 is subjected to fires on floor 96 , the portion of the column above floor 97 is subjected to fires on floor 97 , while portion of the column below floor 96 is subjected to fires on floor 95 . Zero flux boundary conditions were imposed at the top and bottom edge of the column. By extending the column above and below the floor under consideration, the effect of fires on the $95^{\text {th }}$ and $97^{\text {th }}$ floor can be incorporated on the column under study.

Only the portion of the column between the $96^{\text {th }}$ and $97^{\text {th }}$ floor is used for structural analysis. The portions of the column above floor 97 and below floor 96 are not used in the analysis. By extending the length of the column, boundary conditions were applied further away from the region of interest. The procedure also incorporates fireproofing and structural damage to the column above and to the column below the column under consideration, into the thermal analysis.

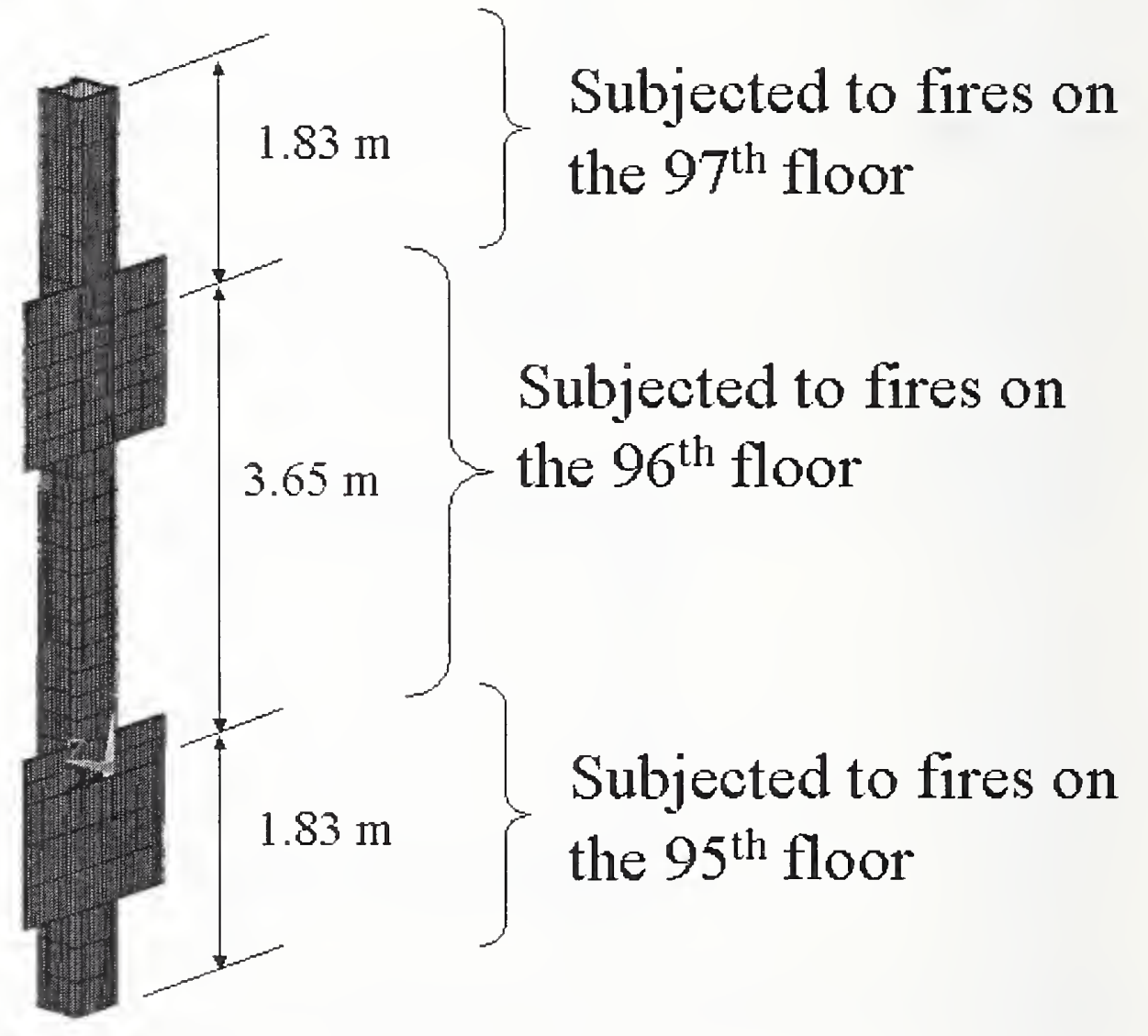

Figure 4-9. Boundary conditions on a typical perimeter column 


\subsection{INCIDENT HEAT FLUX}

Simulating the effects of severe fires on the structural integrity of buildings requires a close coupling between the gas phase energy release and transport phenomena and the stress analysis in the load bearing materials. The connection between the two is established primarily through the interaction of the radiative heat transfer between the solid and gas phases with the conduction of heat through the structural elements. Heat transfer to sub-grid scale structural elements is calculated using a simple radiative transport model that assumes that the compartment is divided into a hot, soot-laden upper layer and a cool, relatively clear lower layer. The properties of the two layers are extracted from temporal averages of the results obtained from the Fire Dynamics Simulator. The incident flux is a function of temperature, hot layer depth, soot concentration, and location and orientation of each structural element. In the remainder of this section, the nature of the incident radiative flux on typical perimeter columns when subjected to realistic fires is described. Results for a few perimeter columns are presented to understand the temporal and spatial variation of the incident flux.

Figure 4-10 shows the heat flux contours incident on a perimeter column. Plots are shown for column number 145 on floor 96 (WTC 1) at 1,000 s intervals. Note that contour levels are shown at the right of each figure and are different from one time to another. At 1,000 s after impact, the flux ranges between a maximum value of $130,000 \mathrm{~W} / \mathrm{m}^{2}$ to a minimum value of $80,000 \mathrm{~W} / \mathrm{m}^{2}$. At $3,000 \mathrm{~s}$ after impact, the flux ranges between a maximum value of $19,000 \mathrm{~W} / \mathrm{m}^{2}$ to a minimum value of $10,000 \mathrm{~W} / \mathrm{m}^{2}$. At $6,000 \mathrm{~s}$ after impact, the flux ranges between $2,200 \mathrm{~W} / \mathrm{m}^{2}$ and $2,700 \mathrm{~W} / \mathrm{m}^{2}$. The flux varies along the height of the column and reaches a peak value somewhere close to the middle of the hot layer. Figure 4-10 illustrates the transient nature of the fire and the resulting flux incident on column 145 of floor 96, WTC 1. It should be noted that there is a horizontal variation in radiative flux, but this variation is relatively small compared to the variation along length of the column. 


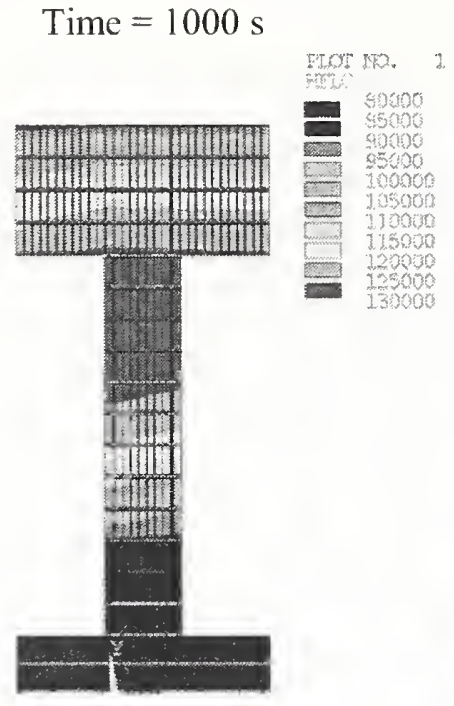

Time $=4000 \mathrm{~s}$

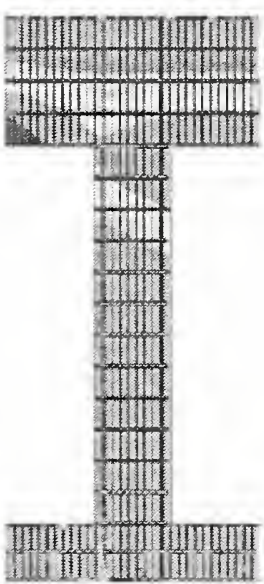

Time $=2000 \mathrm{~s}$

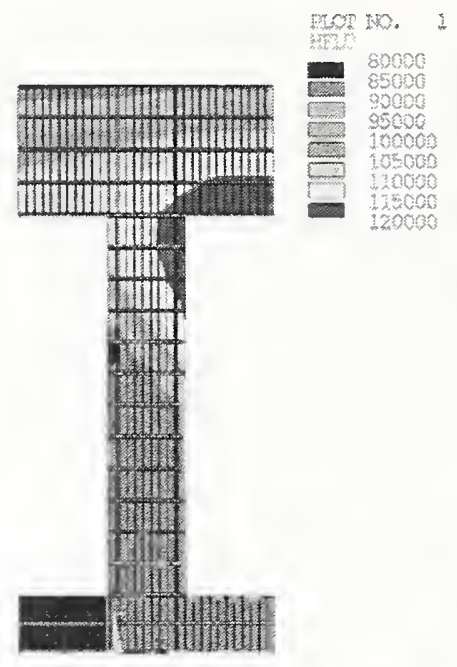

Time $=5000 \mathrm{~s}$

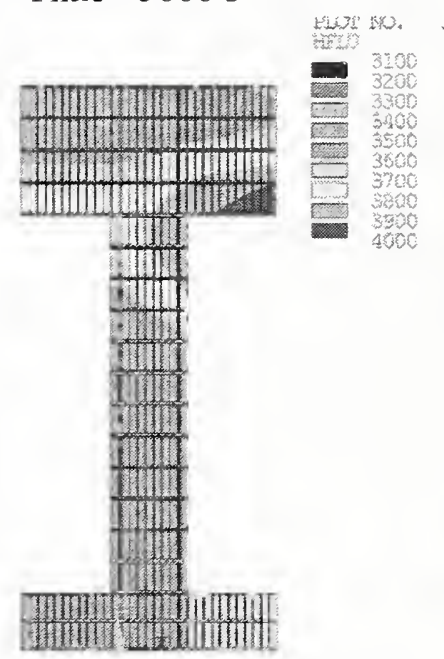

Time $=3000 \mathrm{~s}$

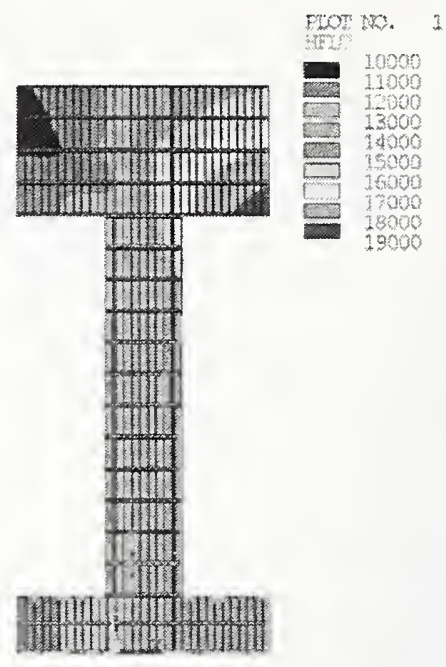

Time $=6000 \mathrm{~s}$

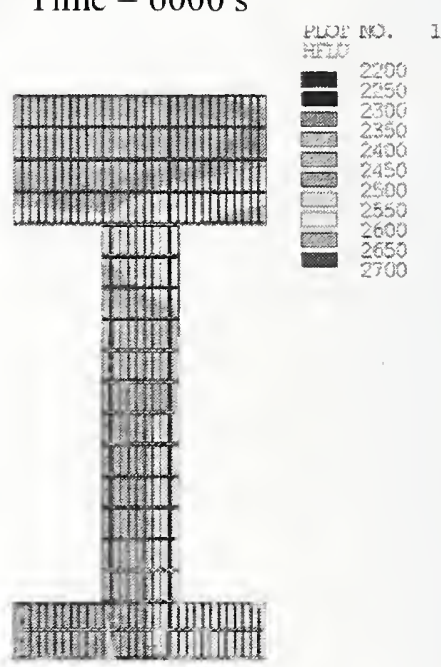

Figure 4-10. Heat flux incident on the inner faces of a perimeter column as a function of time. Plots are shown for Column 145 on floor 96, WTC 1 at 1,000, 2,000, 3,000, 4,000 5,000 and 6,000 s after impact.

The radiative flux incident on a column not only varies in time (Figure 4-10) but also varies from one column to another as shown in Figure 4-11. This figure shows the incident heat flux at $6,000 \mathrm{~s}(100 \mathrm{~min})$ after impact, for perimeter columns 145, 230, 330 and 430 on floor 96 of WTC 1. As for Figure 4-10, we have presented results for a few columns at specific instants in time, coupled to one of the fire simulations to illustrate the fire - thermal coupling. The contour levels are shown at the right of each figure and are different from one column to another. For perimeter column 330 , the flux ranges between $48,000 \mathrm{~W} / \mathrm{m}^{2}$ and $77,000 \mathrm{~W} / \mathrm{m}^{2}$, while for perimeter column 145 the flux ranges between $2,200 \mathrm{~W} / \mathrm{m}^{2}$ and $2,700 \mathrm{~W} / \mathrm{m}^{2}$. This illustrates that the incident flux is not only a function of time, but also varies spatially from one column to another column. Since the fires on the various floors evolve and spread at different rates, it can be stated that the incident radiative flux on a column varies from one floor to another floor (depending on fire growth and spread on those floors). 


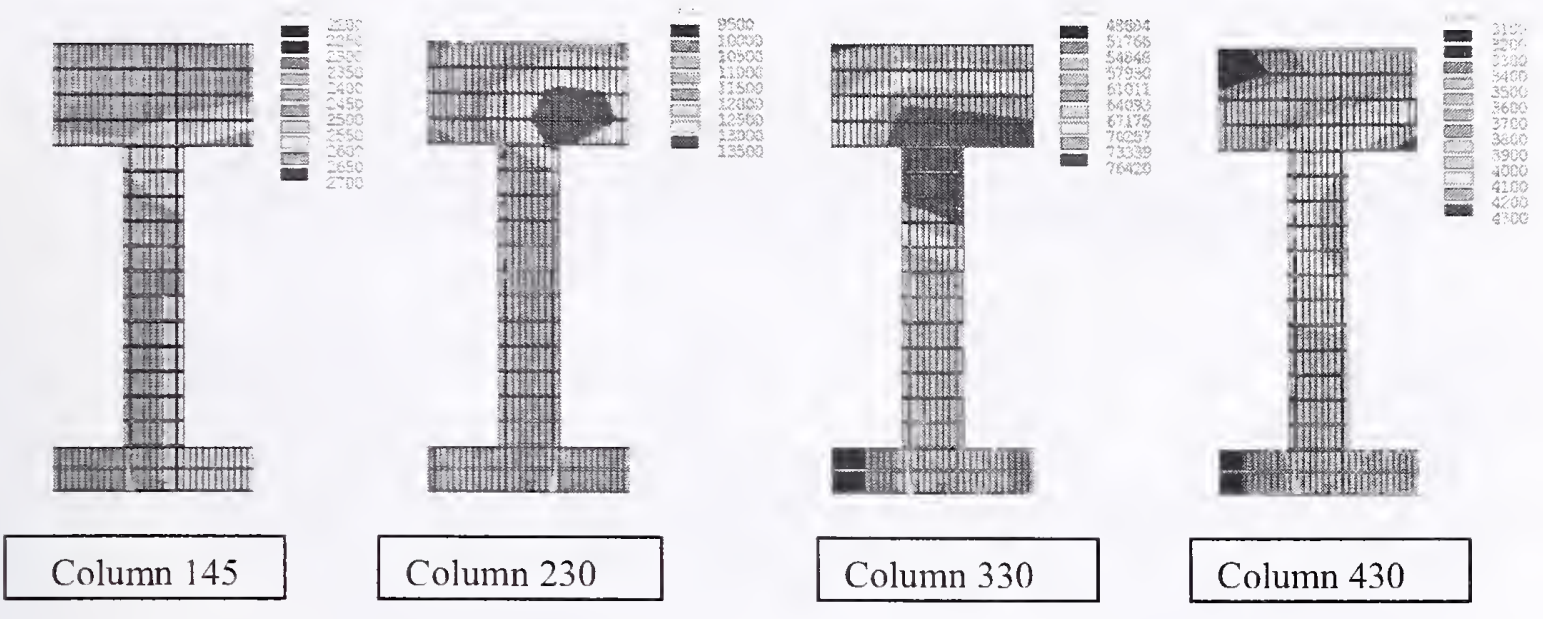

Figure 4-11. Incident heat flux at 6,000 s after impact for perimeter columns 145,230 , 330 and 430 on floor 96 (WTC 1). Partial results from one fire simulation have been used to illustrate the nature of the coupling process.

\subsection{THERMAL RESPONSE OF COLUMNS TO REALISTIC FIRES}

In the previous section, we have demonstrated the temporal and spatial variation of the incident flux on a perimeter column. It was shown that the flux varies not only from one column to another column, but also varies along the length of any one column. The temporally and spatially varying fluxes incident on the perimeter column sets up some interesting temperature contours in the steel column. This section will discuss the temperature contours and temperature gradients that arise in a typical perimeter column.

\subsubsection{Temperature Contours}

Figure 4-12 and Figure 4-13 show the temperature contours on perimeter column 145 of floor 96 (WTC 1). Contours are shown at 10 different instants in time ranging from $600 \mathrm{~s}$ to $6,000 \mathrm{~s}$ and are spaced at $600 \mathrm{~s}$ intervals. Temperature scales ranges from $0{ }^{\circ} \mathrm{C}$ to $675^{\circ} \mathrm{C}$. The temperature contours are a direct result of the incident flux, the geometry of the column, the fireproofing thickness, and the boundary conditions imposed on the perimeter column.

Numerical results indicate that the spandrel plate heats up faster than the perimeter column. This is due to smaller fireproofing thickness on the spandrel plate as compared to the column. The portion of the spandrel plate furthest away from the column shows highest temperature, and heat gradually diffuses into the rest of the columns. Note that only a small portion of the column that lies between two concrete slabs has been shown in these figures. Depending on the thickness of the hot layer and the heat flux contours (shown in Figure 4-6), the upper half of the column heats up faster. The exterior faces of the column are being cooled convectively, and the temperature contours are consistent with these imposed boundary conditions. The radiative flux on column 145 reaches a peak value at approximately $3,000 \mathrm{~s}$. Correspondingly, the temperature contours also exhibit a peak value at 3,000 s, and the column gradually cools down after this point. The temperature contours are also influenced by the fires on floors 95 and 97 (floors above and below floor 96) as energy gradually conducts through the steel. 


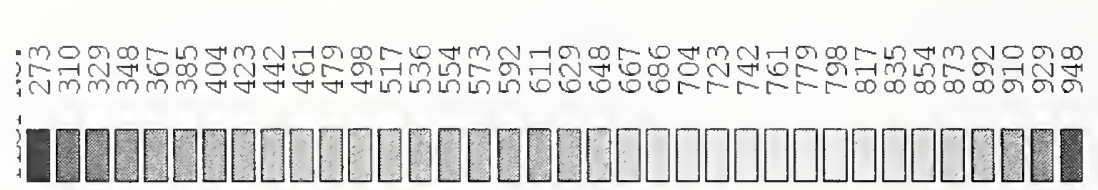
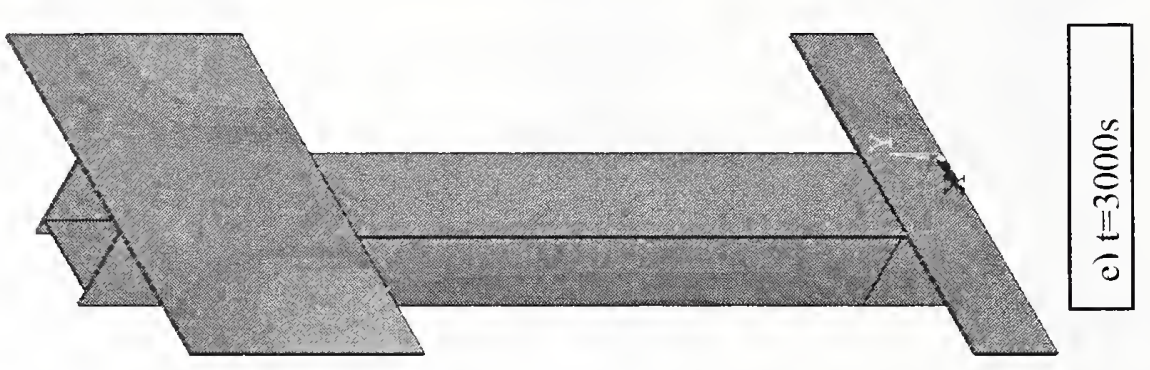

는 은

논

琼

导 导

$\dot{\sim}$

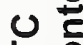

$\sum 0$

$\sum$

果

은 $\frac{\dot{60}}{3}$
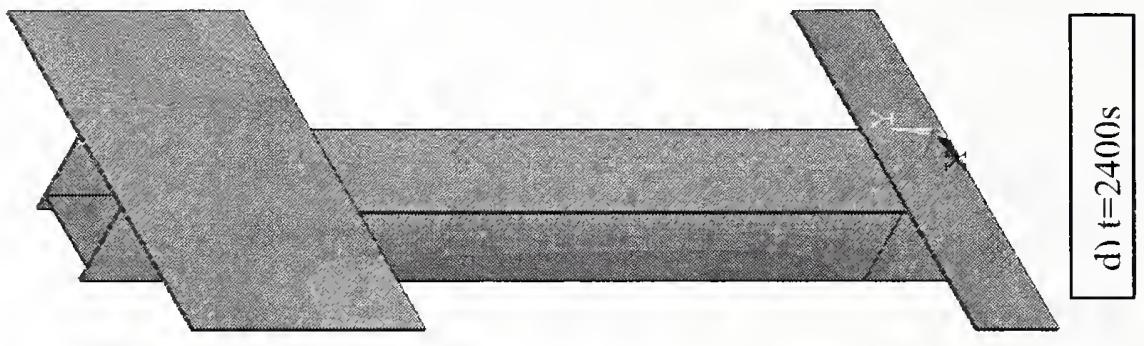

ธ

里

돈

क

올융

อ

है

긍유.

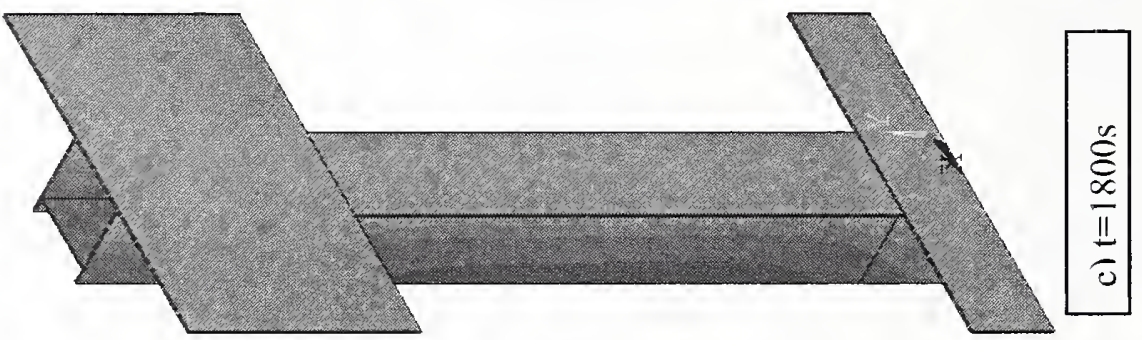

0 응

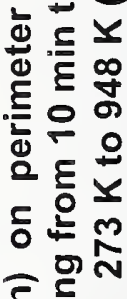

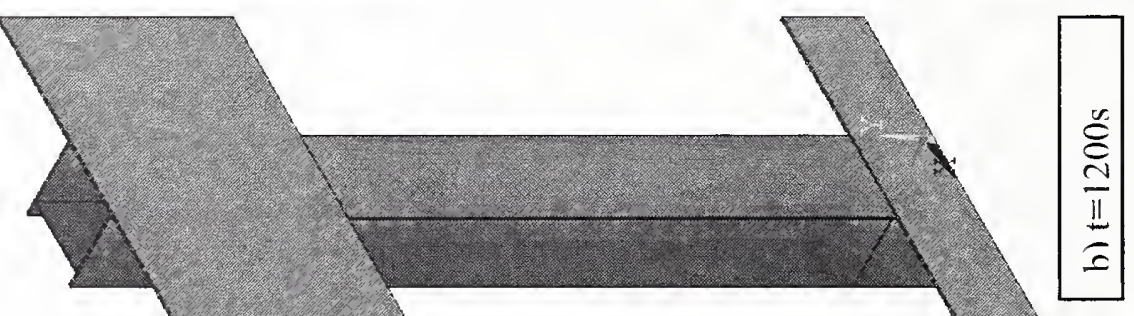

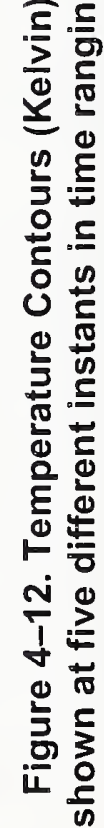

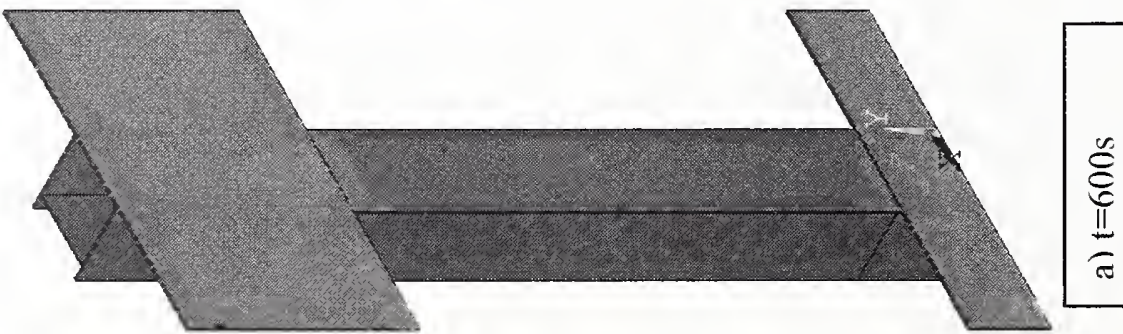



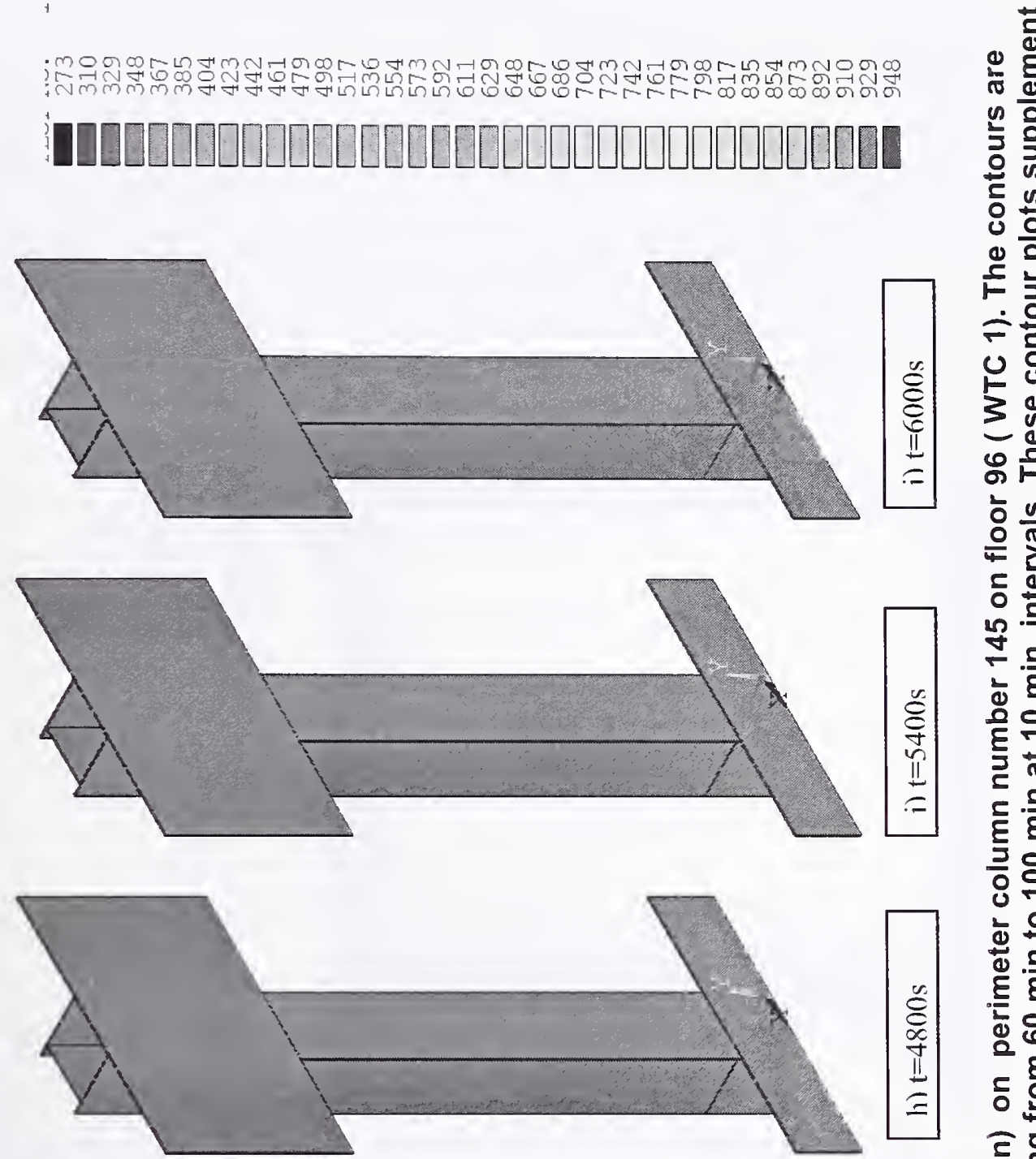

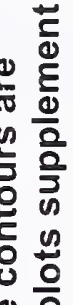

든

$-50$

하용

u 0

눙요

300

둥

or

응 $\frac{\dot{0}}{\pi} \stackrel{\infty}{\frac{1}{8}}$

는

ᄃㄴํㄴ

แn $\subseteq \underline{x}$

$\forall .5 M$

늘 N

을응

춘

들 옳 응

엉응

논

む.

हैं

융응

E 엉

든은

알

돈
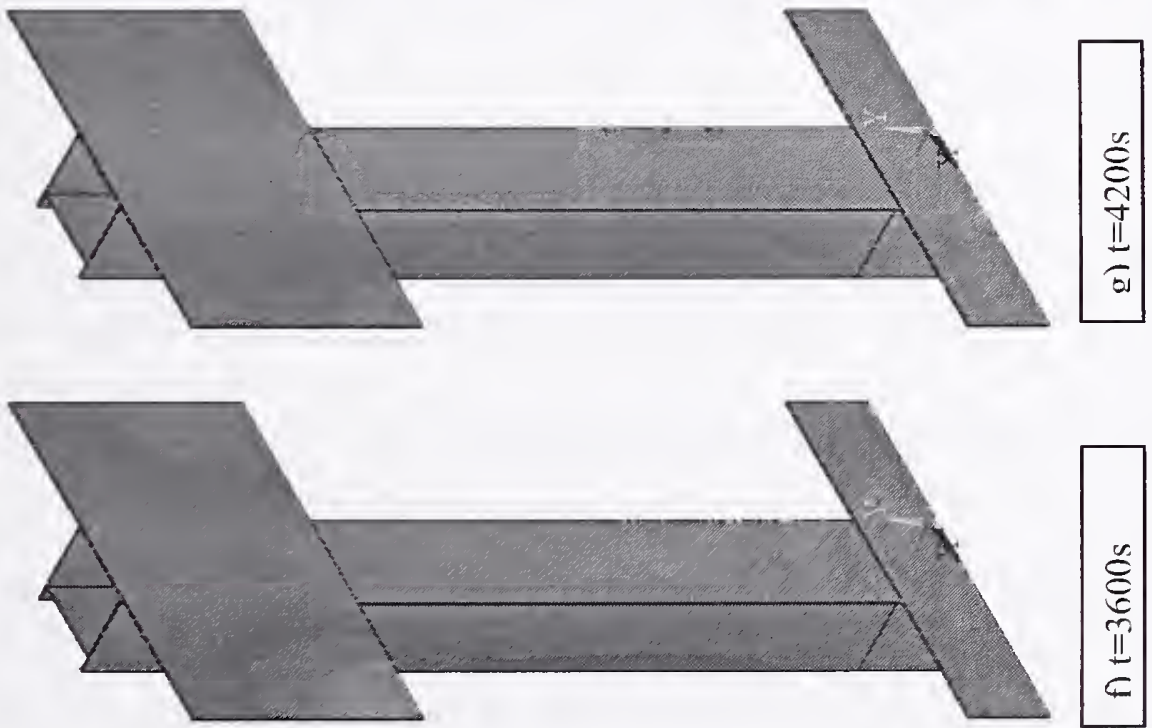

造 $\frac{1}{0}$

ஸ 닌

을 은 은

들

ن n.

을 歾

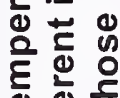

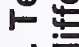

ल

$\frac{\pi}{d} \sum_{i}^{\infty}$

는

논 $\frac{5}{3}$ 


\subsubsection{Fireproofing and Steel Temperature}

Figure 4-14 shows the cross-section view of temperature contours through a perimeter column (Column number 145). In this figure temperature contours in the steel and the fireproofing have been included. The temperature scale ranges between $300 \mathrm{~K}$ and $1200 \mathrm{~K}$. The figure exhibits a very high temperature on the surface of the fireproofing and gradual diffusion of heat through the fireproofing into the steel column. The figure also shows a temperature gradient in the perimeter column between the inner web plate and the outer web plate. This temperature gradient is also visible in Figure 4-12 and Figure 4-13. The temperature gradient through the cross-section of a box column is important because it can result in differential thermal expansion and can influence the structural response of a column.

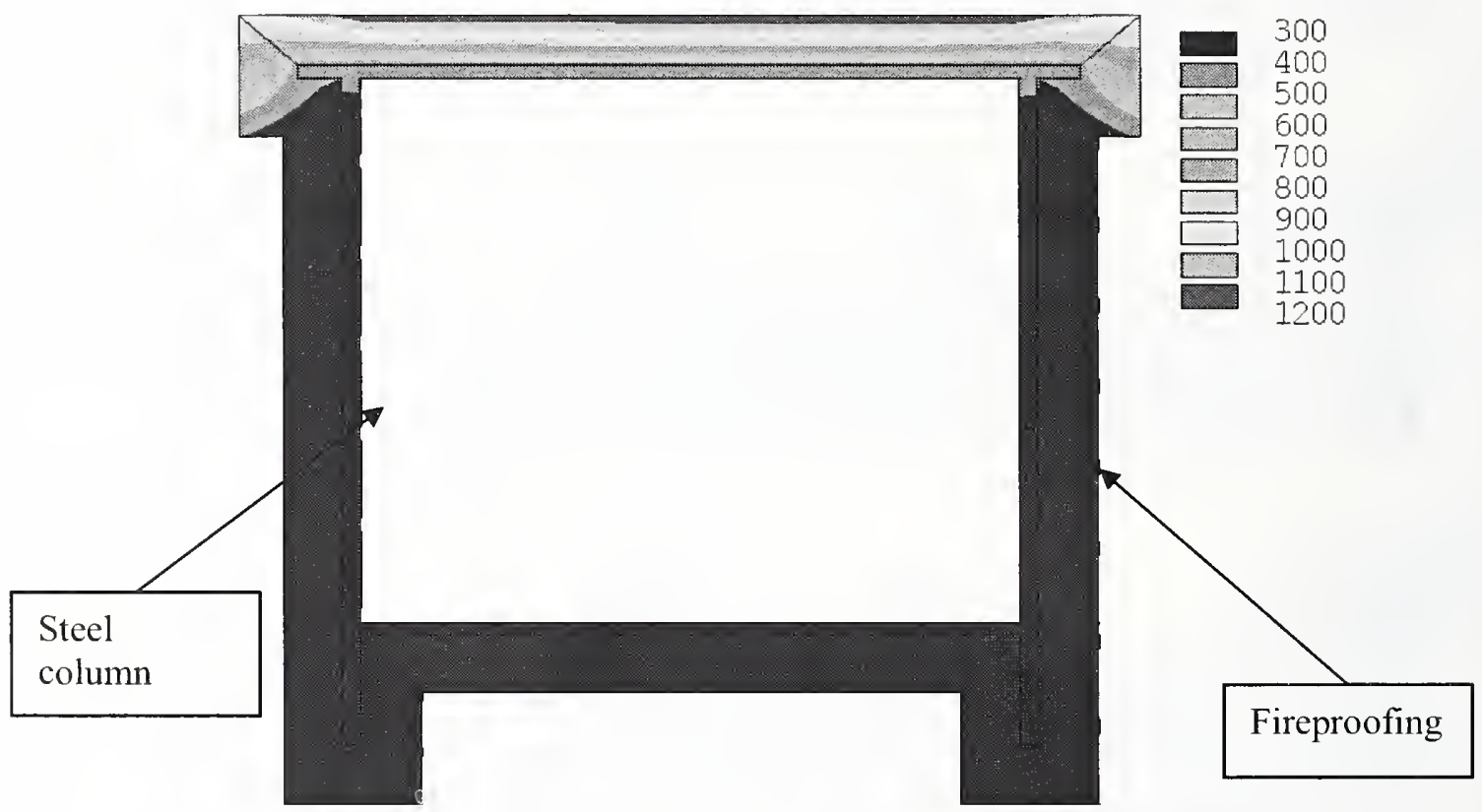

Figure 4-14. Temperature contours (Kelvin) through the cross-section of a perimeter column, showing the temperature gradient between the interior and exterior faces.

\subsubsection{Time-Temperature Plots}

The nature of combustibles and the ventilation patterns are some of the parameters that affect fire growth and spread on a typical floor of the WTC towers (NIST NCSTAR 1-5F). As the combustibles are consumed, the fire activity also dies down. The heat flux incident (see Figure 4-10 and Figure 4-11) on a perimeter column varies in space and time depending on the local fire activity. The temperature contours (Figure 4-12 and Figure 4-13) in a pcrimeter column depend on the geometry, fireproofing status, and boundary conditions. In this section, the detailed time temperature history of various nodes on a perimeter column is discussed.

Figure 4-15 through Figure 4-18 show the time - temperature history for perimeter columns 145, 230, 330 and 430 respectively, on floor 96 of WTC 1 . In each figure, profiles have been shown at four different nodal locations. Red symbols show temperature on the inner web plate. The nodal location is in the center of the web plate, half the distance between the floor and the ceiling. Similarly, green symbols 
denote the temperature history of the flange plates, and blue symbols show the temperature of the outer web plate. Again the nodes are located in the center of the plate, half the distance between the floor and the ceiling. Black symbols are used to indicate the temperature of the spandrel plate. The nodal location used for the spandrel plate is half the distance between two perimeter columns.

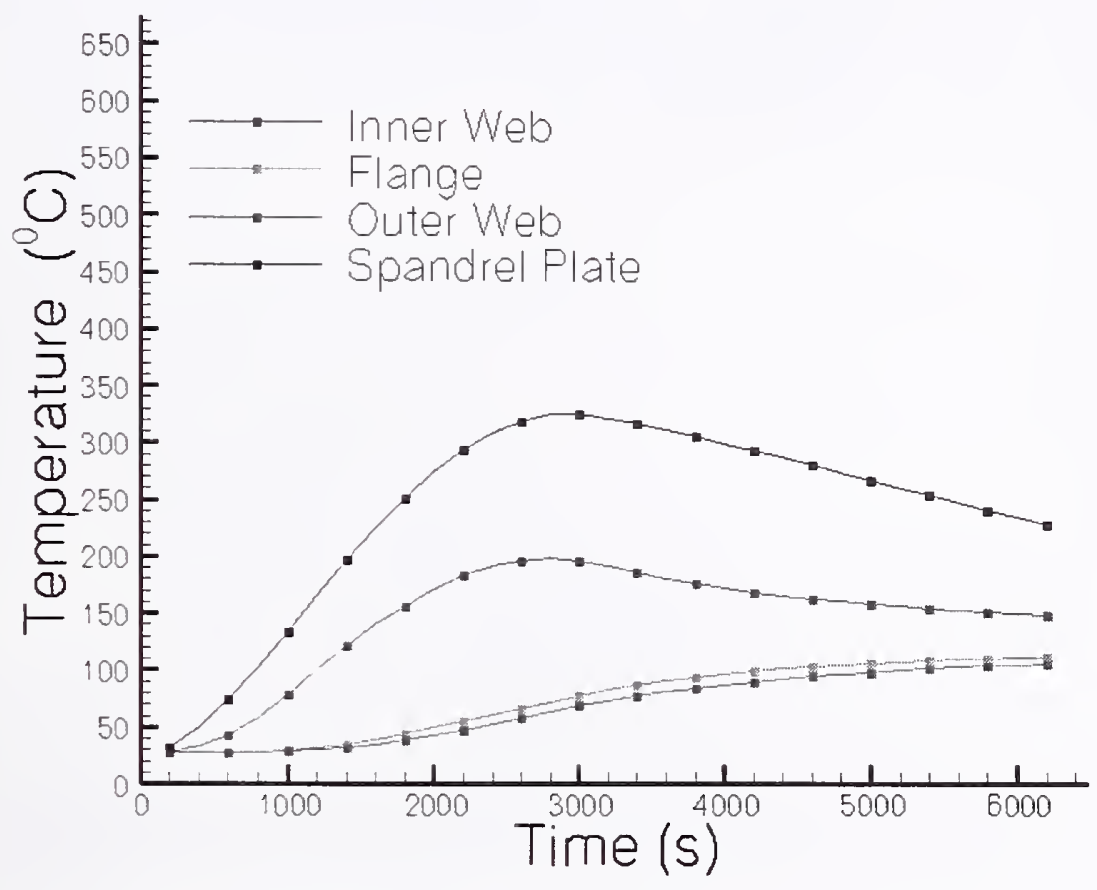

Figure 4-15. Time-temperature plot for perimeter Column 145, floor 96, WTC 1.

For perimeter column 145, Figure 4-15 shows a maximum inner web plate temperature of $200{ }^{\circ} \mathrm{C}$ while the spandrel plate shows a maximum temperature of $325^{\circ} \mathrm{C}$ at approximately $3,000 \mathrm{~s}$ after impact. After $3.000 \mathrm{~s}$ the temperature of the inner web plate and spandrel plate gradually decreases to $150{ }^{\circ} \mathrm{C}$ and $250^{\circ} \mathrm{C}$, respectively. The temperatures of the flange plate and the outer web plate continue to increase monotonically for the entire duration of the simulation. The flange plate shows higher temperature than the outer web plate. This picture is consistent with the fire activity in this region. Note that for the purpose of illustration, we have presented results for a few columns from one fire simulation. Global cases are discussed in Chapter 8 through Chapter 11. Perimeter columns 145, 230, and 430 have no fireproofing damage and show similar time-temperature plots. However because the fire activity in the vicinity of these columns peaks at different times, these columns show peak temperature at correspondingly different times.

Perimeter column 330 (Figure 4-17) shows different behavior due to fireproofing damage on the interior plates of the column. Peak temperatures of approximately $450{ }^{\circ} \mathrm{C}$ are predicted, and the resulting time temperature profile depends heavily on the local fire activity. Numerical simulations for perimeter column 330 do not indicate any significant temperature gradient between the inner web and the outer web plate. Note that the fireproofing on the exterior faces of the column is assumed to be intact for this simulation. 


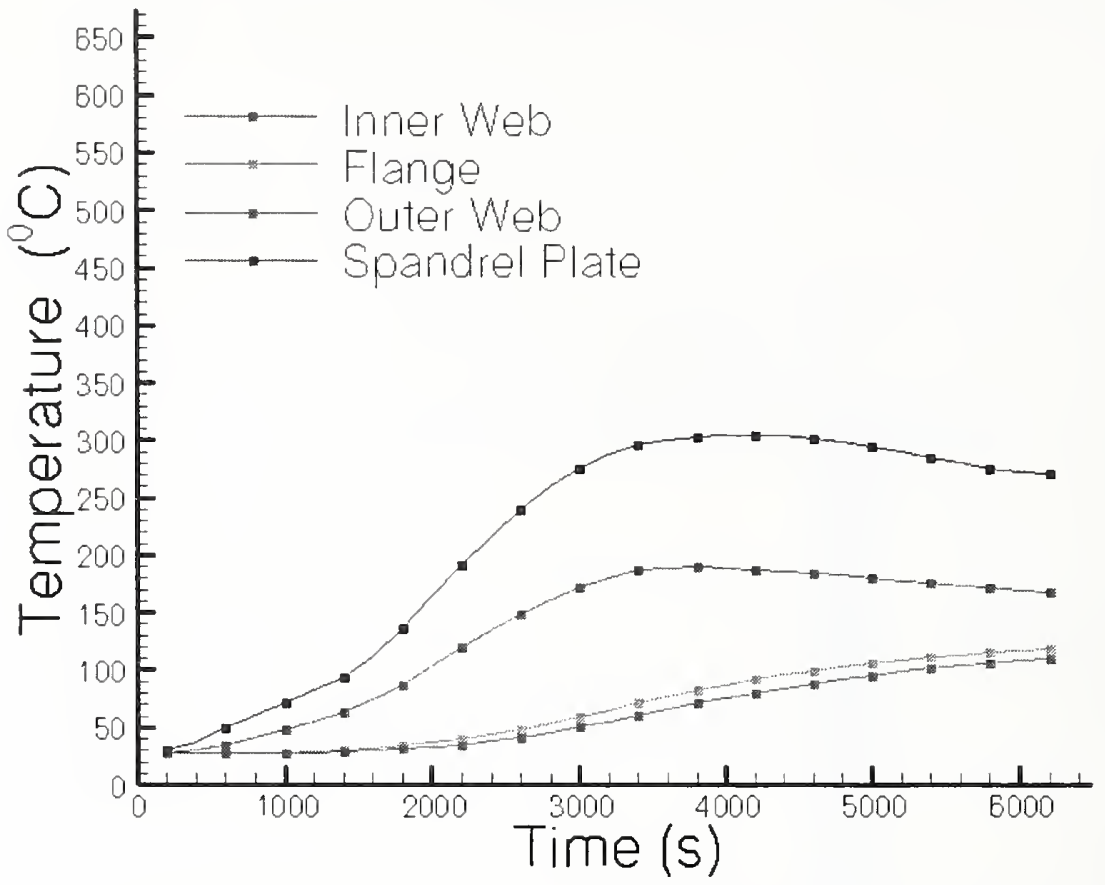

Figure 4-16. Time-temperature plot for perimeter Column 230, floor 96, WTC 1.

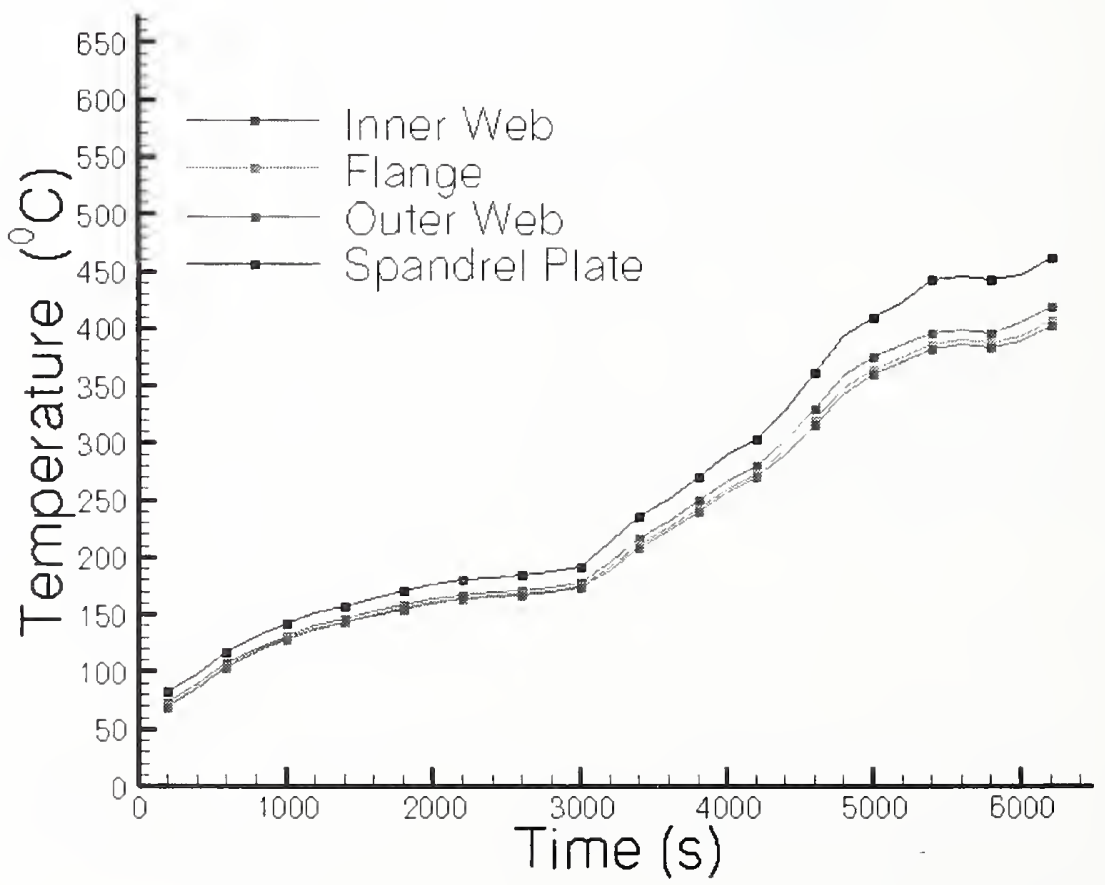

Figure 4-17. Time-temperature plot for perimeter Column 330, floor 96, WTC 1. 


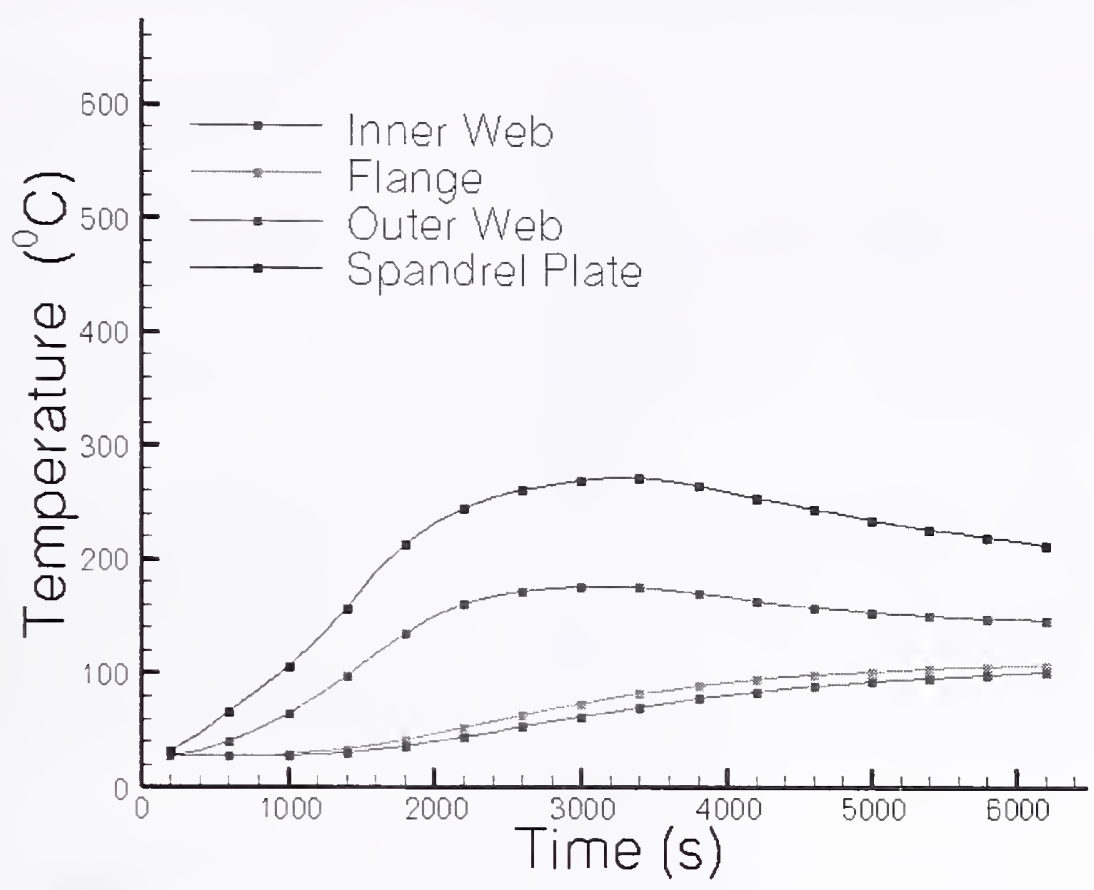

Figure 4-18. Time temperature plot for perimeter Column 430, floor 96, WTC 1.

\subsection{MODELING FIREPROOFING AND STRUCTURAL DAMAGE ON PERIMETER COLUMNS}

One objective of this Investigation was to simulate the thermally induced structural response of the towers damaged by the impact of the aircraft. Aircraft impact into the towers and the resulting debris field moving through the various floors can sever perimeter columns (NIST NCSTAR 1-2). A perimeter column that has been severed by aircraft impact changes the boundary conditions and affects the heat capacity of the column. The debris field can also damage the fireproofing that covers a perimeter column. Damaged fireproofing can drastically affect the thermal response of the column (Figure 4-17). Since fireproofing and structural damage can have a large effect on the thermally induced structural response, it was necessary to include this damage in our analysis. This section describes a methodology for incorporating fireproofing and structural damage on a perimeter column.

\subsubsection{Fireproofing Damage}

Each element in a finite element model is assigned certain material attributes, which, in turn establishes the elements material properties. Fireproofing damage on a column was modeled by changing the material attributes of the element. The new material attributes are such that they offer negligibly small resistance to heat flow. Such an element would have extremely low heat capacity and extremely high thermal conductivity. 
The following procedure was followed to include fireproofing damage on a perimeter column.

1. Identify all the elements that have material attributes of fireproofing.

2. Select the subset of these elements that are damaged due to the impact of the aircraft.

3. Define a new material ("Non Material") that has extremely high thermal conductivity and very low density and heat capacity. The assumed properties of this "Non Material" are described in 0.

4. Change the material attributes of the selected elements to that of the new material defined in step 3 .

Figure 4-19 shows a perimeter column that has fireproofing damage. The damage elements are assigned different material attributes as indicated by the blue color. Extending the column above and below the column under consideration provides a method to include the results of fireproofing damage on the columns above and below the column of interest. In Figure 4-19 (middle figure) fireproofing damage is limited to the column under consideration. The figure on the extreme right has fireproofing damage on the column above the $97^{\text {th }}$ floor, while the figure on the extreme left has fireproofing damage below the $96^{\text {th }}$ floor.
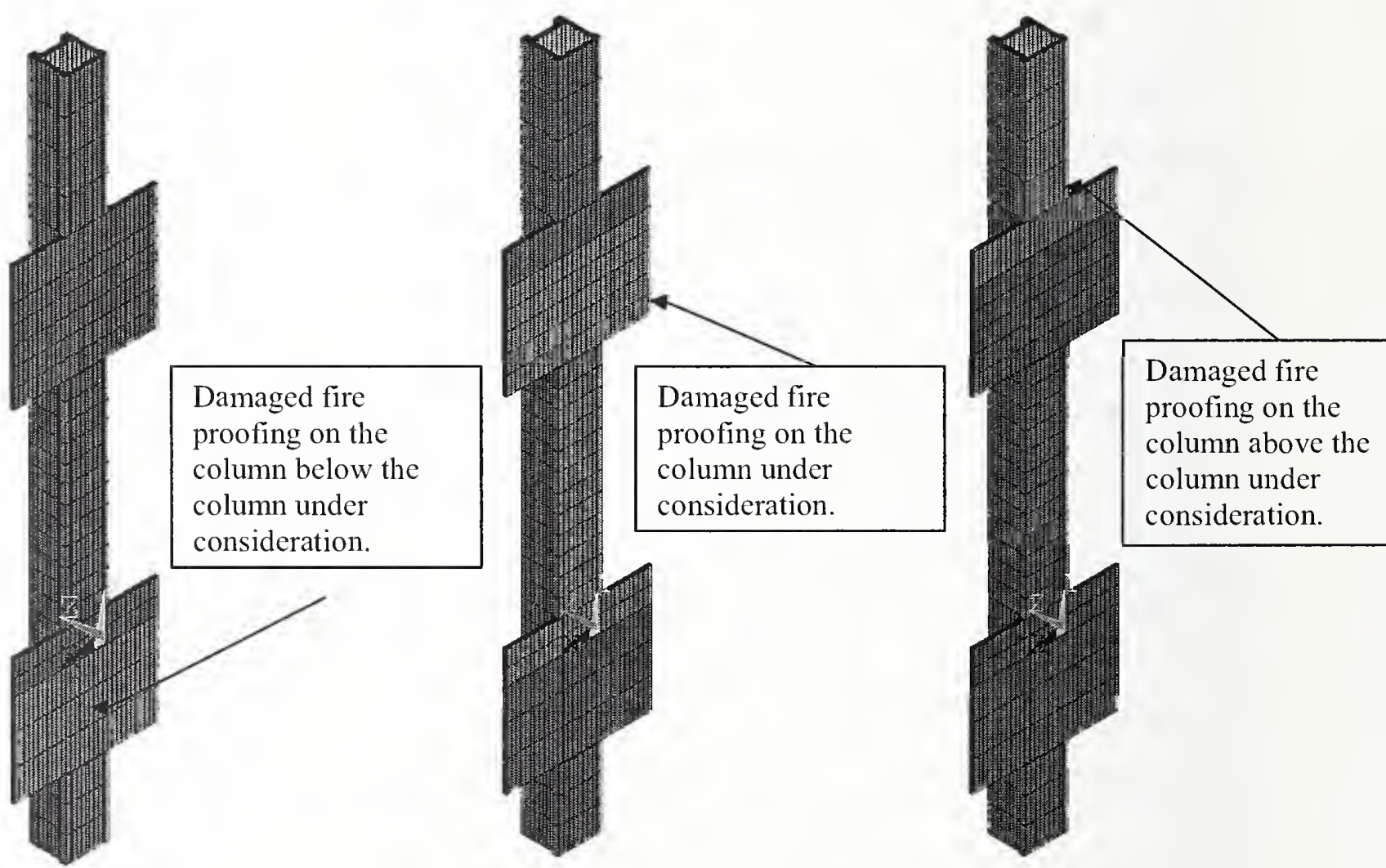

Figure 4-19. Incorporating fireproofing damage on the interior faces of a perimeter column. Figure on the left shows fireproofing damage on a part of the column below the column under consideration. Figure on the right shows fireproofing damage on part of the column above the column under consideration, while the figure in the middle shows fireproofing damage on the column of interest. 
Fireproofing damage may not be only limited to the interior faces of the column. Figure 4-20 shows fireproofing damage on the exterior and interior faces of the column under consideration.

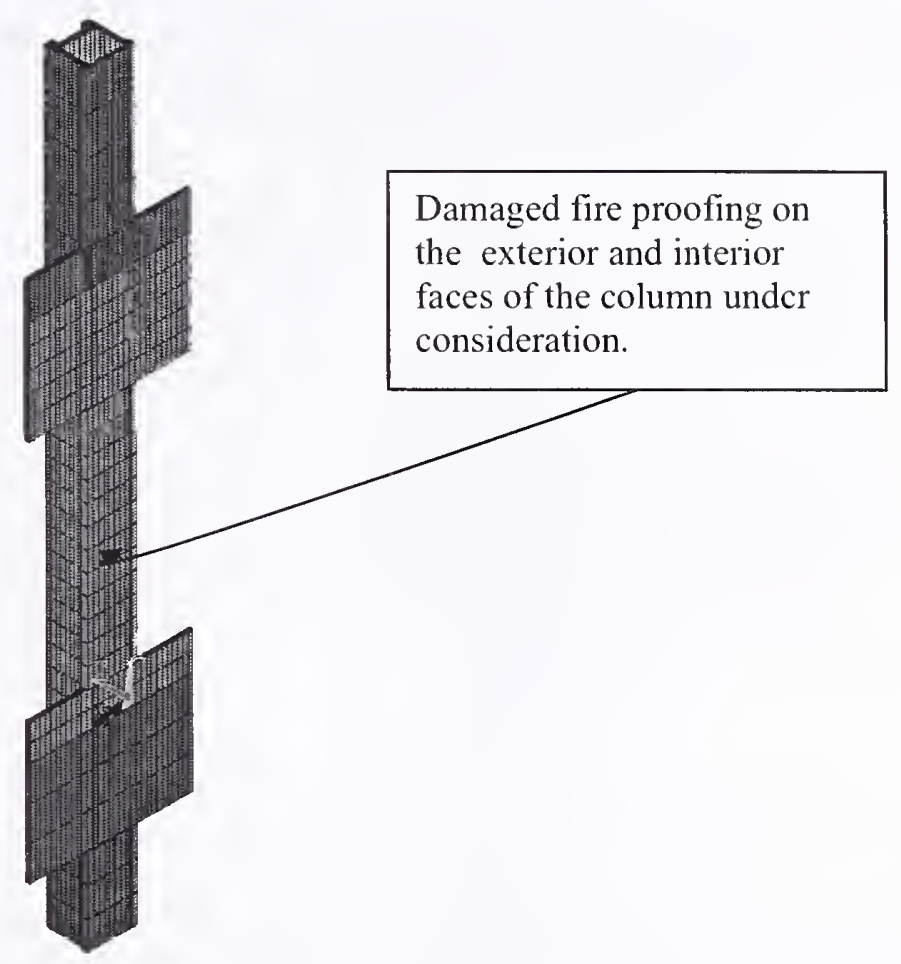

Figure 4-20. Incorporating fireproofing damage on the interior and exterior faces of a perimeter column. Material attributes of the fireproofing elements were changed to model damage to fireproofing.

\subsubsection{Structural Damage}

Modeling a structure that is damaged by the impact of the aircraft (NIST NCSTAR 1-2) and studying the role of structural damage was an important objective of this Investigation. Structural damage can reduce both the load bearing capacity and the heat carrying capacity of the structure and can also affect the boundary conditions on a perimeter column. If a perimeter column above or below the column under consideration is severed by the impact of the aircraft, then energy can no longer be conducted up or down the steel column. Reduction in heat loss due to the damage can increase the tcmperature of the portion of the column of interest over what it would have been without the damage.

Figure 4-21 shows the methodology for incorporating structural damage on the pcrimeter column. The plot on the left shows damage to the steel column below the column under consideration, while the figure on the right shows damage to the steel column above and below the column under consideration. The following steps outline the methodology for incorporating structural damage.

1. Construct a finite element model of a perimeter column.

2. Identify portions of the column which have structural damage. 
3. Identify and select the nodes and elements in the damaged column with material attributes of steel.

4. Deletc the selected elements and nodes, or alternatively, change the material attributes to that of fireproofing.
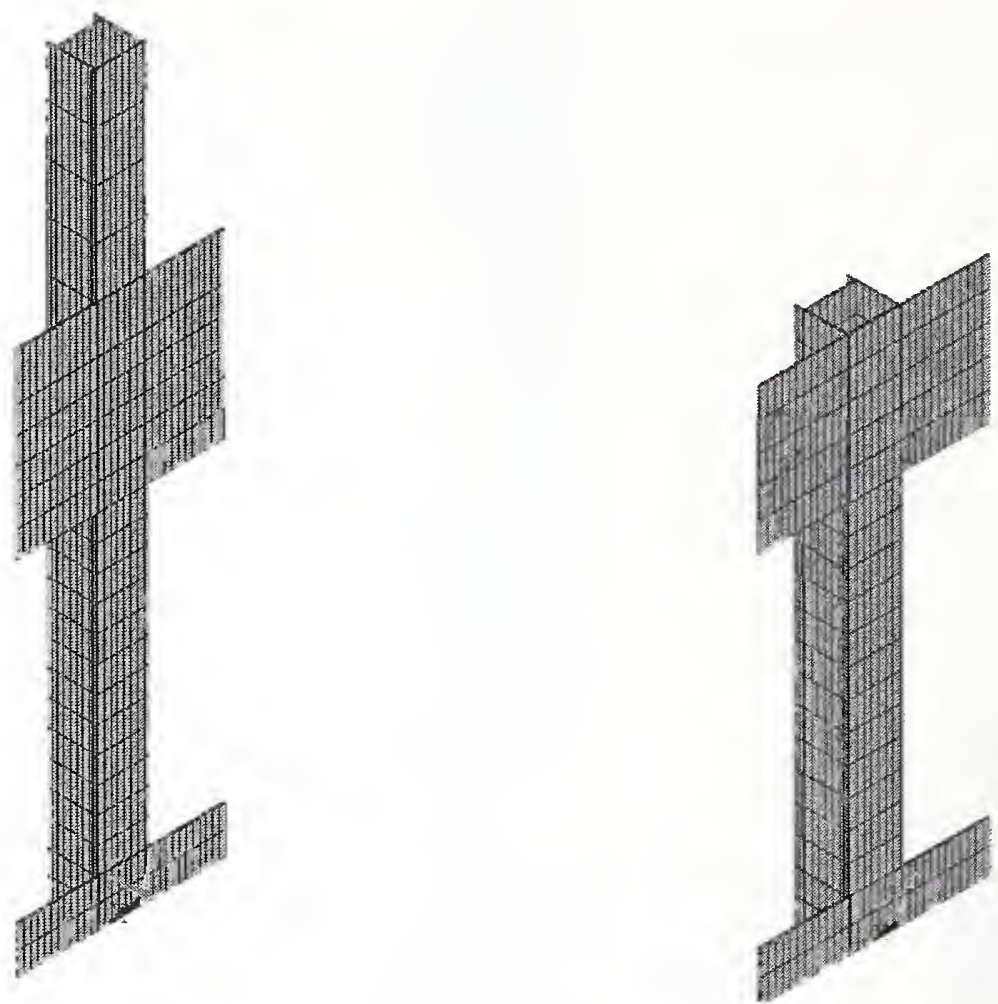

Figure 4-21. Incorporating structural damage caused by the aircraft impact on the steel columns. The plot on the left shows damage to the steel column below the column under consideration, while the figure on the right shows damage to the steel column above and below the column under consideration.

\subsection{INTERFACE BETWEEN THERMAL AND STRUCTURAL MODELS.}

The thermal analysis predicts the spatially and tcmporally evolving temperature ficlds in all the perimeter columns (structural components) of interest. The output of the thermal analysis is in the form of a timetemperature curve at each and every node in the thermal model. The thermal models (database file and the rcsults files containing the time-temperature histories) can now be subjected to gravity loading to perform a structural analysis (stress analysis) in a sequential manner. Three major difficulties prevent us from following such an approach:

1. Non-linear structural analysis performed with solid models can be computationally prohibitive. Structural analysis for large, complex building assemblies is normally performed with beam or shell elements. Beam elements are either linear ( 2 node) or quadratic ( 3 node) and can have six degrees of freedom. Beam elements are suitable for linear, large rotation and/or large strain nonlinear applications. Thermal analysis, on the other hand, requires solid clements as opposed to 
beam or shell elements for analysis to accurately model both the radiative flux incident on the surface and heat conduction.

2. Thermal models of steel columns include fireproofing. A large fraction of the nodes and elements of a thermal model have material attributes of fireproofing. Using the thermal models directly in a structural analysis would un-necessarily complicate the analysis due to the presence of fireproofing elements.

3. Structural analysis can be specialized to account for buckling of the columns or may include the effect of failure of bolts or connections. These effects are generally not included in a thermal analysis. The thermal and structural models are resolving different physical processes, and the meshing criteria may not be identical in the two models.

For the reasons mentioned above, it was necessary to construct two different models, one for the thermal analysis and another for structural analysis and then to transfer the thermal data between the two models. This section describes a methodology for transferring the data between the thermal and the structural models.

\subsubsection{Mapping of Thermal Data}

The transfer of temperature data between the thermal and structural models for a perimeter column has been shown schematically in Figure 4-22.

The figure on the left shows the nodes and elements used for studying the thermal response of a perimeter column. The steel column and spandrel plates are modeled with solid elements. The figure in the middle shows the elements of a structural model for a perimeter column. The column is made up of beam elements. while the spandrel plate is made of shell elements. The figure on the right shows the nodal locations for the elements of the structural model. The goal is to transfer the temperature and temperature gradient data from the thermal to the structural model. The detailed step by step procedure for transferring the thermal data between the two models is described in the following section. 

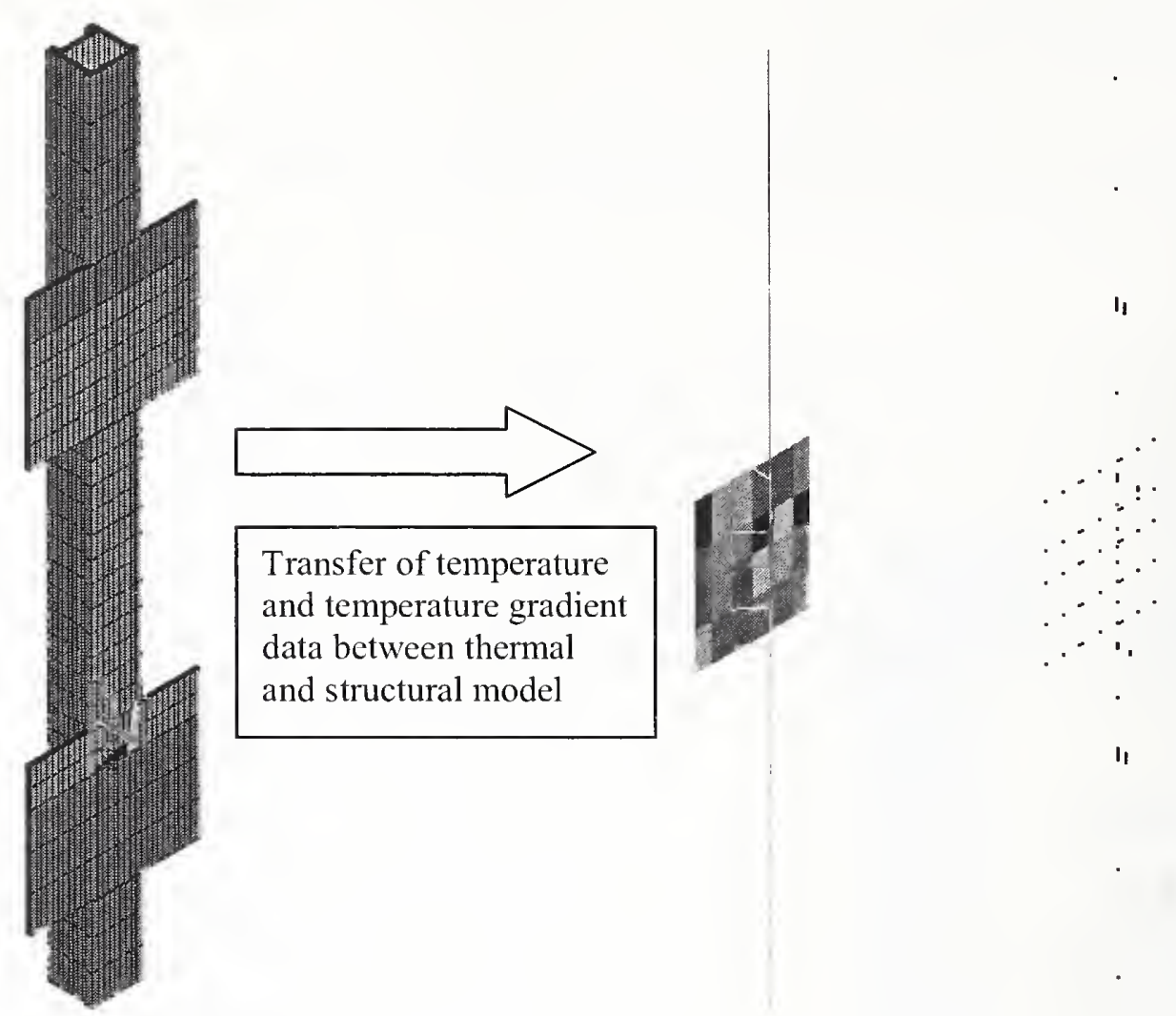

Thermal model of a perimeter column Element nlot

Node location and spandrel plate showing element density.

Structural model of a perimeter column and spandrel plate showing element density (color) and node locations

Figure 4-22. Mapping between the thermal models (left) and the structural model (right) for a typical perimeter column. Both temperature and temperature gradient information was transferred from the thermal model to the structural model for predicting the thermally induced response of the column.

\subsubsection{Procedure for Mapping Thermal Data onto the Structural Model}

- Open the structural model database file and select the perimeter column for which thermal data is required.

- Identify a portion of the perimeter column that is modeled with beam elements. Temperature gradient data is provided for columns that were modeled with beam elements. For each beam element write the element number and co-ordinate location (x,y and $\mathrm{z}$ ) of the centroid of the element. The location of the elements is written to a file, with respect to a global co-ordinate system.

- Identify a portion of the structural model that is modeled with shell elements. The spandrel plates were commonly modeled with shell elements. For these elements only temperature data was 
provided at the structural nodes. Identify and select the nodes of the shell elements. Write the node number and the spatial location ( $\mathrm{x}, \mathrm{y}$ and $\mathrm{z}$ location) of the nodes to a file. The location of the node is in reference to a global co-ordinate system.

- Open the thermal model database file. Load the solution data files at a specific time where the thermal loading data file has to be created.

- Read the element number and the co-ordinate location (of structural model) for temperature gradient data. Compute the temperature gradient at the nodes closest to the co-ordinate location specified by the structural model. Write the thermal gradient information in a thermal loading data file.

- Repeat step 5 for all the structural elements that require temperature gradient information.

- Read the node number and co-ordinate location for temperature data. Compute the temperature at the node closest to the structural node. Write the temperature data in a thermal loading data file.

- Repeat step 7 for all the structural elements that require temperature data.

- Repeat steps 4-8 for each time step where a thcrmal loading data file is need.

- Close the thermal models, and open the structural databasc.

- Read the thermal loading data files to apply body loads on the structural model.

Thermal data were provided as a set of thermal load files (text files) for structural analysis. Thermal load files for all perimeter columns in each tower were created at each time step where thermal data were required. The text files were formatted for the ANSYS finite element analysis software and structural models. For WTC 1, ten thermal load files were created at 10 min intervals ranging from $10 \mathrm{~min}$ to 100 min. For WTC 2, six thermal load files were generated at $10 \mathrm{~min}$ intervals ranging from $10 \mathrm{~min}$ to $60 \mathrm{~min}$.

Figure 4-23 shows the time vs. temperature plot for perimeter column 145, floor 96, WTC 1. In this figure, the small symbols indicate the frequency at which the thermal data are plotted (200 s), while the large symbols indicate the frequency at which the thermal data were mapped onto the structural models for analysis (600 s). Perimeter column temperatures were found to vary slowly rclative to the gas temperature fluctuations; the $200 \mathrm{~s}$ interval in the figure represents the thermal response of the column to the fires without missing significant peaks or fluctuations. The $10 \mathrm{~min}$ time intervals captured the computed thermal profiles reasonably well, as indicated in the figure. The structural response analysis used linear interpolation between two time intervals for modeling changes in temperatures of the structure. 


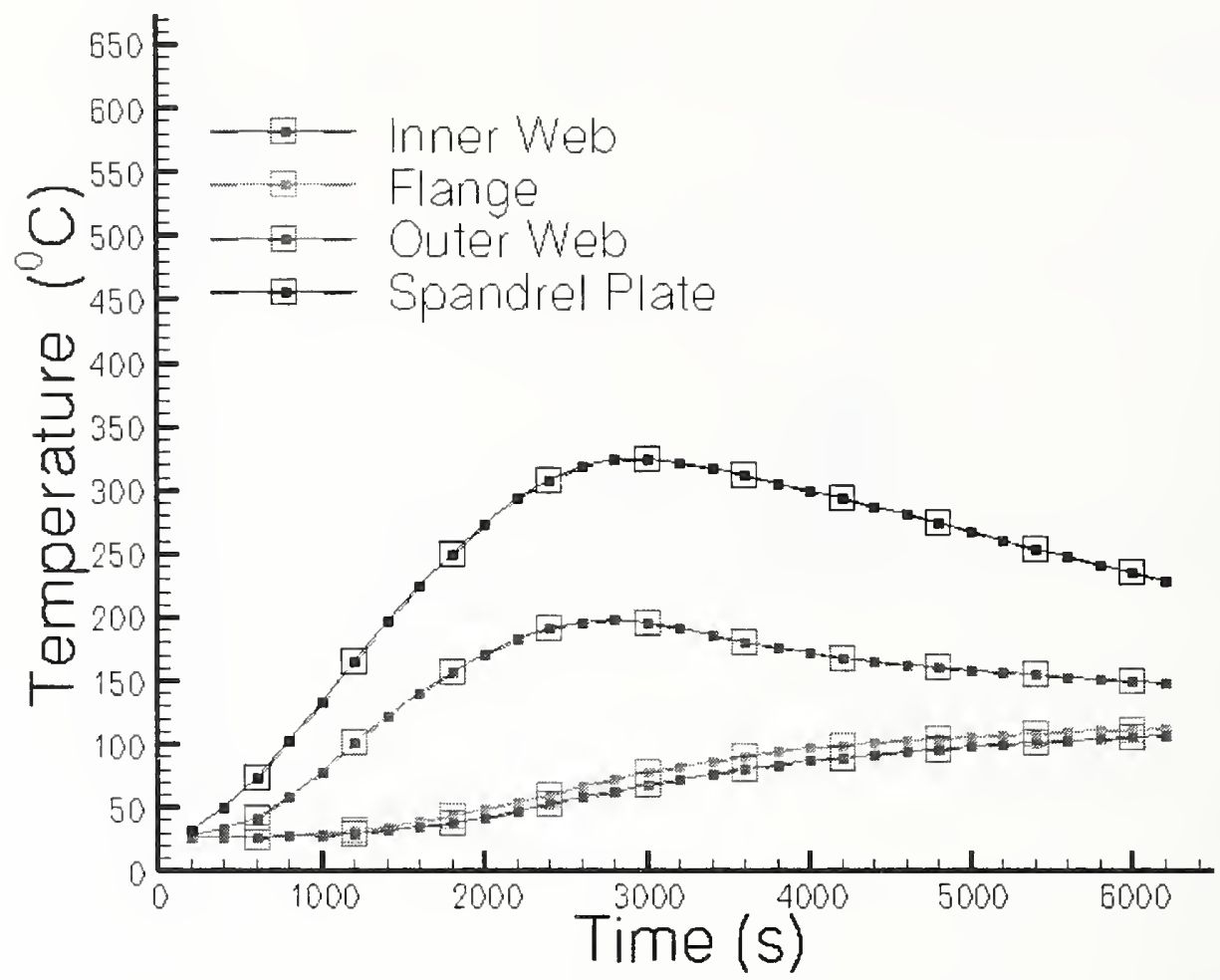

Figure 4-23. Time temperature plot for perimeter column 145, floor 96, WTC1, indicating the frequency at which the thermal data is plotted (small symbols) and the frequency at which it is transferred into the structural models (large symbols).

\subsubsection{Full Floor and Multiple Floor Mapping of Thermal Data}

Figure 4-24 shows the mapping of thermal data, based on the algorithm described above, on to a full floor structural model (NIST NCSTAR 1-6D) for WTC 2, floor 82. Thermal mapping has been shown at one specific instant in time. The mapping includes the temperature on the spandrel plates and temperature gradients for all the perimeter columns on a floor. Figure 4-25 shows a similar mapping for floors 92-99 of WTC 1, at one specific instant in time.

The approach presented in this chapter for predicting the thermal response of perimeter columns and transferring or mapping the thermal data on a structural model was used extensively throughout the Investigation. The perimeter columns shown in Chapter 8 through Chapter 11 (global response of the towers) show results from a similar mapping for four specific scenarios, two each for WTC 1 and WTC 2. The figures presented in those chapters are visual representations of the thermal state of the perimeter columns at specific instants in time. This information is provided in the form of a text file to apply body loads on the structural model and to subsequently perform thermally induced stress analysis. 


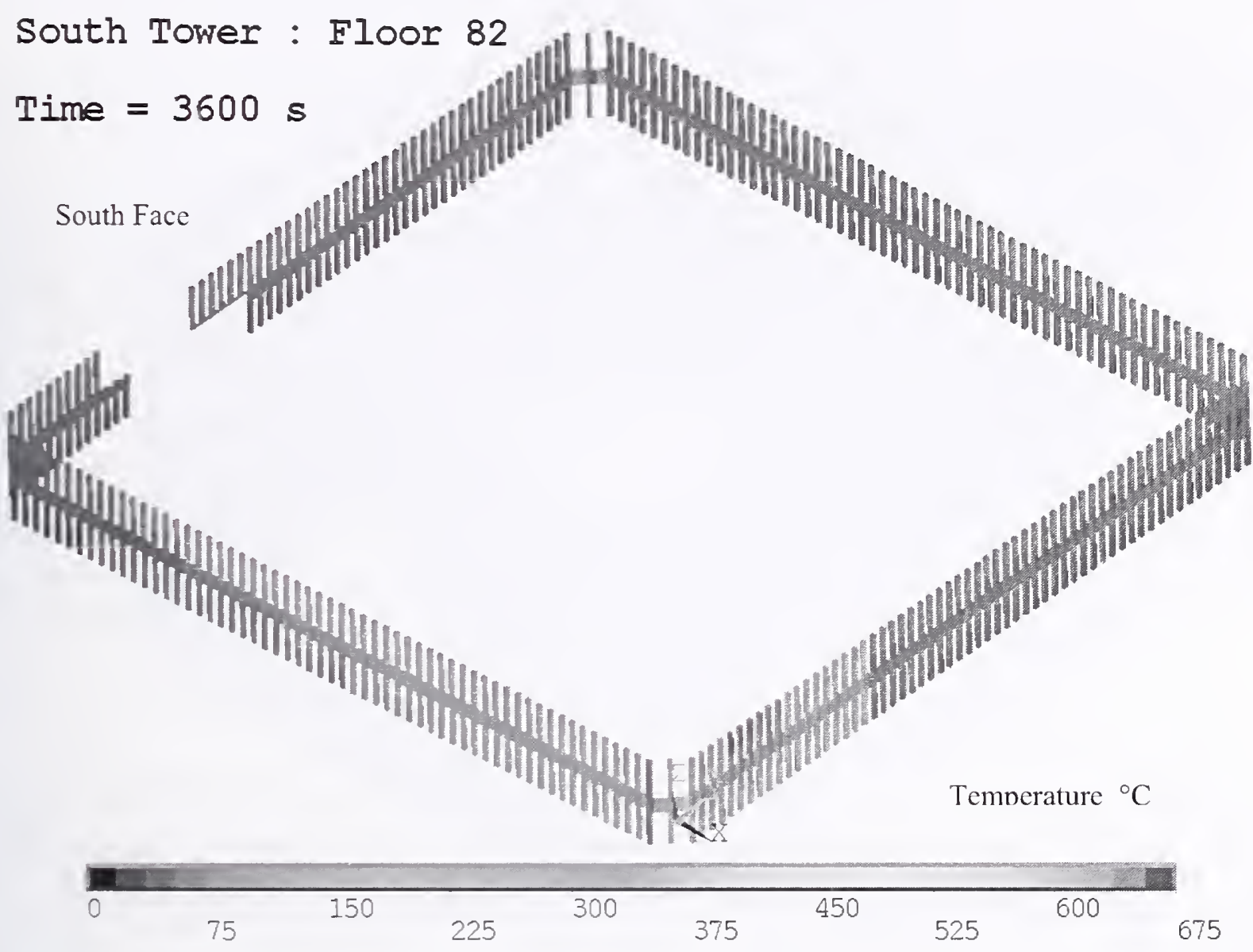

Figure 4-24. Perimeter columns on floor 82 of WTC 2 . The perimeter columns on the south face are damaged due to the impact of the aircraft, while many columns on the north and east faces exhibit fireproofing damage. 


\section{North Tower}

\section{Time $=6000 \mathrm{~s}$}

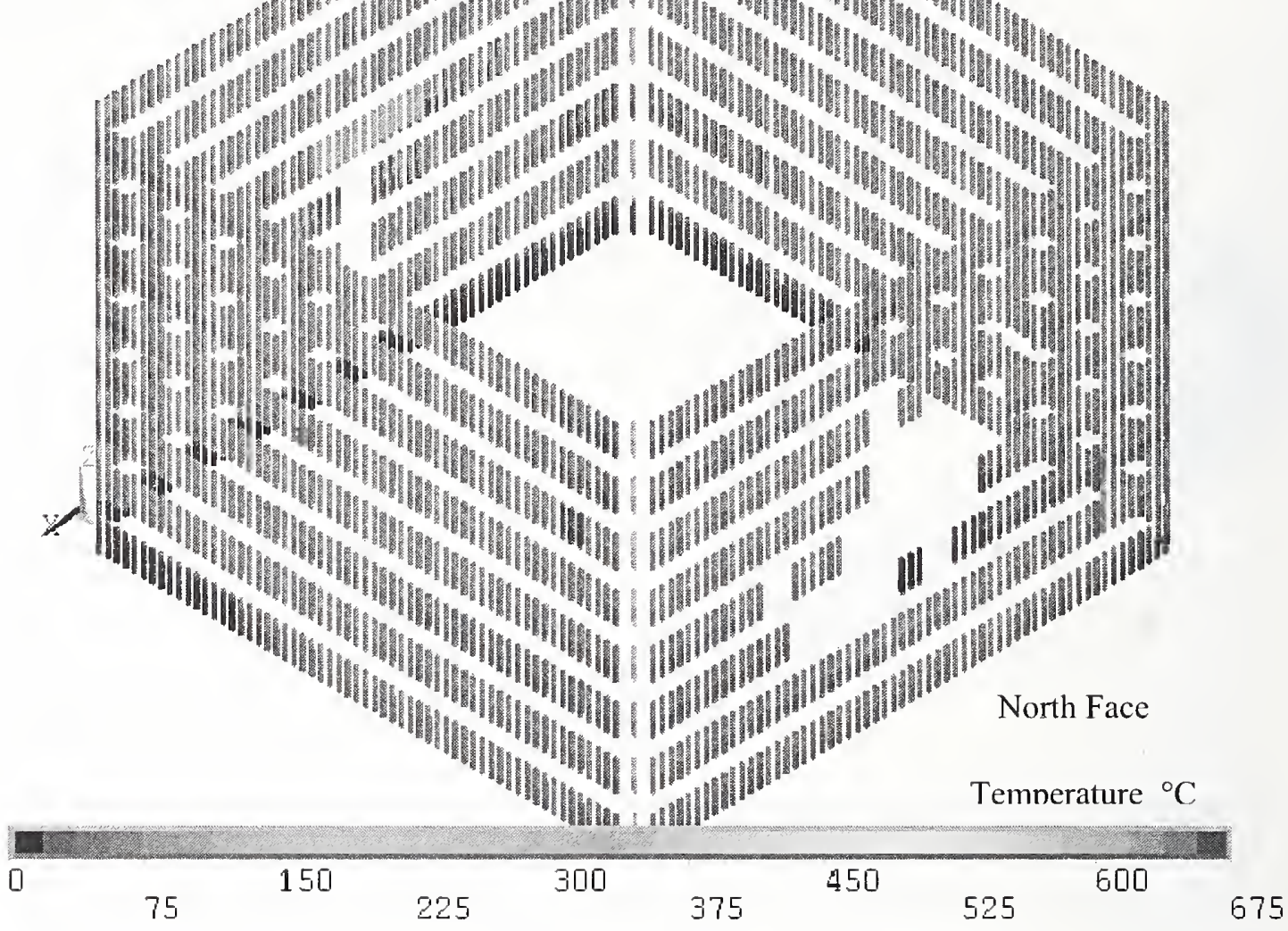

Figure 4-25. Visualization of the temperatures and temperature gradient information transferred to the WTC 1 structural model (floor 92-99) at $6000 \mathrm{~s}$ after impact. The thermal data is provided as a body load file. 


\section{Chapter 5 \\ Floor TRusses AND CoRe Beams}

This chapter is the second is a series of four chapters that details how the major structural components (along with their fireproofing) in the building were represented with finite element models. The first of those four chapters (Chapter 4) dealt with perimeter columns. The focus of this chapter in on the modeling of floor trusses and core beams that support the concrete slab of each floor of World Trade Center (WTC) 1 and WTC 2. A detailed description of finite element models for the basic building block of primary and bridging truss is provided. The method for coupling with fire simulations and transferring the thermal data on to the structural models is discussed. The approach for applying boundary conditions and including fireproofing and structural damage is outlined. Time-temperature profiles and temperature contours are provided to understand the spatial and temporal nature of fire damage. The description in this chapter applies for floors 92-99 of WTC 1 and floors 78-83 of WTC 2. As for perimeter columns, partial results from one of the fire simulations are utilized to understand the coupled fire-thermal response. A full delineation of all the cases will be presented in Chapter 8 through Chapter 11.

\subsection{TYPICAL FLOOR PLAN}

In the WTC towers, floor construction typically consisted of 4 in. of lightweight concrete on 1.5 in., 22 gauge non-composite steel deck. In the core area, slab thickness was $5 \mathrm{in}$. Outside the central core, the floor deck was supported by a series of composite floor trusses that spanned between the central core and exterior wall. Composite behavior with the floor slab was achieved by extending the truss diagonals above the top chord to form knuckles that acted much like shear studs. Detailing of the trusses was similar to that employed in open-web joist fabrication. However, the floor system design was not typical of openweb-joist floor systems. It was considerably more redundant and was well braced with transverse bridging truss members. Trusses were placed in pairs, with spacing of $6 \mathrm{ft} 8 \mathrm{in}$. and spans of approximately $60 \mathrm{ft}$ to the sides and $35 \mathrm{ft}$ at the ends of the central core. The metal deck spanned parallel to the main trusses and was directly supported by continuous transverse bridging trusses spaced at $13 \mathrm{ft} 4$ in. and intermediate deck support angles spaced at $6 \mathrm{ft} 8 \mathrm{in}$. from the transverse trusses. The combination of main trusses, transverse trusses, and deck support enabled the floor system to act as a grillage to distribute load to the various columns.

At the exterior wall, truss top chords were supported in bearing seats extending from the spandrels at alternate columns. Welded plate connection, with an estimated ultimate capacity of 90 kips tied the pairs of trusses to the exterior wall for out-of-plane forces. At the central core, trusses were supported on seats off a channel section that ran continuously past and was supported by the core columns. Floors were designed for a uniform live load of 100 pounds per square foot over any 200 -square foot area with allowable live load reduction taken over larger areas.

Since the trusses that support the concrete slab were considered as important structural elements (Usmani et al. 2001), it was necessary to study their thermally induced structural response. Finite element models were developed for trusses that cover an entire floor of the WTC Towers. This chapter describes 
the devclopment of the finite element models and the methodology for coupling the thermal response of a truss to the temperature flow field determined by fire dynamic simulations.

\section{$5.2 \quad$ FINITE ELEMENT MODEL OF THE FLOOR TRUSS}

This section describes the development of finite element models of the basic building block of a truss element using the ANSYS parametric design language. The basic building block was replicated to cover an entire floor of the World Trade Center towers. In this section, the challenges that were faced as these models were developed, mesh requirements, choice of elements for analysis, and the approximations that are built into the analysis is described.

\subsubsection{Primary Truss}

Figure 5-1 shows an isometric view of a portion of the main truss (primary truss). In order to predict the thermal response of the truss, a solid model was constructed for the steel and fireproofing that covers the truss model. The truss model consists of an upper flange and a lower flange held together by web diagonals. The upper flange and the lower flange each consist of $\mathrm{L}$ shaped angles. Note that the dimensions of the $\mathrm{L}$ shaped angles are different for the upper flange and the lower flange. In these pictures, the elements have been color coded with the material attributes. Cyan colored elements have material attributes of steel, while violet colored elements have attributes of fireproofing (BLAZE-SHIELD DC/F).

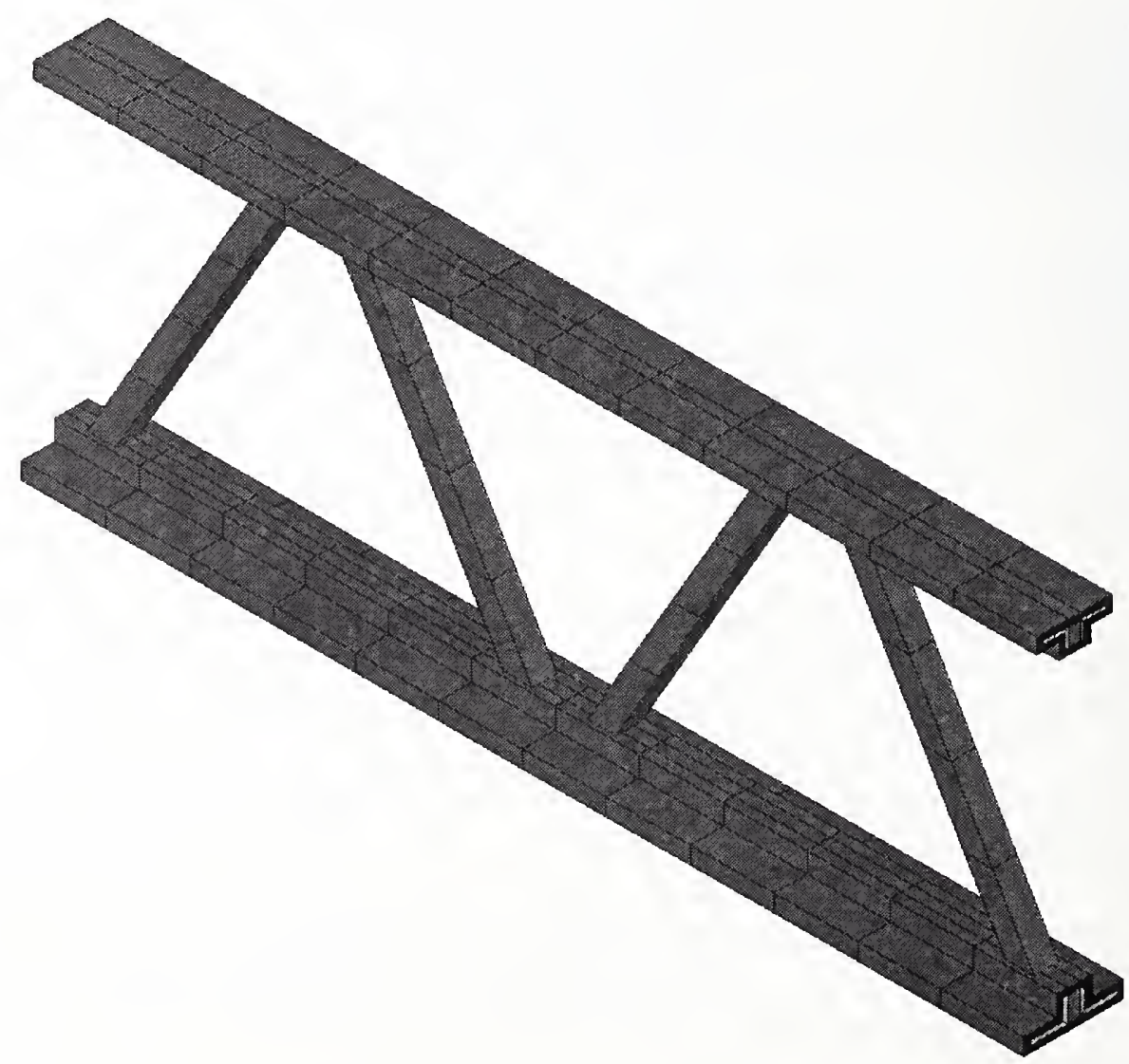

Figure 5-1. Isometric view of a finite element model of a portion of the main truss. 
Figure 5-2 shows the end view of the truss model showing the finite element construction of the upper and lower flange. The plot on the left shows a model which is covered with $2.2 \mathrm{in}$. of fireproofing. This model was adopted for modeling the trusses in WTC 1. The figure on right shows a model of a truss, covered with 0.6 in. of fireproofing. This model was adopted for the trusses in WTC 2 (Choi, Burgess and Plank, 2003, Liew and Chen, 2004).

The thermo-physical properties of all the materials are discussed in Appendix A.

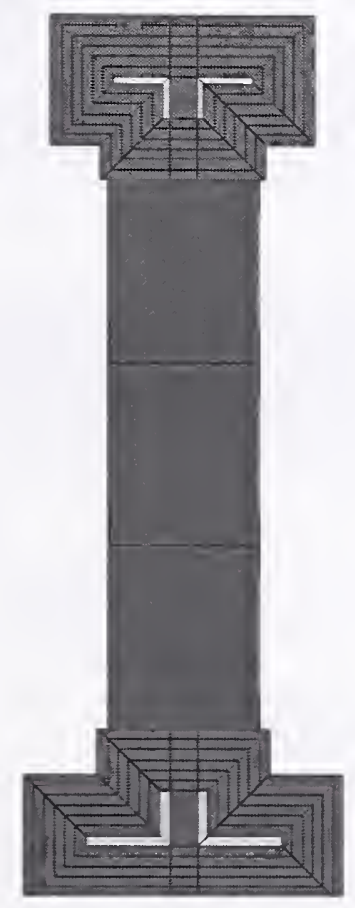

a) Insulation Thickness 2.2 in.

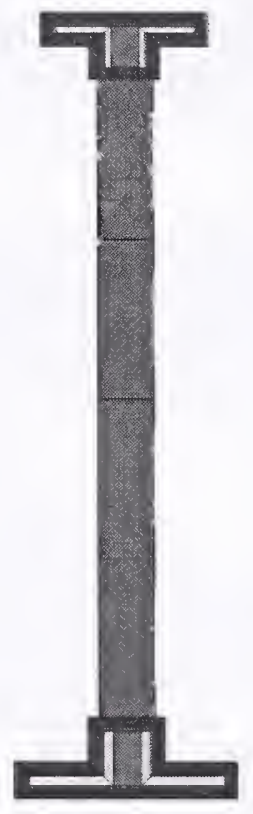

b) Insulation Thickness 0.6 in.

\section{Figure 5-2. End view of the truss model showing upper and lower steel flanges (cyan colored) covered with fireproofing (violet colored).}

Figure 5-3 shows the front and top views of the finite element model of the primary truss, indicating the element density used for the simulations. The truss upper and lower flanges were constructed using a system of keypoints, areas, and volumes. The volumes were subsequently meshed to create elements and nodes for finite element analysis. Since the truss model covers an entire floor, it was clear that it would require a very large number of elements to cover the entire floor. The computational time scales approximately as $\mathrm{N}^{2}$ where, $\mathrm{N}$ is the number of nodes in the model. Increasing the resolution in the model by a factor of two or more, for example, can quickly result in calculations that would not be computationally feasible (large CPU time). Another major limitation was the RAM available on the fast personal computers used for the investigation. It was necessary to limit the size of the model such that it would not be larger than the RAM available for the simulation (to avoid memory swapping). To avoid prohibitively large CPU costs and memory swapping (which results in very slow computational speed), it was necessary to control the number of elements and nodes used in the simulation. The truss model was designed such that it would results in the minimum number of volumes that required meshing. Since we wanted to control the mesh density in the trusses (to reduce computation costs), it was also necessary to have regular shaped elements. 


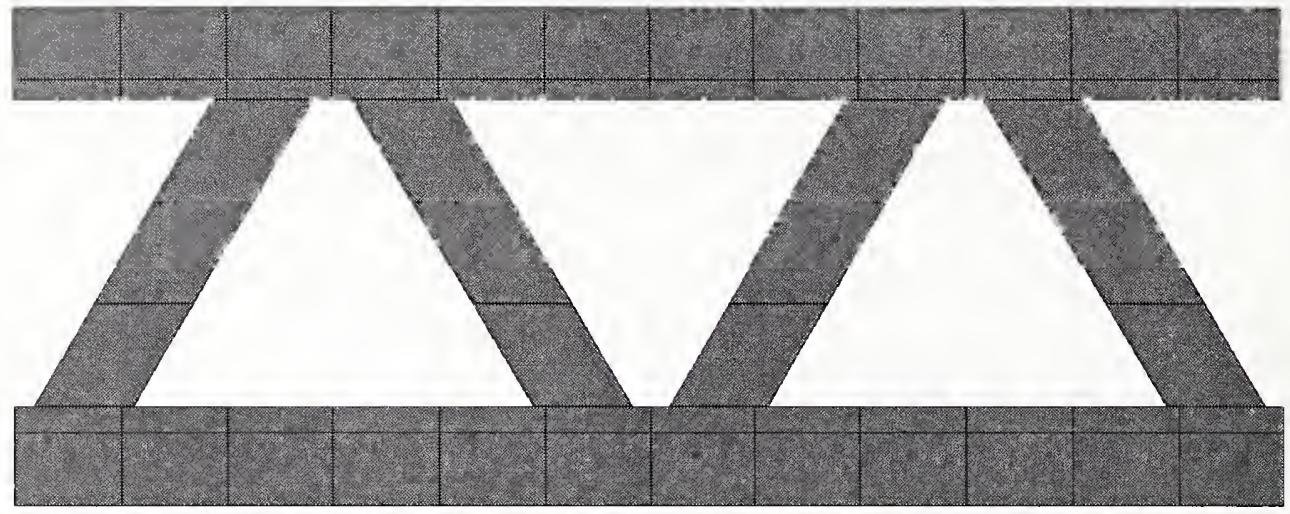

Front View

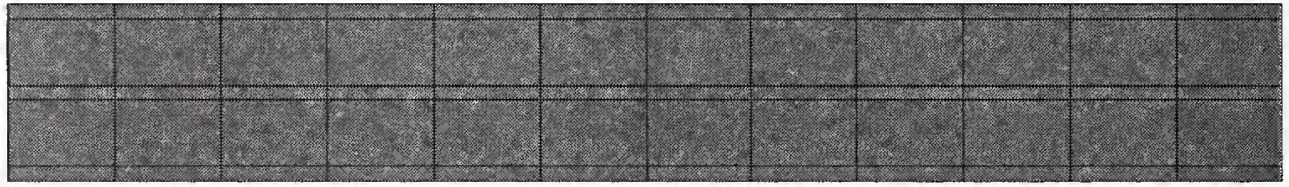

Top View

Figure 5-3. Front and top views of the truss model.

\subsubsection{Connections}

Figure 5-4 shows the connectivity between the steel and fireproofing in the upper and lower flanges. The model was designed such that the fireproofing does not result in cuts in the L shaped steel flanges, and similarly, the steel flanges do not introduce additional cuts in the fireproofing.
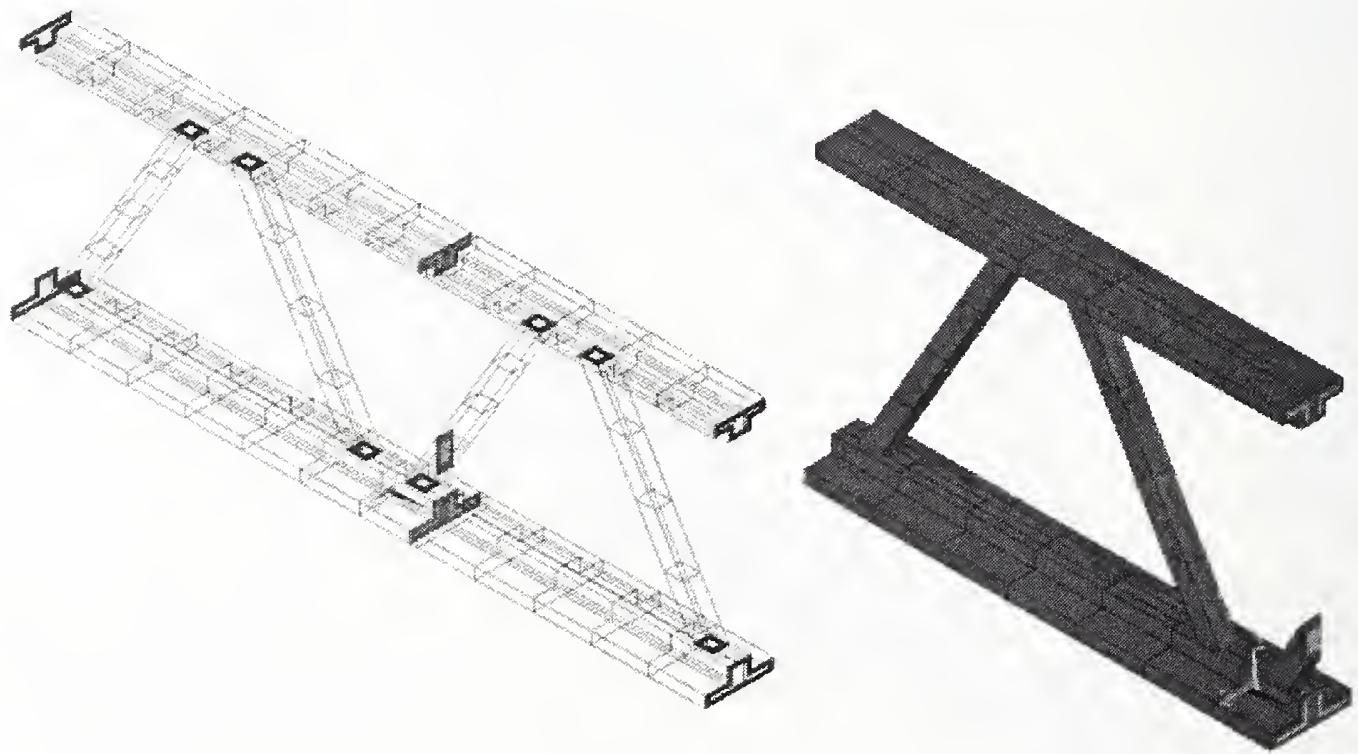

Figure 5-4. Finite element model of a primary truss showing truss construction details. 
Attaching the web diagonals to the upper and lower flanges can result in additional cuts through the flanges. To avoid these cuts in the model, the diagonals were attached to the flanges with link elements. Use of link elements allows the diagonals to be meshed independently of the flanges and results in the minimum possible volumes for the meshing.

Link elements were also used to model heat transfer between the upper flange and the concrete slab. The cross-sectional area of the link element was chosen to be equal to the contact surface between the upper flange and concrete slab.

The basic finite element model of the truss component and insulation, shown in Figure 5-1 through Figure 5-4. was replicated to cover a $60 \mathrm{ft}$ long truss shown in Figure 5-5. The end connections for the trusses were modified on an individual basis to account for the connections with the perimeter and core columns.

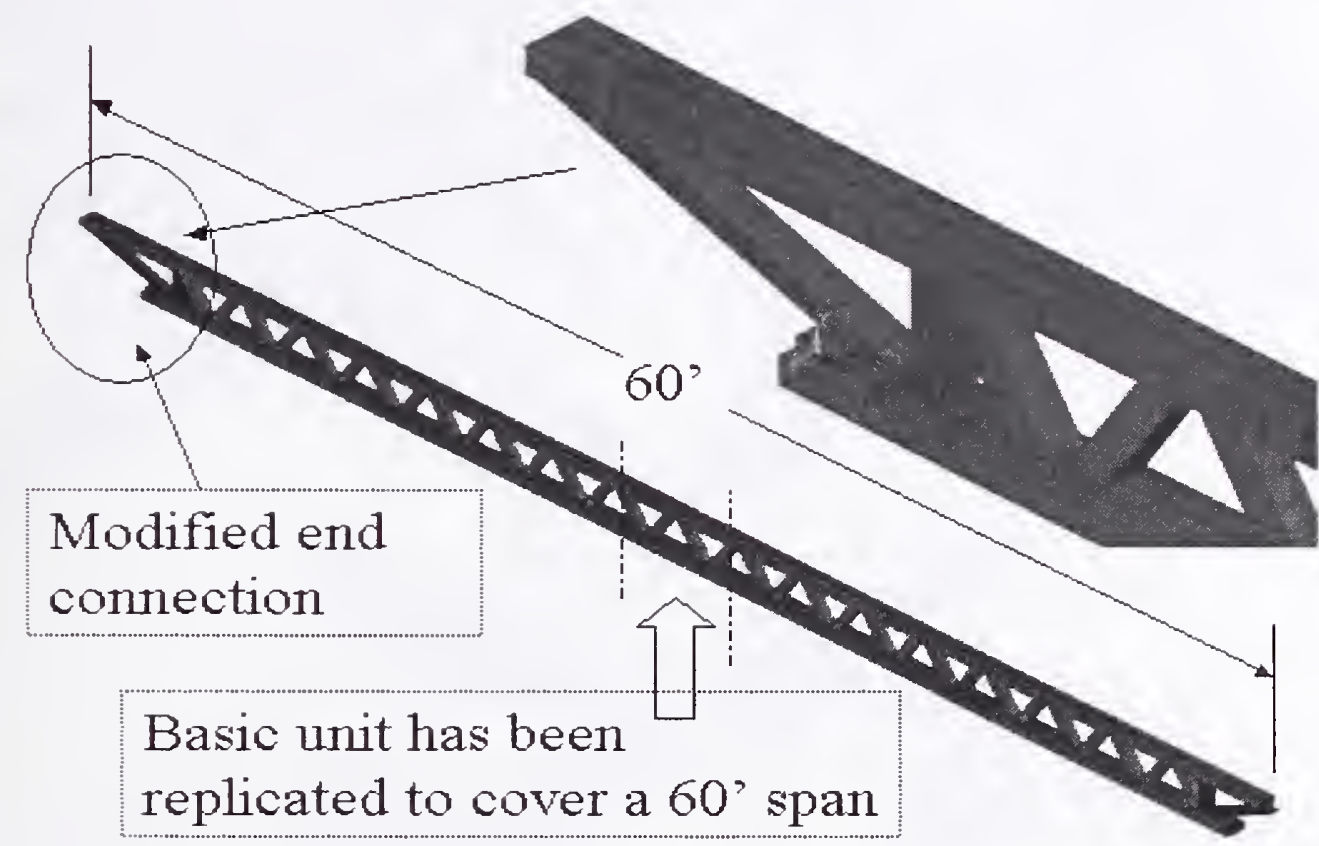

Figure 5-5. Replications of the basic element of the truss model to create a $60^{\prime}$ long truss. The ends of the truss were modified to properly account for the connections to the core columns and perimeter columns.

\subsubsection{Bridging Truss}

The next task in building a finite element model for the entire floor was to construct the bridging trusses (transverse trusses). Figure 5-6 shows several views of the basic unit of the primary and bridging truss system. Again, intersecting solid geometries can result in cuts in the model and will result in a very large number of elements. Link elements were used to model the heat conduction between the primary and transverse trusses. The procedure for creating the link elements can be summarized as follows:

1. Identify the two surfaces that are in contact (e.g. lower part of the upper flange in the main truss and the upper part of the upper flange in the transverse truss). 
2. Identify the nodes and elements with material attributes of steel on each surface.

3. Define link element attributes by dividing the cross-sectional area by the number of links.

4. Identify a pair of nodes (one on each surface) that will be linked. The nodes are chosen such that the length of the link element is as small as possible. This results in a link between two nodes that are closest to each other.

5. Create a link element between the two nodes.

6. Repeat steps 4 and 5 for all the nodes on the two contact surfaces.

7. Repeat steps 1 through 6 for the various contact surfaces.
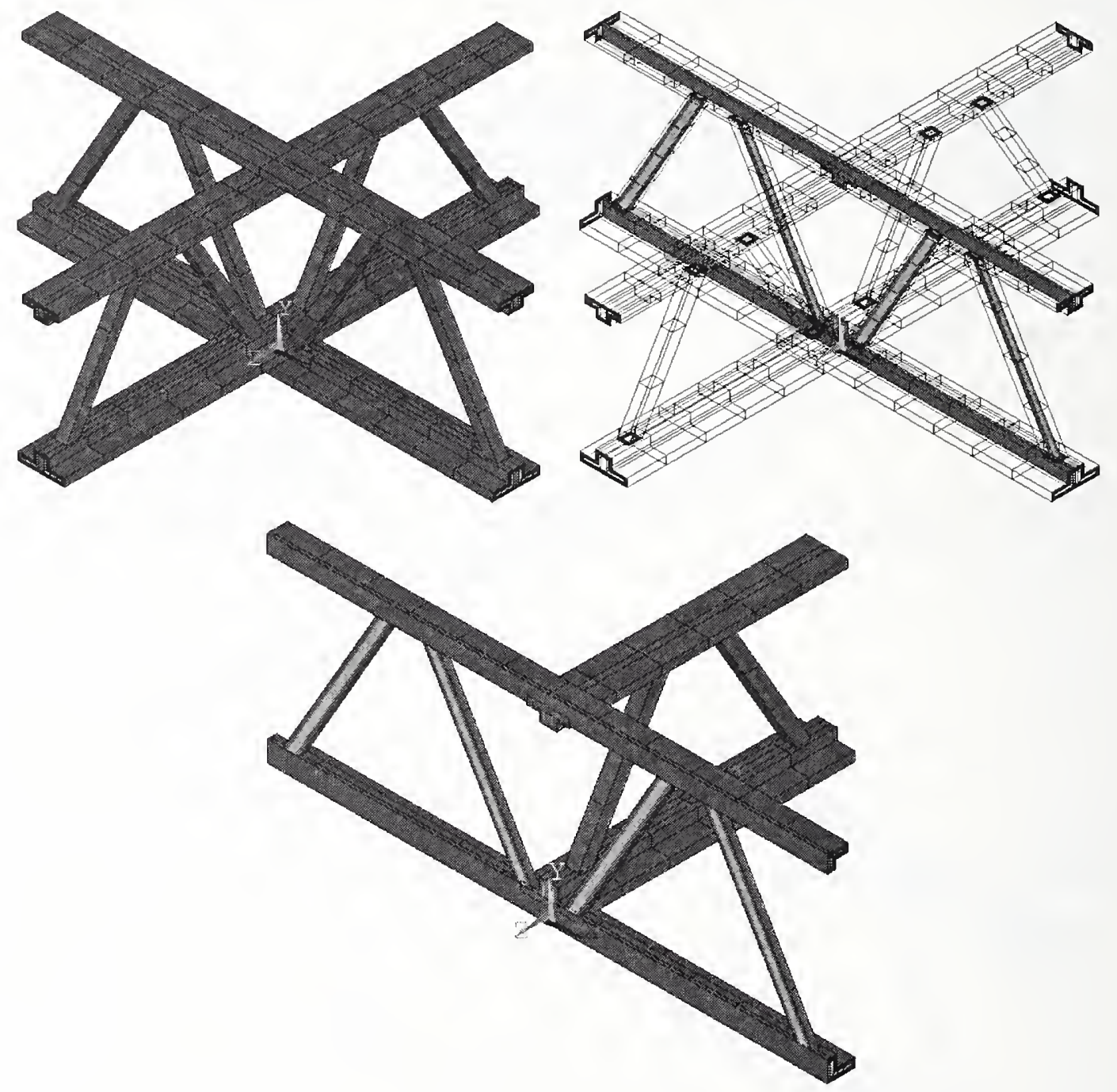

Figure 5-6. Basic unit of the primary and transverse truss.

The basic unit of the primary and transverse truss (shown in Figure 5-6) can be replicated several times to cover a portion of the slab as shown in Figure 5-7 or to cover the entire floor slab as shown in Figure 5-8. 


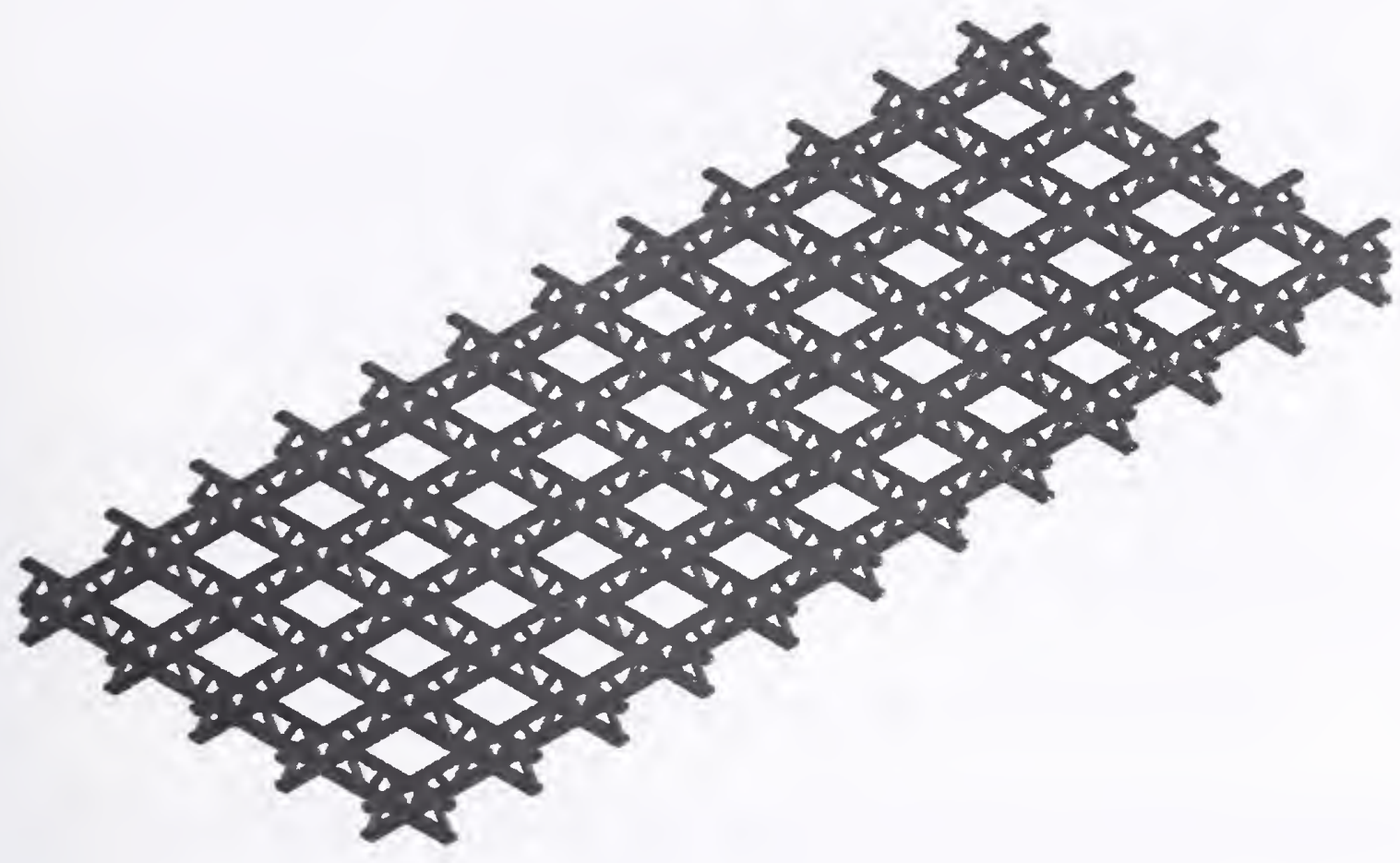

Figure 5-7. Replication of the basic truss unit to cover a small portion of the floor slab.

Figure 5-8. Finite element model of the entire truss assembly (steel only) that supports the concrete slab on floor 96 of WTC 1. 


\subsection{STRUCTURAL AND FIREPROOFING DAMAGE}

An important concern throughout the Investigation was to simulate the thermally induced structural response of the towers damaged by impact of the aircraft. Aircraft impact can damage the floor trusses and core beams that support a concrete slab. The damage can take two forms (as discussed in Chapter 4):

- Structural damage, where the steel has been severed. This can result in changes in boundary conditions for thermal analysis and the overall heat capacity of the structure.

- Fireproofing damage can result in rapid heating or cooling of the structure, which in turn can have a large impact on the structural response.

In this section we will briefly describe the methodology for including structural or fireproofing damage on the steel trusses and/or core beams.

\subsubsection{Incorporating Structural Damage on Floor Trusses or Core Beams}

Figure 5-9 shows structural damage on a portion of the steel truss that covers an entire floor of the WTC tower. Structural damage on the trusses was incorporated by first constructing a model of a floor truss with no damage. Subsequently, portions of the steel truss with structural damage were identified, and the nodes and elements in that portion were selected. The nodes and elements were deleted from the database.

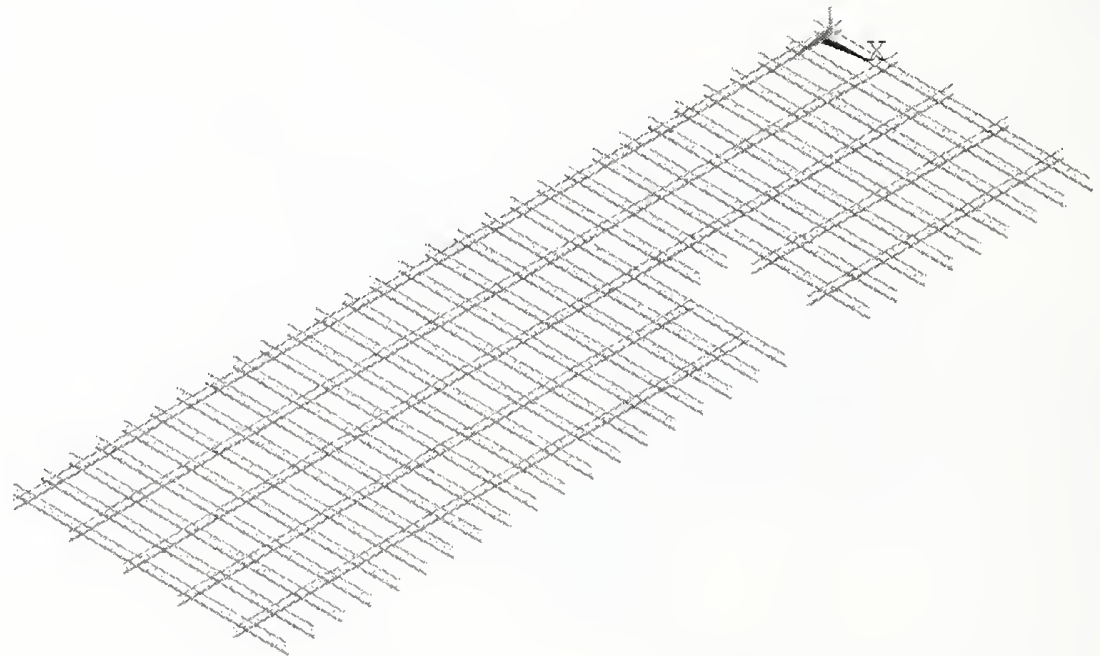

Figure 5-9. Incorporating structural damage due to aircraft impact on the truss model.

\subsubsection{Incorporating Fireproofing Damage on Trusses or Core Beams}

Fireproofing damage on the floor trusses was modeled by changing the material attributes of the elements such that the element offers no resistance to heat flow. Extremely low heat capacity and very high thermal conductivity is a requirement for such materials. Figure 5-10 shows fireproofing and structural damage on a portion of the floor truss. The procedure is very similar to the one described for perimeter columns in Chapter 4. 


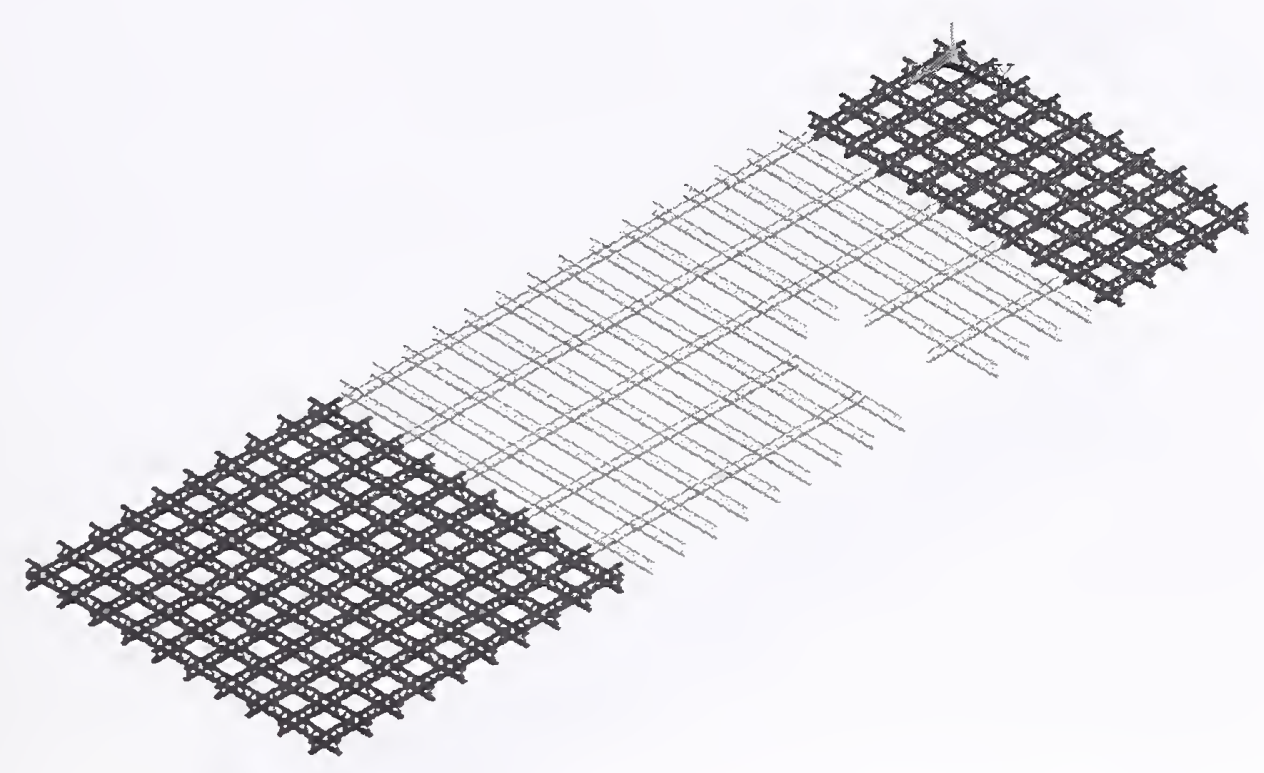

Figure 5-10. Incorporating structural and fireproofing damage on the truss assembly.

\subsection{INITIAL AND BOUNDARY CONDITIONS}

As for perimeter columns described in Chapter 4, the thermal responses of floor trusses and core beams depend on a specific set of initial and boundary conditions and surface loads that are applied on the full floor model. In this section, we will point out the peculiarities of applying boundary conditions that are specific to floor trusses and core beams.

Heat flux boundary conditions (surface loads predicted from a plane layer analysis) were applied to the exposed faces of the floor truss. The flux is incident normally on the fireproofing (if the fireproofing is intact) or on the steel (if the fireproofing is considered to be damaged). The flux varies as a function of space and time, depending on the location of the truss element relative to the fire.

Figure 5-11 and Figure 5-12 show the flux boundary condition on a portion of the truss element. The finite element model for floor trusses has surfaces that can be classified as either horizontal or vertical surfaces. Among the horizontal surfaces, some are facing upwards while others are facing downwards. The upward and downward facing surfaces of the truss were identified and appropriate radiative fluxes obtained from a plane layer analysis were applied. Figure 5-11 shows that upward facing surfaces were subjected to a flux Qc, while downward facing surfaces were subjected to flux Qf. The truss model also has vertical surfaces and these surfaces were subjected to flux Qs as shown in Figure 5-11.

The incident flux is strongly coupled with the fire growth and spread through the various floors of the World Trade Center Towers. The flux is a function of the instantaneous hot layer thickness, absorption coefficients, hot layer temperature, and ambient temperature as predicted by the fire simulations. The radiative flux also varies depending on the location and orientation of the structural element. Figure 5-12 shows the actual values of the flux incident on the various elements of a truss model at one instant in time. As the fire evolves and spreads on the floor, the flux incident on the surface also changes with time. 


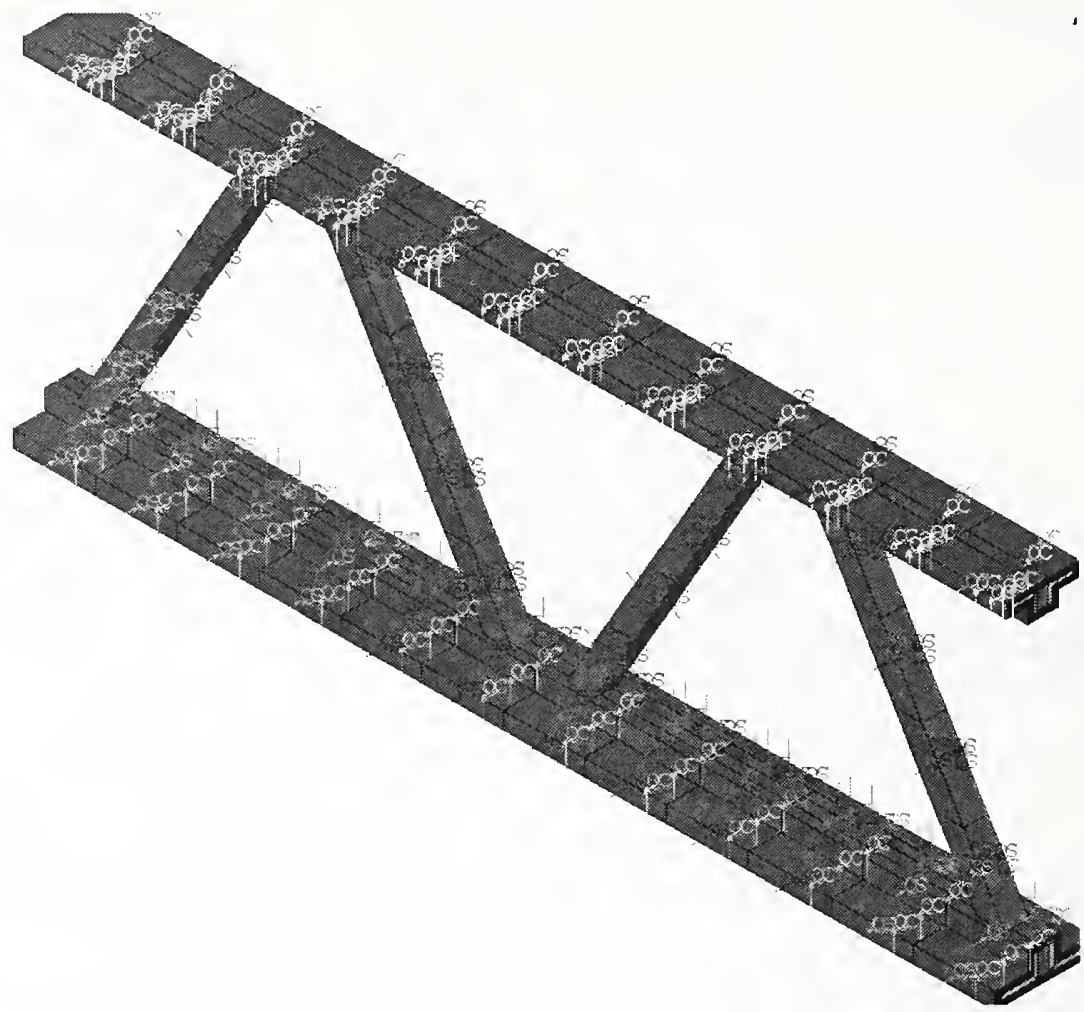

Figure 5-11. Radiative flux boundary conditions on truss elements.

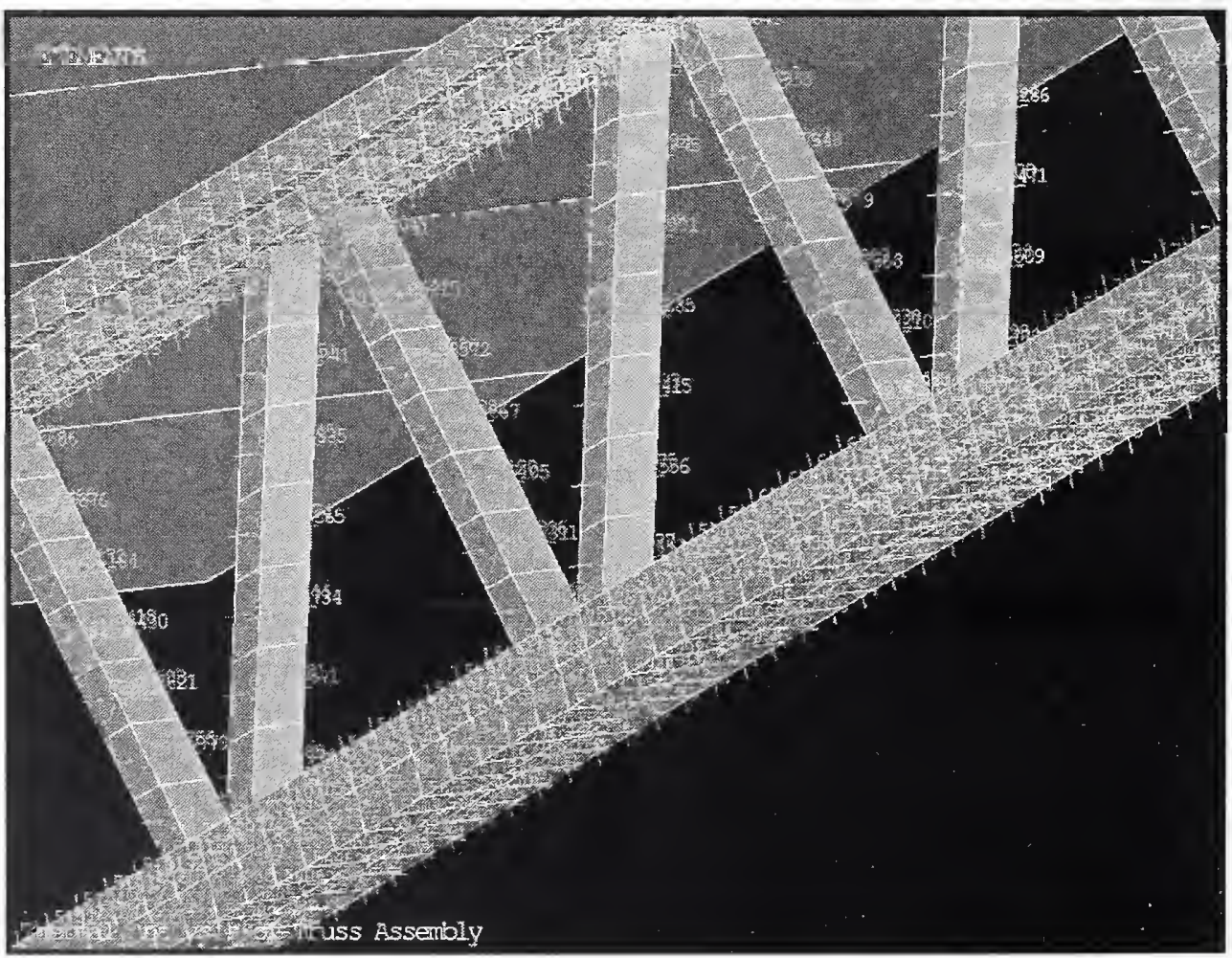

Figure 5-12. Radiative fluxes coupled with realistic fire simulations are applied as surface loads on a truss model. 


\subsection{TIME-TEMPERATURE PROFILES}

The fire growth is dependent on the combustibles and the ventilation pattern on the various floors of the WTC towers. As the combustibles are consumed, or if all the oxygen is consumed, the fire activity can die down. The flux incident on the truss elements varied from one location to another and is a function of the local, instantaneous properties of the hot layer as well as the location and orientation of the element. In this section time-temperature history on a few nodes of the steel trusses is presented to understand the nature of the thermal insult.

Four locations were chosen on the model of the steel trusse that supports floor 96, WTC 1. Two locations were on the north face of WTC 1, while the remaining two were on the south face. Figure 5-13 shows the temperature time history for the four locations. The temperature range is between $0-800{ }^{\circ} \mathrm{C}$. Results are presented for the duration of the simulation $(6300 \mathrm{~s})$. The sub-figures $\mathrm{a}$ and $\mathrm{b}$ are for nodes located on the north face, while sub-figures $c$ and $d$ are for nodes located on the south face. It should be noted that there is a wide variation of time-temperature curves that hold at different points in the structure and that these curve do not resemble those from a "standard time temperature curve" used in furnace tests.
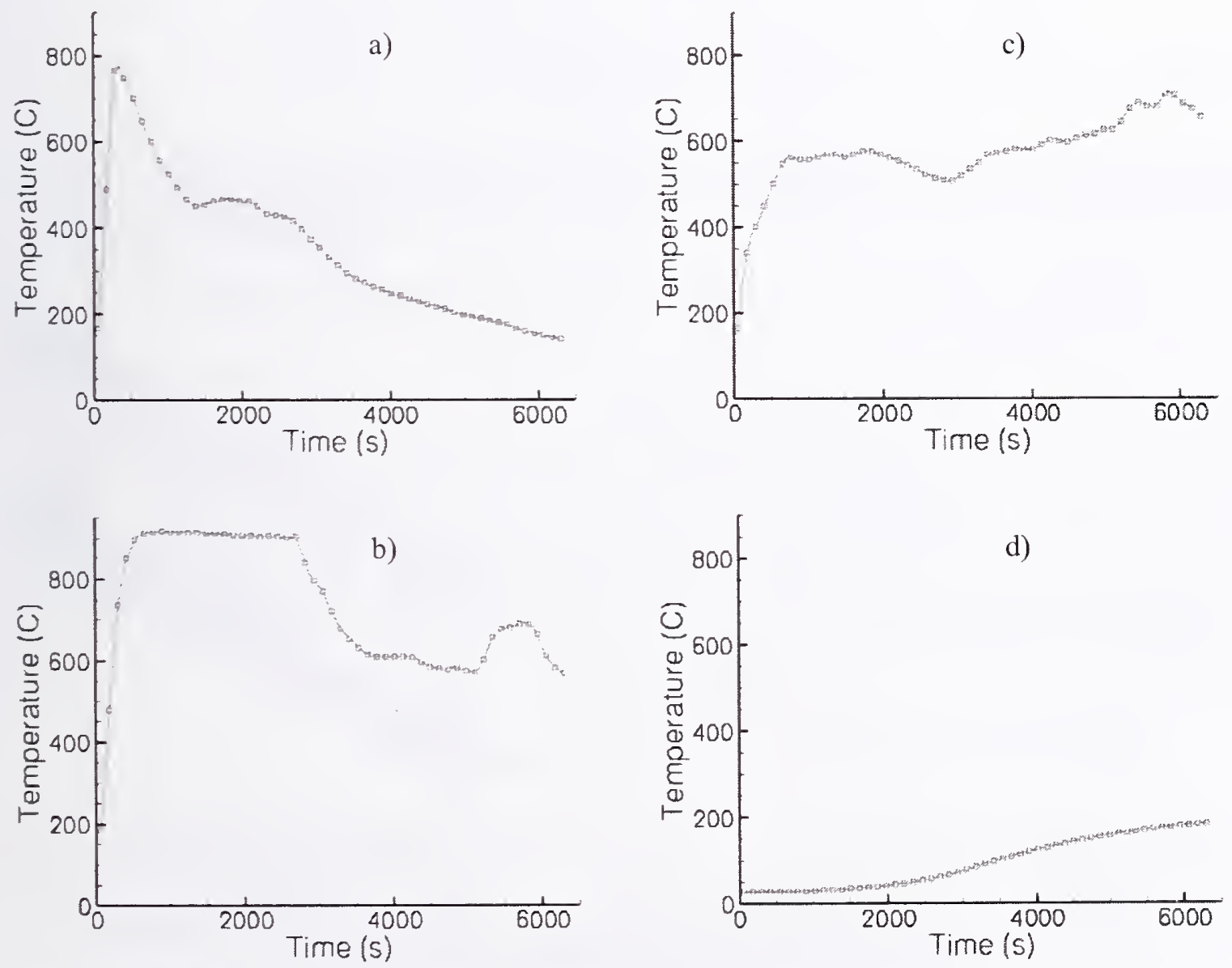

Figure 5-13. Temperature profile as a function of time at four different locations on the steel truss. Sub-plot $a$ and $b$ are for locations on the north face, while sub-plots $c$ and $d$ are for locations on the south face of WTC 1, floor 96. 


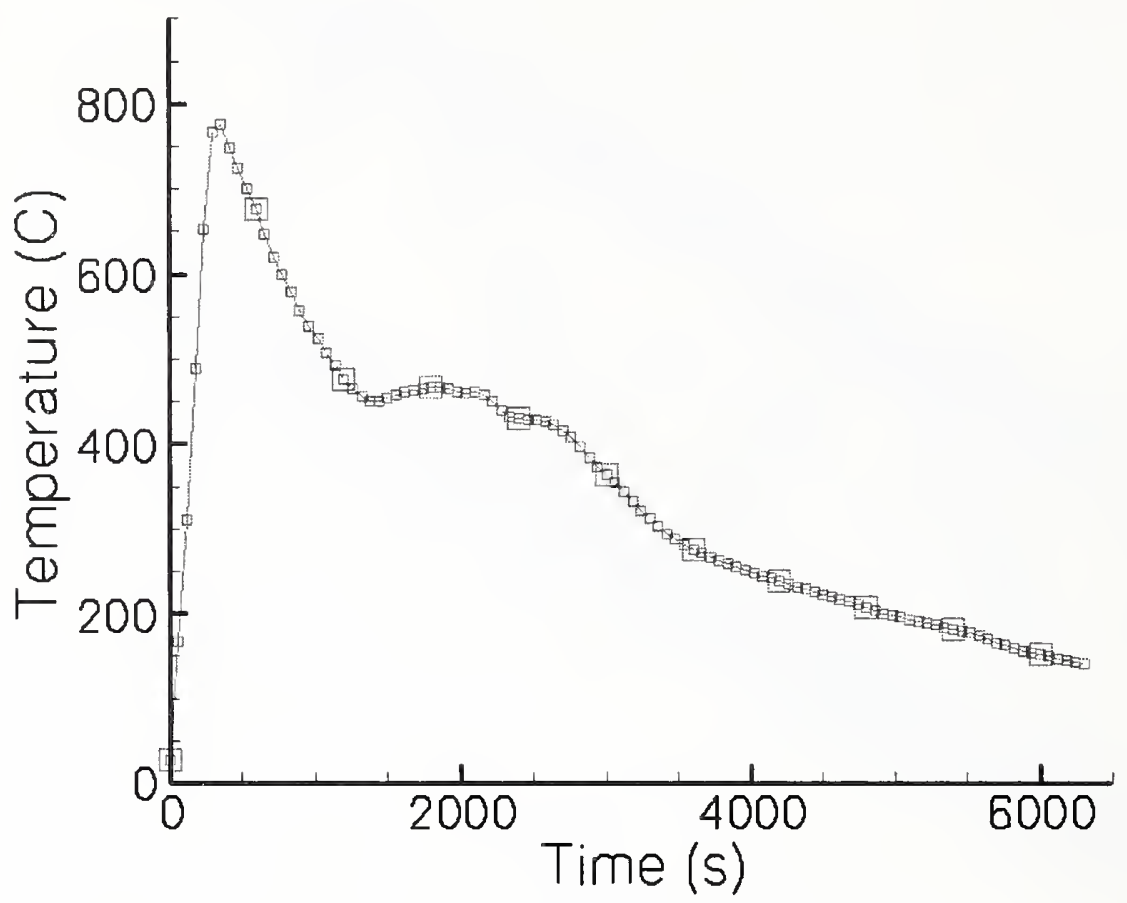

Figure 5-14. Time temperature plot on the steel truss (north face, floor 96 WTC 1) indicating the frequency at which the thermal data is plotted (small symbols) as well as the frequency at which it is transferred into the structural models (large symbols).

\subsection{INTERFACE BETWEEN THERMAL AND STRUCTURAL MODELS}

Thermal analysis predicts the time temperature curve at each and every node of a thermal model. Some of these time-temperature curves were discussed in the previous section. As discussed in Chapter 4 , the thermal and structural models are two entirely different models, consisting of different basic element types and nodal locations. The thermal data, computed as part of the thermal analysis, needs to be transferred on to the structural model to apply body loads as a function of time. The procedure is very similar to that for perimeter columns described in Chapter 4. In this section, the special requirements and peculiarities of the mapping procedure for floor trusses are discussed. Although the focus is on floor trusses, the analysis is equally valid for core beams.

\subsubsection{Mapping of Thermal Data}

The transfer of temperature data between thermal and structural models for full floor trusses is shown schematically in Figure 5-15 and Figure 5-16. In Figure 5-15, the sub-figure on the left shows a portion of full floor truss model used in the thermal analysis. In this case, elements in the steel and fireproofing have been shown. The sub-figure on the right shows the elements of a corresponding structural model. Each element is represented by a different color. Similarly, Figure 5-16 shows mapping of thermal data from the nodes of the thermal model (left sub-figure) to the nodes of the structural model (right subfigure). The structural models are meshed with beam elements (NIST NCSTAR 1-6D), which are capable of handling both a temperature and temperature gradient. However, thermal analysis indicates that the 
temperature gradient through the upper flange cross-section (or the lower flange or web diagonal) is relatively small. This is due to the fact that the uppcr flange, lower flange, and web diagonals have relatively small thickness. Temperature data was transferred from the thermal model to the structural models only, at discreet intervals in time, as discussed below.

\subsubsection{Procedure for Mapping Thermal Data}

The following algorithm summarizes the procedure for transferring temperaturc data between thermal and structural models.

- Open the structural model database file.

- Identify and select the elements that form the entire floor truss.

- Identify and select the nodes associated with the elements.

- Write node number and spatial location ( $x, y$ and $z$ location) of the nodes. The location of the node is in reference to a global co-ordinate system.

- Open the thermal database file. Load the solution data files at a specific time where the thermal loading data file has to be created.

- Read the node number and co-ordinate locations for temperature data. Compute the temperature at the node closest to the structural node. Write the temperature data in a thermal loading data file.

- Repeat for all nodes in the model, on various floors and at various time steps where thermal loading data is needed.
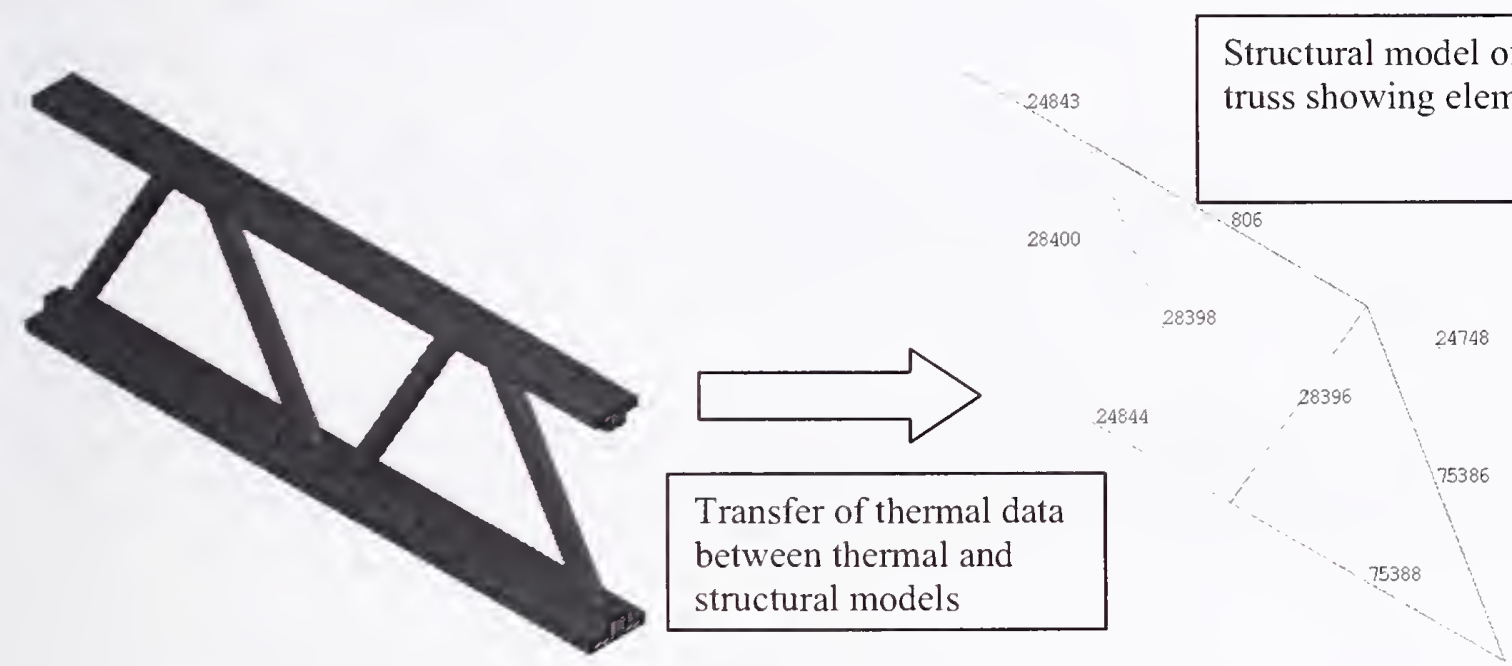

Thermal Model of a truss.

Figure 5-15. Mapping of the thermal data between the thermal models and the structural models showing element density. 
Thermal Model of a truss showing nodal density

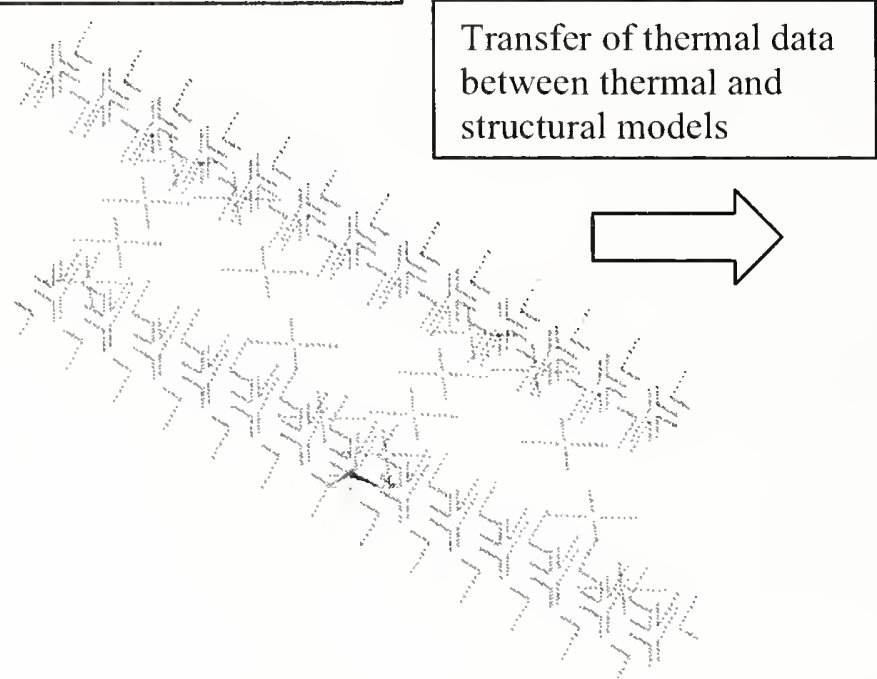

Structural Model of a truss showing node density

35621

.1297

.35455

.35822

. 188 \&

.90008

\section{Figure 5-16. Mapping of the thermal data between the thermal models and the structural models showing nodal density.}

Full Floor Mapping of Thermal Data Figure 5-17 shows the results of mapping of thermal data (using the procedure described in the previous sub-section) onto a full floor truss model (NIST NCSTAR 1-6D). Temperature data was transferred for the trusses and core beams from the thermal model to the structural model. For each floor and for each time step, a thermal loading data file was constructed that contains the temperature data. The thermal loading data file is in a format that is consistent with structural models and can be easily read in to apply body loads on the structural model. Thermal loading data files were constructed at each time step and were transferred to the structural analysis. Figure 5-17 is a visual representation of the data contained in the thermal loading data file. Partial results from one floor fire are used for demonstration; a full description of all the cases is in Chapter 8 through Chapter 11.

The approach outlined in this chapter for constructing thermal models for floor trusses and core beams, for coupling the fire simulations with the thermal response and for mapping the thermal data between the thermal and the structural models was used extensively in the WTC Investigation, as described in the global tower results presented in Chapter 8 through Chapter 11 . 


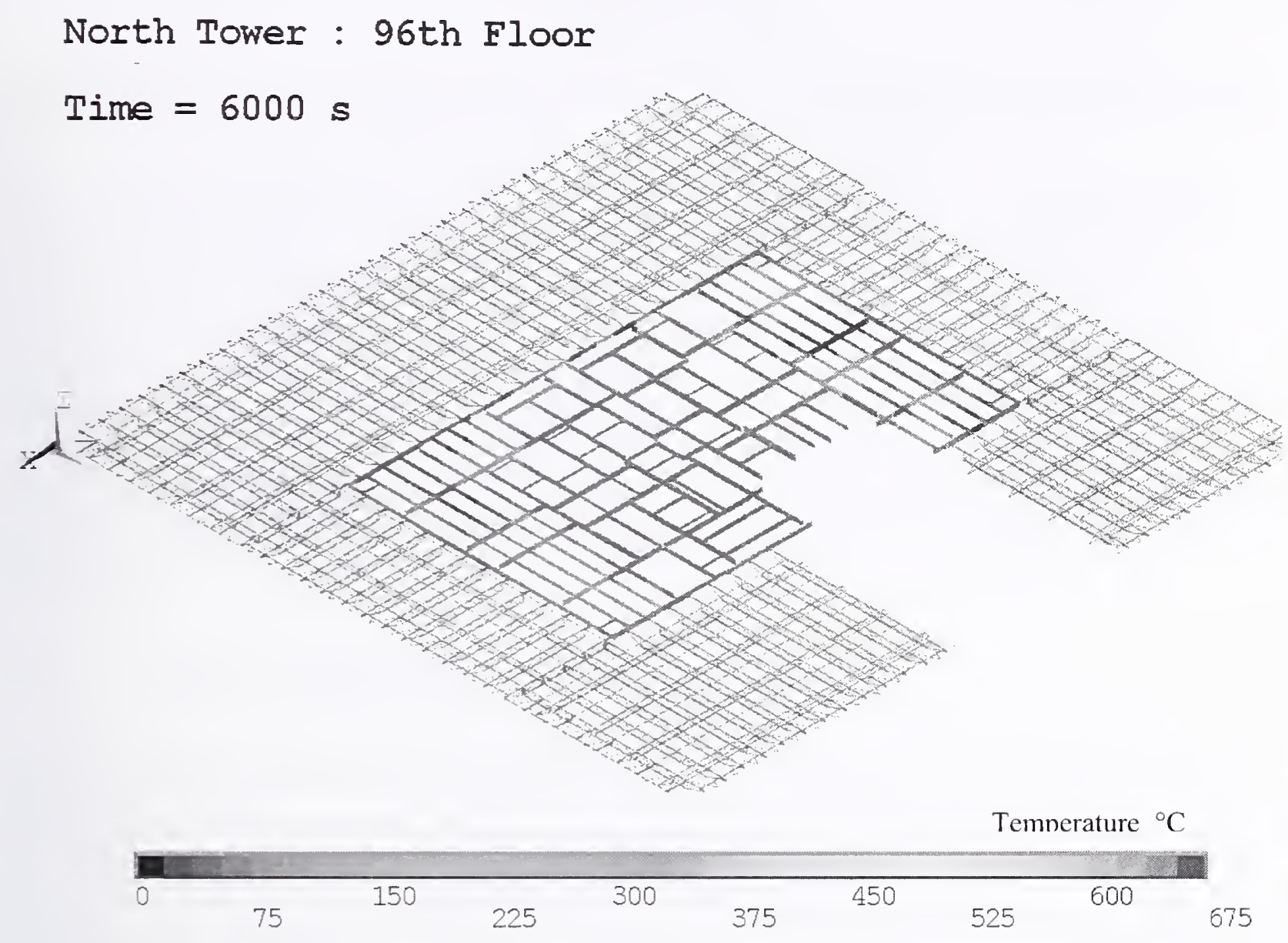

Figure 5-17. Mapping of the thermal data for floor 96, WTC 1 onto the structural models.

Thermal data is provided as a body load file for the structural model. In this picture results are shown at $6000 \mathrm{~s}$ after impact. 
This page intentionally left blank. 


\section{Chapter 6 \\ CONCRETE SLABS}

This chapter is the third in a series of four chapters (Chapter 4 through Chapter 7) that details how the major structural components in the building were represented with finite element models and the method for coupling the thermal response to multiple floor fires in the World Trade Center (WTC) towers evolving in space and time. The focus of this chapter is on concrete slabs. Finite element models of concrete slabs along with mesh restrictions and approximations are discussed. The thermal response to an incident radiative flux on a concrete slab from fires evolving on two floors is described. Temperature plots through thickness of the slab at different instants in time are provided to understand the thermal loading on concrete. Results from one of the fire simulations are used to understand the coupled response. The description applies to the fire floors, floors 93-99 of WTC 1 and floors 79-83 in WTC 2. As discussed before, global response of the towers is presented in Chapter 8 through Chapter 11. Finally, the approach and the challenges of mapping body loads from thermal models to structural models are discussed.

\subsection{FINITE ELEMENT MODELS OF CONCRETE SLAB}

In the WTC towers, floor construction typically consisted of 4 in. of lightweight concrete on $1 \frac{1 / 2}{\mathrm{in}} ., 22$ gauge non-composite steel deck. In the core area, the concrete slab thickness was $5 \mathrm{in}$. (NIST

NCSTAR 1-1). The concrete slab was one of the heaviest structural elements of the WTC towers. It was necessary to perform a thermal analysis of the concrete slab to understand its thermally induced structural response to fire growth and spread. This section describes the development of a finite element model, including mesh requirements and challenges in resolving the thermal waves that can move during fire induced heating of the a concrete slab (Ahmed and Hurst, 1995, Bailey and Moore, 2000, Buchanan 2001, Lamont, Usmani and Drysdale, 2001).

Figure 6-1 shows the top view of a concrete slab that was used to predict the thermal response. The concrete slab was meshed with solid brick elements with 3-D thermal conduction capability (as discussed in Chapter 4). Surface effect elements were superimposed on the brick elements to model convective and re-radiative heat transfer to the slab. The length and width of the slab $(60 \mathrm{~m})$, shown in Figure 6-1, was chosen to be consistent with the fire simulations (NIST NCSTAR 1-5F). The mapping algorithm discussed at the end of this chapter accounts for the appropriate scaling between the thermal and structural models.

Simulations were performed with approximately 120 equally spaced elements along the length and width of the concrete slab. The choice of mesh density was based on a number of considerations. The mesh density was chosen such that it was finer than the resolution of the structural models (which take the thermal data as an input) as well as the fire dynamics simulation. This ensured that thermal analysis did not add to the uncertainty in the fire simulations or the structural calculations. Increasing the number of elements along the length or width of the slab results in higher computational time and can significantly slow down the mapping procedure (search algorithm associated with the interpolation routine). A parametric study was performed to study the effect of mesh density. Doubling the number of elements 
along the length and width of the slab was found to have only a minor effect on the predicted temperatures in the concrete slab.

The thermo-physical properties (NIST NCSTAR 1-3, NIST NCSTAR 1-6A, Phan 2003) required for thermal analysis of all the materials are discussed in Appendix A.

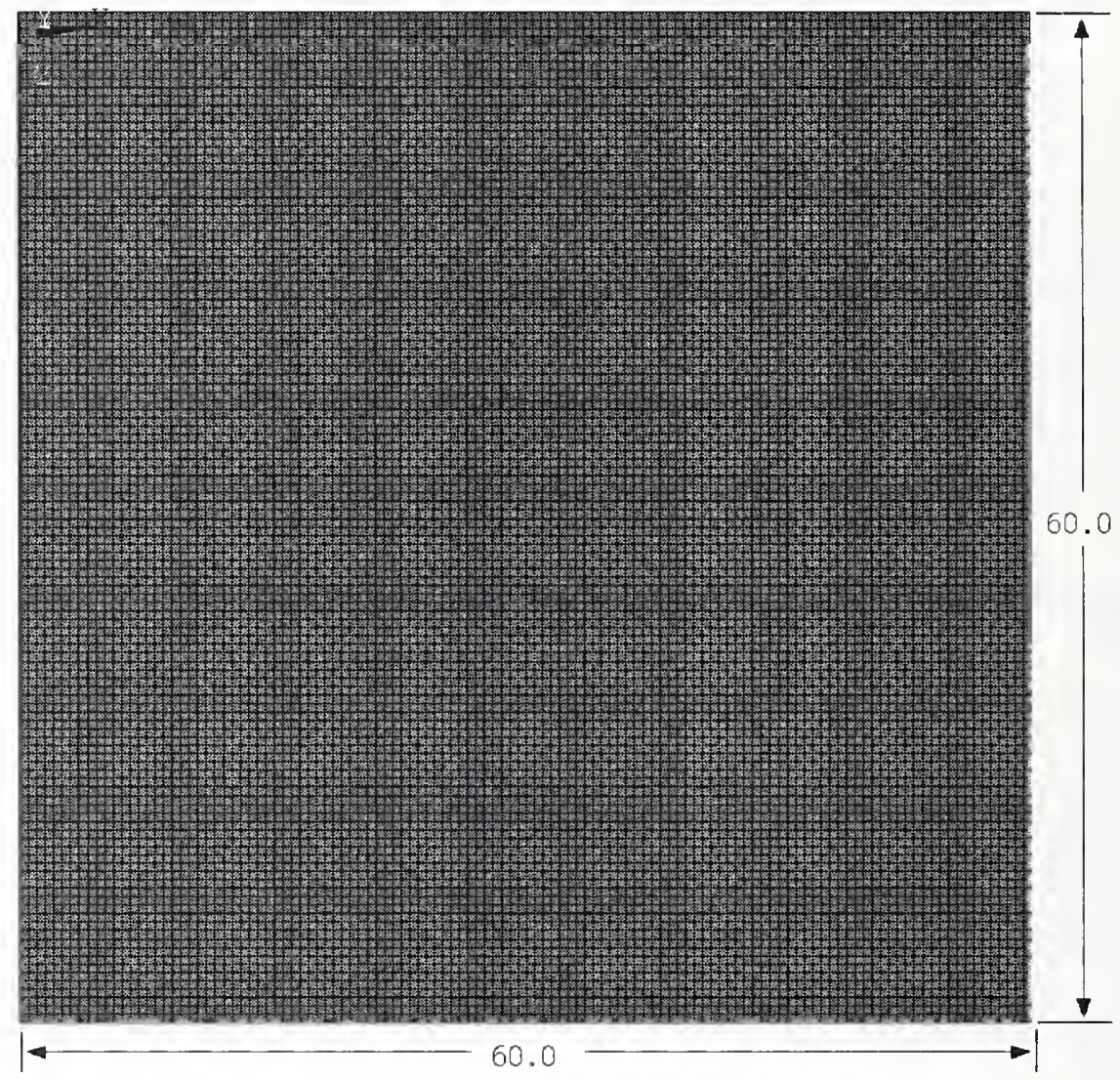

Figure 6-1. Finite element model of a concrete slab (top view) showing element density.

Figure 6-2 shows a finite element model of a corner of the concrete slab, again showing the element density along the length and width of the slab relative to the density through the thickness of the slab. The finite element models (the thermal and the structural models) of the concrete slab do not account for the 22 gauge non-composite steel deck. The structural analysis discussed in NIST NCSTAR 1-6 prescribed an equivalent thickness of $4.35 \mathrm{in}$. to account for both the concrete and steel deck. This equivalent thickness was used in all the calculations and is consistent with the structural models.

The element density through the thickness of the concrete slab was dictated by the need to adequately resolve the both the thermal wave propagating through the slab and the steep temperature gradients that exist at the surface. Temperature gradients can lead to differential thermal expansion, which can have a significant effect on the structural response. Simulations were performed with approximately 16 elements through the thickness of concrete slab to resolve the thermal wave. Again, this resolution was significantly higher than the resolution of the structural models. Note that in the structural models, the slab was modeled with a single shell element with four layers and a total thickness of $4.35 \mathrm{in}$. It should be pointed out that increasing the number of elements through the thickness of the slab has a significant 
effect on computational time and effort. Parametric studies were conducted to understand the role of mesh density on the computed results. Based on these parametric studies, resolution in the structural models, and the computational time associated with increasing mesh density, it was decided that 16 elements was an optimum number of elements through the slab thickness.

The number of elements through the thickness of the slab could not be changed arbitrarily, but was constrained by the mesh element size in the horizontal directions, so as to maintain a reasonable aspect ratio for the thermal elements.

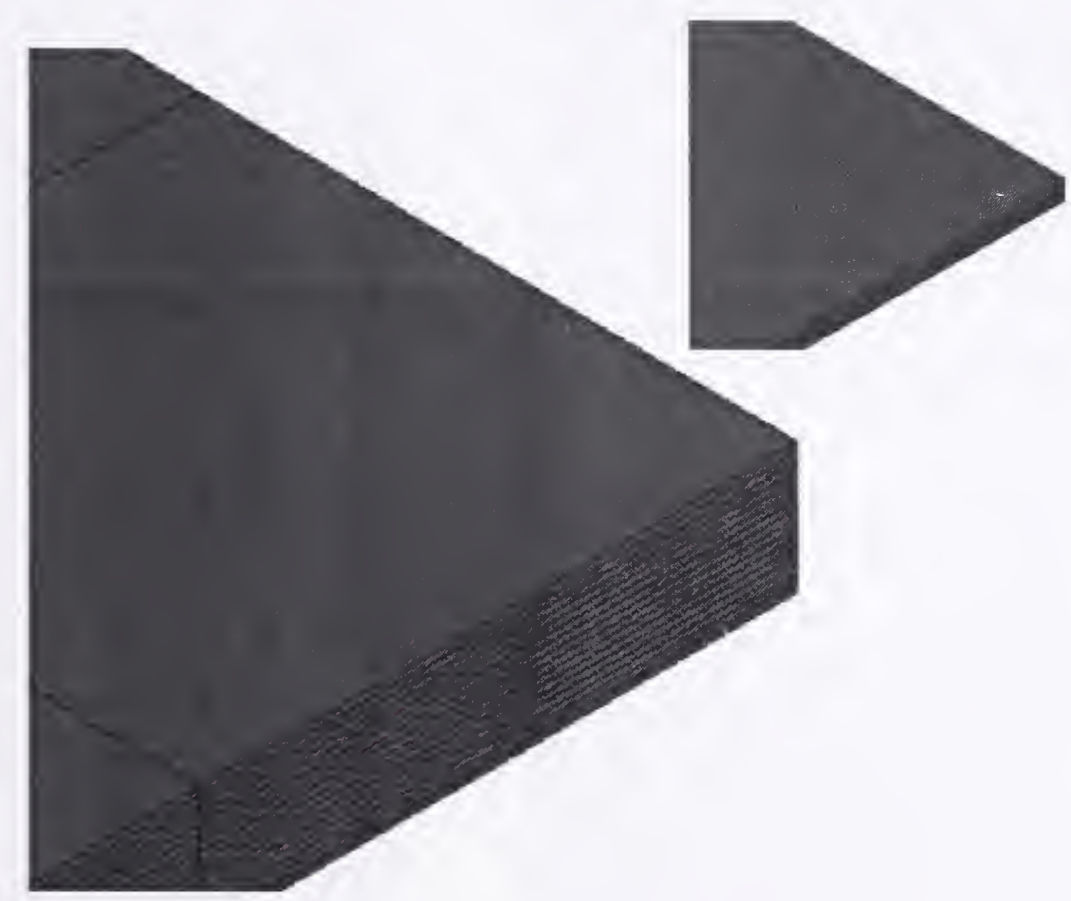

Figure 6-2. Finite element model of a concrete slab indicating element density through the thickness of the slab.

\section{2} INITIAL AND BOUNDARY CONDITIONS

The initial temperature of the concrete slab was assumed to be $27^{\circ} \mathrm{C}$. Radiative flux from the fire was applied as a surface loads on the top and bottom surface of the slab, while the edges of the slab were assumed to be adiabatic (zero flux boundary condition). This section describes the transient and spatially varying heat flux incident on a concrete slab.

A concrete slab is subjected to radiative fluxes on its top and bottom surfaces due to fire activity above and below the slab. Fire on the floor below the concrete slab provides radiative flux to the bottom face of the concrete slab. Radiation from the fires above the slab provides radiative flux to the top surface of the slab. Figure 6-3 shows the concrete slab on the $96^{\text {th }}$ floor, WTC 1. It is subjected to radiative flux from fires on the $95^{\text {th }}$ floor on its bottom face and a flux corresponding to fires on the $96^{\text {th }}$ floor on its top face. The lengths of the arrows are proportional to the intensity of the radiative flux incident on the surface. Since the fire evolves and grows from one part of the floor to another, the radiative flux incident on the 
concrete slab varies with location and with time. The top and bottom surfaces of the concrete slab were covered with surface effect elements to model convective and radiate heat flux to the slab. Convective flux on the bottom surface of the slab is from fires on the $95^{\text {th }}$ floor while that on the top surface is from fires on the $96^{\text {th }}$ floor. Chapter 4 gave a detailed description of the method for applying convective and reradiative fluxes on perimeter columns and that discussion is equally valid for concrete slabs.

Figure 6-4 shows contours of radiative flux incident on the top surface of a concrete slab representing the $96^{\text {th }}$ floor of WTC 1 . This flux is due to fires on the $96^{\text {th }}$ floor. The contour maps have been shown at six different instants in time, ranging from $1,000 \mathrm{~s}$ to $6,000 \mathrm{~s}$ at $1,000 \mathrm{~s}$ intervals. The heat flux contours range from 0 to $140,000 \mathrm{~W} / \mathrm{m}^{2}\left(140 \mathrm{~kW} / \mathrm{m}^{2}\right)$. Figure $6-5$ similarly shows contours of radiative flux incident on the bottom surface of the concrete slab. This flux is due to fires on the $95^{\text {th }}$ floor. Again, the contours maps have been shown at the same six instants in time. For both Figure 6-4 and Figure 6-5, the north face of floor 96 is the top while the east face is on the right. Since the fires on floor 95 and floor 96 evolve in a different manncr and at a different pace, the flux contours on the top and bottom surface are not in sync with each other.

Figure 6-4 shows intense fire activity on the north and west faces at 1,000 s after impact, while at 2,000 s, the fire is located in the southwest comer and the northeast corner. This is followed by gradual cooling of the fires on $96^{\text {th }}$ floor (NIST NCSTAR 1-5F). Fire activity on the $95^{\text {th }}$ floor (Figure 6-5) results in high radiative flux to the concrete slab on the north and east faces $(1,000-3,000 \mathrm{~s})$ followed by hot spots in the south face at 4,000-6,000 s after impact. The hot spots indicate a peak flux level of $140 \mathrm{~kW} / \mathrm{m}^{2}$. In these simulations, a fraction of all the results from one typical fire simulation are presented to indicate the transient nature of the fires and the resulting fluxes on the concrete slab. A full discussion of all the global calculations is provided in Chapter 8 through Chapter 11 .

Figure 6-4 and Figure 6-5 demonstrate two points: (1) the radiative fluxes on a slab varies as a function of both space and time, depending on the local fire behavior, and (2) the flux on the top and bottom faces are almost completely independent of each other.

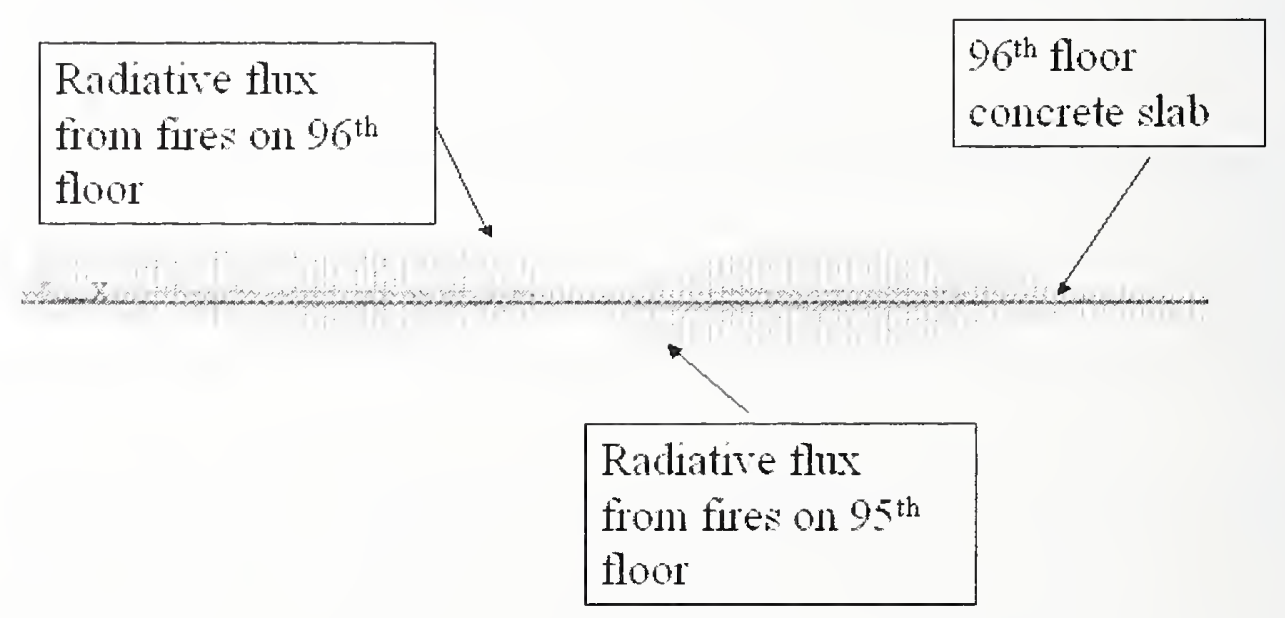

Figure 6-3. Variation of radiative heat flux incident on the surface of a concrete slab representing the $96^{\text {th }}$ floor of the WTC 1 . Arrows pointing downwards indicate flux incident on the floor from a fire on top of the concrete slab, while arrows pointing upwards indicate flux incident on the ceiling of the concrete slab from a fire below. 

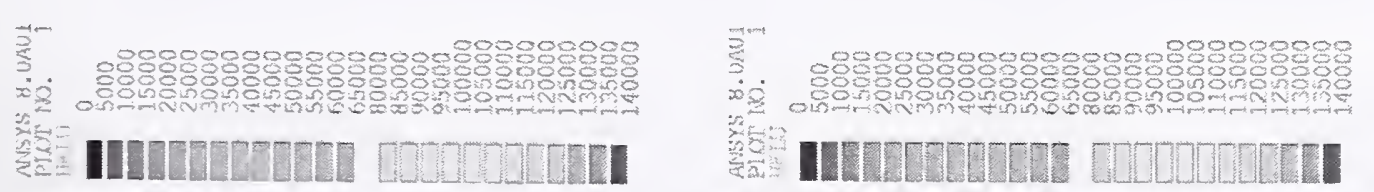

흔
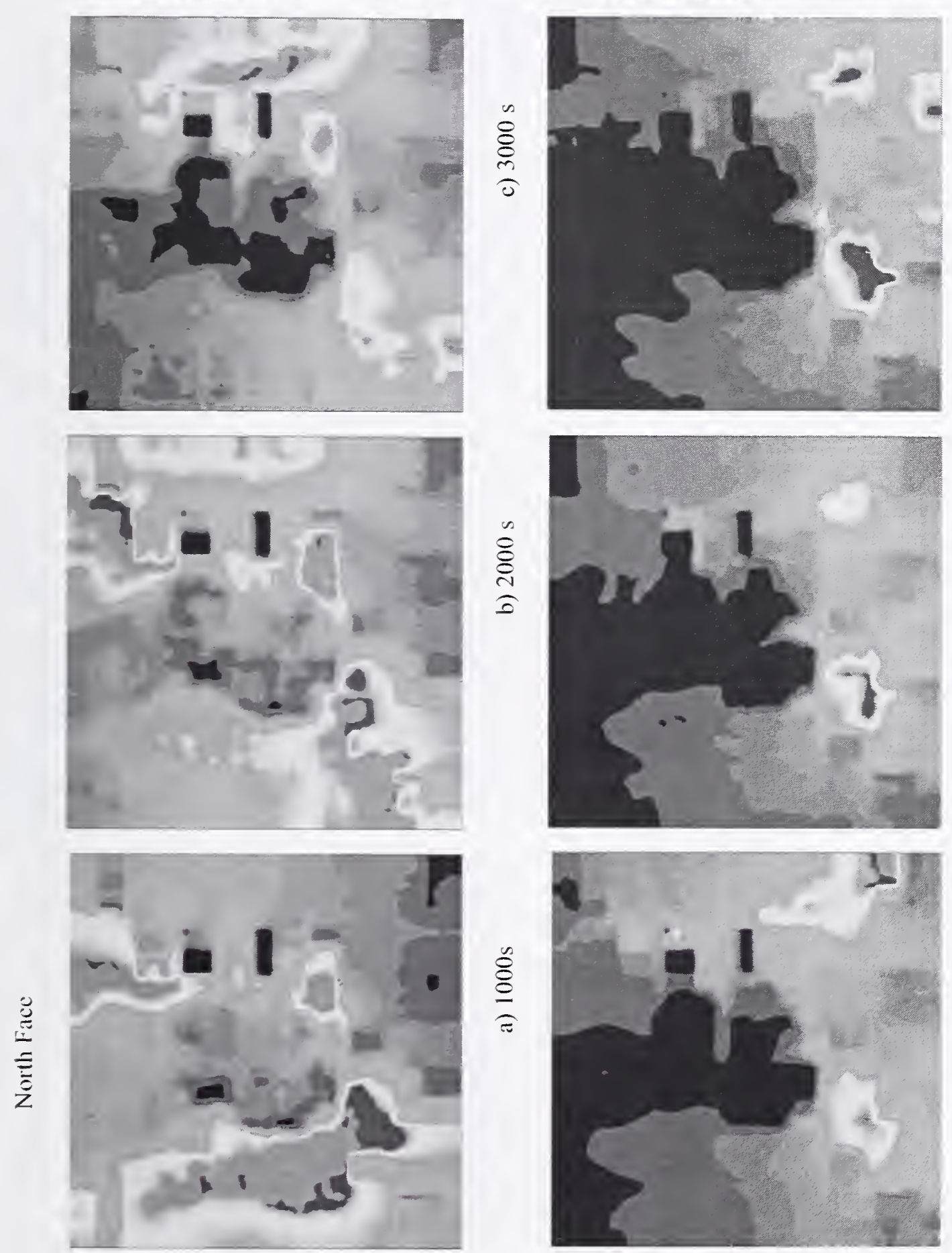

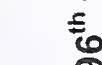

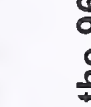

ธุ์

हु)

包

$\frac{0}{\frac{6}{6}}$

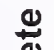

แํำ

잉

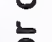

은

๕ั

我

ก

웅

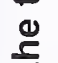

등

름

응

은

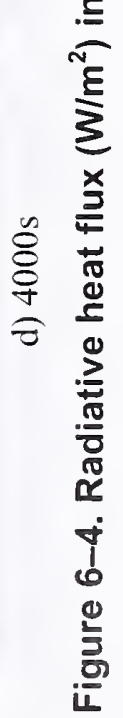



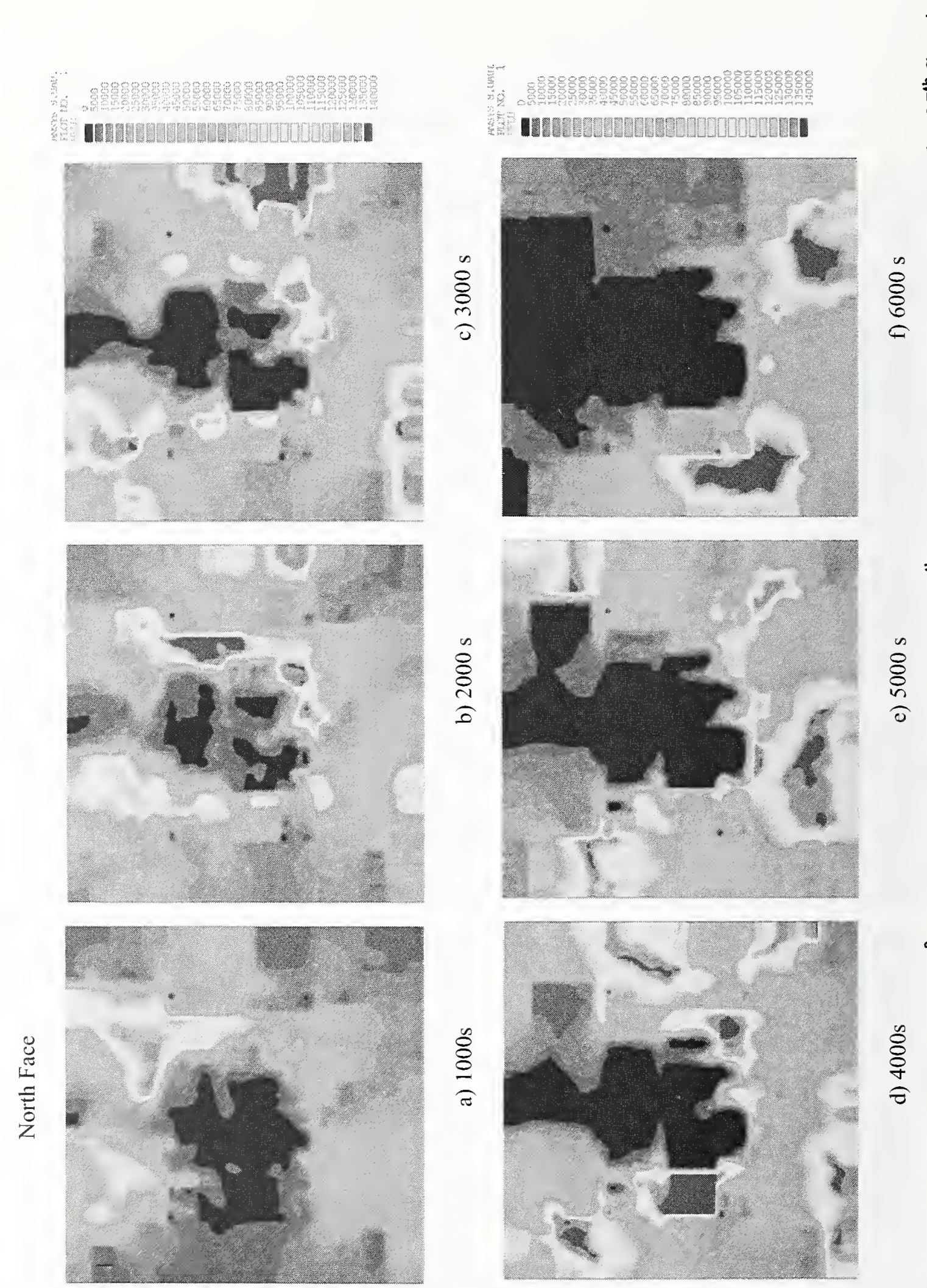

응

โم

造

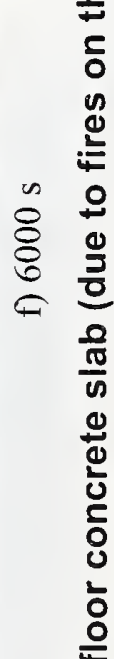




\subsection{TEMPERATURE AND TEMPERATURE GRADIENT IN CONCRETE SLAB}

The temperature of the slab responds to the spatially and temporally varying fires and the resulting flux incident on the concrete slab. High temperatures and temperature gradients can result in differential thermal expansion in the concrete slab and can influence its structural response. This section describes typical temperature contours on the slab surface as well as temperatures inside the slab. Temperature profiles through the thickness of the slab are plotted as a function of time to understand the nature of the thermal insult to the slab.

\subsubsection{Surface Temperature}

Figure 6-6 shows temperatures (Kelvin) of the top and bottom faces of a concrete slab at $100 \mathrm{~min}$ $(6.000 \mathrm{~s})$ after impact. A portion of the concrete slab on the north face (top) was damaged by the impact of the aircraft and that portion has been removed from the visual. The temperature scale ranges from $273 \mathrm{~K}$ to $1,273 \mathrm{~K}\left(0^{\circ} \mathrm{C}\right.$ to $\left.1,000^{\circ} \mathrm{C}\right)$.

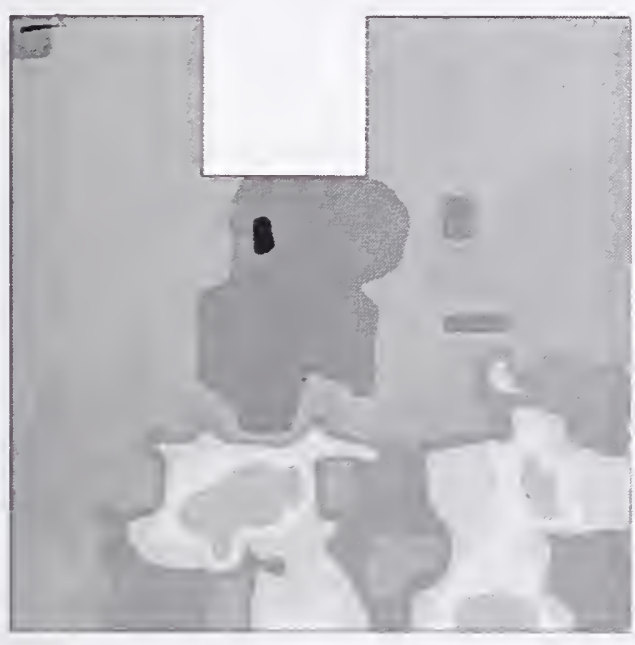

a) Top surface
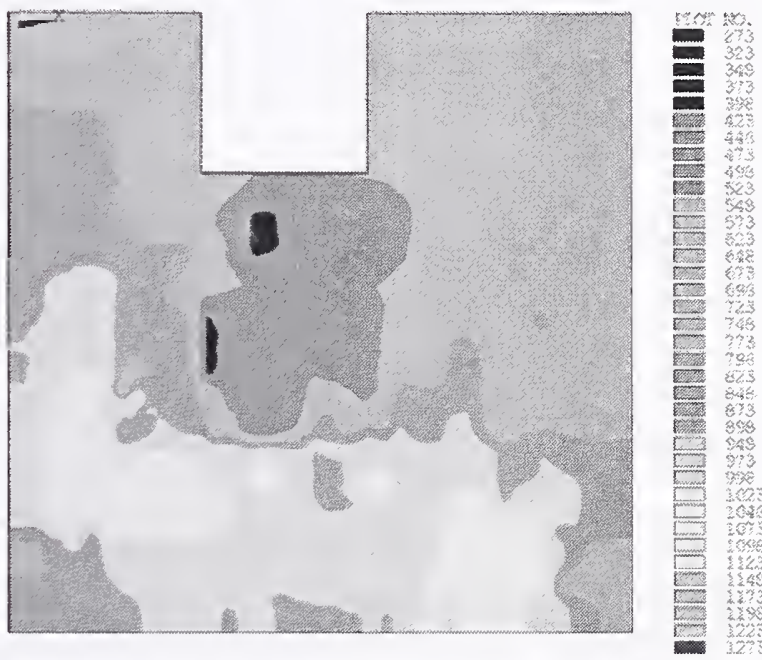

b) Bottom surface

Figure 6-6. Typical temperature contours (Kelvin) on the top and bottom faces of the concrete slab $\left(96^{\text {th }}\right.$ floor, WTC 1$)$ at $6000 \mathrm{~s}$ after impact. A portion of the concrete slab on the north face (top) was damaged by the impact of the aircraft.

Figure 6-7 shows temperature contours through the thickness of a concrete slab, at two different instants of time. The temperature contour scale is the same as that shown in Figure 6-6 and it ranges from $273 \mathrm{~K}$ to $1,273 \mathrm{~K}$. As the top and bottom surfaces heat up, energy gradually conducts throughout the slab and this can result in a very steep temperature gradient at the surface. The temperatures on the top and bottom faces are different since they are subjected to different fire growth and spread patterns. The results shown in this picture were obtained with 16 elements through the thickness of the slab. Increasing the element density can result in steeper temperature gradients at the surface and slightly lower surface temperatures, while decreasing the element density can give rise to higher surface temperature and milder temperature gradients at the surface. 


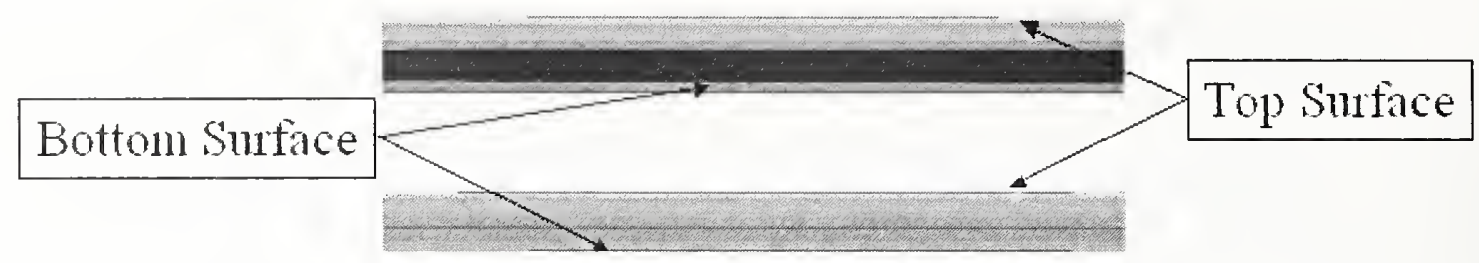

Figure 6-7. Temperature contours through the thickness of the concrete slab at two different instants in time (1,000 s and 3,000 s after impact). The range of temperature contours is the same as shown in Figure 6-6.

\subsubsection{Temperature Profiles through the Concrete Slab}

This section describes the temperature profiles through slab thickness as a function of time. Four locations on a floor were chosen for analysis. These locations have been marked with red dots in Figure 6-8. "Location 1" is in the middle of the north face and is half the distance between the north wall and the core. "Location 2" is in the middle of the south face and is half the distance between the South Wall and the core. "Location 3" is in the middle of the west face and is half the distance between the West Wall and the core, while "Location 4" is in the middle of the east face and is half the distance between the east wall and the core. Temperature profiles through the slab thickness as a function of time at these four locations are discussed in this section.

The profiles presented in this section qualitatively describe a vast spectrum of the thermal data that is presented in Chapter 8 through Chapter 11 as part of the global thermal response of WTC 1 and WTC 2.

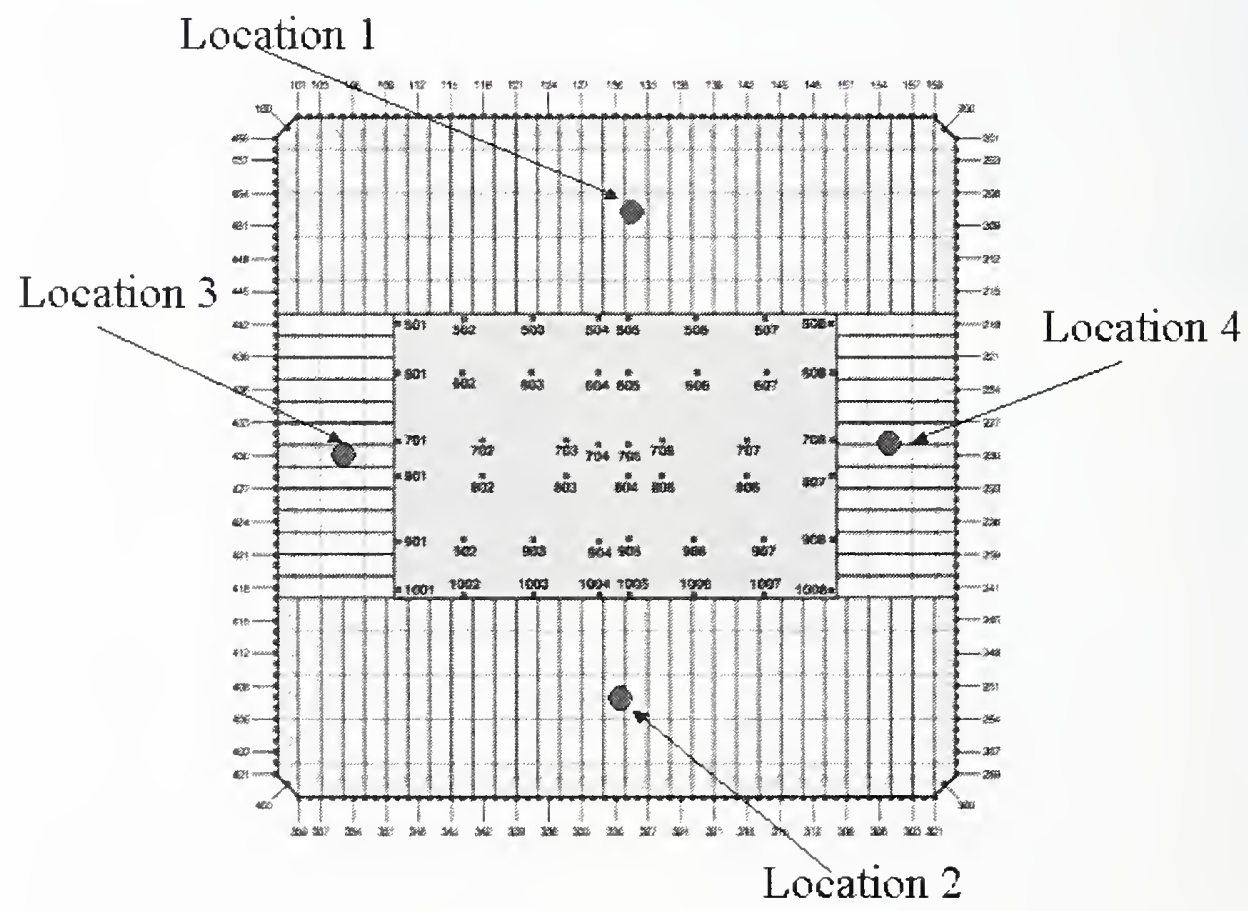

Figure 6-8. Location of the four nodes on the concrete slab where temperature profiles through the slab thickness have been plotted in Figure 6-9 through Figure 6-12 . 
Figure 6-9 shows temperature profiles through the slab thickness at "Location 1". The tcmperature profiles have been plotted at six different instants in time ranging from $1,000 \mathrm{~s}$ to $6,000 \mathrm{~s}$ at $1,000 \mathrm{~s}$ intervals. The slab thickness is $4.35 \mathrm{in} .(0.12 \mathrm{~m})$ and is plotted on the $\mathrm{x}$ axis. "Location 1 " shows very high temperatures at the top and bottom surface at $1,000 \mathrm{~s}$, followed by gradual cooling. As the top and bottom surfaces cool down, heat gradually conducts into the middle of the slab $(2,000 \mathrm{~s})$, which results in a small increase in temperature even though the fire has moved away. At 6,000 s after impact, the slab center shows higher temperature than the top and bottom surfaces due to convective and radiative cooling of the surface. The temperature profiles at different instants in time are approximately symmetric about the center of the slab for this location.

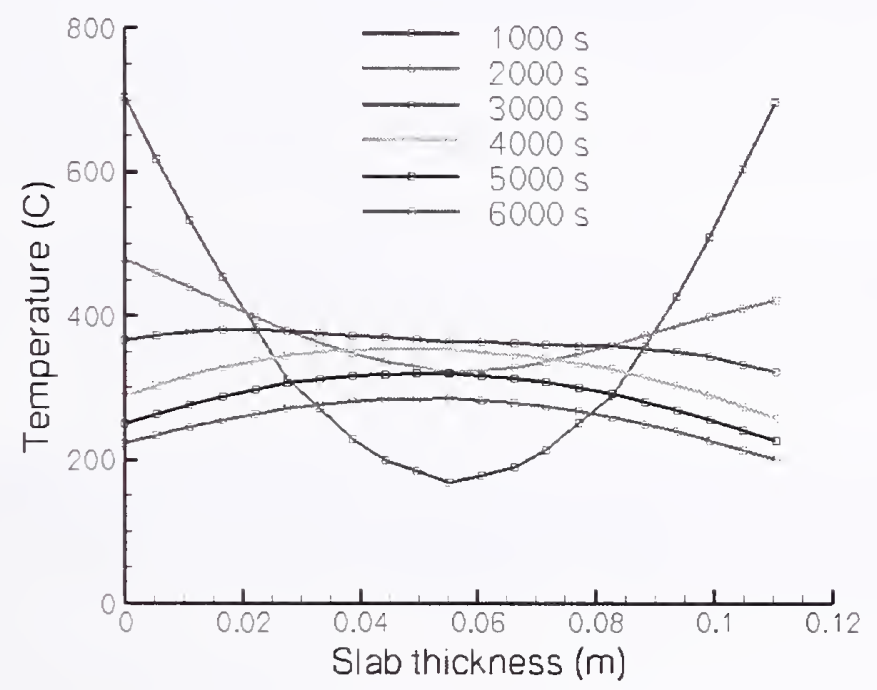

Figure 6-9. Temperature profiles through the slab thickness at Location 1. The temperature profiles have been plotted at six different instants in time at 1,000 s intervals.

Figure 6-10 shows profiles through slab thickness at "Location 2". This location, close to the south wall, shows that the slab is gradually heating as a whole during the entire duration of the event. The temperatures at the top and bottom faces as well the slab center show a gradual increase with time. At $6,000 \mathrm{~s}$ the slab center shows higher temperature than at $1,000 \mathrm{~s}$ or 2,000 s after impact, due to gradual heating of the slab. The temperature profiles at different instants in time are not symmetric about the slab center. The temperature profiles are consistent with fire activity in this area on the $95^{\text {th }}$ and $96^{\text {th }}$ floor. 


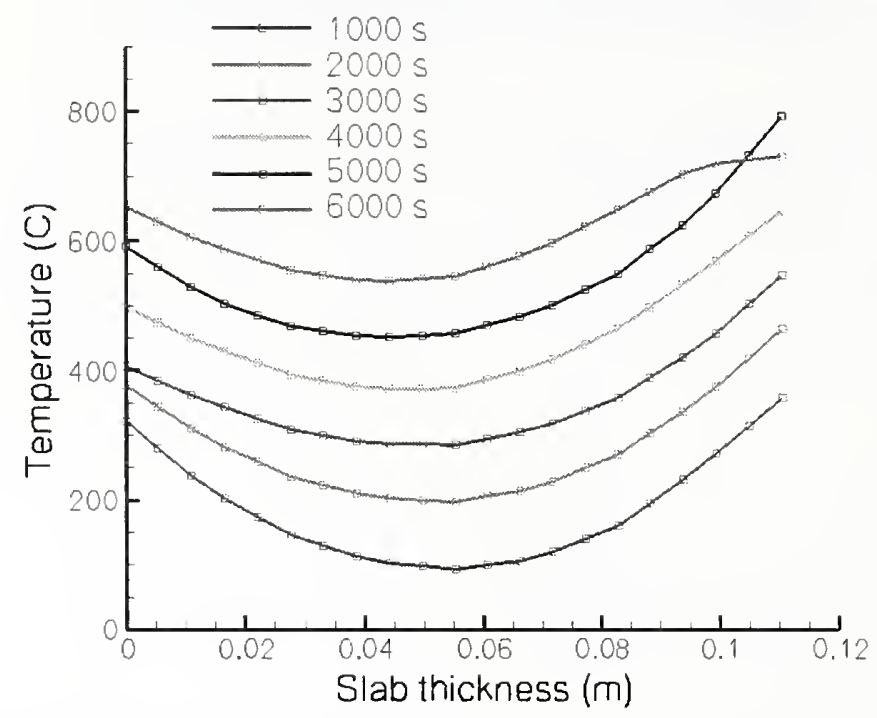

Figure 6-10. Temperature profiles through the slab thickness at Location 2. The temperature profiles have been plotted at six different instants in time at 1,000 s intervals.

Figure 6-11 reflects intense fire activity on the $95^{\text {th }}$ floor resulting in very high surface temperatures $\left(1,000 \mathrm{~s}\right.$ and 2,000 s) at the bottom of the slab (Location 3). Over time the fires on $95^{\text {th }}$ floor die down, resulting in lower slab temperatures. Very little fire activity on $96^{\text {th }}$ floor at 1,000 s results in relatively low temperatures at the top face of the slab. This low activity period is followed by gradual heating at Location 3 over time. It should be noted that the temperature profiles are not symmetric about the center of the slab.

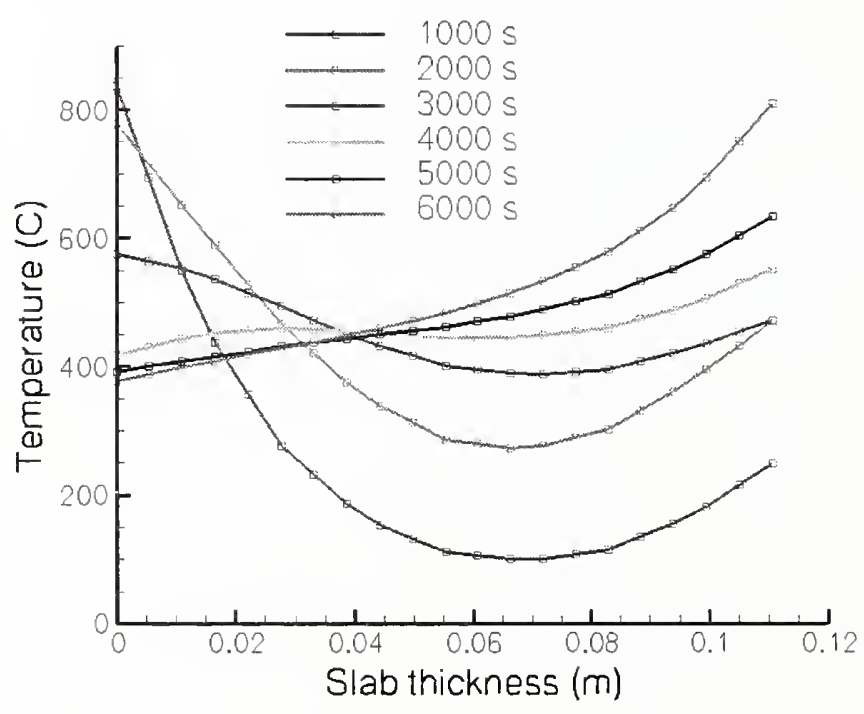

Figure 6-11. Temperature profiles through the slab thickness at Location 3. The temperature profiles have been plotted at six different instants in time at 1,000 s intervals. 
Temperature profiles at "Location 4" show results that are quite different from that at "Location l". Figure 6-12 indicates relatively low surface temperatures at 1,000 s, followed by rapid heating at 3,000 s. Temperature at the slab center reaches a peak value at 5,000 s after impact. The profiles are in general not symmetric about the center line of the slab.

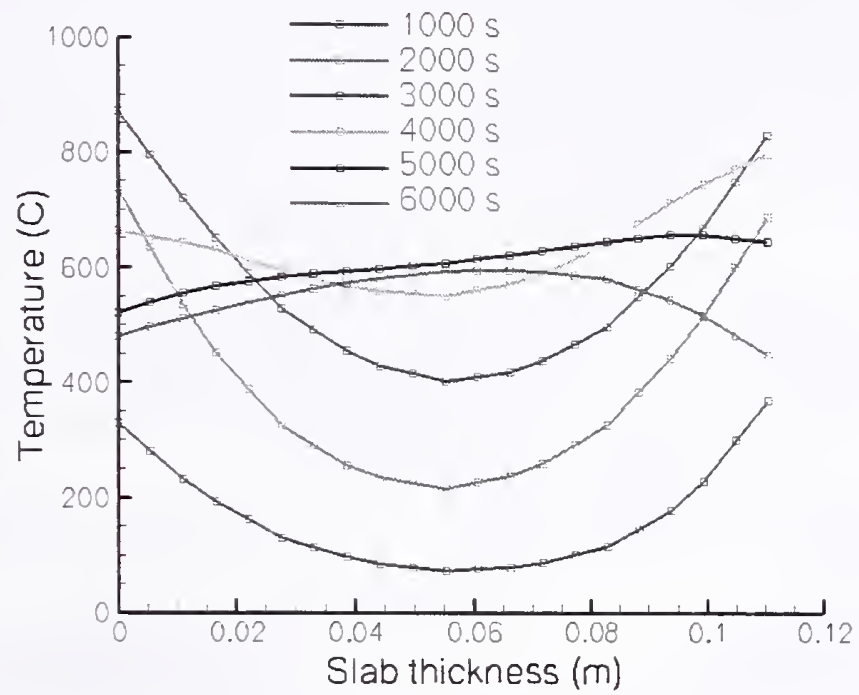

Figure 6-12. Temperature profiles through the slab thickness at Location 4. The temperature profiles have been plotted at six different instants in time at $1,000 \mathrm{~s}$ intervals.

\subsubsection{Time-Temperature Plots}

Top and bottom face temperatures at four locations described in Figure 6-13 are plotted as a function of time to indicate the transient nature of the fires. Symbols in this figure are plotted at $200 \mathrm{~s}$ intervals. Top face of "Location 1" shows a peak temperature at $500 \mathrm{~s}$ after impact, while "Location 2" shows a peak temperature just before collapse $(6,000 \mathrm{~s})$. Top face of "Location 3" and "Location 4" show peak values at approximately $1,500 \mathrm{~s}$ and $3,000 \mathrm{~s}$ respectively. Figure $6-13$ also indicates that the temperatures at the top and bottom faces do not reach peak values at the same time. This figure further illustrates the transient nature of the fires as they develop on the various floors resulting in slab surface temperatures that vary drastically over time. This figure illustrates that the temperature on the top and bottom faces are almost completely independent of each other. Also note, that small symbols in this plot indicate the frequency at which data is plotted, while large symbols indicate the frequency at which data is transferred into the structural models for analysis. 


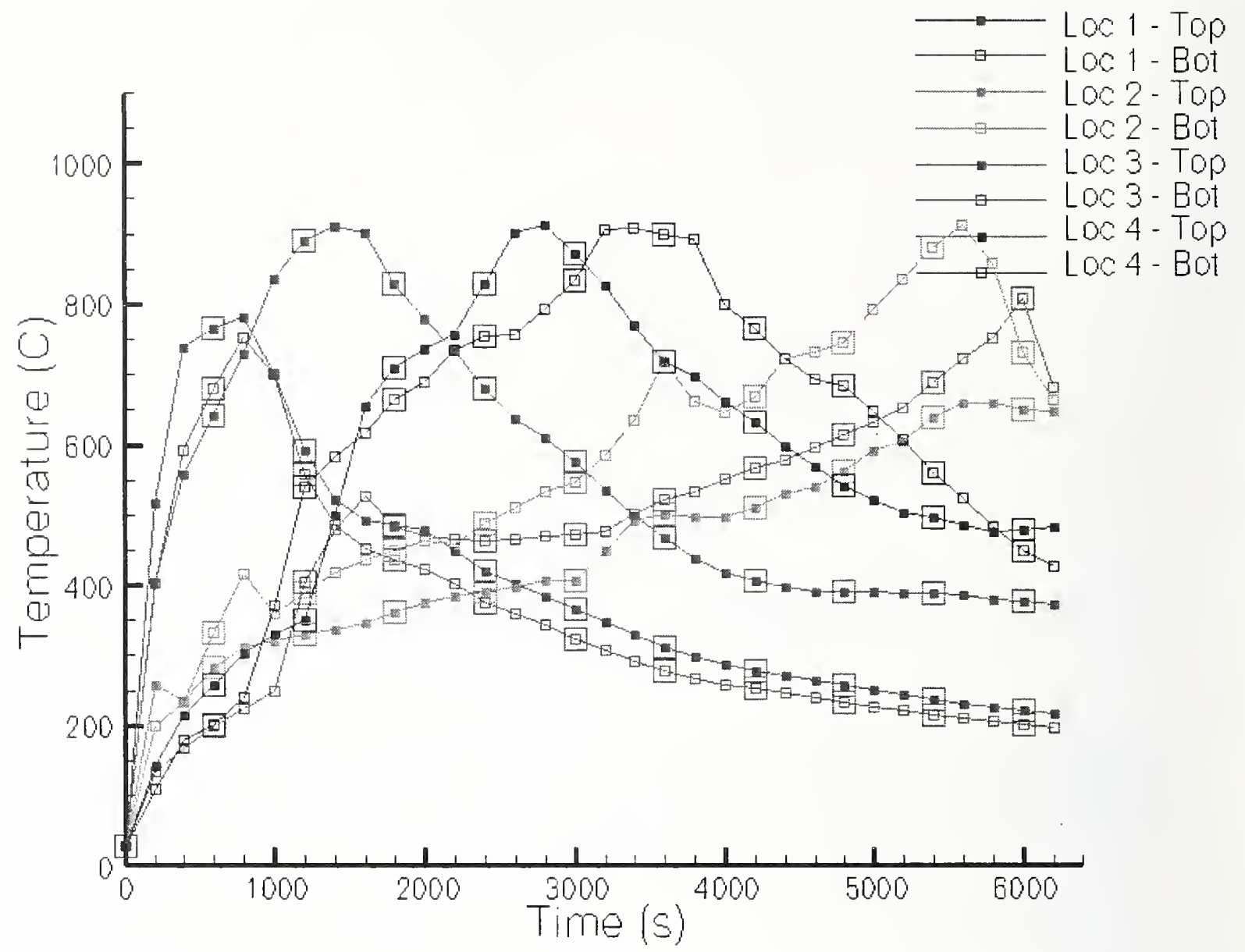

Figure 6-13. Temperature is plotted as a function of time at four different locations (top and bottom surfaces) on a concrete slab representing the $96^{\text {th }}$ floor of WTC 1 . These results clearly demonstrate the transient nature of fire growth through the floors.

\subsection{STRUCTURAL DAMAGE TO THE CONCRETE SLAB}

An objective of the NIST Investigation was to simulate the thermally induced response of the towers damaged by aircraft impact. Aircraft impact modeling results indicated severe damage to the concrete slab (NIST NCSTAR 1-2). It was necessary to include this damage in the thermal and structural models to accurately predict collapse of the towers. Damage to the concrete slab was simulated by the following three step process:

1. Construct a pristine structure (concrete slab) with no structural damage.

2. Identify the elements where the concrete slab is damaged by the impact of the aircraft.

3. Delete the elements where the structure was damaged by aircraft impact.

It was assumed that the concrete slab was not sprayed with fireproofing material and that there was no over spraying of the fireproofing from the trusses onto the concrete slab. 


\subsection{MAPPING OF THERMAL DATA}

As discussed in this chapter, the thermal analysis was performed with solid brick elements, while the structural analysis was performed with shell elements (NIST NCSTAR 1-6). In addition, the two models required different levels of resolutions for the physical processes that are being simulated. Therefore, the temperature data and the temperature gradient information must be transferred from the thermal models to the structural models. This data transfer is the form of a series of thermal loading data files (NIST NCSTAR 1-6D). The thermal loading data files must be compatible with the structural models so that they can be readily used in the analysis. The methodology and algorithm for transferring the thermal data was discussed in Chapter 4. In this section, the peculiarities of the mapping (interpolation) process for concrete slabs, that were not clarified in Chapter 4, are discussed.

Transfer of thermal data between thermal and structural models for concrete slabs has been shown schematically in Figure 6-14 and Figure 6-15. Figure 6-14 shows the thermal model (brick elements) on the left and structural model (shell elements) of a concrete slab on the right.

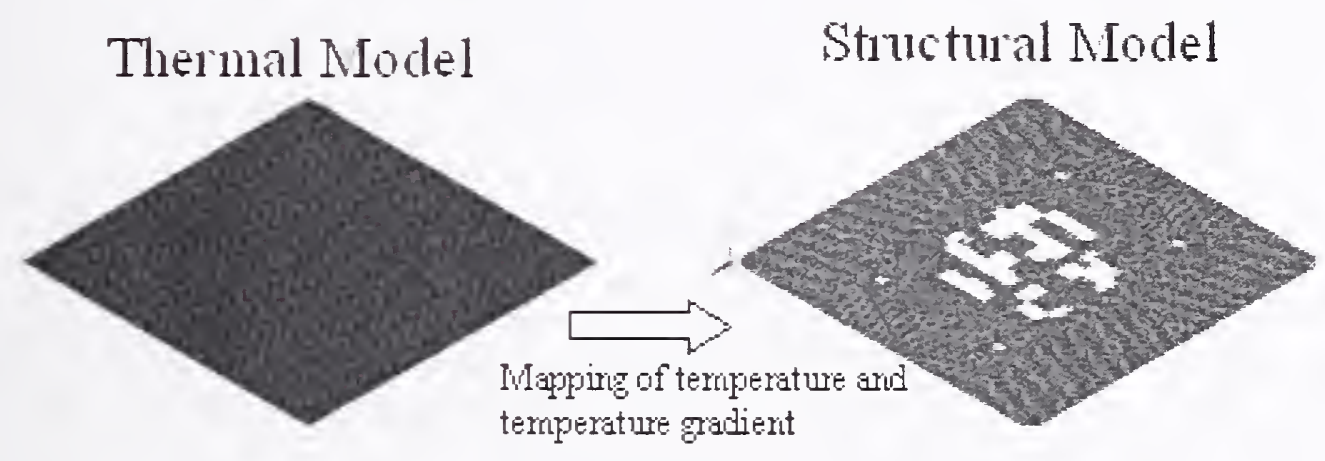

Figure 6-14. Mapping of thermal data (temperature and temperature gradient) from the thermal models to the structural model.

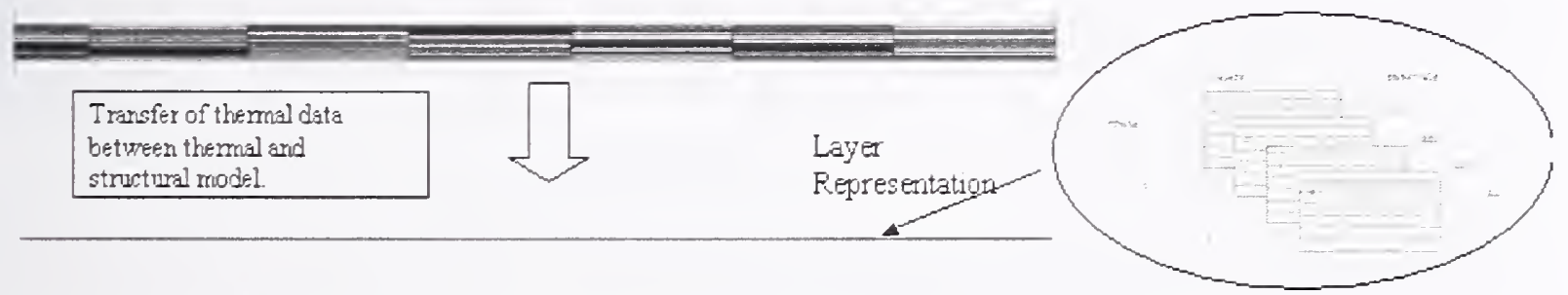

Figure 6-15. Mapping of the thermal data (temperature and temperature gradient) from the thermal models to the structural model.

Figure 6-15 illustrates the number of elements through the thickness of the thermal model. The shell element consists of four layers (ANSYS 2005) that were equally space through the thickness of the slab. Thermal data was provided at the interfaces between the layers and at the top and bottom face. The data transfer was done for shell elements using the methodology described in this chapter. 
The approach presented in this chapter for predicting the thermal response of the concrete slab and transferring or mapping the thermal data on a structural model was used extensively throughout the investigation. The concrete slabs shown in Chapter 8 through Chapter 11 (Global response of the towers) present results from a similar mapping for four specific scenarios, two each for WTC 1 and WTC 2 . The results for the concrete slab, shown in the figures included in Chapter 8 through Chapter 11, is a visual representation of their thermal state. 


\section{Chapter 7 \\ CORE COLUMNS}

This chapter is the last of four chapters (Chapter 4 through Chapter 7 ) that detail how the major structural components in the building were represented with finite element models. In addition, the method for coupling the thermal response of the structural components to multiple floor fires in the World Trade Center (WTC) towers is described. The focus of this chapter is on core columns. The thermal analysis of core columns and coupling of the models with fire simulations and structural models was in general very similar to the one described for perimeter columns in Chapter 4. In this section we will only describe the peculiarities of the core columns (modeling and analysis) that are different from those for perimeter columns. These differences are mainly in model construction and application of boundary conditions. Typical incident radiative flux on core columns and its dependence on fire spread has been presented. Time-temperature profiles are discussed to understand the nature of thermal insult. As for perimeter columns, partial results from one of the fire simulations are utilized to understand the coupled response. The description applies to the fire floors, floors 92-99 of WTC 1 and floors 78-83 of WTC 2 . As noted earlier, global response of the towers is presented in Chapter 8 through Chapter 11.

\subsection{FINITE ELEMENT MODEL FOR CORE COLUMNS}

Figure 4-11 shows a typical layout of the core columns on floor 96 of the WTC 1 . The core was supported by a combination of wide flange and box section columns. Some of these columns wcre very large. with cross-sections measuring 14 in. wide by 36 in. deep (NIST NCSTAR 1-1). Since plasticity and creep of the core columns were an important part of the structural analysis (NIST NCSTAR 1-6C), thermal models were constructed of the steel column and the fireproofing to predict the thermally induced structural response. This section describes the finite element models that were developed for core column analysis.

On a typical floor of the WTC tower, there were a total of 47 core columns. Like the perimeter columns the core columns were not identical in general. Some of these columns were wide flange columns while others had a box shape cross-section.

\subsubsection{Wide Flange Columns}

All wide flange core columns in the WTC towers were not identical. The thickness of the web plates, flange plates, and overall column dimensions varied from one column to another. Figure $7-1$ shows finite element models of two of the wide flange columns. The columns in Figure $7-1$ have been chosen to illustrate the differences in the size of two wide flange columns. The elements have been color coded with the assigned material attributes. Cyan colored elements have material attributes of steel, and violet colored elements have material attributes of fireproofing. 


\subsubsection{Box Shaped Columns}

Figure 7-2 shows finite elcment models of two box columns, illustrating the differences in column size. The thickness of the flange plate, web plate, and overall dimensions varied from one box shaped column to another. The shape and size of the core columns also differed from one floor to another. The elements have been color coded with the assigned material attributes. Cyan colored elements have material attributes of steel, and violet colored elements have material attributes of fireproofing.

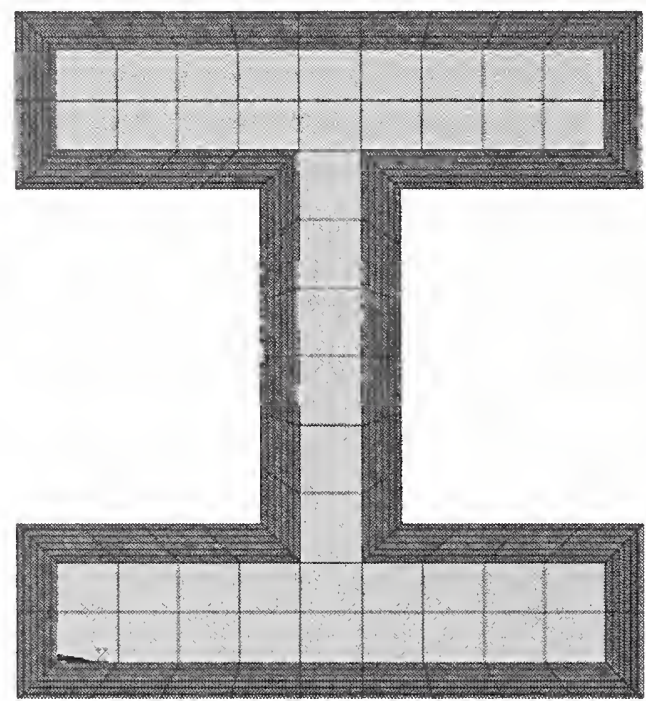

Column 501, Floor 96 North Tower

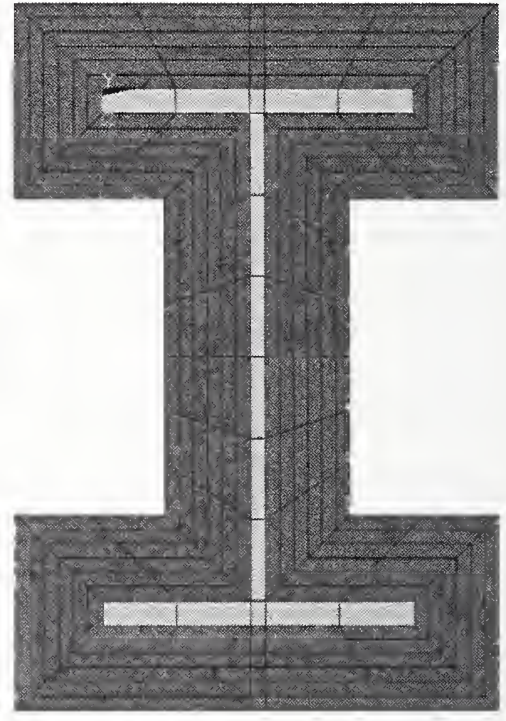

Column 704, Floor 96 North Tower

Figure 7-1. Finite element models of wide flange core columns, including insulation developed for thermal analysis of the World Trade Center Towers. Steel elements are colored cyan and fireproofing elements violet.

Since the thermal response of the column is dependent on the cross-sectional area, the circumference and the insulation, finite element models using the ANSYS parametric design language were constructed to include the variability in shape, size, material properties, and fireproofing of the core columns. The structural descriptions of the core columns on floors 92-99 of WTC land floors 78-83 of WTC 2 are the only ones of interest here and are given in Table B-4 through Table B-8. Table B-4 lists the column types for floor 92. Table B-5 lists the column types for floors 93-95, and Table B-6 lists the column types for floors 96-99. Table B-7 and Table B-8 list the column type for floors 78-80 and floors 81-83 of WTC 2 respectively. For box columns, the dimensions of the columns have been noted while for the wide flange columns the dimensions were obtained from the Steel Construction Handbook. The thermal analysis of the core columns is limited to floors 92-99 in WTC 1 and floor 78-83 in WTC 2.

The thermo-physical properties of all the structural materials used in this analysis are discussed in Appendix A. 


\subsubsection{Fireproofing Thickness for Core Columns}

The fireproofing material used on the core column was BLAZE-SHIELD DC/F (NIST NCSTAR 1-6A). The fireproofing thickness was a function of the core column size. In general there were two different fireproofing thicknesses used on the core columns. The lighter core columns were covered with $2.2 \mathrm{in}$. of fireproofing while the heavier core columns had smaller thickness of $1.2 \mathrm{in}$.

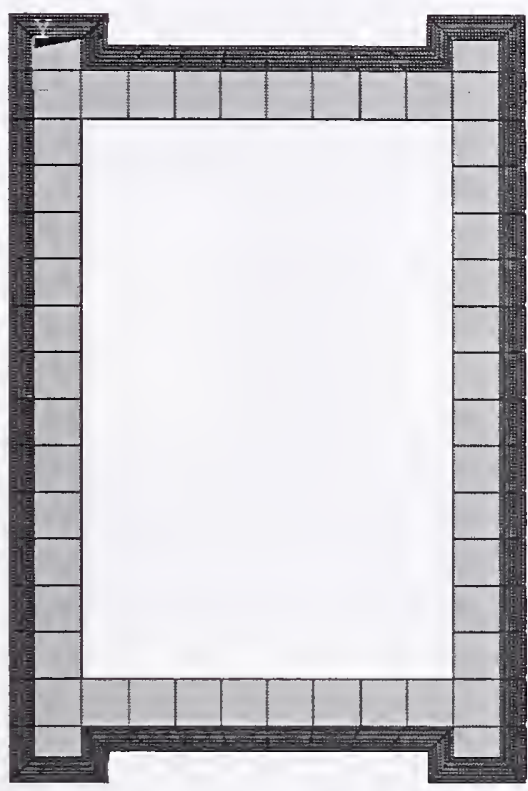

Column 501, Floor 78, South Tower

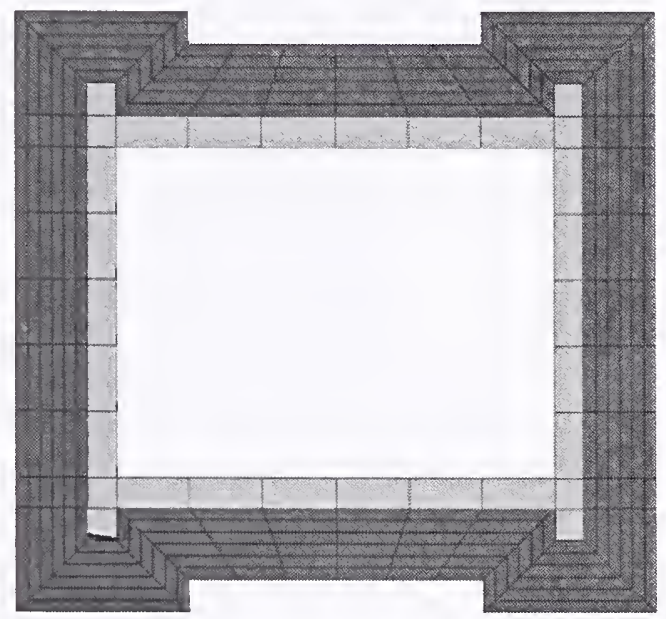

Column 701, Floor 95, WTC 1

\section{Figure 7-2. Finite element models of box columns including insulation used for thermal analysis in the World Trade Center towers. Steel elements are colored cyan, and fireproofing elements are violet.}

Figure 7-2, the elements have been color coded with the assigned material attributes. Typically there were approximately 20 elements along the length of a core column and six elements through the thickness of fireproofing. Along the perimeter the elements were spaced at roughly $6 \mathrm{~cm}$ intervals. Mesh density along the length of the column was governed by the requirement to accurately capture the variation in radiative flux from the hot layer on the column (Chapter 1). The mesh density through the thickness of the fireproofing was dictated by the need to adequately resolve the thermal wave through the fireproofing, and to reduce computational time (Figure 7-3). Exploratory studies described in Chapter 3 also played an important role in the choosing the mesh density. Lightweight columns had only one element through the thickness of the steel plate, while heavy column had two or three elements. Sensitivity studies were performed with a more refined finite element mesh, but the calculations did not result in any significant change in steel temperature. 


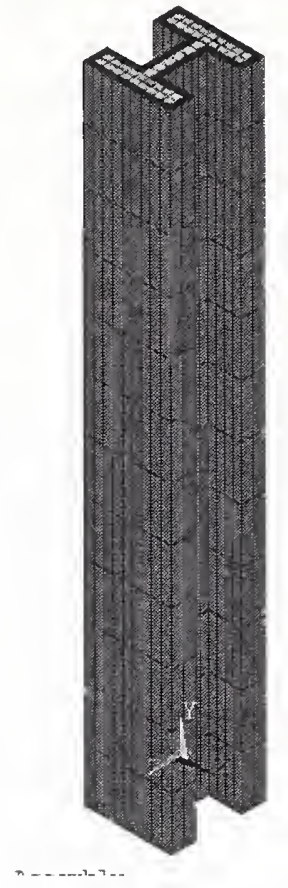

Column 1001, floor 96 WTC 1

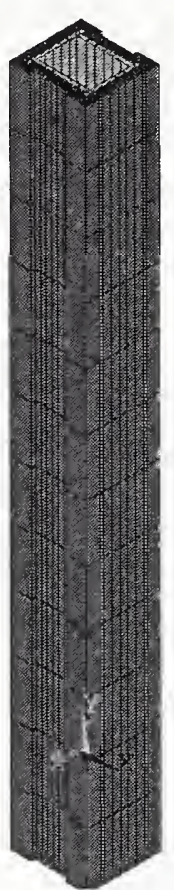

Column 701, floor 95 WTC 1

Figure 7-3. Isometric view of finite element models of the core columns showing mesh density and column construction. The elements are color coded with material attributes. Cyan colored elements have material attributes of steel while violet colored elements have material attributes of fireproofing.

\subsection{INITIAL AND BOUNDARY CONDITIONS}

The thermal rcsponse of core columns to spatially and temporally developing fires (NIST NCSTAR 1-5F) was simulated subject to a set of initial and boundary conditions. The approach for specifying initial and boundary conditions is again very similar to that for perimeter columns described in Chapter 4 . Difference in the application of boundary conditions between core columns and perimeter columns is described in this section.

For perimeter columns, radiative and convective fluxes were applied on the interior faces, while the exterior faces were assumed to be convectively cooled by the ambient atmosphere. Core columns were subjected to radiative and convective fluxes over the entire perimeter. The radiative or convective fluxes incident on wide flange or box columns are indicated with arrows in Figure 7-4. The length and color of the arrows indicates the intensity of the incident flux. As for perimeter columns, the radiative fluxes for core columns were coupled with fire simulations and were obtained by simplifying the radiative transport equation under the plane layer approximation, as described in Chapter 1. The radiative flux obtained from the plane layer analysis varied along the height of the columns and changed with time.

Re-radiation from the surface of the column to ambient atmosphere was modeled with surface effect elements (as for perimeter columns described in Chapter 4). Radiative heat transfer within the cavity of box column was also modeled to allow for heat exchange between the four plates. 


\subsection{INCIDENT RADIATIVE FLUX}

In this section, the nature of the incident radiative flux on a typical core column (wide flange column), when subjected to realistic fires is discussed. These results are based on one typical fire simulations and are provided here to understand the temporal and spatial variation of the incident flux.
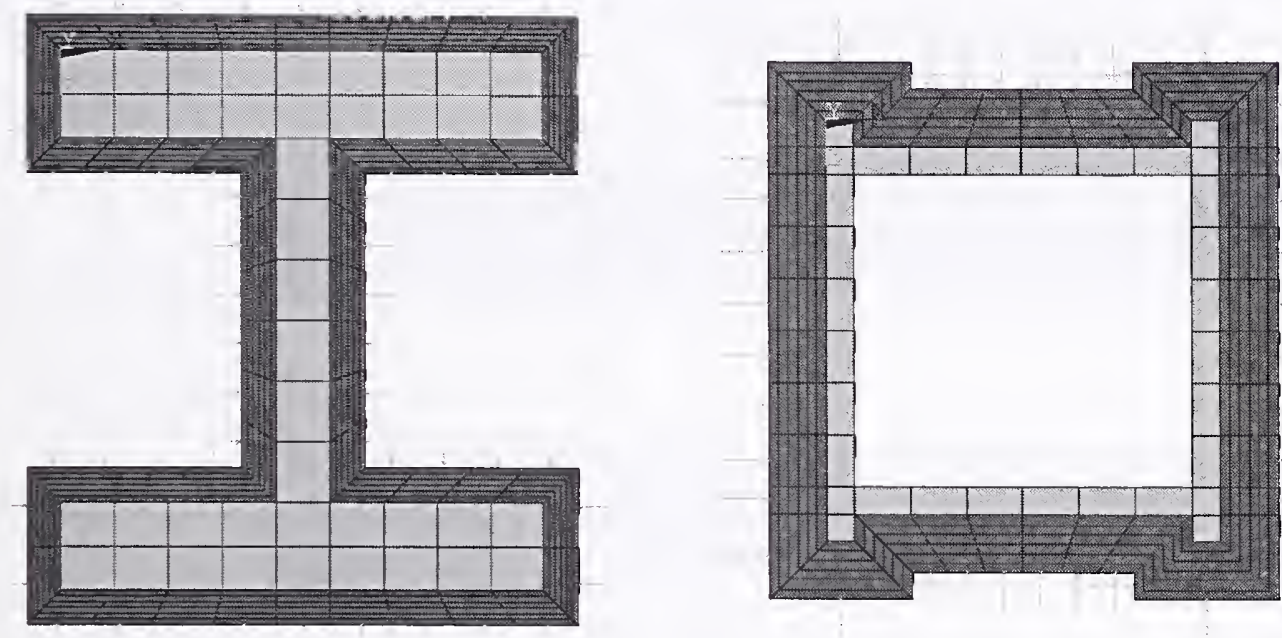

Figure 7-4. Radiative flux and convective flux boundary conditions (indicated by arrows) imposed on wide flange and box shaped core columns.

Figure 7-4 exhibits radiative fluxes incident on core column 501 at six different instants in time. Contours have been shown at $1000 \mathrm{~s}$ intervals ranging between $1000-6000 \mathrm{~s}$. The column under consideration is on the $96^{\text {th }}$ floor, but the model has been extended into both the $97^{\text {th }}$ floor and the $95^{\text {th }}$ floor, as noted above, to account for fires above and below the $96^{\text {th }}$ floor. The portion of the column below floor 96 is subjected to fires on the $95^{\text {th }}$ floor. The part between the $96^{\text {th }}$ and $97^{\text {th }}$ floor is subjected to fires on floor 96 , while the portion of the column above the $97^{\text {th }}$ floor is subjected to fires on floor 97 . Since the fires on the various floors $(95,96$ and 97) evolve independently of each other, the radiative flux incident on the column is not continuous at the slab boundaries.

The radiative flux contours range from 0 to $130 \mathrm{~kW} / \mathrm{m}^{2}$. At $1,000 \mathrm{~s}$ after impact of the aircraft, we find that there are significant fires on $96^{\text {th }}$ floor resulting in high fluxes to the column. Fire intensity on the $97^{\text {th }}$ floor is relatively small, while fire intensity on floor 95 is extremely small resulting in very low fluxes on the column below the $96^{\text {th }}$ floor. Because of the presence of partitions on any floor, the fire activity around the column is not necessarily uniform, and as a result, the flux incident on the column can vary over the perimeter at any given height. At 3,000 s after impact, column 501 experiences relatively low heat flux on floors 95-97. Beyond 4,000 s after impact, the fires in the vicinity of column 501 on floor 96 and 97 have died down, while floor 95 shows intense fire activity.

Figure 7-5 illustrates the variability in flux on a typical core column due to spatially and temporally evolving fires on the $95^{\text {th }}, 96^{\text {th }}$ and $97^{\text {th }}$ floors. It should be noted that there is also a horizontal variation in radiative fluxes, but this variation is quite small. 


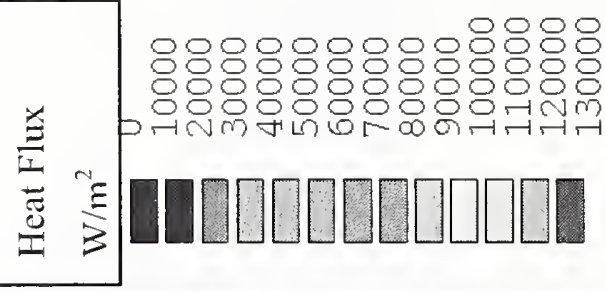
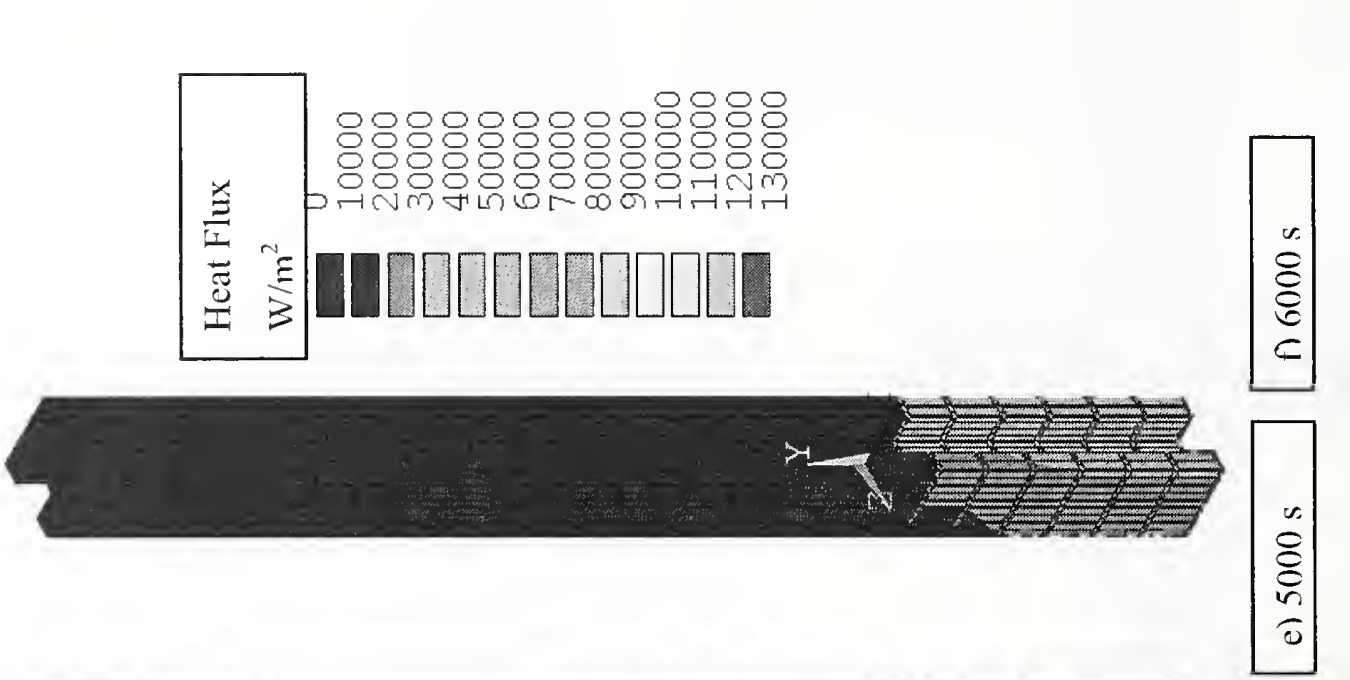

$\stackrel{\oplus}{E}$
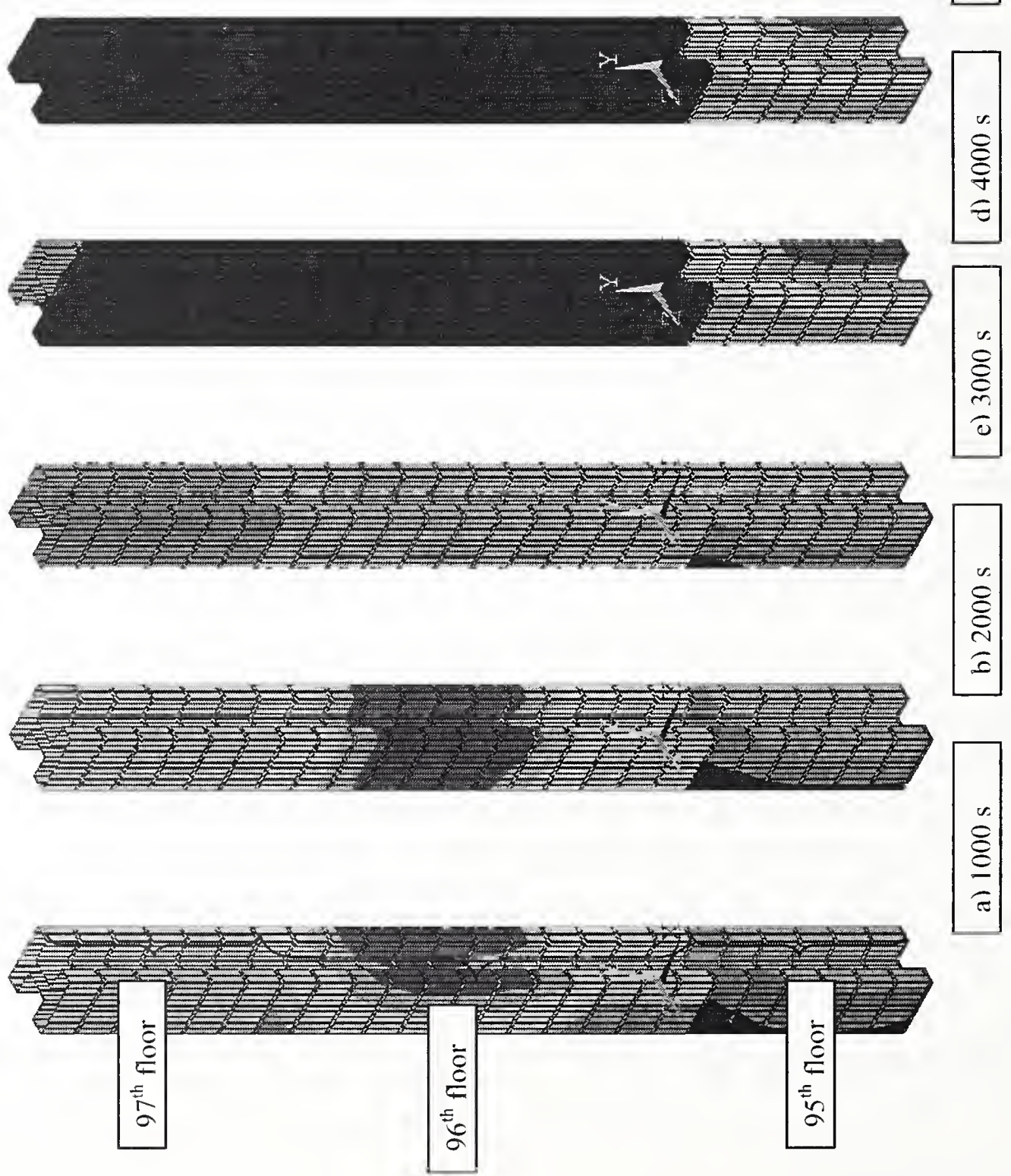


\subsection{CORE COLUMN TEMPERATURE}

This section presents temperature contours and time-temperature profiles for columns in the WTC towers. Temperature of a core column depends on several important factors. They include

- fireproofing status of the column,

- $\quad$ size and shape of the column (heavy or light column),

- fire intensity in the vicinity of the column. Incident flux varies from one column to another and is also a function of time, and

- fireproofing and structural damage status of columns above and below the column under consideration.

\subsubsection{Temperature Contours}

Figure 7-6 shows temperature contours (Kelvin) for typical core columns in the WTC towers. The subfigure on the left is a wide flange column, while the sub-figure on the right is a heavy box shape column. Temperature contours have been shown at one instant in time through the steel and fireproofing element. The contours range from $300 \mathrm{~K}$ to $900 \mathrm{~K}$. The surface of the fireproofing shows very high temperature, and energy gradually diffuses into the steel.

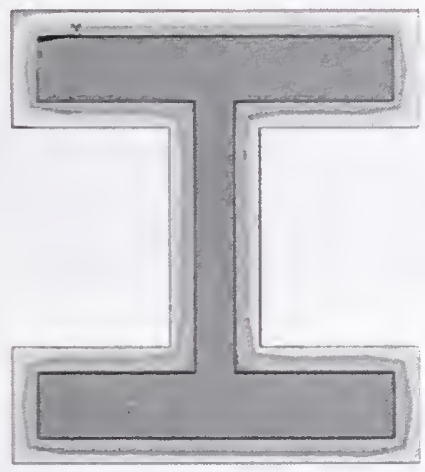

Column 1001, floor 96, WTC 1

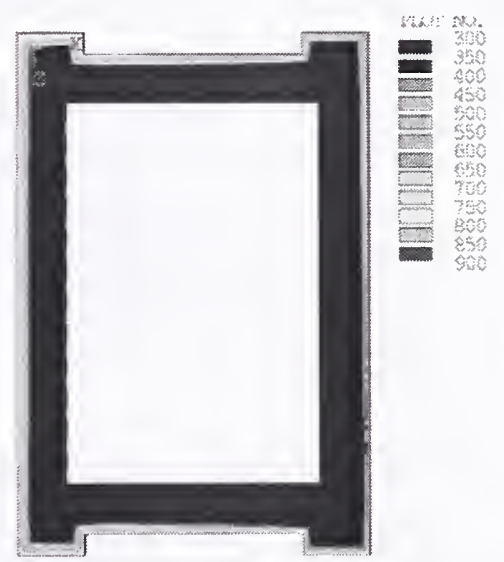

Column 501, floor 78, WTC 2

Figure 7-6. Temperature contours (Kelvin) for core columns in the World Trade Center towers. Both steel and fireproofing elements have been shown.

Figure 7-7 shows temperature contours on typical wide flange core column (Column 501, floor 96, WTC 1). Only a portion of the column between floor 96 and floor 97 is plotted. Temperature contours at six different instants in time, ranging from $1,000-6,000 \mathrm{~s}$ at $1,000 \mathrm{~s}$ intervals are presented to understand the nature of thermal insult on core columns. Temperature contours range between $300 \mathrm{~K}$ and $450 \mathrm{~K}$. 
Column 501 has its fireproofing intact on floor 96 , and is a relatively heavy column. The temperature contours in Figure 7-7 indicate that the mean temperature of the entire column increases gradually over time. Predicted temperatures are slightly higher in the upper half of the column due to higher radiative flux from the high temperatures in the upper layer. There is a small temperature gradient along the length of the column and along the cross section of the column.

\subsubsection{Time Temperature Profiles}

Figure 7-8 through Figure 7-13 shows time-temperature profiles for all the core columns on floor 96, WTC 1. Figure 7-8 shows column temperature for the "Series 5" column, while Figure 7-13 shows the "Series $10 "$ column. The temperature ranges from $0{ }^{\circ} \mathrm{C}$ to $750{ }^{\circ} \mathrm{C}$ and the time ranges from 0 to $6,300 \mathrm{~s}$. Temperature is plotted at $200 \mathrm{~s}$ intervals, but the symbols are placed at every $400 \mathrm{~s}$.

The time-temperature profiles for each core column is quite different from other core columns in terms of its peak temperature value, time to peak value and the overall trend. The core column temperature depends on its fireproofing status, size, shape, and fire intensity in the immediate vicinity of the column. As indicated earlier in this chapter the specified fireproofing thickness also varies from one column to another. Finally the fireproofing status of the column above and below the column under study can also have an effect on its temperature. The time-temperature profiles shown in Figure 7-13 depend on the value of all of these parameters.

The temperature axis has a range from $0-750{ }^{\circ} \mathrm{C}$. Some of the core columns show temperature values that are higher than $750^{\circ} \mathrm{C}$, which results in a break in the time-temperature profile. Temperature range was restricted to $750{ }^{\circ} \mathrm{C}$ since steel has very little strength at these temperatures.

Finally, it should be noted that the time-temperature curves presented in Figure 7-13 do not resemble the "standard" time-temperature curves used in furnace tests of structural elements. 


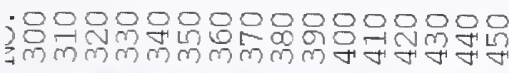

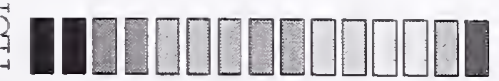
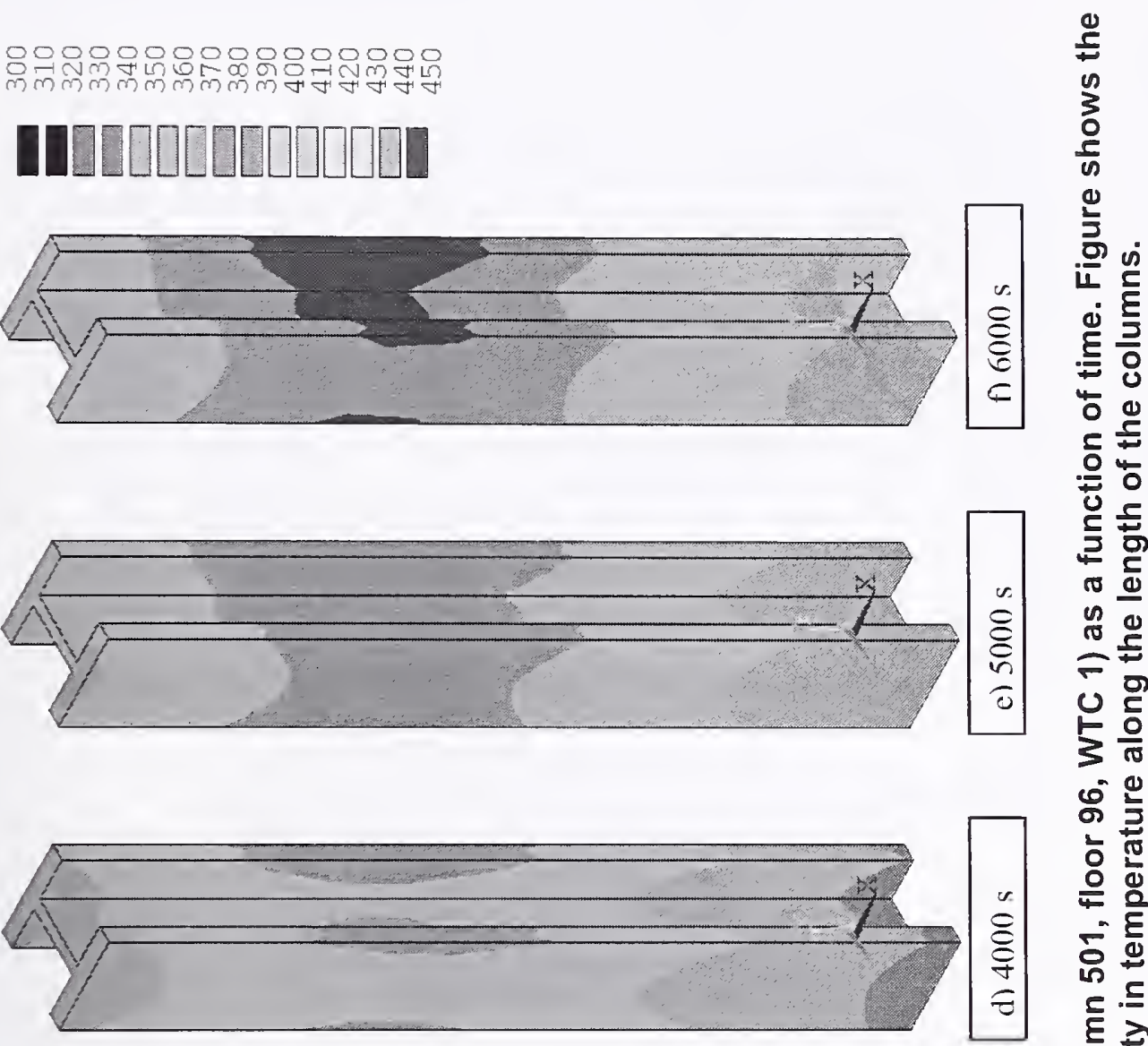

ตำ

능

은

은 을

$5 \frac{E}{0}$

เ

드는

릉

은 은

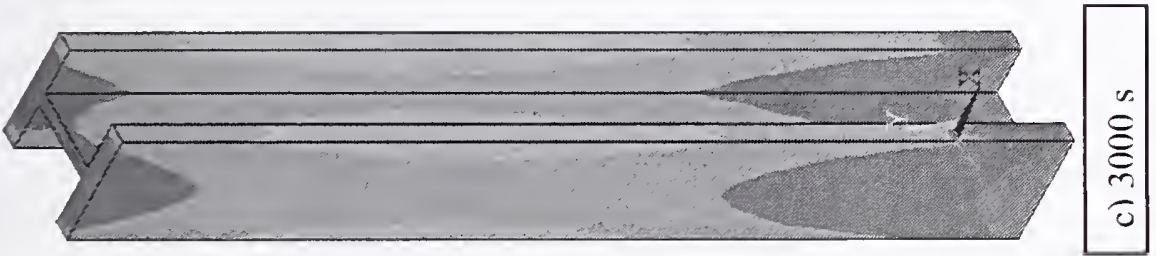

क

is

ब

둥

.

톨

$\underline{1}$

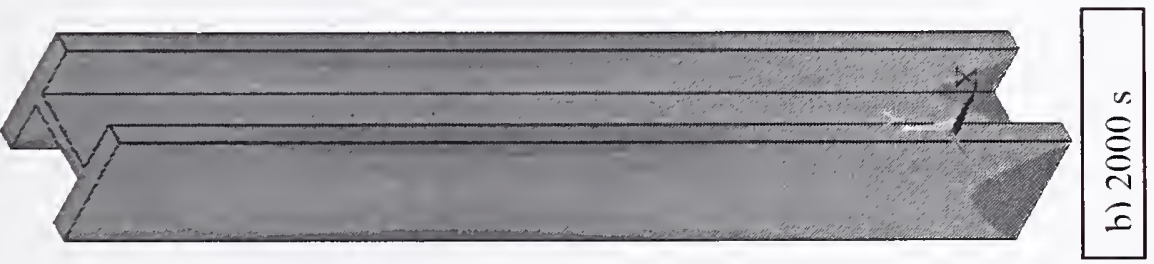

은

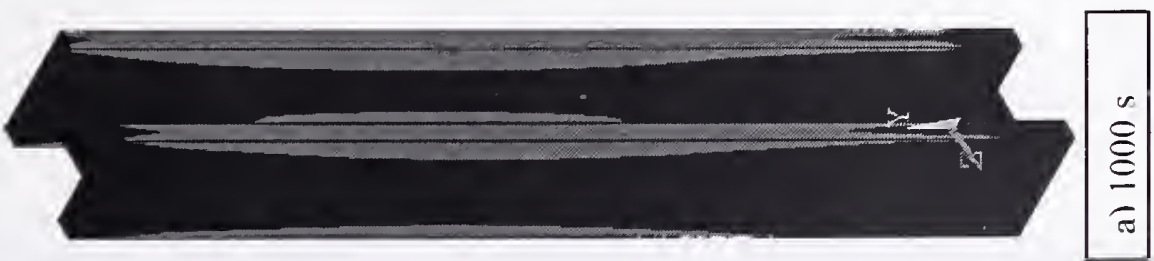




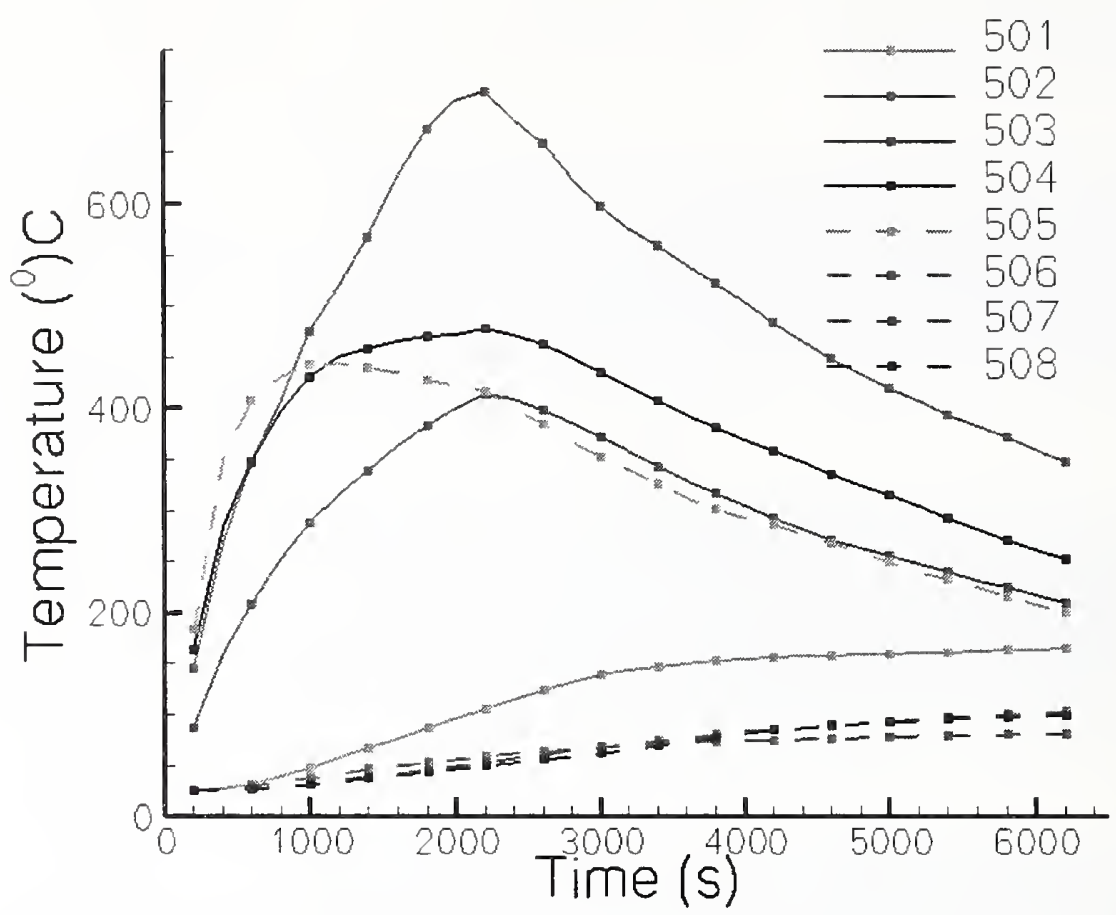

Figure 7-8. Core column temperature for columns 501 through 508 on floor 96 of WTC 1 as a function of time.

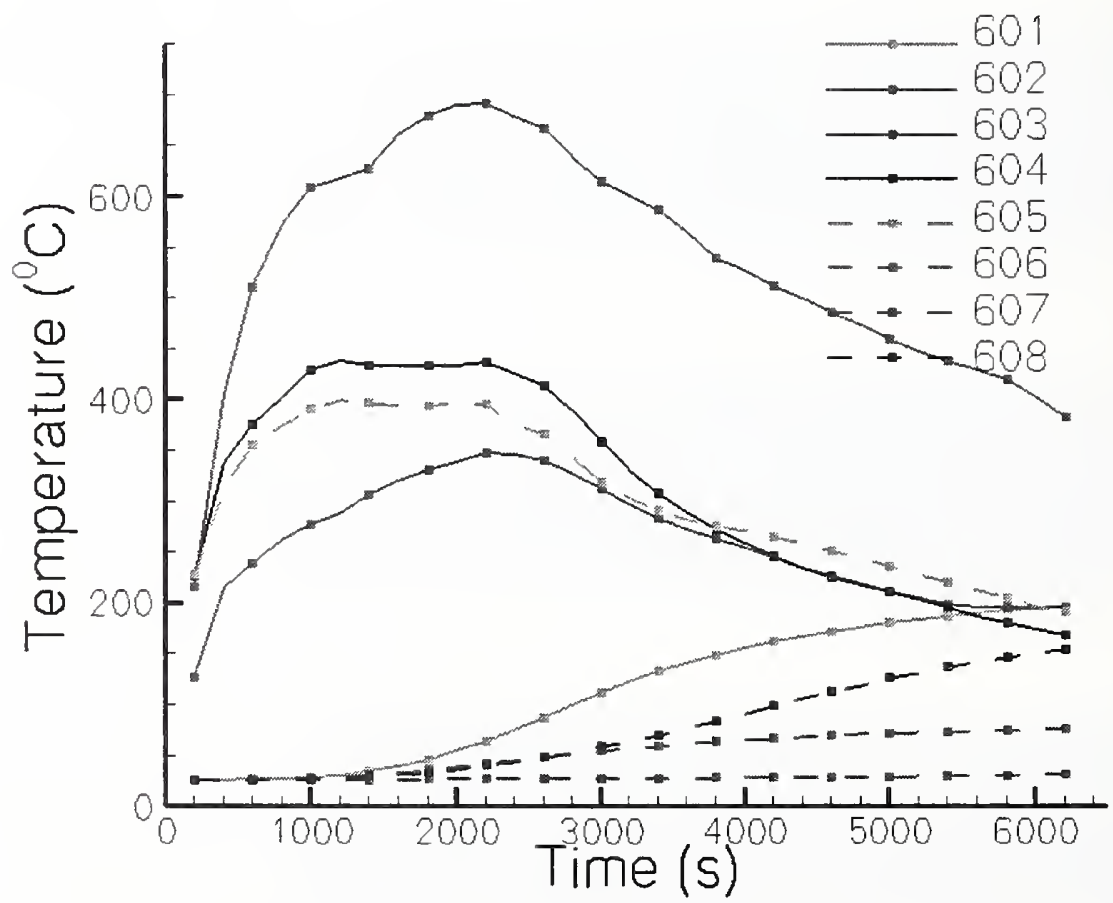

Figure 7-9. Core column temperature for columns 601 through 608 on floor 96 of WTC 1 as a function of time. 


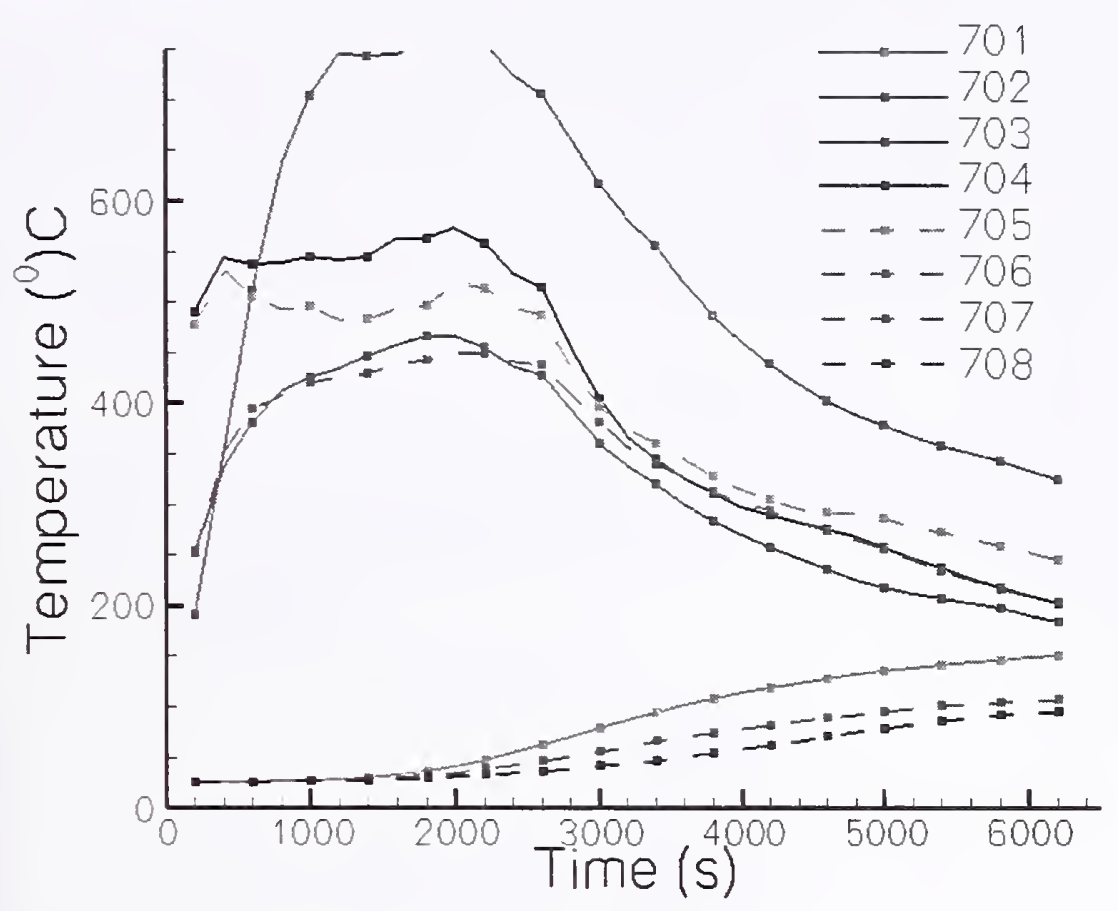

Figure 7-10. Core column temperature for columns 701 through 708 on floor 96 of WTC 1 as a function of time.

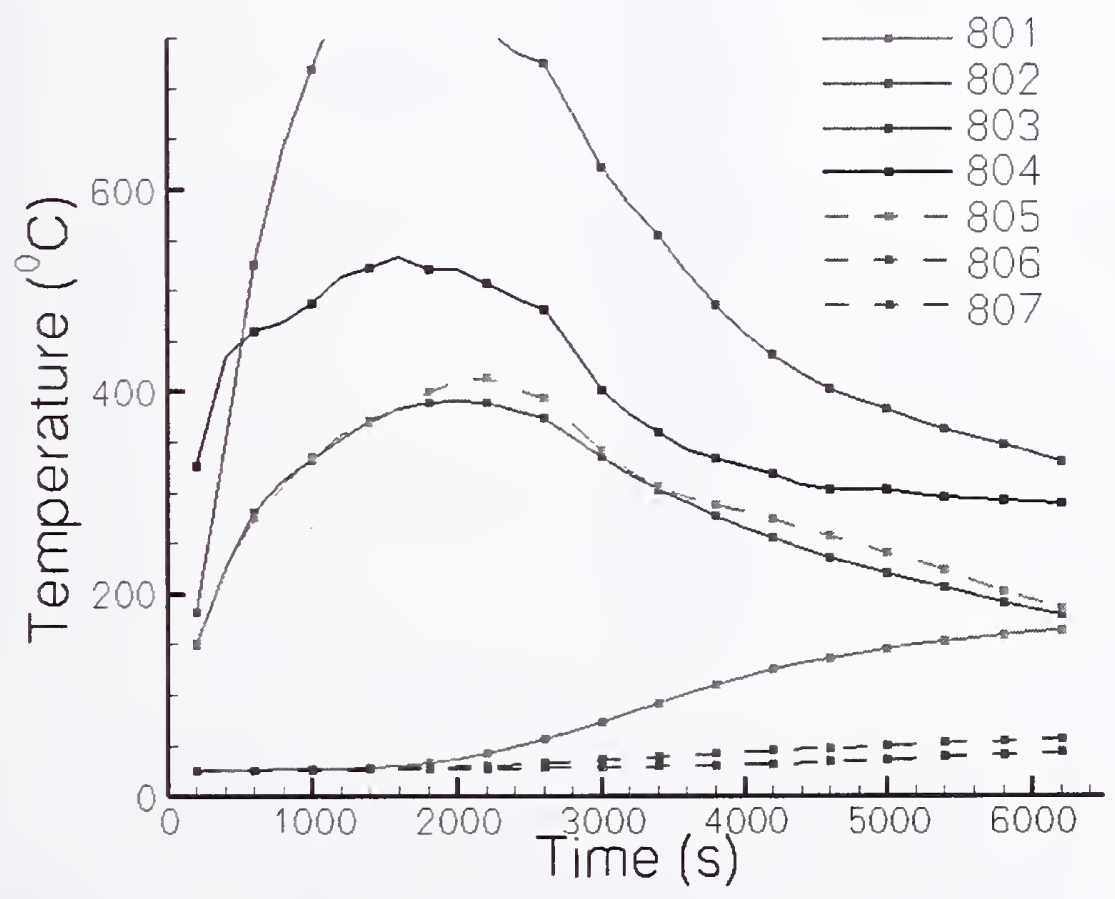

Figure 7-11. Core column temperature for columns 801 through 807 on floor 96 of WTC 1 as a function of time. 


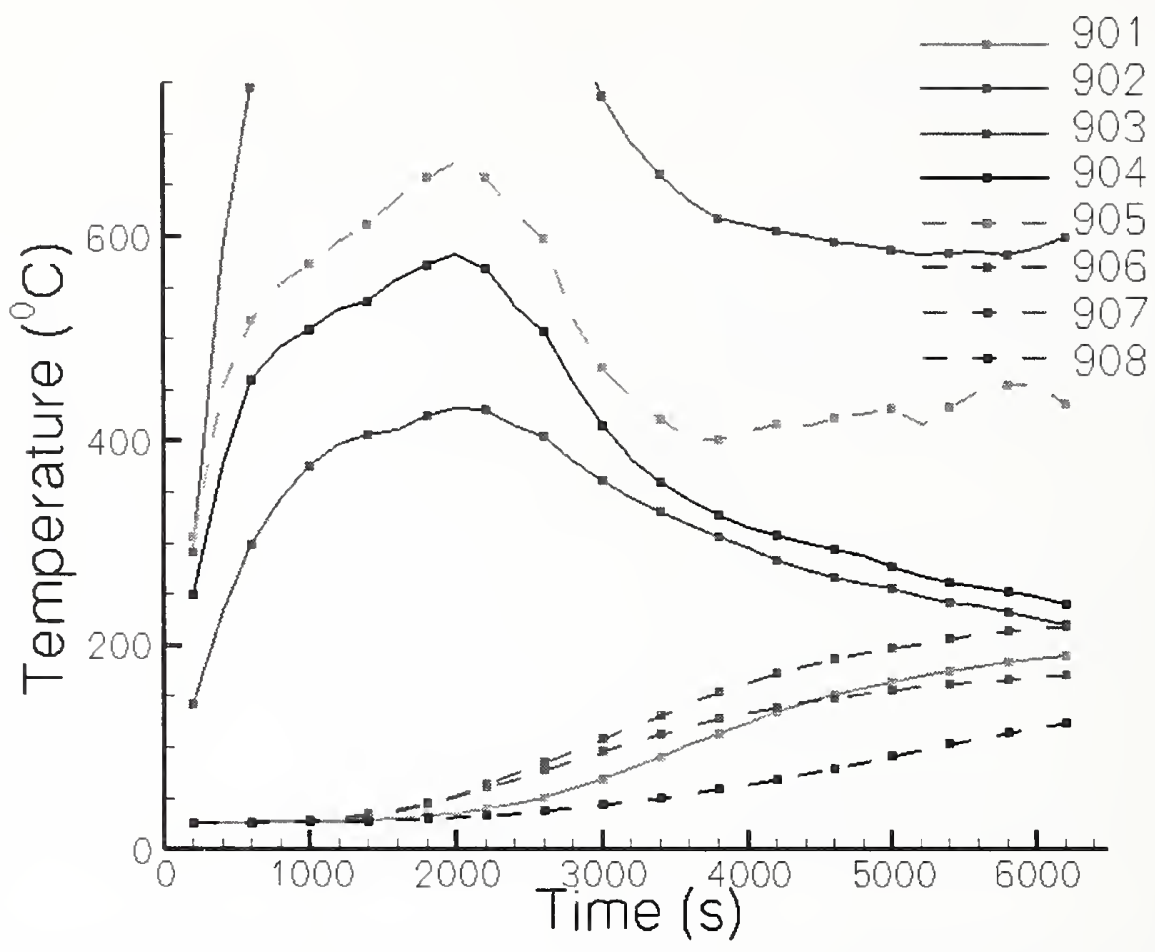

Figure 7-12. Core column temperature for columns 901 through 908 on floor 96 of WTC 1 as a function of time.

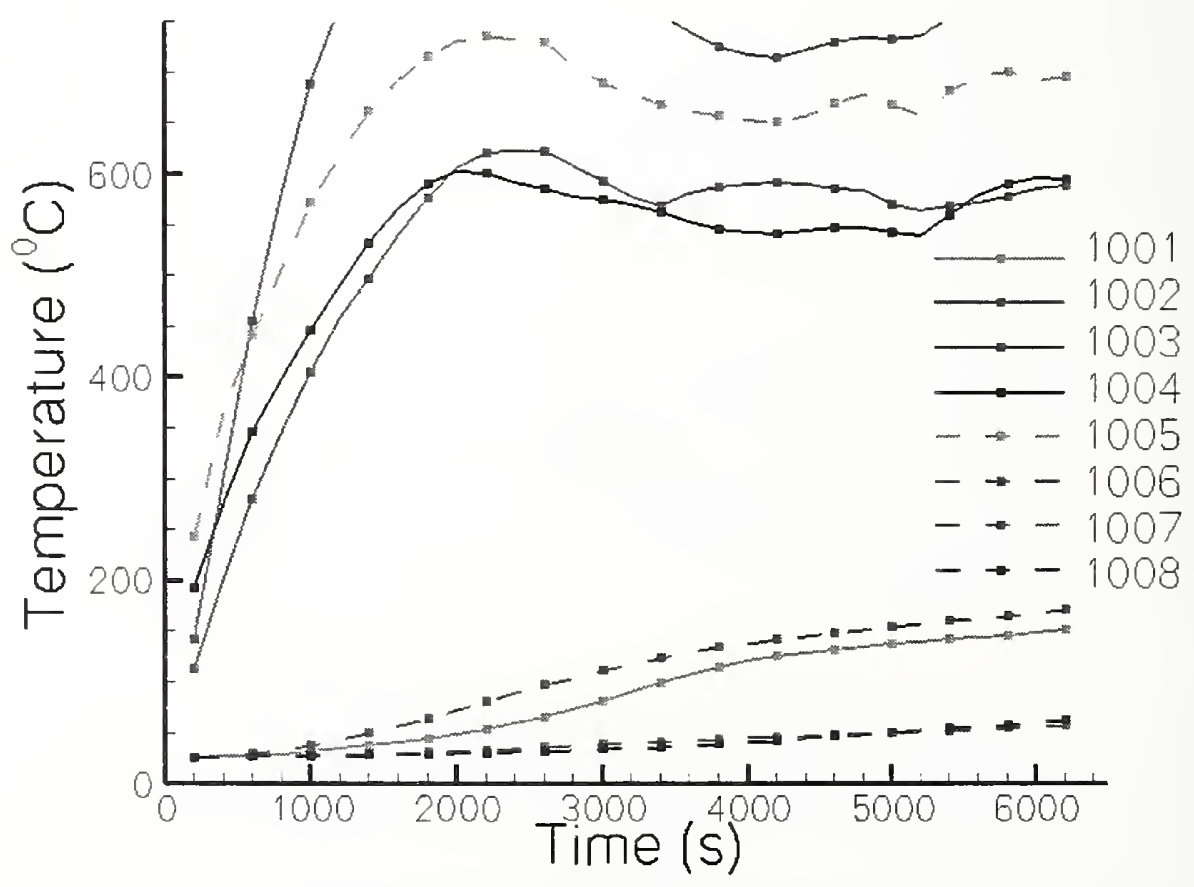

Figure 7-13. Core column temperature for columns 1001 through 1008 on floor 96 of WTC 1 as a function of time. 


\subsection{FIREPROOFING AND STRUCTURAL DAMAGE ON CORE COLUMNS}

Fireproofing and structural damage on core columns is predicted as a result of aircraft impact (NIST NCSTAR 1-2). Some of the debris field generated as a result of aircraft impact can reach the core columns and can damage them. The damage to these columns can be classified under two categories:

1. Structural damage, where the column is severed or heavily damaged. This affects the boundary conditions and heat capacity of the column.

2. Fireproofing damage.

Both structural and fireproofing damage have a large impact on the thermally induced structural response. The methodology for incorporating fireproofing and structural damage has been illustrated schematically in Figure 7-14 for typical wide flange columns. The approach is very similar to the one described for perimeter columns in Chapter 4.
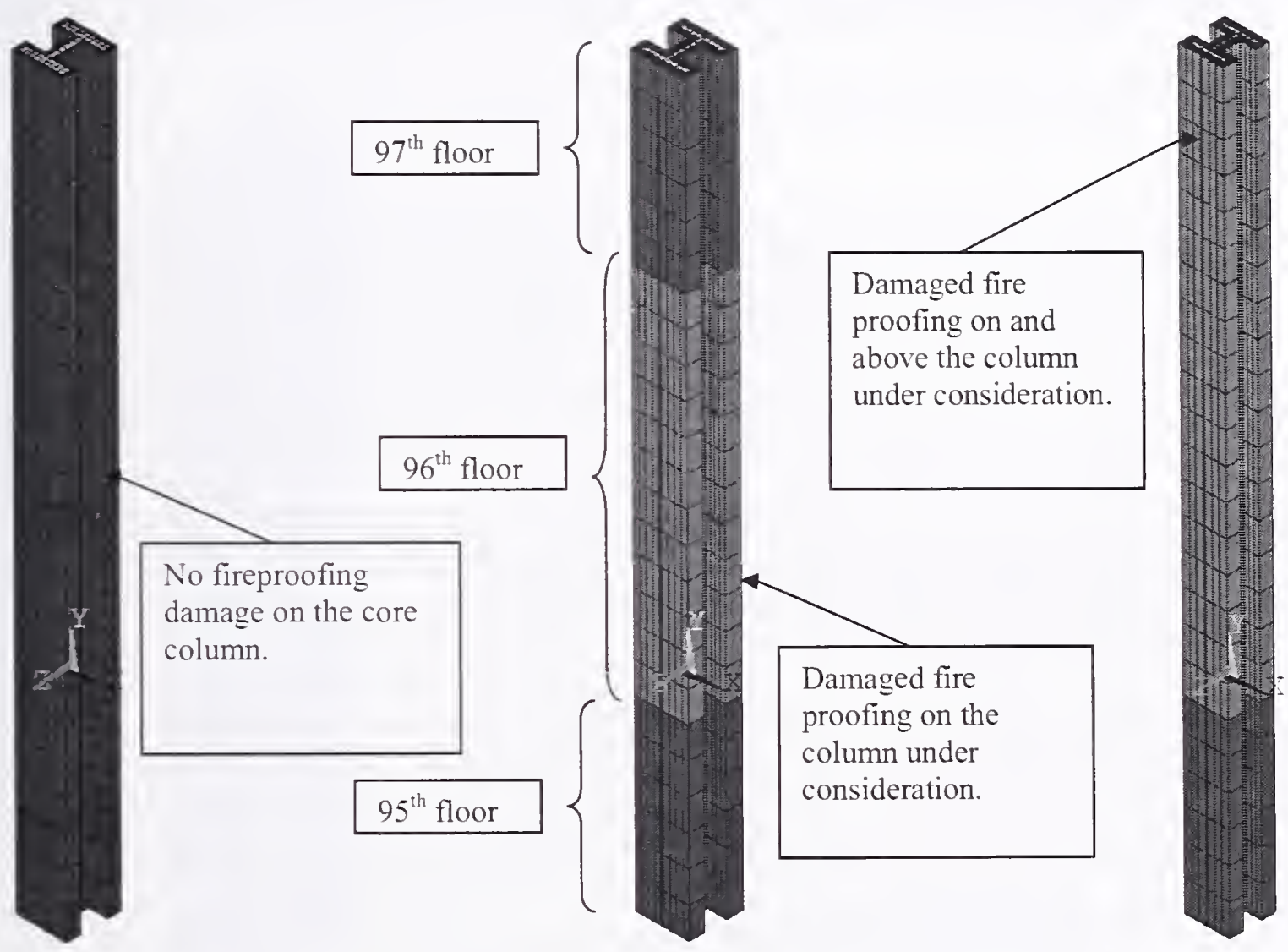

Figure 7-14. Incorporating the effect of fireproofing damage on columns by selectively changing the material attributes of the underlying elements.

Structural damage was incorporated by deleting the elements and nodes associated with the steel column. Fireproofing damage was simulated by changing the material attributes of the damaged fireproofing elements so as to offer negligibly small resistance to heat flow. The methodology is similar to that of perimeter columns, and was described in Chapter 4. 


\subsection{MAPPING OF THERMAL DATA}

The thermal analysis for core columns was performed with solid brick elements, while the structural analysis was performed with beam elements. There is also a significant difference in node and element distributions between the two models, and this difference required a mapping of the temperature data between the thermal and structural models. In general, the mapping procedure for core columns is very similar to that of perimeter columns, described in Chapter 4. The peculiarities of the mapping procedure, specific to core columns, are presented in this section.

\subsubsection{Algorithm}

The transfer of data between the thermal and structural models for a column is shown schematically in Figure 7-15. The sub-figure on the left represents a brick model for thermal analysis of core columns (part between two concrete slabs). The plot on the right shows the nodal locations of a corresponding structural model. The line in the middle shows the beam elements (color coded with element number) in the structural model. The complete algorithm for the mapping procedure can be summarized as follows:

1. Open the structural model database file and select the core column for which thermal data is required.

2. Identify and select core columns that are modeled with beam elements. Core columns modeled with beam elements are prescribed with temperature gradient data. For each beam element write the element number and co-ordinate location ( $x, y$ and $z$ ) of the centroid of the element. The location of the elements is written with respect to a global co-ordinate system.

3. Open the thermal model database file. Load the solution data filcs at a specific time where the load step file has to be created.

4. Rcad the element number and the co-ordinate location of the structural model for which temperature gradient data is requircd. Compute the temperature gradient at the nodes closest to the co-ordinate location specified by the structural model. Write the thermal gradient information in thermal loading data file.

5. Repeat step 4 for all the elements in a core column that require temperature gradient information and for all the core columns of interest.

6. Repeat step 3 through 5 for each time step where a thermal loading data file is required.

\subsubsection{Full Floor Mapping of Thermal Data}

Figure 7-16 shows the mapping between the thermal and structural models for core columns between floor 96 and floor 97 of WTC 1. For each floor, thermal data were provided as a set of thermal load files (text files) for structural analysis. Thermal load files for every floor of each towers were created at each time step where thermal data were required. The text files were formatted for the ANSYS finite element software and structural models. For WTC 1, ten thermal loading files were created at 10 min intervals ranging from $10 \mathrm{~min}$ to $100 \mathrm{~min}$. For WTC 2, six thermal loading files were created at 10 min intervals ranging from $10 \mathrm{~min}$ to $60 \mathrm{~min}$. Figure 7-17 shows time temperature plots for core columns 501 through 
508 on floor 96 of WTC 1. In this figure, the small symbols indicate the frequency at which the thermal data are plotted $(200 \mathrm{~s})$, while the large symbols indicate the frequency at which the thermal data were mapped onto the structural models for analysis ( $600 \mathrm{~s}$ ). Core column temperatures were found to vary slowly relative to the gas temperature fluctuations; the $200 \mathrm{~s}$ interval in the figure represents the thermal response of the column to the fires without missing significant peaks or fluctuations. The $10 \mathrm{~min}$ time intervals captured the computed thermal profiles reasonably well, as indicated in the figure. The structural response analysis used linear interpolation between two time intervals for modeling changes in temperatures of the structure.

Figure 7-16 shows the thermal data on the core columns at 100 min after impact. This figure is a visual representation of the information contained in the thermal loading data files. The approach presented in this chapter for predicting the thermal response of core columns and the transfer of this data to the structural models was used extensively throughout the Investigation. Specifically, the response of the core column to both thermal and structural loading required to analyze the global response of each tower, presented in Chapter 8 through Chapter 11, relied completely upon the mapping described in this chapter. The figures for core columns shown in those chapters are visual representations of the thermal state of the columns at specific instants in time.
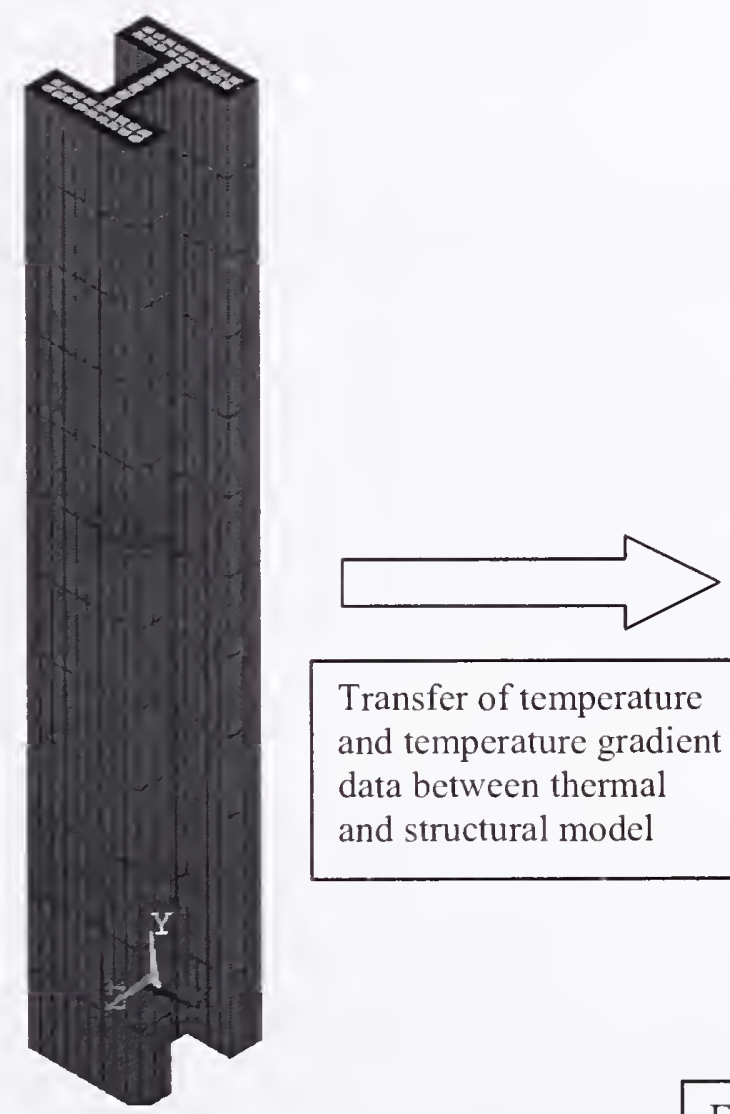

Transfer of temperature and temperature gradient data between thermal and structural model

Thermal Model of a Core Column showing element density.

Elements $\quad$ Nodes

Structural Model of a Core Column showing element density (colors) and node location.

Figure 7-15. Mapping of the thermal data from thermal models of the core column to the structural models. 


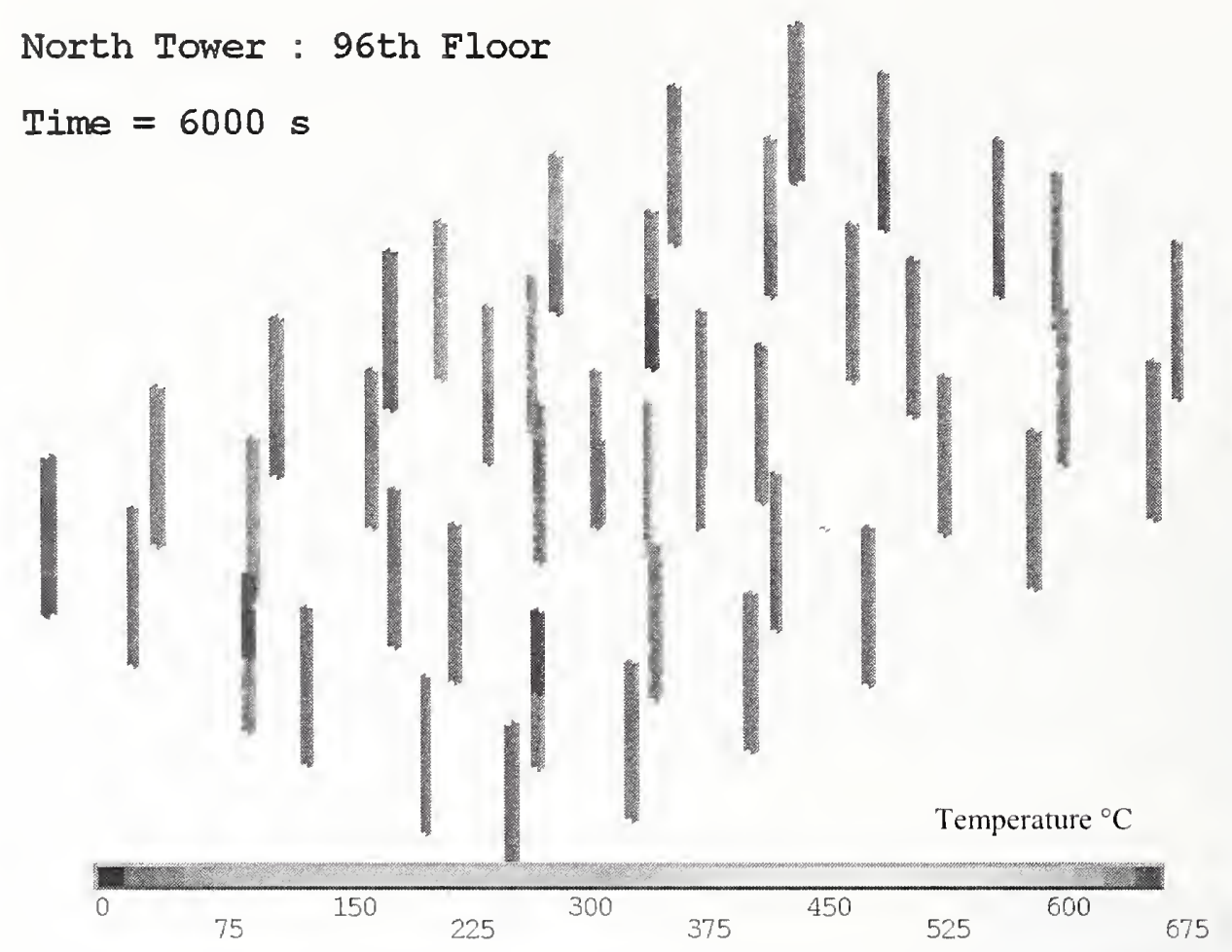

Figure 7-16. Mapping of the thermal data for the core columns onto the structural model for the $96^{\text {th }}$ floor of WTC 1 at $6,000 \mathrm{~s}$ after impact. The temperature data is provided as a body load and is generated in a format that is consistent with the structural model.

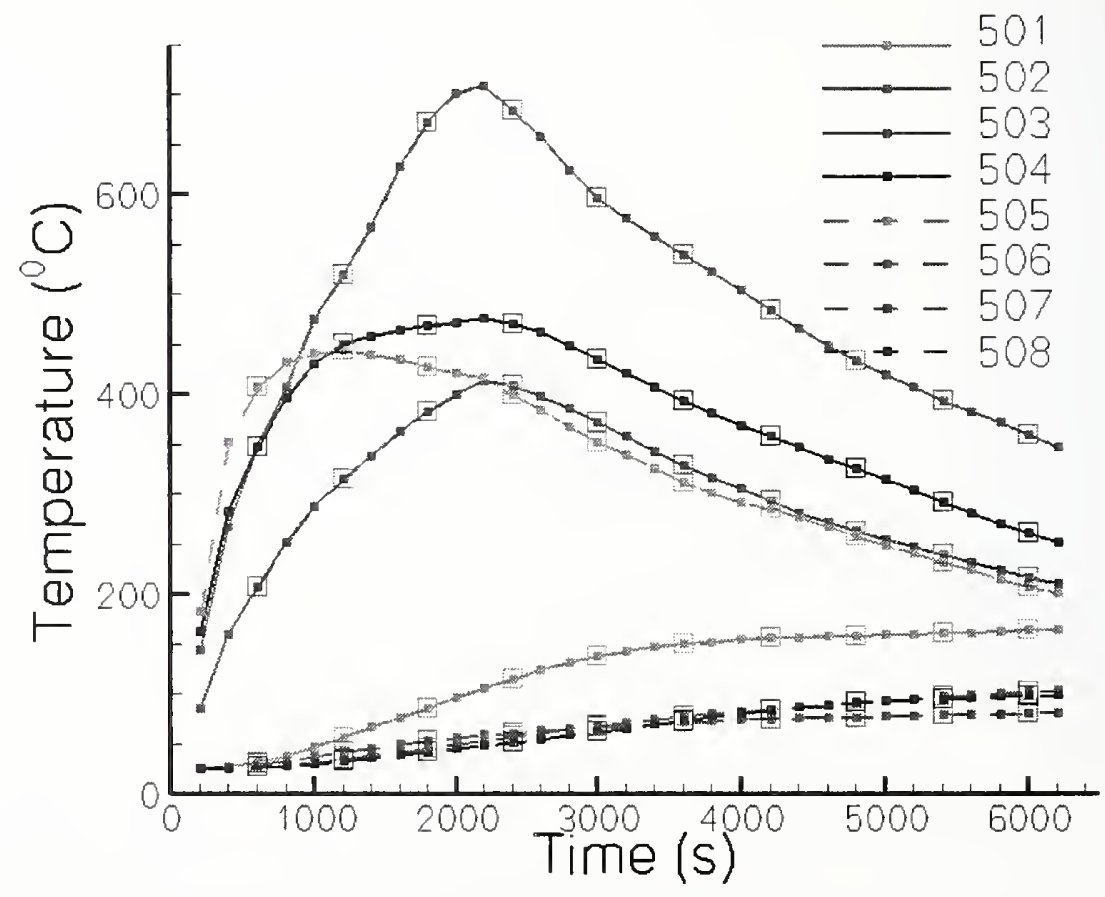

Figure 7-17. Core column temperature for columns 501 through 508 on floor 96 of WTC 1, as a function of time indicating the frequency at which the thermal data is plotted (small symbols) and the frequency at which data is transferred into the structural models (large symbols). 


\section{Chapter 8 \\ Global Thermal Response of WTC 1: CASE A}

During the course of the Investigation, hundreds of preliminary calculations were performed to study the thermal response of individual structural components and full floor systems. Some of these calculations were discussed in Chapter 2 through Chapter 7. Predicted results were compared with experimental data to assess the accuracy of the models and sensitivity to input parameters. The preliminary studies, photographic and visual evidence and published literature, helped guide the development of global models. Four such global simulations, two each for World Trade Center (WTC) 1 and WTC 2, are presented in this report to predict the global thermally induced structural response of WTC 1 and WTC 2. This chapter is the first of four chapters that describe the results of these four cases.

This chapter describes an application of the Fire Structure Interface (FSI) algorithm to predict the time dependent global thermal response of WTC 1. The aim of these calculations was to estimate the temperature of the entire structure (steel and concrete) on floors 92-99 of WTC 1 for prediction of the thermally induced structural response. The period of time that is simulated is $105 \mathrm{~min}$ and it ranges, from the point immediately after impact of the aircraft until collapse.

The focus of this chapter is on the global response of WTC 1 for a specific set of aircraft impact damage and fire dynamics simulation. The results of the thermal calculations (presented in visual form in this chapter) were provided to the structural analysis group in a form that is compatible with the structural models and can be readily used to apply a temporally and spatially varying body force (thermal loading) on the structure. A floor by floor description (along with appropriate visuals) is presented to understand the nature of the thermal insult on the structure. In this chapter the detailed construction of an individual column, truss or concrete slab is not considered. nor the methodology for transferring temperature data onto the structural models. Finite element models at the component level and the methodology for linking the thermal and structural models were presented in Chapter 4 through Chapter 7 . The focus of this chapter is on full single floor or multiple floor level global results at discrete instants in time.

\subsection{OVERVIEW}

The thermally induced structural response and collapse of each tower depends on several analyses and sub tasks that feed their results either directly or indirectly into the collapse analysis. The aircraft impact analysis predicts the structural and fireproofing damage caused by the aircraft to the various structural components. These results directly feed into the thermal analysis of the structure. The aircraft impact damage also feeds the damage data into the fire simulations and the results of the fire simulations were subsequently utilized in the FSI algorithm to predict the coupled thermal response of the structural assembly. The final collapse analysis depends on four major analyses namely:

1. Aircraft impact analysis

2. Fire simulations 
3. Fire structure interface and thermal analysis

4. Structural collapse analysis

Preliminary calculations were performed during the course of this Investigation to study the thermally induced response of structural components and sub-systems. The objective of these preliminary simulations was to:

1. assess the sensitivity of the many input parameters in the various analyses,

2. test the robustness of the numerical models during their development, and

3. gain insight into the fire induced collapse of the WTC towers.

The set of simulations termed "WTC 1, Case A" represent one set of global simulations where base settings (see Table 8-1, Table 8-2 and Table 8-3) were employed for the four major analyses to predict the thermally induced structural response of WTC 1. In this chapter, we present a floor by floor description along with visuals (Figure 8-2 through Figure 8-35) for the thermal response of WTC 1. The thermal data shown in these visuals was provided to the structural analysis group as thermal loading data files (text files) for analyzing the structural response and collapse induced by impact damage and thermal loading.

\subsubsection{Aircraft Impact Analysis}

Aircraft impact analysis was performed with base case settings shown in Table 8-1, to predict the structural and fireproofing damage on floors 92-99 of WTC 1. The main objective of the impact analysis was to estimate the damage to structural systems, including the exterior wall, floor systems, and interior core columns. Table 8-4 shows the fireproofing and structural damage predicted for perimeter columns on floors 92-99 (WTC 1, Case A). In this table a " 0 " indicates that the column and its fireproofing is intact, a " 1 " indicates fireproofing damage on the interior faces and a " 2 " indicates that the column has been severed due to aircraft impact. For WTC1 Case A, none of the perimeter columns were completely stripped of fireproofing on all four sides. The methodology for incorporating fireproofing and structural damage on perimeter columns was discussed extensively in Chapter 4. Table 8-5 shows fireproofing and structural damage predicted for core columns on floor 92-99. In this table, a " 0 " indicates that the column and its fireproofing is intact, a "l" indicates fireproofing damage on one side, a "2" indicates that the column has been severed by aircraft impact, while a "3" indicates fireproofing damage on all the faces. For WTC 1 Case A, the core columns had either no fireproofing damage or complete fireproofing damage on all the faces.Aircraft impact damage also results in structural and fireproofing damage to the floor systems. For each floor, a map was prepared that describes the contours of the region where fireproofing and structural damage was predicted. This damage for floors 94, 95, 96, 97 and 98 have been shown in Figure 8-3, Figure 8-5, Figure 8-9, Figure 8-30 and Figure 8-33 respectively (NIST NCSTAR 1-2). In these figures the area marked by green rectangles indicate structural damage, while the area marked by blue rectangles show fireproofing damage only (steel structure is intact). Structural damage was incorporated into the analysis, by removing the concrete slab, trusses, or core beams located in the area marked by the green rectangles. The method for incorporating structural and fireproofing damage was discussed extensively in Chapter 5 and Chapter 6 of this report. 
Table 8-1. Input parameters for WTC 1 global impact analyses (Base Case).

\begin{tabular}{|c|l|c|}
\hline \multicolumn{2}{|c|}{ Analysis Parameters } & Base Case \\
\hline \multirow{4}{*}{$\begin{array}{c}\text { Flight } \\
\text { Parameters }\end{array}$} & Impact speed & $443 \mathrm{mph}$ \\
\cline { 2 - 3 } & Trajectory - pitch & $10.6^{\circ}$ \\
\cline { 2 - 3 } & Trajectory - yaw & $0.0^{\circ}$ \\
\cline { 2 - 3 } & Orientation - pitch & $8.6^{\circ}$ \\
\cline { 2 - 3 } & Orientation - yaw & $0.0^{\circ}$ \\
\hline \multirow{4}{*}{$\begin{array}{c}\text { Aircraft } \\
\text { Parameters }\end{array}$} & Weight & 100 percent \\
\cline { 2 - 3 } & Failure Strain & 100 percent \\
\hline Tower & Failure Strain & 100 percent \\
\cline { 2 - 3 } Parameters & Live Load Weight & 25 percent \\
\hline
\end{tabular}

a. Live load weight expressed as a percentage if the design live load.

\subsubsection{Fire Dynamics Simulations}

Fire simulations were performed on the focus floors of WTC 1 with base case settings for the various input parameters summarized in Table 8-2 using the FDS software. Window breaking times were prescribed in the fire model as determined from the photographic and video recording. It was found that the distribution and condition of the furnishings and the damage to the core walls / shafts had the greatest influence on the model outcome. Fire activity around the building exterior served as observable to assess the accuracy of the fire model.

Properties of the hot layer were extracted from results of the fire simulations. Upper and lower layer gas temperatures, depth of the smoke layer, and absorption coefficients were computed at the grid locations and written to a text file at $100 \mathrm{~s}$ intervals. The text file also contains information on the underlying grid used for fire simulations as well as the specific instants in time where the data is provided. The text file was subsequently read into the ANSYS finite element analysis software. Figure 8-6 shows the typical upper layer gas temperatures obtained from fire simulations for floor 95, WTC 1 Case A (NIST NCSTAR 1-5F).

Table 8-2. Values of WTC1 Case A fire simulation variables.

\begin{tabular}{|l|l|}
\hline \multicolumn{1}{|c|}{ Variable } & \multicolumn{1}{c|}{ WTC 1 Case A } \\
\hline Fuel load & $20 \mathrm{~kg} / \mathrm{m}^{2}\left(4 \mathrm{lb} / \mathrm{ft}^{2}\right)$ \\
\hline $\begin{array}{l}\text { Distribution of } \\
\text { disturbed } \\
\text { combustibles }\end{array}$ & Even \\
\hline $\begin{array}{l}\text { Condition of } \\
\text { combustibles }\end{array}$ & Undamaged except in impact zone \\
\hline $\begin{array}{l}\text { Representation of } \\
\text { impacted core } \\
\text { walls }\end{array}$ & Fully removed \\
\hline
\end{tabular}




\subsection{FIRE STRUCTURE INTERFACE}

The Fire Structure Interface (FSI) uses the output of a fire simulation performed using the NIST Fire Dynamics Simulator (FDS) together with aircraft impact analysis results to predict the evolving thermal state of WTC 1. Table 8-3 summarizes the data that was used as an input for these calculations. FSI also linked the thermal analysis and structural analysis by creating thermal loading data files in a format that is consistent with the structural models. The global structural response and collapse analysis of WTC 1 under base case conditions described in NIST NCSTAR 1-6C was performed using the thermal data presented in visual form, in this chapter.

Table 8-3. Input for global thermal response of WTC 1, Case A.
\begin{tabular}{|l|c|}
\multicolumn{1}{|c|}{ Input } & WTC 1Case A \\
\hline $\begin{array}{l}\text { Structural damage, } \\
\text { NIST NCSTAR 1-2 } \\
\text { NIST NCSTAR 1-6 }\end{array}$ & $\begin{array}{c}\text { Case A } \\
\text { (Base Case) }\end{array}$ \\
\hline $\begin{array}{l}\text { Fireproofing damage, } \\
\text { NIST NCSTAR 1-6 }\end{array}$ & Case A \\
\hline $\begin{array}{l}\text { Fire Simulations, } \\
\text { NIST NCSTAR 1-5F }\end{array}$ & Case A \\
\hline
\end{tabular}

Exploratory studies, photographic evidence and published literature in this subjeet guided the development of the global models (Quintiere, Di Marzo and Becker 2002; Hori 2004; Abboud et al. 2003; Usmani, Chung and Torero 2003; Rehm et al. 2005.; Hori 2004). Figure 8-1 is a sample plot that shows the thermal data generated with FSI and subsequently transferred to the structural models for analysis. Temperature contours are superimposed on the steel structure of a typical floor of WTC 1 . The figure shows the core beams and floor trusses that support a concrete slab. The concrete slab has not been included in the figure for clarity, but is included as part of the analysis. Portions of the core beams and floor trusses were damaged by the impact of the aircraft and this portion of the structure is not shown in the figure nor was it included in the thermal analysis. The figure also shows the perimeter and core columns extending to the floor above and below the floor under consideration. Perimeter and core columns that were severed by the impact of the aircraft are not shown in this figure. The structural damage varies from one floor to another and has been summarized in Table 8-4 and Table 8 -5. As has been discussed in detail in Chapter 4 through Chapter 7, the thermal and structural finite element models were constructed from information obtained from the LERA database (NIST NCSTAR 1-2) and summarized in Appendix B. The type and location of the fireproofing thickness (not damaged by the aircraft impact) is summarized in Table B-9.

For WTC 1, thermal analysis was performed to cover the period of approximately $6,300 \mathrm{~s}$, immediately following impact and extending all the way to collapse of the tower. The minimum time step for the thermal analysis is $1 \mathrm{~ms}$ while the maximum time step was limited to $50 \mathrm{~s}$. For WTC 1, thermal data at ten instants in time, spaced at $10 \mathrm{~min}(600 \mathrm{~s})$ intervals was provided for the structural analysis. For each step, a set of thermal loading data files was generated to completely specify the thermal state of the tower. The thermal loading data files were in a format that was consistent with the structural models and could be readily read in with the ANSYS finite element software (NIST NCSTAR 1-6D) to specify body loads (temperature and temperature gradient information) on the entire structure. The thermal loading data files 
were provided at $10,20,30,40,5060,70,80,90$, and 100 min after impact of the aircraft. No thermal loading data files were provided at zero seconds after impact. It was assumed that the structure is initially at room temperature. The final load step file was at $100 \mathrm{~min}$ after impact, and it contains the final thermal state of the tower extending all the way to collapse. ANSYS performs a linear interpolation between two consecutive load step files for convergence and stability of the numerical procedure.

Under the plane layer approximation, a simplified form of the radiative transport equation was solved to predict the radiative fluxes incident on the sub-grid scale structural elements. The radiative fluxes are functions of space and time and depend on the location and orientation of the structural elements. Besides the radiative fluxes are related to the local instantaneous properties of the hot layer as defined by the upper and lower layer temperature, absorption coefficient and depth of the hot layer.

The fire simulations and the thermal analysis were performed for floors 92 through 99 . However, in the following sections, discussion is limited to floors 93 through 99 only. Thermal mapping was not performed for floor 92. This is due to a combination of the nature of the structural model and the mapping process (discussed in Chapter 4 through Chapter 7) between the thermal and structural model. The floor model (NIST NCSTAR 1-6, NIST NCSTAR 1-6D) has a single slab and floor truss system, but the columns extend one floor above and below the floor. A mapping for floor 92 would require us to perform a thermal analysis of the columns on floor 91 . Thermal analysis of columns on floor 91 was not performed. Besides the slab on floor 92 is subjected to radiative fluxes from fires on floor 91 on its bottom face and fires on floor 92 on its top face. Since fire simulations were not performed on floor 91 , thermal analysis of the slab on floor 91 could not be completed. Due to these limitations, the thermal mapping was not performed for floor 92.

In the following sections, FSI results for WTC 1 Case A are described on a floor by floor basis. The figures in each of the following sections are a visual representation of the thermal state of that floor at a specific instant in time. The data shown in the various plots were transferred to the structural analysis group for stress analysis. The transfer of data was in the form of thermal loading data files (text files) and was in a format that is consistent with the structural models. 


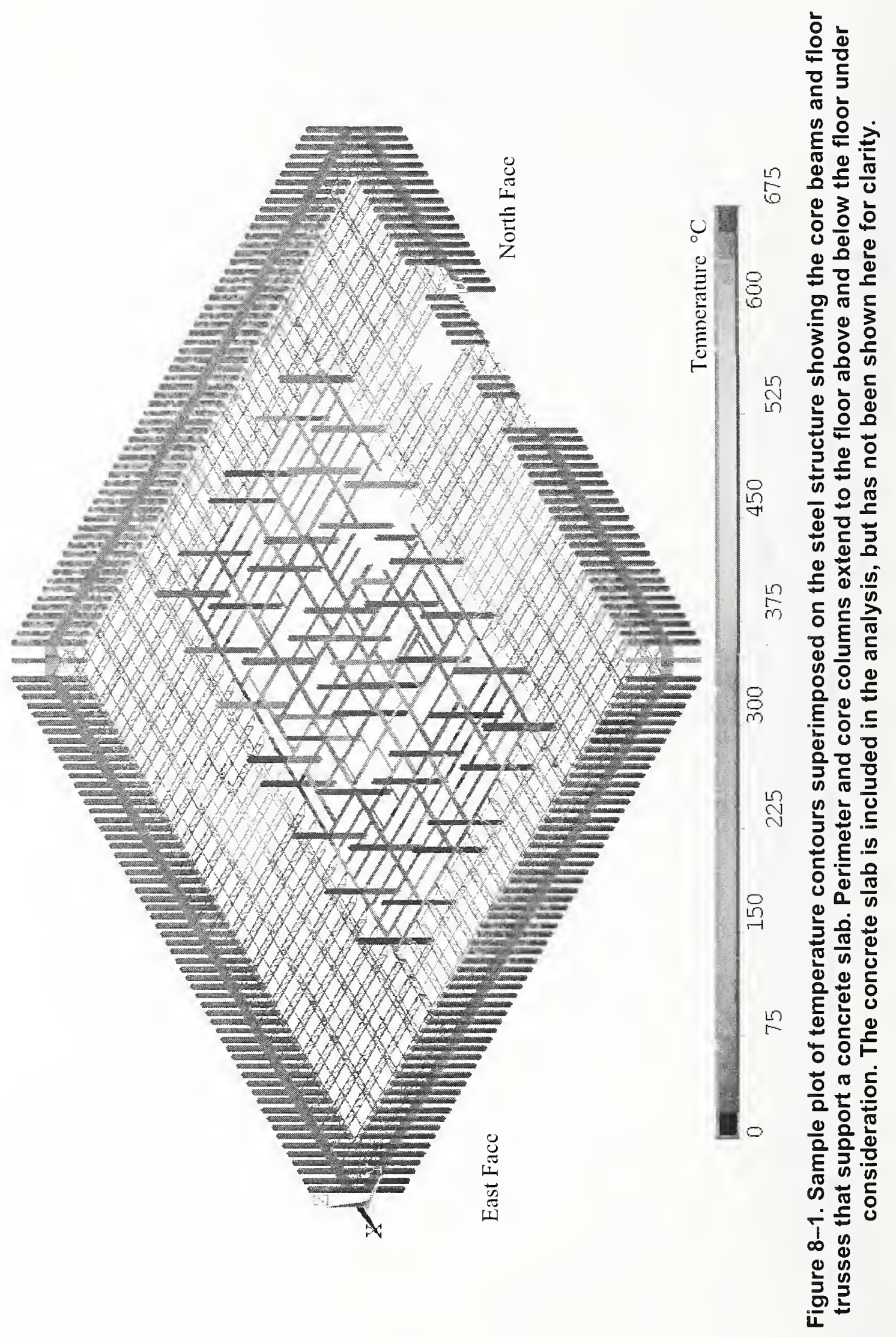




\subsubsection{Floor 93, WTC 1 Case A}

Figure 8-2 shows the thermal response of the $93^{\text {rd }}$ floor WTC 1 Case A at nine different instants of time ranging from $10 \mathrm{~min}(600 \mathrm{~s})$ to $100 \mathrm{~min}(6000 \mathrm{~s})$ at $10 \mathrm{~min}(600 \mathrm{~s})$ intervals. The thermal state of the Iloors at $60 \mathrm{~min}(3600 \mathrm{~s})$ after impact of the aircraft is not shown due to space limitation on one page. Each sub-figure is similar to the sample plot shown in Figure 8-1, and shows the truss assembly and core beams that support the $93^{\text {rd }}$ floor. The floor trusses and core beams are subjected to fires on the $92^{\text {nd }}$ floor. Perimeter and core columns above the $93^{\text {rd }}$ floor concrete slab are subjected to fires on the $93^{\text {rd }}$ floor, while portion of columns below the $93^{\text {rd }}$ floor slab are subjected to fires on the $92^{\text {nd }}$ floor. The first subfigure shows the north face and the east face of the building for orientation.

Aircraft impact analysis results show no structural or fireproofing damage on the trusses or the core beams. Table $8-4$ shows the fireproofing and structural damage predicted for perimeter columns on floors 92-99 (WTC 1, Case A). Aircraft impact analysis resulted in no fireproofing or structural damage for any perimeter column on floor 92 or floor 93 . Table 8-5 shows fireproofing and structural damage predicted for core columns on floors 92-99. Columns 504 and 605 are damaged structurally on floors 92 and 93 , while column 705 is damaged on floor 93 only. There is no fireproofing damage predicted for the core columns on these floors.

Since there is no fireproofing damage, the trusses and columns on Floor 93 shown in Figure 8-2 stay relatively cool. The floor trusses have a mean fireproofing thickness of $2.2 \mathrm{in}$. which can delay the heating of the entire floor system. The core beams are covered with $0.5 \mathrm{in}$. fireproofing and as a result, the core beams heat up faster. This is illustrated by significant heating of the core beams at $1800 \mathrm{~s}$ after impact. The heating of the core beams is consistent with fire activity in this region. As the fire spread towards the south faces of WTC 1, the core beams gradually cooled down as seen by relatively lower temperatures at $6,000 \mathrm{~s}$ after impact. 

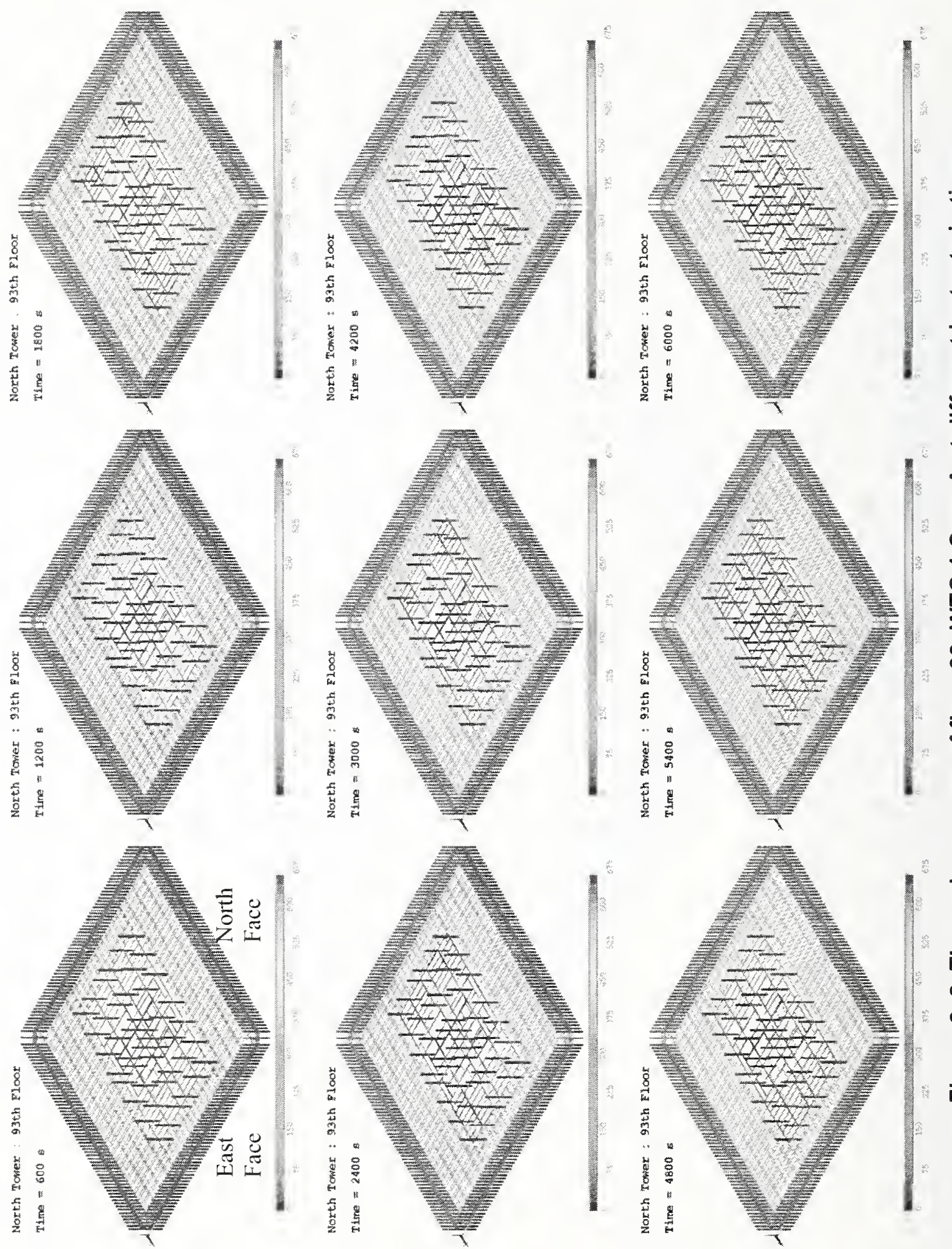

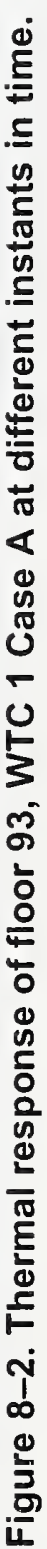




\subsubsection{Floor 94, WTC 1 Case A}

Figure 8-4 shows the thermal response of the $94^{\text {th }}$ floor, WTC 1 Case A at nine different instants in time ranging from $600 \mathrm{~s}$ to $6,000 \mathrm{~s}$ at $600 \mathrm{~s}$ intervals. As for the $93^{\text {rd }}$ floor, the thermal state of the floors at $\hat{3}, 600$ s has not been shown due to space limitation on one page. Each sub-figure shows the truss assembly and core beams that support the $94^{\text {th }}$ floor. Perimeter and core columns above the $94^{\text {th }}$ floor concrete slab are subjected to fires on the $94^{\text {th }}$ floor while columns below the $94^{\text {th }}$ floor slab are subjected to fires on the $93^{\text {rd }}$ floor. The north and east faces of the floor have been marked on the first sub-figure for orientation.

The structural and fireproofing damage due to the aircraft impact is shown in Figure 8-3. The sub-figure on the left shows structural damage (contours in green) to floor 94, while the sub-figures on the right shows fireproofing damage (contours in blue) to floor trusses and core beams that support floor 94 . Structural damage was incorporated by removing the concrete slab, trusses or core beams in the area marked by the green rectangles in Figure 8-3.

Figure 8-3 shows no fireproofing damage and limited structural damage due to aircraft impact on floor $94 .^{3}$ Table 8-4 shows no fireproofing or structural damage for any perimeter column on floor 93. However there is extensive structural damage on the perimeter columns above floor 94 especially on the north face (as evidenced in the photographic observations). Only one perimeter column panel on floor 94 was predicted to have structural damage on the south face (NIST NCSTAR 1-5A). Table 8-5 shows fireproofing and structural damage for core columns on floors 93 and 94 . There is no fireproofing damage predicted for core columns on floor 93 . Columns 504, 604, and 706 were damaged structurally on floors 93 and 94 . There is also extensive fireproofing damage for columns 503-508, 603-607, 703-707, 803-806, 904-906, and 1004-1006 on floor 94 (NIST NCSTAR 1-2).

Figure 8-4 shows the thermal response of the $94^{\text {th }}$ floor, WTC 1 Case A at nine different instants of time ranging from $600 \mathrm{~s}$ to $6,000 \mathrm{~s}$ at $600 \mathrm{~s}$ intervals. The perimeter and core columns that have been damaged by the impact of the aircraft have not been shown in the pictures. Since there is no fireproofing damage on the trusses that support the slab on the $94^{\text {th }}$ floor, Figure 8-4 shows that the trusses stay relatively cool. The trusses have a mean fireproofing thickness of 2.2 in., which results in only a very gradual heat up of the floor system. Peak temperatures on the order $100{ }^{\circ} \mathrm{C}$ in the trusses are predicted, in the northeast corner at $2400 \mathrm{~s}$ after impact of the aircraft and peak temperatures of approximately $150^{\circ} \mathrm{C}$ during the course of the simulation. The core beams are covered with $0.5 \mathrm{in}$. fireproofing and as a result, the core beams heat up faster. This is illustrated by significant heating of the core beams at $1,800 \mathrm{~s}$ and $2,400 \mathrm{~s}$ after impact (northeast corner) followed by a cooling phase (3,000 s and 4,200 s). This is consistent with fire activity in this region. As the fire moves around the core and spreads toward the south face of WTC 1, heating of the core beams on the west face is predicted, due to fire activity on the $93^{\text {rd }}$ floor (Note that the core beams are subjected to fires on the $93^{\text {rd }}$ floor).

The thermal response of the perimeter and core columns is highly dependent on the state of the fireproofing and to a lesser extent on fire growth and spread pattern. The size and shape of the column (cross-sectional area and circumference) also determine the thermal response of the column. As discussed

3 The damage graphics used in the thermal analysis are discussed in detail in NIST NCSTAR 1-6 and have been presented here for reference only. 
in Chapter 4 and Chapter 7 the thermal state of perimeter columns on the $92^{\text {nd }}$ and the $95^{\text {th }}$ floors also have an effect on the thermal response of the perimeter columns on the $93^{\text {rd }}$ and $94^{\text {th }}$ floors. Since there is no fireproofing damage for perimeter columns on the $93^{\text {rd }}$ or the $94^{\text {th }}$ floor, a moderate increase in perimeter column temperature is predicted. Maximum perimeter column temperature at $6,000 \mathrm{~s}$ after impact is approximately $200^{\circ} \mathrm{C}$ to $300^{\circ} \mathrm{C}$ depending on its location.

The core columns above floor 94 exhibit a vast variation in steel temperature. Columns 501, 601, 701, 801,901 , and 1,001 stay relatively cool throughout the duration of the event despite the fire activity in this region. These columns have no damage to their fireproofing. Column 607 shows a very high temperature at $600 \mathrm{~s}$ after impact. At 1,200 s after impact, column 607 has become cooler and continues to cool but shows an incrcase in column temperature at 3,000 s. Since column 607 has fireproofing and has a relatively lighter cross-section, the thermal response of this column is closely coupled and consistent with the fire activity in the vicinity of this column (NIST NCSTAR 1-5F). Fire simulations indicate upper layer temperatures on the order of $1,000{ }^{\circ} \mathrm{C}$ in the northeast corner at 15 minutes into the simulation, followed by a cool down phase.

All core columns that have lost their fireproofing do not heat up at the same rate. Columns 1004, 1005, and 1,006 (no fireproofing on any of the columns) heat up at different rates. This is due to differences in the size of the columns and differences in fire exposure. (Note that because of the presence of partitions, the fire exposure on four sides of a core column could be different.) These columns exhibit significantly high temperatures in the $500{ }^{\circ} \mathrm{C}$ to $600{ }^{\circ} \mathrm{C}$ range from $1,800 \mathrm{~s}$ until the end of the simulation. This is due to constant fire activity in the area surrounding these columns on floor 94 .

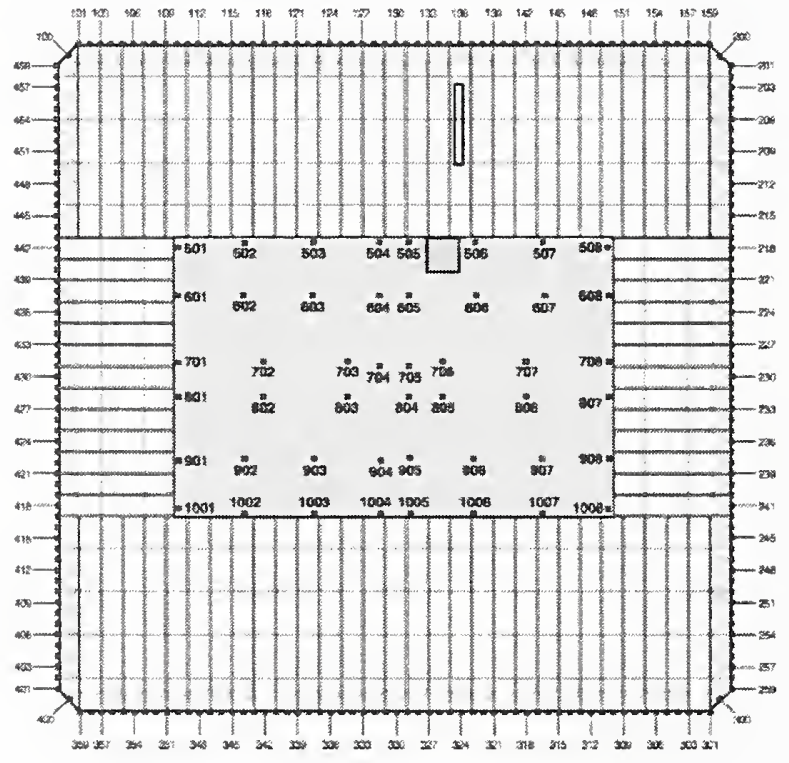

Structural damage for floor 94

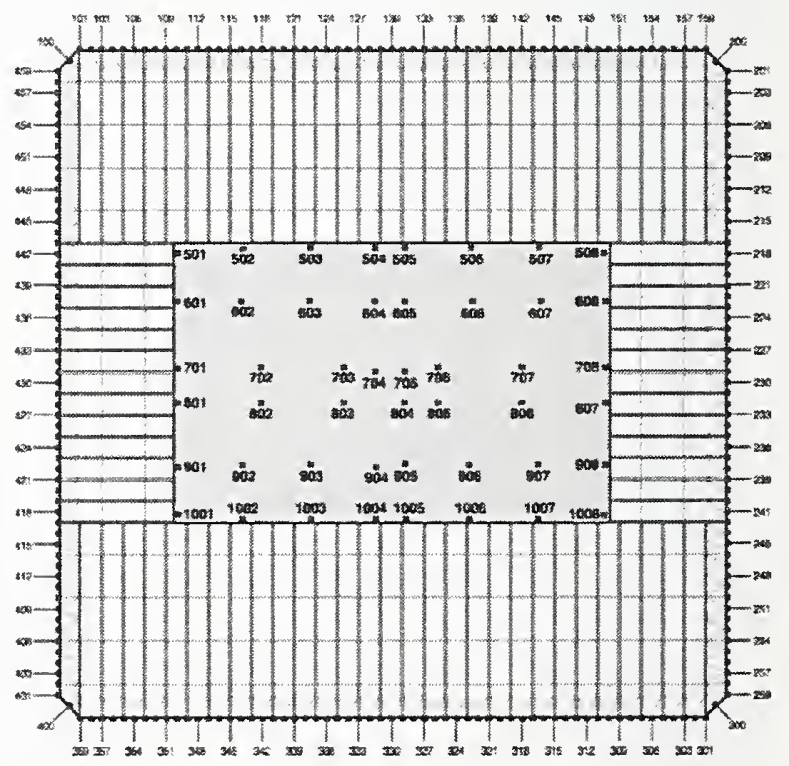

Fireproofing damage on floor trusses and core beams that support floor 94 

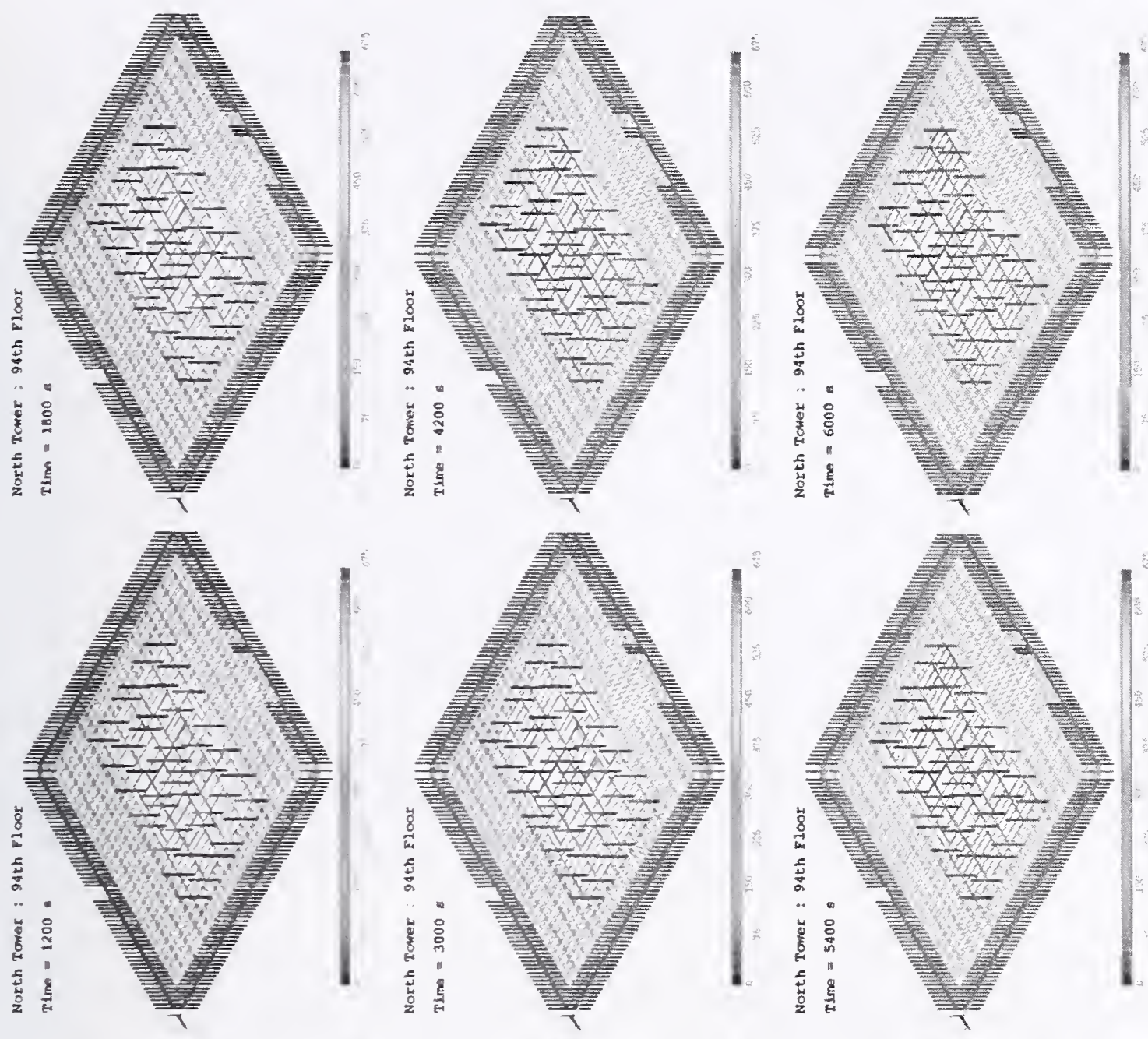

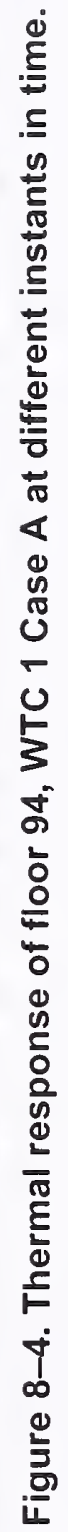




\subsubsection{Floor 95, WTC 1 Case A}

Figure 8-7 and Figure 8-8 shows the thermal response of the $95^{\text {th }}$ floor, WTC 1 Case A at nine different instants in time ranging from $600 \mathrm{~s}$ to $6,000 \mathrm{~s}$ at $600 \mathrm{~s}$ intervals. The figure shows the truss assembly and core beams that support the $95^{\text {th }}$ floor. Perimeter and core columns above the $95^{\text {th }}$ floor concrete slab are subjected to fires on the $95^{\text {th }}$ floor, while columns below the $95^{\text {th }}$ floor are subjected to fires on the $94^{\text {th }}$ floor. The north and east faces have been marked for orientation.

The structural and fireproofing damage caused by the aircraft impact is shown in Figure 8-5. This figure shows structural damage to floor 95 and fireproofing damage to the trusses and core beams that support floor 95. Figure indicates extensive fireproofing and structural damage on the north face for floor trusses, core beams and concrete slabs on floor 95 . Table 8-4 shows no fircproofing damage for any of the perimeter columns on floor 94 or floor 95 . However, there is extensive structural damage on the perimeter columns on these floors, especially on the north face (as evidenced in the photographic observations NIST NCSTAR 1-5A). Only one perimeter column panel on floor 94 and 95 had structural damage on the south face (again observed in photographic evidence). Table $8-5$ shows fireproofing and structural damage for core columns. Columns 504, 604, and 706 are damaged structurally on floors 94 and 95 . There is also extensive fireproofing damage for columns 503-508, 603-607, 703-707, 803-806, 904-906, and 10041006 on floor 94 (below the $95^{\text {th }}$ floor concrete slab). On floor 95 fireproofing damage is indicated for columns 503-506, 603-606, 703-708, 803-806, 904-906, and 1004-1006.

Figure 8-6 shows upper layer temperatures for floor 95, WTC 1 Case A predicted from the fire dynamics simulations at six different instants in time (NIST NCSTAR 1-5F). These upper layer temperatures are directly responsible for heating the perimeter and core columns above floor 95 and the trusses that support floor 96. The bottom face of the concrete slab on floor 96 , and the top face of the concrete slab on floor 95 was subjected to radiative fluxes from fire growth on floor 95.

Figure 8-7 and Figure 8-8 show the thermal response of the $95^{\text {th }}$ floor WTC 1 Case $A$ at nine different instants of time ranging from $600 \mathrm{~s}$ to $6,000 \mathrm{~s}$ at $600 \mathrm{~s}$ intervals. The perimeter and core columns, core beams and trusses severed by the impact of the aircraft have not been included. Since there is extensive fireproofing damage on the trusses that support the slab on the $95^{\text {th }}$ floor, Figure $8-7$ shows that the trusses in the north face heat up rapidly. There is significant fire activity in the northeast corner on floor 94 and this fact coupled with lack of fireproofing thickness results in very high temperatures in the trusses (sub-figures for the $600 \mathrm{~s}-1800 \mathrm{~s}$ duration). As the fires spread towards the south face of the building, the steel trusses in the northeast corner loose heat convectively and radiatively and this results in gradual cooling of the truss elements $(4200 \mathrm{~s})$. The rcst of the truss (other than the one with no fireproofing) has a mean fireproofing thickness of $2.2 \mathrm{in}$., which can result in only a very gradual heat up of the floor system. Peak temperatures of the order $100^{\circ} \mathrm{C}$ are predicted in the trusses on the west face at $2,400 \mathrm{~s}$ after impact of the aircraft and peak temperatures of approximately $150{ }^{\circ} \mathrm{C}$ during the course of the simulation.

The thermal response of the perimeter and core columns is highly dependent on the state of the fireproofing and to a lesser extent on fire growth and spread pattern. The size and shape of the column (cross-sectional area and circumference) also determine the thermal response of the column. As discussed in Chapter 4 and Chapter 7 the thermal state of perimeter columns on the $93^{\text {rd }}$ floor and the $96^{\text {th }}$ floor also have an effect on the thermal response of the perimeter columns on $94^{\text {th }}$ and $95^{\text {th }}$ floor. Lack of fireproofing damage for perimeter columns on the $94^{\text {th }}$ floor or the $95^{\text {th }}$ floor, can result in moderate 
increase in perimeter column temperature. The core columns exhibit a vast variation in steel temperature as opposed to the perimeter columns. The west side of the core continues to stay cool, because of lack of fireproofing damage on those columns. Since the fireproofing damage is in the center of the core and towards the east side. the columns in this area show rapid changes in temperature depending on fire intensity and column size. Column 508 at 3000 s shows high temperature below the slab and low temperatures above the concrete slab. This is due to change in fireproofing status of this column across the concrete slab. Toward the end of the simulation. heating of the core columns on the south side is predicted. as there is significant fire activity on the south face on the $94^{\text {th }}$ and $95^{\text {th }}$ floor. At $6,000 \mathrm{~s}$ after impact, the core columns on north side of the core are relative cooler as compared with core columns in the south side of the core.

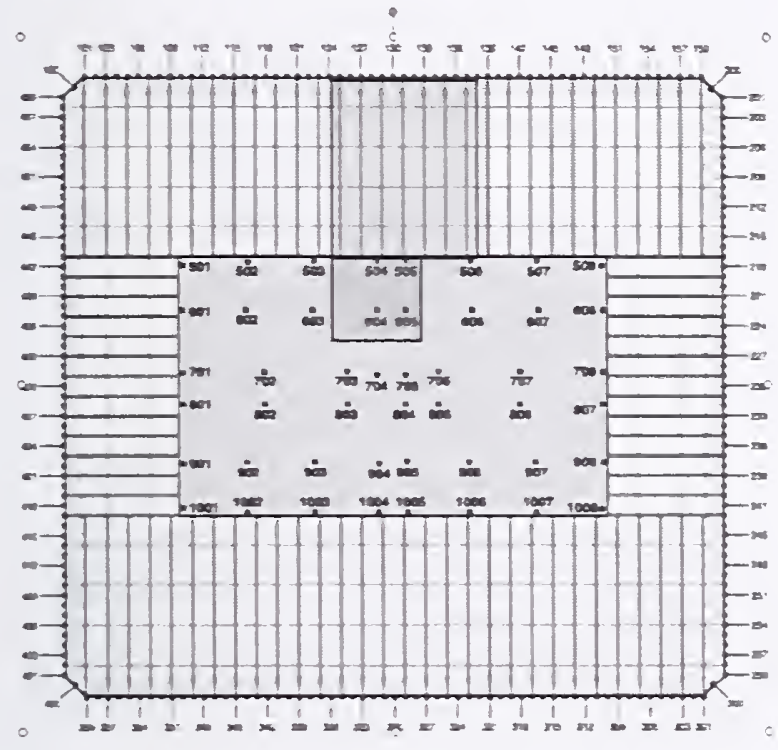

Structural damage for floor 95

Structural Damage

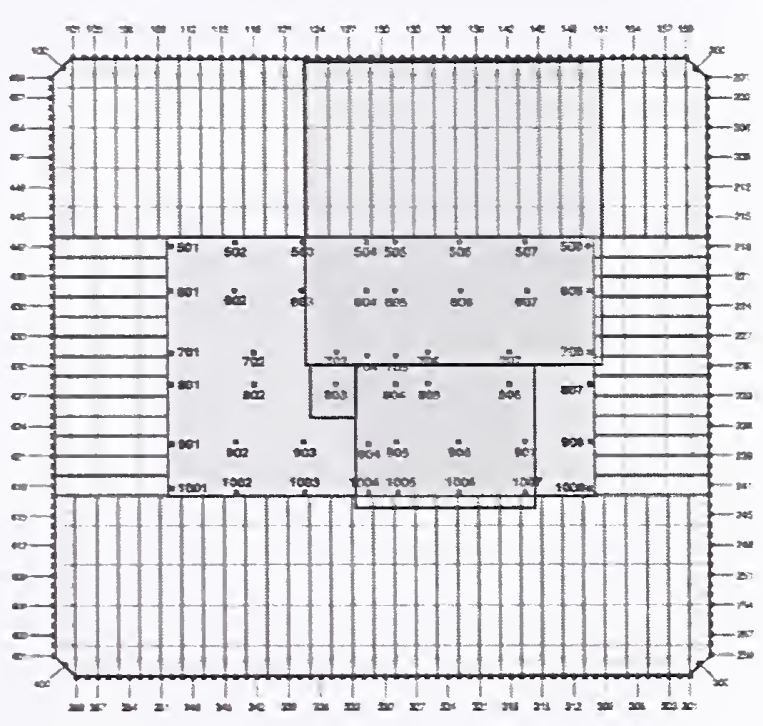

Fireproofing damage on floor trusses and core beams that support floor 95

Fireproofing Damage

Figure 8-5. Structural and fireproofing damage on floor 95, WTC 1 Case $A_{i}$. 

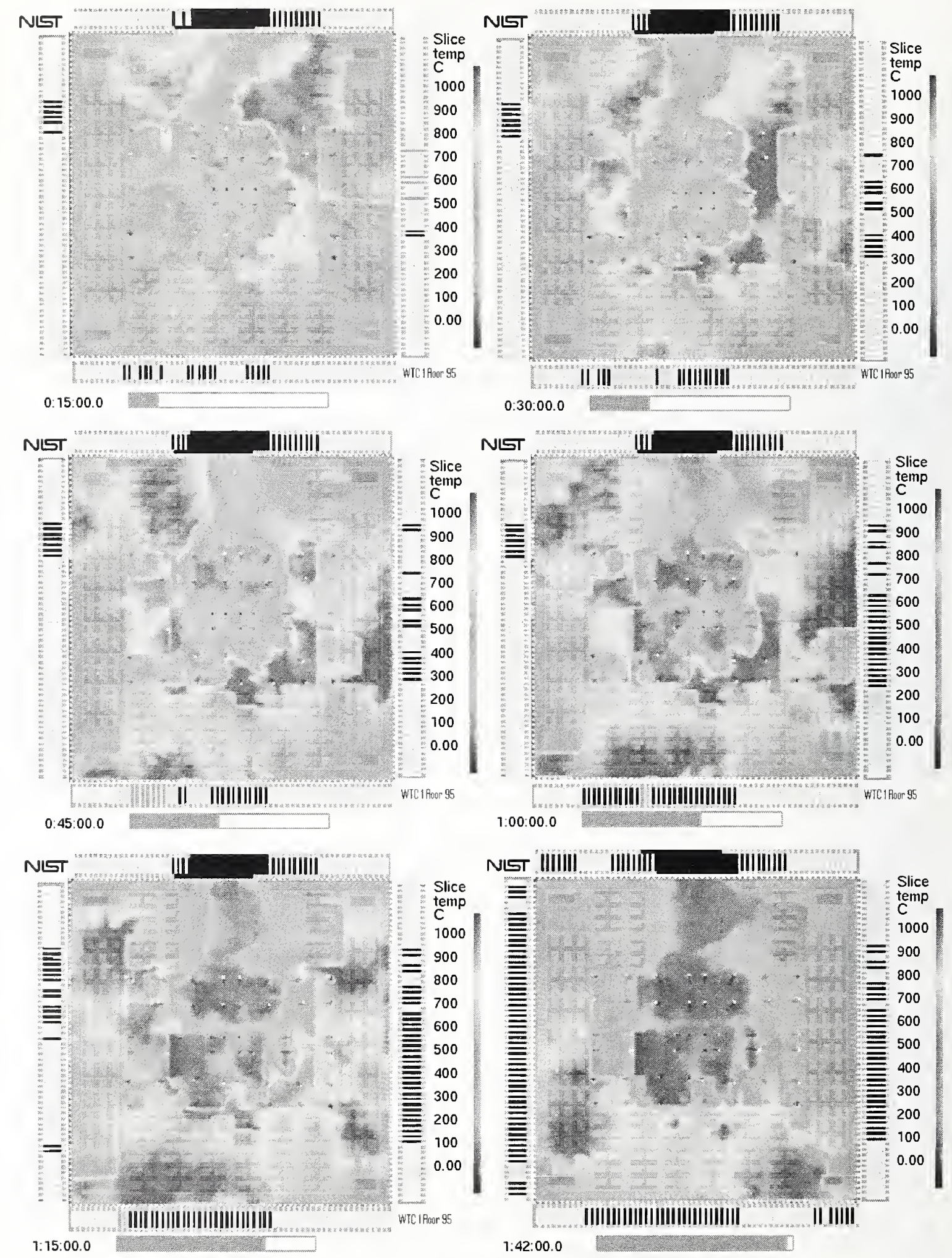

Figure 8-6. Upper layer temperature predicted by fire dynamics simulation for floor 95 , WTC 1 Case A. 

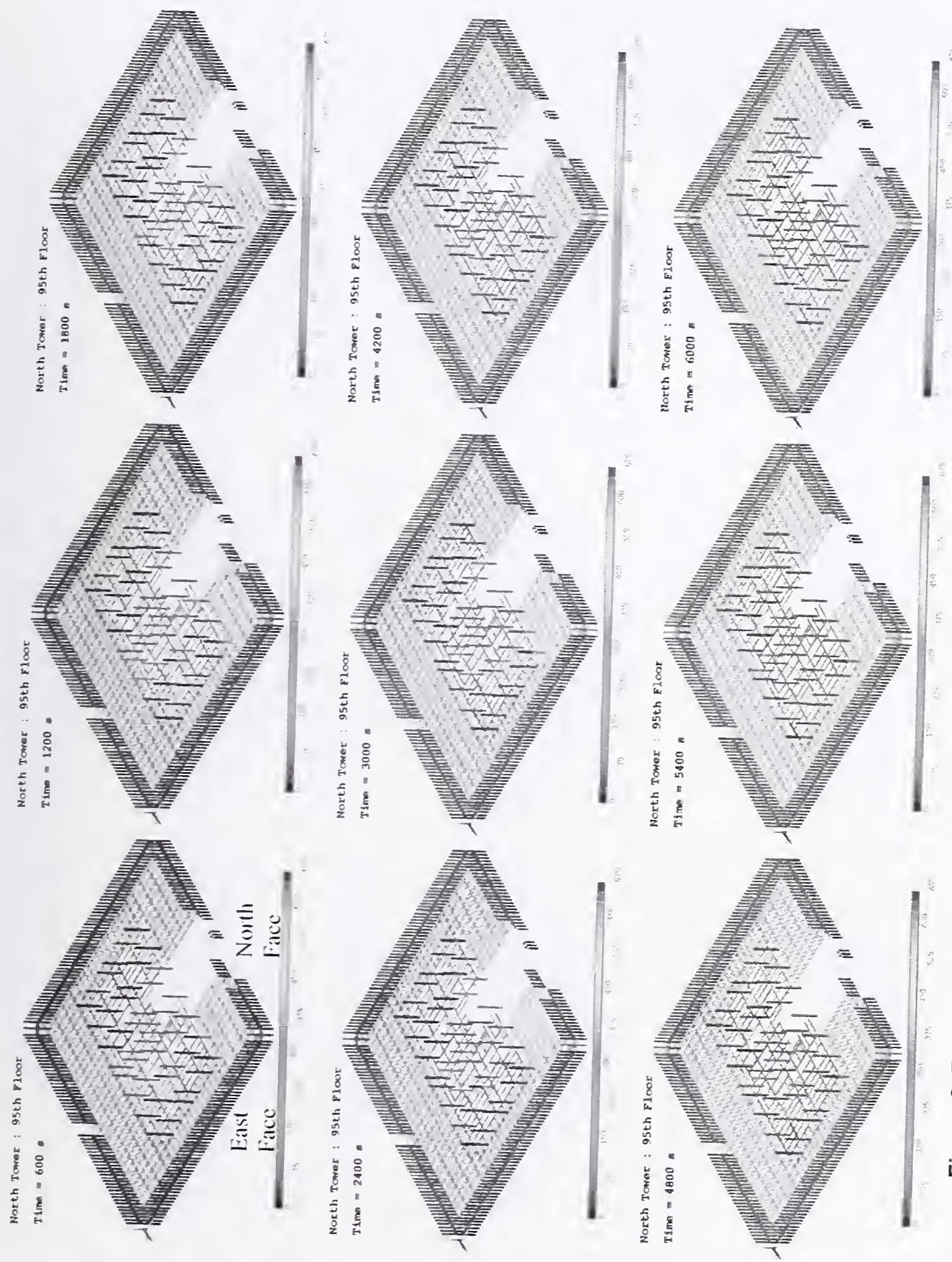

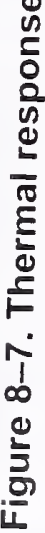



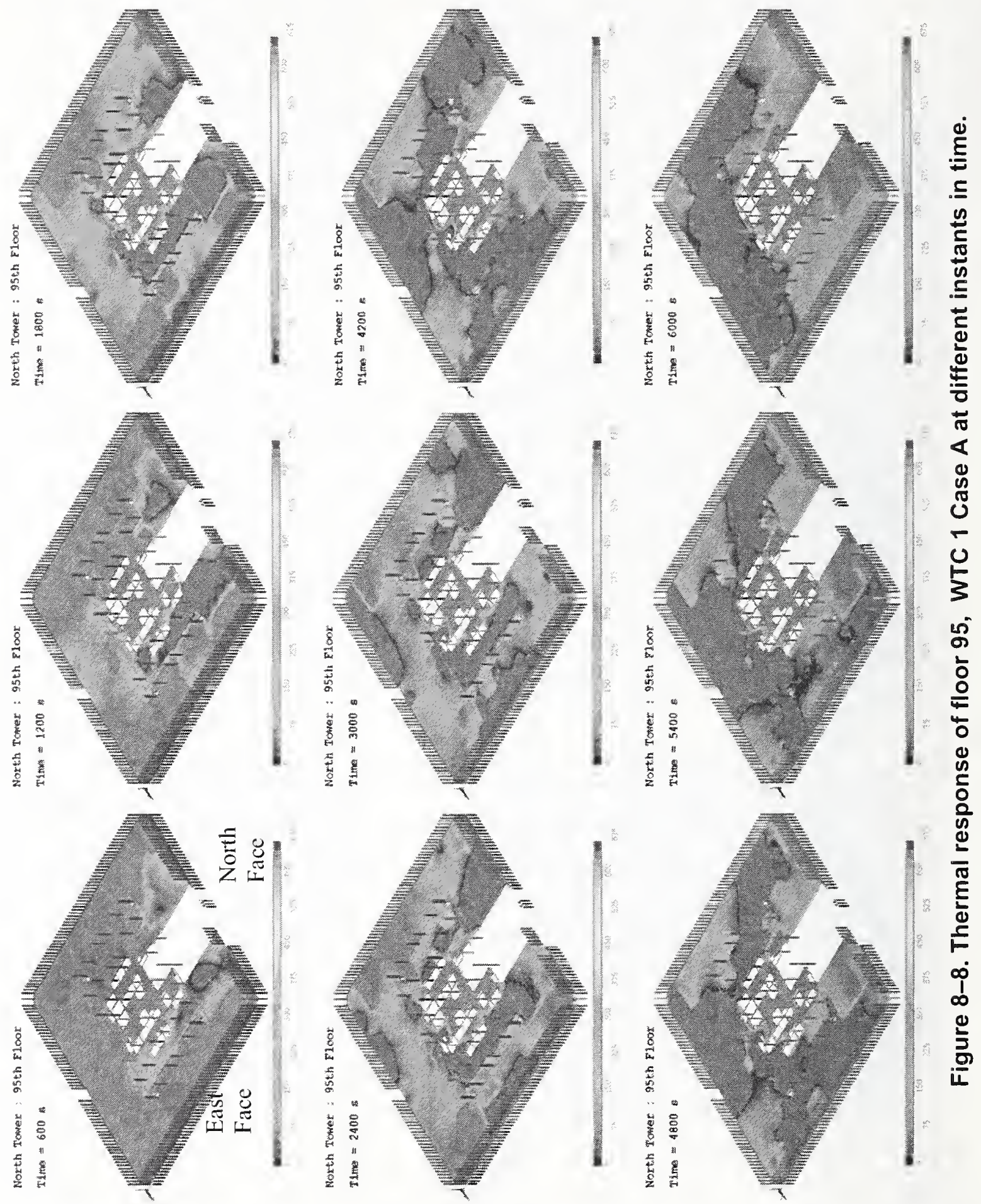

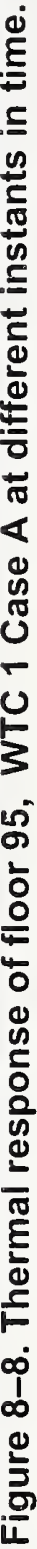




\subsubsection{Floor 96, WTC 1 Case A}

The thermal state of the $96^{\text {th }}$ floor WTC 1 Case A is shown in Figure 8-10 through Figure 8-29 at ninc different instants in time ranging from $600 \mathrm{~s}$ to $6,000 \mathrm{~s}$ at $600 \mathrm{~s}$ intervals. Each figure shows the truss assembly and core beams that support the $96^{\text {th }}$ floor. Perimeter and core columns above the $96^{\text {th }}$ floor concrete slab are subjected to fires on the $96^{\text {th }}$ floor while columns below the $96^{\text {th }}$ floor slab are subjected to fires on the $95^{\text {th }}$ floor. The north and east faces have been marked in Figure 8-10 for orientation purposes.

The aircraft impact analysis and fireproofing damage results have been shown in Figure 8-9. The figure shows extensive fireproofing and structural damage on the north face. Table $8-4$ shows the fireproofing and structural damage status for perimeter columns on floors 95 and 96. (WTC 1 Case A). There is no fireproofing damage for perimeter columns on floor 95 , and only a single panel on the south face on floor 96 is assumed to have fireproofing damage. This panel is directly above the panel that was damaged (structurally) by the impact of the aircraft on the south face of WTC 1. There is also extensive structural damage on the perimeter columns on floor 95 and 96, especially on the north face (as cvidenccd in the photographic observations NIST NCSTAR 1-5A). Only one perimeter column panel on floor 95 was assumed to have structural damage on the south face (again observed in photographic evidence). Table 8-5 shows fireproofing and structural damage for core columns on floors 95 and floor 96. Columns 504. 604 and 706 on floor 95, and column 504 and 604 on floor 96 were damaged structurally. Fireproofing damage is predicted for column 503-506, 603-606, 703-708, 803-806, 904-906 and 10041006 below the concrete slab on $96^{\text {th }}$ floor. Above the slab, fireproofing damage on core columns is restricted to 502-506, 602-606, 702-705, 803-805, 902-905 and 1002-1005. Floor 96 has the maximum number of core columns that have their fireproofing damaged due to the impact of the aircraft.

Figure 8-10 through Figure 8-29 show the thermal response of the $96^{\text {th }}$ floor, WTC 1 Case A at nine different instants in time ranging from $600 \mathrm{~s}$ to $6000 \mathrm{~s}$ at $600 \mathrm{~s}$ intervals. The perimeter and core columns damaged by the impact of the aircraft are not included in the pictures. Also the core bcams and trusses severed by the impact have not been included (Figure 8-10 through Figure 8-29). Since there is extensive fireproofing damage on the trusses that support the slab on the $96^{\text {th }}$ floor, Figure 8-10 shows that the truss elements in the north face (fireproofing damaged) heat up rapidly. There is significant fire activity on the north face on floor 95 and this fact coupled with lack of fireproofing thickness rcsults in very high temperatures in the trusses ( $600 \mathrm{~s}-1,800 \mathrm{~s})$. As the fires spread towards the south facc of the building, the steel trusses in this region looses heat convectively and radiatively, and this results in gradual cooling of the truss elements $(4,200 \mathrm{~s})$. The rest of the truss (other than the one with no fircproofing) has a mean fireproofing thickness of $2.2 \mathrm{in}$. which results in only a very gradual heat up of the floor system. Peak temperatures are of the order of $100^{\circ} \mathrm{C}$ in the trusses on the west face at $2,400 \mathrm{~s}$ after impact of the aircraft, and peak temperatures of approximately $150^{\circ} \mathrm{C}$ are predicted during the course of the simulation. In the area where fireproofing is intact, the fire activity has very little impact on the thcrmal response of the trusses. 


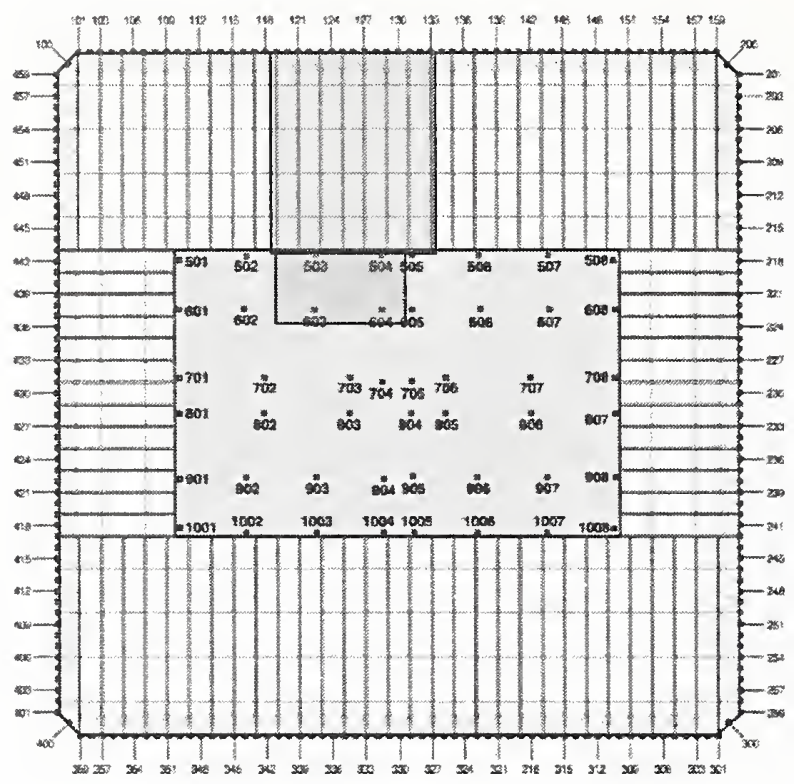

Structural damage for floor 96

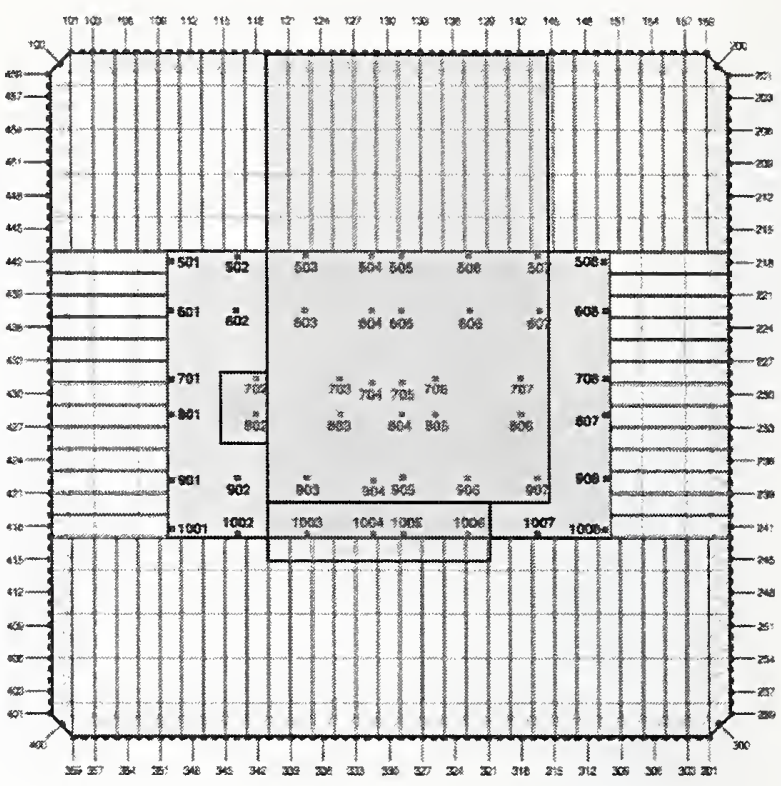

Fireproofing damage on floor trusses and core beams that support floor 96

Structural Damage

Fireproofing Damage

\section{Figure 8-9. Structural and fireproofing damage on floor 96, WTC 1 Case $A_{i}$.}

Since there is no fireproofing damage for perimeter columns on floor 95, moderate increase in perimeter column temperature is predicted. The core columns exhibited a vast variation in steel temperature as opposed to the perimeter columns. The west side of the core (as discussed in previous sections) continues to stay cool, because of lack of fireproofing damage on those columns. The fireproofing damage is in the center of the core but is shaded towards the west side. The columns in this area show rapid changes in temperature depending on fire intensity and column size. Columns 502, 602, 702, 802, 902, and 1002 show significant heating on the $96^{\text {th }}$ floor (because of lack of fireproofing) and are relatively cool on the $95^{\text {th }}$ floor (columns on this floor are fireproofed). 


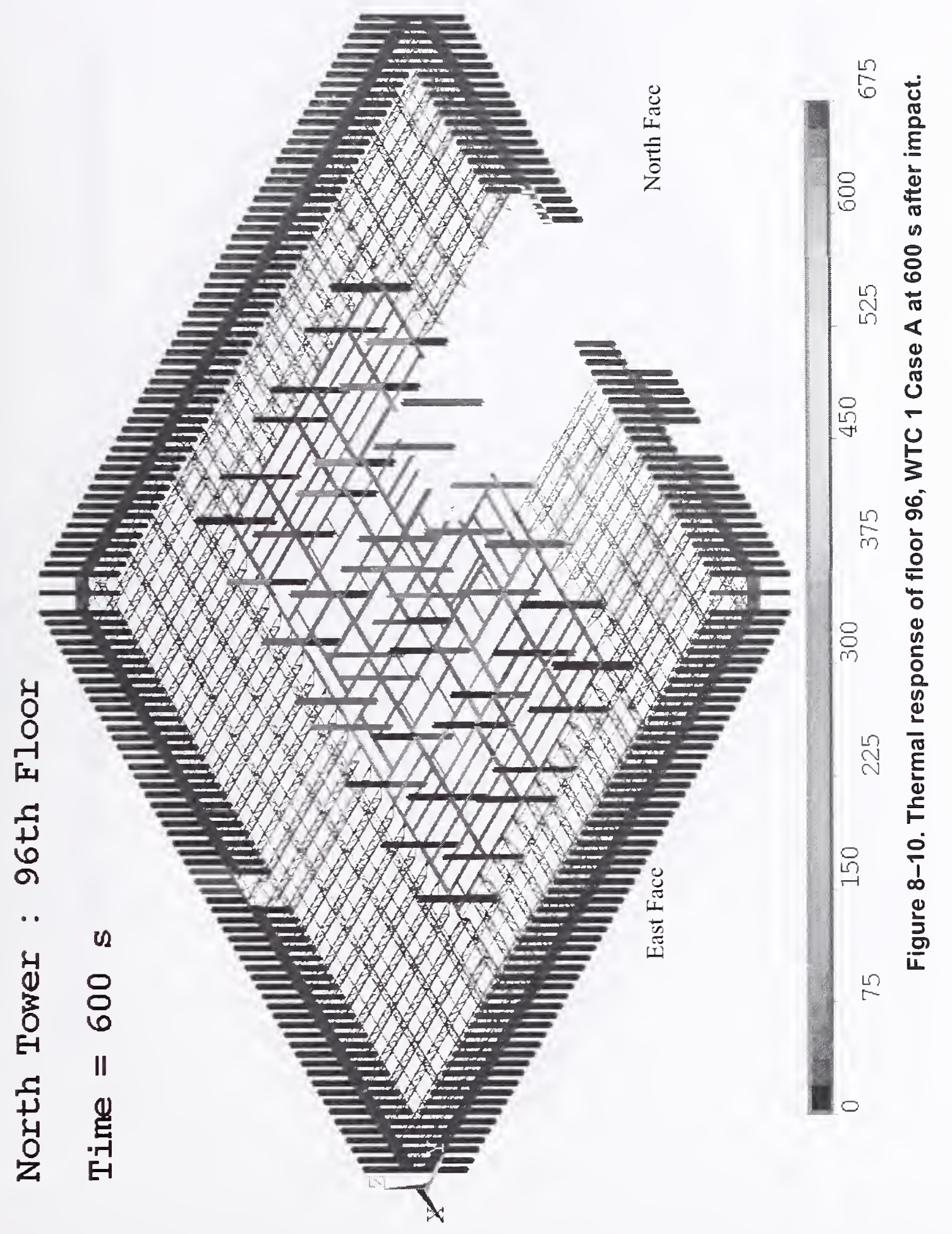




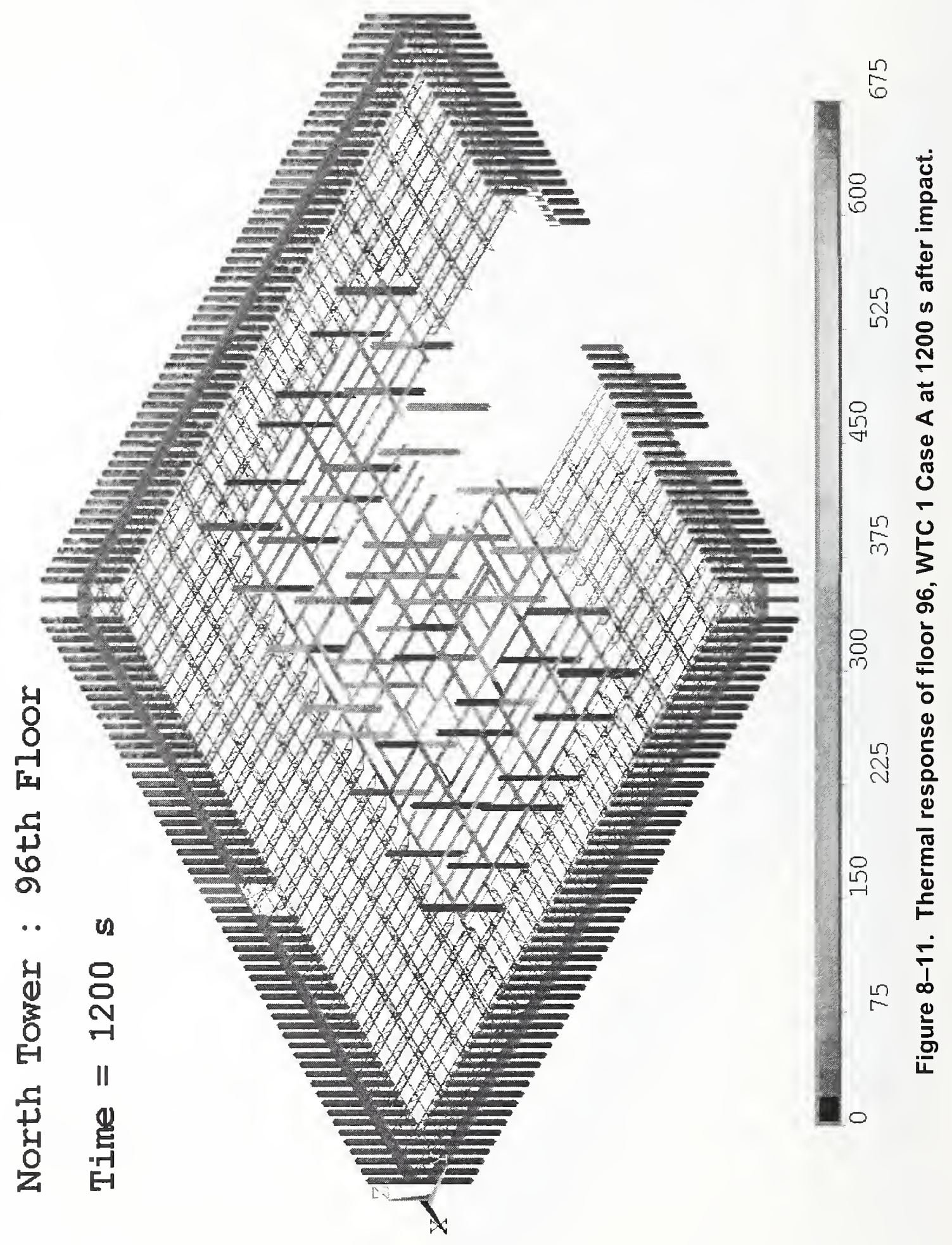




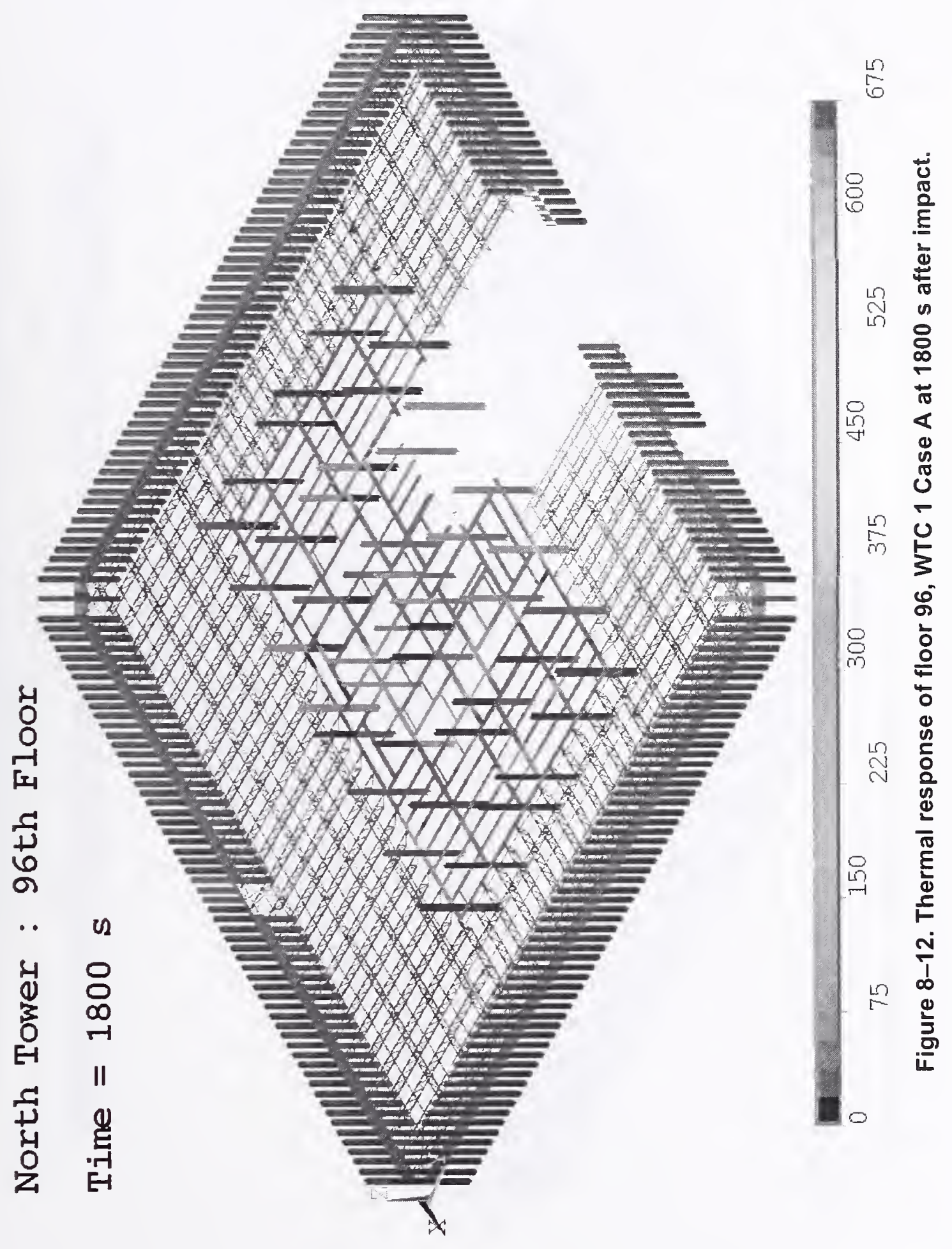




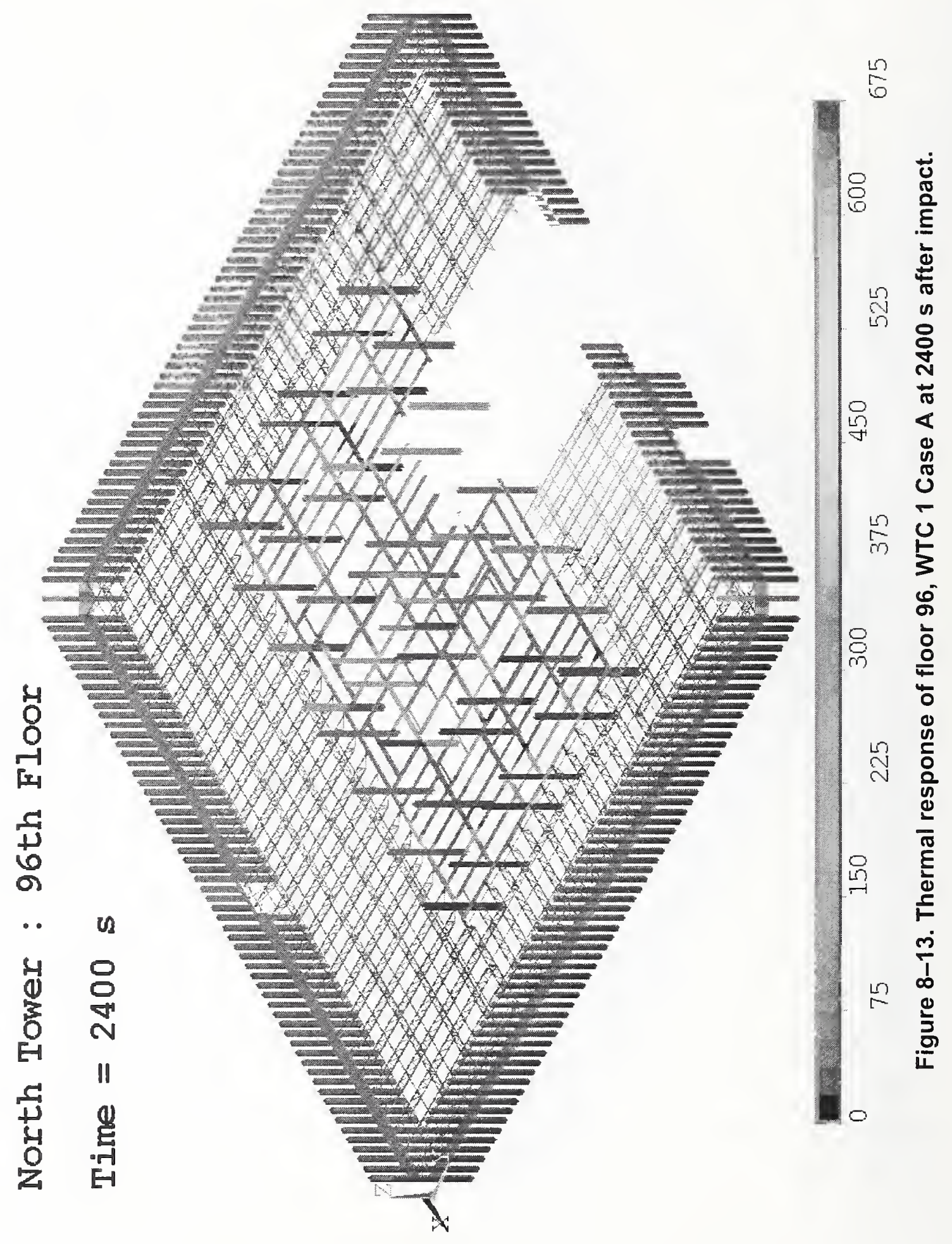




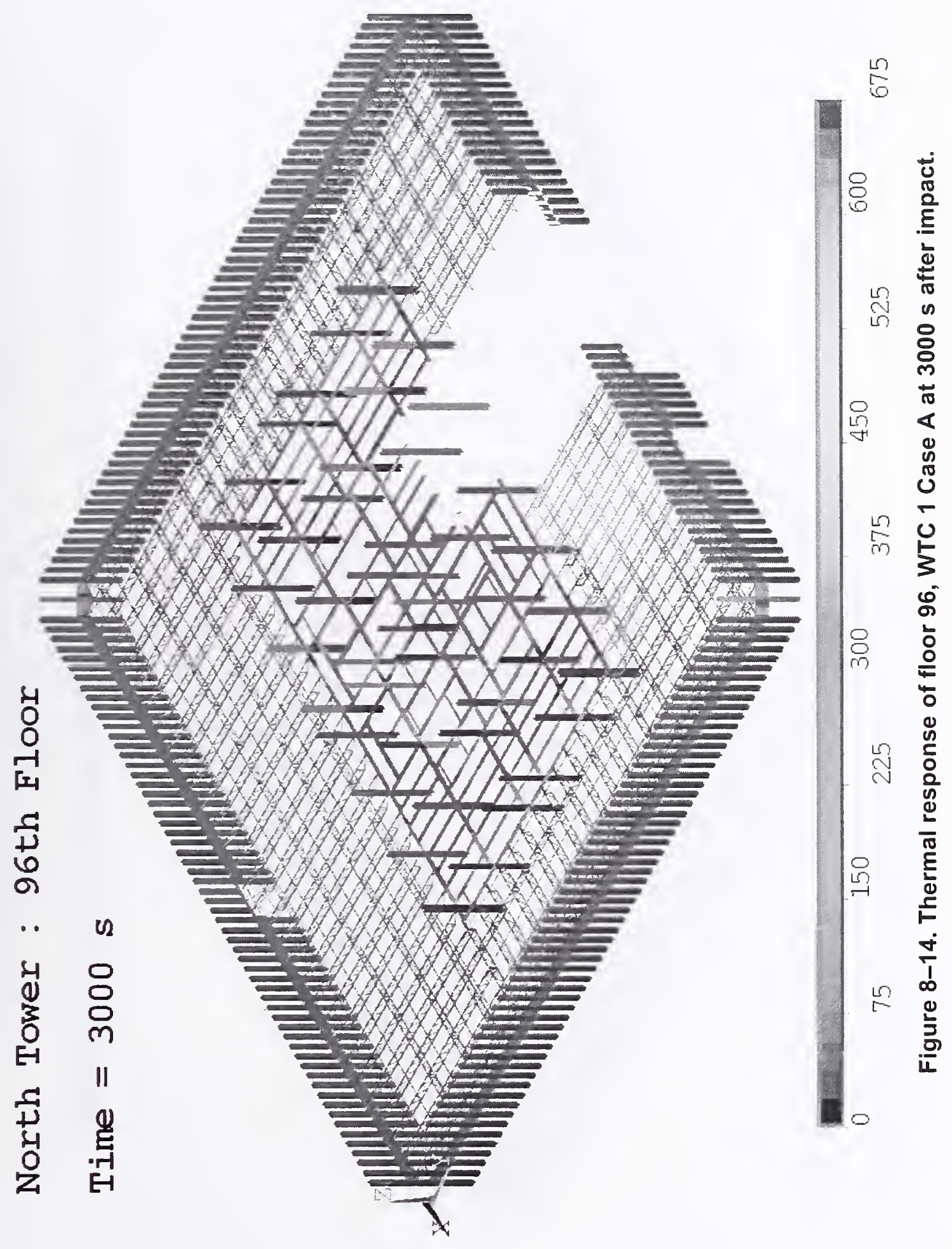




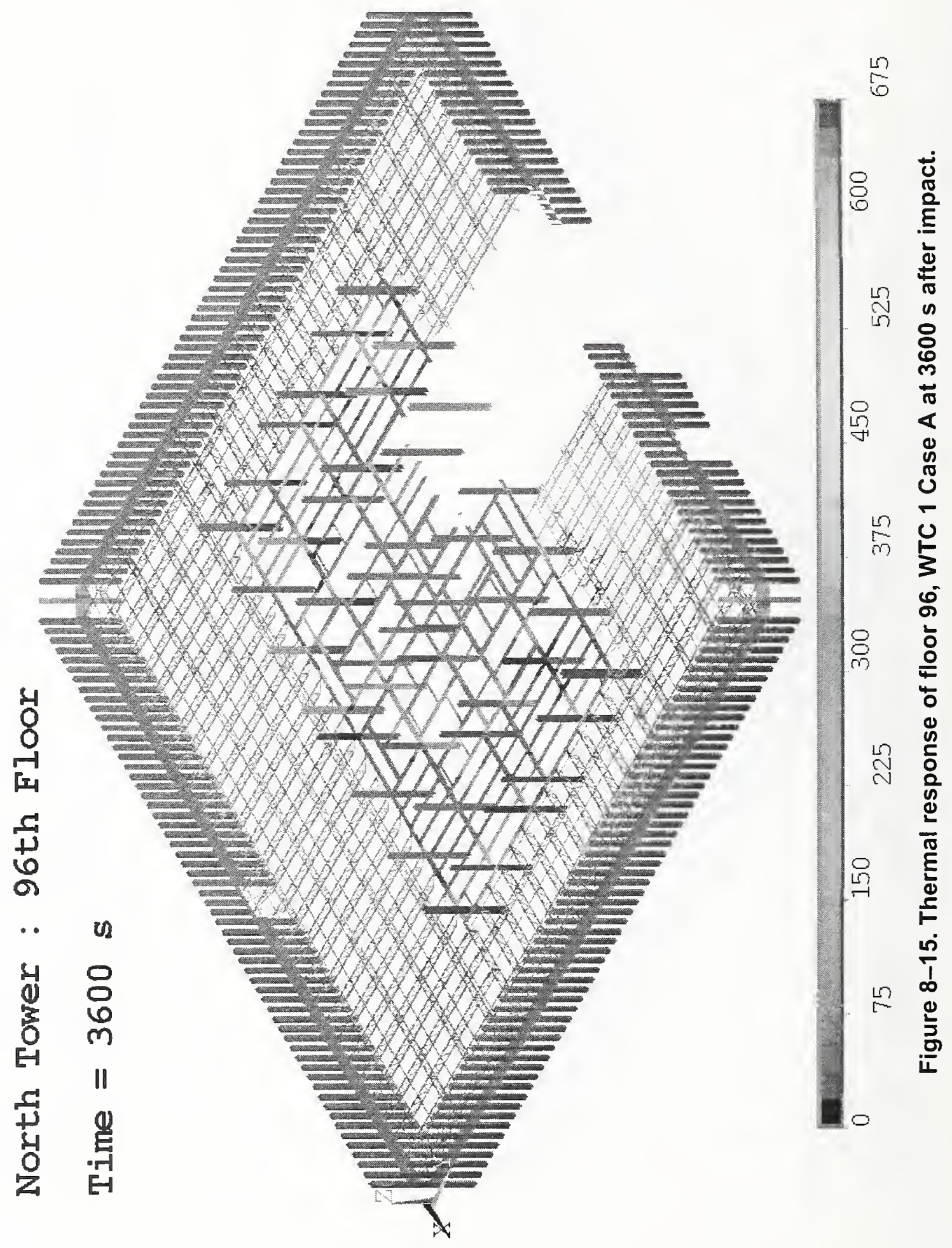




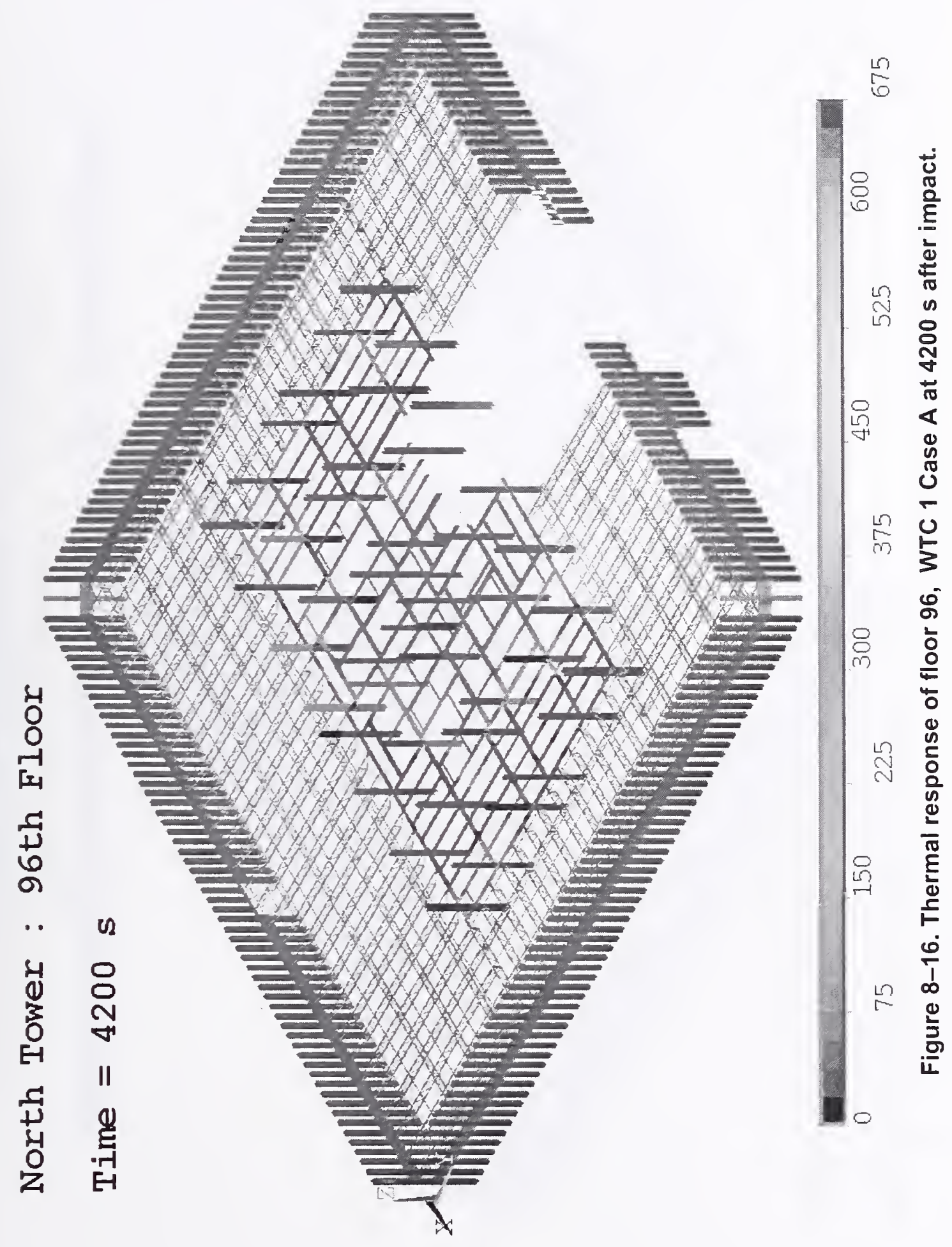




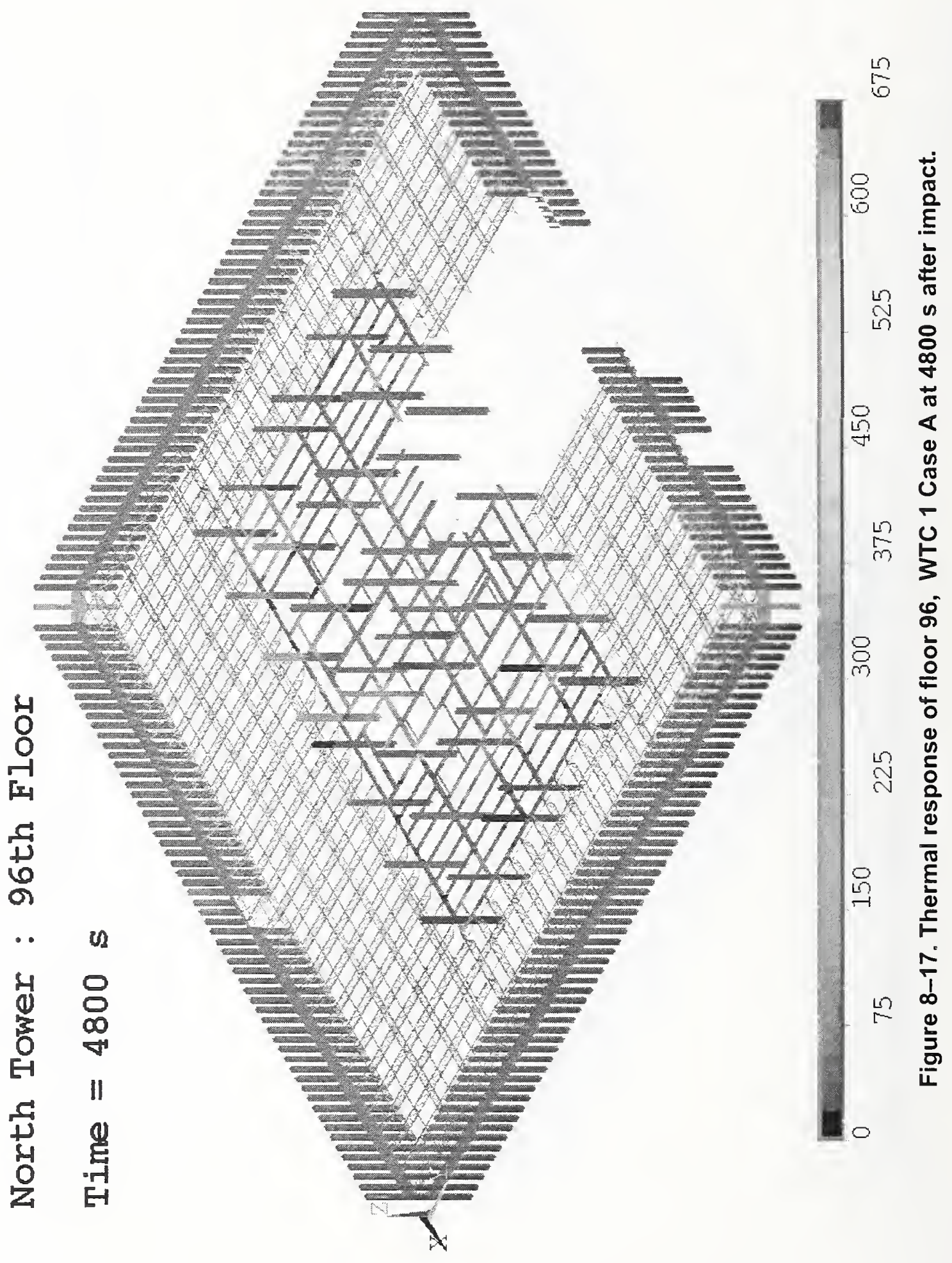




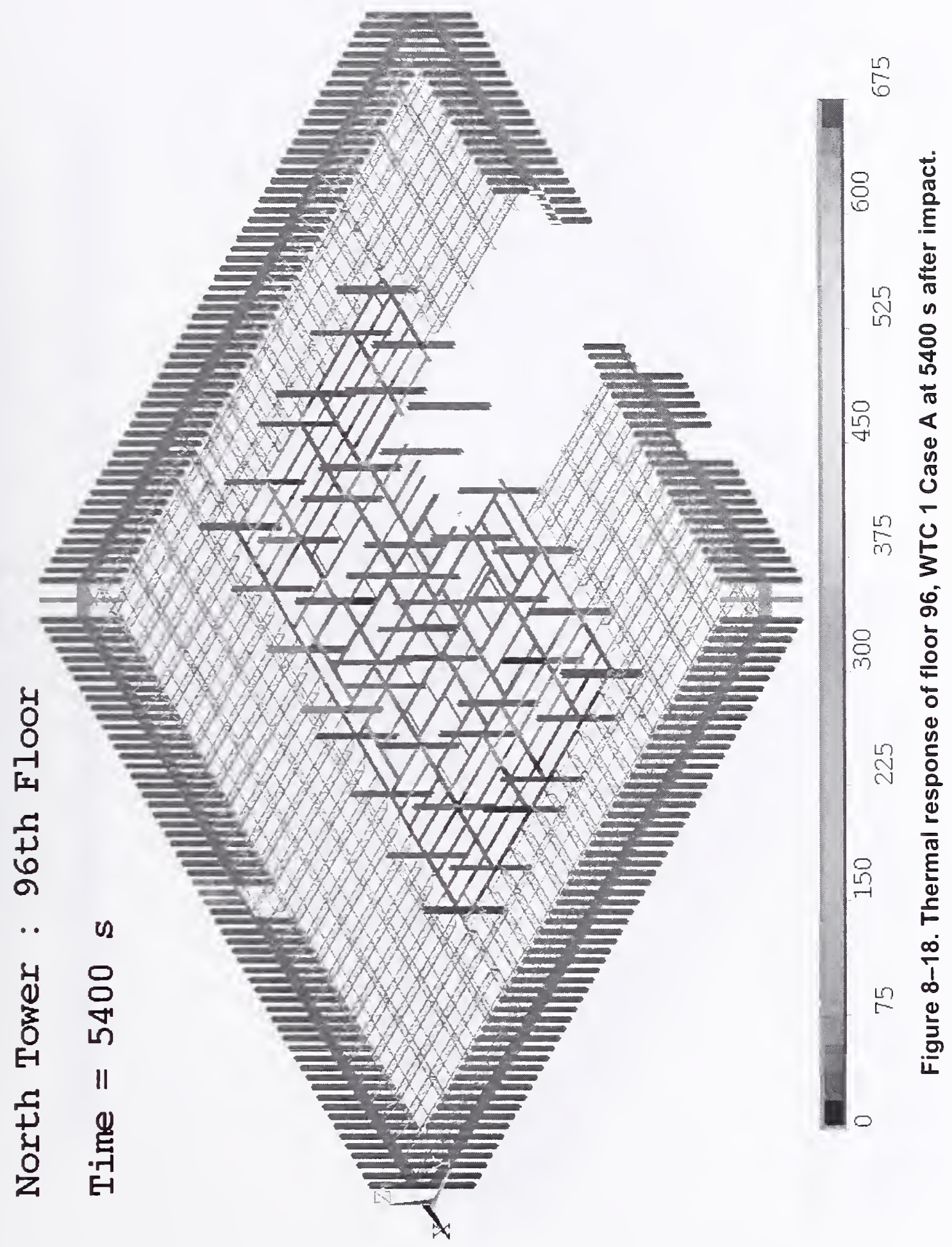




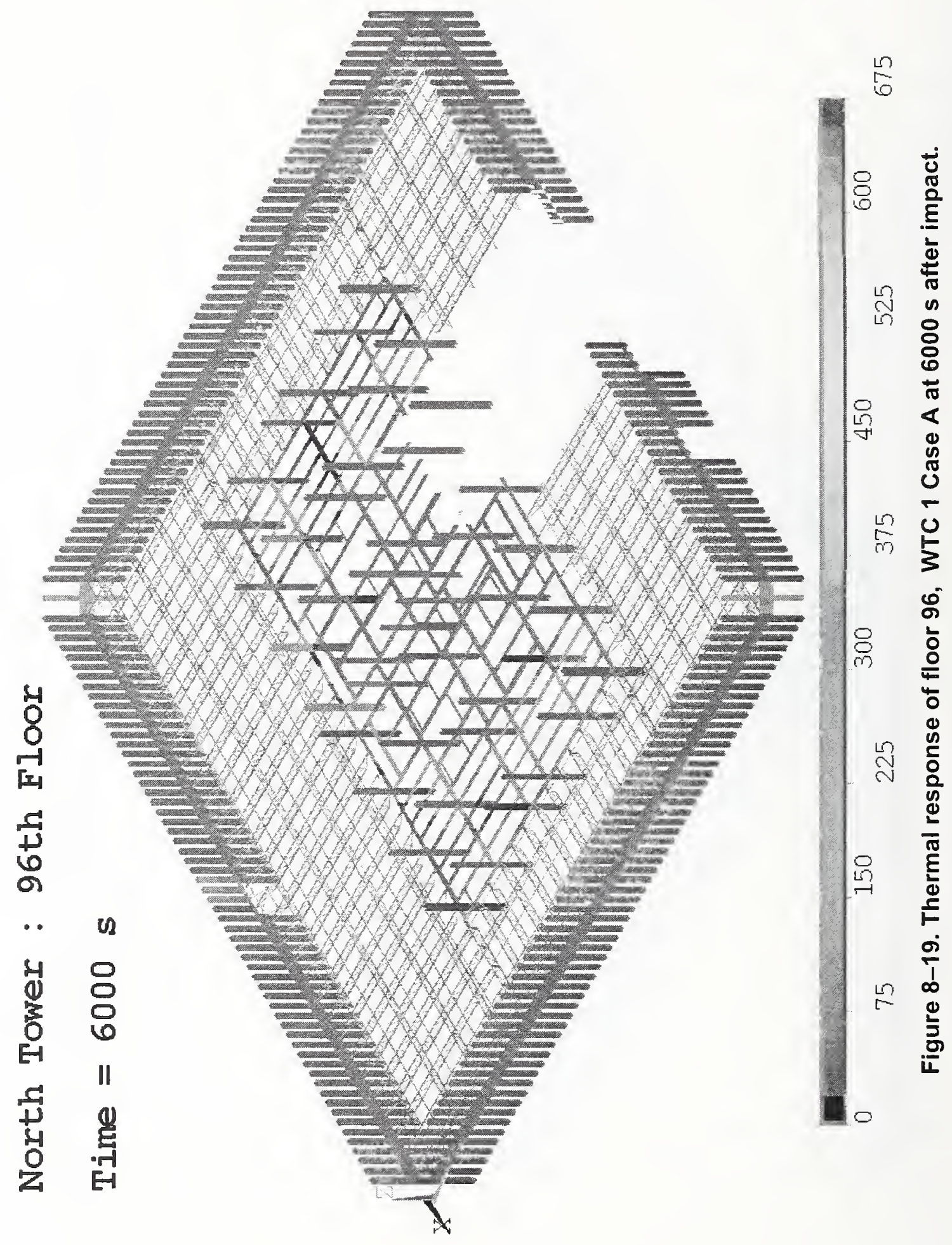




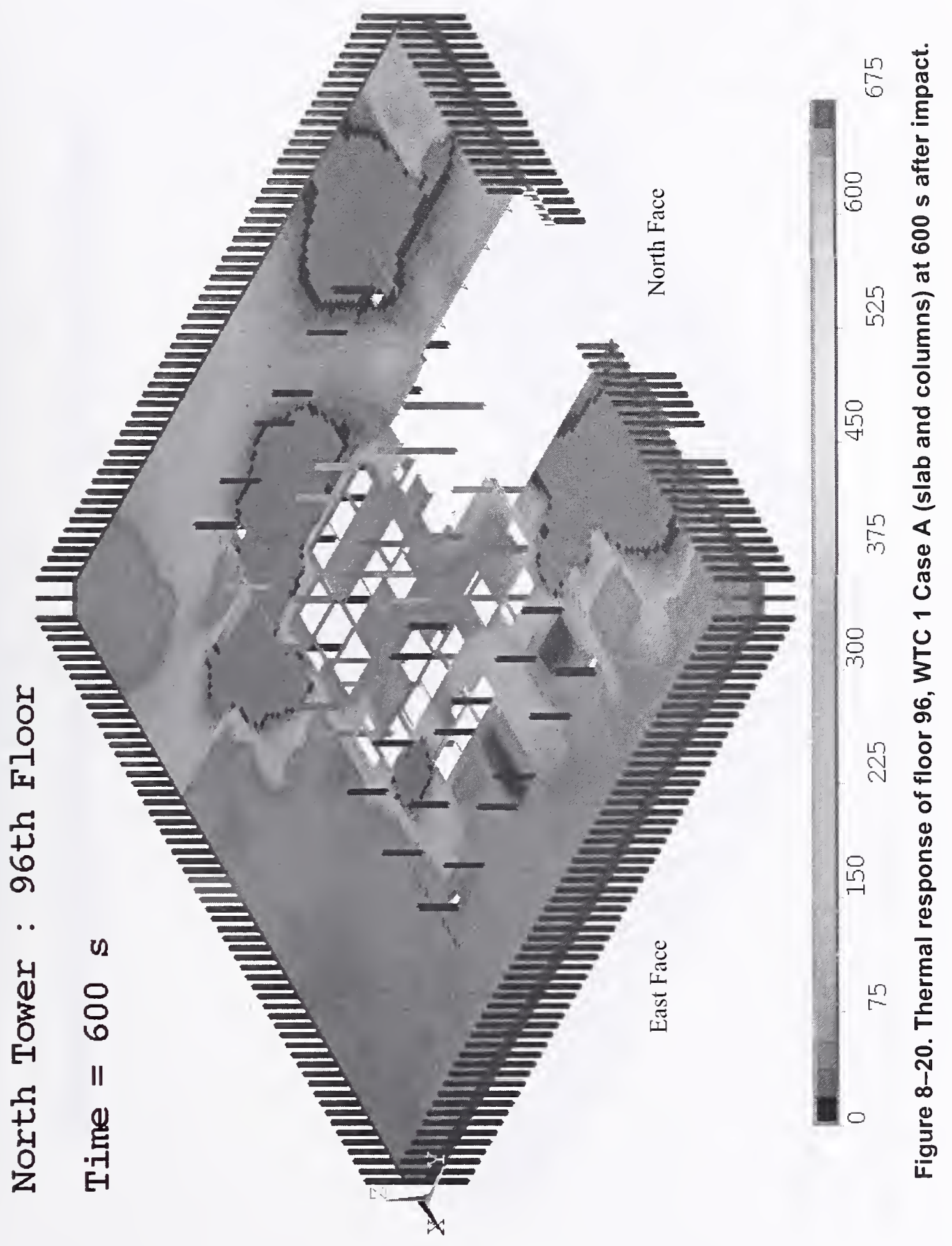




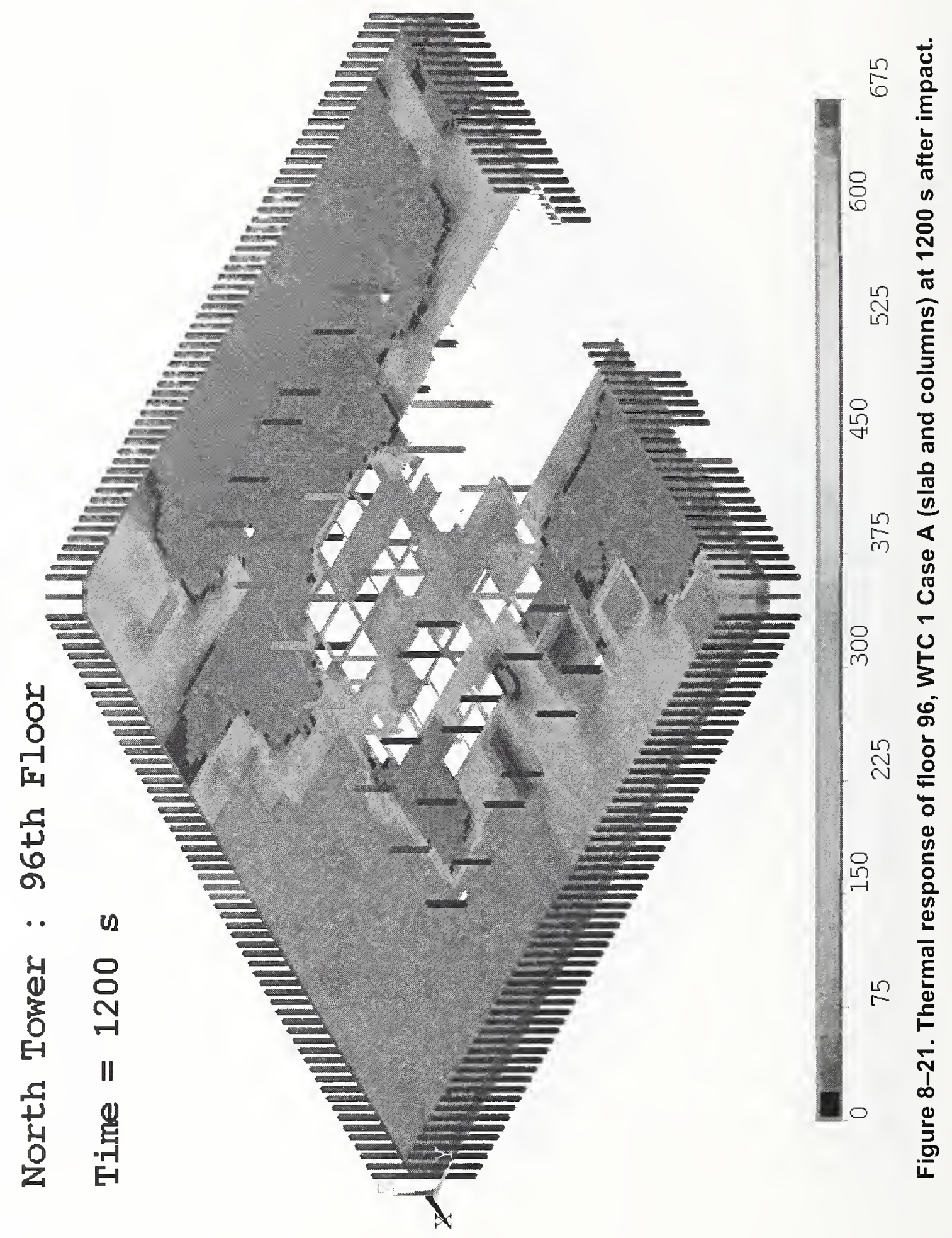




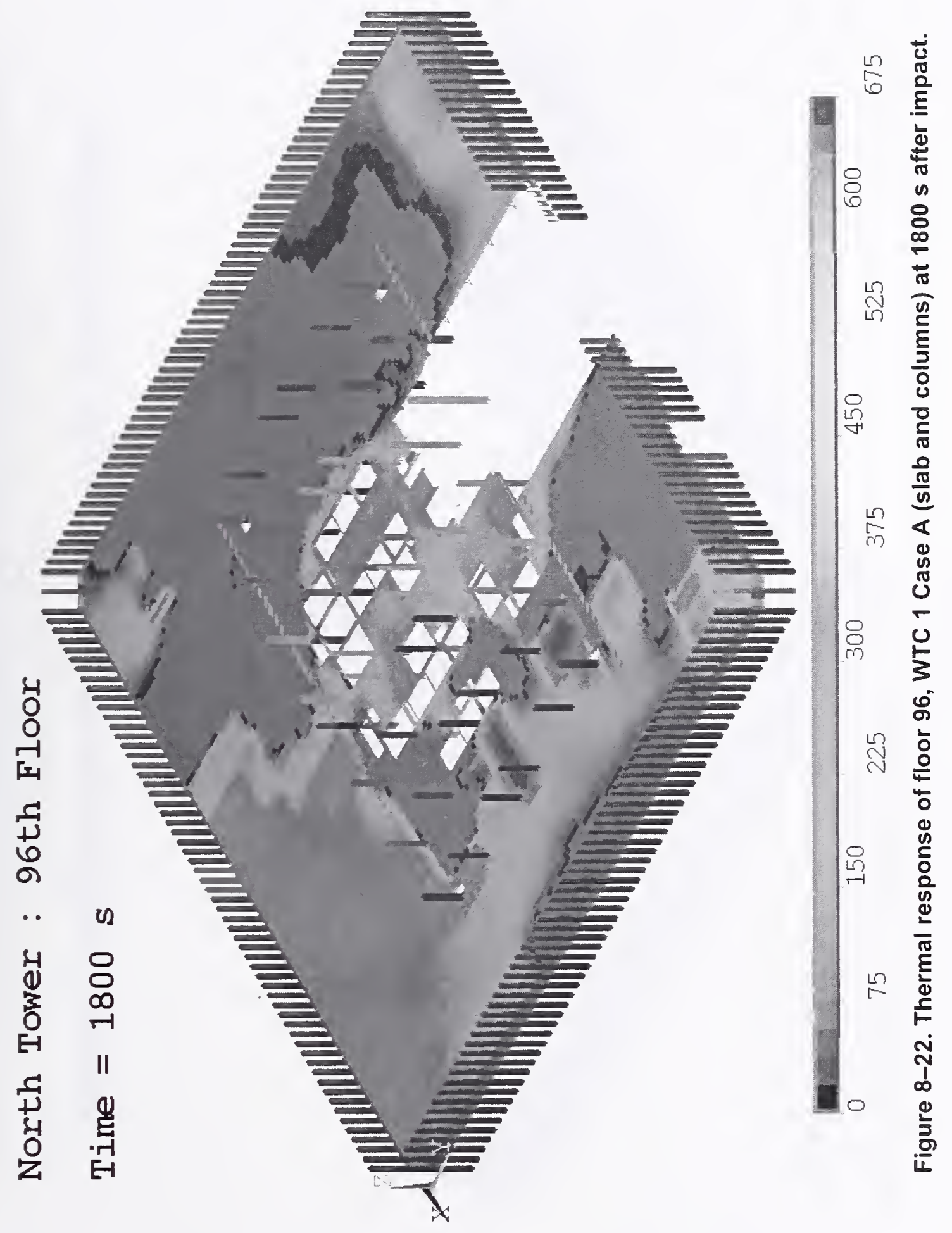




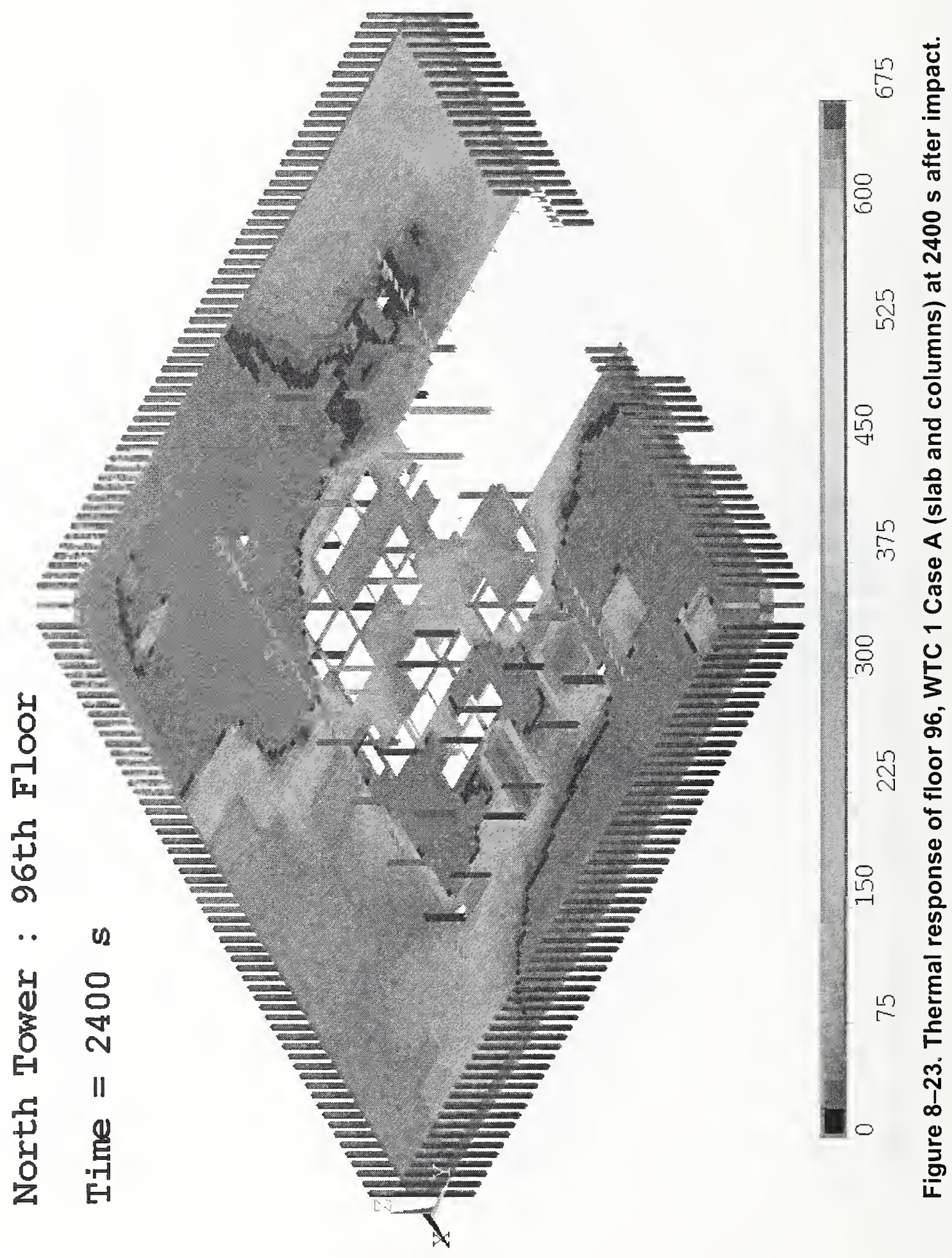




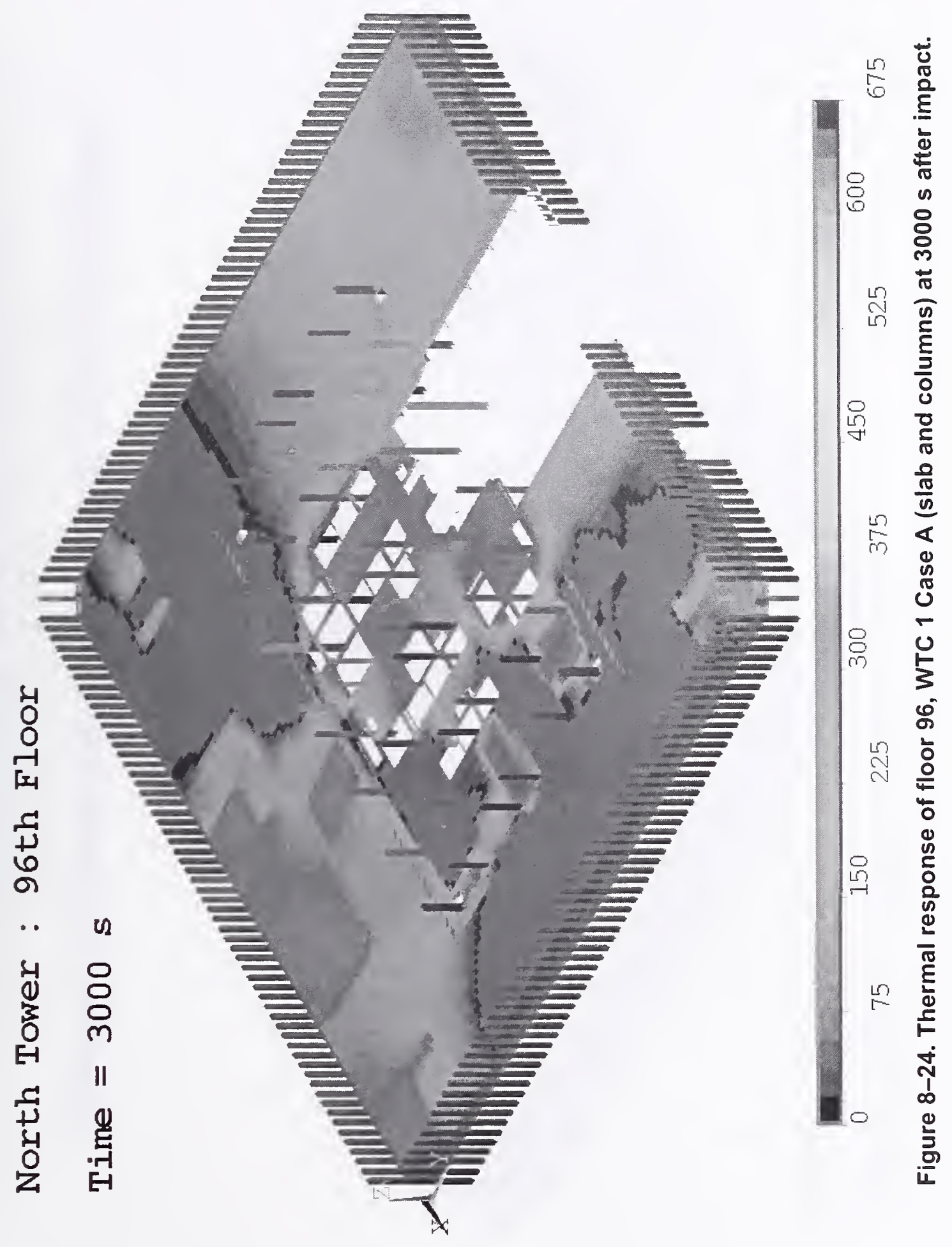




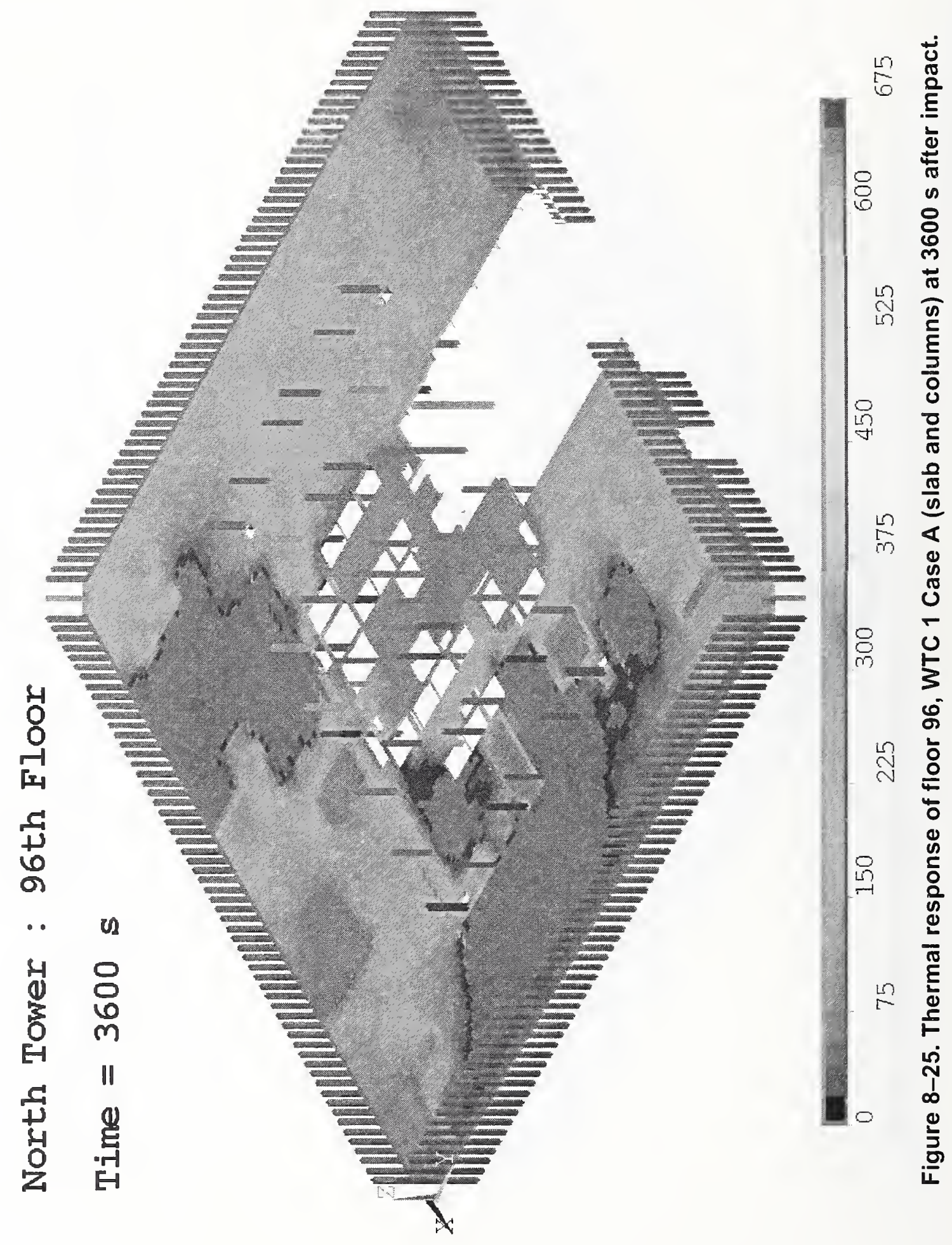




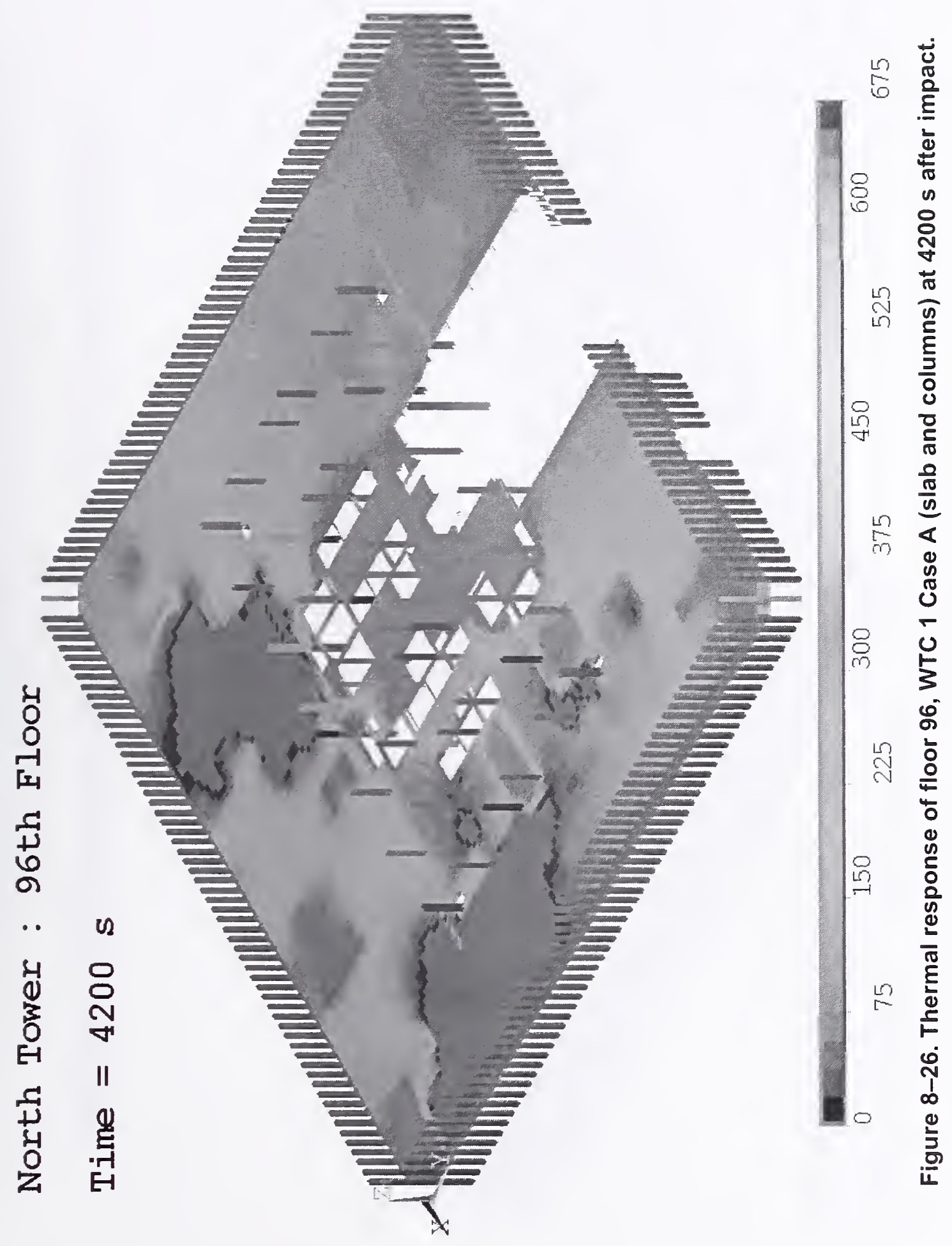




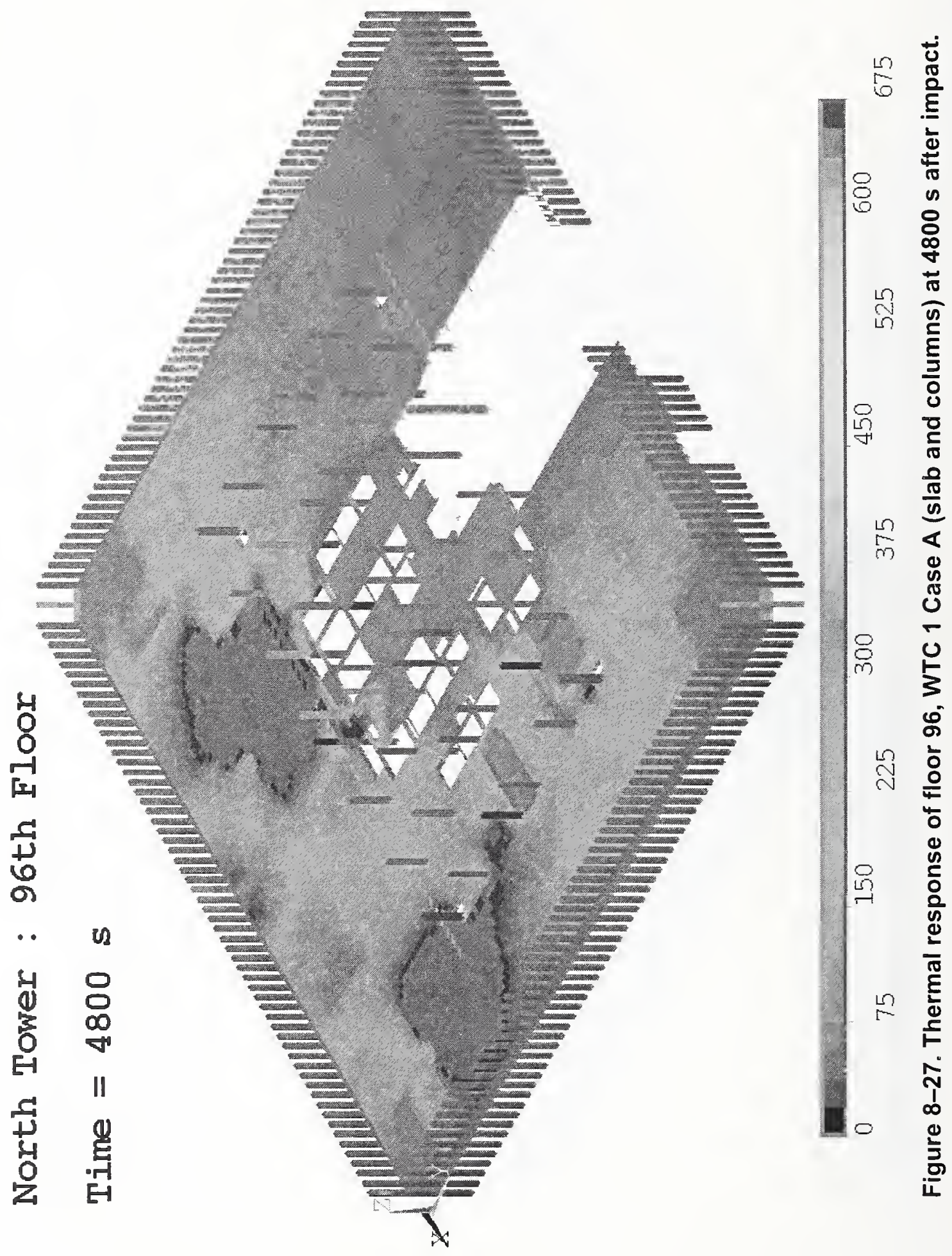




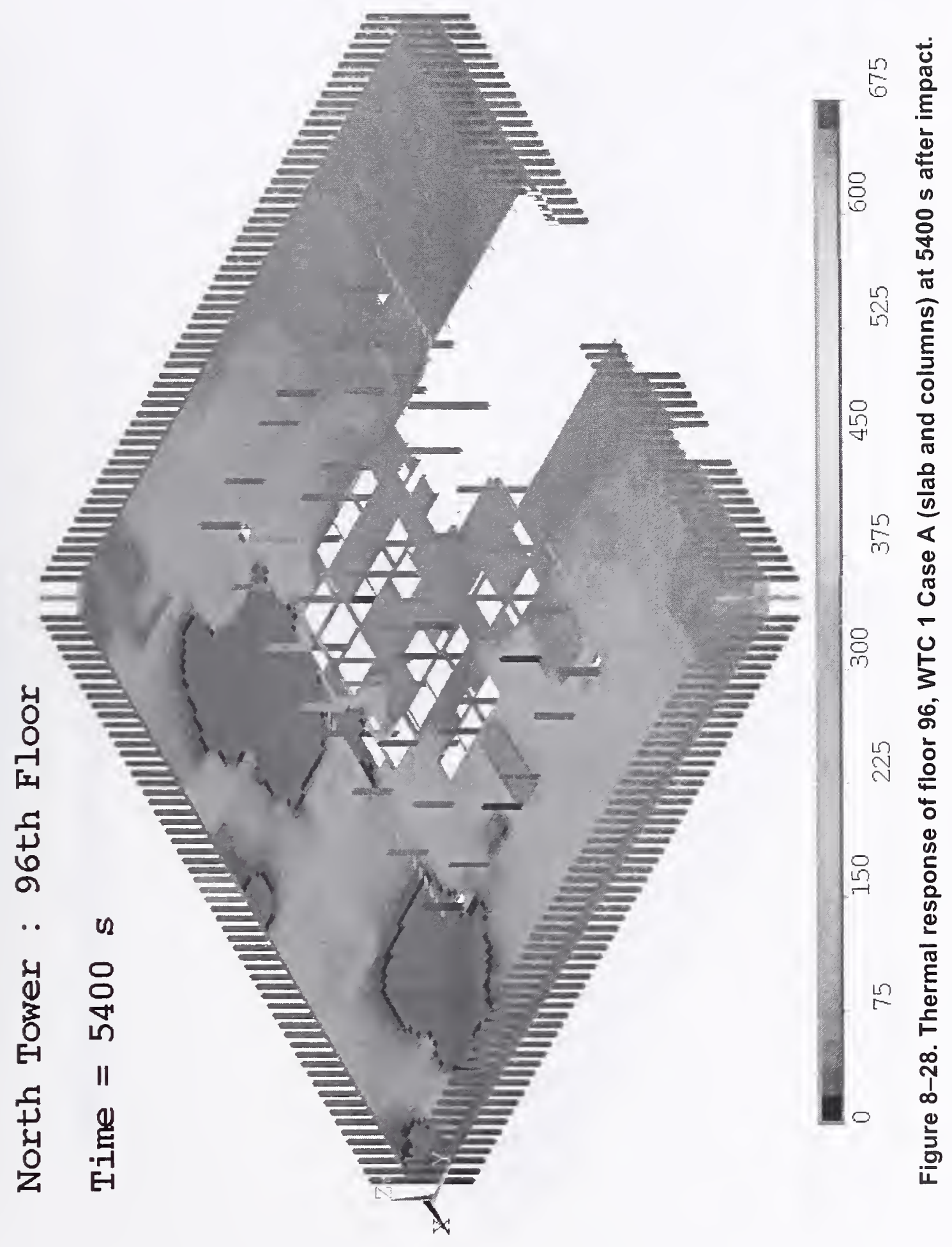




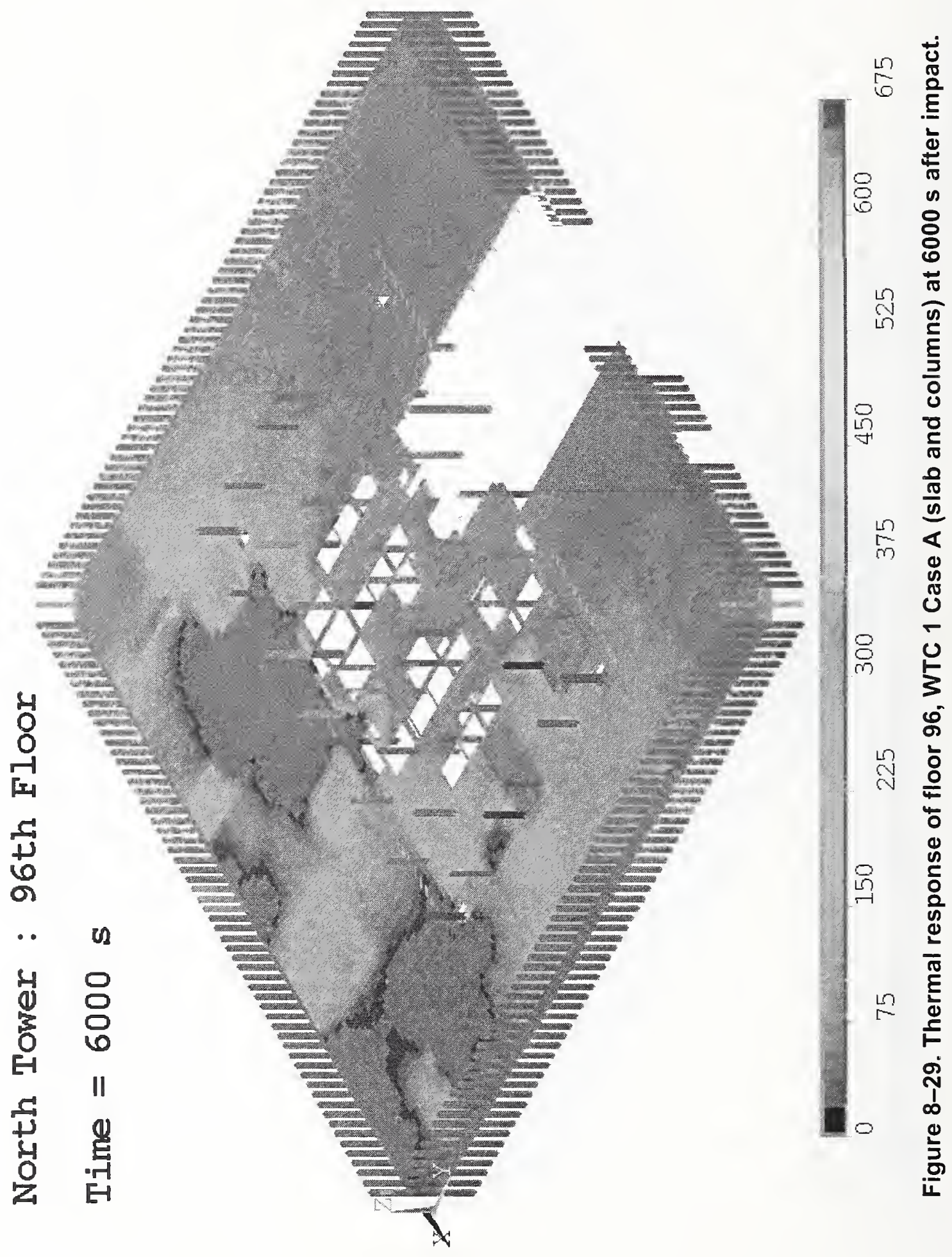




\subsubsection{Floor 97, WTC 1 Case A}

Figure 8-31 and Figure 8-32 shows the thermal response of the $97^{\text {th }}$ floor WTC 1 Case A at nine different instants of time ranging from $600 \mathrm{~s}$ to $6000 \mathrm{~s}$ at $600 \mathrm{~s}$ intervals. The thermal state of the floors at $3600 \mathrm{~s}$ has not been shown due to space limitation. The figure shows the truss assembly and core beams that support the $97^{\text {th }}$ floor. Perimeter and core columns above the $97^{\text {th }}$ floor concrete slab are subjected to fires on the $97^{\text {th }}$ floor while columns below the $97^{\text {th }}$ floor slab are subjected to fires on the $96^{\text {th }}$ floor.

The structural and fireproofing damage due to aircraft impact is shown in Figure 8-30. This figure shows structural damage to floor 97 and fireproofing damage to floor trusses and core beams supporting the floor. The figure shows extensive fireproofing damage on the north and south faces and limited structural damage. Table 8-4 shows no fireproofing damage to perimeter columns on floor 97 . A single panel on the south face on floor 96 is assumed to have fireproofing damage. This panel is directly above the panel that was damage (structurally) by the impact of the aircraft on the south face of WTC 1. There is also extensive structural damage on the perimeter columns on floor 96, especially on the north face (as evidenced in the photographic observations) and damage to a lesser extent on floor 97. Table 8-5 shows fireproofing and structural damage assumed for core columns on floors 96 and 97 . All the core columns on floor 97 are assumed to be intact, while columns 504 and 604 on floor 96 are structurally damaged. Fireproofing damage is assumed for columns 501-504, 601-604, 702-705, 802-803, 903-904, and 1003 above the concrete slab on $97^{\text {th }}$ floor. Below the slab, fireproofing damage on core columns is restricted to 502-506, 602-606, 702-705, 803-805, 902-905, and 1002-1005.

Figure 8-31 and Figure 8-32 shows the thermal response of the $97^{\text {th }}$ floor WTC 1 Case A at nine different instants of time ranging from $600 \mathrm{~s}$ to $6000 \mathrm{~s}$ at $600 \mathrm{~s}$ intervals. The damaged structural elements are not included in the pictures. The west side of the core on floor 97 has suffered extensive fireproofing damage and this results in heating up of the core columns. Core columns on the east side of the core have their fireproofing intact and as a result stay relatively cool. 


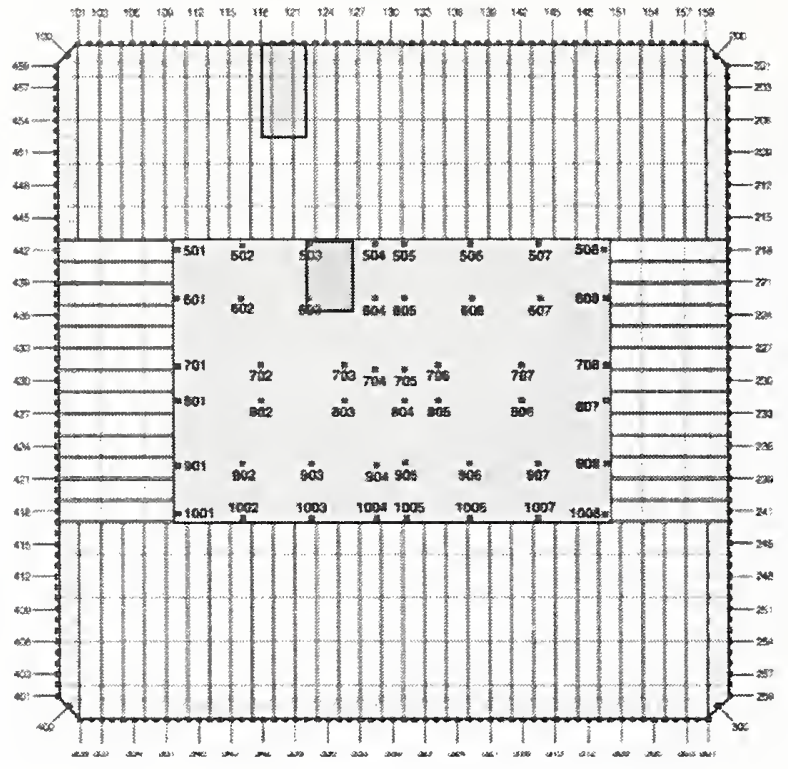

Structural damage for floor 97

Structural Damage

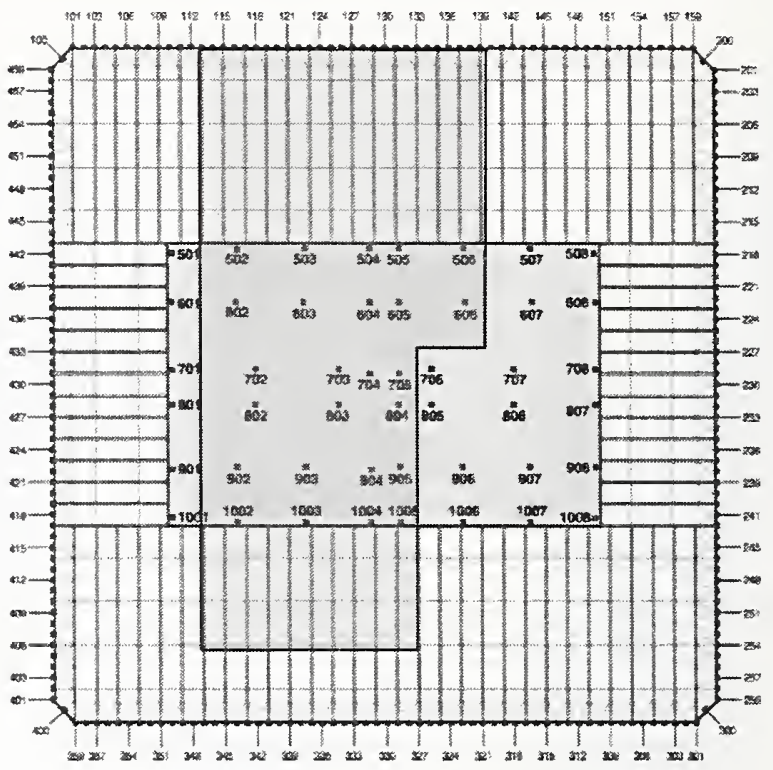

Fireproofing damage on floor trusses and core beams that support floor 97

Fireproofing Damage

Figure 8-30. Structural and fireproofing damage on floor 97 WTC 1 Case $A_{i}$. 

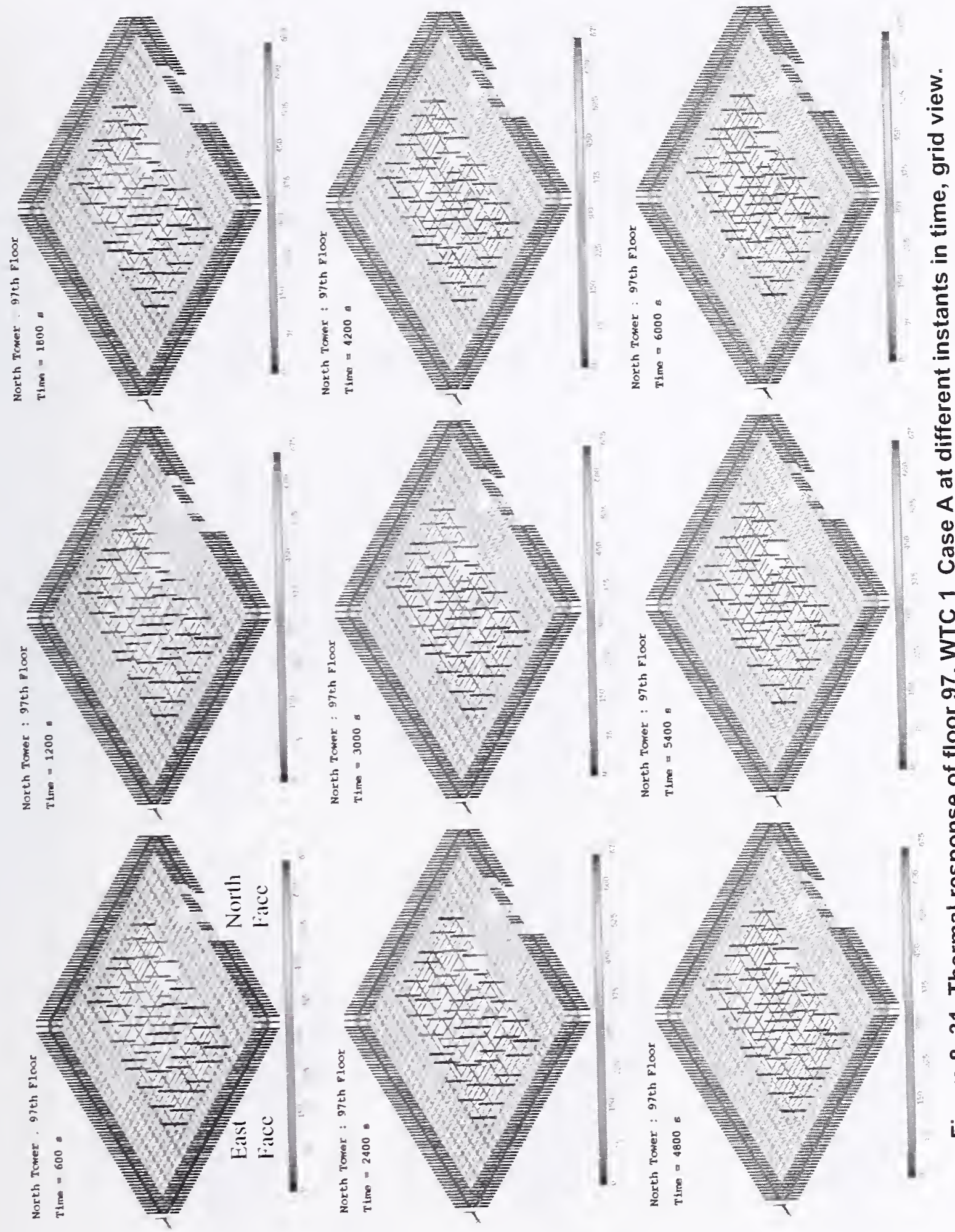

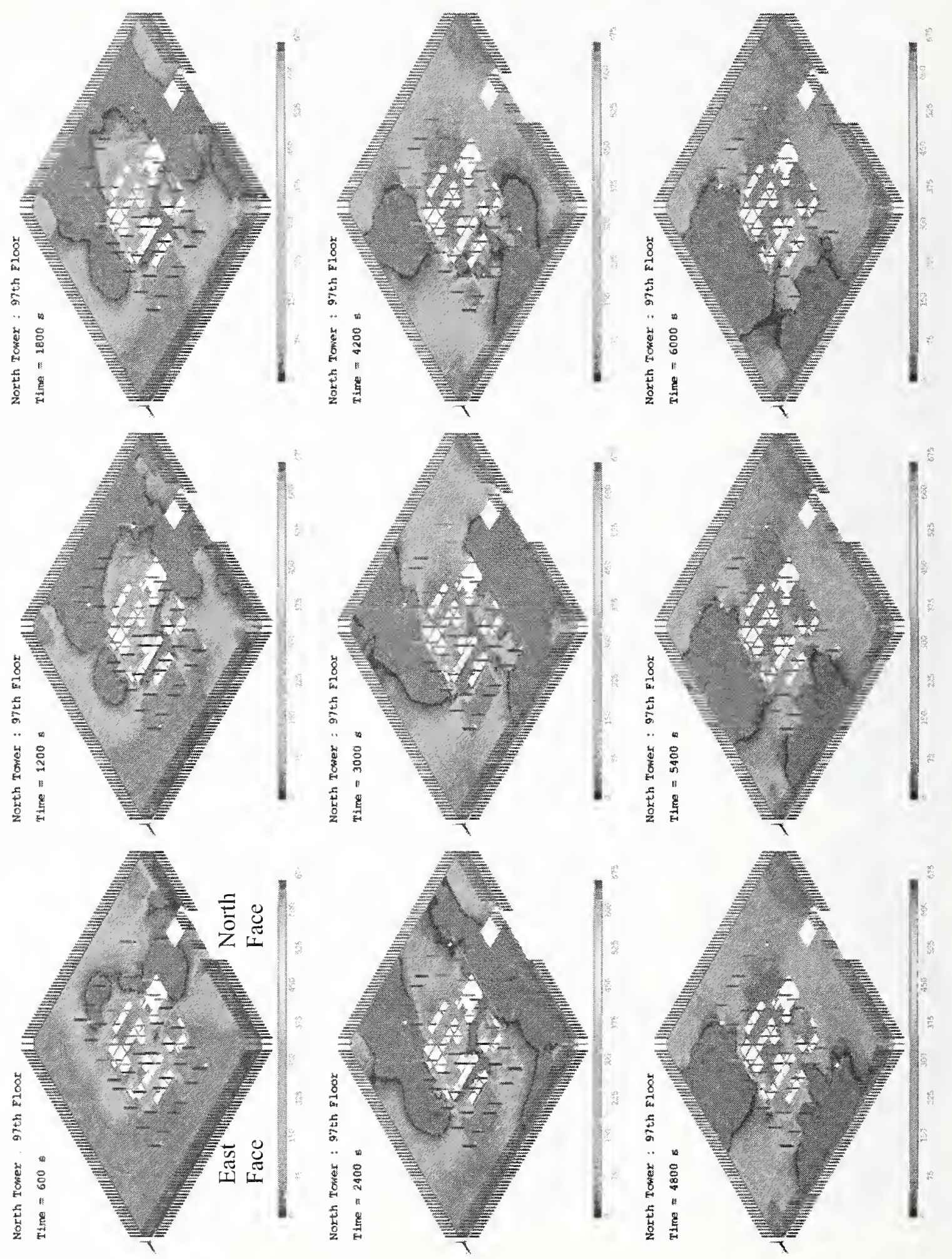

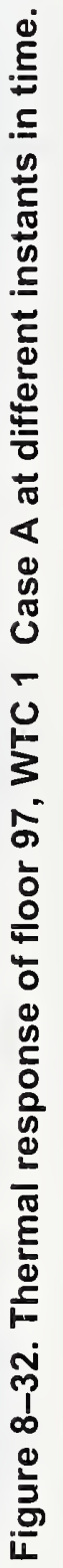




\subsubsection{Floor 98, WTC 1 Case A}

The thermal state of floor 98, WTC 1 Case A is shown in Figure 8-34. The portion below the concrete slab is subjected to fires on the $97^{\text {th }}$ floor. while structural elements above floor 98 are subjected to fires on the $98^{\text {th }}$ floor. Fireproofing damage and structural damage results for this floor are shown in Figure 8-33. Fireproofing and structural damage for perimeter and core columns have been provided in tabular format. The thermal response of floor 98 is consistent with the fire activity on this floor and with the predicted fireproofing and structural damage. For the core columns, numerical simulations predict higher temperatures on the west side. because of fireproofing damage and fire activity in this region. Some core columns indicate very high temperatures below the concrete slab and relatively low temperatures above the slab. This is due to differences in fireproofing status and fire activity in the immediate vicinity of these columns on floors 97 and 98.

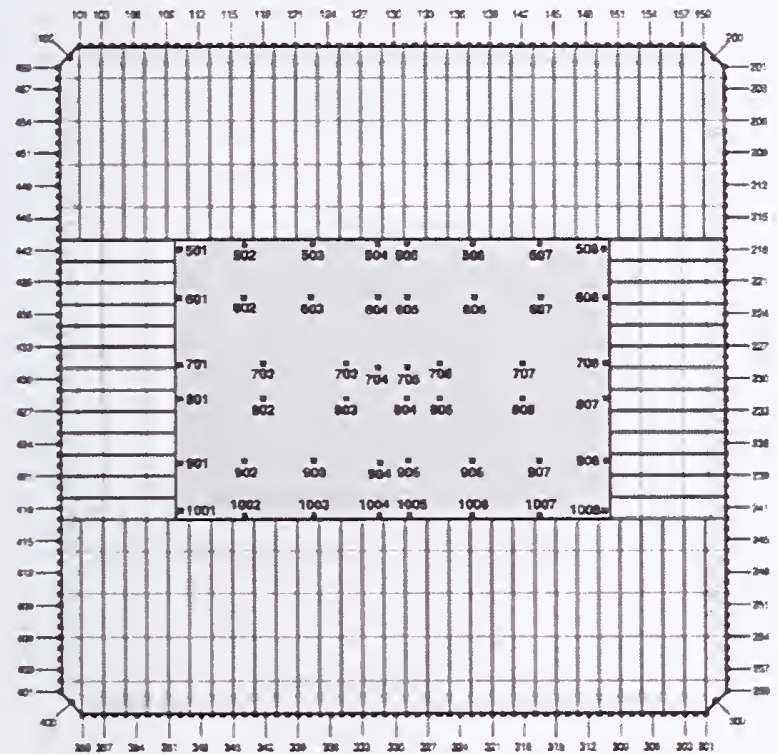

Structural damage for floor 98

Structural damage

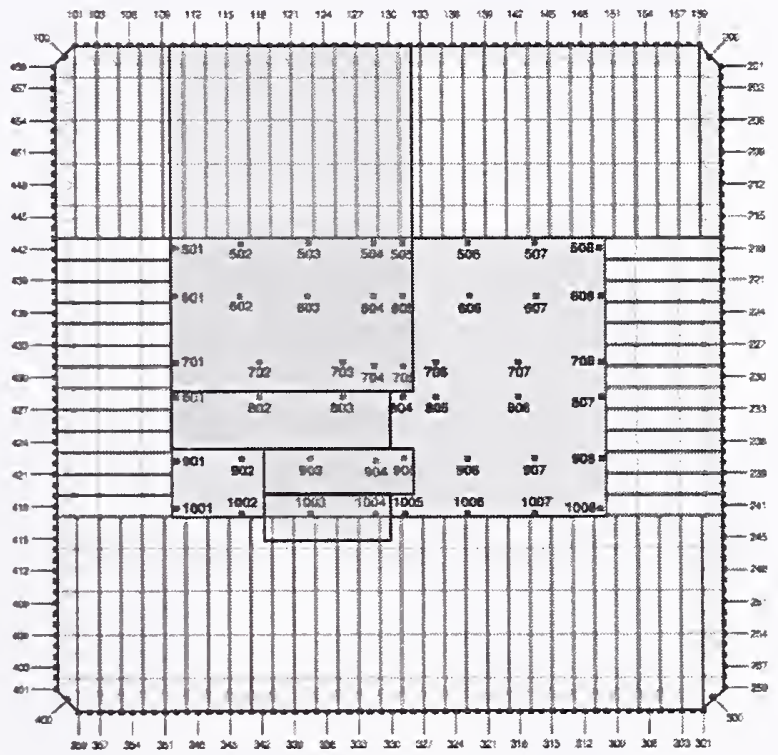

Fireproofing damage on floor trusses and core beams that support floor 98

Fireproofing Damage

Figure 8-33. Structural and fireproofing damage on floor 98 WTC 1 Case $A_{i}$. 

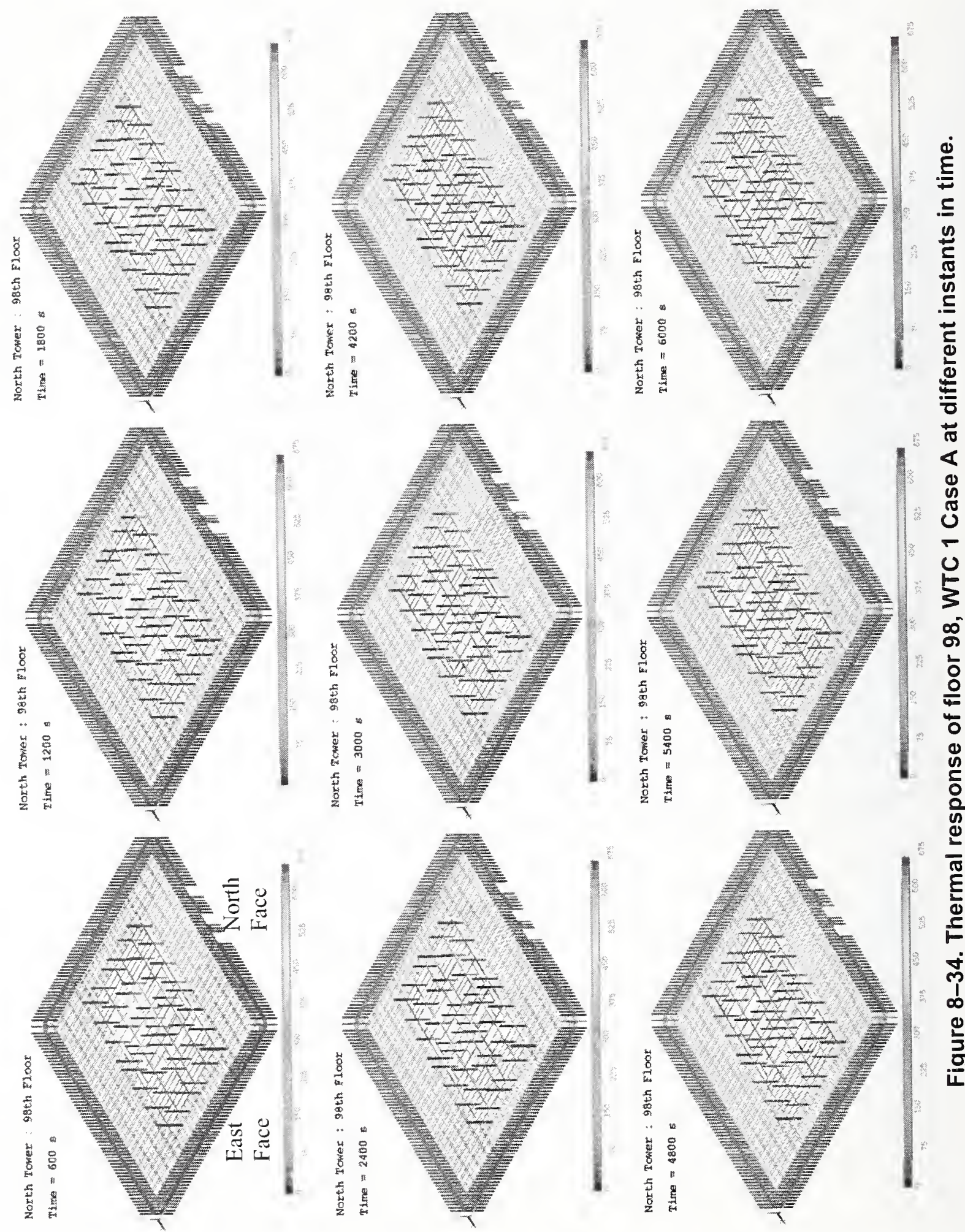


\subsubsection{Floor 99, WTC 1 Case A}

Figure 8-35 shows the thermal response of the 99th floor WTC 1 Case A at nine different instants of time ranging from $600 \mathrm{~s}$ to $6,000 \mathrm{~s}$ at $600 \mathrm{~s}$ intervals. The thermal state of the floors at $3600 \mathrm{~s}$ has not been shown due to space limitation. Aircraft impact analysis results show no structural or fireproofing damage to the trusses or the core beams. There is no fireproofing or structural damage for any perimeter column on floor 98 or floor 99 . There is no fireproofing or structural damage assumed on floor 98 and 99 . Since there is no fireproofing damage, the trusses and columns in Figure 8-35 stay relatively cool. The core columns have their fireproofing intact on these floors and do not reach any significantly high temperature.

\subsection{DATA TRANSFER FOR STRUCTURAL ANALYSIS}

The thermal results presented in this chapter were passed on to the structural analysis group (NIST NCSTAR 1-6D) for stress analysis in the load bearing elements. The data was provided on a floor by floor basis ranging from floor 93 through 99 . For each floor, the thermal results were provided at ten instants in time, spaced at 10 min interval. For each instant in time a thermal loading data file was generated to completely specify the thermal state of the floor. The thermal loading data files were generated at $10 \mathrm{~min}, 20 \mathrm{~min}, 30 \mathrm{~min}, 40 \mathrm{~min}, 50 \mathrm{~min}, 60 \mathrm{~min}, 70 \mathrm{~min}, 80 \mathrm{~min}, 90 \mathrm{~min}$, and $100 \mathrm{~min}$ after aircraft impact. Each file was generated in a format that is consistent with the structural models and could be readily read in with the ANSYS software to specify body loads (temperature or temperature gradient) on the structure. The files were transferred using a file transfer protocol (ftp) utility.

The results shown in Figure 8-2 through Figure 8-35 are visual renderings of the information contained in the thermal loading data files. 

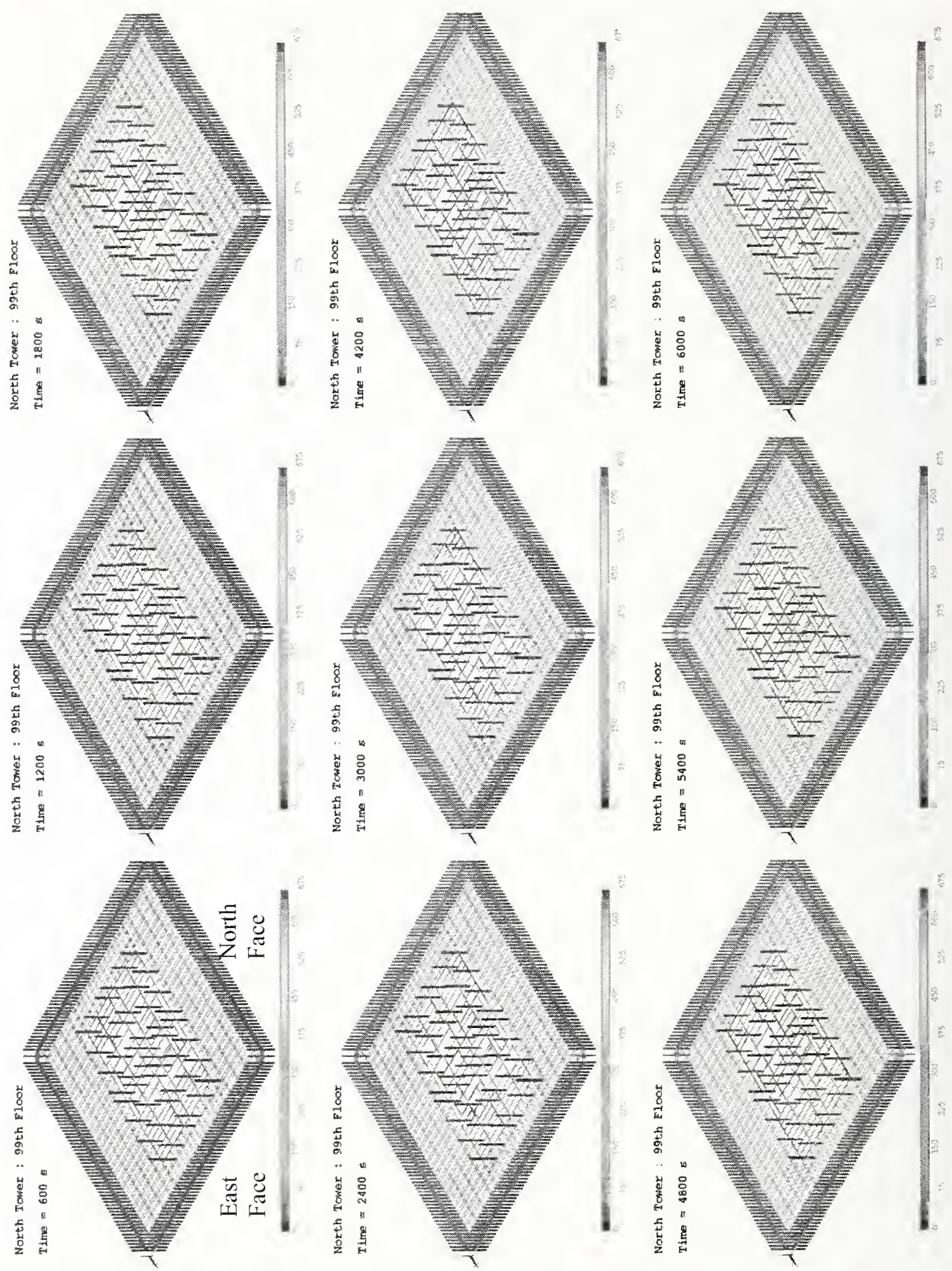

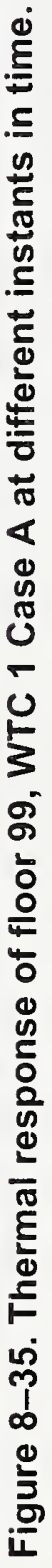


Table 8-4. Perimeter column damage status for WTC 1, Case A.

\begin{tabular}{|c|c|c|c|c|c|c|c|c|}
\hline Column & Floor 92 & Floor 93 & Floor 94 & Floor 95 & Floor 96 & Floor 97 & Floor 98 & Floor 99 \\
\hline 101 & 0 & 0 & 0 & 0 & 0 & 0 & 0 & 0 \\
\hline 103 & 0 & 0 & 0 & 0 & 0 & 0 & 0 & 0 \\
\hline 106 & 0 & 0 & 0 & 0 & 0 & 0 & 0 & 0 \\
\hline 109 & 0 & 0 & 0 & 0 & 0 & 0 & 0 & 0 \\
\hline 112 & 0 & 0 & 0 & 0 & 0 & 0 & 0 & 0 \\
\hline 115 & 0 & 0 & 0 & 0 & 0 & 0 & 0 & 0 \\
\hline 118 & 0 & 0 & 0 & 0 & 0 & 2 & 0 & 0 \\
\hline 121 & 0 & 0 & 0 & 0 & 2 & 0 & 0 & 0 \\
\hline 124 & 0 & 0 & 0 & 2 & 2 & 0 & 0 & 0 \\
\hline 127 & 0 & 0 & 2 & 2 & 2 & 2 & 0 & 0 \\
\hline 130 & 0 & 0 & 0 & 2 & 2 & 0 & 0 & 0 \\
\hline 133 & 0 & 0 & 2 & 2 & 2 & 2 & 0 & 0 \\
\hline 136 & 0 & 0 & 2 & 2 & 0 & 0 & 0 & 0 \\
\hline 139 & 0 & 0 & 2 & 0 & 0 & 0 & 0 & 0 \\
\hline 142 & 0 & 0 & 2 & 0 & 0 & 0 & 0 & 0 \\
\hline 145 & 0 & 0 & 0 & 2 & 0 & 0 & 0 & 0 \\
\hline 148 & 0 & 0 & 0 & 0 & 0 & 0 & 0 & 0 \\
\hline 151 & 0 & 0 & 0 & 0 & 0 & 0 & 0 & 0 \\
\hline 154 & 0 & 0 & 0 & 0 & 0 & 0 & 0 & 0 \\
\hline 157 & 0 & 0 & 0 & 0 & 0 & 0 & 0 & 0 \\
\hline 201 & 0 & 0 & 0 & 0 & 0 & 0 & 0 & 0 \\
\hline 203 & 0 & 0 & 0 & 0 & 0 & 0 & 0 & 0 \\
\hline 206 & 0 & 0 & 0 & 0 & 0 & 0 & 0 & 0 \\
\hline 209 & 0 & 0 & 0 & 0 & 0 & 0 & 0 & 0 \\
\hline 212 & 0 & 0 & 0 & 0 & 0 & 0 & 0 & 0 \\
\hline 215 & 0 & 0 & 0 & 0 & 0 & 0 & 0 & 0 \\
\hline 218 & 0 & 0 & 0 & 0 & 0 & 0 & 0 & 0 \\
\hline 221 & 0 & 0 & 0 & 0 & 0 & 0 & 0 & 0 \\
\hline 224 & 0 & 0 & 0 & 0 & 0 & 0 & 0 & 0 \\
\hline 227 & 0 & 0 & 0 & 0 & 0 & 0 & 0 & 0 \\
\hline 230 & 0 & 0 & 0 & 0 & 0 & 0 & 0 & 0 \\
\hline
\end{tabular}




\begin{tabular}{|c|c|c|c|c|c|c|c|c|}
\hline 233 & 0 & 0 & 0 & 0 & 0 & 0 & 0 & 0 \\
\hline 236 & 0 & 0 & 0 & 0 & 0 & 0 & 0 & 0 \\
\hline 239 & 0 & 0 & 0 & 0 & 0 & 0 & 0 & 0 \\
\hline 242 & 0 & 0 & 0 & 0 & 0 & 0 & 0 & 0 \\
\hline 245 & 0 & 0 & 0 & 0 & 0 & 0 & 0 & 0 \\
\hline 248 & 0 & 0 & 0 & 0 & 0 & 0 & 0 & 0 \\
\hline 251 & 0 & 0 & 0 & 0 & 0 & 0 & 0 & 0 \\
\hline 254 & 0 & 0 & 0 & 0 & 0 & 0 & 0 & 0 \\
\hline 257 & 0 & 0 & 0 & 0 & 0 & 0 & 0 & 0 \\
\hline 301 & 0 & 0 & 0 & 0 & 0 & 0 & 0 & 0 \\
\hline 303 & 0 & 0 & 0 & 0 & 0 & 0 & 0 & 0 \\
\hline 306 & 0 & 0 & 0 & 0 & 0 & 0 & 0 & 0 \\
\hline 309 & 0 & 0 & 0 & 0 & 0 & 0 & 0 & 0 \\
\hline 312 & 0 & 0 & 0 & 0 & 0 & 0 & 0 & 0 \\
\hline 315 & 0 & 0 & 0 & 0 & 0 & 0 & 0 & 0 \\
\hline 318 & 0 & 0 & 0 & 0 & 0 & 0 & 0 & 0 \\
\hline 321 & 0 & 0 & 0 & 0 & 0 & 0 & 0 & 0 \\
\hline 324 & 0 & 0 & 0 & 0 & 0 & 0 & 0 & 0 \\
\hline 327 & 0 & 0 & 0 & 0 & 0 & 0 & 0 & 0 \\
\hline 330 & 0 & 0 & 2 & 2 & 1 & 0 & 0 & 0 \\
\hline 333 & 0 & 0 & 0 & 0 & 0 & 0 & 0 & 0 \\
\hline 336 & 0 & 0 & 0 & 0 & 0 & 0 & 0 & 0 \\
\hline 339 & 0 & 0 & 0 & 0 & 0 & 0 & 0 & 0 \\
\hline 342 & 0 & 0 & 0 & 0 & 0 & 0 & 0 & 0 \\
\hline 345 & 0 & 0 & 0 & 0 & 0 & 0 & 0 & 0 \\
\hline 348 & 0 & 0 & 0 & 0 & 0 & 0 & 0 & 0 \\
\hline 351 & 0 & 0 & 0 & 0 & 0 & 0 & 0 & 0 \\
\hline 354 & 0 & 0 & 0 & 0 & 0 & 0 & 0 & 0 \\
\hline 357 & 0 & 0 & 0 & 0 & 0 & 0 & 0 & 0 \\
\hline 401 & 0 & 0 & 0 & 0 & 0 & 0 & 0 & 0 \\
\hline 403 & 0 & 0 & 0 & 0 & 0 & 0 & 0 & 0 \\
\hline
\end{tabular}




\begin{tabular}{|l|l|l|l|l|l|l|l|l|}
\hline 406 & 0 & 0 & 0 & 0 & 0 & 0 & 0 & 0 \\
\hline 409 & 0 & 0 & 0 & 0 & 0 & 0 & 0 & 0 \\
\hline 412 & 0 & 0 & 0 & 0 & 0 & 0 & 0 & 0 \\
\hline 415 & 0 & 0 & 0 & 0 & 0 & 0 & 0 & 0 \\
\hline 418 & 0 & 0 & 0 & 0 & 0 & 0 & 0 & 0 \\
\hline 421 & 0 & 0 & 0 & 0 & 0 & 0 & 0 & 0 \\
\hline 424 & 0 & 0 & 0 & 0 & 0 & 0 & 0 & 0 \\
\hline 427 & 0 & 0 & 0 & 0 & 0 & 0 & 0 & 0 \\
\hline 430 & 0 & 0 & 0 & 0 & 0 & 0 & 0 & 0 \\
\hline 433 & 0 & 0 & 0 & 0 & 0 & 0 & 0 & 0 \\
\hline 436 & 0 & 0 & 0 & 0 & 0 & 0 & 0 & 0 \\
\hline 439 & 0 & 0 & 0 & 0 & 0 & 0 & 0 & 0 \\
\hline 442 & 0 & 0 & 0 & 0 & 0 & 0 & 0 & 0 \\
\hline 445 & 0 & 0 & 0 & 0 & 0 & 0 & 0 & 0 \\
\hline 448 & 0 & 0 & 0 & 0 & 0 & 0 & 0 & 0 \\
\hline 451 & 0 & 0 & 0 & 0 & 0 & 0 & 0 & 0 \\
\hline 454 & 0 & 0 & 0 & 0 & 0 & 0 & 0 & 0 \\
\hline 457 & 0 & 0 & 0 & 0 & 0 & 0 & 0 & 0 \\
\hline
\end{tabular}


Table 8-5. Core column damage status for WTC 1, Case A

\begin{tabular}{|c|c|c|c|c|c|c|c|c|}
\hline Column & Floor 92 & Floor 93 & Floor 94 & Floor 95 & Floor 96 & Floor 97 & Floor 98 & Floor 99 \\
\hline 501 & 0 & 0 & 0 & 0 & 0 & 3 & 0 & 0 \\
\hline 502 & 0 & 0 & 0 & 0 & 3 & 3 & 0 & 0 \\
\hline 503 & 0 & 0 & 3 & 3 & 3 & 3 & 0 & 0 \\
\hline 504 & 2 & 2 & 2 & 2 & 2 & 3 & 0 & 0 \\
\hline 505 & 0 & 0 & 3 & 3 & 3 & 0 & 0 & 0 \\
\hline 506 & 0 & 0 & 3 & 3 & 3 & 0 & 0 & 0 \\
\hline 507 & 0 & 0 & 3 & 0 & 0 & 0 & 0 & 0 \\
\hline 508 & 0 & 0 & 3 & 0 & 0 & 0 & 0 & 0 \\
\hline 601 & 0 & 0 & 0 & 0 & 0 & 3 & 0 & 0 \\
\hline 602 & 0 & 0 & 0 & 0 & 3 & 3 & 0 & 0 \\
\hline 603 & 0 & 0 & 3 & 3 & 3 & 3 & 0 & 0 \\
\hline 604 & 2 & 2 & 2 & 2 & 2 & 3 & 0 & 0 \\
\hline 605 & 0 & 0 & 3 & 3 & 3 & 0 & 0 & 0 \\
\hline 606 & 0 & 0 & 3 & 3 & 3 & 0 & 0 & 0 \\
\hline 607 & 0 & 0 & 3 & 0 & 0 & 0 & 0 & 0 \\
\hline 608 & 0 & 0 & 0 & 0 & 0 & 0 & 0 & 0 \\
\hline 701 & 0 & 0 & 0 & 0 & 0 & 0 & 0 & 0 \\
\hline 702 & 0 & 0 & 0 & 0 & 3 & 3 & 0 & 0 \\
\hline 703 & 0 & 0 & 3 & 3 & 3 & 3 & 0 & 0 \\
\hline 704 & 0 & 0 & 3 & 3 & 3 & 3 & 0 & 0 \\
\hline 705 & 0 & 0 & 3 & 3 & 3 & 3 & 0 & 0 \\
\hline 706 & 0 & 2 & 2 & 2 & 0 & 0 & 0 & 0 \\
\hline 707 & 0 & 0 & 3 & 3 & 0 & 0 & 0 & 0 \\
\hline 708 & 0 & 0 & 0 & 0 & 0 & 0 & 0 & 0 \\
\hline 801 & 0 & 0 & 0 & 0 & 0 & 0 & 0 & 0 \\
\hline 802 & 0 & 0 & 0 & 0 & 3 & 3 & 0 & 0 \\
\hline 803 & 0 & 0 & 3 & 3 & 3 & 3 & 0 & 0 \\
\hline 804 & 0 & 0 & 3 & 3 & 3 & 0 & 0 & 0 \\
\hline
\end{tabular}




\begin{tabular}{|l|l|l|l|l|l|l|l|l|}
\hline $\mathbf{8 0 5}$ & 0 & 0 & 3 & 3 & 0 & 0 & 0 & 0 \\
\hline $\mathbf{8 0 6}$ & 0 & 0 & 3 & 0 & 0 & 0 & 0 & 0 \\
\hline $\mathbf{8 0 7}$ & 0 & 0 & 0 & 0 & 0 & 0 & 0 & 0 \\
\hline $\mathbf{9 0 1}$ & 0 & 0 & 0 & 0 & 0 & 0 & 0 & 0 \\
\hline $\mathbf{9 0 2}$ & 0 & 0 & 0 & 0 & 3 & 0 & 0 & 0 \\
\hline $\mathbf{9 0 3}$ & 0 & 0 & 0 & 0 & 3 & 3 & 0 & 0 \\
\hline $\mathbf{9 0 4}$ & 0 & 0 & 3 & 3 & 3 & 3 & 0 & 0 \\
\hline $\mathbf{9 0 5}$ & 0 & 0 & 3 & 3 & 3 & 0 & 0 & 0 \\
\hline $\mathbf{9 0 6}$ & 0 & 0 & 3 & 3 & 0 & 0 & 0 & 0 \\
\hline $\mathbf{9 0 7}$ & 0 & 0 & 0 & 0 & 0 & 0 & 0 & 0 \\
\hline $\mathbf{9 0 8}$ & 0 & 0 & 0 & 0 & 0 & 0 & 0 & 0 \\
\hline 1001 & 0 & 0 & 0 & 0 & 0 & 0 & 0 & 0 \\
\hline 1002 & 0 & 0 & 0 & 0 & 3 & 0 & 0 & 0 \\
\hline 1003 & 0 & 0 & 0 & 0 & 3 & 3 & 0 & 0 \\
\hline 1004 & 0 & 0 & 3 & 3 & 3 & 0 & 0 & 0 \\
\hline 1005 & 0 & 0 & 3 & 3 & 3 & 0 & 0 & 0 \\
\hline 1006 & 0 & 0 & 3 & 3 & 0 & 0 & 0 & 0 \\
\hline 1007 & 0 & 0 & 0 & 0 & 0 & 0 & 0 & 0 \\
\hline 1008 & 0 & 0 & 0 & 0 & 0 & 0 & 0 & 0 \\
\hline
\end{tabular}


This page intentionally left blank. 


\section{Chapter 9 \\ GLobal Thermal Response of WTC 1: CASE B}

\subsection{OVERVIEW}

Four major simulations are presented in this report to predict the global thermally induced structural response of World Trade Center (WTC) 1 and WTC 2. This chapter is the second of four chapters that describe the results of the four cases. The focus of this chapter is on a set of simulations termed "WTC 1 Case B."

Following the completion of the Case A simulation of WTC 1 (described in Chapter 8), the calculation was rerun with changes made to several important input parameters. The methodology for performing the simulations is identical to that for Case A. In this chapter we focus on the model inputs and simulation results for WTC 1 Case B. The differences in model inputs and simulations results between WTC 1 Case A and WTC 1 Case B are summarized in Chapter 12. By analyzing the thermal and structural results for Case A and Case B, sensitivity of our results to changes in model input can be assessed.

\subsubsection{Aircraft Impact Analysis}

As in Case A, structural and fireproofing damage to the columns, trusses, and floor slabs were obtained from an aircraft impact analysis. The impact analysis was performed with more severe settings summarized in Table 9-1. The severe settings resulted in more structural and fireproofing damage to the various structural elements (NIST NCSTAR 1-2). The predicted damage for Case B is more than that for Case A, but the damage for Case B does not necessarily include the damage for Case A. In other words, the damage for Case A was not a subset of the damage for Case B.

Table 9-4 (presented later) shows the fireproofing and structural damage predicted for perimeter columns on floors 92-99 (Case B). In this table a " 0 " indicates that the column and its fireproofing are intact, a "1" indicates fireproofing damage to the interior faces and a " 2 " indicates a column that has been severed by the aircraft impact. Table 9-5 (presented later) shows fireproofing and structural damage predicted for core columns on floor 92-99 (NIST NCSTAR 1-5A). In this table a " 0 " indicates that the column and its fireproofing is intact, a " 1 " indicates fireproofing damage on one face, a " 2 " indicates a column that has been severed by the aircraft impact while a " 3 " indicates fireproofing damage on all the faces. For WTC 1 Case B, core columns had their fireproofing intact or the fireproofing was damaged on all the faces.

Aircraft impact damage (NIST NCSTAR 1-2) also results in structural and fireproofing damage on the floor systems. For each floor, a map was prepared that describes the contours of the region where fireproofing and structural damage was predicted. This damage for floors 95 through 98 is provided as contour maps in Figure 9-3 through Figure 9-8 (later in this chapter). 
Table 9-1. Input parameters for WTC 1 global impact analyses (More Severe).

\begin{tabular}{|c|l|c|}
\hline \multicolumn{2}{|c|}{ Analysis Parameters } & More Severe \\
\hline \multirow{4}{*}{$\begin{array}{c}\text { Flight } \\
\text { Parameters }\end{array}$} & Impact speed & $472 \mathrm{mph}$ \\
\cline { 2 - 3 } & Trajectory - pitch & $7.6^{\circ}$ \\
\cline { 2 - 3 } & Trajectory - yaw & $0.0^{\circ}$ \\
\cline { 2 - 3 } & Orientation - pitch & $5.6^{\circ}$ \\
\cline { 2 - 3 } & Orientation - yaw & $0.0^{\circ}$ \\
\hline \multirow{4}{*}{$\begin{array}{c}\text { Aircraft } \\
\text { Parameters }\end{array}$} & Weight & 105 percent \\
\cline { 2 - 3 } & Failure Strain & 125 percent \\
\hline \multirow{2}{*}{$\begin{array}{c}\text { Tower } \\
\text { Parameters }\end{array}$} & Failure Strain & 80 percent \\
\cline { 2 - 3 } & Live Load Weight & \\
\hline
\end{tabular}

a. Live load weight expressed as a percentage of the design live load.

\subsubsection{Fire Dynamics Simulations}

Fire simulations were performed as in Case A but with different input parameters to predict contours of upper layer temperature, absorption coefficient, layer depth, and ambient temperatures as a function of space and time on each floor of the WTC 1. For Case B the area of the core identified in the impact study to have sustained major damage had only partially open walls. By opening the walls partially, oxygen could still reach the fire, but the hot gases were trapped resulting in higher temperatures. The input parameters for fire simulations are listed in Table 9-2. The fire simulation results for Case B were not qualitatively very different from Case A (NIST NCSTAR 1-5F).

Table 9-2. Values of WTC fire simulation variables.

\begin{tabular}{|l|l|}
\hline \multicolumn{1}{|c|}{ Variable } & \multicolumn{1}{|c|}{ WTC 1 Case B } \\
\hline Fuel load & $25 \mathrm{~kg} / \mathrm{m}^{2}\left(5 \mathrm{lb} / \mathrm{ft}^{2}\right)$ \\
\hline $\begin{array}{l}\text { Distribution of } \\
\text { disturbed } \\
\text { combustibles }\end{array}$ & $\begin{array}{l}\text { Weighted toward } \\
\text { the core }\end{array}$ \\
\hline $\begin{array}{l}\text { Condition of } \\
\text { combustibles }\end{array}$ & $\begin{array}{l}\text { Displaced furniture } \\
\text { rubblized }\end{array}$ \\
\hline $\begin{array}{l}\text { Representation of } \\
\text { impacted core walls }\end{array}$ & Soffit remained \\
\hline
\end{tabular}

\section{$9.2 \quad$ FIRE STRUCTURE INTERFACE}

The Fire Structure Interface couples the thermal response to the fire simulations for a specific set of structural and fireproofing damage scenario. Changes in fire dynamics between Case A and Case B result in a new set of thermal results. Fireproofing damage and structural damage caused by the aircraft impact analysis also has a large impact on the thermal results. Table 9-3 summarizes the input for global thermal response of WTC 1 Case B. In the next section, thermal results for WTC 1 Case B are presented, on a floor by floor basis. As in Chapter 8, the goal in this chapter is to understand the nature of the thermal 
insult on the structure for each floor of the WTC 1. The differences in model inputs and simulations results between Case A and Case B are summarized in Chapter 12. The thermal results were provided for analysis in a manner that is suitable for the structural analysis package that was employed for collapse analysis.

Figure 9-1 through Figure 9-1 1 shows the thermal state of floors 93 through 99 in WTC 1, respectively, at nine different instants in time ranging from $10 \mathrm{~min}$ to $100 \mathrm{~min}$ at $10 \mathrm{~min}$ interval. The thermal state at 60 min after impact has not been shown due to space limitation on each page. Each sub-figure shows the truss assembly, the core beams, and perimeter columns and core columns above and below the concrete slab. Color contours are superimposed on the structural elements ranging from 0 to $675^{\circ} \mathrm{C}$.

Table 9-3. Input for global thermal response
of WTC 1, Case B.
\begin{tabular}{|l|c|}
\hline \multicolumn{1}{|c|}{ Input } & WTC 1 Case B \\
\hline $\begin{array}{l}\text { Structural damage, } \\
\text { NIST NCSTAR 1-2 } \\
\text { NIST NCSTAR 1-6 }\end{array}$ & $\begin{array}{c}\text { Case B } \\
\text { (More severe) }\end{array}$ \\
\hline $\begin{array}{l}\text { Fireproofing damage, } \\
\text { NIST NCSTAR 1-6 }\end{array}$ & Case B \\
\hline $\begin{array}{l}\text { Fire Simulations, } \\
\text { NIST NCSTAR 1-5F }\end{array}$ & Case B \\
\hline
\end{tabular}

\subsubsection{Floor 93, WTC 1 Case B}

The truss system that supports floor 93 shows slightly higher temperatures for "Case A" as compared to "Case B". Although "Case B" has more severe fires, the intensity of the fires varied from one floor to another. Core beams in the northwest corner show higher temperature for "Case B" at 100 min after impact. The temperature of the core beams for "Case A" cooled down by the end of the simulation. Neither case shows fireproofing or structural damage for floor systems due to aircraft impact.

\subsubsection{Floor 94, WTC 1 Case B}

Core columns (1005-1007) in "Case B" show higher temperatures compared to Case A at 20-30 min after impact. Core columns on the east side of the core indicate higher temperature for Case B. The thermal state of the perimeter columns and floor trusses is not significantly different. The core beams exhibit slightly higher temperature in Case B as compared to Case A at 100 min after impact. 

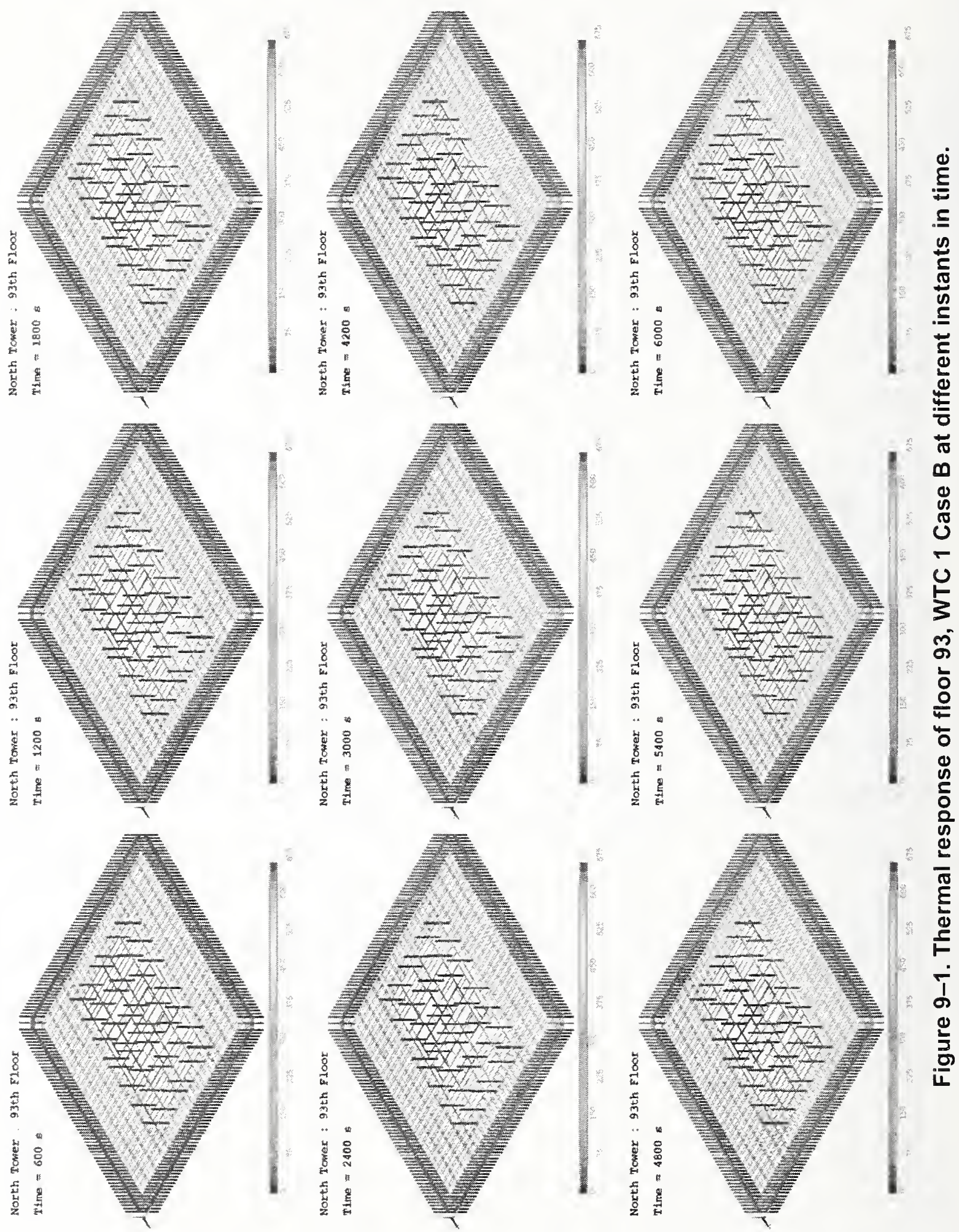

है 

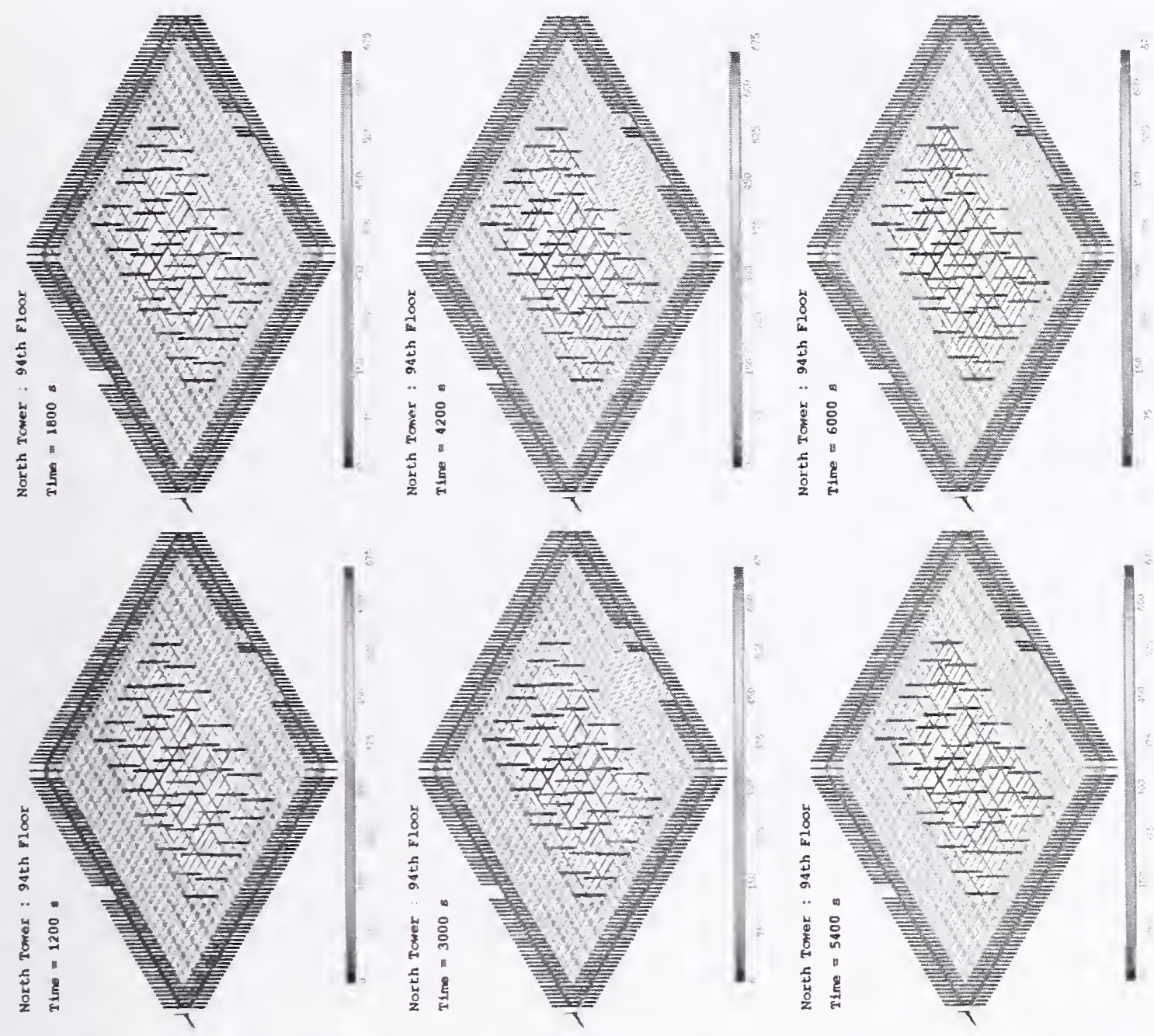

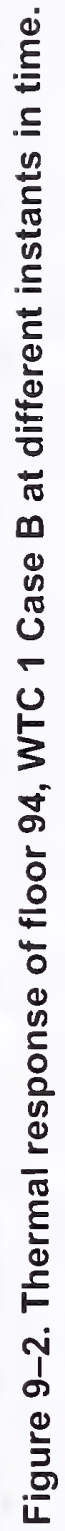




\subsubsection{Floor 95, WTC 1 Case B}

The structural damage on truss elements that support floor 95 is shifted toward the east face for Case B. ${ }^{4}$ Fireproofing damage on the trusses extends south of the core, which results in higher thermal loading on floor trusses throughout the simulation. Perimeter columns in the south face indicate higher temperature for Case B due to more extensive fireproofing damage. A larger fraction of core columns in Case B exhibits higher temperature as compared to Case A. The peak temperatures in the two cases were not very different, but in Case B, a larger fraction of the structural elements shows thermal heating.

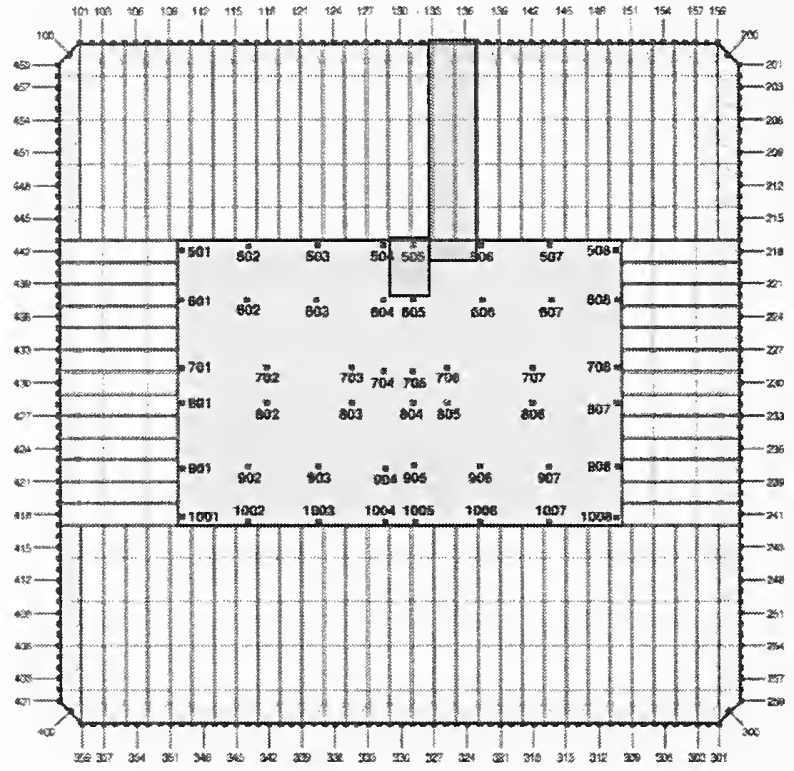

Structural damage for floor 95

Structural Damage

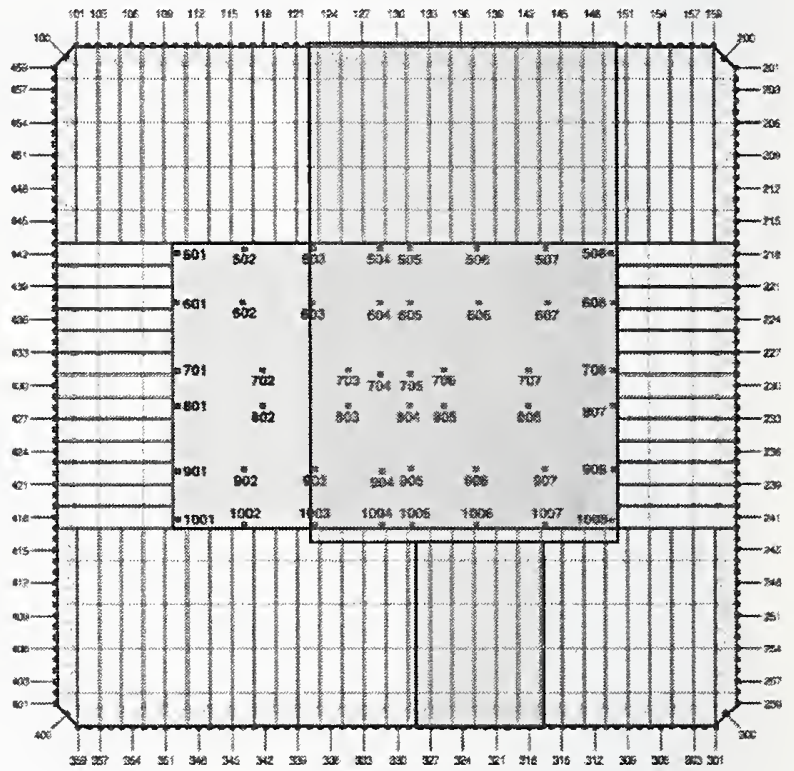

Fireproofing damage on floor trusses and core beams that support floor 95

Fireproofing Damage

Figure 9-3. Structural and fireproofing damage on floor 95, WTC 1, Case $B_{i}$.

\footnotetext{
4 The damage graphics used in the thermal analysis are discussed in detail in NIST NCSTAR 1-6 and have been presented here
} for reference only. 

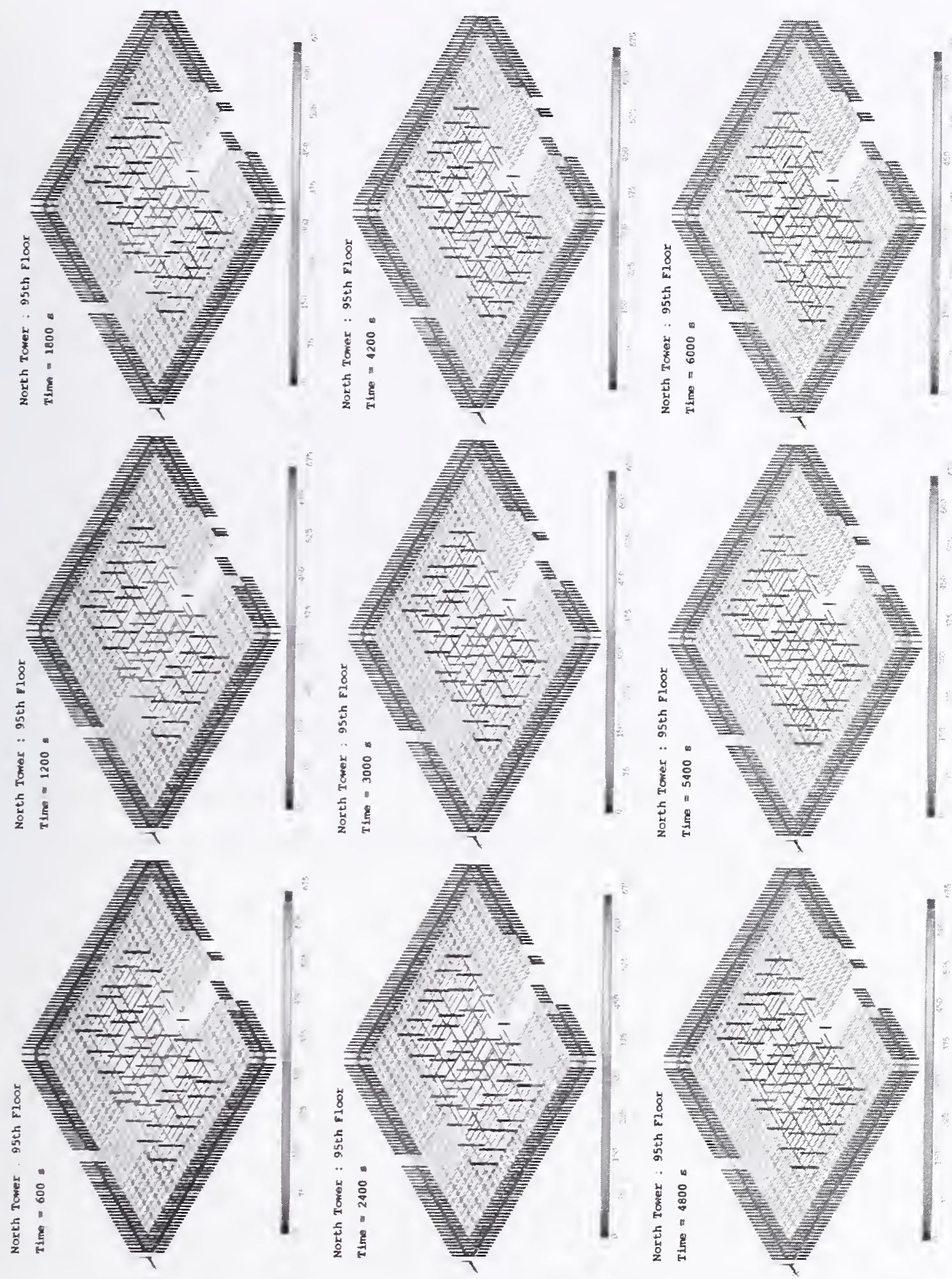

章 


\subsubsection{Floor 96, WTC 1 Case B}

Case B shows higher temperature on trusses in the region south of the core. Fireproofing damage on the truss elements is more extensive for Case B. Truss elements south of the core show a temperature of $600{ }^{\circ} \mathrm{C}$ at $20 \mathrm{~min}$ after impact. Perimeter columns on the south face also exhibit higher temperature due to more extensive fireproofing damage. There is more structural damage to core columns and a larger fraction of the core columns exhibit fire induced damage.

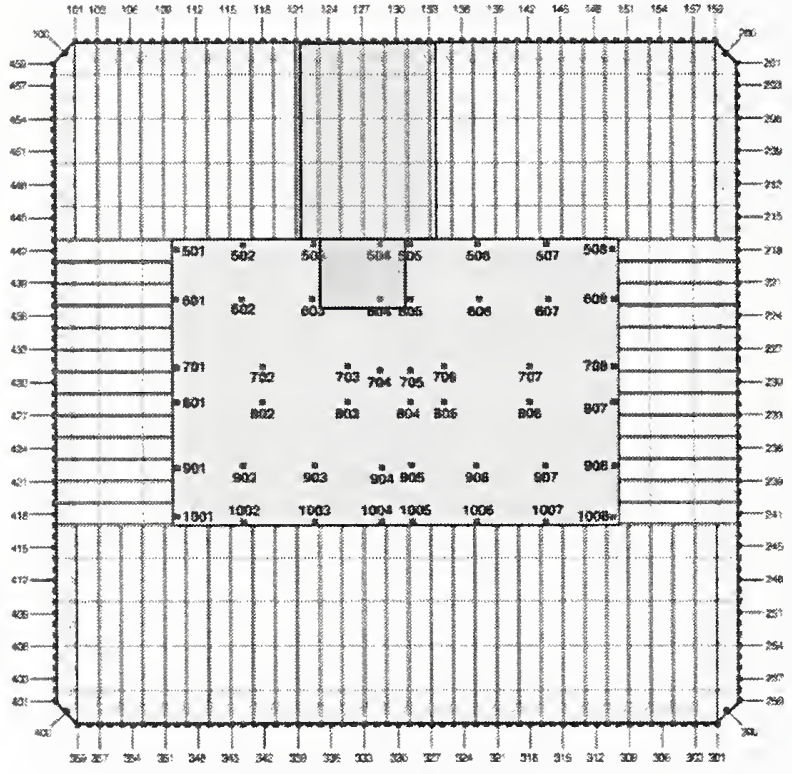

Structural damage for floor 96

Structural Damage

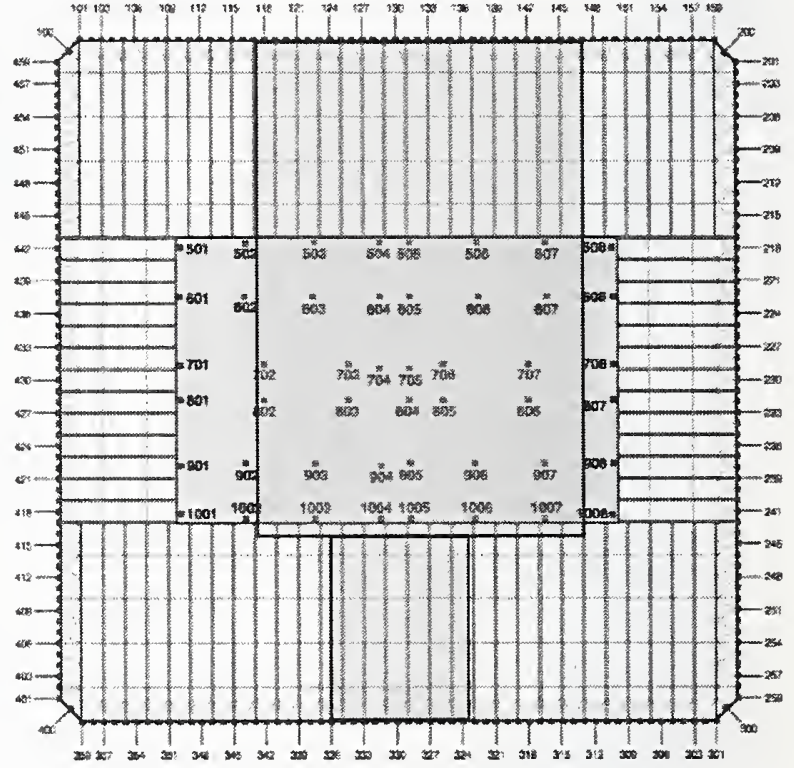

Fireproofing damage on floor trusses and eore beams that support floor 96

Fireproofing Damage

Figure 9-5. Structural and fireproofing damage on floor 96, WTC 1, Case $B_{\mathrm{i}}$. 

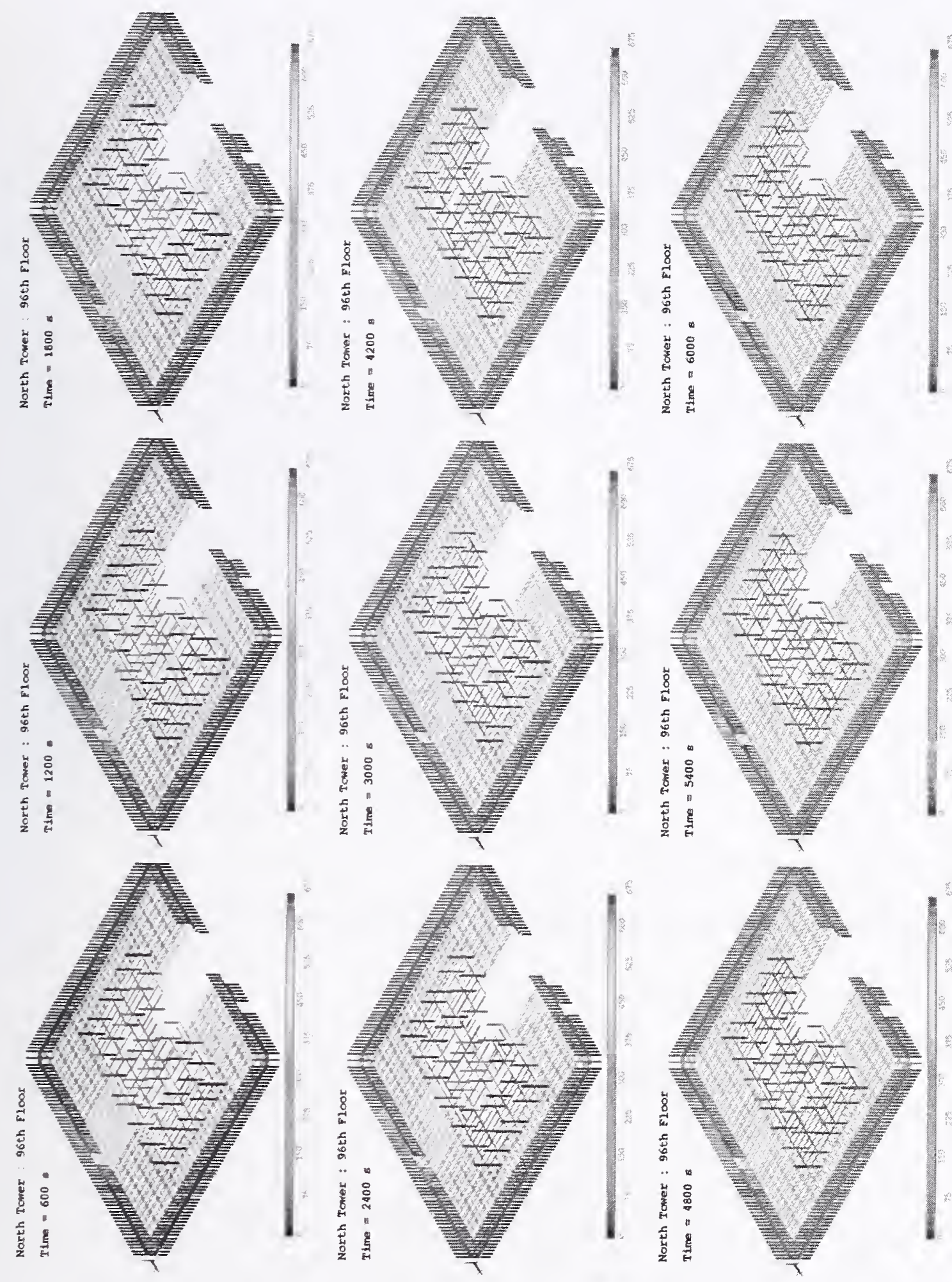

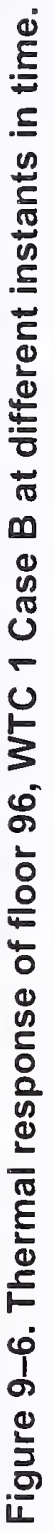




\subsubsection{Floors 97, 98, and 99, WTC 1 Case B}

Floor 97 shows similar differences in thermal response as observed on floor 96 . The damage patterns are skewed towards the west face on floor 97 . Very extensive heating of the truss elements, south of the core is observed for Case B. Core columns on the west face show more fire induced heating in Case B as compared to Case A. The differences between Case A and Case B for floor 98 are similar to those described for floor 96 and 97 . Floor 99 in both cases stays relatively cool during the entire simulation. The truss elements do not heat up significantly, despite fire activity in this region, because of the larger 2.2 in. equivalent fireproofing thickness on the trusses.

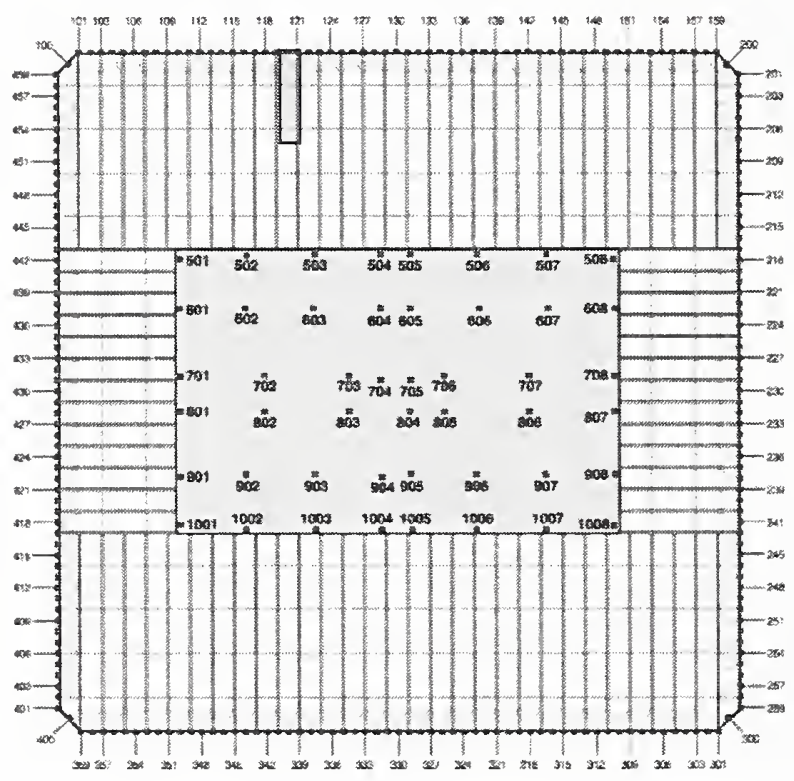

Structural damage for floor 97

Structural damage

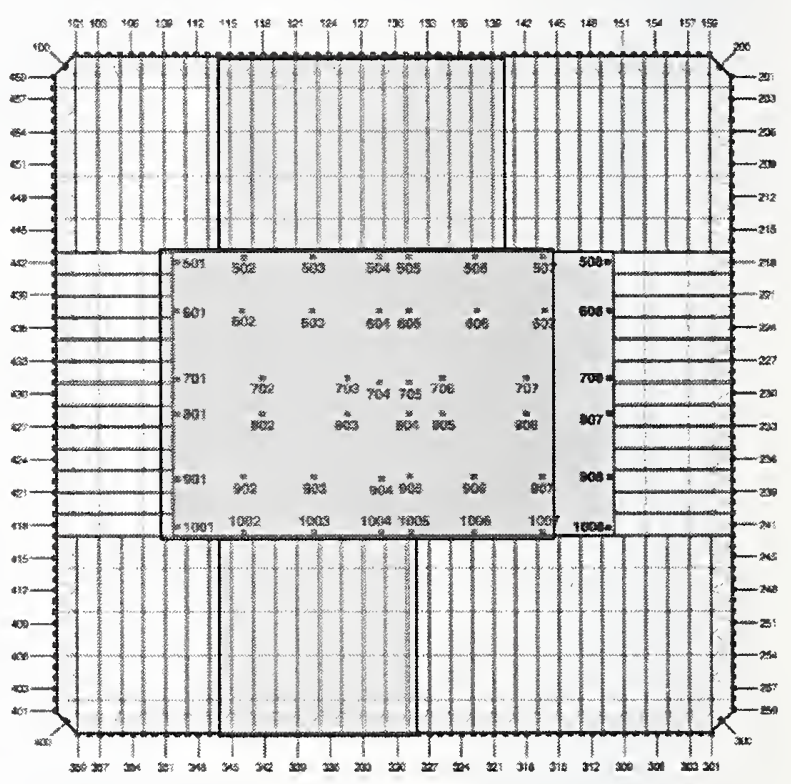

Fireproofing damage on floor trusses and core beams that support floor 97

Fireproofing Damage

Figure 9-7. Structural and fireproofing damage on floor 97, WTC 1, Case $B_{i}$. 


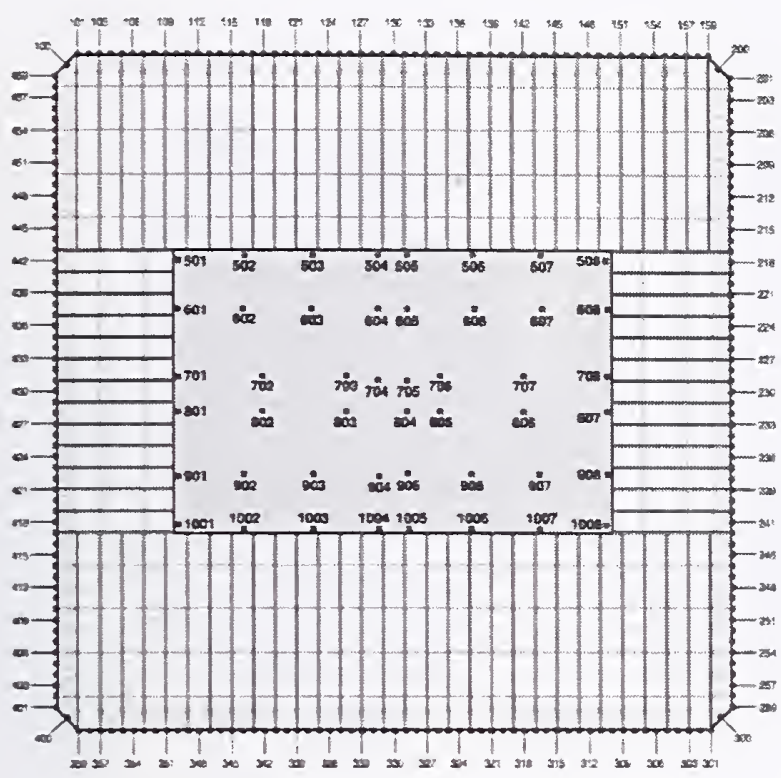

Structural damage for floor 98

Structural Damage

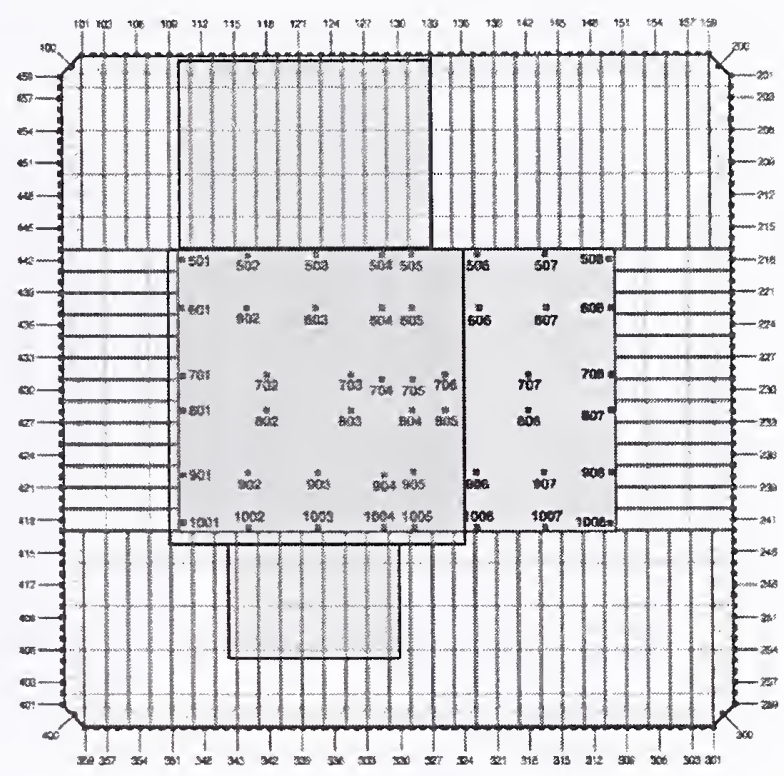

Fireproofing damage on floor trusses and core beams that support floor 98

Filepronfing Damage

Figure 9-8. Structural and fireproofing damage on floor 98, WTC 1, Case $B_{i}$.

\subsection{DATA TRANSFER FOR STRUCTURAL ANALYSIS}

The data transfer is performed in a manner that is identical to that described in the previous chapter for WTC 1 Case A (see Section 8.3). 

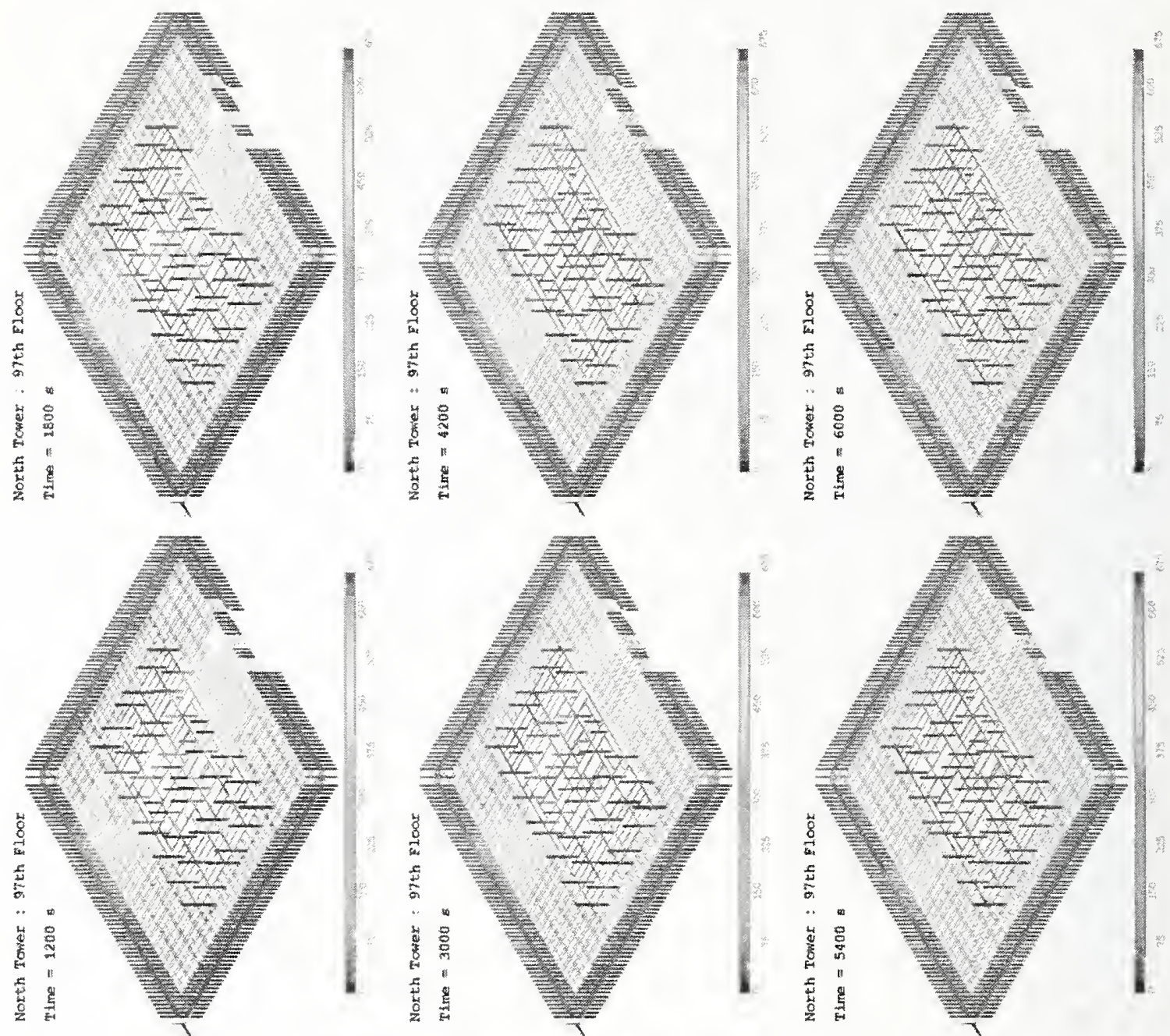

ב⿱艹
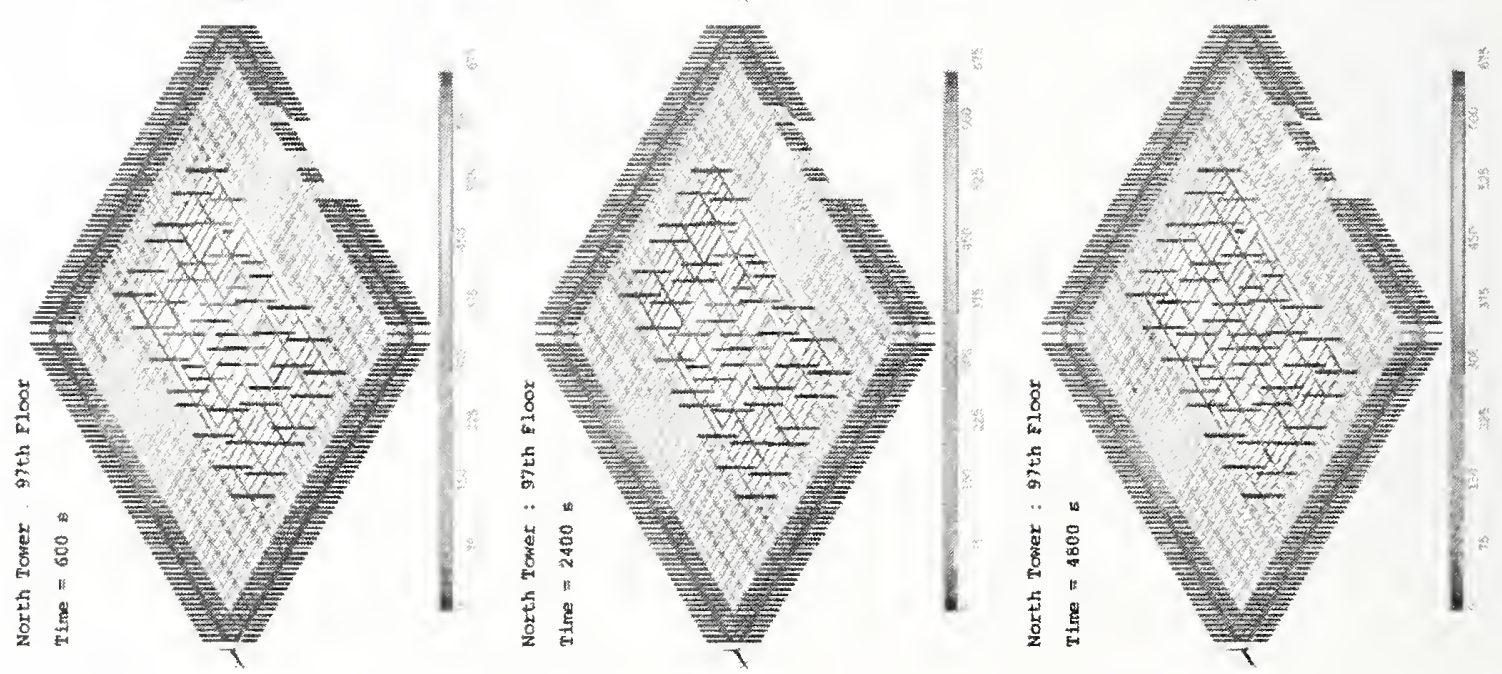

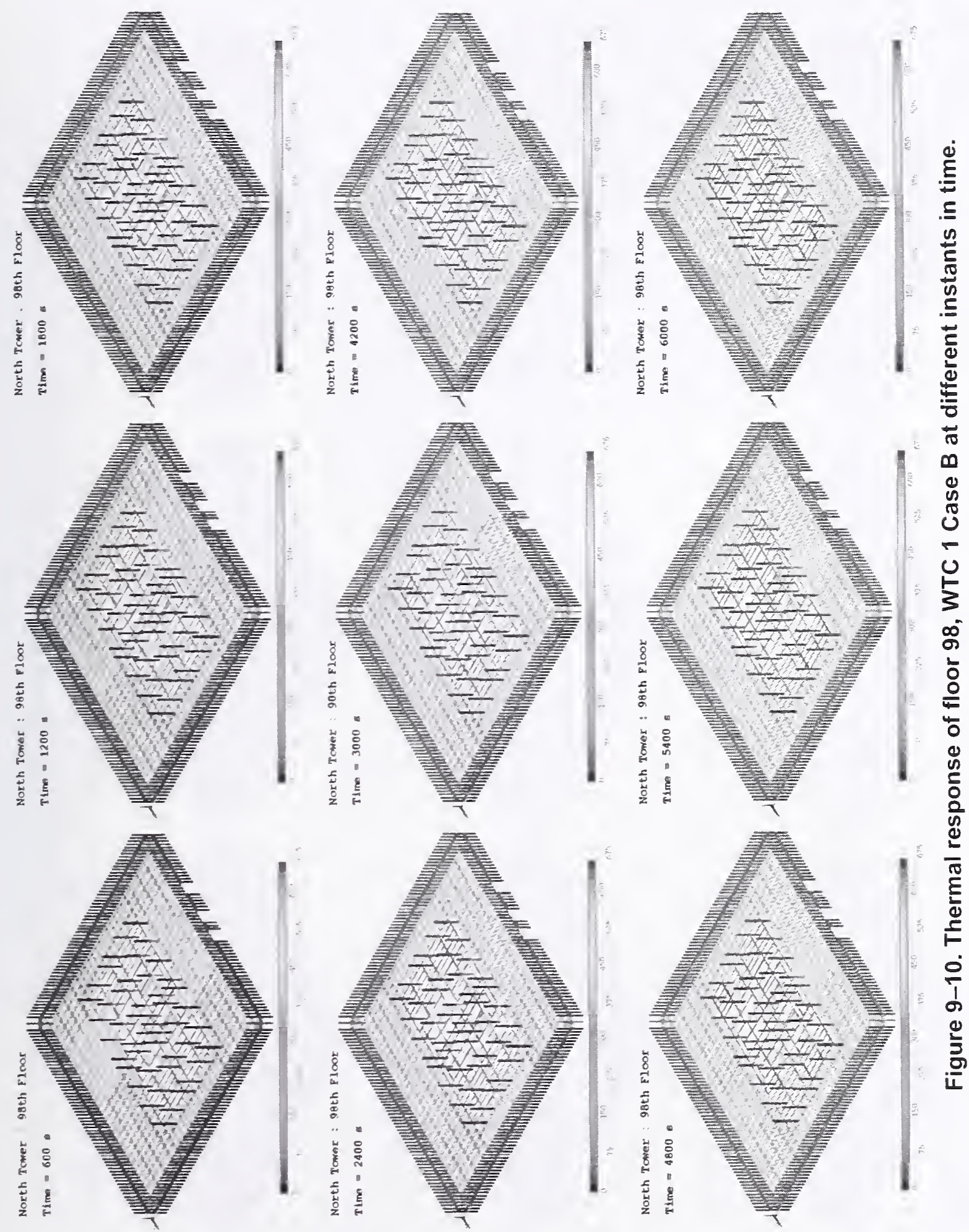

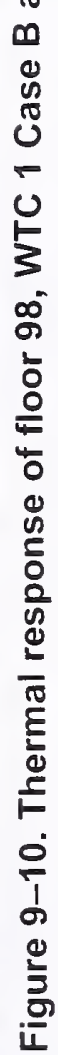



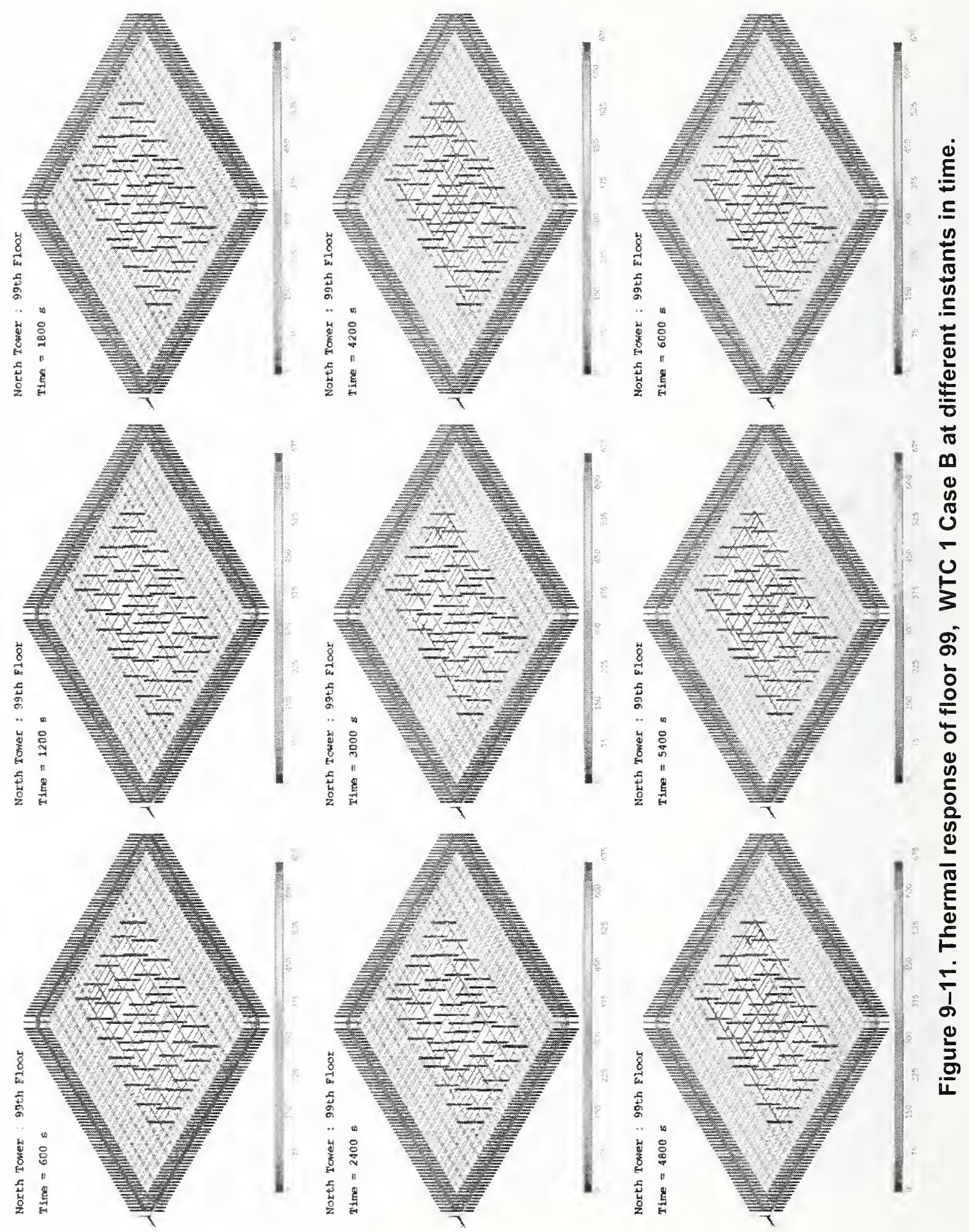
Table 9-4. Perimeter column damage status for WTC 1, Case B.

\begin{tabular}{|c|c|c|c|c|c|c|c|c|}
\hline Column & Floor 92 & Floor 93 & Floor 94 & Floor 95 & Floor 96 & Floor 97 & Floor 98 & Floor 99 \\
\hline 101 & 0 & 0 & 0 & 0 & 0 & 0 & 0 & 0 \\
\hline 103 & 0 & 0 & 0 & 0 & 0 & 0 & 0 & 0 \\
\hline 106 & 0 & 0 & 0 & 0 & 0 & 0 & 0 & 0 \\
\hline 109 & 0 & 0 & 0 & 0 & 0 & 0 & 0 & 0 \\
\hline 112 & 0 & 0 & 0 & 0 & 0 & 0 & 0 & 0 \\
\hline 115 & 0 & 0 & 0 & 0 & 0 & 0 & 0 & 0 \\
\hline 118 & 0 & 0 & 0 & 0 & 0 & 2 & 0 & 0 \\
\hline 121 & 0 & 0 & 0 & 0 & 2 & 0 & 0 & 0 \\
\hline 124 & 0 & 0 & 0 & 2 & 2 & 0 & 0 & 0 \\
\hline 127 & 0 & 0 & 2 & 2 & 2 & 2 & 0 & 0 \\
\hline 130 & 0 & 0 & 0 & 2 & 2 & 0 & 0 & 0 \\
\hline 133 & 0 & 0 & 2 & 2 & 2 & 2 & 0 & 0 \\
\hline 136 & 0 & 0 & 2 & 2 & 0 & 0 & 0 & 0 \\
\hline 139 & 0 & 0 & 2 & 0 & 0 & 0 & 0 & 0 \\
\hline 142 & 0 & 0 & 2 & 0 & 0 & 0 & 0 & 0 \\
\hline 145 & 0 & 0 & 0 & 2 & 0 & 0 & 0 & 0 \\
\hline 148 & 0 & 0 & 0 & 0 & 0 & 0 & 0 & 0 \\
\hline 151 & 0 & 0 & 0 & 0 & 0 & 0 & 0 & 0 \\
\hline 154 & 0 & 0 & 0 & 0 & 0 & 0 & 0 & 0 \\
\hline 157 & 0 & 0 & 0 & 0 & 0 & 0 & 0 & 0 \\
\hline 201 & 0 & 0 & 0 & 0 & 0 & 0 & 0 & 0 \\
\hline 203 & 0 & 0 & 0 & 0 & 0 & 0 & 0 & 0 \\
\hline 206 & 0 & 0 & 0 & 0 & 0 & 0 & 0 & 0 \\
\hline 209 & 0 & 0 & 0 & 0 & 0 & 0 & 0 & 0 \\
\hline 212 & 0 & 0 & 0 & 0 & 0 & 0 & 0 & 0 \\
\hline 215 & 0 & 0 & 0 & 0 & 0 & 0 & 0 & 0 \\
\hline 218 & 0 & 0 & 0 & 0 & 0 & 0 & 0 & 0 \\
\hline 221 & 0 & 0 & 0 & 0 & 0 & 0 & 0 & 0 \\
\hline 224 & 0 & 0 & 0 & 0 & 0 & 0 & 0 & 0 \\
\hline 227 & 0 & 0 & 0 & 0 & 0 & 0 & 0 & 0 \\
\hline 230 & 0 & 0 & 0 & 0 & 0 & 0 & 0 & 0 \\
\hline 233 & 0 & 0 & 0 & 0 & 0 & 0 & 0 & 0 \\
\hline 236 & 0 & 0 & 0 & 0 & 0 & 0 & 0 & 0 \\
\hline 239 & 0 & 0 & 0 & 0 & 0 & 0 & 0 & 0 \\
\hline 242 & 0 & 0 & 0 & 0 & 0 & 0 & 0 & 0 \\
\hline 245 & 0 & 0 & 0 & 0 & 0 & 0 & 0 & 0 \\
\hline 248 & 0 & 0 & 0 & 0 & 0 & 0 & 0 & 0 \\
\hline
\end{tabular}




\begin{tabular}{|c|c|c|c|c|c|c|c|c|}
\hline Column & Floor 92 & Floor 93 & Floor 94 & Floor 95 & Floor 96 & Floor 97 & Floor 98 & Floor 99 \\
\hline 251 & 0 & 0 & 0 & 0 & 0 & 0 & 0 & 0 \\
\hline 254 & 0 & 0 & 0 & 0 & 0 & 0 & 0 & 0 \\
\hline 257 & 0 & 0 & 0 & 0 & 0 & 0 & 0 & 0 \\
\hline 301 & 0 & 0 & 0 & 0 & 0 & 0 & 0 & 0 \\
\hline 303 & 0 & 0 & 0 & 0 & 0 & 0 & 0 & 0 \\
\hline 306 & 0 & 0 & 0 & 0 & 0 & 0 & 0 & 0 \\
\hline 309 & 0 & 0 & 0 & 0 & 0 & 0 & 0 & 0 \\
\hline 312 & 0 & 0 & 0 & 0 & 0 & 0 & 0 & 0 \\
\hline 315 & 0 & 0 & 0 & 0 & 0 & 0 & 0 & 0 \\
\hline 318 & 0 & 0 & 0 & 0 & 0 & 0 & 0 & 0 \\
\hline 321 & 0 & 0 & 0 & 0 & 0 & 0 & 0 & 0 \\
\hline 324 & 0 & 0 & 0 & 1 & 0 & 0 & 0 & 0 \\
\hline 327 & 0 & 0 & 0 & 1 & 1 & 0 & 0 & 0 \\
\hline 330 & 0 & 0 & 2 & 2 & 1 & 0 & 0 & 0 \\
\hline 333 & 0 & 0 & 0 & 1 & 1 & 0 & 0 & 0 \\
\hline 336 & 0 & 0 & 0 & 1 & 1 & 0 & 0 & 0 \\
\hline 339 & 0 & 0 & 0 & 0 & 1 & 0 & 0 & 0 \\
\hline 342 & 0 & 0 & 0 & 0 & 1 & 0 & 0 & 0 \\
\hline 345 & 0 & 0 & 0 & 0 & 1 & 0 & 0 & 0 \\
\hline 348 & 0 & 0 & 0 & 0 & 0 & 0 & 0 & 0 \\
\hline 351 & 0 & 0 & 0 & 0 & 0 & 0 & 0 & 0 \\
\hline 354 & 0 & 0 & 0 & 0 & 0 & 0 & 0 & 0 \\
\hline 357 & 0 & 0 & 0 & 0 & 0 & 0 & 0 & 0 \\
\hline 401 & 0 & 0 & 0 & 0 & 0 & 0 & 0 & 0 \\
\hline 403 & 0 & 0 & 0 & 0 & 0 & 0 & 0 & 0 \\
\hline 406 & 0 & 0 & 0 & 0 & 0 & 0 & 0 & 0 \\
\hline 409 & 0 & 0 & 0 & 0 & 0 & 0 & 0 & 0 \\
\hline 412 & 0 & 0 & 0 & 0 & 0 & 0 & 0 & 0 \\
\hline 415 & 0 & 0 & 0 & 0 & 0 & 0 & 0 & 0 \\
\hline 418 & 0 & 0 & 0 & 0 & 0 & 0 & 0 & 0 \\
\hline 421 & 0 & 0 & 0 & 0 & 0 & 0 & 0 & 0 \\
\hline 424 & 0 & 0 & 0 & 0 & 0 & 0 & 0 & 0 \\
\hline 427 & 0 & 0 & 0 & 0 & 0 & 0 & 0 & 0 \\
\hline 430 & 0 & 0 & 0 & 0 & 0 & 0 & 0 & 0 \\
\hline 433 & 0 & 0 & 0 & 0 & 0 & 0 & 0 & 0 \\
\hline 436 & 0 & 0 & 0 & 0 & 0 & 0 & 0 & 0 \\
\hline 439 & 0 & 0 & 0 & 0 & 0 & 0 & 0 & 0 \\
\hline
\end{tabular}




\begin{tabular}{|c|c|c|c|c|c|c|c|c|}
\hline Column & Floor 92 & Floor 93 & Floor 94 & Floor 95 & Floor 96 & Floor 97 & Floor 98 & Floor 99 \\
\hline 442 & 0 & 0 & 0 & 0 & 0 & 0 & 0 & 0 \\
\hline 445 & 0 & 0 & 0 & 0 & 0 & 0 & 0 & 0 \\
\hline 448 & 0 & 0 & 0 & 0 & 0 & 0 & 0 & 0 \\
\hline 451 & 0 & 0 & 0 & 0 & 0 & 0 & 0 & 0 \\
\hline 454 & 0 & 0 & 0 & 0 & 0 & 0 & 0 & 0 \\
\hline 457 & 0 & 0 & 0 & 0 & 0 & 0 & 0 & 0 \\
\hline 459 & 0 & 0 & 0 & 0 & 0 & 0 & 0 & 0 \\
\hline
\end{tabular}


Table 9-5. Core dolumn damage status for WTC 1, Case B.

\begin{tabular}{|c|c|c|c|c|c|c|c|c|}
\hline Column & Floor 92 & Floor 93 & Floor 94 & Floor 95 & Floor 96 & Floor 97 & Floor 98 & Floor 99 \\
\hline 501 & 0 & 0 & 0 & 0 & 0 & 0 & 0 & 0 \\
\hline 502 & 0 & 0 & 0 & 3 & 3 & 3 & 0 & 0 \\
\hline 503 & 0 & 0 & 3 & 2 & 2 & 3 & 0 & 0 \\
\hline 504 & 2 & 2 & 2 & 2 & 2 & 3 & 0 & 0 \\
\hline 505 & 0 & 0 & 3 & 2 & 3 & 0 & 0 & 0 \\
\hline 506 & 0 & 0 & 3 & 3 & 0 & 0 & 0 & 0 \\
\hline 507 & 0 & 0 & 3 & 0 & 0 & 0 & 0 & 0 \\
\hline 508 & 0 & 0 & 3 & 0 & 0 & 0 & 0 & 0 \\
\hline 601 & 0 & 0 & 0 & 0 & 0 & 0 & 0 & 0 \\
\hline 602 & 0 & 0 & 0 & 3 & 3 & 3 & 0 & 0 \\
\hline 603 & 0 & 0 & 3 & 3 & 3 & 3 & 0 & 0 \\
\hline 604 & 2 & 2 & 2 & 2 & 2 & 3 & 0 & 0 \\
\hline 605 & 0 & 0 & 3 & 3 & 3 & 0 & 0 & 0 \\
\hline 606 & 0 & 0 & 3 & 3 & 0 & 0 & 0 & 0 \\
\hline 607 & 0 & 0 & 3 & 0 & 0 & 0 & 0 & 0 \\
\hline 608 & 0 & 0 & 3 & 0 & 0 & 0 & 0 & 0 \\
\hline 701 & 0 & 0 & 0 & 0 & 0 & 0 & 0 & 0 \\
\hline 702 & 0 & 0 & 0 & 0 & 3 & 3 & 0 & 0 \\
\hline 703 & 0 & 0 & 3 & 3 & 3 & 3 & 0 & 0 \\
\hline 704 & 2 & 2 & 2 & 2 & 2 & 3 & 0 & 0 \\
\hline 705 & 0 & 0 & 3 & 3 & 3 & 0 & 0 & 0 \\
\hline 706 & 0 & 2 & 2 & 2 & 3 & 0 & 0 & 0 \\
\hline 707 & 0 & 0 & 3 & 0 & 0 & 0 & 0 & 0 \\
\hline 708 & 0 & 0 & 3 & 0 & 0 & 0 & 0 & 0 \\
\hline 801 & 0 & 0 & 0 & 0 & 0 & 0 & 0 & 0 \\
\hline 802 & 0 & 0 & 0 & 0 & 3 & 3 & 0 & 0 \\
\hline 803 & 0 & 0 & 3 & 3 & 3 & 3 & 0 & 0 \\
\hline 804 & 0 & 0 & 3 & 3 & 3 & 0 & 0 & 0 \\
\hline 805 & 0 & 0 & 3 & 3 & 3 & 0 & 0 & 0 \\
\hline 806 & 0 & 0 & 3 & 0 & 0 & 0 & 0 & 0 \\
\hline 807 & 0 & 0 & 0 & 0 & 0 & 0 & 0 & 0 \\
\hline 901 & 0 & 0 & 0 & 0 & 0 & 0 & 0 & 0 \\
\hline 902 & 0 & 0 & 0 & 0 & 3 & 3 & 0 & 0 \\
\hline 903 & 0 & 0 & 0 & 3 & 3 & 3 & 0 & 0 \\
\hline 904 & 0 & 0 & 3 & 3 & 3 & 3 & 0 & 0 \\
\hline 905 & 0 & 0 & 3 & 3 & 3 & 0 & 0 & 0 \\
\hline 906 & 0 & 0 & 3 & 3 & 0 & 0 & 0 & 0 \\
\hline
\end{tabular}




\begin{tabular}{|c|c|c|c|c|c|c|c|c|}
\hline Column & Floor 92 & Floor 93 & Floor 94 & Floor 95 & Floor 96 & Floor 97 & Floor 98 & Floor 99 \\
\hline 907 & 0 & 0 & 3 & 0 & 0 & 0 & 0 & 0 \\
\hline 908 & 0 & 0 & 0 & 0 & 0 & 0 & 0 & 0 \\
\hline 1001 & 0 & 0 & 0 & 0 & 0 & 0 & 0 & 0 \\
\hline 1002 & 0 & 0 & 0 & 0 & 3 & 3 & 0 & 0 \\
\hline 1003 & 0 & 0 & 0 & 0 & 3 & 3 & 0 & 0 \\
\hline 1004 & 0 & 0 & 3 & 3 & 3 & 3 & 0 & 0 \\
\hline 1005 & 0 & 0 & 3 & 3 & 3 & 0 & 0 & 0 \\
\hline 1006 & 0 & 0 & 3 & 3 & 0 & 0 & 0 & 0 \\
\hline 1007 & 0 & 0 & 3 & 0 & 0 & 0 & 0 & 0 \\
\hline 1008 & 0 & 0 & 0 & 0 & 0 & 0 & 0 & 0 \\
\hline
\end{tabular}


This page intentionally left blank. 


\section{Chapter 10 \\ GLobal Thermal Response OF WTC 2 : CASE C}

Four global simulations, two each for World Trade Center (WTC) 1 and WTC 2, are presented in this report to predict the thermally induced structural response of the World Trade Center towers. This chapter is the third of four chapters (Chapter 8 through Chapter 11) that describe the results of the four cases. Chapter 8 and Chapter 9 describe results for WTC 1 Case A and Case B respectively, while this chapter and Chapter 11 focus on WTC 2.

The focus of this chapter is on the global thermal response of WTC 2 for a specific set of aircraft impact damage and fire dynamics simulation. The temporally and spatially varying temperatures on floors 78 through 83 of WTC 2 were estimated for all the structural elements including the concrete slab. These temperatures were subsequently used for prediction of thermally induced structural response including collapse of WTC 2. Floors below floor 78 and above floor 83 were assumed to be convectively cooled by air at room temperature. The period of time simulated is $60 \mathrm{~min}$, and it ranges from point of impact to collapse of the WTC 2 tower. The results of the thermal analysis (presented in visual form in this chapter) were provided for structural analysis in a format that is consistent with the structural models. A floor by floor description of each floor is presented to understand the nature of the thermal insult on WTC 2.

\subsection{OVERVIEW}

During the course of this Investigation, preliminary calculations were performed to study the thermally induced response at the component or single floor level. The objective of these preliminary simulations was to assess the sensitivity of the input parameters, test the robustness of the numerical models and gain insight. The set of simulations termed "WTC 2 Case C" represent one such set of simulations where base settings (see Table 10-1, Table 10-2 and Table 10-3) were employed for the various input parameters to predict the thermally induced structural response of WTC 2 . In this chapter, a floor by floor description along with visuals (Figure 10-2 through Figure 10-7) is presented to understand the thermal loading caused by the fires. The thermal data was provided in the form of thermal loading data files for structural analysis and for predicting collapse induced by heating of the structure.

\subsubsection{Aircraft Impact Analysis}

Aircraft impact analysis was performed for WTC 2 with base settings to predict the structural and fireproofing damage on floors 78 through 83 of WTC 2. The input parameters for the impact analysis are summarized in Table 10-1. The main objective of this analysis was to predict the damage to columns, trusses, and floor slabs due to aircraft impact (NIST NCSTAR 1-2).

Table 10-4 shows the structural and fireproofing damage observed (NIST NCSTAR 1-5A) on perimeter columns for WTC 2 (floors 78 through 83 ). In this table a " 0 " indicates that the column and its fireproofing is intact, " 1 " indicates fireproofing damage on the interior face only and a " 2 " indicates a column that has been severed by aircraft impact. The methodology for incorporating fireproofing and structural damage for perimeter columns was discussed in Chapter 4. 
Table 10-5 shows fireproofing damage predicted for core columns in WTC 2 (floors 78-83). In this table a " 0 " indicates that the column and its fireproofing is intact, a " 2 " indicates fireproofing damage on one face, and a " 3 " indicates fireproofing damage on all the faces. Core columns in WTC 2 Case C were either complete stipped of their fireproofing or their fireproofing was fully intact. Table 10-6 shows structural damage predicted for core columns due to aircraft impact in WTC 2 (floors 78-83). In this table a " 0 " indicates that the column is intact while a " 2 " indicates that the columns has been severed (NIST NCSTAR 1-2).

Aircraft impact can also result in structural and fireproofing damage to the floor system. For each floor, a map was prepared showing contours of the region where fireproofing and structural damage was predicted. This damage for floors $79,80,81,82$, and 83 is shown in Figure 10-2, Figure 10-4, Figure 10-6, Figure 10-14, Figure 10-16, respectively (NIST NCSTAR 1-2). In these figures, the regions marked by green rectangles indicate structural damage, while the region marked by blue rectangles shows fireproofing damage only (steel structure is intact). Structural damage was incorporated in the analysis by removing the concrete slab, trusses, or core beams in the area marked by the green rectangles.

Fireproofing damage was included in the finite element model by changing the material attributes of the element. The method for incorporating structural and fireproofing damage has been discussed extensively in Chapter 5 and Chapter 6 of this report.

Table 10-1. Input parameters for WTC 2 global impact analyses (Base Case).

\begin{tabular}{|c|l|c|}
\hline \multicolumn{2}{|c|}{ Analysis Parameters } & Base Case \\
\hline \multirow{4}{*}{$\begin{array}{c}\text { Flight } \\
\text { Parameters }\end{array}$} & Impact Velocity & $546 \mathrm{mph}$ \\
\cline { 2 - 3 } & Trajectory - pitch & $6.0^{\circ}$ \\
\cline { 2 - 3 } & Trajectory - yaw & $13.0^{\circ}$ \\
\cline { 2 - 3 } & Orientation - pitch & $5.0^{\circ}$ \\
\cline { 2 - 3 } Aircraft & Orientation - yaw & $10.0^{\circ}$ \\
\hline \multirow{4}{*}{$\begin{array}{c}\text { Tarameters } \\
\text { Parameters }\end{array}$} & Weight & 100 percent \\
\cline { 2 - 3 } & Failure Strain & 100 percent \\
\cline { 2 - 3 } & Contents Strength & 100 percent \\
\cline { 2 - 3 } & Failure Strain & 100 percent \\
\cline { 2 - 3 } & Live Load Weight & 25 percent \\
\hline \hline
\end{tabular}

a. Live load weight expressed as a percentage of the design live load.

\subsubsection{Fire Dynamics Simulations}

Fire activity in WTC 2 was more difficult to simulate than that in WTC 1 due to the lack of a detailed floor by floor layout and due to the nature of the impact damage on the various floors. Fire simulations were performed using the NIST Fire Dynamics Simulator (NIST NCSTAR 1-5F). Table 10-2 shows the input parameters for the fire simulations. 
Table 10-2. Values of WTC fire

simulation variables.

\begin{tabular}{|l|l|}
\hline \multicolumn{1}{|c|}{ Variable } & \multicolumn{1}{c|}{ Case C } \\
\hline Fuel load & $20 \mathrm{~kg} / \mathrm{m}^{2}\left(4 \mathrm{lb} / \mathrm{ft}^{2}\right)$ \\
\hline $\begin{array}{l}\text { Distribution of } \\
\text { disturbed } \\
\text { combustibles }\end{array}$ & $\begin{array}{l}\text { Heavily } \\
\text { concentrated in the } \\
\text { northeast corner }\end{array}$ \\
\hline $\begin{array}{l}\text { Condition of } \\
\text { combustibles }\end{array}$ & All rubblized \\
\hline $\begin{array}{l}\text { Representation of } \\
\text { impacted core walls }\end{array}$ & Fully removed \\
\hline
\end{tabular}

In the fire simulations, workstations were damaged throughout most of the six focus floors of WTC 2 included in the simulations. For each floor, temporally averaged properties that describe the hot layer at $100 \mathrm{~s}$ intervals were recorded at each grid point in the fire simulation. The properties of the hot layer include upper layer temperature, absorption coefficients, height of the hot layer, and ambient temperature. The text file also contains information on spatial locations (underlying FDS grid) where the properties were recorded. Such text files were created for floors 78-83 of WTC 2 and wcre provided as input to the ANSYS finite element analysis software.

\subsection{FIRE STRUCTURE INTERFACE}

The Fire Structure Interface (FSI) uses the output of the fire simulations together with the aircraft impact damage results to predict the evolving thermal state of WTC 2. The important inputs that are required for FSI are listed in Table 10-3. The thermal data computed was subsequently mapped on the structural elements and was provided in a format that was consistent with the finite element software as well as the model used for performing structural analysis. The structural response of WTC 2 and collapse analysis described in NIST NCSTAR 1-6C was performed using the thermal data presented in this chapter.

Figure 10-1 is a sample plot that shows the thermal data generated with FSI and subsequently transferred to the structural models for analysis. Temperature contours are superimposed on the steel structure of a typical floor of WTC 2. The figure shows the core beams and floor trusses that support a concrete slab. The concrete slab has not been included in the figure for clarity, but is included as part of the analysis. Portions of the core beams and floor trusses were damaged by the impact of the aircraft and this portion of the structure is not shown in the figure nor was it included in the thermal analysis. The figure also shows the perimeter and core columns extending to the floor above and below the floor under consideration. Perimeter and core columns that were severed by the impact of the aircraft are not shown in this figure. The structural damage varies from one floor to another and has been summarized in Table 10-4 through Table 10-6. As has been discussed in detail in Chapter 4 through Chapter 7, the thermal and structural finite element models were constructed from the data discussed in NIST NCSTAR 1-2 and summarized in Appendix B. The type and location of the fireproofing thickness (not damaged by the aircraft impact) is summarized in Table B-9.

The total simulation time for WTC 2 is approximately $60 \mathrm{~min}(3,600 \mathrm{~s})$ and it ranges from the point of aircraft impact until collapse. The time steps for thermal analysis ranged from $1 \mathrm{~ms}$ to $50 \mathrm{~s}$. Thermal data at six instants in time, spaced at $10 \mathrm{~min}(600 \mathrm{~s})$ intervals was provided for structural analysis. For each 
time step, a set of thermal loading data files were created to completely specify the thermal state of each floor. The thermal loading data files were in a format consistent with the structural models and could be easily read in with the ANSYS finite element software to specify body loads on the structure. Thermal loading data files were created at $10 \mathrm{~min}, 20 \mathrm{~min}, 30 \mathrm{~min}, 40 \mathrm{~min}, 50 \mathrm{~min}$, and $60 \mathrm{~min}$ after impact. The structure was assumed to be initially at room temperature. The final load step file was at 60 min $(3,600 \mathrm{~s})$ and it contained the final thermal state of the tower.

Table 10-3. Input for global thermal response of WTC 2.

\begin{tabular}{|l|c|}
\hline \multicolumn{1}{|c|}{ Input } & WTC 2 Case C \\
\hline $\begin{array}{l}\text { Structural damage, } \\
\text { NIST NCSTAR 1-2 }\end{array}$ & Base Case \\
\hline $\begin{array}{l}\text { Fireproofing damage, } \\
\text { NIST NCSTAR 1-2 }\end{array}$ & Base Case \\
\hline $\begin{array}{l}\text { Fire simulations, } \\
\text { NIST NCSTAR 1-5F }\end{array}$ & Case C \\
\hline
\end{tabular}

Fire simulations and thermal analyses were performed for WTC 2 on floors 78 through 83 . The full floor structural models (NIST NCSTAR 1-6D) had a single slab and floor truss system with the columns extending on one floor above and one floor below the slab. A mapping for floor 78 would have required fire simulations on floor 77 and thermal analysis on the columns between floor 77 and 78 to completely specify the thermal state of floor 78. Since no significant fires were observed on floor 77 , fire simulations were not performed for that floor. As a consequence thermal mapping was not performed for floor 78 .

In the following sections, the thermal mapping results for floors 79 through 83 is described. The thermal data provided for structural analysis as body load files is presented in visual format on a floor by floor basis, preceded by a brief discussion of the significant features. 

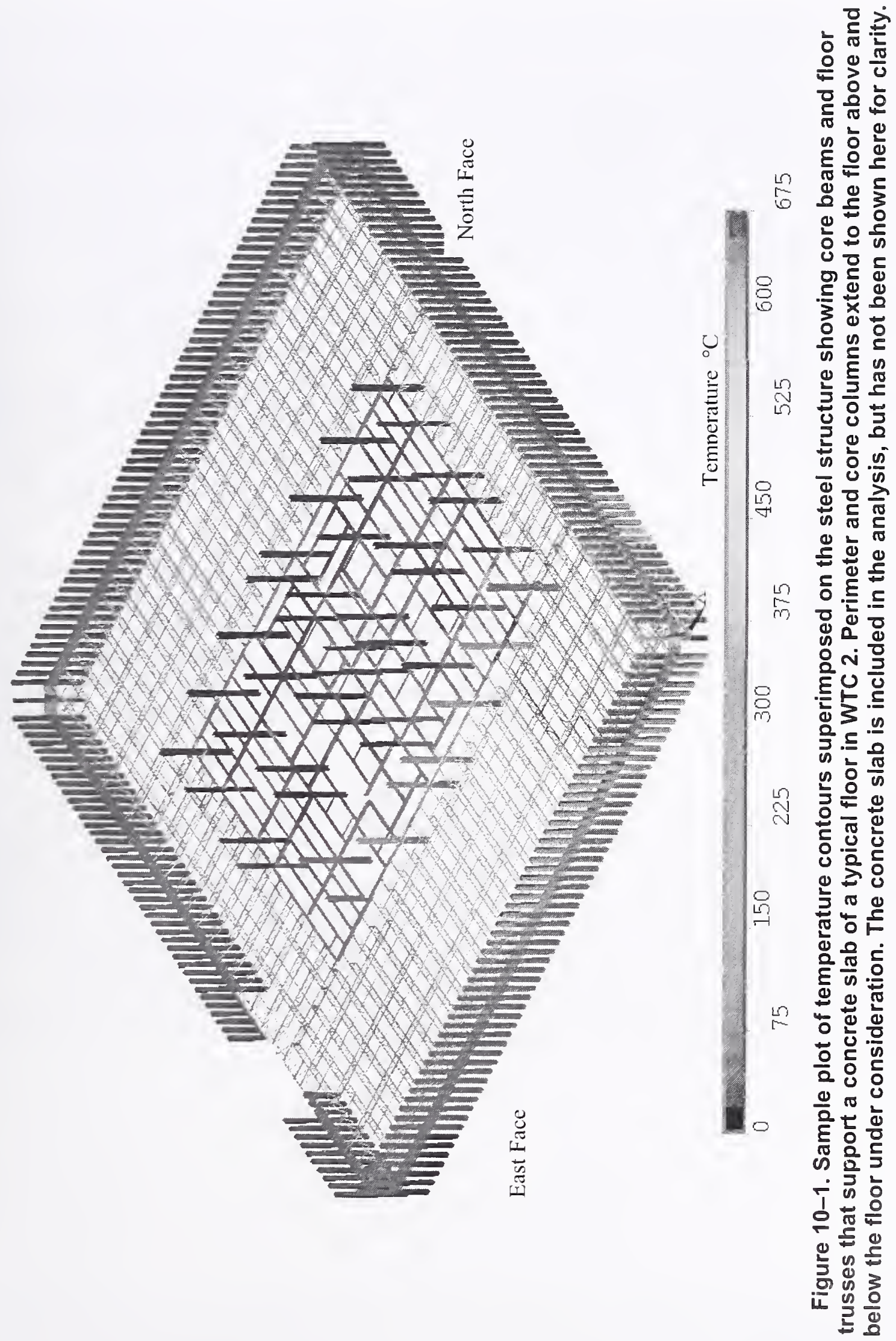


\subsubsection{Floor 79, WTC 2 Case C}

The aircraft impact analysis and fireproofing damage results for floor 79, WTC 2 Case C are shown in Figure 10-2 indicating extensive fireproofing damage on the south face and in the core area (southeast corner) $)^{5}$. There is also limited structural damage on the trusses and core beams.

Table 10-4 shows the fireproofing and structural damage predicted for perimeter columns on floors 78 and 79. There is no fireproofing damage on any of the perimeter columns on floor 78 or 79 (NIST NCSTAR 1-2). However several perimeter columns on floors 78 and 79 were severed due to aircraft impact, especially on the south face (as evidenced in the photographic observations, NIST

NCSTAR 1-5A). Finite element models of perimcter columns and the methodology for incorporating structural damage were discussed extensively in Chapter 4.

Table 10-5 and Table 10-6 show fireproofing and structural damage predicted for core columns on floors 78 and 79. The tables indicate extensive fireproofing damage to core columns on the east side of the core on floors 78 and 79. Column 903 and 1001 are severed (damaged) by the aircraft impact on floor 78, while columns 901, 903, 1001, and 1002 are severed on floor 79. The methodology for incorporating structural and fireproofing damage was discussed extensively in Chapter 7.

Figure 10-3 shows the thermal response of the $79^{\text {th }}$ floor of WTC 2 Case C at six different instants in time, ranging from $10 \mathrm{~min}$ to $60 \mathrm{~min}$ at $10 \mathrm{~min}$ intervals. The figure shows the truss assembly and core beams that support the $79^{\text {th }}$ floor. Perimeter and core columns above the $79^{\text {th }}$ floor concrete slab are subjected to fires on the $79^{\text {th }}$ floor while columns below $79^{\text {th }}$ floor slab are subjected to fires on the $78^{\text {th }}$ floor. The pcrimeter and core columns damaged by impact of the aircraft are not been shown in the pictures. Also the core beams and trusses severed by impact of the aircraft have not shown in the pictures (Figure 10-3).

Inspite of extensive fireproofing damage on the trusses that supports the slab on the $79^{\text {th }}$ floor, Figure 10-3 shows that trusses in the south face do not heat up significantly. Fire simulations indicate that there was only light fire activity on the $78^{\text {th }}$ floor due to a small amount of jet fuel released on this floor during impact. As a result trusses and core beams that were subjected to fires on the $78^{\text {th }}$ floor did not show significant temperature increase (Figure 10-3). The perimeter and core columns between floor 78 and floor 79 also remained relatively cool through out the simulation, due to insufficient fire activity on the floor. Core columns on the east side (1000 series) above floor 79 indicate heating due to a combination of fireproofing damage and fire activity on the $79^{\text {th }}$ floor. Core column 1008 has fireproofing damage but shows gradual heating because of its high thermal inertia (thicker, heavier cross-section).

\footnotetext{
5 The damage graphics used in the thermal analysis are discussed in detail in NIST NCSTAR 1-6 and have been presented here for reference only.
} 


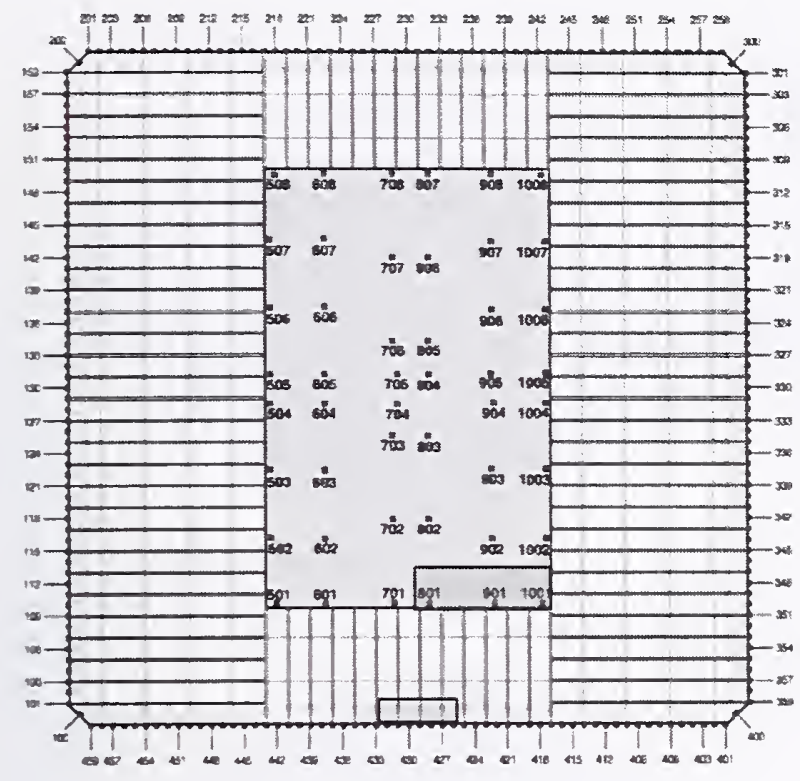

Structural damage for floor 79

Structural Damage

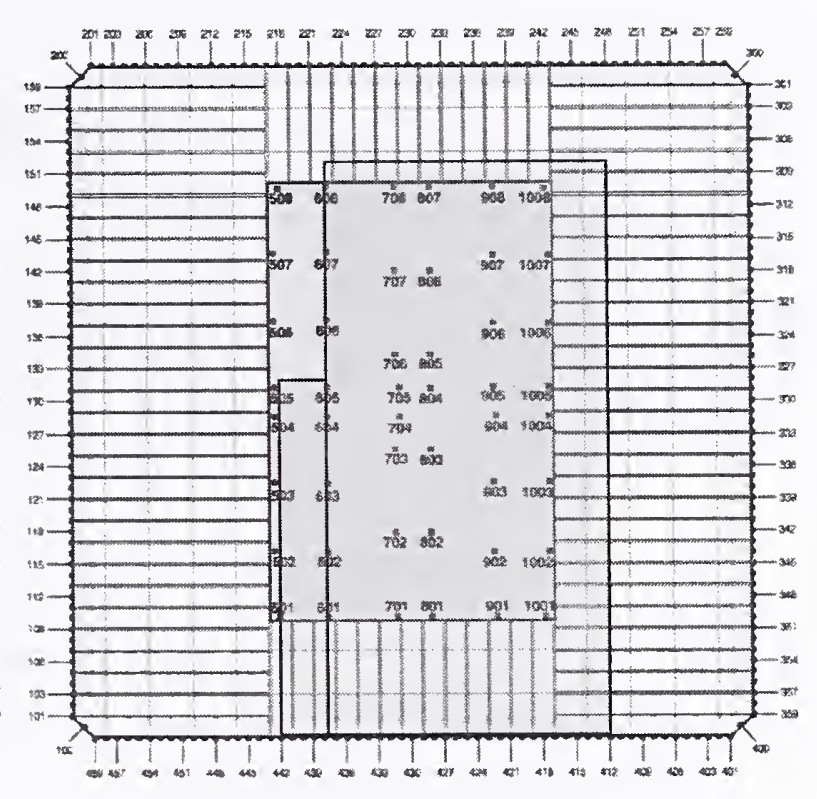

Fireproofing damage on floor trusses and core beams that support floor 79

Fireproofing Damage

Figure 10-2. Structural and fireproofing damage on floor 79 WTC 2, Case $C_{i \cdot}$ 

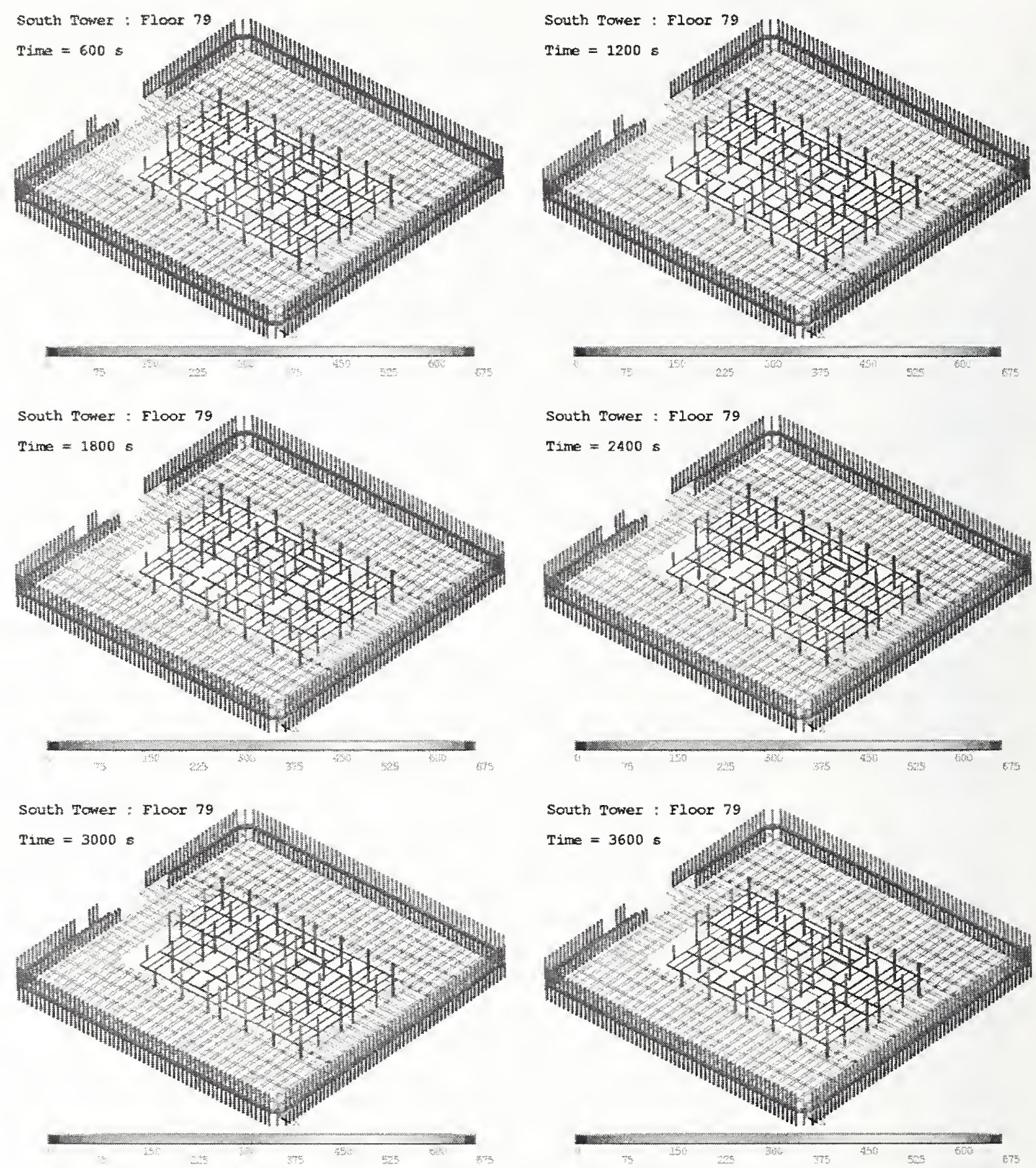

Figure 10-3. Thermal response of floor 79 WTC 2 Case C at six different instants in time. 


\subsubsection{Floor 80, WTC 2 Case C}

Structural and fireproofing damage due to aircraft impact on floor 80 (floor trusses and slabs) is shown in Figure 10-4. The figure indicates extensive fireproofing damage in the south face of WTC 2 and the southeast comer of the core. There is also limited amount of structural damage for trusses, core beams, and concrete slabs. Structural damage was incorporated into the analysis by removing the concrete slab, trusses or core beams in the area marked by the green rectangles. Fireproofing damage was included in the simulations by changing the material attributes of the elements to those of a perfect conductor. The method for incorporating structural and fireproofing damage on truss and floor slabs was discussed extensively in Chapter 5 and Chapter 6.

There is no fireproofing damage on any of the perimeter columns below floor 80 , but fireproofing damage was predicted (NIST NCSTAR 1-2) for perimeter columns 251-259 above floor 80, on the north face of WTC 2 (Table 10-4). The fireproofing damage on these columns is limited to the interior faces of the column. Several perimeter columns on floors 79 and 80 were severed due to aircraft impact, especially on the south face (NIST NCSTAR 1-5A). Table 10-5 and Table 10-6 indicate extensive fireproofing damage to core columns on east side of the core on floors 79 and 80 , especially in the 9 and 10 series columns.

Figure 10-5 shows the thermal response of the $80^{\text {th }}$ floor of WTC 2, Case C at six different instants in time ranging from $10 \mathrm{~min}$ to $60 \mathrm{~min}$ at $10 \mathrm{~min}$ intervals. The figure shows the truss assembly and core beams that support floor 80 , subjected to fires on floor 79 . Perimeter and core columns above the $80^{\text {th }}$ floor slab are subjected to fires on $80^{\text {th }}$ floor, while columns below the $80^{\text {th }}$ floor slab are subjected to fires on the $79^{\text {th }}$ floor. The perimeter and core columns, core beams, truss, and slab damaged by the aircraft have been removed from the pictures.

Trusses and core beams that have fireproofing damage show higher temperatures in the areas where there is intense fire activity (10 $\mathrm{min}$ and $20 \mathrm{~min}$ after impact). There are portions of the floor truss that do not heat up as quickly (even though they have lost their fireproofing) due to lack of fire activity in this area. Fire simulations indicate little fire activity in the south face and moderate activity in the north face. Some fire activity is predicted in the east and west faces. Truss elements in WTC 2 are covered with 0.6 in. equivalent thickness of BLAZE-SHIELD DC/F product. These elements show thermal heating in the northeast corner and in the east face. Simulation results predict heating of the truss element on the west face, due to fire activity in this area (NIST NCSTAR 1-5F). It should be noted that visual observations (window breaking) do not indicate the predicted level of fire activity; as a result, heating of the truss elements in this area might have been significantly lower.

Perimeter columns in the north face of WTC 2, between floor 80 and floor 81 show significant heating due to lack of fireproofing damage on the columns and intense fire activity. As a result perimeter columns in the northeast corner show temperatures on the order of $500^{\circ} \mathrm{C}$ to $600{ }^{\circ} \mathrm{C}$. Numerical simulations predict heating of the perimeter column on the west face of floor 79 . Heating of core columns was predicted on the east side on floor 79 , but relatively cool core columns were predicted above floor 80 . This is due to lack of high upper layer temperatures in the core on floor 80 as indicated by the fire simulations (NIST NCSTAR 1-5F). 


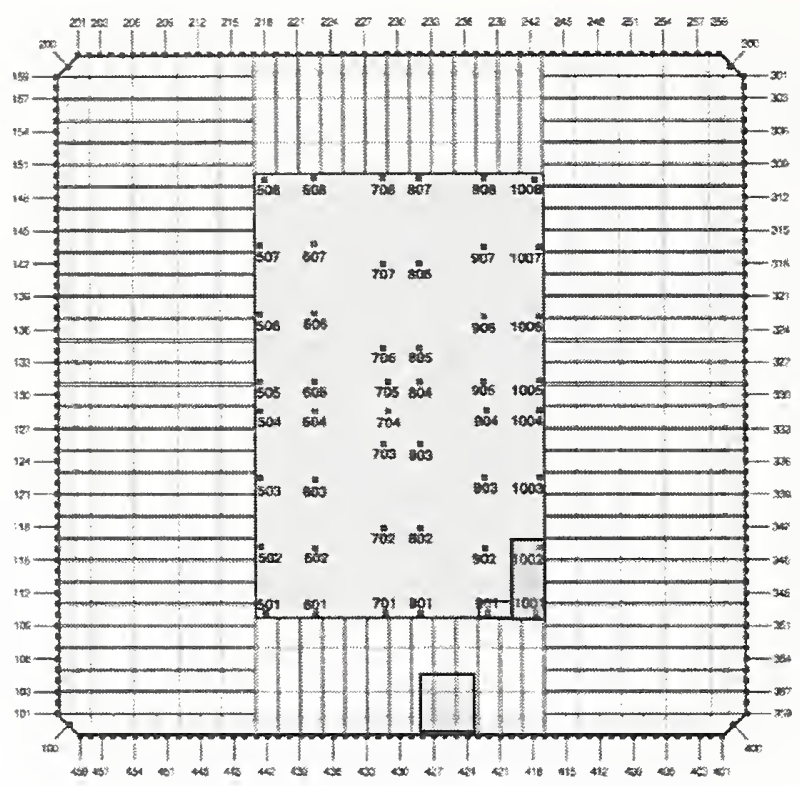

Structural damage for floor 80

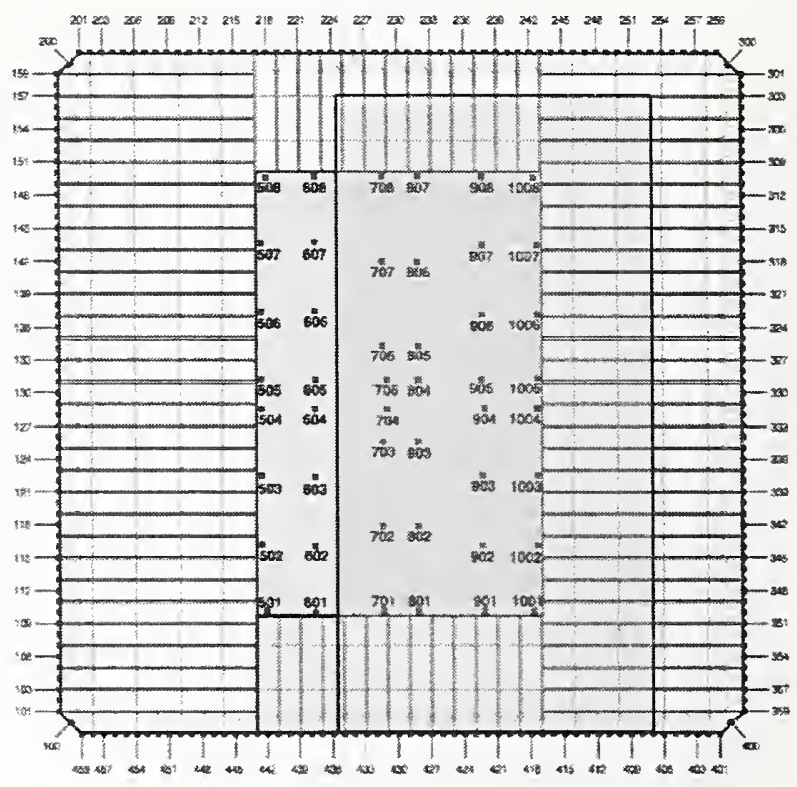

Fireproofing damage on floor trusses and core beams that support floor 80

Fireproofing Damage

Figure 10-4. Structural and fireproofing damage on floor 80, WTC 2 Case $_{C_{i}}$. 

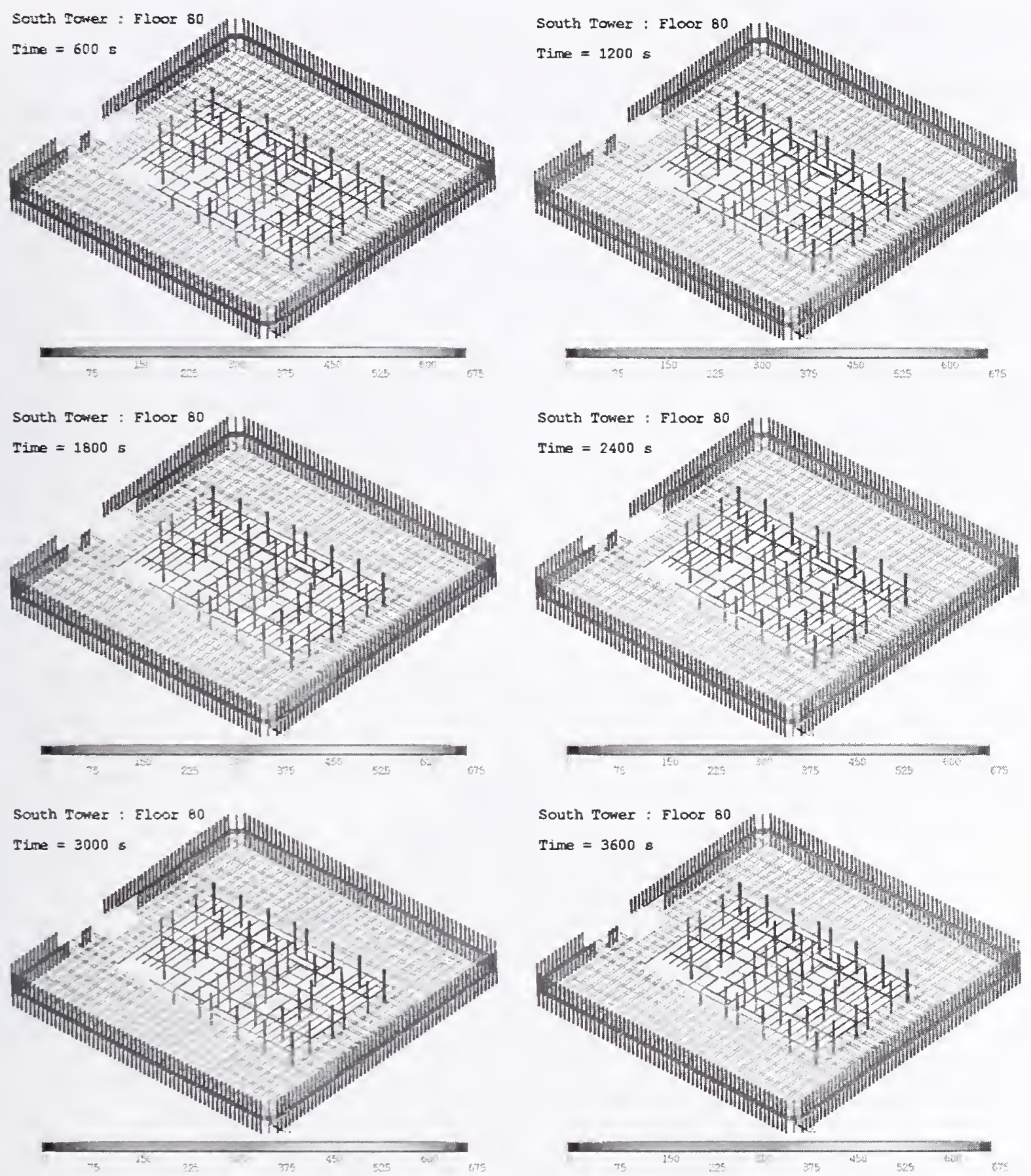

Figure 10-5. Thermal response of floor 80 , WTC 2 at different instants in time, Case C. 


\subsubsection{Floor 81, WTC 2 Case C}

Aircraft impact analysis and fireproofing damage contour maps for floor 81 are shown in Figure 10-6. These maps apply to floor trusses and core beams that support the slab on floor 81 . Considerable damage is predicted along a path from the south central to northeast corner of the floor. Extensive fireproofing damage is predicted for perimeter columns above floor 81 ranging from column 251-351. Below floor 81 , fireproofing damage is on the north face, toward the northeast corner. Fireproofing damage is due to the predicted path of the aircraft debris (NIST NCSTAR 1-2). Structural damage is limited to the south face of WTC 2 (Table 10-4). Fireproofing damage for core columns is quite extensive above and below floor 81 (Table 10-5).

Figure 10-7 through Figure 10-13 show contour maps of temperature superimposed on the structural elements on floor 81 , WTC 2 Case $\mathrm{C}$ at various instants in time. Trusses and core beans that have fireproofing damage show higher temperatures in the area where there is intense fire activity. Figure 10-7 shows significant heating of the trusses, 10 min after impact, but the trusses indicate cooling down at $20 \mathrm{~min}$ and $30 \mathrm{~min}$ after impact. Some heating of the trusses in the northwest corner is observed at $50 \mathrm{~min}$ to $60 \mathrm{~min}$ after impact. Although there is no fireproofing damage to the trusses in this region, the truss elements are covered with $0.6 \mathrm{in}$. of fireproofing, which results in gradual heating of the trusses in the region where there is fire activity. Fire simulations indicate less activity in the northeast corner on floor 80 as compared to floors 81 and 82 .

Perimeter columns above floor 81 show significant heating, due to lack of fireproofing and intense fire activity over the entire east face and northeast corner. Temperature greater than $600{ }^{\circ} \mathrm{C}$ is predicted for these perimeter columns at $30 \mathrm{~min}$ after impact. The rest of the perimeter columns stay relatively cool. Core column heating is observed for the 10 series columns above floor 81 due to a combination of fireproofing damage and fire activity in this area. 


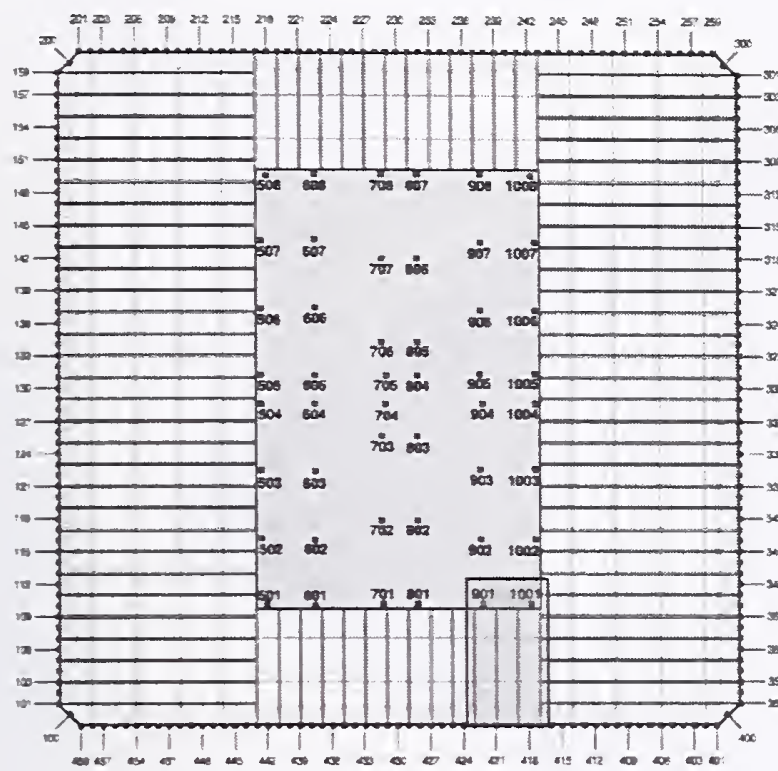

Structural damage for floor 81

Structural Damage

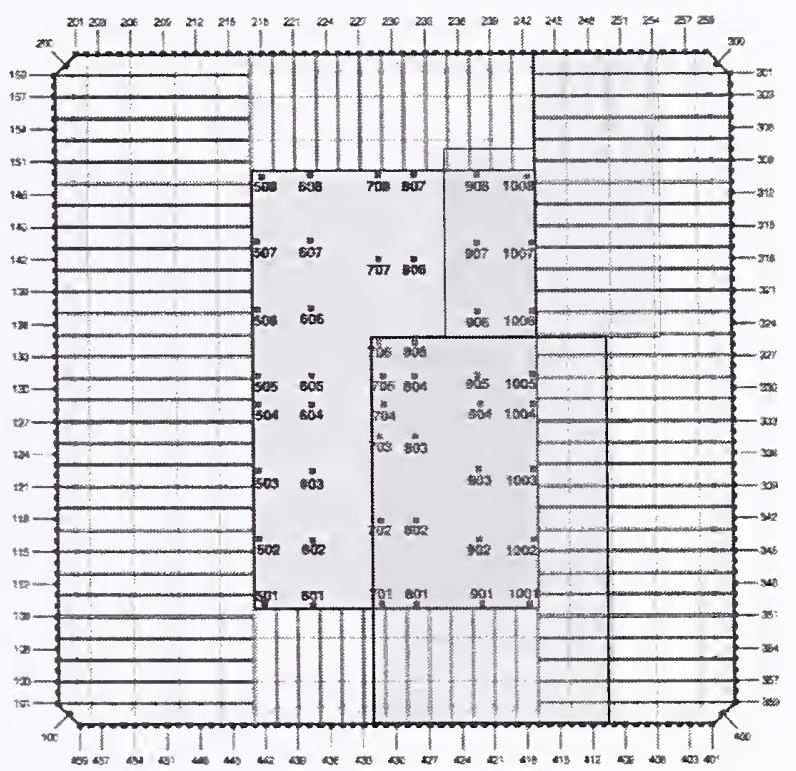

Fireproofing damage on floor trusses and core beams that support floor 81

Fireproofing Damage $\square$

Figure 10-6. Structural and fireproofing damage on floor 81, WTC 2, Case $C_{i}$.

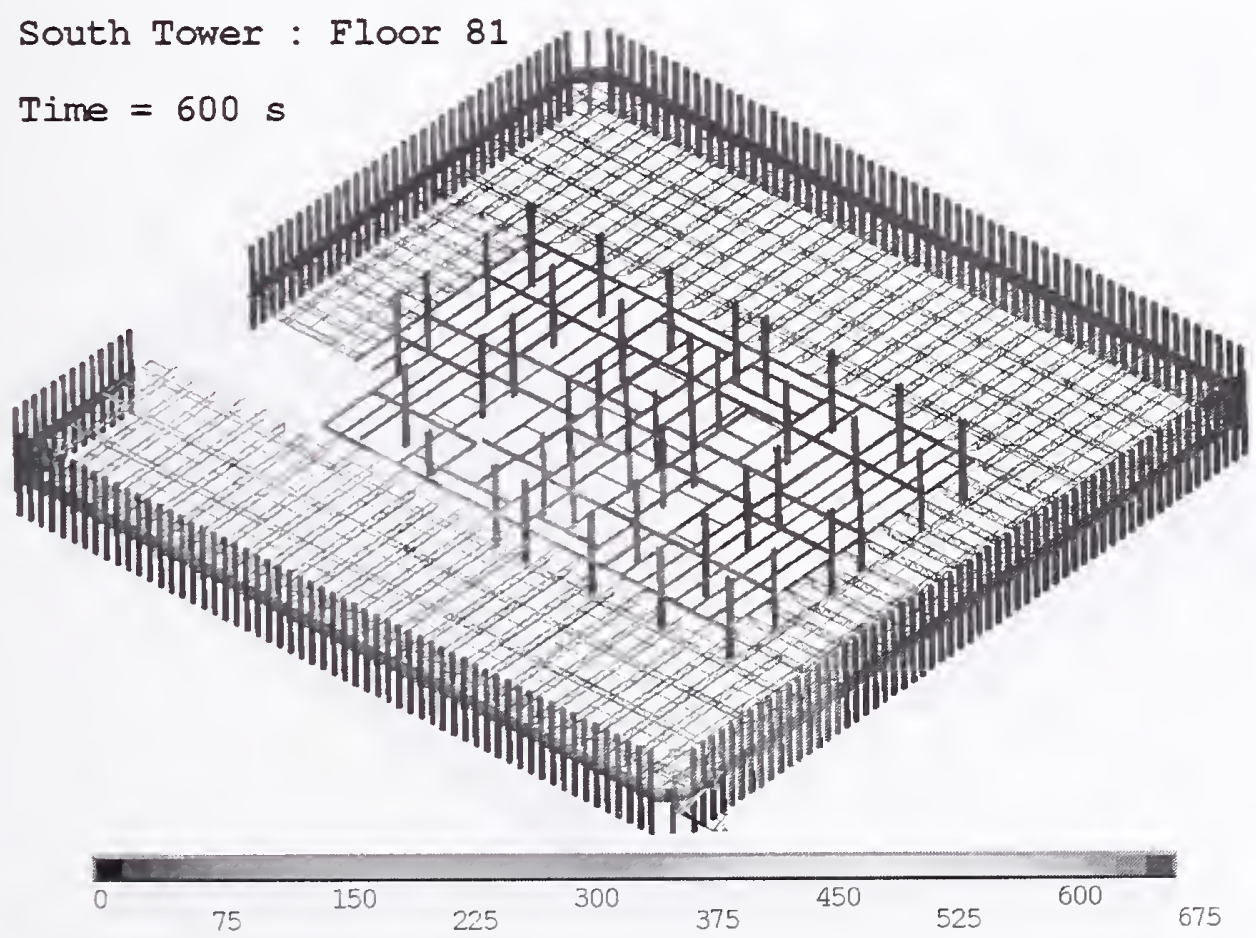

Figure 10-7. Thermal response of floor 81, WTC 2 Case $C$ at $600 \mathrm{~s}$ after impact. 


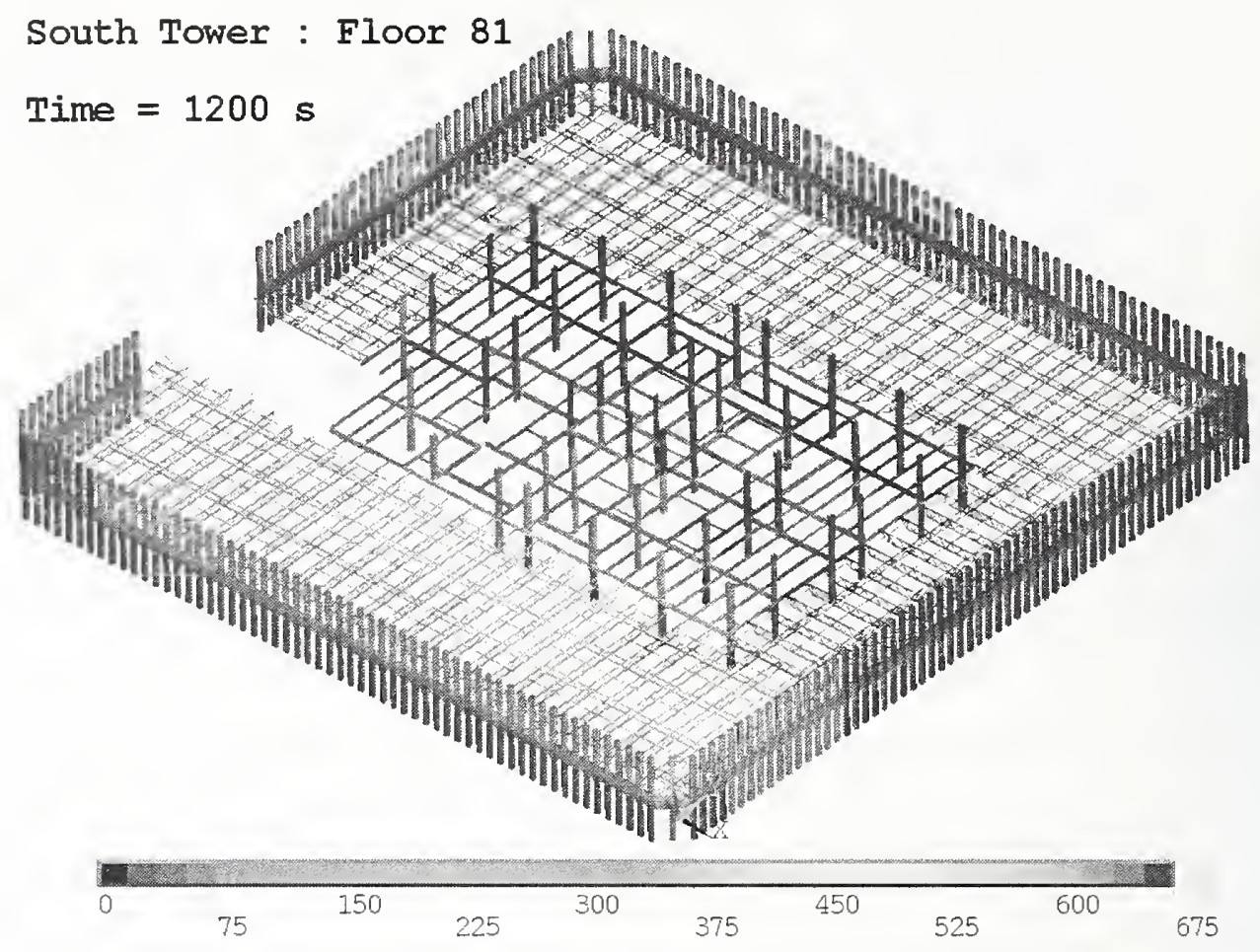

Figure 10-8. Thermal response of floor 81 , WTC 2 Case $C$ at 1,200 s after impact.

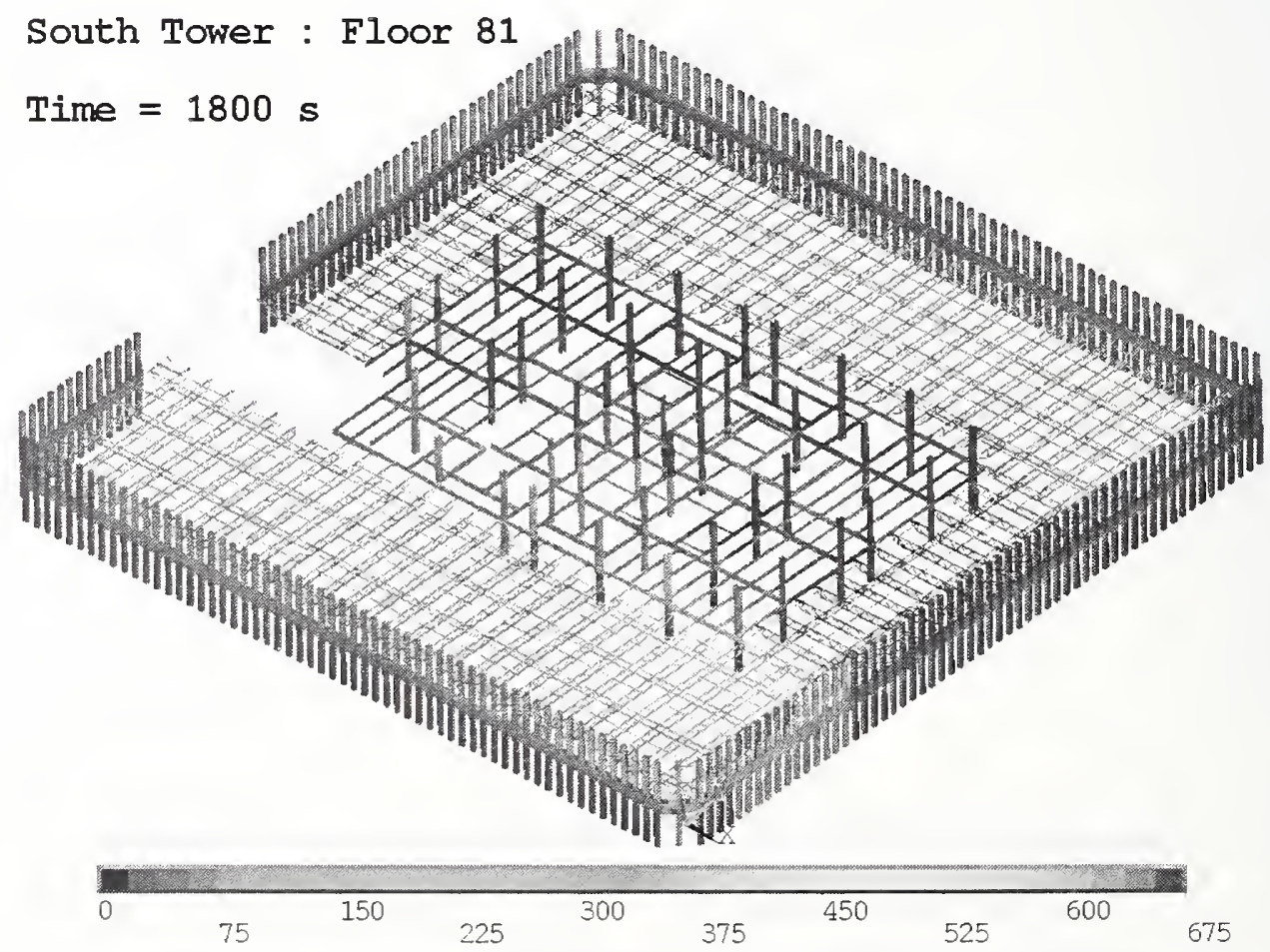

Figure 10-9. Thermal response of floor 81 , WTC 2 Case $C$ at $1,800 \mathrm{~s}$ after impact. 


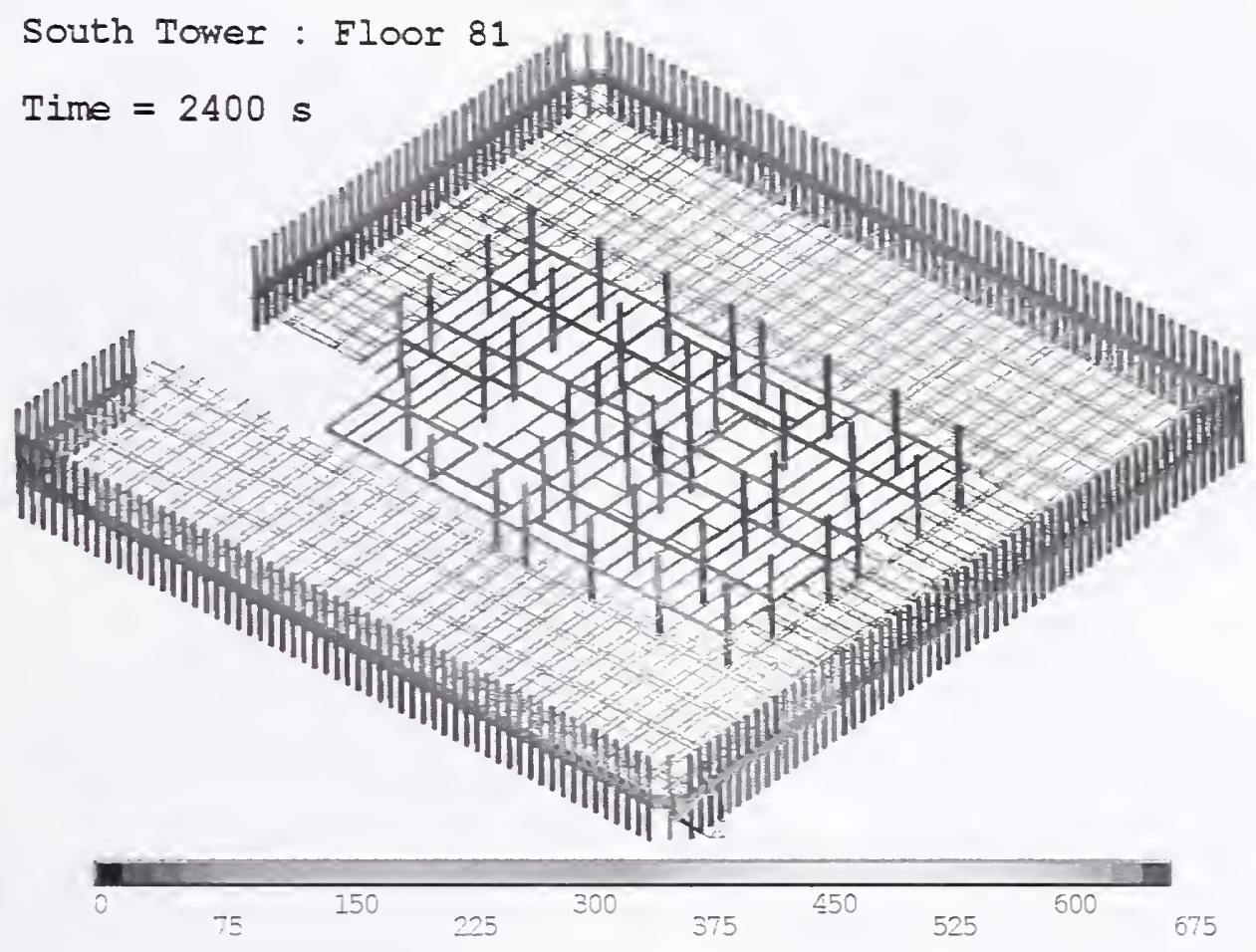

Figure 10-10. Thermal response of floor 81 , WTC 2 Case C at 2,400 s after impact.

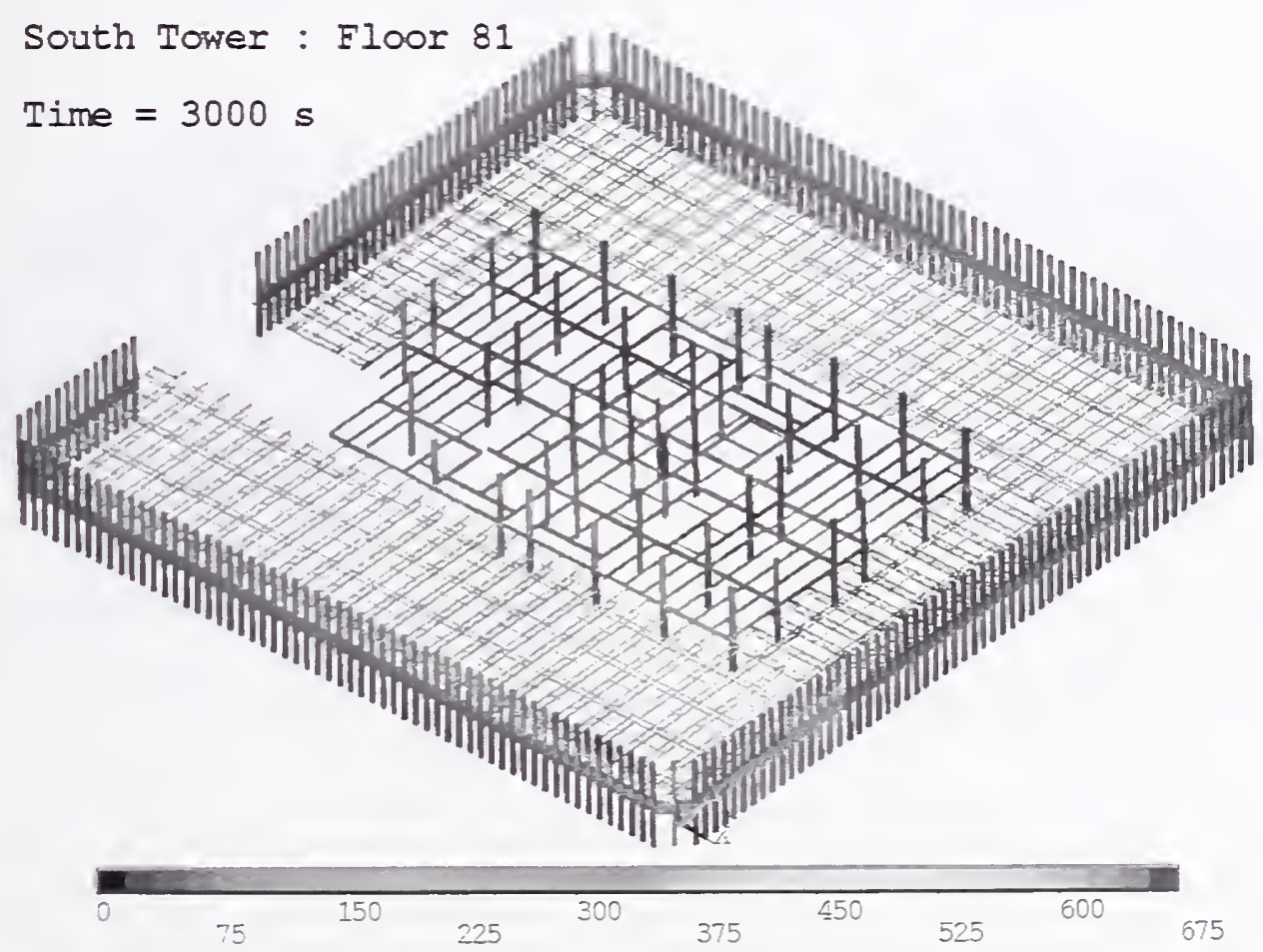

Figure 10-11. Thermal response of floor 81 , WTC 2 Case $C$ at 3,000 s after impact. 


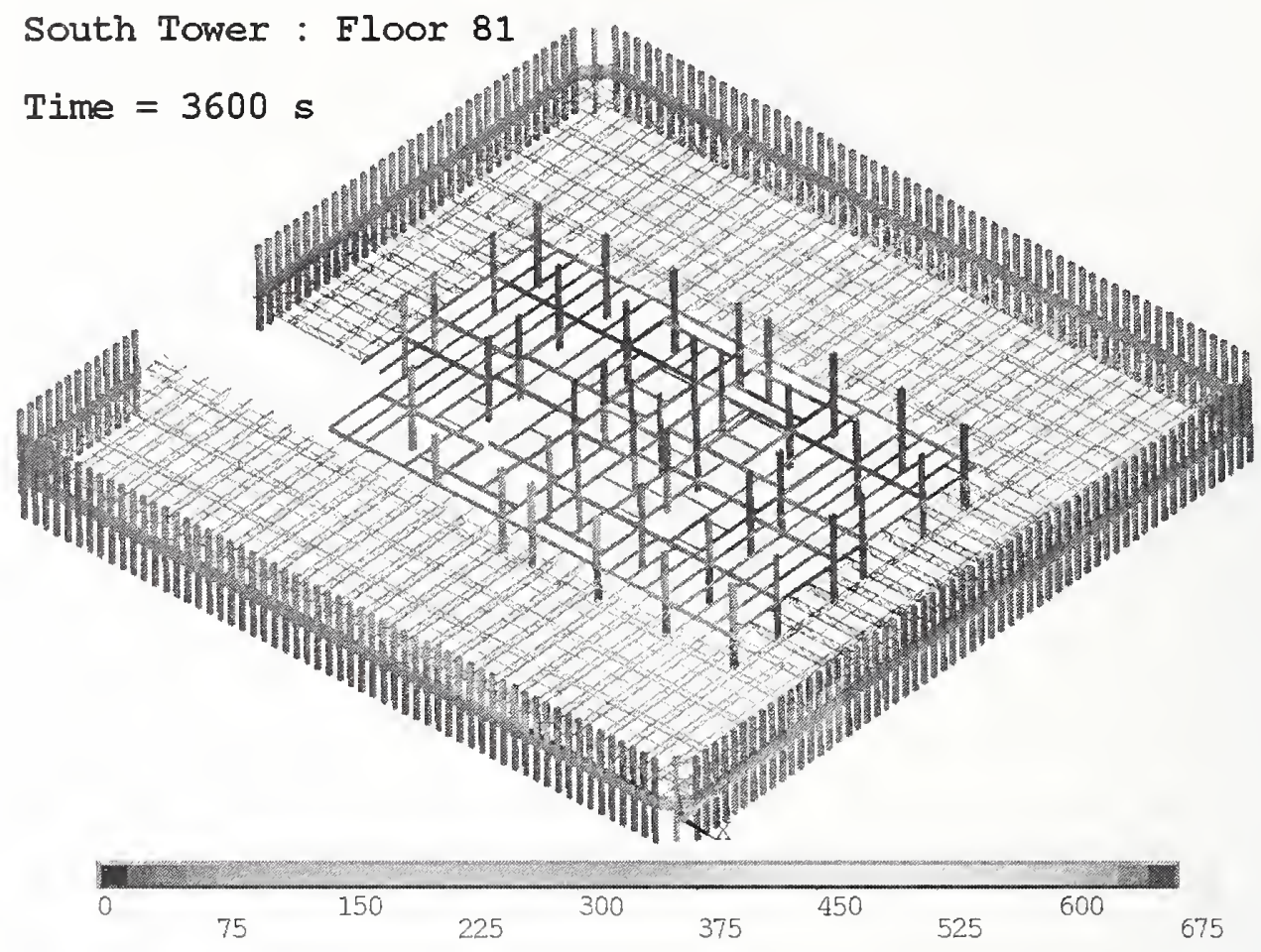

Figure 10-12. Thermal response of floor 81 , WTC 2 Case $\mathrm{C}$ at 3,600 s after impact. 

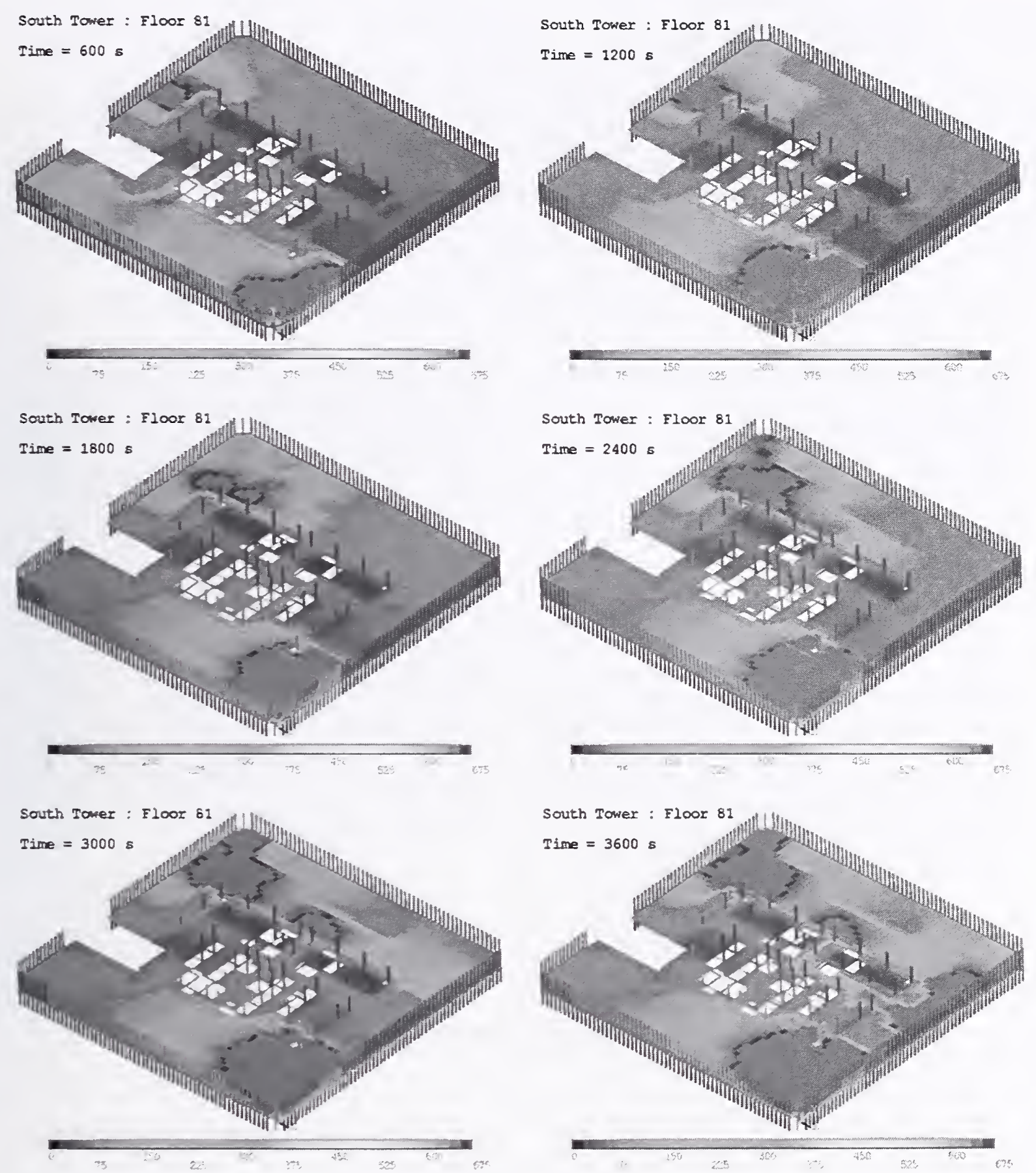

Figure 10-13. Thermal response of floor 81 , WTC 2 Case $C$ (concrete slab and columns) at different instants in time. 


\subsubsection{Floor 82, WTC 2 Case C}

Extensive fireproofing damage is predicted on the floor trusses and core beams in the east face of the tower as shown in Figure 10-14. This results in significant heating of the trusses for the entire duration of the simulation (see Figure 10-15). Temperatures in the truss elements above $675^{\circ} \mathrm{C}$ are predicted. Some heating is also observed in the southwest corner at $60 \mathrm{~min}$ after impact (due to the small thickness of fireproofing). Perimeter columns above floor 82 showed high temperatures at $40 \mathrm{~min}$ to $60 \mathrm{~min}$ after impact on the east face, and core columns on the east side of the core also experience extreme heating.

The west side of the core stays relative cool, and there is very little activity in the northwest corner.

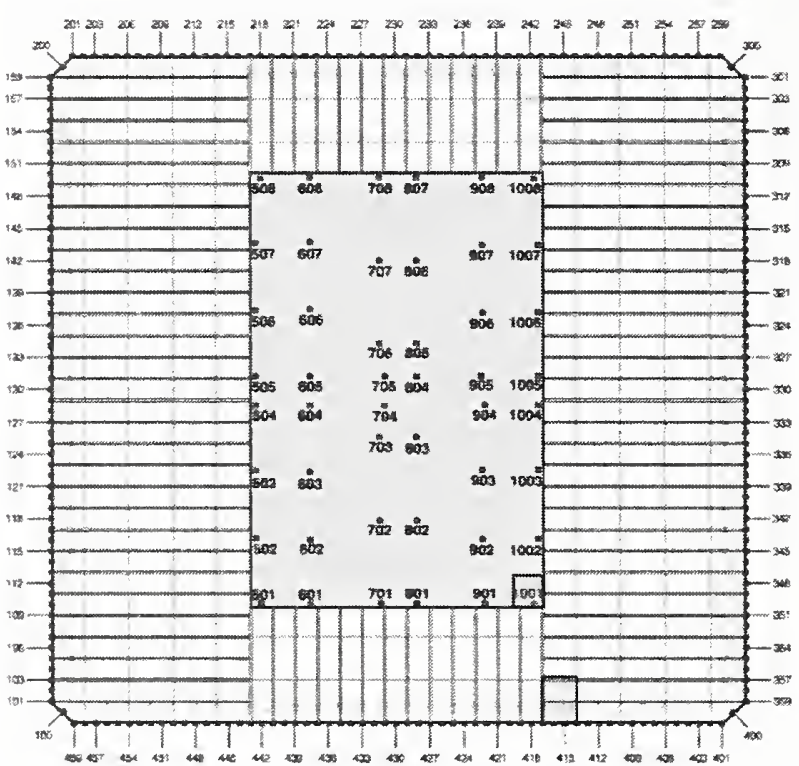

Structural damage for floor 82

Structural Damage

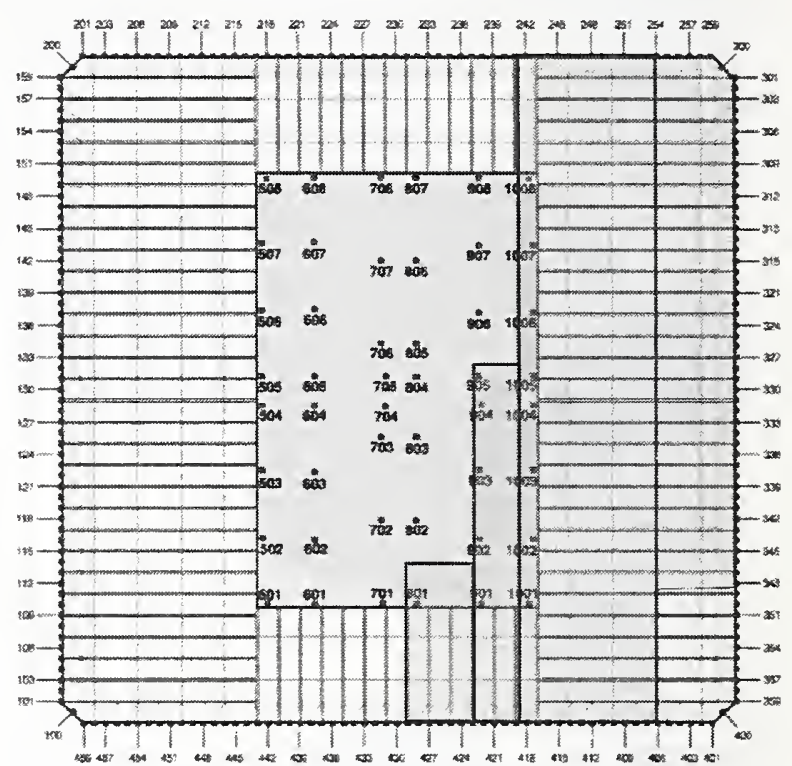

Fireproofing damage for floor trusses and core beams that support floor 82

Fireproofing Damage $\square$

Figure 10-14. Structural and fireproofing damage on floor 82 , WTC 2, Case $\mathrm{C}_{\mathrm{i}}$. 

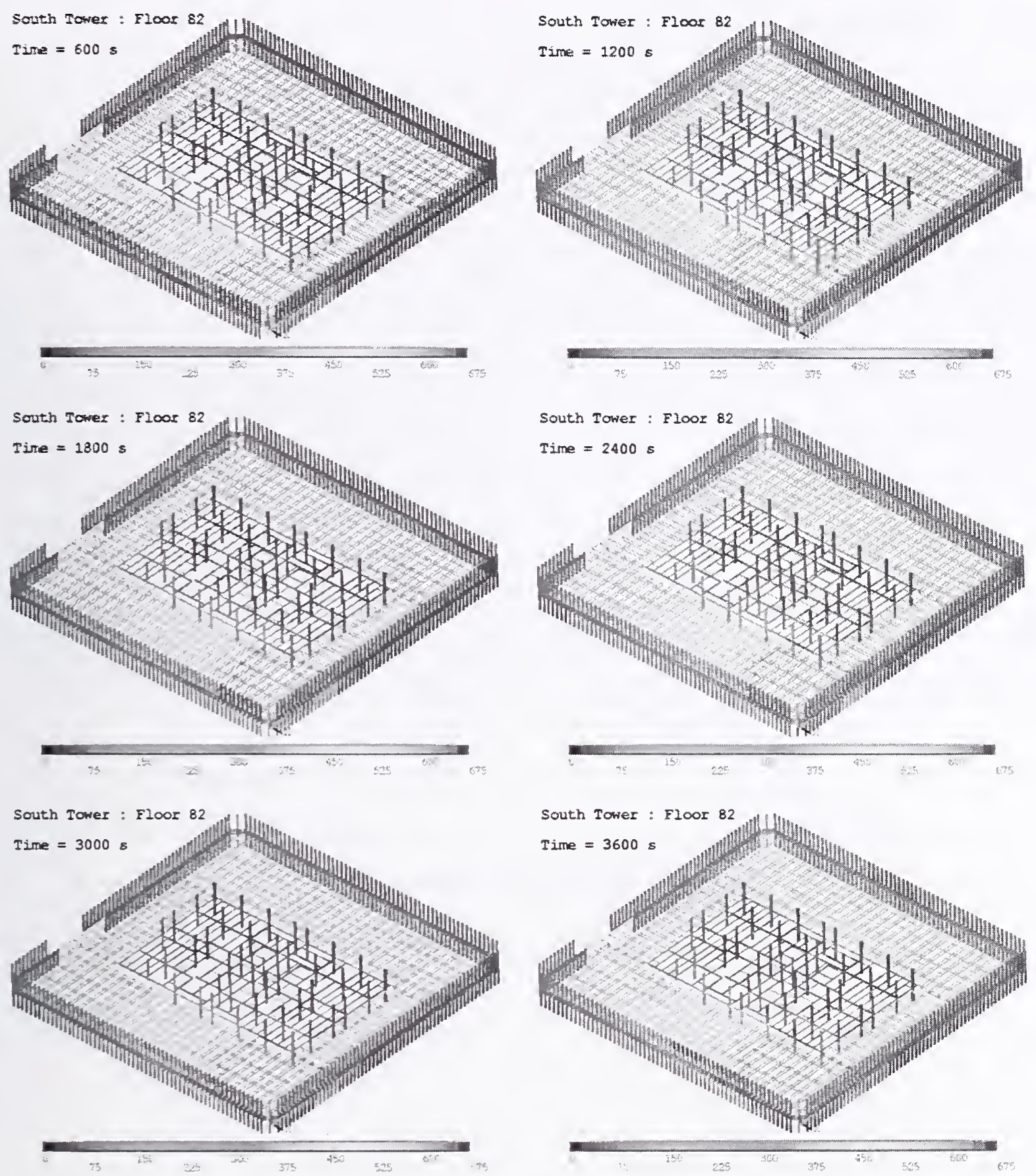

Figure 10-15. Thermal response of floor 82 , WTC 2 Case $C$ at different instants in time. 


\subsubsection{Floor 83, WTC 2 Case C}

The thermal response of floor 83 is consistent with the fireproofing damage shown in Figure 10-16 and the predicted fire activity on floors 82 and 83 . Thermal mapping results for floor 83 at six different instants in time have been shown in Figure 10-17.

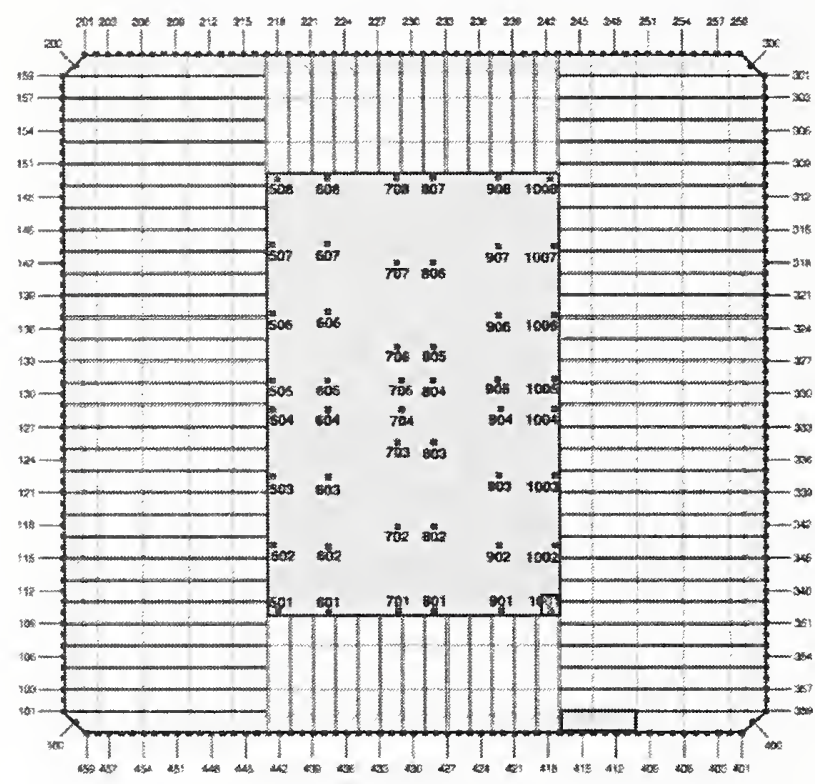

Structural damage for floor 83

Structural Damage

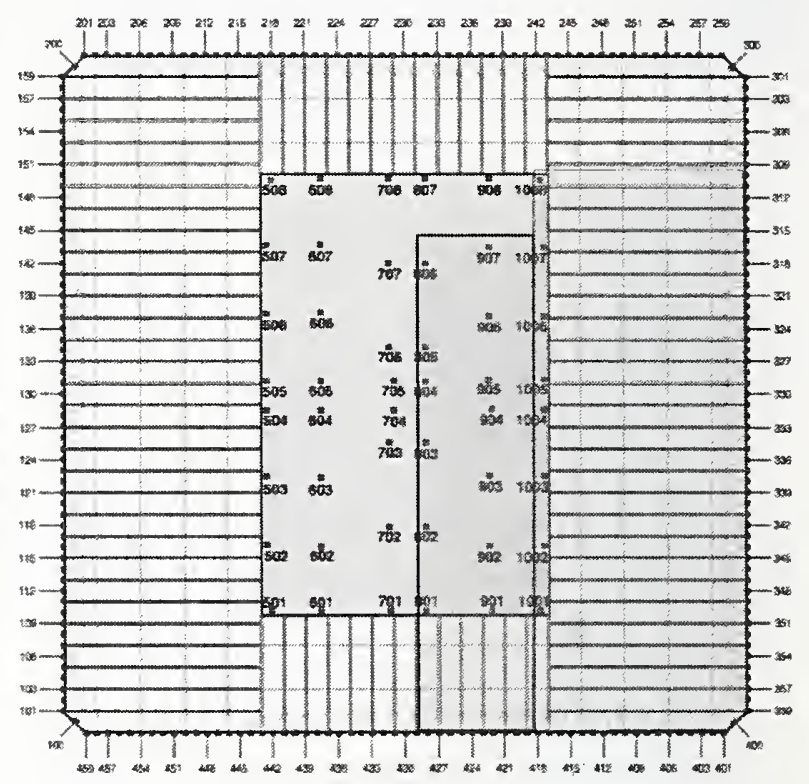

Fireproofing damage on floor trusses and core beams that support floor 83

Fireproofing Damage

Figure 10-16. Structural and fireproofing damage on floor 83 , WTC 2, Case $\mathrm{C}_{\mathrm{i}}$ - 

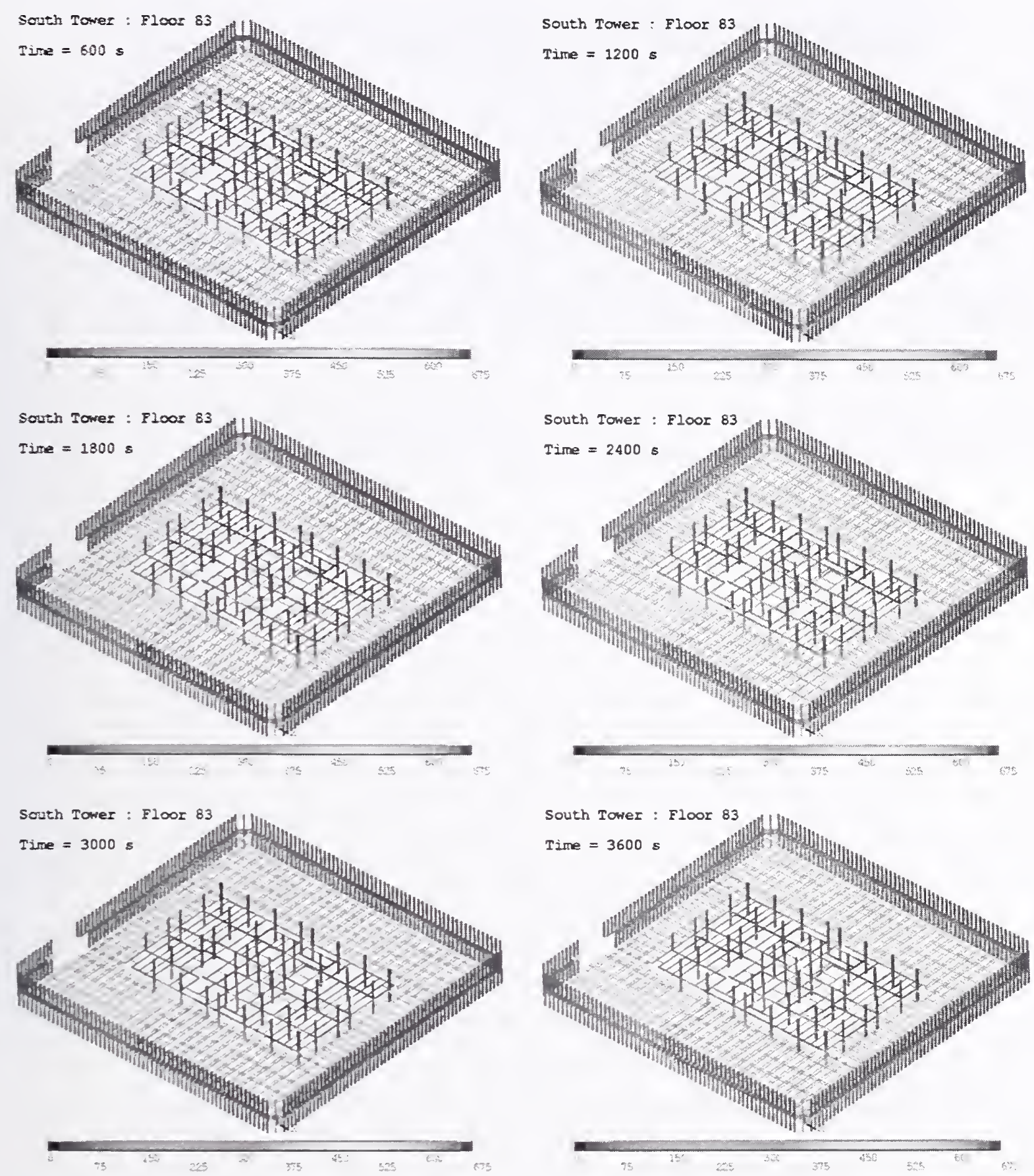

Figure 10-17. Thermal response of floor 83, WTC 2 Case C, at different instants in time. 


\section{$10.3 \quad$ DATA TRANSFER FOR STRUCTURAL ANALYSIS}

The thermal results presented in this chapter were passed on for structural analysis (NIST NCSTAR 1-6D, NIST NCSTAR 1-6) in the load bearing elements. As for Case A and Case B, the data was provided on a floor by floor basis ranging from floor 79 through floor 83 . For each floor, the thermal results were provided at six instants in time, spaced at $10 \mathrm{~min}$ interval. For each instant in time a thermal loading data file was generated to completely specify the thermal state of the floor. The thermal loading data files were generated at $10 \mathrm{~min}, 20 \mathrm{~min}, 30 \mathrm{~min}, 40 \mathrm{~min}, 50 \mathrm{~min}$, and $60 \mathrm{~min}$ after aircraft impact. Each file was generated in a format that is consistent with the structural models and could be readily read in, to specify body loads (temperature or temperature gradient) on the structure. The files were transferred using a file transfer protocol (ftp) utility.

The thermal results shown in Figure 10-2 through Figure 10-17 Figure 10-17 are visual renderings of the information contained in the thermal loading data files provided for stress analysis. 
Table 10-4. Perimeter column damage status for WTC 2 Case C.

\begin{tabular}{|c|c|c|c|c|c|c|}
\hline Column \# & Floor 78 & Floor 79 & Floor 80 & Floor 81 & Floor 82 & Floor 83 \\
\hline 101 & 0 & 0 & 0 & 0 & 0 & 0 \\
\hline 103 & 0 & 0 & 0 & 0 & 0 & 0 \\
\hline 106 & 0 & 0 & 0 & 0 & 0 & 0 \\
\hline 109 & 0 & 0 & 0 & 0 & 0 & 0 \\
\hline 112 & 0 & 0 & 0 & 0 & 0 & 0 \\
\hline 115 & 0 & 0 & 0 & 0 & 0 & 0 \\
\hline 118 & 0 & 0 & 0 & 0 & 0 & 0 \\
\hline 121 & 0 & 0 & 0 & 0 & 0 & 0 \\
\hline 124 & 0 & 0 & 0 & 0 & 0 & 0 \\
\hline 127 & 0 & 0 & 0 & 0 & 0 & 0 \\
\hline 130 & 0 & 0 & 0 & 0 & 0 & 0 \\
\hline 133 & 0 & 0 & 0 & 0 & 0 & 0 \\
\hline 136 & 0 & 0 & 0 & 0 & 0 & 0 \\
\hline 139 & 0 & 0 & 0 & 0 & 0 & 0 \\
\hline 142 & 0 & 0 & 0 & 0 & 0 & 0 \\
\hline 145 & 0 & 0 & 0 & 0 & 0 & 0 \\
\hline 148 & 0 & 0 & 0 & 0 & 0 & 0 \\
\hline 151 & 0 & 0 & 0 & 0 & 0 & 0 \\
\hline 154 & 0 & 0 & 0 & 0 & 0 & 0 \\
\hline 157 & 0 & 0 & 0 & 0 & 0 & 0 \\
\hline 201 & 0 & 0 & 0 & 0 & 0 & 0 \\
\hline 203 & 0 & 0 & 0 & 0 & 0 & 0 \\
\hline 206 & 0 & 0 & 0 & 0 & 0 & 0 \\
\hline 209 & 0 & 0 & 0 & 0 & 0 & 0 \\
\hline 212 & 0 & 0 & 0 & 0 & 0 & 0 \\
\hline 215 & 0 & 0 & 0 & 0 & 0 & 0 \\
\hline 218 & 0 & 0 & 0 & 0 & 0 & 0 \\
\hline 221 & 0 & 0 & 0 & 0 & 0 & 0 \\
\hline 224 & 0 & 0 & 0 & 0 & 0 & 0 \\
\hline 227 & 0 & 0 & 0 & 0 & 0 & 0 \\
\hline 230 & 0 & 0 & 0 & 0 & 0 & 0 \\
\hline 233 & 0 & 0 & 0 & 0 & 0 & 0 \\
\hline
\end{tabular}




\begin{tabular}{|c|c|c|c|c|c|c|}
\hline 236 & 0 & 0 & 0 & 0 & 0 & 0 \\
\hline 239 & 0 & 0 & 0 & 0 & 0 & 0 \\
\hline 242 & 0 & 0 & 0 & 0 & 0 & 0 \\
\hline 245 & 0 & 0 & 0 & 0 & 0 & 0 \\
\hline 248 & 0 & 0 & 0 & 0 & 0 & 0 \\
\hline 251 & 0 & 0 & 1 & 1 & 0 & 0 \\
\hline 254 & 0 & 0 & 1 & 1 & 0 & 0 \\
\hline 257 & 0 & 0 & 1 & 1 & 0 & 0 \\
\hline 301 & 0 & 0 & 0 & 1 & 0 & 0 \\
\hline 303 & 0 & 0 & 0 & 1 & 0 & 0 \\
\hline 306 & 0 & 0 & 0 & 1 & 0 & 0 \\
\hline 309 & 0 & 0 & 0 & 1 & 0 & 0 \\
\hline 312 & 0 & 0 & 0 & 1 & 0 & 0 \\
\hline 315 & 0 & 0 & 0 & 1 & 0 & 0 \\
\hline 318 & 0 & 0 & 0 & 1 & 0 & 0 \\
\hline 321 & 0 & 0 & 0 & 1 & 0 & 0 \\
\hline 324 & 0 & 0 & 0 & 1 & 1 & 0 \\
\hline 327 & 0 & 0 & 0 & 1 & 1 & 0 \\
\hline 330 & 0 & 0 & 0 & 1 & 1 & 0 \\
\hline 333 & 0 & 0 & 0 & 1 & 1 & 0 \\
\hline 336 & 0 & 0 & 0 & 1 & 1 & 0 \\
\hline 339 & 0 & 0 & 0 & 1 & 1 & 0 \\
\hline 342 & $\overline{0}$ & 0 & 0 & 1 & 1 & 0 \\
\hline 345 & 0 & 0 & 0 & 1 & 1 & 0 \\
\hline 348 & 0 & 0 & 0 & 1 & 1 & 0 \\
\hline 351 & 0 & 0 & 0 & 1 & 1 & 0 \\
\hline 354 & 0 & 0 & 0 & 0 & 1 & 0 \\
\hline 357 & 0 & 0 & 0 & 0 & 1 & 0 \\
\hline 401 & 0 & 0 & 0 & 0 & 0 & 0 \\
\hline 403 & 0 & 0 & 0 & 0 & 0 & 0 \\
\hline 406 & 0 & 0 & 0 & 0 & 0 & 0 \\
\hline 409 & 0 & 0 & 0 & 0 & 0 & 0 \\
\hline 412 & 0 & 0 & 0 & 0 & 2 & 2 \\
\hline
\end{tabular}




\begin{tabular}{|l|l|l|l|l|l|l|}
\hline 415 & 0 & 0 & 2 & 2 & 2 & 2 \\
\hline 418 & 0 & 2 & 2 & 2 & 2 & 0 \\
\hline 421 & 0 & 0 & 2 & 2 & 0 & 0 \\
\hline 424 & 0 & 2 & 2 & 2 & 0 & 0 \\
\hline 427 & 0 & 2 & 0 & 0 & 0 & 0 \\
\hline 430 & 2 & 2 & 0 & 0 & 0 & 0 \\
\hline 433 & 2 & 2 & 0 & 0 & 0 & 0 \\
\hline 436 & 2 & 0 & 0 & 0 & 0 & 0 \\
\hline 439 & 2 & 0 & 0 & 0 & 0 & 0 \\
\hline 442 & 0 & 0 & 0 & 0 & 0 & 0 \\
\hline 445 & 0 & 0 & 0 & 0 & 0 & 0 \\
\hline 448 & 0 & 0 & 0 & 0 & 0 & 0 \\
\hline 451 & 0 & 0 & 0 & 0 & 0 & 0 \\
\hline 454 & 0 & 0 & 0 & 0 & 0 & 0 \\
\hline 457 & 0 & 0 & 0 & 0 & 0 & 0 \\
\hline
\end{tabular}


Table 10-5. Core column fireproofing damage status for WTC 2, Case C.

\begin{tabular}{|c|c|c|c|c|c|c|}
\hline Column No. & Floor 78 & Floor 79 & Floor 80 & Floor 81 & Floor 82 & Floor 83 \\
\hline 501 & 0 & 0 & 0 & 0 & 0 & 0 \\
\hline 502 & 0 & 0 & 0 & 0 & 0 & 0 \\
\hline 503 & 0 & 0 & 0 & 0 & 0 & 0 \\
\hline 504 & 0 & 0 & 0 & 0 & 0 & 0 \\
\hline 505 & 0 & 0 & 0 & 0 & 0 & 0 \\
\hline 506 & 0 & 0 & 0 & 0 & 0 & 0 \\
\hline 507 & 0 & 0 & 0 & 0 & 0 & 0 \\
\hline 508 & 0 & 0 & 0 & 0 & 0 & 0 \\
\hline 601 & 0 & 3 & 0 & 0 & 0 & 0 \\
\hline 602 & 0 & 3 & 0 & 0 & 0 & 0 \\
\hline 603 & 0 & 3 & 0 & 0 & 0 & 0 \\
\hline 604 & 0 & 0 & 0 & 0 & 0 & 0 \\
\hline 605 & 0 & 0 & 0 & 0 & 0 & 0 \\
\hline 606 & 0 & 0 & 0 & 0 & 0 & 0 \\
\hline 607 & 0 & 0 & 0 & 0 & 0 & 0 \\
\hline 608 & 0 & 0 & 0 & 0 & 0 & 0 \\
\hline 701 & 3 & 3 & 3 & 0 & 0 & 0 \\
\hline 702 & 3 & 3 & 3 & 0 & 0 & 0 \\
\hline 703 & 3 & 3 & 3 & 0 & 0 & 0 \\
\hline 704 & 3 & 3 & 3 & 0 & 0 & 0 \\
\hline 705 & 3 & 3 & 0 & 0 & 0 & 0 \\
\hline 706 & 3 & 3 & 0 & 0 & 0 & 0 \\
\hline 707 & 0 & 3 & 0 & 0 & 0 & 0 \\
\hline 708 & 0 & 0 & 0 & 0 & 0 & 0 \\
\hline 801 & 3 & 3 & 3 & 3 & 0 & 0 \\
\hline 802 & 3 & 3 & 3 & 0 & 0 & 0 \\
\hline 803 & 3 & 3 & 3 & 0 & 0 & 0 \\
\hline 804 & 3 & 3 & 3 & 0 & 0 & 0 \\
\hline 805 & 3 & 3 & 3 & 0 & 0 & 0 \\
\hline 806 & 0 & 3 & 0 & 0 & 0 & 0 \\
\hline 807 & 0 & 0 & 0 & 0 & 0 & 0 \\
\hline
\end{tabular}




\begin{tabular}{|l|l|l|l|l|l|l|}
\hline 901 & 3 & 3 & 3 & 3 & 3 & 0 \\
\hline 902 & 3 & 3 & 3 & 3 & 3 & 0 \\
\hline 903 & 3 & 3 & 3 & 3 & 0 & 0 \\
\hline 904 & 3 & 3 & 3 & 3 & 0 & 0 \\
\hline 905 & 3 & 3 & 3 & 3 & 0 & 0 \\
\hline 906 & 0 & 3 & 3 & 3 & 0 & 0 \\
\hline 907 & 0 & 3 & 0 & 3 & 0 & 0 \\
\hline 908 & 0 & 3 & 0 & 3 & 0 & 0 \\
\hline 1001 & 3 & 3 & 3 & 3 & 3 & 0 \\
\hline 1002 & 3 & 3 & 3 & 3 & 3 & 0 \\
\hline 1003 & 3 & 3 & 3 & 3 & 3 & 0 \\
\hline 1004 & 3 & 3 & 3 & 3 & 3 & 0 \\
\hline 1005 & 0 & 3 & 0 & 3 & 3 & 0 \\
\hline 1006 & 0 & 3 & 0 & 3 & 3 & 0 \\
\hline 1007 & 0 & 3 & 0 & 3 & 3 & 0 \\
\hline 1008 & 0 & 3 & 0 & 3 & 3 & 0 \\
\hline & & & & & & 3 \\
\hline
\end{tabular}


Table 10-6. Core column structural damage status for WTC 2, Case C.

\begin{tabular}{|c|c|c|c|c|c|c|}
\hline $\begin{array}{c}\text { Column } \\
\text { No. }\end{array}$ & Floor 78 & Floor 79 & Floor 80 & Floor 81 & Floor 82 & Floor 83 \\
\hline 501 & 0 & 0 & 0 & 0 & 0 & 0 \\
\hline 502 & 0 & 0 & 0 & 0 & 0 & 0 \\
\hline 503 & 0 & 0 & 0 & 0 & 0 & 0 \\
\hline 504 & 0 & 0 & 0 & 0 & 0 & 0 \\
\hline 505 & 0 & 0 & 0 & 0 & 0 & 0 \\
\hline 506 & 0 & 0 & 0 & 0 & 0 & 0 \\
\hline 507 & 0 & 0 & 0 & 0 & 0 & 0 \\
\hline 508 & 0 & 0 & 0 & 0 & 0 & 0 \\
\hline 601 & 0 & 0 & 0 & 0 & 0 & 0 \\
\hline 602 & 0 & 0 & 0 & 0 & 0 & 0 \\
\hline 603 & 0 & 0 & 0 & 0 & 0 & 0 \\
\hline 604 & 0 & 0 & 0 & 0 & 0 & 0 \\
\hline 605 & 0 & 0 & 0 & 0 & 0 & 0 \\
\hline 606 & 0 & 0 & 0 & 0 & 0 & 0 \\
\hline 607 & 0 & 0 & 0 & 0 & 0 & 0 \\
\hline 608 & 0 & 0 & 0 & 0 & 0 & 0 \\
\hline 701 & 0 & 0 & 0 & 0 & 0 & 0 \\
\hline 702 & 0 & 0 & 0 & 0 & 0 & 0 \\
\hline 703 & 0 & 0 & 0 & 0 & 0 & 0 \\
\hline 704 & 0 & 0 & 0 & 0 & 0 & 0 \\
\hline 705 & 0 & 0 & 0 & 0 & 0 & 0 \\
\hline 706 & 0 & 0 & 0 & 0 & 0 & 0 \\
\hline 707 & 0 & 0 & 0 & 0 & 0 & 0 \\
\hline 708 & 0 & 0 & 0 & 0 & 0 & 0 \\
\hline 801 & 0 & 0 & 0 & 0 & 0 & 0 \\
\hline 802 & 0 & 0 & 0 & 0 & 0 & 0 \\
\hline 803 & 0 & 0 & 0 & 0 & 0 & 0 \\
\hline 804 & 0 & 0 & 0 & 0 & 0 & 0 \\
\hline 805 & 0 & 0 & 0 & 0 & 0 & 0 \\
\hline 806 & 0 & 0 & 0 & 0 & 0 & 0 \\
\hline 807 & 0 & 0 & 0 & 0 & 0 & 0 \\
\hline
\end{tabular}




\begin{tabular}{|l|l|l|l|l|l|l|}
\hline 901 & 0 & 2 & 2 & 2 & 2 & 0 \\
\hline 902 & 0 & 0 & 0 & 0 & 0 & 0 \\
\hline 903 & 2 & 2 & 2 & 2 & 2 & 2 \\
\hline 904 & 0 & 0 & 0 & 0 & 0 & 0 \\
\hline 905 & 0 & 0 & 0 & 0 & 0 & 0 \\
\hline 906 & 0 & 0 & 0 & 0 & 0 & 0 \\
\hline 907 & 0 & 0 & 0 & 0 & 0 & 0 \\
\hline 908 & 0 & 0 & 0 & 0 & 0 & 0 \\
\hline 1001 & 2 & 2 & 2 & 2 & 2 & 2 \\
\hline 1002 & 0 & 2 & 2 & 2 & 0 & 0 \\
\hline 1003 & 0 & 0 & 2 & 0 & 0 & 0 \\
\hline 1004 & 0 & 0 & 0 & 0 & 0 & 0 \\
\hline 1005 & 0 & 0 & 0 & 0 & 0 & 0 \\
\hline 1006 & 0 & 0 & 0 & 0 & 0 & 0 \\
\hline 1007 & 0 & 0 & 0 & 0 & 0 & 0 \\
\hline 1008 & 0 & 0 & 0 & 0 & 0 & 0 \\
\hline & & & & & & \\
\hline
\end{tabular}


This page intentionally left blank. 


\section{Chapter 11 \\ Global Thermal Response of WTC 2 : CASE D}

\subsection{OVERVIEW}

This chapter is the last of four chapters that describe the results of the four global simulations (two each for WTC 1 and WTC 2). The focus of this chapter is on WTC 2 Case D.

Following the completion of the Case C analysis of WTC 2 (described in Chapter 10), the calculations were re-run with more severe settings for the input parameters (described in Table 11-1, Table 11-2 and Table 11-3). The methodology for performing the simulations is identical to that for Case C. In this chapter, the focus is on the model inputs and simulation results for WTC 2 Case D. Analysis of the differences and similarities in thermal and structural results for Case C and Case D, presented in Chapter 12 will help to assess the sensitivity of the results to changes in input parameters.

\subsubsection{Aircraft Impact Analysis}

Aircraft impact analysis was performed for WTC 2 with more severe settings for the various input parameters. The input parameters used in the analysis are summarized in Table 11-1. Structural and fireproofing damage to columns, trusses, and floor slabs was obtained from the impact analysis. The predicted structural and fireproofing damage for Case D is different and in general more extensive than that for Case C (NIST NCSTAR 1-2).

Table 11-1. Input parameters for WTC 2 global impact analyses (more severe).

\begin{tabular}{|c|l|c|}
\hline \multicolumn{2}{|c|}{ Analysis Parameters } & More Severe \\
\hline \multirow{4}{*}{$\begin{array}{c}\text { Flight } \\
\text { Parameters }\end{array}$} & Impact Velocity & $570 \mathrm{mph}$ \\
\cline { 2 - 3 } & Trajectory - pitch & $5.0^{\circ}$ \\
\cline { 2 - 3 } & Trajectory - yaw & $13.0^{\circ}$ \\
\cline { 2 - 3 } & Orientation - pitch & $4.0^{\circ}$ \\
\cline { 2 - 3 } & Orientation - yaw & $10.0^{\circ}$ \\
\hline $\begin{array}{c}\text { Aircraft } \\
\text { Parameters }\end{array}$ & Weight & 105 percent \\
\cline { 2 - 3 } & Failure Strain & 115 percent \\
\hline \multirow{2}{*}{$\begin{array}{c}\text { Tower } \\
\text { Parameters }\end{array}$} & Contents Strength & 80 percent \\
\cline { 2 - 3 } & Failure Strain & 90 percent \\
\cline { 2 - 3 } & Live Load Weight & \\
\hline
\end{tabular}

Live load weight expressed as a percentage of the design live load.

The main objective of the impact analysis was to estimate the damage to structural systems, including the exterior wall, floor systems and interior core columns. Table 11-4 shows the fireproofing and structural damage predicted for perimeter columns on floors 78 through 83, WTC 2 Case D (NIST NCSTAR 1-5A). 
In this table a " 0 " indicates that the column and its fireproofing is intact, a " 1 " indicates fireproofing damage on the interior face, and a "2" indicates that a column has been severed by the aircraft impact. Table 11-5 shows fireproofing and structural damage predicted for core columns on floor 78-83 In this table a "0" indicates that the column and its fireproofing are intact, a "l" indicates fireproofing damage on one face, a " 2 " indicates a column that has been severed by the aircraft impact while a " 3 " indicates fireproofing damage on all the faces. For WTC 2 Case D,core columns had their fireproofing intact or the fireproofing was damaged on all the faces.

Aircraft impact damage also results in structural and fireproofing damage on the floor systems. For each floor, a map was prepared that describes the contours of the region where fireproofing and structural damage was predicted. This damage for floors 79 through 83 is displayed as contour maps in the aircraft impact analysis report (NIST NCSTAR 1-2).

\subsubsection{Fire Dynamics Simulation}

Fire simulations were performed as in Case $\mathrm{C}$ to predict contours of upper layer temperature, absorption coefficient, layer depth, and ambient temperatures as a function of space and time on each floor of WTC 2. For Case D, the combustible load for fire simulations was kept at $20 \mathrm{~kg} / \mathrm{m}^{2}$, the same as Case C, but the aircraft debris and "rubble" was spread out over a wider area. In Case C the debris pile was concentrated in the northeast corner, while in Case D it was less concentrated. The input parameters for WTC 2 Case D fire simulations are summarized in Table 11-2.

Fire simulations for Case D indicated high temperatures over greater areas. This was due to increased burning rate of the furnishing and large number of broken windows (NIST NCSTAR 1-5F). The fires in WTC 2 were fuel-limited, unlike those in WTC 1, which were oxygen limited. Since the fires in WTC 2 were fuel limited, the results for WTC 2 Case C are in some instances substantially different from those for WTC 2 Case D.

Table 11-2. Values of WTC fire simulation variables.

\begin{tabular}{|l|l|}
\hline \multicolumn{1}{|c|}{ Variable } & \multicolumn{1}{c|}{ WTC 2 Case D } \\
\hline Fuel load & $20 \mathrm{~kg} / \mathrm{m}^{2}\left(5 \mathrm{lb} / \mathrm{ft}^{2}\right)$ \\
\hline $\begin{array}{l}\text { Distribution of } \\
\text { disturbed } \\
\text { combustibles }\end{array}$ & $\begin{array}{l}\text { Moderately } \\
\text { concentrated in the } \\
\text { northeast corner }\end{array}$ \\
\hline $\begin{array}{l}\text { Condition of } \\
\text { combustibles }\end{array}$ & $\begin{array}{l}\text { Undamaged except in } \\
\text { impact zone }\end{array}$ \\
\hline $\begin{array}{l}\text { Representation of } \\
\text { impacted core walls }\end{array}$ & Soffit remained \\
\hline
\end{tabular}




\subsection{FIRE STRUCTURE INTERFACE}

Changes in fire dynamics between Case C and Case D affect the thermal response of the structural elements. Fireproofing damage and structural damage caused by the aircraft impact analysis also has a large impact on the temperatures of the structure. FSI simulations were performed with different input conditions to predict the time evolving thermal state of WTC 2 . The input parameters are listed in Table 11-3.

In the next section, the thermal results for WTC 2 Case D are presented on a floor by floor basis. As in Chapter 10 our goal in this chapter is to understand the nature of the thermal insult on the structure for each floor in WTC 2.

Figure 11-2 through Figure 11-10 show the thermal state of floors 79 through 83 in WTC 2, respectively, at six different instants in time ranging from $10 \mathrm{~min}$ to $60 \mathrm{~min}$ at $10 \mathrm{~min}$ interval. Each sub-figure shows the truss assembly, the core beams, perimeter columns and core columns above and below the concrete slab. Color contours are superimposed on the structural elements ranging from 0 to $675^{\circ} \mathrm{C}$.

Table 11-3. Input for global thermal response
of WTC 2 .
\begin{tabular}{|l|c|}
\hline \multicolumn{1}{|c|}{ Input } & WTC 2 Case D \\
\hline $\begin{array}{l}\text { Structural damage, } \\
\text { NIST NCSTAR 1-2 } \\
\text { NIST NCSTAR 1-6 }\end{array}$ & $\begin{array}{c}\text { Case D } \\
\text { More severe }\end{array}$ \\
\hline $\begin{array}{l}\text { Fireproofing damage, } \\
\text { NIST NCSTAR 1-6 }\end{array}$ & Case D \\
\hline $\begin{array}{l}\text { Fire Simulations, } \\
\text { NiST NCSTAR 1-5F }\end{array}$ & Case D \\
\hline
\end{tabular}

\subsubsection{Floor 79, WTC 2 Case D}

The truss system that supports floor 79 has extensive fireproofing damage to trusses and core beams (see Figure $11-1) .{ }^{6}$ Structural damage due to aircraft impact is not very significant.

The truss system that supports floor 79 shows slightly higher temperatures for Case D as compared to Case C, especially in the southeast corner at 20 min after impact. This is due to continuous fire activity on floor 78 in this area. The thermal state of floor 79 at 10 min intervals is shown in Figure 11-2.

${ }^{6}$ The damage graphics used in the thermal analysis are discussed in detail in NIST NCSTAR 1-6 and have been presented here for reference only. 


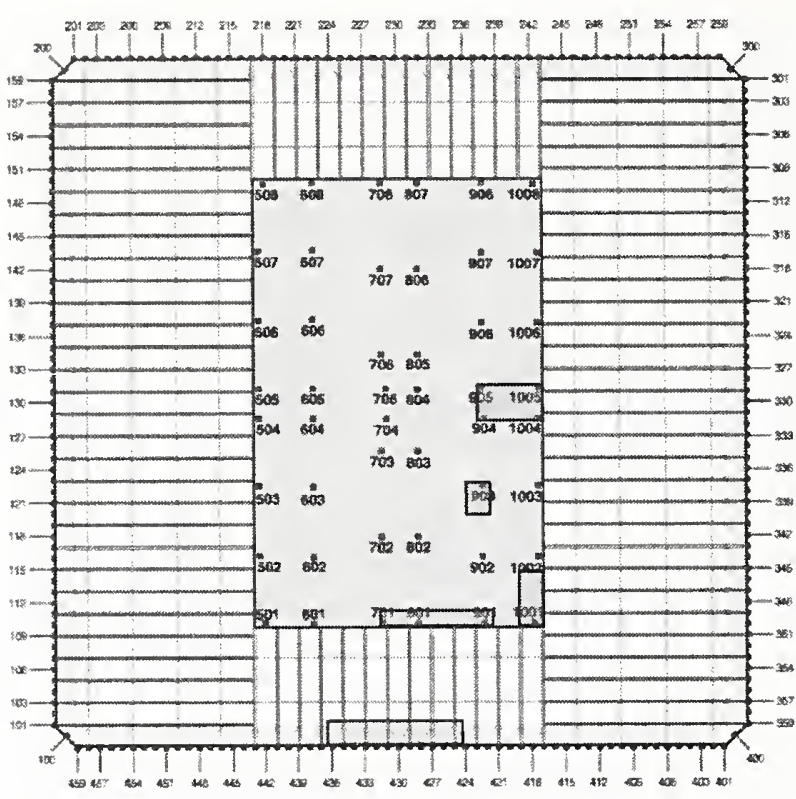

Structural damage for floor 79

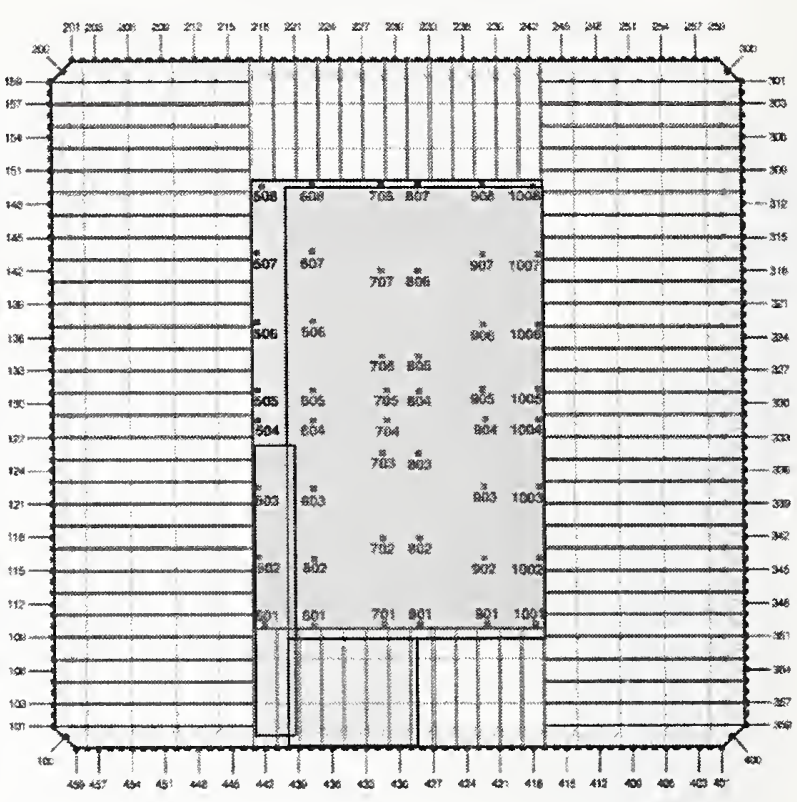

Fireproofing damage for floor trusses and core beams that support floor 79

Structural Damage

Fireproofing Damage

Figure 11-1. Structural and fireproofing damage on floor 79 , WTC 2 Case $D_{i}$. 

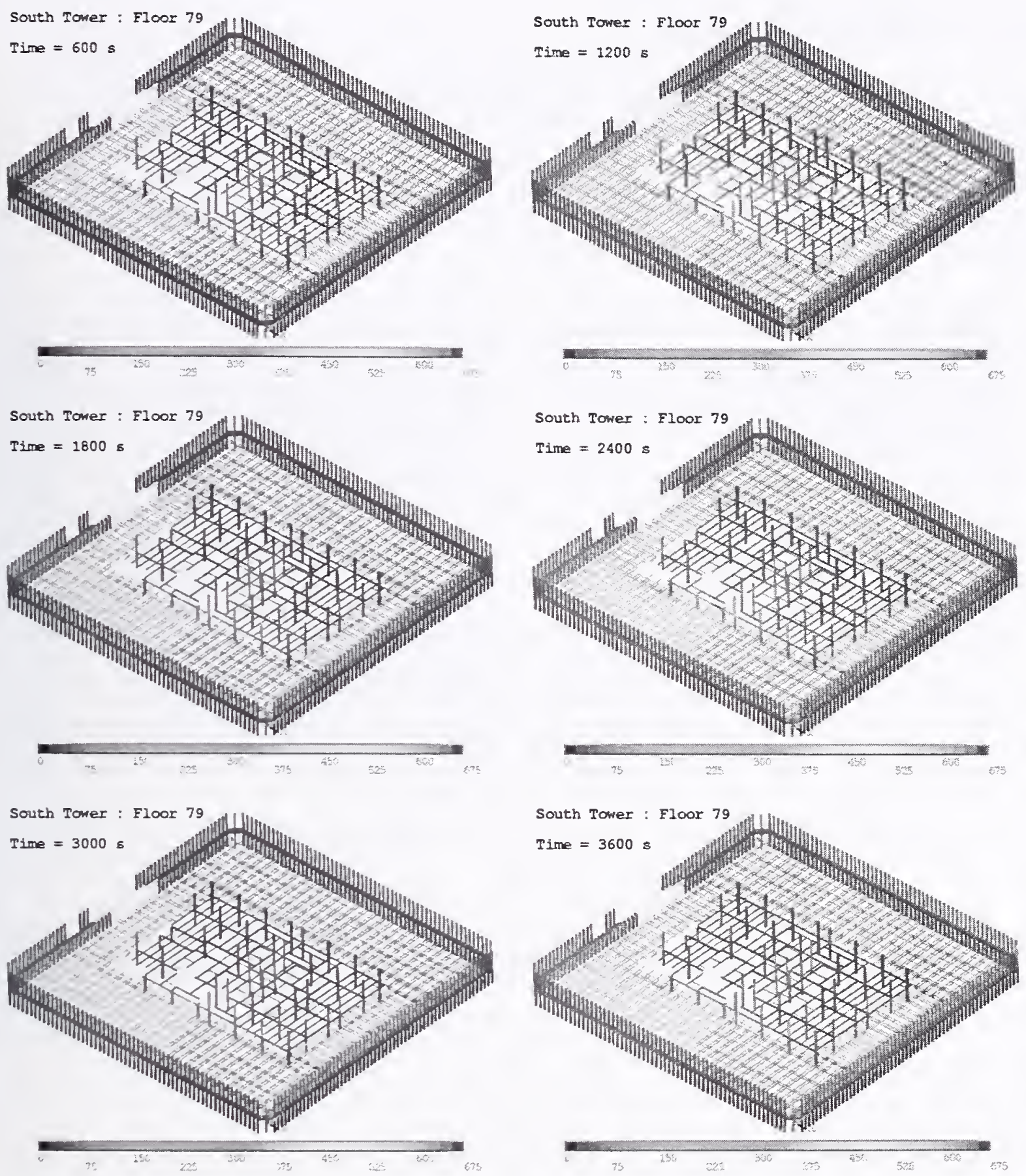

Figure 11-2. Thermal response of floor 79, WTC 2 Case D at different instants in time. 


\subsubsection{Floor 80, WTC 2 Case D}

The east side of the truss system that supports floor 80 shows high temperatures duc to continuous fire activity on floor 79. The heating of the truss system was more extensive than that for Case C. Core columns showed more extensive structural damage in the southeast corner as compared to Case C. Fireproofing damage was also more extensive in Case D, especially in the east side of the core. Fireproofing damage results in higher temperature on the core columns in this case. Thermal states of floor 80 at 10 min intervals are shown in Figure 11-4

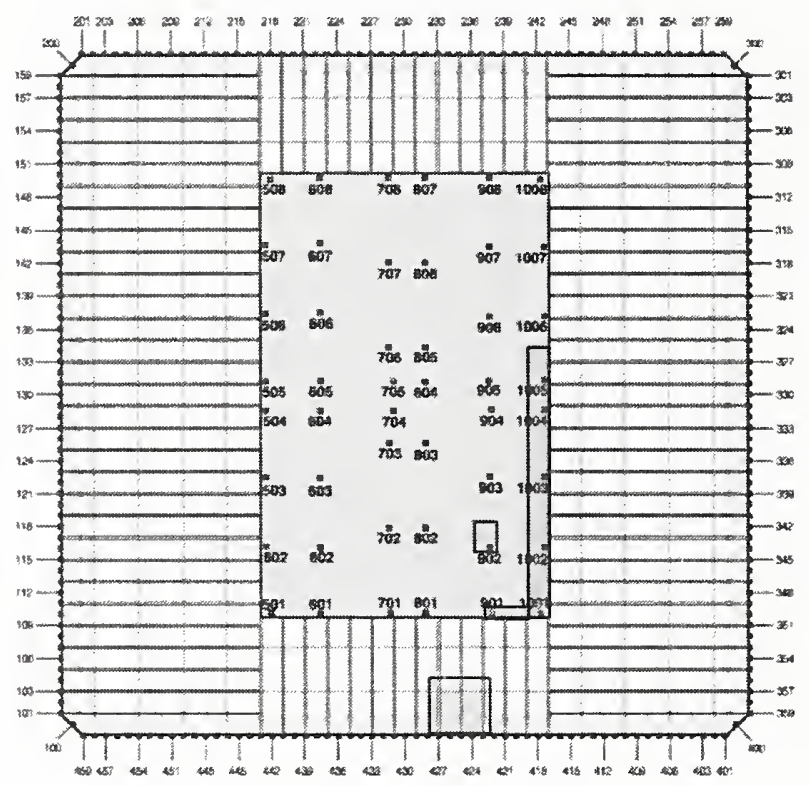

Structural damage for floor 80

Structural Damage

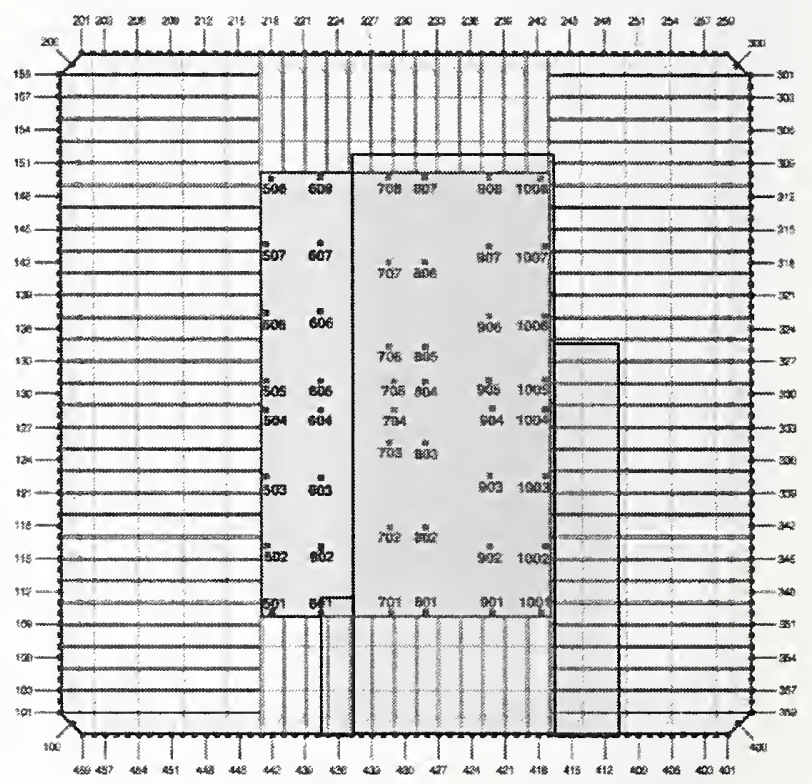

Fireproofing damage for floor trusses and core beams that support floor 80

Fireproofing Damage

Figure 11-3. Structural and fireproofing damage on floor 80 , WTC 2, Case $D_{i}$. 

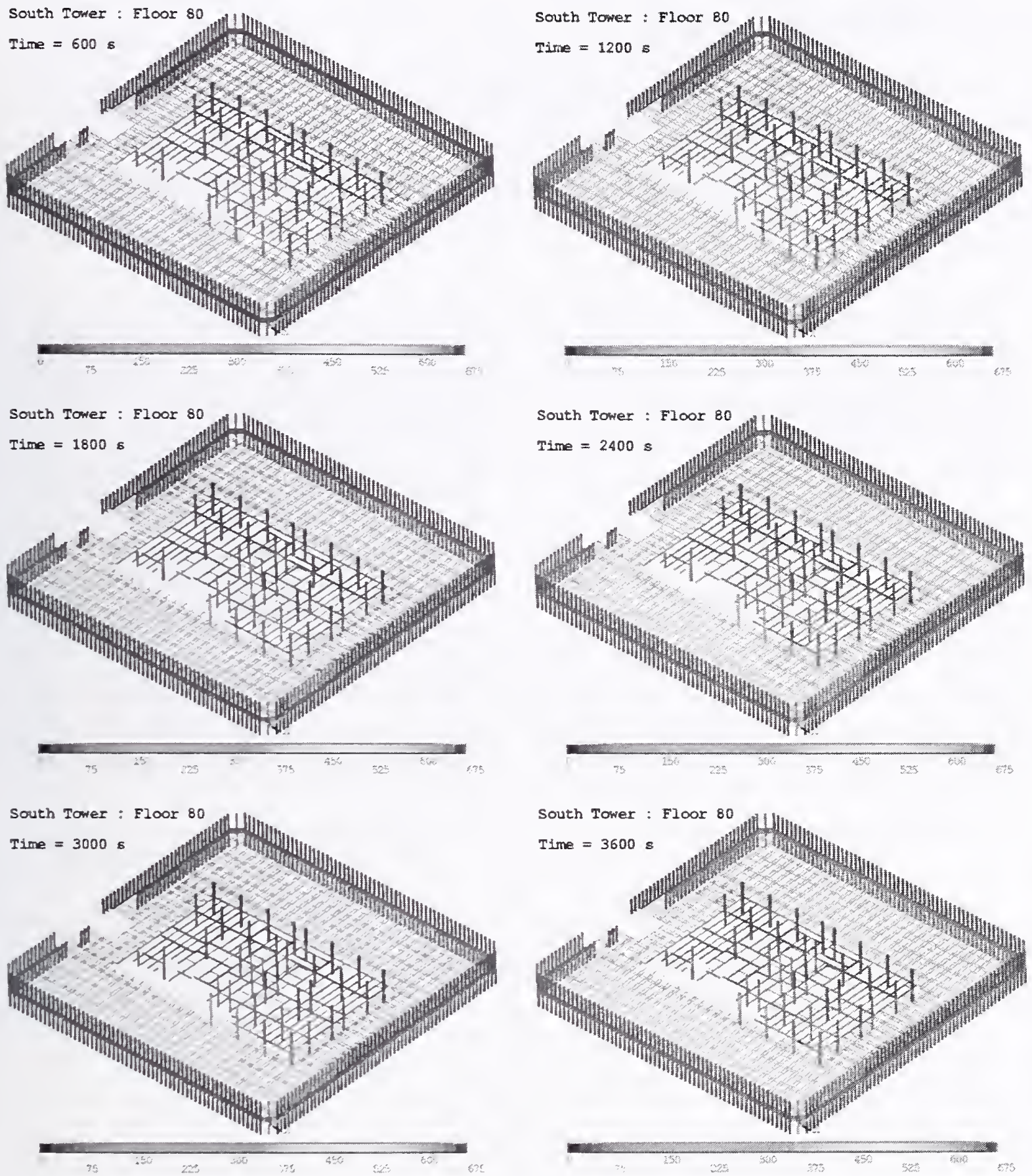

Figure 11-4. Thermal response of floor 80, WTC 2 Case D at different instants in time. 


\subsubsection{Floor 81, WTC 2 Case D}

The truss system that supports floor 81 shows intense heating on the east side and in the northeast corner. Perimeter columns in the northeast corner, as well as core columns, show significant heating due to a combination of fireproofing damage and fire activity in this area. Structural damage due to aircraft impact in Case D was more extensive on the floor systems and core columns. Fireproofing damage was also more extensive on this floor as compared to Case $\mathrm{C}$. The thermal state of floor 81 at $10 \mathrm{~min}$ intervals is shown in Figure 11-6.

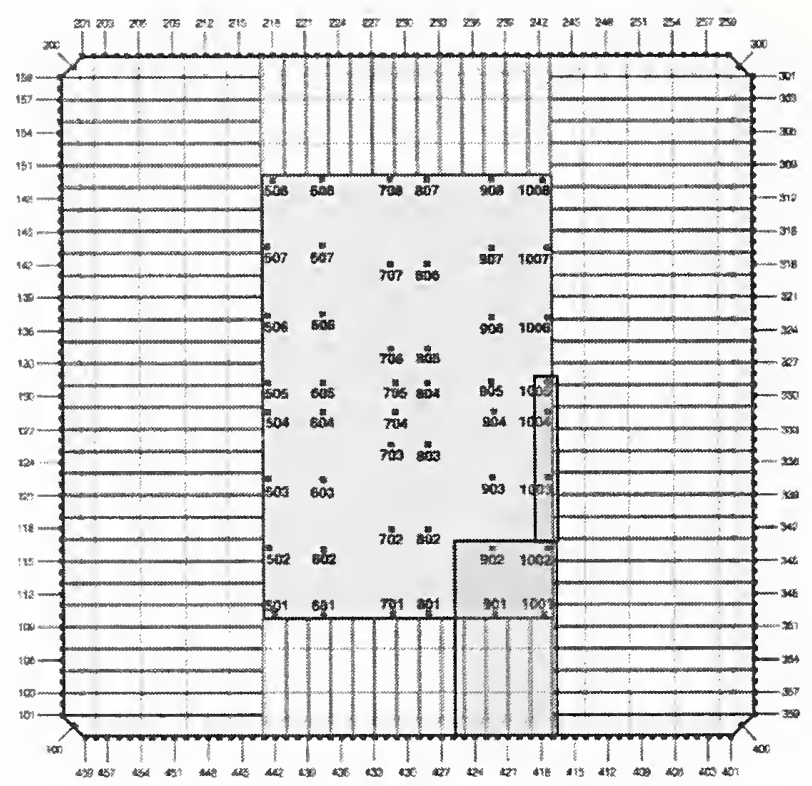

Structural damage for floor 81

Structural Damage

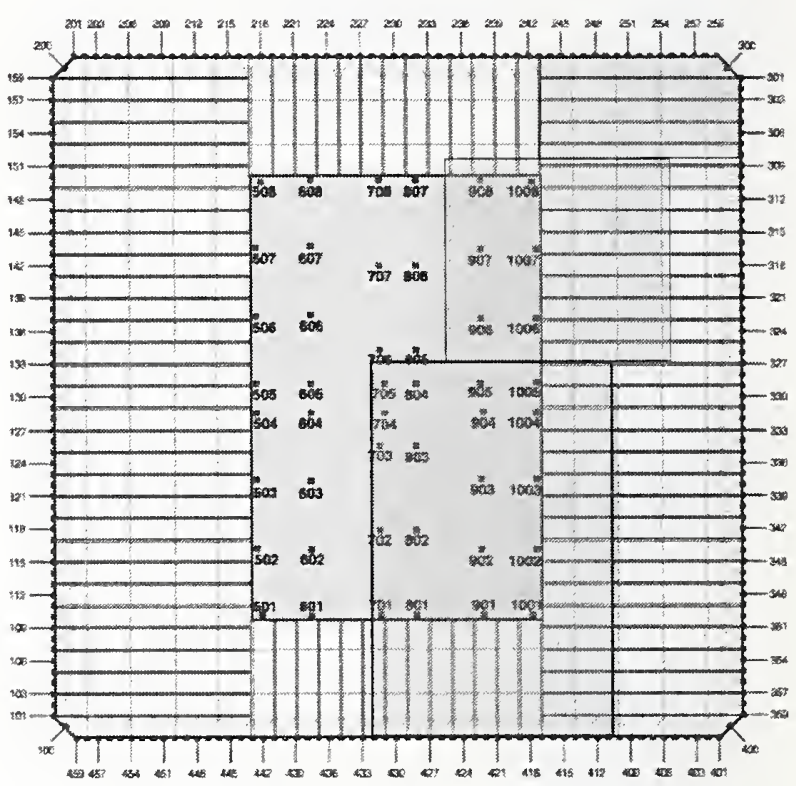

Fireproofing damage on floor trusses and core beams that support floor 81

Fireproofing Damage

Figure 11-5. Structural and fireproofing damage on floor 81, WTC 2, Case $D_{i}$. 

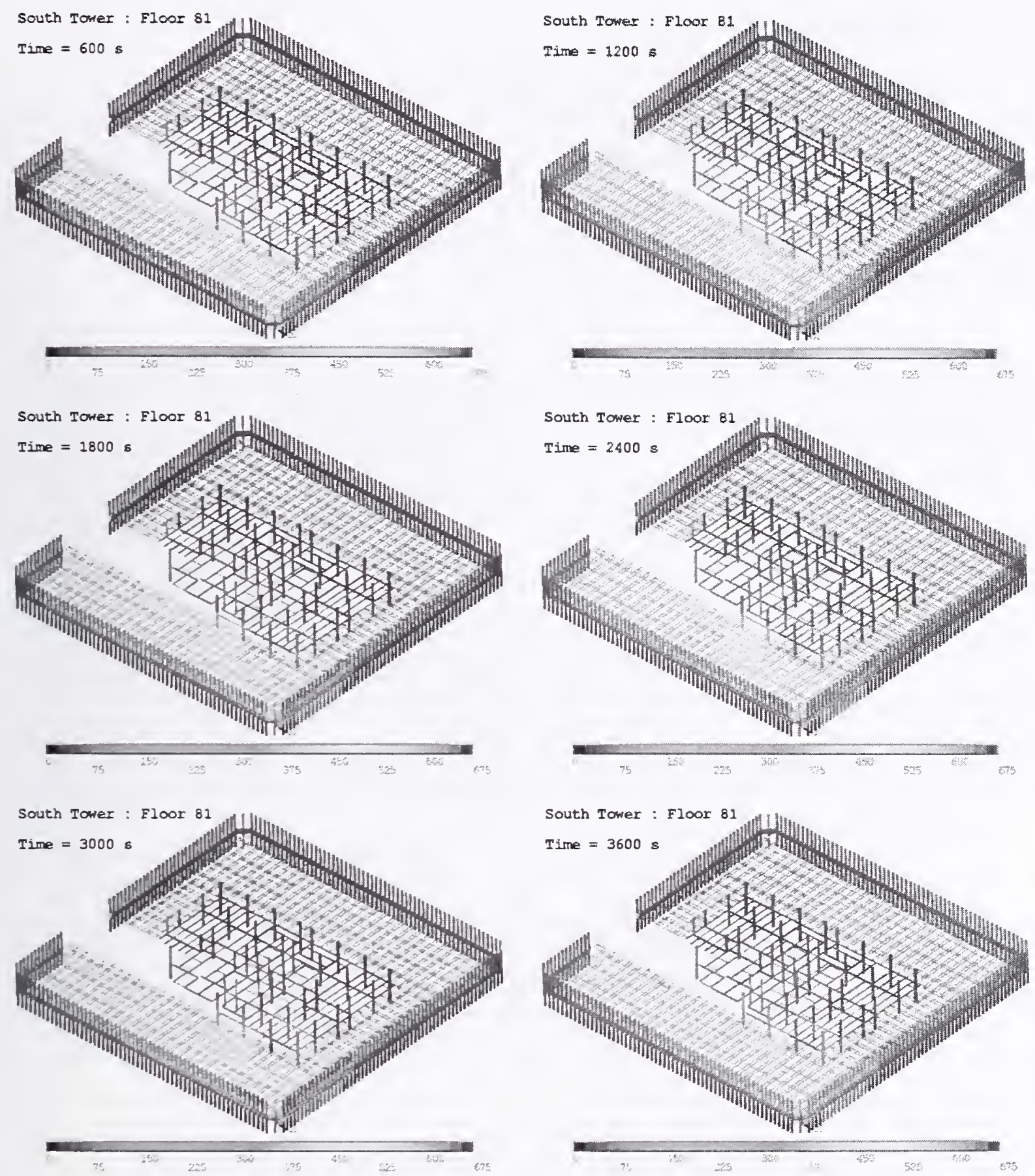

Figure 11-6. Thermal response of floor 81 , WTC 2 Case D at different instants in time. 


\subsubsection{Floor 82, WTC 2 Case D}

Floor 82 shows large regions on the east side of the core that suffered fire damage as indicated by very high temperatures in the east face and northeast corner. This floor is one of the most severely damaged floors in our simulations. Fire simulations predict burnout in the northeast corner at $50 \mathrm{~min}$ to $60 \mathrm{~min}$ after impact, and the simulation results do not match with the visual and photographic observations, which indicate continuous fire activity until collapse. The lack of predicted fire activity may have resulted in prediction of lower temperatures for floor trusses and columns in the northeast corner. The thermal state of floor 82 at 10 min intervals is shown in Figure 11-8.

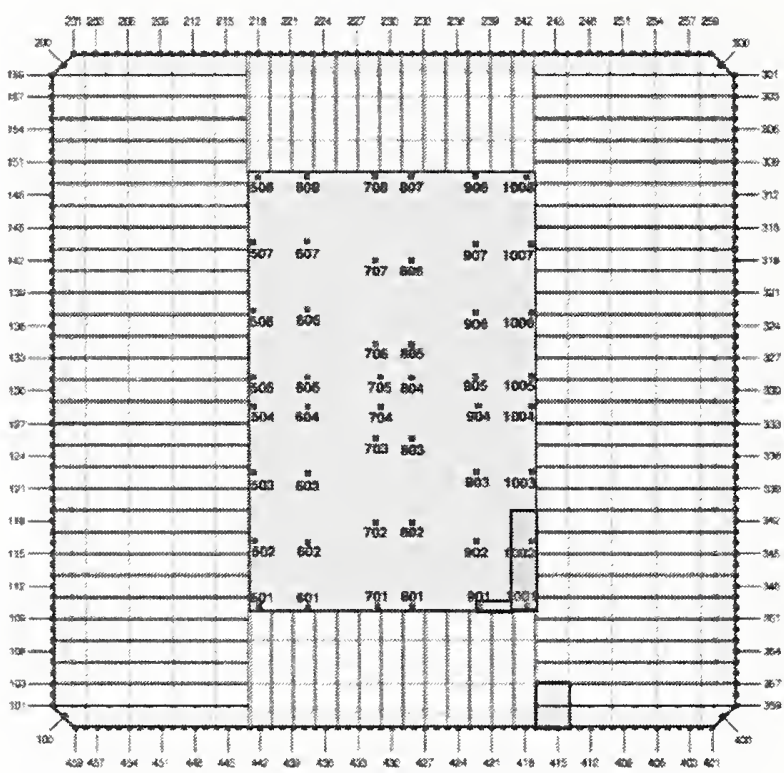

Structural damage for floor 82

Structural Damage

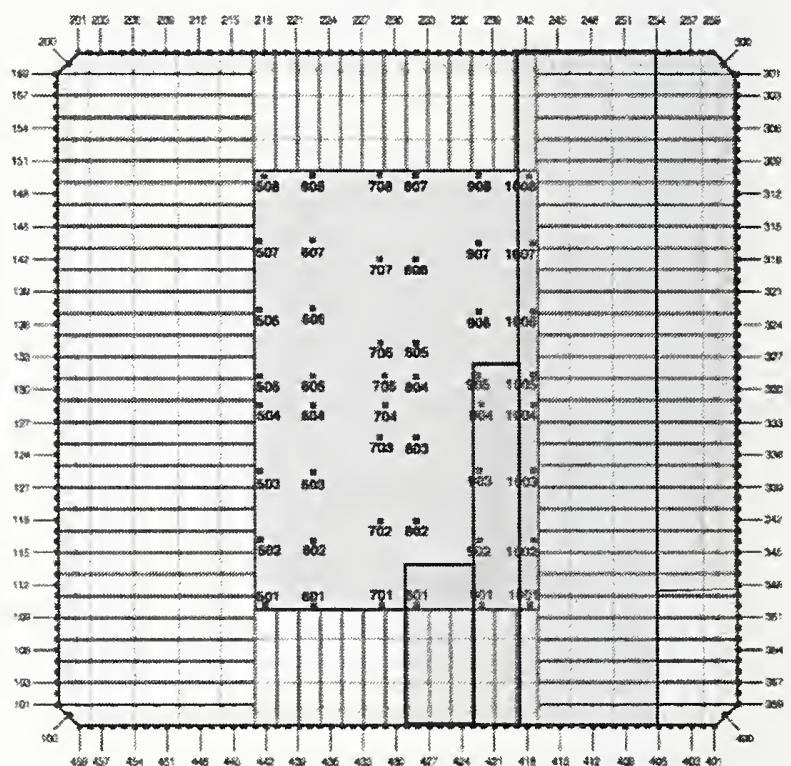

Fireproofing damage on floor trusses and core beams that support floor 82

Fireproofing Damage

Figure 11-7. Structural and fireproofing damage on floor 82, WTC 2, Case $D_{i}$. 

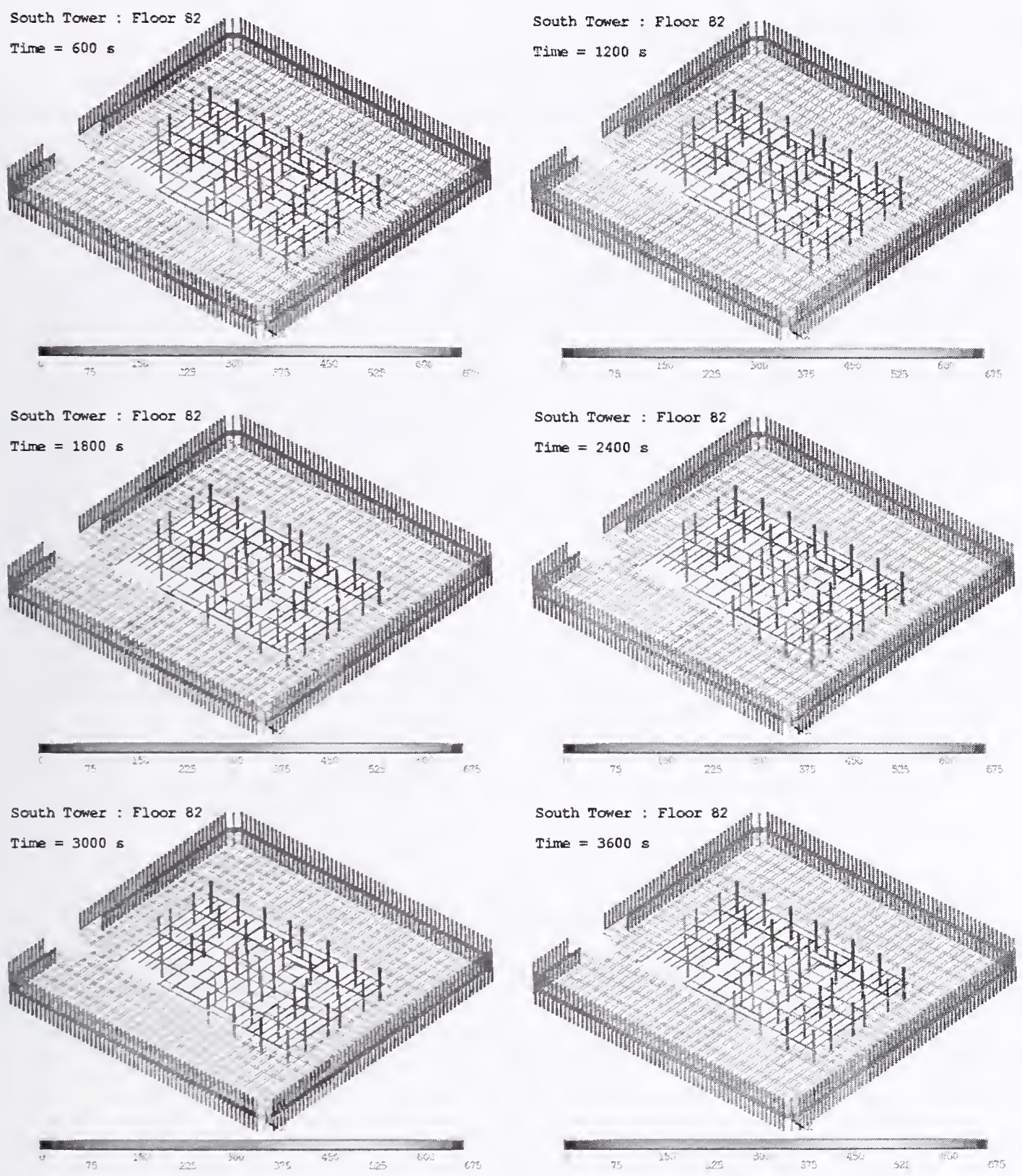

Figure 11-8. Thermal response of floor 82 , WTC 2 Case D at different instants in time. 


\subsubsection{Floor 83, WTC 2 Case D}

Like floor 82 , floor 83 also indicates very intense fire activity throughout the simulation resulting in extreme fire induced damage on the east side of the building. The thermal insult on this floor is predicted for the entire duration of the simulation. The thermal state of floor 83 at $10 \mathrm{~min}$ intervals is shown in Figure 11-10.

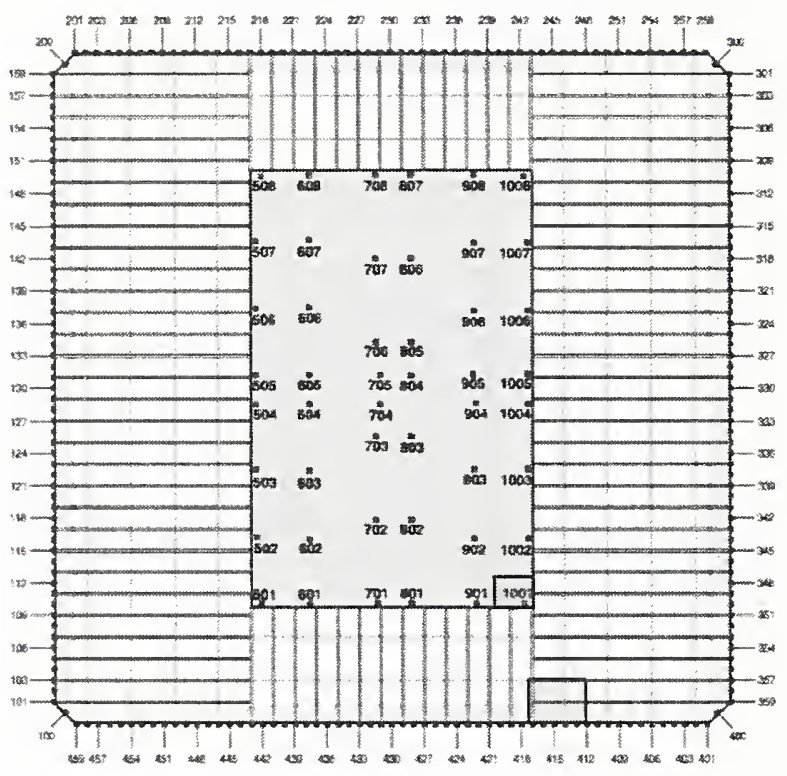

Structural damage for floor 83

Structural Damage

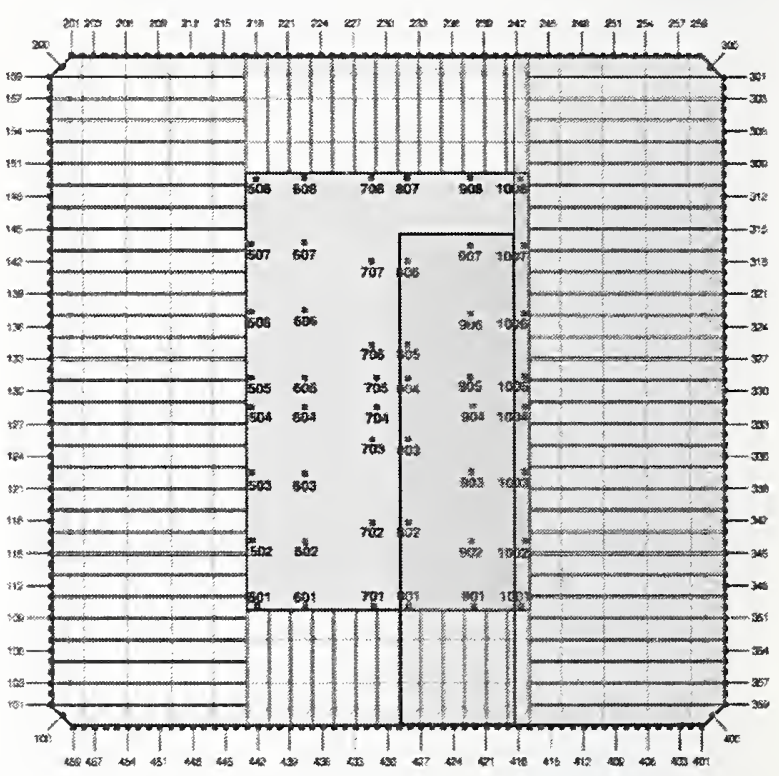

Fireproofing damage on floor trusses and core beams that support floor 83

Fireproofing Damage

Figure 11-9. Structural and fireproofing damage on floor 83, WTC 2, Case $D_{i}$.

\section{$11.3 \quad$ DATA TRANSFER FOR STRUCTURAL ANALYSIS}

The data transfer for WTC 2 Case D is identical to that described in the previous chapter for WTC 2 Case C (see Section 10.3). 

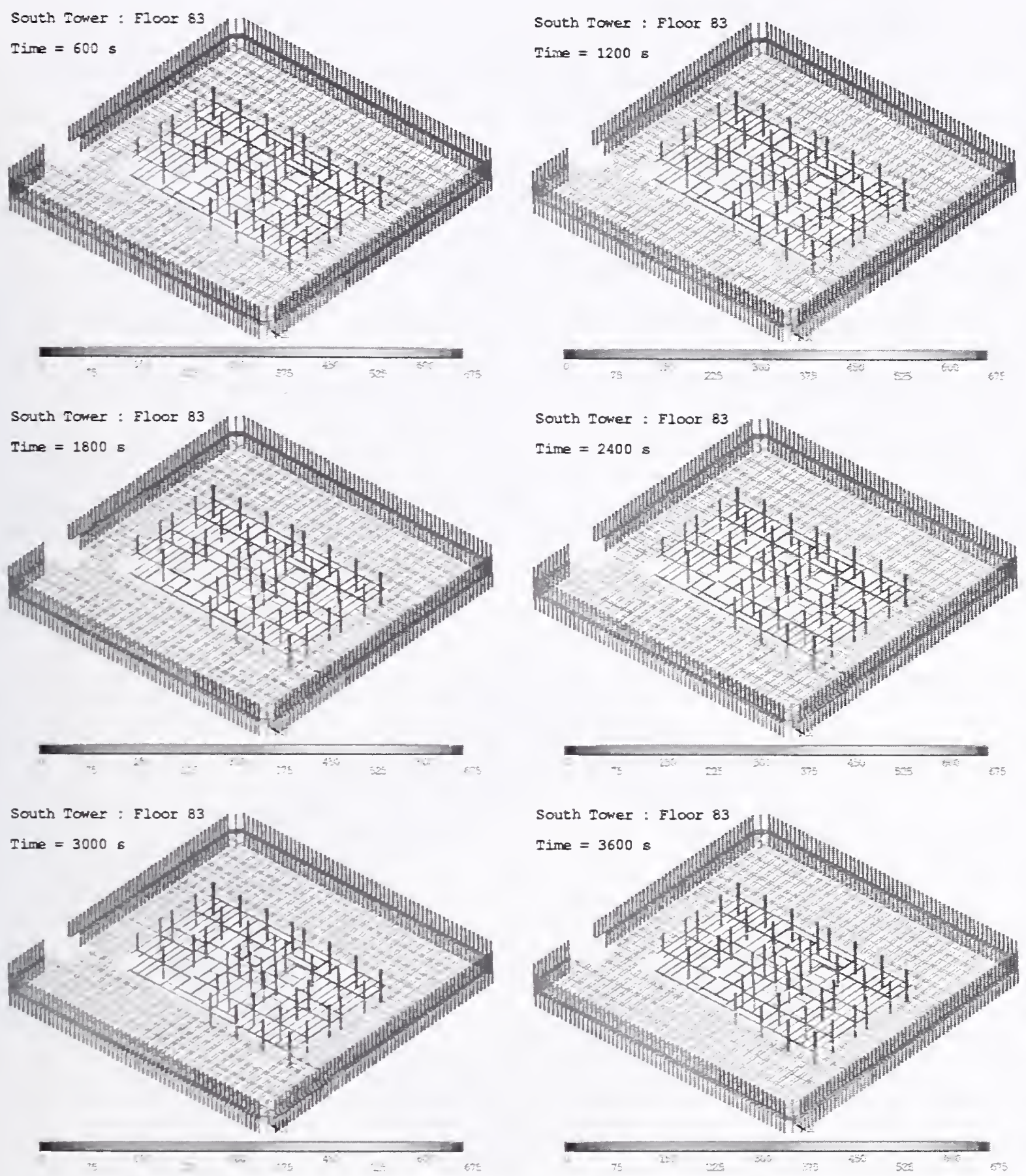

Figure 11-10. Thermal response of floor 83, WTC 2 Case D, at different instants in time. 


\section{$11.4 \quad$ EXTENDED RUN SIMULATIONS}

The thermal response analysis of WTC 2 described above was limited to $60 \mathrm{~min}(1 \mathrm{~h})$ for both Case C and Case D, as described in Chapter 10 and Chapter 11.

In order to assess the possible outcome of a severe fire in a tower for which no fireproofing damage due to aircraft impact had occurred, a simulation was performed in which the Case D fires were allowed to burn an additional $2 \mathrm{~h}$ (see NIST NCSTAR 1-5F). This simulation assumed that all the windows were broken at the $1 \mathrm{~h}$ point. This resulted in intense fire activity in the west side of WTC 2.

Thermal results indicated significant heating of the floor trusses on the west side (where the insulated was undamaged), with peak temperatures of approximately $760{ }^{\circ} \mathrm{C}$. Temperatures of $700{ }^{\circ} \mathrm{C}$ to $760{ }^{\circ} \mathrm{C}$ were reached over approximately 15 percent of the west floor area for less than $10 \mathrm{~min}$. Approximately 60 percent of the floor steel had temperatures between $600{ }^{\circ} \mathrm{C}$ and $700{ }^{\circ} \mathrm{C}$ for about $15 \mathrm{~min}$.

Approximately 70 percent of the floor steel had temperatures that exceeded $500{ }^{\circ} \mathrm{C}$ for about $45 \min$ (see Fig. 11-11). After approximately $2 \mathrm{~h}$, all the combustibles on the west side were consumed and this resulted in a gradual cool down of the steel temperature (see Fig. 11-12).

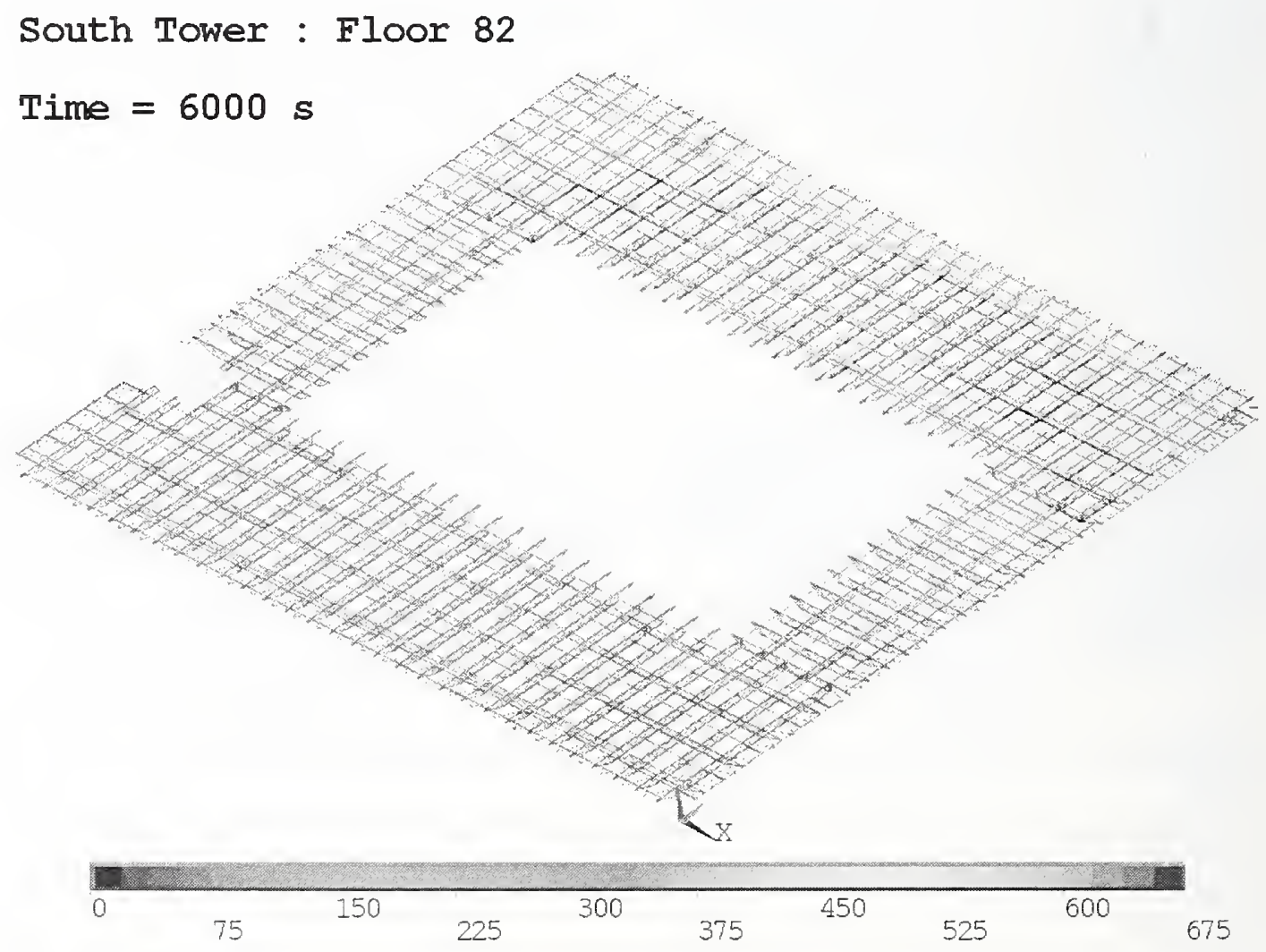

Figure 11-11. Thermal response of floor trusses that support the concrete slab on floor 82, WTC 2 at 6,000 s after impact (extended simulation for Case D). 


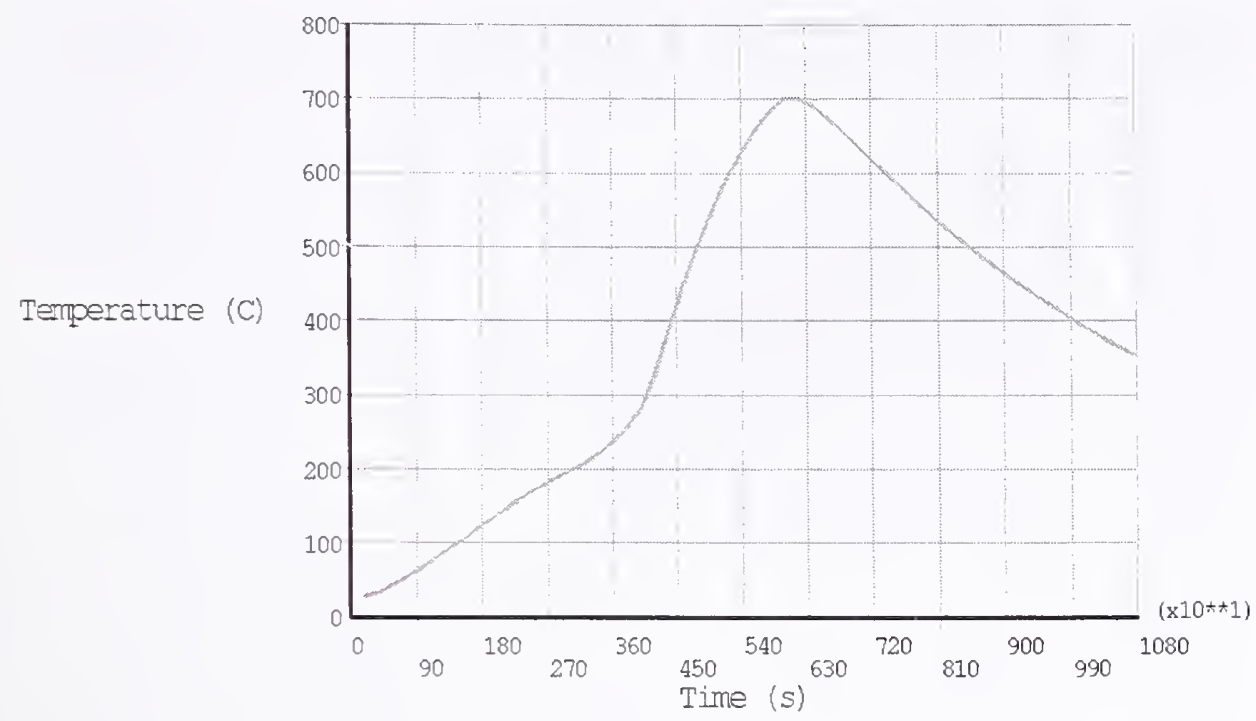

Figure 11-12. Typical time-temperature plot for floor trusses on the west side for the extended run, indicating rapid heating at $6000 \mathrm{~s}$ after impact followed by gradual cooling. 
Table 11-4. Perimeter Column Damage Status for WTC 2 Case D. \begin{tabular}{|l|l|l|l|l|l|l|}
\hline Column \# & Floor 78 & Floor 79 & Floor 80 & Floor 81 & Floor 82 & Floor 83 \\
\hline
\end{tabular}

\begin{tabular}{|c|c|c|c|c|c|c|}
\hline & & & & & & \\
\hline 101 & 0 & 0 & 0 & 0 & 0 & 0 \\
\hline 103 & 0 & 0 & 0 & 0 & 0 & 0 \\
\hline 106 & 0 & 0 & 0 & 0 & 0 & 0 \\
\hline 109 & 0 & 0 & 0 & 0 & 0 & 0 \\
\hline 112 & 0 & 0 & 0 & 0 & 0 & 0 \\
\hline 115 & 0 & 0 & 0 & 0 & 0 & 0 \\
\hline 118 & 0 & 0 & 0 & 0 & 0 & 0 \\
\hline 121 & 0 & 0 & 0 & 0 & 0 & 0 \\
\hline 124 & 0 & 0 & 0 & 0 & 0 & 0 \\
\hline 127 & 0 & 0 & 0 & 0 & 0 & 0 \\
\hline 130 & 0 & 0 & 0 & 0 & 0 & 0 \\
\hline 133 & 0 & 0 & 0 & 0 & 0 & 0 \\
\hline 136 & 0 & 0 & 0 & 0 & 0 & 0 \\
\hline 139 & 0 & 0 & 0 & 0 & 0 & 0 \\
\hline 142 & 0 & 0 & 0 & 0 & 0 & 0 \\
\hline 145 & 0 & 0 & 0 & 0 & 0 & 0 \\
\hline 148 & 0 & 0 & 0 & 0 & 0 & 0 \\
\hline 151 & 0 & 0 & 0 & 0 & 0 & 0 \\
\hline 154 & 0 & 0 & 0 & 0 & 0 & 0 \\
\hline 157 & 0 & 0 & 0 & 0 & 0 & 0 \\
\hline 201 & 0 & 0 & 0 & 0 & 0 & 0 \\
\hline 203 & 0 & 0 & 0 & 0 & 0 & 0 \\
\hline 206 & 0 & 0 & 0 & 0 & 0 & 0 \\
\hline 209 & 0 & 0 & 0 & 0 & 0 & 0 \\
\hline 212 & 0 & 0 & 0 & 0 & 0 & 0 \\
\hline 215 & 0 & 0 & 0 & 0 & 0 & 0 \\
\hline 218 & 0 & 0 & 0 & 0 & 0 & 0 \\
\hline 221 & 0 & 0 & 0 & 0 & 0 & 0 \\
\hline 224 & 0 & 0 & 0 & 0 & 0 & 0 \\
\hline 227 & 0 & 0 & 0 & 0 & 0 & 0 \\
\hline 230 & 0 & 0 & 0 & 0 & 0 & 0 \\
\hline
\end{tabular}




\begin{tabular}{|c|c|c|c|c|c|c|}
\hline 233 & 0 & 0 & 0 & 0 & 0 & 0 \\
\hline 236 & 0 & 0 & 0 & 0 & 0 & 0 \\
\hline 239 & 0 & 0 & 0 & 0 & 0 & 0 \\
\hline 242 & 0 & 0 & 0 & 1 & 1 & 0 \\
\hline 245 & 0 & 0 & 1 & 1 & 1 & 0 \\
\hline 248 & 0 & 0 & 1 & 1 & 1 & 0 \\
\hline 251 & 0 & 0 & 1 & 1 & 1 & 0 \\
\hline 254 & 0 & 0 & 1 & 1 & 1 & 0 \\
\hline 257 & 0 & 0 & 0 & 1 & 1 & 0 \\
\hline 301 & 0 & 0 & 0 & 1 & 1 & 0 \\
\hline 303 & 0 & 0 & 0 & 1 & 1 & 0 \\
\hline 306 & 0 & 0 & 0 & 1 & 1 & 0 \\
\hline 309 & 0 & 0 & 0 & 1 & 1 & 0 \\
\hline 312 & 0 & 0 & 0 & 1 & 1 & 0 \\
\hline 315 & 0 & 0 & 0 & 1 & 1 & 0 \\
\hline 318 & 0 & 0 & 0 & 1 & 1 & 1 \\
\hline 321 & 0 & 0 & 0 & 1 & 1 & 1 \\
\hline 324 & 0 & 0 & 0 & 1 & 1 & 1 \\
\hline 327 & 0 & 0 & 0 & 1 & 1 & 1 \\
\hline 330 & 0 & 0 & 0 & 1 & 1 & 1 \\
\hline 333 & 0 & 0 & 0 & 1 & 1 & 1 \\
\hline 336 & 0 & 0 & 0 & 1 & 1 & 1 \\
\hline 339 & 0 & 0 & 0 & 1 & 1 & 1 \\
\hline 342 & 0 & 0 & 0 & 1 & 1 & 1 \\
\hline 345 & 0 & 0 & 0 & 1 & 1 & 1 \\
\hline 348 & 0 & 0 & 0 & 1 & 1 & 1 \\
\hline 351 & 0 & 0 & 0 & 1 & 1 & 1 \\
\hline 354 & 0 & 0 & 0 & 0 & 1 & 1 \\
\hline 357 & 0 & 0 & 0 & 0 & 1 & 1 \\
\hline 401 & 0 & 0 & 0 & 0 & 0 & 0 \\
\hline 403 & 0 & 0 & 0 & 0 & 0 & 0 \\
\hline 406 & 0 & 0 & 0 & 0 & 0 & 0 \\
\hline
\end{tabular}




\begin{tabular}{|l|l|l|l|l|l|l|}
\hline 409 & 0 & 0 & 0 & 0 & 0 & 0 \\
\hline 412 & 0 & 0 & 0 & 0 & 2 & 2 \\
\hline 415 & 0 & 0 & 2 & 2 & 2 & 2 \\
\hline 418 & 0 & 2 & 2 & 2 & 2 & 0 \\
\hline 421 & 0 & 0 & 2 & 2 & 0 & 0 \\
\hline 424 & 0 & 2 & 2 & 2 & 0 & 0 \\
\hline 427 & 0 & 2 & 0 & 0 & 0 & 0 \\
\hline 430 & 2 & 2 & 0 & 0 & 0 & 0 \\
\hline 433 & 2 & 2 & 0 & 0 & 0 & 0 \\
\hline 436 & 2 & 0 & 0 & 0 & 0 & 0 \\
\hline 439 & 2 & 0 & 0 & 0 & 0 & 0 \\
\hline 442 & 0 & 0 & 0 & 0 & 0 & 0 \\
\hline 445 & 0 & 0 & 0 & 0 & 0 & 0 \\
\hline 448 & 0 & 0 & 0 & 0 & 0 & 0 \\
\hline 451 & 0 & 0 & 0 & 0 & 0 & 0 \\
\hline 454 & 0 & 0 & 0 & 0 & 0 & 0 \\
\hline 457 & 0 & 0 & 0 & 0 & 0 & 0 \\
\hline
\end{tabular}


Table 11-5. Core Column Damage Status for WTC 2, Case D.

\begin{tabular}{|c|c|c|c|c|c|c|}
\hline $\begin{array}{l}\text { Column } \\
\text { No. }\end{array}$ & Floor 78 & Floor 79 & Floor 80 & Floor 81 & Floor 82 & Floor 83 \\
\hline 501 & 0 & 0 & 0 & 0 & 0 & 0 \\
\hline 502 & 0 & 0 & 0 & 0 & 0 & 0 \\
\hline 503 & 0 & 0 & 0 & 0 & 0 & 0 \\
\hline 504 & 0 & 0 & 0 & 0 & 0 & 0 \\
\hline 505 & 0 & 0 & 0 & 0 & 0 & 0 \\
\hline 506 & 0 & 0 & 0 & 0 & 0 & 0 \\
\hline 507 & 0 & 0 & 0 & 0 & 0 & 0 \\
\hline 508 & 0 & 0 & 0 & 0 & 0 & 0 \\
\hline 601 & 3 & 0 & 0 & 0 & 0 & 0 \\
\hline 602 & 3 & 0 & 0 & 0 & 0 & 0 \\
\hline 603 & 3 & 0 & 0 & 0 & 0 & 0 \\
\hline 604 & 3 & 0 & 0 & 0 & 0 & 0 \\
\hline 605 & 3 & 0 & 0 & 0 & 0 & 0 \\
\hline 606 & 3 & 0 & 0 & 0 & 0 & 0 \\
\hline 607 & 3 & 0 & 0 & 0 & 0 & 0 \\
\hline 608 & 3 & 0 & 0 & 0 & 0 & 0 \\
\hline 701 & 3 & 2 & 2 & 0 & 0 & 0 \\
\hline 702 & 3 & 3 & 3 & 0 & 0 & 0 \\
\hline 703 & 3 & 3 & 3 & 0 & 0 & 0 \\
\hline 704 & 3 & 3 & 3 & 0 & 0 & 0 \\
\hline 705 & 3 & 3 & 3 & 0 & 0 & 0 \\
\hline 706 & 3 & 3 & 0 & 0 & 0 & 0 \\
\hline 707 & 3 & 3 & 0 & 0 & 0 & 0 \\
\hline 708 & 3 & 3 & 0 & 0 & 0 & 0 \\
\hline 801 & 3 & 2 & 2 & 3 & 3 & 0 \\
\hline 802 & 2 & 2 & 2 & 0 & 3 & 0 \\
\hline 803 & 2 & 2 & 2 & 0 & 3 & 0 \\
\hline 804 & 3 & 3 & 3 & 0 & 3 & 0 \\
\hline 805 & 3 & 3 & 0 & 0 & 3 & 0 \\
\hline 806 & 3 & 3 & 0 & 0 & 3 & 0 \\
\hline
\end{tabular}




\begin{tabular}{|l|l|l|l|l|l|l|}
\hline 807 & 3 & 3 & 0 & 0 & 0 & 0 \\
\hline 901 & 3 & 3 & 2 & 2 & 2 & 0 \\
\hline 902 & 3 & 3 & 3 & 3 & 3 & 0 \\
\hline 903 & 2 & 2 & 2 & 2 & 2 & 2 \\
\hline 904 & 3 & 3 & 3 & 3 & 3 & 0 \\
\hline 905 & 3 & 3 & 3 & 3 & 3 & 0 \\
\hline 906 & 3 & 3 & 3 & 0 & 3 & 0 \\
\hline 907 & 3 & 3 & 3 & 0 & 3 & 0 \\
\hline 908 & 3 & 3 & 3 & 0 & 0 & 0 \\
\hline 1001 & 2 & 2 & 2 & 2 & 2 & 2 \\
\hline 1002 & 3 & 2 & 2 & 2 & 2 & 2 \\
\hline 1003 & 3 & 2 & 2 & 2 & 2 & 2 \\
\hline 1004 & 3 & 2 & 2 & 2 & 2 & 2 \\
\hline 1005 & 3 & 3 & 3 & 3 & 3 & 0 \\
\hline 1006 & 3 & 3 & 3 & 3 & 3 & 0 \\
\hline 1007 & 3 & 3 & 3 & 3 & 3 & 0 \\
\hline 1008 & 3 & 3 & 3 & 3 & 3 & 0 \\
\hline & & & & & & \\
\hline
\end{tabular}




\section{Chapter 12 \\ SUMMARY OF TECHNICAL RESULTS}

The attack on the World Trade Center (WTC) Towers and their subsequent collapse on September 11,2001, sparked an active debate in the engineering community regarding what was the maximum temperature reached within the steel structure and how the heating of the steel led to structural collapse. Software tools that could simulate the thermally induced structural response to spatially and temporally developing fires, on one or more floors of each WTC tower damaged by the impact of the aircraft, were needed to carry out the investigation.

This report presents numerical simulation results for the evolving thermal state of all the structural components on focus floors of the WTC towers. A methodology to couple the fire simulations with structural response for each tower is described. This methodology, termed the Fire Structure Interface (FSI), utilizes the output of a fire dynamics simulation together with aircraft impact analysis results to produce a representation of the temperature distributions in the steel and concrete structure. A simple radiative transport model was developed, that permits the prediction of radiative flux incident on the surface as a function of orientation of the structural element, temperature, hot layer depth and soot concentration. The resulting thermal data was generated in a format that is consistent with the structural models and the software that was used to perform structural analysis.

FSI links the fire simulations and damage predicted by the aircraft debris with stress analysis in the load bearing structure. This methodology was used extensively throughout investigation. To test the accuracy of the methodology, a series of large-scale experiments were conducted in the NIST Large Fire Laboratory. The experiments established a dataset, which was used to test that the models were accurately capturing the thermal response of the structural elements. Results indicate that FSI can reliably predict the temperature in the structural components and that it does not add any more uncertainty in the overall analysis than what is inherent in the aircraft impact analysis and fire dynamic simulations.

A large number of exploratory studies were conducted to understand the nature of the thermal insult caused by the fire on the structure. Sensitivity studies were performed to estimate the role of fireproofing on steel temperature. These studies included the effect of fireproofing thickness, its statistical variability and damage or gaps in fireproofing thickness. Fireproofing thickness and fireproofing damage due to aircraft impact is identified as the single most important parameter in the simulations that has a direct effect on steel temperature.

The exploratory studies, photographic evidence and published literature in this subject guided the development of three-dimensional finite element models for global thermal analysis of each WTC tower. The construction of these models was constrained by the need to adequately resolve the physical processes in a computationally efficient manner. Four global simulation results, two each for WTC 1 and WTC 2 are presented in this report. Each global thermal simulation was coupled with a corresponding fire simulation and includes aircraft impact damage estimates. The figures included in Chapter 8 through Chapter 11 similar to the sample plot shown in Figure 8-1 of this report are visual representations of the 
thermal state of the towers at specific instants in time. These figures provide a valuable insight into the thermal response of the structural components for each tower.

In the remainder of this chapter, the important differences in input parameters and the results of the thermal analysis for the four global simulations are summarized.

\subsection{GLOBAL THERMAL RESPONSE OF THE WORLD TRADE CENTER TOWERS}

The methodology described in this report was used extensively throughout the World Trade Center Investigation to predict the evolving thermal state of each tower. Four global simulations were performed, two each for WTC 1 and WTC 2. Each of the global simulations was coupled with a corresponding fire simulation and the finite element models included the aircraft impact damage estimates.

The four global simulations were different in terms of the input parameters that were used to perform the aircraft impact analysis for each tower. Table 12-1 lists the input parameters for "Base Case" and "More Severe" case used in the impact analysis for WTC 1. Similarly Table 12-2 lists the input parameters used in the impact analysis for WTC 2.

Table 12-1. Input parameters for WTC 1 global impact analyses.

\begin{tabular}{|c|l|c|c|}
\hline \multicolumn{2}{|c|}{ Analysis Parameters } & Base Case & More Severe \\
\hline Flight Parameters & Impact speed & $443 \mathrm{mph}$ & $472 \mathrm{mph}$ \\
\cline { 2 - 4 } & Trajectory - pitch & $10.6^{\circ}$ & $7.6^{\circ}$ \\
\cline { 2 - 4 } & Trajectory - yaw & $0.0^{\circ}$ & $0.0^{\circ}$ \\
\cline { 2 - 4 } & Orientation - pitch & $8.6^{\circ}$ & $5.6^{\circ}$ \\
\cline { 2 - 4 } & Orientation - yaw & $0.0^{\circ}$ & $0.0^{\circ}$ \\
\hline \multirow{4}{*}{$\begin{array}{c}\text { Aircraft } \\
\text { Parameters }\end{array}$} & Weight & 100 percent & 105 percent \\
\cline { 2 - 4 } Tower & Failure Strain & 100 percent & 125 percent \\
\hline \multirow{2}{*}{\begin{tabular}{c} 
Tarameters \\
\cline { 2 - 4 }
\end{tabular}} & Failure Strain & 100 percent & 80 percent \\
\cline { 2 - 4 } & Live Load Weight & 25 percent & 20 percent \\
\hline
\end{tabular}

a. Live load weight expressed as a percentage of the design live load.

The "More Severe" case for each tower had higher impact speed, assumed weight and failure strain for the aircraft. On the other hand, the tower parameters for the "More Severe" case were less than the "Base Case". The impact analysis predicted the structural and fireproofing damage to the various structural components for each tower. As a direct result of the choice of the input parameters used in the simulations, the "More Severe" case resulted in more structural and fireproofing damage to the structural components. The structural and fireproofing damage data as predicted by the impact analysis was subsequently used in the FSI simulations for predicting the global thermal response of each tower. The methodology for incorporating the structural and fireproofing damage in the finite element models was discussed in Chapter 4 through Chapter 7. 
Table 12-2. Input parameters for WTC 2 global impact analyses.

\begin{tabular}{|c|c|c|c|}
\hline \multicolumn{2}{|c|}{ Analysis Parameters } & Base Case & More Severe \\
\hline \multirow{5}{*}{$\begin{array}{c}\text { Flight } \\
\text { Parameters }\end{array}$} & Impact speed & $546 \mathrm{mph}$ & $570 \mathrm{mph}$ \\
\hline & Trajectory - pitch & $6.0^{\circ}$ & $5.0^{\circ}$ \\
\hline & Trajectory - yaw & $13.0^{\circ}$ & $13.0^{\circ}$ \\
\hline & Orientation - pitch & $5.0^{\circ}$ & $4.0^{\circ}$ \\
\hline & Orientation - yaw & $10.0^{\circ}$ & $10.0^{\circ}$ \\
\hline \multirow{2}{*}{$\begin{array}{c}\text { Aircraft } \\
\text { Parameters }\end{array}$} & Weight & 100 percent & 105 percent \\
\hline & Failure Strain & 100 percent & 115 percent \\
\hline \multirow{3}{*}{$\begin{array}{c}\text { Tower } \\
\text { Parameters }\end{array}$} & Contents Strength & 100 percent & 80 percent \\
\hline & Failure Strain & 100 percent & 90 percent \\
\hline & Live Load Weight ${ }^{1}$ & 25 percent & 20 percent \\
\hline
\end{tabular}

a. Live load weight expressed as a percentage of the design live load.

The four global simulations were also different from each other in terms of the input parameters used for the fire simulations. Table 12-3 lists the input parameters for the four global simulations. Changes in the fuel loading, distribution and condition of the combustibles and representation of impacted core walls affected the fire growth and spread on the various floors of each tower. The large scale temperature and other thermo-physical properties in the gas phase as predicted by the FDS simulations were used in the FSI methodology for predicting the radiative flux to the sub-grid scale structural elements.

Table 12-3. Values of WTC fire simulation variables.

\begin{tabular}{|c|c|c|c|c|}
\hline \multirow[b]{2}{*}{ Variable } & \multicolumn{2}{|c|}{ WTC 1} & \multicolumn{2}{|c|}{ WTC 2} \\
\hline & Case A & Case B & Case $\mathrm{C}$ & Case D \\
\hline Fuel load & $20 \mathrm{~kg} / \mathrm{m}^{2}\left(4 \mathrm{lb} / \mathrm{ft}^{2}\right)$ & $25 \mathrm{~kg} / \mathrm{m}^{2}\left(5 \mathrm{lb} / \mathrm{ft}^{2}\right)$ & $20 \mathrm{~kg} / \mathrm{m}^{2}\left(4 \mathrm{lb} / \mathrm{ft}^{2}\right)$ & $20 \mathrm{~kg} / \mathrm{m}^{2}\left(5 \mathrm{lb} / \mathrm{ft}^{2}\right)$ \\
\hline $\begin{array}{l}\text { Distribution of } \\
\text { disturbed } \\
\text { combustibles }\end{array}$ & Even & $\begin{array}{l}\text { Weighted toward } \\
\text { the core }\end{array}$ & $\begin{array}{l}\text { Heavily } \\
\text { concentrated in the } \\
\text { northeast corner }\end{array}$ & $\begin{array}{l}\text { Moderately } \\
\text { concentrated in the } \\
\text { northeast corner }\end{array}$ \\
\hline $\begin{array}{l}\text { Condition of } \\
\text { combustibles }\end{array}$ & $\begin{array}{l}\text { Undamaged except } \\
\text { in impact zone }\end{array}$ & $\begin{array}{l}\text { Displaced furniture } \\
\text { rubblized }\end{array}$ & All rubblized & $\begin{array}{l}\text { Undamaged except } \\
\text { in impact zone }\end{array}$ \\
\hline $\begin{array}{l}\text { Representation of } \\
\text { impacted core walls }\end{array}$ & Fully removed & Soffit remained & Fully removed & Soffit remained \\
\hline
\end{tabular}

Global thermal response of each tower was computed using the FSI methodology. Each global thermal simulation was coupled with a corresponding fire simulation and included the structural and fireproofing damage estimates due to aircraft impact. Table 12-4 lists the various input parameters for the four global simulations described in detail in Chapter 8 through Chapter 11. As an example, the global thermal response of WTC 1 Case B, used the aircraft damage estimates predicted with "More Severe" input parameters (Table 12-1), used the fire simulation results for Case B (Table 12-3) and used the column schedule and fireproofing thickness data as described in Appendix B. 
Table 12-4. Input for global thermal response of WTC 1 and WTC 2.

\begin{tabular}{|l|c|c|c|c|}
\hline \multirow{2}{*}{\multicolumn{1}{|c|}{ Input }} & \multicolumn{2}{c|}{ WTC 1 } & \multicolumn{2}{c|}{ WTC 2 } \\
\cline { 2 - 5 } & $\begin{array}{c}\text { Case A } \\
\text { (Chapter 8) }\end{array}$ & $\begin{array}{c}\text { Case B } \\
\text { (Chapter 9) }\end{array}$ & $\begin{array}{c}\text { Case C } \\
\text { (Chapter 10) }\end{array}$ & $\begin{array}{c}\text { Case D } \\
\text { (Chapter 11) }\end{array}$ \\
\hline $\begin{array}{l}\text { Structural damage, } \\
\text { NIST NCSTAR 1-2 } \\
\text { NIST NCSTAR 1-6 }\end{array}$ & $\begin{array}{c}\text { Case A } \\
\text { (Base Case) }\end{array}$ & $\begin{array}{c}\text { Case B } \\
\text { (More severe) }\end{array}$ & $\begin{array}{c}\text { Case D } \\
\text { (Base Case) }\end{array}$ & (More severe) \\
\hline $\begin{array}{l}\text { Fireproofing damage, } \\
\text { NIST NCSTAR 1-6 }\end{array}$ & Case A & Case B & Case D \\
\hline $\begin{array}{l}\text { Fire simulations, } \\
\text { NIST NCSTAR 1-5F }\end{array}$ & Case A & Case B & Case C & Case D \\
\hline Column schedule & $\begin{array}{l}\text { Table B-1, } \\
\text { Table B-4, } \\
\text { Table B-5, } \\
\text { Table B-6 }\end{array}$ & $\begin{array}{l}\text { Table B-1, } \\
\text { Table B-4, } \\
\text { Table B-5, }\end{array}$ & $\begin{array}{c}\text { Table B-7, } \\
\text { Table B-8 }\end{array}$ & $\begin{array}{l}\text { Table B-2, } \\
\text { Table B-7, } \\
\text { Table B-8 }\end{array}$ \\
\hline $\begin{array}{l}\text { Fireproofing thickness } \\
\text { Thermo-physical } \\
\text { properties }\end{array}$ & Table B-9 & Table B-9 & Table B-9 & Table B-9 \\
\hline
\end{tabular}

As the input data for the FSI simulations changes, the thermal response predicted for the various structural elements on the focus floors of each tower also changed. In the next two sections the differences in the global thermal response due to differences in input parameters for WTC 1 and WTC 2 is summarized. The global simulation results indicate that the fireproofing thickness and the damage to the fireproofing due to aircraft impact was the single most important parameter that has the largest effect on the predicted thermal response of the structural elements.

\subsection{GLOBAL THERMAL RESPONSE OF WTC 1 : COMPARISON OF CASE A AND CASE B}

Global thermal response of WTC 1 Case A was described in detail in Chapter 8, while thermal analysis for WTC 1 Case B was discussed in Chapter 9. For each case a detailed floor by floor analysis was provided along with visuals, to describe the evolving thermal state of the various structural elements such as floor trusses, core beams, concrete slabs perimeter and core columns. In this section, a comparison is made between the global thermal results of WTC 1 Case A and WTC 1 Case B.

Figure 12-1 and Figure 12-2 summarize the thermal response for WTC 1 Case A and WTC 1 Case B, respectively. Each figure consists of six sub-figures. Each sub-figure shows all the core columns and every third perimeter column. A column is represented by a square symbol. If a column is damaged at any location on a floor, it is not included in the corresponding sub-figure. The color of the square symbol is related to the temperature of the column. The temperature value for a column shown in the plot is the maximum temperature of that column and could occur any where between floor 92 through floor 99 . Temperature range has been selected to lie between $0-800{ }^{\circ} \mathrm{C}$. Each sub-figure shows the thermal results at a specific instant in time. Results over a period ranging from $1000 \mathrm{~s}$ to $6000 \mathrm{~s}$ at $1000 \mathrm{~s}$ interval are presented. 
The size of the square symbol representing a perimeter or a core column is proportional to the product of the cross-sectional area of that column and its yield strength. The product of the cross-sectional area and yield strength is a measure of the load carrying capacity of a column. The yield strength is a function of temperature, decreasing with increasing temperature (See Figure 3-2). As the temperature of the column increases or decreases with time, the size of the symbol decreases or increases. Changes in the size of the symbol indicate a change in the load carrying capacity of that column.

The size of the square symbol is related to the column cross-sectional area and since each column has a different cross-sectional area (Appendix B), the size of the square symbols can be different from one column to another, even if all the columns are at room temperature. Thus at a point in time just before the aircraft impact when all the columns are at room temperature, the load carrying capacity of the heavier columns is more than those of light columns. The heavier columns such as the corner core columns are therefore represented with a larger square symbol as compared to a lighter core column located in the center of the core.

The most notable difference in the thermal response of perimeter columns for Case A and Case B was for columns located in the middle of the south face of WTC 1. These perimeter columns show temperatures of approximately $350{ }^{\circ} \mathrm{C}$ for Case A and temperatures of approximately $800{ }^{\circ} \mathrm{C}$ for Case B. Significantly higher temperatures for Case B was due to fireproofing damage on the south face of WTC 1 as predicted by the aircraft impact analysis. Note that at a temperature of $800^{\circ} \mathrm{C}$, the yield strength of the column is a small fraction of its room temperature value. As a result the cross-sectional area of the square symbol representing a column that has reached a temperature of $800^{\circ} \mathrm{C}$ is extremely small.

The thermal response of perimeter columns located on the north face, east face and west face was similar for Case A and Case B. These columns do not heat up significantly because of lack of fireproofing damage. This was also observed in Figure 12-3, where the final thermal state of perimeter columns at $6000 \mathrm{~s}$ after impact has been shown for Case A and Case B.

Core column 501 shows significant heating in Case A and reaches a peak temperature of approximately $700{ }^{\circ} \mathrm{C}$ at $2000 \mathrm{~s}$ after impact. This column subsequently cools down to $400{ }^{\circ} \mathrm{C}$ at $6000 \mathrm{~s}$ after impact. For Case $\mathrm{B}$, core column 501 does not show significant heating and peak temperatures of $200{ }^{\circ} \mathrm{C}$ were predicted. This difference in heating pattern is due to the fireproofing status of the column in the two cases. Column 501 was a very heavy comer column and the thermal response of this column could have a large impact on the structural stability of WTC 1. The thermal response of the other corner columns, 508, 1001 and 1008 was in general very similar for the two cases. Note that structural damage was not predicted for any of the corner columns in Case A or Case B.

Column 502 show's significant heating at 2000 and 3000 s after impact in Case B, but only moderate temperature were attained in Case A. This column had fireproofing damage in both cases, and the differences in heating pattern was due to differences in fire activity in the vicinity of this column in the two cases. The aircraft impact analysis for Case B predicted more structural damage to core column as compared to Case A. Columns 503, 504 and 505 were damaged in Case B, while only core column 504 was damaged in Case A. The thermal resporise of core columns 506 and 507 was similar for Case A and Case B. 
Core columns on the east side of the core (Column 608 and 708) attain very high temperatures for Case B and are relatively cool for Case A. The remaining columns on the east side of the core (Column 808 and 908) have similar thermal response for Case A and Case B.

FSI simulations predict similar temperatures for columns 1002, 1003, 1004, 1005 and 1006 at 1000, 2000 and 3000s after impact for Case A and Casc B. Beyond $3000 \mathrm{~s}$, these columns cool down for Case A, but in Case B, these columns continue to stay hot. This difference in heating pattern is due to differences in fire activity in the vicinity of these columns. Column 1007 remains relative cool during the entire duration of the simulation for Case A. On the other hand column 1007 in Case B reaches very high temperatures of $800{ }^{\circ} \mathrm{C}$, due to fireproofing damage on this column. Differences in the thermal response of the 1000 series columns between Case A and Case B was expected to have a large impact on the corresponding structural analysis and stability of WTC 1 .

Core columns 701,801 and 901 on the west side of the core indicate similar thermal response for the two cases. Column 601 has fireproofing damage for Case A and no fireproofing damage for Case B, which explains the differences in the predicted thermal response.

Table 12-5 and Table 12-6 compare the predicted temperature range for perimeter columns for WTC 1 Case A and Case B. Similar comparison for core columns is shown in Table 12-7 and Table 12-8, and for floor trusses in Table 12-9 and Table 12-10. In each table, the minimum and maximum temperature are noted for floors 93-99 at five different instants in time. These tables clearly illustrate the differences in the thermal response of WTC 1 for Case A and Case B. Floor trusses in WTC 1 were covered with an equivalent fireproofing thickness of 2.2" and the fireproofing in some places was damaged extensively due to the impact of the aircraft. Temperature range of $27-921^{\circ} \mathrm{C}$ was predicted for floor trusses in WTC 1, Case A. Floor trusses on floor 95, 96 and 98 show significantly higher temperature in Case B as compared to Case A. Numerical simulations predict a gradual monotonic increase in maximum temperature on floors 93, 94 and 99 in Case B. On floors 95-98, the maximum temperature is consistently above $700{ }^{\circ} \mathrm{C}$ (temperature at which steel looses most of its yield strength).

Overall, the perimeter and core column temperature depends on several important factors. They include:

1. state of fireproofing,

2. intensity and duration of fires in the vicinity of the column.

3. size and shape of the column.

In addition the thermal state of a column on a given floor can also depend on the structural and fireproofing damage status of the column above or below the floor under consideration, as well as the fire growth and spread pattern on those floors. The global simulation results indicate that the fireproofing thickness and the damage to the fireproofing due to aircraft impact was the single most important parameter that had the largest effect on the predicted thermal response of the structural elements in WTC 1. 


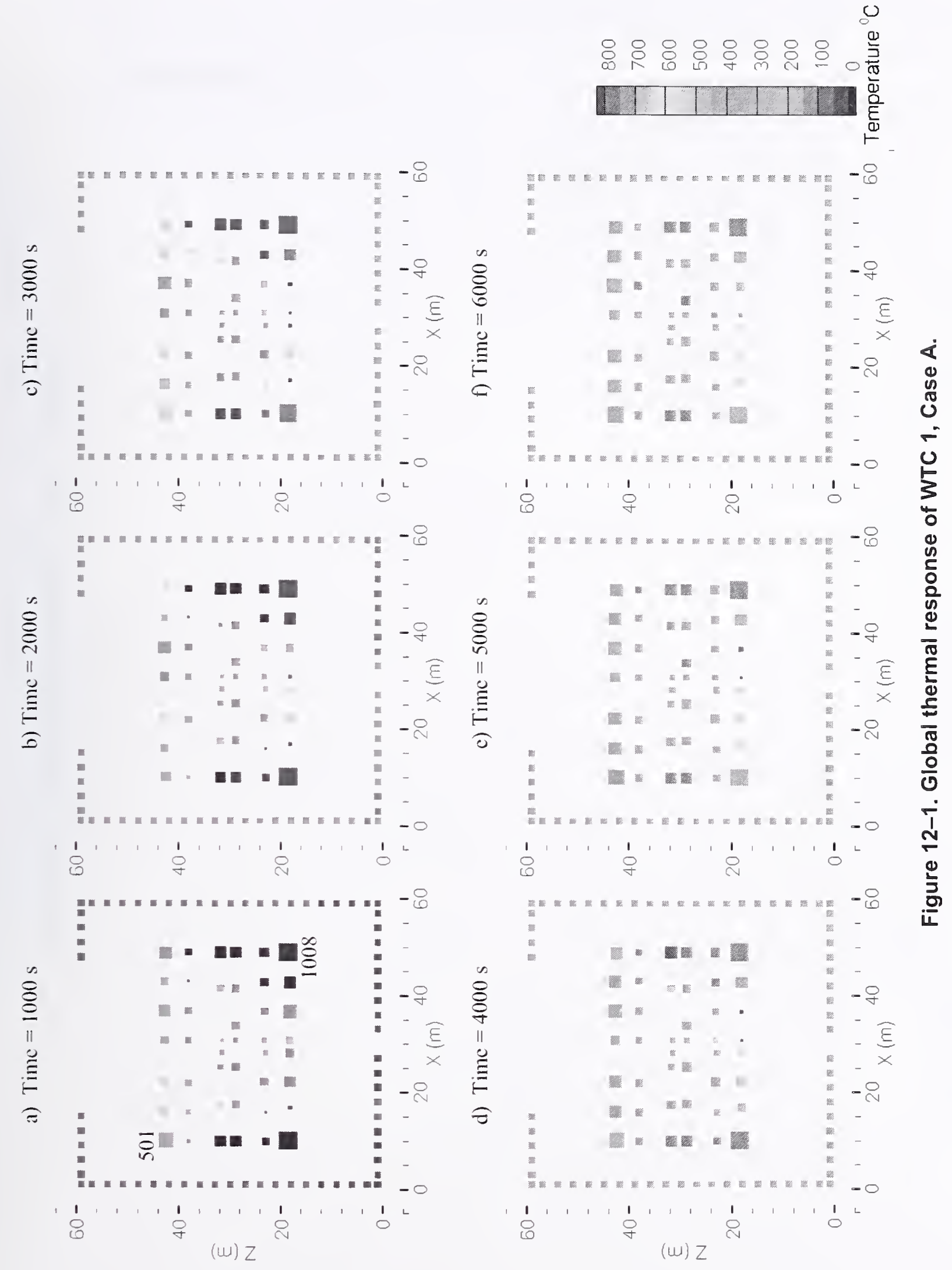



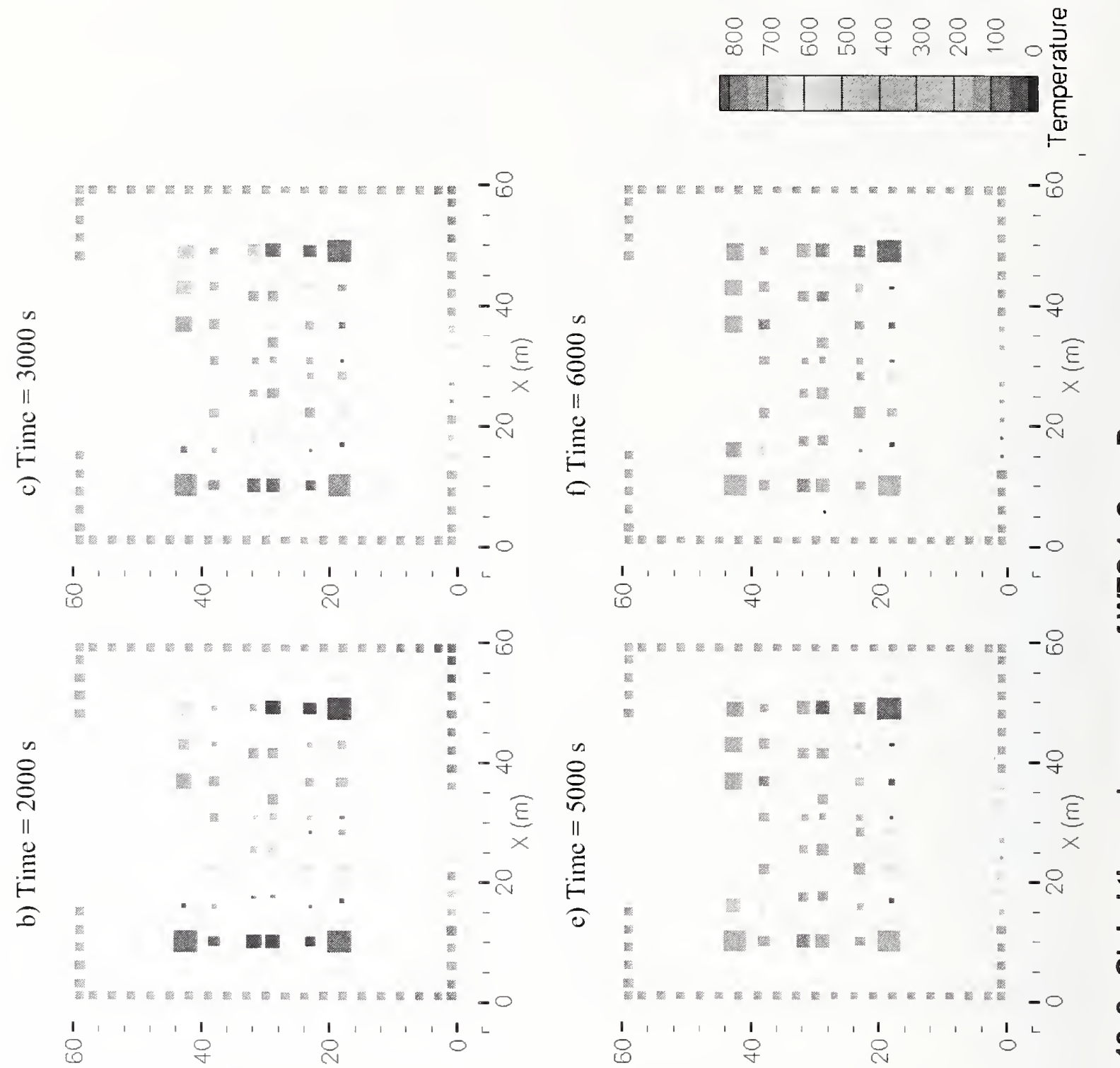
Table 12-5. Temperature range $\left({ }^{\circ} \mathrm{C}\right)$ for perimeter columns on various floors at five instants in time, WTC 1, Case A.

\begin{tabular}{|c|c|c|c|c|c|}
\hline & $20 \mathrm{~min}$ & $40 \mathrm{~min}$ & $60 \mathrm{~min}$ & $80 \mathrm{~min}$ & $100 \mathrm{~min}$ \\
\hline Floor 93 & $25-210$ & $25-278$ & $25-322$ & $30-339$ & $39-352$ \\
\hline Floor 94 & $25-214$ & $25-303$ & $27-346$ & $27-327$ & $28-332$ \\
\hline Floor 95 & $25-210$ & $25-252$ & $27-331$ & $37-362$ & $34-350$ \\
\hline Floor 96 & $25-225$ & $25-301$ & $28-304$ & $34-297$ & $40-454$ \\
\hline Floor 97 & $25-205$ & $25-310$ & $26-322$ & $30-418$ & $35-473$ \\
\hline Floor 98 & $25-241$ & $25-331$ & $28-344$ & $32-352$ & $46-320$ \\
\hline Floor 99 & $25-210$ & $25-305$ & $28-340$ & $36-332$ & $45-316$ \\
\hline
\end{tabular}

Table 12-6. Temperature range $\left({ }^{\circ} \mathrm{C}\right)$ for perimeter columns on various floors at five instants in time, WTC 1, Case B.

\begin{tabular}{|c|c|c|c|c|c|}
\hline & $20 \min$ & $40 \mathrm{~min}$ & $60 \mathrm{~min}$ & $80 \mathrm{~min}$ & $100 \mathrm{~min}$ \\
\hline Floor 93 & $25-213$ & $25-264$ & $25-328$ & $30-337$ & $44-360$ \\
\hline Floor 94 & $25-355$ & $26-292$ & $27-334$ & $27-369$ & $29-448$ \\
\hline Floor 95 & $26-582$ & $25-706$ & $29-758$ & $36-669$ & $46-717$ \\
\hline Floor 96 & $26-464$ & $26-599$ & $28-661$ & $34-656$ & $39-796$ \\
\hline Floor 97 & $25-413$ & $25-430$ & $25-539$ & $26-553$ & $35-786$ \\
\hline Floor 98 & $25-247$ & $25-315$ & $27-352$ & $34-361$ & $45-351$ \\
\hline Floor 99 & $25-179$ & $25-294$ & $28-341$ & $33-317$ & $43-347$ \\
\hline
\end{tabular}


Table 12-7. Temperature range $\left({ }^{\circ} \mathrm{C}\right)$ for core columns on various floors at five instants in time, WTC 1, Case A.

\begin{tabular}{|c|c|c|c|c|c|}
\hline & $20 \mathrm{~min}$ & $40 \mathrm{~min}$ & $60 \mathrm{~min}$ & $80 \mathrm{~min}$ & $100 \mathrm{~min}$ \\
\hline Floor 93 & $27-65$ & $27-98$ & $28-121$ & $28-156$ & $28-198$ \\
\hline Floor 94 & $27-832$ & $27-820$ & $28-788$ & $28-749$ & $28-590$ \\
\hline Floor 95 & $27-565$ & $29-823$ & $31-871$ & $33-822$ & $35-696$ \\
\hline Floor 96 & $27-913$ & $27-888$ & $28-707$ & $28-687$ & $29-748$ \\
\hline Floor 97 & $27-773$ & $30-775$ & $35-713$ & $39-556$ & $46-636$ \\
\hline Floor 98 & $27-49$ & $29-97$ & $32-144$ & $36-203$ & $41-252$ \\
\hline Floor 99 & $27-50$ & $29-81$ & $31-119$ & $33-148$ & $36-175$ \\
\hline
\end{tabular}

Table 12-8. Temperature range $\left({ }^{\circ} \mathrm{C}\right)$ for core columns on various floors at five instants in time, WTC 1, Case B.

\begin{tabular}{|c|c|c|c|c|c|}
\hline & $20 \min$ & $40 \min$ & $60 \min$ & $80 \min$ & $100 \mathrm{~min}$ \\
\hline Floor 93 & $27-63$ & $27-108$ & $27-126$ & $27-150$ & $28-193$ \\
\hline Floor 94 & $27-870$ & $27-738$ & $28-741$ & $29-861$ & $31-904$ \\
\hline Floor 95 & $28-553$ & $31-819$ & $36-822$ & $44-804$ & $52-761$ \\
\hline Floor 96 & $27-896$ & $27-909$ & $28-763$ & $28-745$ & $29-780$ \\
\hline Floor 97 & $27-846$ & $30-938$ & $34-916$ & $39-817$ & $45-901$ \\
\hline Floor 98 & $27-52$ & $29-101$ & $32-156$ & $37-191$ & $41-227$ \\
\hline Floor 99 & $27-49$ & $29-84$ & $31-129$ & $36-161$ & $41-192$ \\
\hline
\end{tabular}


Table 12-9. Temperature range $\left({ }^{\circ} \mathrm{C}\right)$ for floor trusses on various floors at five instants in time, WTC 1, Case A.

\begin{tabular}{|c|c|c|c|c|c|}
\hline & $20 \mathrm{~min}$ & $40 \mathrm{~min}$ & $60 \mathrm{~min}$ & $80 \mathrm{~min}$ & $100 \mathrm{~min}$ \\
\hline Floor 93 & $29-58$ & $35-165$ & $47-283$ & $73-319$ & $92-325$ \\
\hline Floor 94 & $28-61$ & $31-146$ & $37-222$ & $47-328$ & $60-408$ \\
\hline Floor 95 & $27-882$ & $30-653$ & $33-494$ & $40-440$ & $48-389$ \\
\hline Floor 96 & $28-875$ & $36-782$ & $46-734$ & $61-516$ & $79-427$ \\
\hline Floor 97 & $28-921$ & $33-887$ & $40-873$ & $51-897$ & $70-897$ \\
\hline Floor 98 & $27-919$ & $29-907$ & $33-706$ & $39-468$ & $45-469$ \\
\hline Floor 99 & $28-51$ & $32-129$ & $41-265$ & $58-406$ & $79-449$ \\
\hline
\end{tabular}

Table 12-10. Temperature range $\left({ }^{\circ} \mathrm{C}\right)$ for floor trusses on various floors at five instants in time, WTC 1, Case B.

\begin{tabular}{|c|c|c|c|c|c|}
\hline & $20 \mathrm{~min}$ & $40 \mathrm{~min}$ & $60 \mathrm{~min}$ & $80 \mathrm{~min}$ & $100 \mathrm{~min}$ \\
\hline Floor 93 & $27-56$ & $27-142$ & $28-263$ & $29-349$ & $30-386$ \\
\hline Floor 94 & $28-62$ & $31-154$ & $37-212$ & $44-346$ & $50-411$ \\
\hline Floor 95 & $27-798$ & $30-760$ & $34-664$ & $41-881$ & $48-861$ \\
\hline Floor 96 & $23-911$ & $36-883$ & $48-831$ & $63-839$ & $82-902$ \\
\hline Floor 97 & $27-886$ & $32-888$ & $40-852$ & $51-777$ & $66-927$ \\
\hline Floor 98 & $27-913$ & $29-914$ & $33-896$ & $41-876$ & $51-926$ \\
\hline Floor 99 & $28-54$ & $32-143$ & $41-275$ & $57-420$ & $78-461$ \\
\hline
\end{tabular}



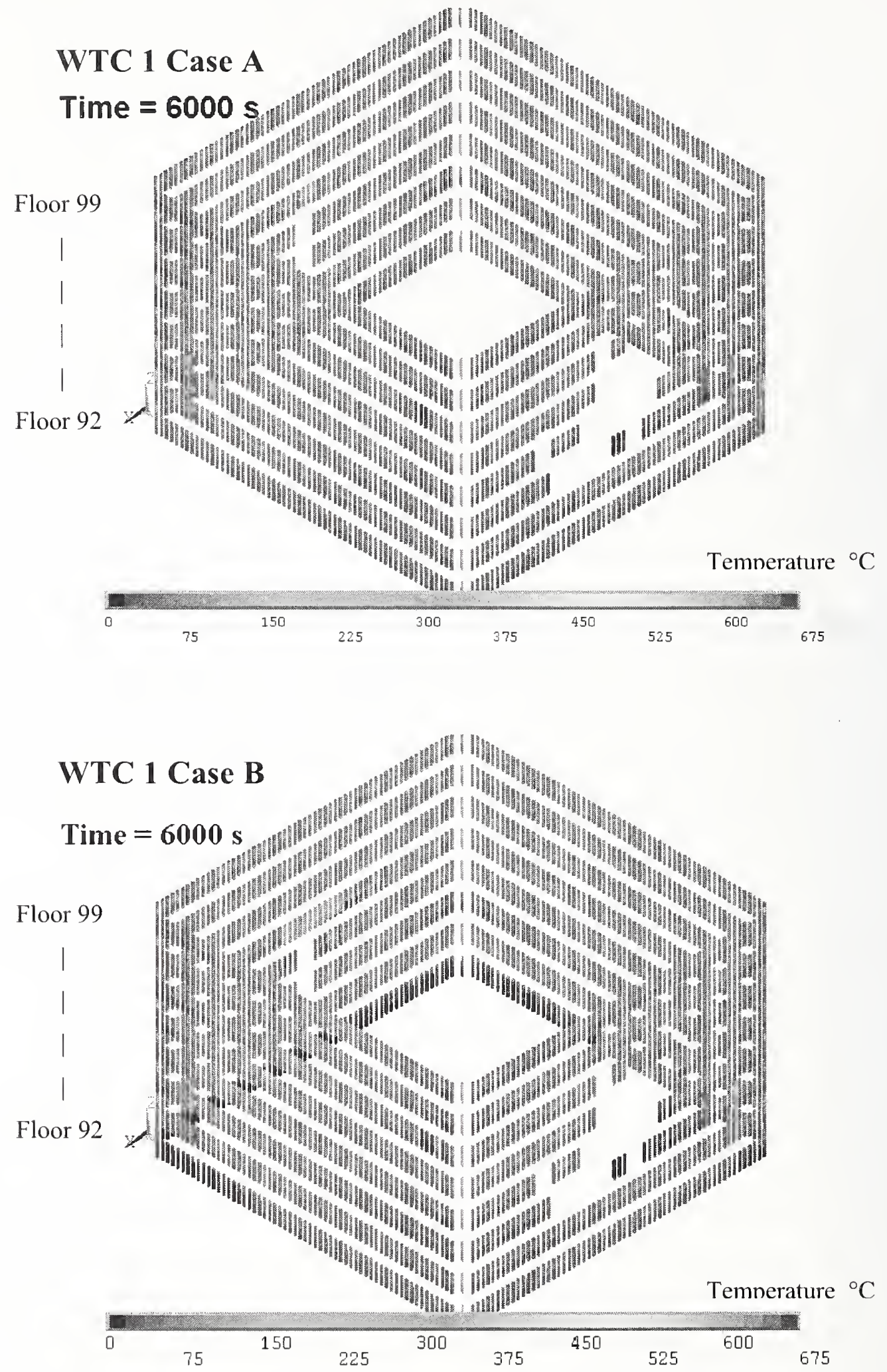

Figure 12-3. Comparison of the final thermal state of perimeter columns for WTC 1, Case A, with WTC 1, Case B. 


\subsection{GLOBAL THERMAL RESPONSE OF WTC 2 : COMPARISON OF CASE C AND CASE D}

Global thermal response of WTC 2 Case C and Case D were discussed on a floor by floor basis in Chapter 10 and Chapter 11. For each case, the time evolving thermal state of the various structural elements such as floor trusses, core beams, concrete slabs perimeter and core columns was presented in a visual format. In this section, a comparison is made between the global thermal results of WTC 2 Case C and WTC 2 Case D.

Figure 12-4 and Figure 12-5 summarize the thermal response for WTC 2 Case C and WTC 2 Case D, respectively. These figures are similar to Figure 12-1 and Figure 12-2 discussed earlier for WTC 1. Each figure consists of six sub-figures. Each sub-figure shows all the core columns and every third perimeter column. A column is represented by a square symbol. If a column is damaged at any location on a floor, it is not included in the corresponding sub-figure. The color of the square symbol is related to the temperature of the column. The temperature value for a column shown in the plot is the maximum temperature of that column and could occur any where between floor 78 through floor 83 . Temperature range has been selected to lie between $0-800^{\circ} \mathrm{C}$. Each sub-figure shows the thermal results at a specific instant in time. Results over a period ranging from $600 \mathrm{~s}$ to $3600 \mathrm{~s}$ at $600 \mathrm{~s}$ interval are presented.

The size of the square symbol representing a perimeter or a core column is proportional to the product of the cross-sectional area of that column and its yield strength. The product of the cross-sectional area and yield strength is a measure of the load carrying capacity of a column. The yield strength is a function of temperature, decreasing with increasing temperature (See Figure 3-2). As the temperature of the column increases or decreases with time, the size of the symbol decreases or increases. Changes in the size of the symbol indicate a change in the load carrying capacity of that column.

The size of the square symbol is related to the column cross-sectional area and since each column has a different cross-sectional area (Appendix B), the size of the square symbols can be different from one column to another, even if all the columns are at room temperature. Thus at a point in time just before the aircraft impact when all the columns are at room temperature, the load carrying capacity of the heavier columns is more than those of light columns. The heavier columns such as the corner core columns are therefore represented with a larger square symbol as compared to a lighter core column located in the center of the core.

Table 12-11 and Table 12-12 compare the predicted temperature range for perimeter columns for WTC 2 Case C and Case D. Similar comparison for core columns is shown in Table 12-13 and Table 12-14 and for floor trusses in Table 12-15 and Table 12-16. In each table, the minimum and maximum temperature are noted for floors 79-83 at five different instants in time. These tables clearly illustrate the differences in the thermal response of WTC 2 for Case C and Case D.

The thermal response of perimeter columns located on the east face of WTC 2 and in the north-east corner is quite different in Case C as compared to Case D. For WTC 2 Case C, perimeter columns in the northeast corner heat up rapidly and reach a temperature of approximately $800^{\circ} \mathrm{C}$ at $1200 \mathrm{~s}$ after impact. These columns stay at this high temperature for the duration of the simulation. Approximately half of the perimeter columns on the east wall reach a peak temperature value of $800{ }^{\circ} \mathrm{C}$. These columns have their fireproofing damaged due to the impact of the aircraft. The remaining columns on the east face reach a peak temperature of approximately $350-400{ }^{\circ} \mathrm{C}$. 
On the other hand, perimeter columns on the entire east wall of WTC 2 Case D, have their fireproofing damaged and as a result quickly heat up to temperatures of the order of $800{ }^{\circ} \mathrm{C}$ at $1,800 \mathrm{~s}$ and $2,400 \mathrm{~s}$ after impact of the aircraft. Beyond 2,400 s, numerical simulations predict gradual cooling of these columns to the $400-500{ }^{\circ} \mathrm{C}$ range at $3600 \mathrm{~s}$ after impact. Similar cooling is predicted for perimeter columns in the north-east corner for WTC 2 Case D. The final thermal state of perimeter columns on floor 78-83 are compared for WTC 2 Case C and Case D in Figure 12-6.

Structural damage to core columns is significantly more in Case D as compared to Case C. Both Case C and Casc D predict structural damage to column 1001 and to other core columns in the south-east corner. The thermal response of 500,600, 700, 800 and 900 series core columns is similar for Case C and Case D. Core columns on the west side of the core stay relatively cool due to lack of fireproofing damage on these columns. Some differences in heating rates are observed for core columns 1005, 1006, and 1007. Core column 1008 is a relatively heavy column and its thermal response for Case $\mathrm{C}$ is similar to that for Case D. Although there is intense fire activity in the vicinity of column 1008, the column does not heat up since its fireproofing is intact and since it is a relatively heavy column.

As for WTC 1, the perimeter and core column temperature for WTC 2 depends on the state of fireproofing, intensity and duration of fires in the vicinity of the column and the size and shape of the column. In addition the thermal state of a column on a given floor can also depend on the structural and fireproofing damage status of the column above or below the floor under consideration, as well as the fire growth and spread pattern on those floors. The WTC 2 global simulation results indicate that the damage to the fireproofing due to aircraft impact was the single most important parameter that had the largest effect on the predicted thermal response of the structural elements. 


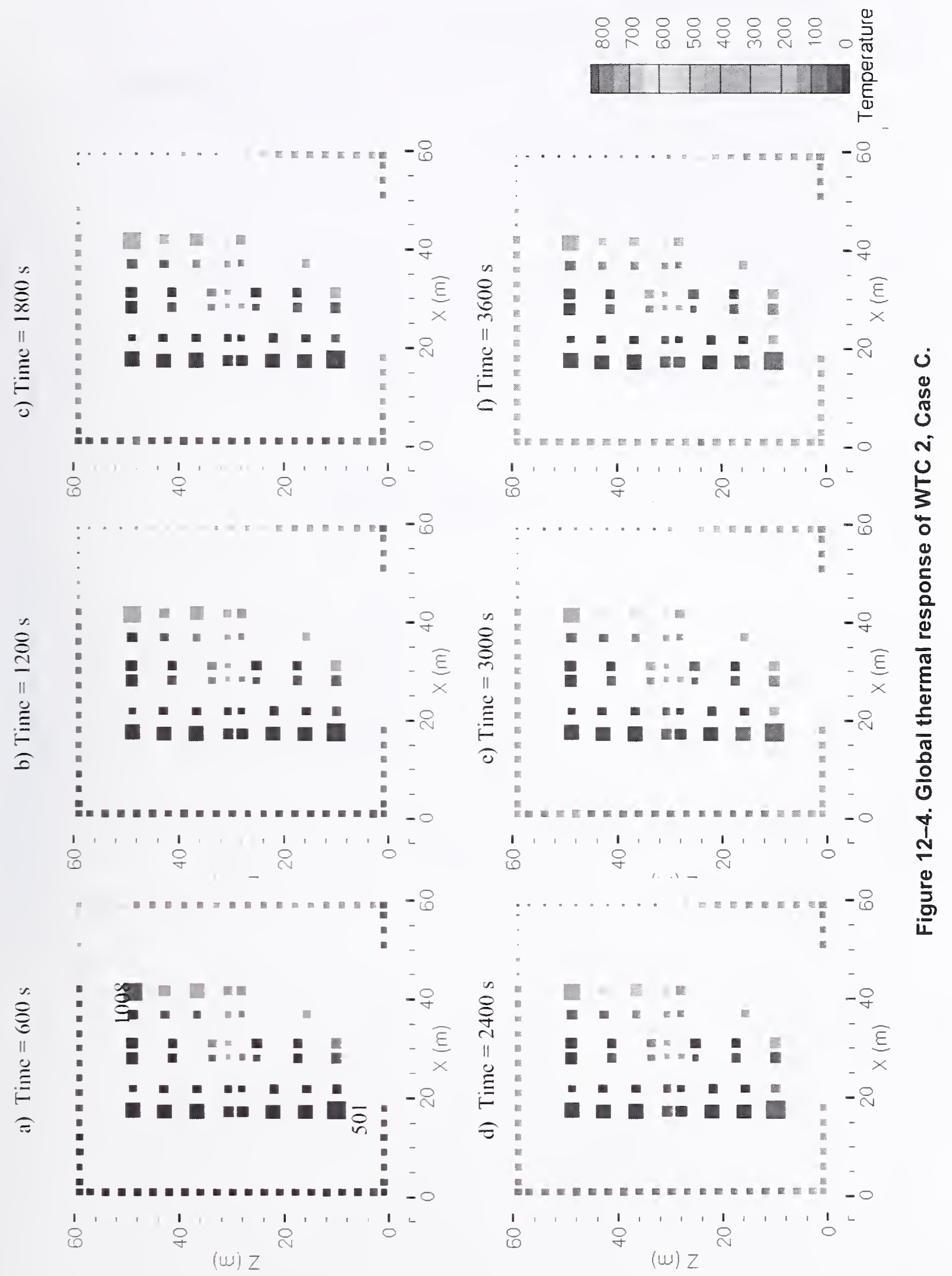




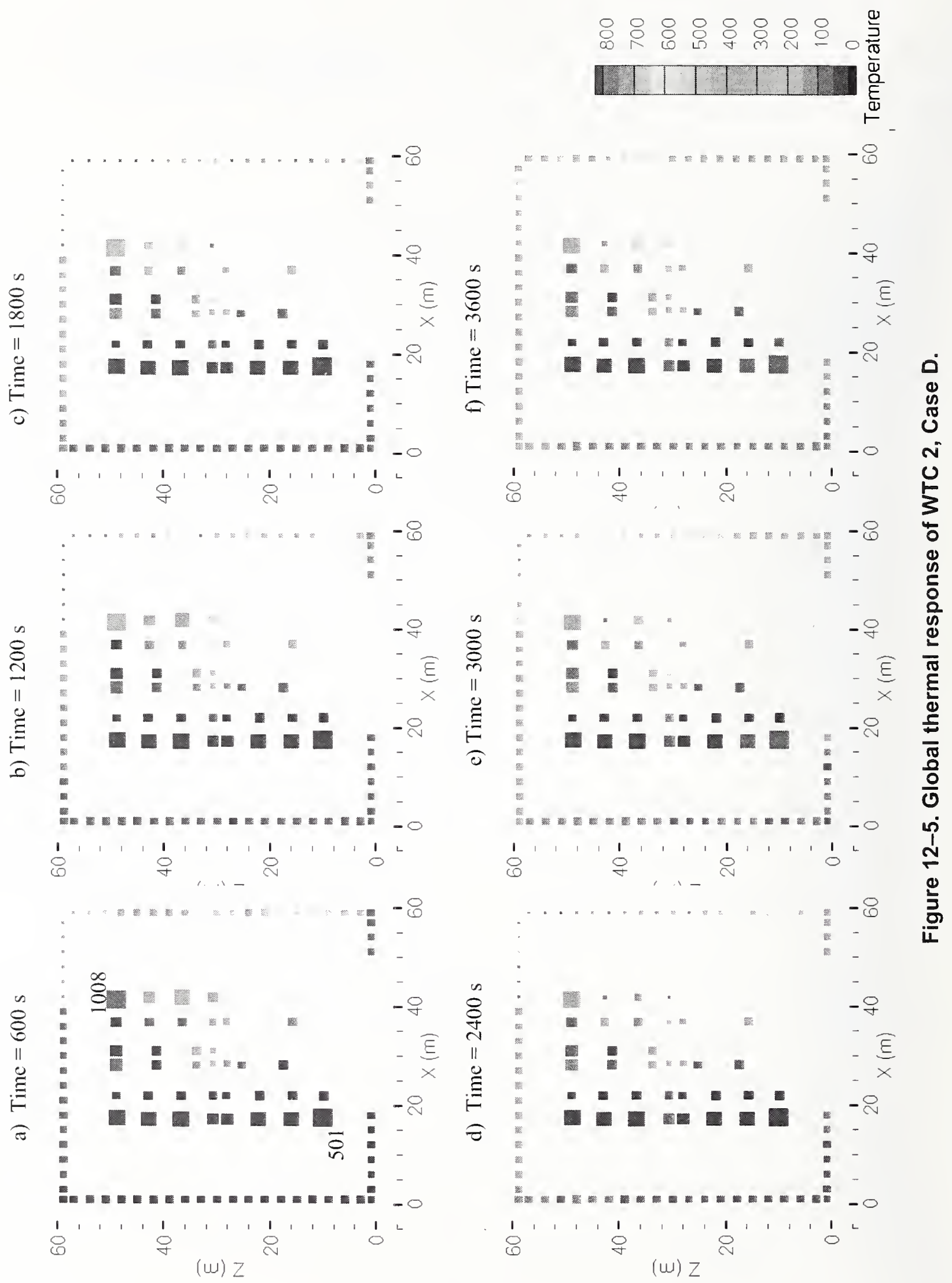


Table 12-11. Temperature range $\left({ }^{\circ} \mathrm{C}\right)$ for perimeter columns on various floors at six instants in time, WTC 2, Case C.

\begin{tabular}{|l|c|c|c|c|c|c|}
\hline & $10 \mathrm{~min}$ & $20 \mathrm{~min}$ & $30 \mathrm{~min}$ & $40 \mathrm{~min}$ & $50 \mathrm{~min}$ & $60 \mathrm{~min}$ \\
\hline Floor 78 & $27-143$ & $27-146$ & $27-173$ & $27-198$ & $27-206$ & $27-203$ \\
\hline Floor 79 & $27-143$ & $27-189$ & $27-229$ & $27-262$ & $27-266$ & $27-264$ \\
\hline Floor 80 & $27-566$ & $27-585$ & $27-514$ & $27-523$ & $27-505$ & $27-505$ \\
\hline Floor 81 & $27-684$ & $27-809$ & $27-832$ & $27-846$ & $27-855$ & $27-861$ \\
\hline Floor 82 & $25-663$ & $25-796$ & $25-816$ & $25-828$ & $25-836$ & $25-841$ \\
\hline Floor 83 & $27-435$ & $27-702$ & $27-778$ & $27-791$ & $27-801$ & $27-807$ \\
\hline
\end{tabular}

Table 12-12. Temperature range $\left({ }^{\circ} \mathrm{C}\right)$ for perimeter columns on various floors at six instants in time, WTC 2, Case D.

\begin{tabular}{|l|c|c|c|c|c|c|}
\hline & $10 \mathrm{~min}$ & $20 \mathrm{~min}$ & $30 \mathrm{~min}$ & $40 \mathrm{~min}$ & $50 \mathrm{~min}$ & $60 \mathrm{~min}$ \\
\hline Floor 78 & $27-115$ & $27-165$ & $27-217$ & $27-243$ & $27-227$ & $27-242$ \\
\hline Floor 79 & $27-117$ & $27-211$ & $27-270$ & $27-295$ & $27-305$ & $27-300$ \\
\hline Floor 80 & $27-325$ & $27-393$ & $27-401$ & $27-431$ & $27-394$ & $27-300$ \\
\hline Floor 81 & $27-750$ & $27-813$ & $27-831$ & $27-845$ & $27-740$ & $27-638$ \\
\hline Floor 82 & $27-720$ & $27-804$ & $27-819$ & $27-830$ & $27-782$ & $27-673$ \\
\hline Floor 83 & $27-696$ & $27-796$ & $27-810$ & $27-817$ & $27-771$ & $27-669$ \\
\hline
\end{tabular}


Table 12-13. Temperature range $\left({ }^{\circ} \mathrm{C}\right)$ for core columns on various floors at six instants in time, WTC 2, Case C.

\begin{tabular}{|c|c|c|c|c|c|c|}
\hline & $10 \mathrm{~min}$ & $20 \mathrm{~min}$ & $30 \mathrm{~min}$ & $40 \mathrm{~min}$ & $50 \mathrm{~min}$ & $60 \mathrm{~min}$ \\
\hline Floor 78 & $27-282$ & $27-426$ & $27-453$ & $27-473$ & $27-482$ & $27-484$ \\
\hline Floor 79 & $27-329$ & $27-454$ & $27-472$ & $27-488$ & $28-496$ & $28-497$ \\
\hline Floor 80 & $25-267$ & $27-325$ & $27-322$ & $27-313$ & $27-307$ & $28-303$ \\
\hline Floor 81 & $27-317$ & $27-411$ & $27-464$ & $27-516$ & $27-563$ & $27-603$ \\
\hline Floor 82 & $27-256$ & $27-493$ & $27-569$ & $27-582$ & $27-638$ & $27-687$ \\
\hline Floor 83 & $27-31$ & $27-49$ & $27-70$ & $27-88$ & $27-103$ & $27-122$ \\
\hline
\end{tabular}

Table 12-14. Temperature range $\left({ }^{\circ} \mathrm{C}\right)$ for core columns on various floors at six instants in time, WTC 2, Case D.

\begin{tabular}{|c|c|c|c|c|c|c|}
\hline & $10 \mathrm{~min}$ & $20 \mathrm{~min}$ & $30 \mathrm{~min}$ & $40 \mathrm{~min}$ & $50 \mathrm{~min}$ & $60 \mathrm{~min}$ \\
\hline Floor 78 & $27-288$ & $27-534$ & $27-574$ & $27-555$ & $27-511$ & $27-482$ \\
\hline Floor 79 & $27-318$ & $27-552$ & $27-586$ & $27-557$ & $27-604$ & $27-567$ \\
\hline Floor 80 & $27-299$ & $27-444$ & $27-625$ & $27-712$ & $27-726$ & $27-690$ \\
\hline Floor 81 & $27-356$ & $27-576$ & $27-708$ & $27-791$ & $27-767$ & $27-703$ \\
\hline Floor 82 & $27-319$ & $27-590$ & $27-766$ & $27-817$ & $27-726$ & $27-666$ \\
\hline Floor 83 & $27-32$ & $27-49$ & $27-72$ & $27-98$ & $27-125$ & $27-146$ \\
\hline
\end{tabular}


Table 12-15. Temperature range $\left({ }^{\circ} \mathrm{C}\right)$ for floor trusses on various floors at six instants in time, WTC 2, Case C.

\begin{tabular}{|l|c|c|c|c|c|c|}
\hline & $10 \mathrm{~min}$ & $20 \mathrm{~min}$ & $30 \mathrm{~min}$ & $40 \mathrm{~min}$ & $50 \mathrm{~min}$ & $60 \mathrm{~min}$ \\
\hline Floor 79 & $27-385$ & $28-194$ & $28-184$ & $29-173$ & $29-163$ & $30-154$ \\
\hline Floor 80 & $28-825$ & $29-790$ & $30-620$ & $31-583$ & $33-580$ & $34-597$ \\
\hline Floor 81 & $28-787$ & $29-694$ & $30-530$ & $30-559$ & $31-580$ & $31-603$ \\
\hline Floor 82 & $30-834$ & $35-910$ & $42-898$ & $48-900$ & $53-913$ & $58-911$ \\
\hline Floor 83 & $30-764$ & $37-891$ & $43-905$ & $50-911$ & $58-912$ & $65-914$ \\
\hline
\end{tabular}

Table 12-16. Temperature range $\left({ }^{\circ} \mathrm{C}\right)$ for floor trusses on various floors at six instants in time, WTC 2, Case D.

\begin{tabular}{|c|c|c|c|c|c|c|}
\hline & $10 \mathrm{~min}$ & $20 \mathrm{~min}$ & $30 \mathrm{~min}$ & $40 \mathrm{~min}$ & $50 \mathrm{~min}$ & $60 \mathrm{~min}$ \\
\hline Floor 79 & $28-348$ & $28-432$ & $29-549$ & $30-610$ & $30-606$ & $31-551$ \\
\hline Floor 80 & $28-821$ & $28-859$ & $30-860$ & $31-647$ & $32-606$ & $34-636$ \\
\hline Floor 81 & $28-654$ & $28-656$ & $29-763$ & $29-778$ & $30-860$ & $32-856$ \\
\hline Floor 82 & $28-865$ & $30-916$ & $33-921$ & $37-917$ & $40-789$ & $46-852$ \\
\hline Floor 83 & $29-877$ & $33-910$ & $41-917$ & $46-913$ & $52-899$ & $58-820$ \\
\hline
\end{tabular}



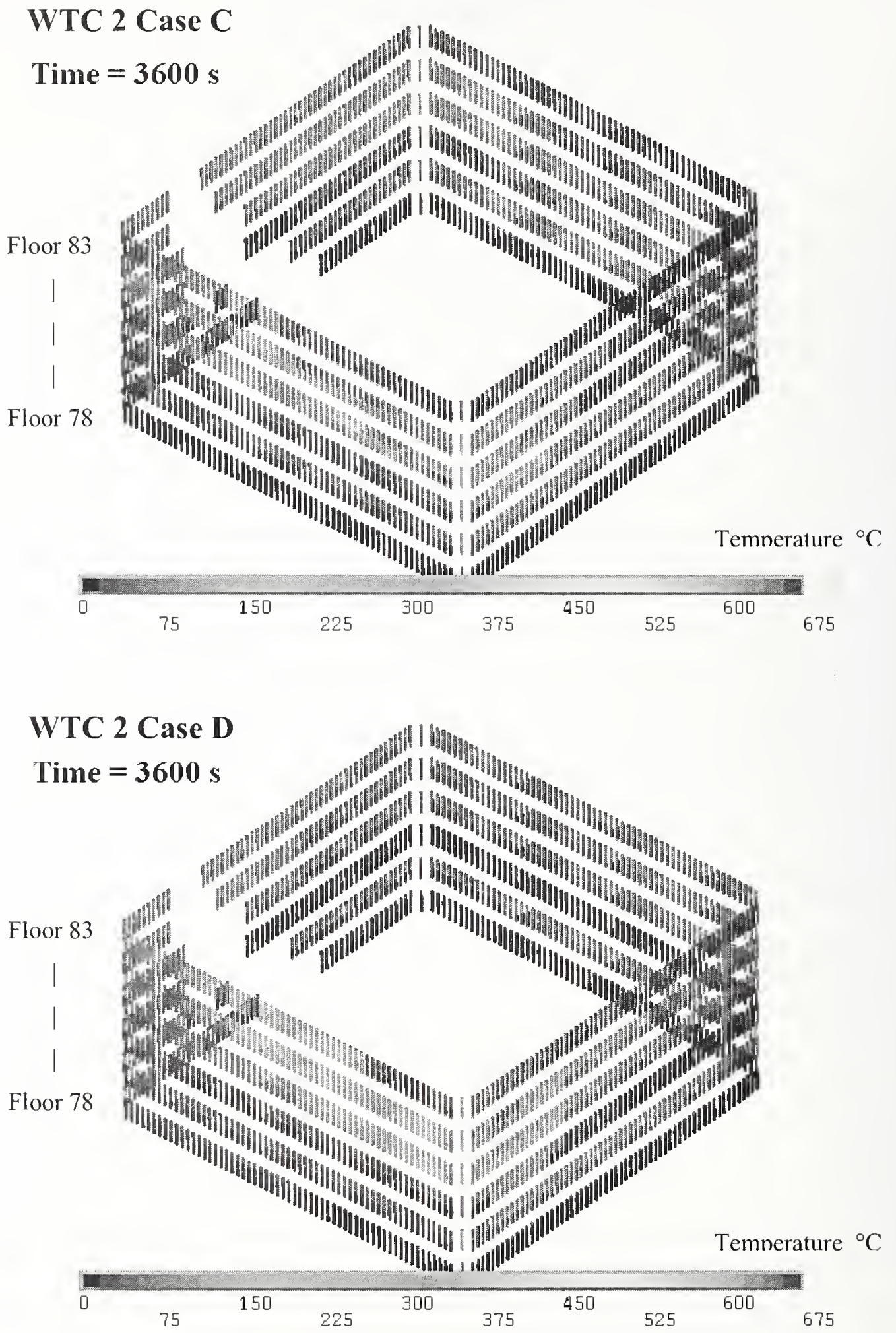

Figure 12-6. Comparison of the final thermal state of perimeter columns for WTC 2, Case C with WTC 2, Case D. 


\section{Chapter 13 \\ REFERENCES}

ANSYS, Inc., ANSYS Release 8.0 Documentation, 2003.

Abboud. N., Levy, M., Tennant, D., Mould, J., Levine, H., King, S., Ekwueme, C., Jain, A. and Hart, G., "Anatomy of the World Trade Center Collapse: A Structural Engineering Investigation," Designing Structures for Fire, Society of Fire Protection Engineers and Structural Engineering Institute, Sept. 30-Oct. 1, 2003, Baltimore, MD.

Abramowitz, A. and Stegun, I.A., Handbook of Mathematical Functions with formulas, Graphs, and Mathematical Tables, National Bureau of Standards, AMS 55, pp. 228-230, (1964).

Abramowitz, A. and Stegun, I.A., Handbook of Mathematical Functions with formulas, Graphs, and Mathematical Tables, National Bureau of Standards, AMS 55, pp. 482-483, (1964).

Ahmed, G. N., and Hurst, J. P., Modeling the thermal behavior of concrete slabs subjected to the ASTM E 119 Standard Fire condition, Journal of Fire Protection Engineering, 7, 4,125-132, 1995.

Bailey, C.G. and Moore, D.B., "The Structural Behavior of Steel Frames with Composite Floor slabs Subject to Fire: Part 1: Theory, and Part 2: Design," The Structural Engineer, London, vol. 78, no. 11, 6 June 2000, pp. 19-27 and 28-33.

Buchanan, A.H., "Structiral Design for Fire Safety," John Wiley, London, 2001.

Chang, J., Buchanan, A. H. and Moss, P. J., "Effect of Insulation on the Fire Behavior of Steel Floor Trusses," Fire and Materials, 2005; 29:181-194.

Choi, S.K., Burgess, I.W. and Plank, R.J., "The Behavior of Lightweight Composite Floor Trusses in Fire," Designing Structures for Fire, Society of Fire Protection Engineers and Structural Engineering Institute, Sept. 30-Oct. 1, 2003, Baltimore, MD.

FEMA 403, "World Trade Center Building Performance Study: Data Collection, Preliminary Observations, and Recommendations," McAllister, T. ed., Federal Emergency Management Agency, Washington, D.C., May 2002.

Franssen, J. M., "A Comparison Between Five Structural Fire Codes Applied to Steel Elements," IAFSS, Fire Safety Science, Proceedings of the Fourth International Symposium, 1995.

Harmathy T.Z., Properties of Building Materials at Elevated Temperatures, paper NRCC-20956 (DBR-P1080), Division of Building Research, National Research Council, Canada, (1080), pp. 72, March 1983.

Hori, A., "Analytical Method for High Temperature Collapse of a 3-D Steel Frame," Fire Science and Technology, vol. 23, no. 3, 2004, pp. 208-221. 
Lamont, S., Usmani, A. S., and Drysdale, D., Heat Transfer Analysis of the composite slab in the Cardington frame fire tests, Fire Safety Journal, 36 (8):815-839, 2001.

Liew, J.Y.R. and H. Chen "Explosion and Fire Analysis of Steel frames Using Fiber Element Approach," ASCE Journal of Structural Engineering, vol. 130, no. 7, July 2004, pp. 991-1000.

McGrattan, K. B., Baum, H.R., Rehm, R.G., Hamins, A., Forney, G.P., Floyd, J.E., Hostikka, S., and Prasad, K., "Fire Dynamics Simulator (Version 3) - Technical Reference Guide", Nat. Inst. Stds. And Tech. Report NISTIR 6783, 2003, Ed., Nov 2002.

Phan, Long T., 2003, "Properties of Concrete at Elcvated Temperatures," NIST Reference Document, Building and Fire Research Laboratory.

Prasad, K. and Baum H., Coupled Fire Dynamics and Thermal Response of Complex Building Structures, Proc. $30^{\text {th }}$ Symposium International on Combustion, 30 (2005) 2255-2262.

Quintiere, J. G., J. Fire Protection Engineering, Vol. 1, pp. 99-119, (1989).

Quintiere, J.G., Di Marzo, M. and Becker, R., "A Suggested Cause of the Fire-induccd Collapse of the World Trade Towers, “Fire Safety Journal, vol. 37, no. 7, Oct. 2002, pp. 707-716.

Rahman, A.A., Haiwileh, R.A. and Mahamid, M., "Computational Model for Steel Connections in Fire Loading," Designing Structures for Fire, Society of Fire Protection Engineers and Structural Engineering Institute, Sept. 30-Oct. 1, 2003, Baltimore, MD.

Rehm, R.G., Pitts, W. M., Baum, H.R., Evans, D.D., Prasad, K., McGrattan, K.B., and Forney, G. P., Initial Model for Fircs in the World Trade Center Tower, NISTIR 6879, 2005.

Siegel, R. and Howell, J. R., Thermal Radiation Heat Transfer, Third Ed., Hemisphcre, Washington, D.C.,pp. 699-722, (1992).

Sterner, E. and Wickstrom, U., TASEF - Temperature Analysis of Structures Exposed to Fire, SP Report 1990:05, Swedish National Testing and Research Institute, Boras, 1990.

Tien, C.L., Lee, K.Y., and Stretton, A. J., "Radiation Heat Transfer", The SFPE Handbook of Fire Protection Engineering, Third, Ed., Nat. Fire Prot. Ass'n, Quincy, MA pp. 1-73 - 1-90, (2002).

Usmani, A. S., Rotter, J. M., Lamont, S., Sanad, A. M. and Gillie, M., Fundamental principles of structural behavior under thermal effects, Fire Safety Journal, 36 (8): 721-744, 2001.

Usmani, A.S., Chung, Y.C. And Torero, J.L., "How did the WTC Towers Collapse: A New Theory," Fire Safety Journal, vol. 38, no. 6, Oct. 2003, pp. 501-533.

Zhang, W., Carpenter, D.J., Roby, R.J., Viehe, D. and Hamer, A., "The Prediction of Thermal Loading for Structural Analysis under Fire Exposure," Designing Structures for Fire, Society of Fire Protection Engineers and Structural Engineering Institute, Sept. 30-Oct. 1, 2003, Baltimore, MD. 


\section{Appendix A \\ THERMO-PHYSICAL PROPERTIES}

This appendix presents the thermo-physical properties of various materials used in the World Trade Center Investigation. Thermo-physical properties include

1. Specific Heat

2. Density

3. Thermal Conductivity

The materials for which thermo-physical properties were needed include

1. A36 steel

2. A 242 steel

3. BLAZE-SHIELD DC/F

4. Monokote

5. Lightweight Concrete

6. Non material. This material was used to incorporate fireproofing damage. This material provides very little resistance to heat flow.

Each thermo-physical property is in general a function of temperature. Plots are presented to indicate this variation of the property with temperature. The data were determined as part of the investigation and is reported in companion reports (NIST NCSTAR 1-3, NIST NCSTAR 1-6A, Phan 2003). 


\section{SPECIFIC HEAT}
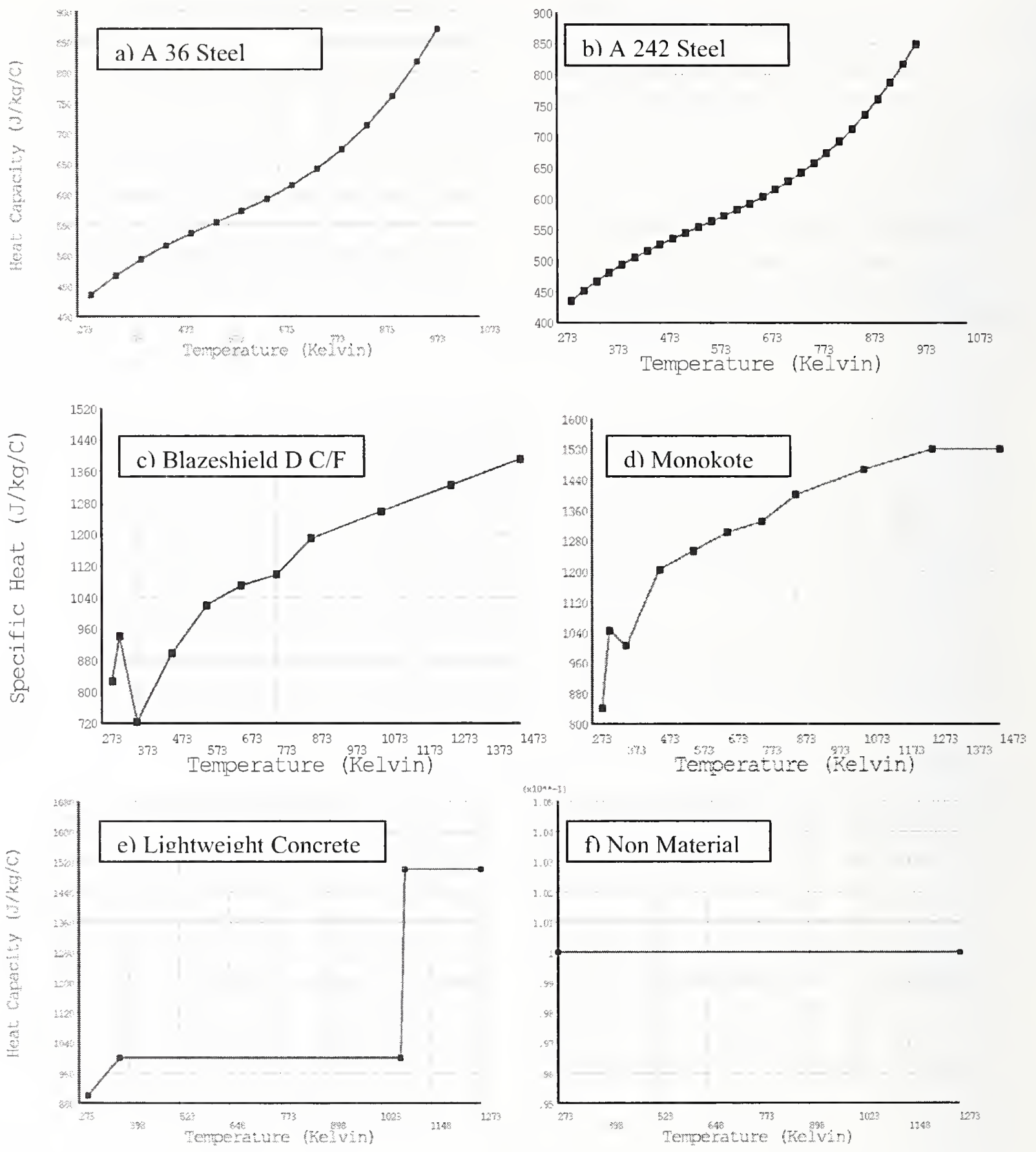

Figure A-1. Specific heats of various materials used in the World Trade Center Investigation plotted as a function of temperature. 


\section{DENSITY}
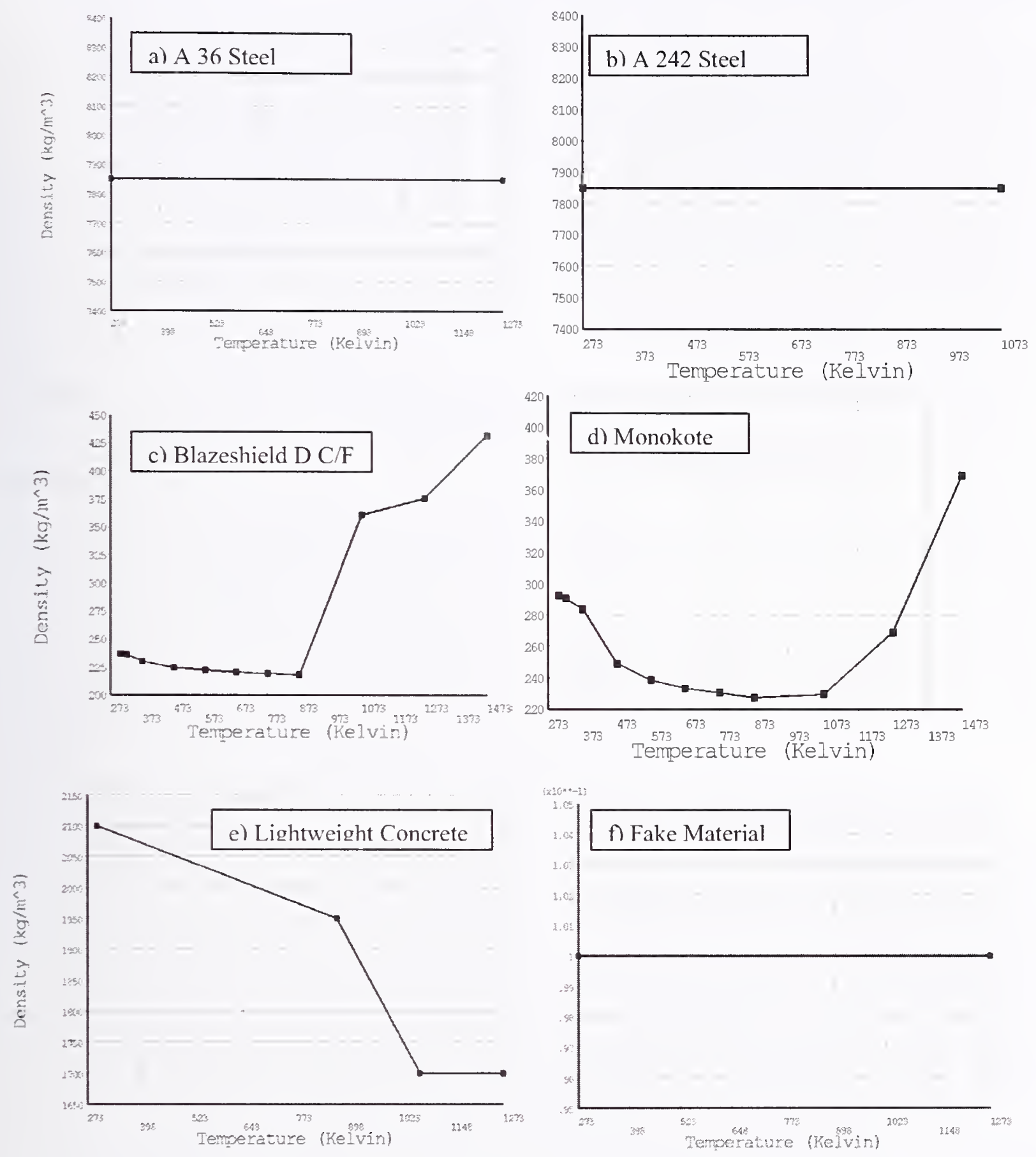

Figure A-2. Density of various materials used in the World Trade Center Investigation, plotted as a function of temperature. 


\section{THERMAL CONDUCTIVITY}
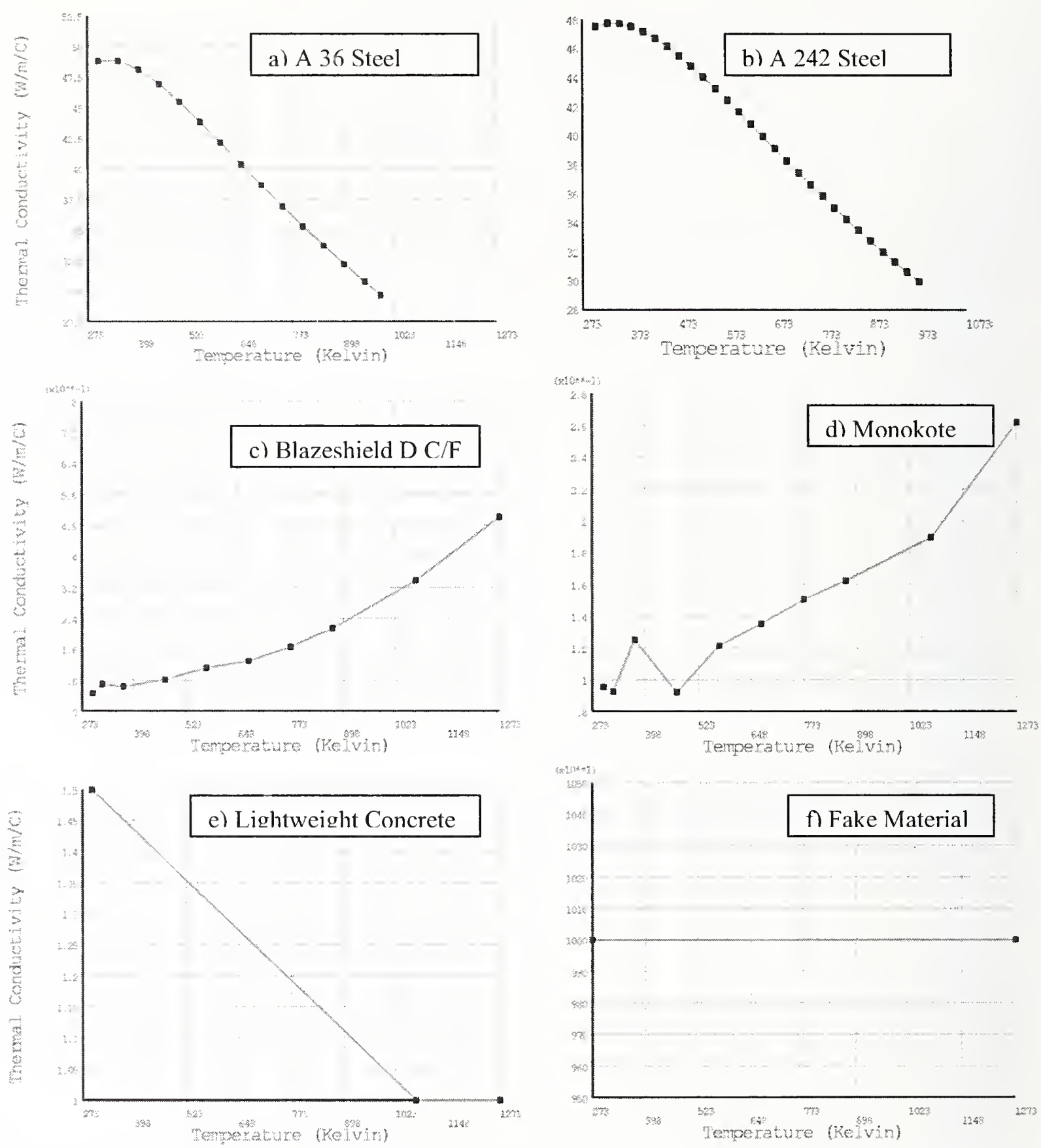

Figure A-3. Thermal conductivity of various materials used in the World Trade Center Investigation plotted as a function of temperature. 


\section{ENTHALPY}
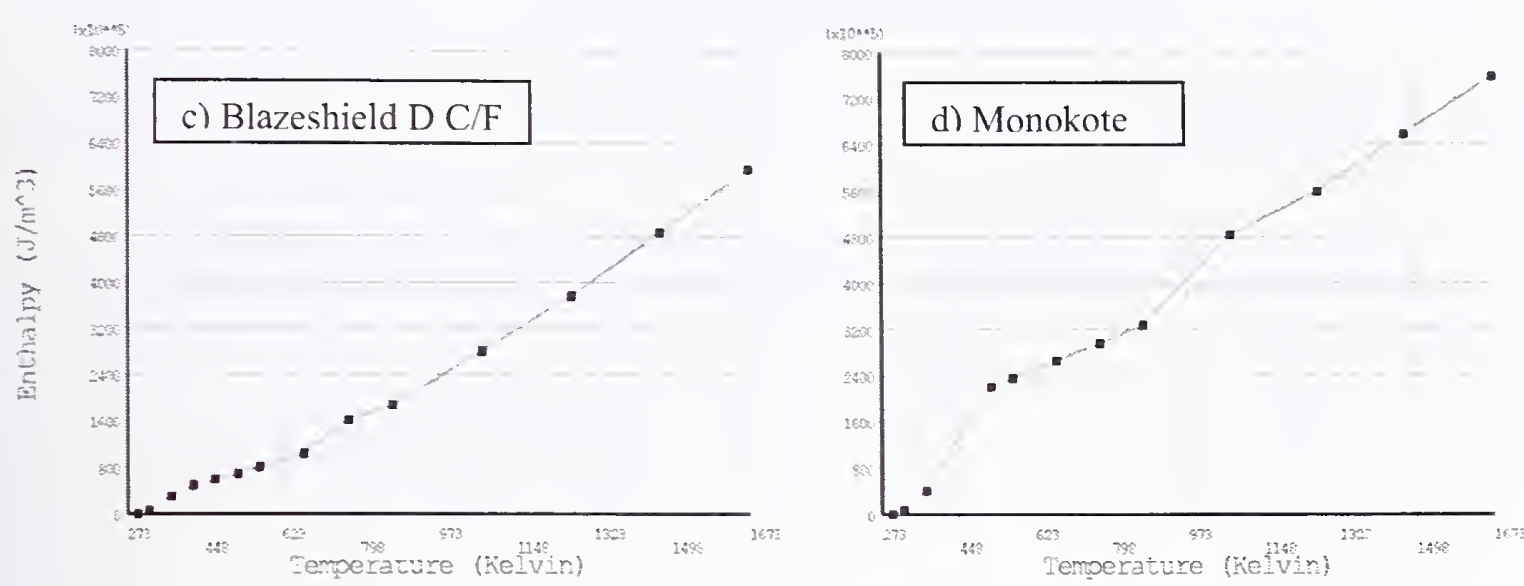

Figure A-4. Enthalpy of fireproofing used in the World Trade Center Investigation plotted as a function of temperature.

\section{REFERENCES}

Phan, Long T., 2003, "Properties of Concrete at Elevated Temperatures," NIST Reference Document, Building and Fire Research Laboratory. 
This page intentionally left blank. 


\section{Appendix B \\ Column Schedule}

Table B-1. Exterior Column Type Schedule for WTC 1, Floor 92-99. ${ }^{\text {a }}$

\begin{tabular}{|c|c|c|c|c|c|c|c|c|}
\hline Column \# & Floor 92 & Floor 93 & Floor 94 & Floor 95 & Floor 96 & Floor 97 & Floor 98 & Floor 99 \\
\hline 101 & 120 & 120 & 120 & 120 & 120 & 120 & 120 & 120 \\
\hline 103 & 120 & 120 & 120 & 120 & 120 & 120 & 120 & 120 \\
\hline 106 & 123 & 122 & 122 & 122 & 121 & 121 & 121 & 120 \\
\hline 109 & 123 & 123 & 123 & 122 & 122 & 122 & 121 & 121 \\
\hline 112 & 124 & 124 & 123 & 123 & 23 & 121 & 121 & 121 \\
\hline 115 & 125 & 123 & 123 & 123 & 122 & 122 & 122 & 120 \\
\hline 118 & 124 & 124 & 124 & 122 & 122 & 122 & 121 & 121 \\
\hline 121 & 124 & 124 & 123 & 123 & 123 & 121 & 121 & 121 \\
\hline 124 & 124 & 123 & 123 & 123 & 122 & 122 & 122 & 120 \\
\hline 127 & 124 & 124 & 124 & 122 & 122 & 122 & 121 & 121 \\
\hline 130 & 125 & 125 & 123 & 123 & 123 & 122 & 122 & 122 \\
\hline 133 & 125 & 125 & 125 & 123 & 123 & 123 & 122 & 122 \\
\hline 136 & 126 & 124 & 124 & 124 & 123 & 123 & 123 & 121 \\
\hline 139 & 125 & 125 & 124 & 124 & 124 & 122 & 122 & 122 \\
\hline 142 & 124 & 124 & 124 & 123 & 123 & 123 & 121 & 121 \\
\hline 145 & 125 & 123 & 123 & 123 & 122 & 122 & 122 & 120 \\
\hline 148 & 124 & 124 & 123 & 123 & 123 & 121 & 121 & 121 \\
\hline 151 & 123 & 123 & 123 & 122 & 122 & 122 & 121 & 121 \\
\hline 154 & 123 & 122 & 122 & 122 & 121 & 121 & 121 & 120 \\
\hline 157 & 120 & 120 & 120 & 120 & 120 & 120 & 120 & 120 \\
\hline 201 & 120 & 120 & 120 & 120 & 120 & 120 & 120 & 120 \\
\hline 203 & 120 & 120 & 120 & 120 & 120 & 120 & 120 & 120 \\
\hline 206 & 120 & 120 & 120 & 120 & 120 & 120 & 120 & 120 \\
\hline 209 & 120 & 120 & 120 & 120 & 120 & 120 & 120 & 120 \\
\hline 212 & 120 & 120 & 120 & 120 & 120 & 120 & 120 & 120 \\
\hline 215 & 120 & 120 & 120 & 120 & 120 & 120 & 120 & 120 \\
\hline 218 & 120 & 120 & 120 & 120 & 120 & 120 & 120 & 120 \\
\hline
\end{tabular}




\begin{tabular}{|c|c|c|c|c|c|c|c|c|}
\hline Column \# & Floor 92 & Floor 93 & Floor 94 & Floor 95 & Floor 96 & Floor 97 & Floor 98 & Floor 99 \\
\hline 221 & 120 & 120 & 120 & 120 & 120 & 120 & 120 & 120 \\
\hline 224 & 120 & 120 & 120 & 120 & 120 & 120 & 120 & 120 \\
\hline 227 & 120 & 120 & 120 & 120 & 120 & 120 & 120 & 120 \\
\hline 230 & 120 & 120 & 120 & 120 & 120 & 120 & 120 & 120 \\
\hline 233 & 120 & 120 & 120 & 120 & 120 & 120 & 120 & 120 \\
\hline 236 & 120 & 120 & 120 & 120 & 120 & 120 & 120 & 120 \\
\hline 239 & 120 & 120 & 120 & 120 & 120 & 120 & 120 & 120 \\
\hline 242 & 120 & 120 & 120 & 120 & 120 & 120 & 120 & 120 \\
\hline 245 & 120 & 120 & 120 & 120 & 120 & 120 & 120 & 120 \\
\hline 248 & 120 & 120 & 120 & 120 & 120 & 120 & 120 & 120 \\
\hline 251 & 120 & 120 & 120 & 120 & 120 & 120 & 120 & 120 \\
\hline 254 & 120 & 120 & 120 & 120 & 120 & 120 & 120 & 120 \\
\hline 257 & 120 & 120 & 120 & 120 & 120 & 120 & 120 & 120 \\
\hline 301 & 120 & 120 & 120 & 120 & 120 & 120 & 120 & 120 \\
\hline 303 & 120 & 120 & 120 & 120 & 120 & 120 & 120 & 120 \\
\hline 306 & 123 & 122 & 122 & 122 & 121 & 121 & 121 & 120 \\
\hline 309 & 123 & 123 & 123 & 122 & 122 & 122 & 121 & 121 \\
\hline 312 & 124 & 124 & 123 & 123 & 123 & 121 & 121 & 121 \\
\hline 315 & 125 & 123 & 123 & 123 & 122 & 122 & 122 & 120 \\
\hline 318 & 124 & 124 & 124 & 122 & 122 & 122 & 121 & 121 \\
\hline 321 & 124 & 124 & 123 & 123 & 123 & 121 & 121 & 121 \\
\hline 324 & 125 & 123 & 123 & 123 & 122 & 122 & 122 & 120 \\
\hline 327 & 124 & 124 & 124 & 122 & 122 & 122 & 121 & 121 \\
\hline 330 & 125 & 125 & 123 & 123 & 123 & 122 & 122 & 122 \\
\hline 333 & 125 & 125 & 125 & 123 & 123 & 123 & 122 & 122 \\
\hline 336 & 126 & 124 & 124 & 124 & 123 & 123 & 123 & 121 \\
\hline 339 & 125 & 125 & 124 & 124 & 124 & 122 & 122 & 122 \\
\hline 342 & 124 & 124 & 124 & 123 & 123 & 123 & 121 & 121 \\
\hline 345 & 125 & 123 & 123 & 123 & 122 & 122 & 122 & 120 \\
\hline 348 & 124 & 124 & 123 & 123 & 123 & 121 & 121 & 121 \\
\hline 351 & 123 & 123 & 123 & 122 & 122 & 122 & 121 & 121 \\
\hline 354 & 123 & 122 & 122 & 122 & 121 & 121 & 121 & 120 \\
\hline
\end{tabular}




\begin{tabular}{|c|c|c|c|c|c|c|c|c|}
\hline Column \# & Floor 92 & Floor 93 & Floor 94 & Floor 95 & Floor 96 & Floor 97 & Floor 98 & Floor 99 \\
\hline 357 & 120 & 120 & 120 & 120 & 120 & 120 & 120 & 120 \\
\hline 401 & 120 & 120 & 120 & 120 & 120 & 120 & 120 & 120 \\
\hline 403 & 120 & 120 & 120 & 120 & 120 & 120 & 120 & 120 \\
\hline 406 & 120 & 120 & 120 & 120 & 120 & 120 & 120 & 120 \\
\hline 409 & 120 & 120 & 120 & 120 & 120 & 120 & 120 & 120 \\
\hline 412 & 120 & 120 & 120 & 120 & 120 & 120 & 120 & 120 \\
\hline 415 & 120 & 120 & 120 & 120 & 120 & 120 & 120 & 120 \\
\hline 418 & 120 & 120 & 120 & 120 & 120 & 120 & 120 & 120 \\
\hline 421 & 120 & 120 & 120 & 120 & 120 & 120 & 120 & 120 \\
\hline 424 & 120 & 120 & 120 & 120 & 120 & 120 & 120 & 120 \\
\hline 427 & 120 & 120 & 120 & 120 & 120 & 120 & 120 & 120 \\
\hline 430 & 120 & 120 & 120 & 120 & 120 & 120 & 120 & 120 \\
\hline 433 & 120 & 120 & 120 & 120 & 120 & 120 & 120 & 120 \\
\hline 436 & 120 & 120 & 120 & 120 & 120 & 120 & 120 & 120 \\
\hline 439 & 120 & 120 & 120 & 120 & 120 & 120 & 120 & 120 \\
\hline 442 & 120 & 120 & 120 & 120 & 120 & 120 & 120 & 120 \\
\hline 445 & 120 & 120 & 120 & 120 & 120 & 120 & 120 & 120 \\
\hline 448 & 120 & 120 & 120 & 120 & 120 & 120 & 120 & 120 \\
\hline 451 & 120 & 120 & 120 & 120 & 120 & 120 & 120 & 120 \\
\hline 454 & 120 & 120 & 120 & 120 & 120 & 120 & 120 & 120 \\
\hline 457 & 120 & 120 & 120 & 120 & 120 & 120 & 120 & 120 \\
\hline
\end{tabular}

a. Column types and dimensions are described in detail in NIST NCSTAR 1-2A. 
Table B-2. Exterior column type schedule for WTC 2 Floor 78-83.

\begin{tabular}{|c|c|c|c|c|c|c|}
\hline & Floor 78 & Floor 79 & Floor 80 & Floor 81 & Floor 82 & Floor 83 \\
\hline 101 & 126 & 126 & 124 & 124 & 123 & 123 \\
\hline 103 & 126 & 124 & 124 & 124 & 123 & 123 \\
\hline 106 & 129 & 129 & 129 & 127 & 127 & 127 \\
\hline 109 & 131 & 131 & 129 & 129 & 129 & 128 \\
\hline 112 & 132 & 129 & 129 & 129 & 129 & 129 \\
\hline 115 & 132 & 132 & 132 & 129 & 129 & 129 \\
\hline 118 & 132 & 132 & 129 & 129 & 129 & 128 \\
\hline 121 & 132 & 129 & 129 & 129 & 129 & 129 \\
\hline 124 & 132 & 132 & 132 & 129 & 129 & 129 \\
\hline 127 & 132 & 132 & 129 & 129 & 129 & 128 \\
\hline 130 & 132 & 130 & 130 & 130 & 129 & 129 \\
\hline 133 & 132 & 132 & 129 & 129 & 129 & 129 \\
\hline 136 & 132 & 132 & 132 & 129 & 129 & 129 \\
\hline 139 & 132 & 130 & 130 & 130 & 129 & 129 \\
\hline 142 & 132 & 132 & 129 & 129 & 129 & 128 \\
\hline 145 & 132 & 132 & 132 & 129 & 129 & 129 \\
\hline 148 & 132 & 129 & 129 & 129 & 129 & 129 \\
\hline 151 & 131 & 131 & 129 & 129 & 129 & 128 \\
\hline 154 & 129 & 129 & 129 & 127 & 127 & 127 \\
\hline 157 & 126 & 124 & 124 & 124 & 123 & 123 \\
\hline 201 & 124 & 122 & 122 & 122 & 122 & 121 \\
\hline 203 & 121 & 120 & 120 & 120 & 120 & 120 \\
\hline 206 & 122 & 122 & 122 & 120 & 120 & 120 \\
\hline 209 & 122 & 122 & 120 & 120 & 120 & 120 \\
\hline 212 & 123 & 121 & 121 & 121 & 120 & 120 \\
\hline 215 & 125 & 125 & 125 & 123 & 123 & 123 \\
\hline 218 & 126 & 126 & 124 & 124 & 124 & 123 \\
\hline 221 & 126 & 124 & 124 & 124 & 123 & 123 \\
\hline 224 & 125 & 125 & 125 & 123 & 123 & 123 \\
\hline 227 & 125 & 125 & 123 & 123 & 123 & 122 \\
\hline 230 & 125 & 124 & 124 & 124 & 123 & 123 \\
\hline
\end{tabular}




\begin{tabular}{|c|c|c|c|c|c|c|}
\hline & Floor 78 & Floor 79 & Floor 80 & Floor 81 & Floor 82 & Floor 83 \\
\hline 233 & 125 & 125 & 123 & 123 & 123 & 122 \\
\hline 236 & 125 & 125 & 125 & 123 & 123 & 123 \\
\hline 239 & 126 & 124 & 124 & 124 & 123 & 123 \\
\hline 242 & 126 & 126 & 124 & 124 & 124 & 123 \\
\hline 245 & 125 & 125 & 125 & 123 & 123 & 123 \\
\hline 248 & 123 & 121 & 121 & 121 & 120 & 120 \\
\hline 251 & 122 & 122 & 120 & 120 & 120 & 120 \\
\hline 254 & 122 & 122 & 122 & 120 & 120 & 120 \\
\hline 257 & 121 & 120 & 120 & 120 & 120 & 120 \\
\hline 301 & 126 & 126 & 124 & 124 & 123 & 123 \\
\hline 303 & 126 & 124 & 124 & 124 & 123 & 123 \\
\hline 306 & 129 & 129 & 129 & 127 & 127 & 127 \\
\hline 309 & 131 & 131 & 129 & 129 & 129 & 128 \\
\hline 312 & 132 & 129 & 129 & 129 & 129 & 129 \\
\hline 315 & 132 & 132 & 132 & 129 & 129 & 129 \\
\hline 318 & 132 & 132 & 129 & 129 & 129 & 128 \\
\hline 321 & 132 & 129 & 129 & 129 & 129 & 129 \\
\hline 324 & 132 & 132 & 132 & 129 & 129 & 129 \\
\hline 327 & 132 & 132 & 129 & 129 & 129 & 128 \\
\hline 330 & 132 & 130 & 130 & 130 & 129 & 129 \\
\hline 333 & 132 & 132 & 129 & 129 & 129 & 129 \\
\hline 336 & 132 & 132 & 132 & 129 & 129 & 129 \\
\hline 339 & 132 & 130 & 130 & 130 & 129 & 129 \\
\hline 342 & 132 & 132 & 129 & 129 & 129 & 128 \\
\hline 345 & 132 & 132 & 132 & 129 & 129 & 129 \\
\hline 348 & 132 & 129 & 129 & 129 & 129 & 129 \\
\hline 351 & 131 & 131 & 129 & 129 & 129 & 128 \\
\hline 354 & 129 & 129 & 129 & 127 & 127 & 127 \\
\hline 357 & 126 & 124 & 124 & 124 & 123 & 123 \\
\hline 401 & 124 & 122 & 122 & 122 & 122 & 121 \\
\hline 403 & 121 & 120 & 120 & 120 & 120 & 120 \\
\hline
\end{tabular}




\begin{tabular}{|c|c|c|c|c|c|c|}
\hline & Floor 78 & Floor 79 & Floor 80 & Floor 81 & Floor 82 & Floor 83 \\
\hline 406 & 122 & 122 & 122 & 120 & 120 & 120 \\
\hline 409 & 122 & 122 & 120 & 120 & 120 & 120 \\
\hline 412 & 123 & 121 & 121 & 121 & 120 & 120 \\
\hline 415 & 125 & 125 & 125 & 123 & 123 & 123 \\
\hline 418 & 126 & 126 & 124 & 124 & 124 & 123 \\
\hline 421 & 126 & 124 & 124 & 124 & 123 & 123 \\
\hline 424 & 125 & 125 & 125 & 123 & 123 & 123 \\
\hline 427 & 125 & 125 & 123 & 123 & 123 & 122 \\
\hline 430 & 125 & 124 & 124 & 124 & 123 & 123 \\
\hline 433 & 125 & 125 & 123 & 123 & 123 & 122 \\
\hline 436 & 125 & 125 & 125 & 123 & 123 & 123 \\
\hline 439 & 126 & 124 & 124 & 124 & 123 & 123 \\
\hline 442 & 126 & 126 & 124 & 124 & 124 & 123 \\
\hline 445 & 125 & 125 & 125 & 123 & 123 & 123 \\
\hline 448 & 123 & 121 & 121 & 121 & 120 & 120 \\
\hline 451 & 122 & 122 & 120 & 120 & 120 & 120 \\
\hline 454 & 122 & 122 & 122 & 120 & 120 & 120 \\
\hline 457 & 121 & 120 & 120 & 120 & 120 & 120 \\
\hline
\end{tabular}


Table B-3. Plate dimensions $(m)$ for the various exterior column types.

\begin{tabular}{|c|c|c|c|}
\hline & ${\text { PLATE }{ }^{\mathrm{a}}}^{\mathrm{a}}$ & ${\text { PLATE } 2^{\mathrm{b}}}^{\mathrm{P}}$ & PLATE $^{\mathrm{c}}$ \\
\hline Column & $\mathrm{t} 1$-meters & t2-meters $^{\text {t3-meters }}$ \\
\hline 120 & 0.0064 & 0.0064 & 0.0064 \\
\hline 121 & 0.0079 & 0.0064 & 0.0064 \\
\hline 122 & 0.0095 & 0.0064 & 0.0064 \\
\hline 123 & 0.0111 & 0.0064 & 0.0064 \\
\hline 124 & 0.0127 & 0.0064 & 0.0064 \\
\hline 126 & 0.0143 & 0.0064 & 0.0064 \\
\hline 127 & 0.0159 & 0.0064 & 0.0064 \\
\hline 128 & 0.0175 & 0.0064 & 0.0064 \\
\hline 129 & 0.0191 & 0.0064 & 0.0064 \\
\hline 130 & 0.0206 & 0.0079 & 0.0079 \\
\hline 131 & 0.0238 & 0.0079 & 0.0079 \\
\hline 132 & 0.0254 & 0.0095 & 0.0095 \\
\hline
\end{tabular}

a. Plate $I$ is the flange component that are perpendicular to the building face.

b. Plate 2 is the outside web component parallel to the building face.

c. Plate 3 is the inside web component (adjacent to the spandrel) parallel to the building face. 
Table B-4. Core Column Schedule for WTC 1, Floor 92.

\begin{tabular}{|c|c|c|c|c|c|c|c|}
\hline Column no. & Shape & $\begin{array}{c}B \\
\text { (width in.) }\end{array}$ & $\begin{array}{c}D \\
\text { (Depth in.) }\end{array}$ & $\begin{array}{c}\mathrm{t1} \\
\text { (in.) }\end{array}$ & $\begin{array}{c}\text { t2 } \\
\text { (in.) }\end{array}$ & $\begin{array}{c}\mathrm{t} 3 \\
\text { (in.) }\end{array}$ & Rotation \\
\hline 501 & 14 WF550 & & & & & & 1 \\
\hline 502 & $14 W F 370$ & & & & & & 0 \\
\hline 503 & 14WF370 & & & & & & 0 \\
\hline 504 & 14WF342 & & & & & & 0 \\
\hline 505 & 14WF287 & & & & & & 0 \\
\hline 506 & 14WF398 & & & & & & 0 \\
\hline 507 & 14WF370 & & & & & & 0 \\
\hline 508 & 14WF605 & & & & & & 1 \\
\hline 601 & 12WF161 & & & & & & 0 \\
\hline 602 & 14WF193 & & & & & & 0 \\
\hline 603 & 14WF202 & & & & & & 0 \\
\hline 604 & 12WF161 & & & & & & 0 \\
\hline 605 & 12WF161 & & & & & & 0 \\
\hline 606 & 14WF202 & & & & & & 0 \\
\hline 607 & 14WF184 & & & & & & 0 \\
\hline 608 & 12WF161 & & & & & & 0 \\
\hline 701 & & 15 & 14 & 1.125 & 1.125 & 1 & 1 \\
\hline 702 & 14WF237 & & & & & & 0 \\
\hline 703 & $14 W F 142$ & & & & & & 0 \\
\hline 704 & 14WF68 & & & & & & 1 \\
\hline 705 & 14WF53 & & & & & & 0 \\
\hline 706 & $14 \mathrm{WF} 142$ & & & & & & 0 \\
\hline 707 & 14WF219 & & & & & & 0 \\
\hline 708 & & 15 & 14 & 1.250 & 1.188 & 1 & 1 \\
\hline 801 & & 15 & 16 & 1.188 & 1.188 & 1 & 1 \\
\hline 802 & $14 W F 264$ & & & & & & 0 \\
\hline 803 & & 15 & 17 & 0.813 & 0.813 & 1 & 1 \\
\hline 804 & 12 WF106 & & & & & & 0 \\
\hline
\end{tabular}




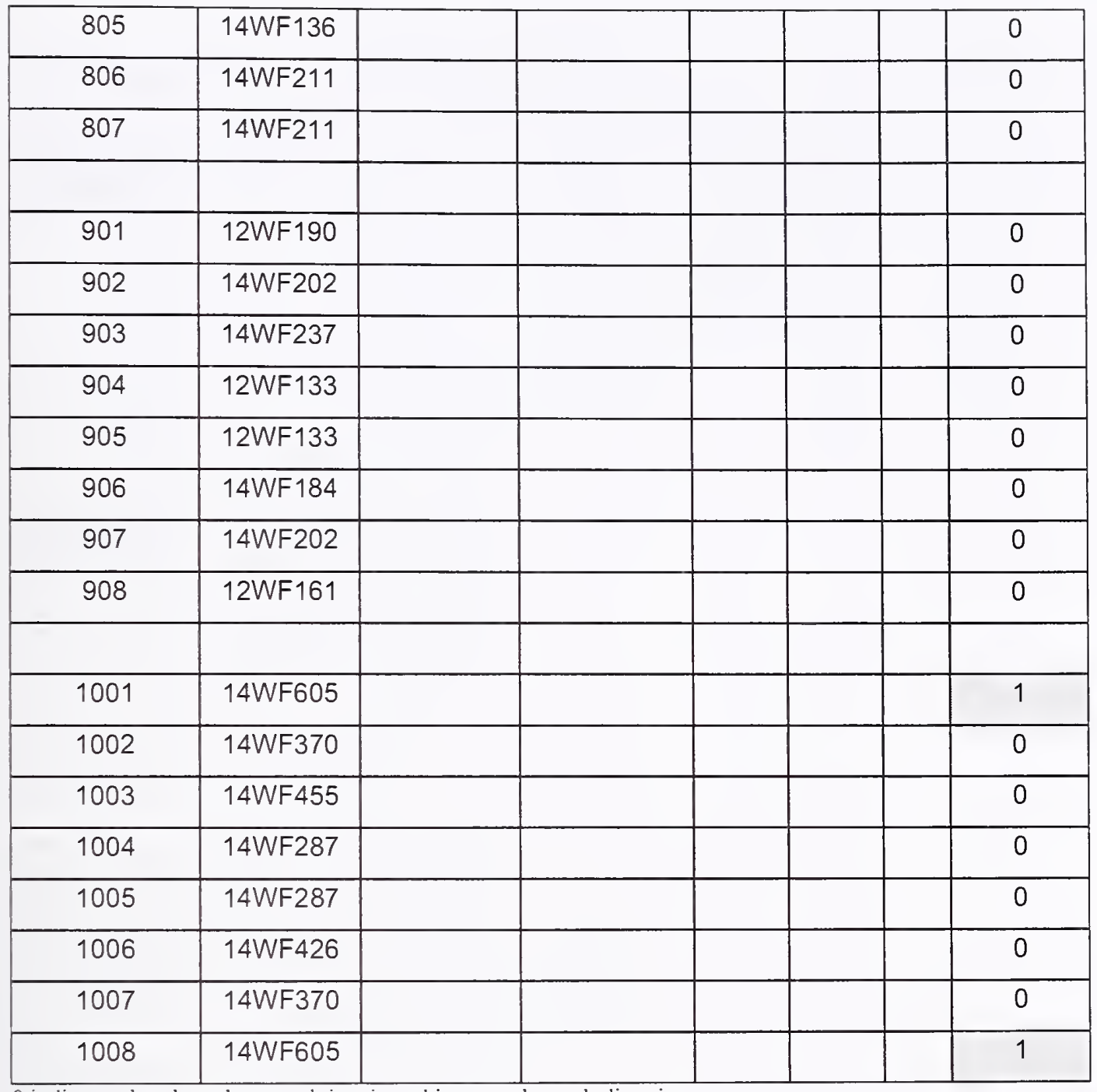

0 indicates that the column web is oriented in a north-south direction

1 indicated that the column web is oriented in an east-west direction 
Table B-5. Core Column Schedule for WTC 1, Floors 93, 94 and 95

\begin{tabular}{|c|c|c|c|c|c|c|c|}
\hline Column No. & Shape & $\begin{array}{c}\mathrm{B} \\
\text { (width in.) }\end{array}$ & \begin{tabular}{c|}
$\mathrm{D}$ \\
(Depth in.)
\end{tabular} & $\begin{array}{c}1 \\
\text { (in.) }\end{array}$ & $\begin{array}{c}\mathrm{t} 2 \\
\text { (in.) }\end{array}$ & $\begin{array}{c}\mathrm{t3} \\
\text { (in.) }\end{array}$ & Rotation \\
\hline 501 & 14WF500 & & & & & & 1 \\
\hline 502 & 14WF314 & & & & & & 0 \\
\hline 503 & $14 W F 314$ & & & & & & 0 \\
\hline 504 & 14WF287 & & & & & & 0 \\
\hline 505 & 14WF264 & & & & & & 0 \\
\hline 506 & $14 W F 342$ & & & & & & 0 \\
\hline 507 & 14WF314 & & & & & & 0 \\
\hline 508 & $14 W F 500$ & & & & & & 1 \\
\hline 601 & 12WF133 & & & & & & 0 \\
\hline 602 & 14WF176 & & & & & & 0 \\
\hline 603 & 14WF184 & & & & & & 0 \\
\hline 604 & 14WF120 & & & & & & 0 \\
\hline 605 & 14WF133 & & & & & & 0 \\
\hline 606 & 14 WF176 & & & & & & 0 \\
\hline 607 & 14WF167 & & & & & & 0 \\
\hline 608 & 12WF133 & & & & & & 0 \\
\hline 701 & & 15 & 14 & 0.938 & 0.875 & 1 & 1 \\
\hline 702 & 14WF211 & & & & & & 0 \\
\hline 703 & 14WF127 & & & & & & 0 \\
\hline 704 & 14WF61 & & & & & & 1 \\
\hline 705 & 14WF48 & & & & & & 0 \\
\hline 706 & 14WF142 & & & & & & 0 \\
\hline 707 & 14WF219 & & & & & & 0 \\
\hline 708 & 12WF190 & & & & & & 0 \\
\hline 801 & & 15 & 16 & 1.063 & 1.063 & 1 & 1 \\
\hline 802 & 14WF228 & & & & & & 0 \\
\hline 803 & & 15 & 17 & 0.750 & 0.688 & 1 & 1 \\
\hline 804 & 12WF92 & & & & & & 0 \\
\hline
\end{tabular}




\begin{tabular}{|c|c|c|c|c|c|c|c|}
\hline Column No. & Shape & $\begin{array}{c}\mathrm{B} \\
\text { (width in.) }\end{array}$ & $\begin{array}{c}\mathrm{D} \\
\text { (Depth in.) }\end{array}$ & $\begin{array}{c}\mathrm{t} 1 \\
\text { (in.) }\end{array}$ & $\begin{array}{c}\text { t2 } \\
\text { (in.) }\end{array}$ & $\begin{array}{c}\text { t3 } \\
\text { (in.) }\end{array}$ & Rotation \\
\hline 805 & $14 W F 119$ & & & & & & 0 \\
\hline 806 & 14WF184 & & & & & & 0 \\
\hline 807 & 14 WF 193 & & & & & & 0 \\
\hline 901 & 12 WF 161 & & & & & & 0 \\
\hline 902 & 14 WF184 & & & & & & 0 \\
\hline 903 & 14WF211 & & & & & & 0 \\
\hline 904 & $12 \mathrm{WF} 120$ & & & & & & 0 \\
\hline 905 & $12 W F 120$ & & & & & & 0 \\
\hline 906 & 14 WF 167 & & & & & & 0 \\
\hline 907 & $14 W F 176$ & & & & & & 0 \\
\hline 908 & 12WF133 & & & & & & 0 \\
\hline 1001 & 14 WF550 & & & & & & 1 \\
\hline 1002 & 14WF314 & & & & & & 0 \\
\hline 1003 & 14WF398 & & & & & & 0 \\
\hline 1004 & 14WF264 & & & & & & 0 \\
\hline 1005 & 14WF237 & & & & & & 0 \\
\hline 1006 & 14 WF370 & & & & & & 0 \\
\hline 1007 & 14WF314 & & & & & & 0 \\
\hline 1008 & 14WF550 & & & & & & 1 \\
\hline
\end{tabular}

0 indicates that the column web is oriented in a north-south direction

1 indicated that the column web is oriented in an east-west direction 
Table B-6. Core Column Schedule for Floors 96 - 99.

\begin{tabular}{|c|c|c|c|c|c|c|c|c|}
\hline Column no. & Floor 96 & Floor 96 & Floor 97 & Floor 97 & Floor 98 & Floor 98 & Floor 99 & Floor 99 \\
\hline & Shape & Rotation & Shape & Rotation & Shape & Rotation & Shape & Rotation \\
\hline 501 & 14WF426 & 1 & 14WF426 & 1 & 14WF426 & 1 & 14WF342 & 1 \\
\hline 502 & 14WF264 & 0 & 14WF264 & 0 & 14WF264 & 0 & $14 W F 211$ & 0 \\
\hline 503 & 14WF264 & 0 & 14WF264 & 0 & 14WF264 & 0 & 14WF228 & 0 \\
\hline 504 & 14WF246 & 0 & 14 WF246 & 0 & 14WF246 & 0 & 14WF193 & 0 \\
\hline 505 & 14WF219 & 0 & 14WF219 & 0 & $14 W F 219$ & 0 & 14WF184 & 0 \\
\hline 506 & 14WF287 & 0 & 14WF287 & 0 & 14WF287 & 0 & 14WF237 & 0 \\
\hline 507 & 14WF264 & 0 & 14WF264 & 0 & 14WF264 & 0 & $14 W F 211$ & 0 \\
\hline 508 & 14WF426 & 1 & 14WF426 & 1 & 14WF426 & 1 & 14WF342 & 1 \\
\hline 601 & $12 W F 106$ & 0 & 12WF106 & 0 & 12WF106 & 0 & 12WF92 & 0 \\
\hline 602 & $14 W F 150$ & 0 & 14WF150 & 0 & 14WF150 & 0 & 14WF127 & 0 \\
\hline 603 & 14WF158 & 0 & 14WF158 & 0 & 14WF158 & 0 & $14 W F 127$ & 0 \\
\hline 604 & 12WF106 & 0 & 12WF106 & 0 & 12WF106 & 0 & 12 WF85 & 0 \\
\hline 605 & $12 W F 120$ & 0 & 12WF120 & 0 & $12 \mathrm{WF} 120$ & 0 & 12WF92 & 0 \\
\hline 606 & 14WF150 & 0 & 14WF150 & 0 & 14WF150 & 0 & 14WF 127 & 0 \\
\hline 607 & 14WF142 & 0 & 14WF142 & 0 & 14WF142 & 0 & 14WF119 & 0 \\
\hline 608 & 12WF106 & 0 & 12WF106 & 0 & 12WF106 & 0 & 12WF92 & 0 \\
\hline 701 & 12WF161 & 0 & 12WF161 & 0 & 12WF161 & 0 & 12WF120 & 0 \\
\hline 702 & $14 \mathrm{WF} 176$ & 0 & 14WF176 & 0 & 14WF176 & 0 & 14WF150 & 0 \\
\hline 703 & 14WF103 & 0 & 14WF103 & 0 & 14WF103 & 0 & 14WF84 & 0 \\
\hline 704 & 14WF53 & 1 & 14WF53 & 1 & 14WF53 & 1 & 14WF43 & 1 \\
\hline 705 & 14WF43 & 0 & 14WF43 & 0 & 14WF43 & 0 & 14WF43 & 0 \\
\hline 706 & 14WF111 & 0 & 14WF111 & 0 & 14WF111 & 0 & 14WF95 & 0 \\
\hline 707 & 14WF167 & 0 & 14WF167 & 0 & 14WF167 & 0 & 14WF150 & 0 \\
\hline 708 & 12WF190 & 0 & 12WF190 & 0 & 12WF190 & 0 & 12WF161 & 0 \\
\hline 801 & 12WF 161 & 0 & 12WF161 & 0 & 12WF161 & 0 & $12 W F 161$ & 0 \\
\hline 802 & 14WF176 & 0 & 14WF176 & 0 & $14 \mathrm{WF} 176$ & 0 & 14WF158 & 0 \\
\hline 803 & 12WF133 & 0 & 12WF133 & 0 & $12 \mathrm{WF} 133$ & 0 & $12 W F 120$ & 0 \\
\hline 804 & 12 WF79 & 0 & 12WF79 & 0 & 12WF79 & 0 & 12WF65 & 0 \\
\hline
\end{tabular}




\begin{tabular}{|c|c|c|c|c|c|c|c|c|}
\hline Column no. & Floor 96 & Floor 96 & Floor 97 & Floor 97 & Floor 98 & Floor 98 & Floor 99 & Floor 99 \\
\hline 805 & 14WF111 & 0 & 14WF111 & 0 & 14WF111 & 0 & 14WF95 & 0 \\
\hline 806 & 14WF167 & 0 & 14WF167 & 0 & 14WF167 & 0 & 14WF142 & 0 \\
\hline 807 & 14WF167 & 0 & 14WF167 & 0 & 14WF167 & 0 & 14WF136 & 0 \\
\hline 901 & $12 \mathrm{WF} 120$ & 0 & 12WF120 & 0 & $12 \mathrm{WF} 120$ & 0 & 12 WF99 & 0 \\
\hline 902 & 14WF150 & 0 & 14WF150 & 0 & 14WF150 & 0 & 14WF127 & 0 \\
\hline 903 & 14WF193 & 0 & 14WF193 & 0 & 14WF193 & 0 & 14WF167 & 0 \\
\hline 904 & 12WF92 & 0 & 12WF92 & 0 & 12WF92 & 0 & 12 WF79 & 0 \\
\hline 905 & 12WF99 & 0 & 12WF99 & 0 & 12 WF99 & 0 & 12 WF79 & 0 \\
\hline 906 & $14 W F 142$ & 0 & 14WF142 & 0 & 14WF142 & 0 & 14WF127 & 0 \\
\hline 907 & 14WF150 & 0 & 14WF150 & 0 & 14WF150 & 0 & 14WF127 & 0 \\
\hline 908 & 12WF120 & 0 & 12WF120 & 0 & 12WF120 & 0 & 12 WF99 & 0 \\
\hline 1001 & $14 W F 426$ & 1 & 14WF426 & 1 & 14WF426 & 1 & 14WF370 & 1 \\
\hline 1002 & 14WF264 & 0 & 14WF264 & 0 & 14WF264 & 0 & 14WF219 & 0 \\
\hline 1003 & $14 W F 342$ & 0 & 14WF342 & 0 & 14WF342 & 0 & 14WF287 & 0 \\
\hline 1004 & 14WF219 & 0 & 14WF219 & 0 & 14WF219 & 0 & 14WF193 & 0 \\
\hline 1005 & 14WF202 & 0 & 14WF202 & 0 & 14WF202 & 0 & 14WF176 & 0 \\
\hline 1006 & 14WF314 & 0 & 14WF314 & 0 & 14WF314 & 0 & 14WF237 & 0 \\
\hline 1007 & 14WF287 & 0 & 14WF287 & 0 & 14WF287 & 0 & 14WF228 & 0 \\
\hline 1008 & 14 WF 426 & 1 & 14WF426 & 1 & 14WF426 & 1 & 14WF370 & 1 \\
\hline
\end{tabular}

0 . Indicates that the column web is oriented in a north-south direction.

1. Indicated that the column web is oriented in an east-west direction. 
Table B-7. WTC 2 Core Column Schedule for floor 78-80.

\begin{tabular}{|c|c|c|c|c|c|c|c|c|}
\hline Column no. & Shape & $\begin{array}{c}\mathrm{B} \\
\text { (width in.) }\end{array}$ & $\begin{array}{c}\mathrm{D} \\
\text { (Depth in.) }\end{array}$ & $\begin{array}{l}\mathrm{t} 1 \\
\text { (in.) }\end{array}$ & $\begin{array}{c}\mathrm{t} 2 \\
\text { (in.) }\end{array}$ & $\begin{array}{l}\text { t3 } \\
\text { (in.) }\end{array}$ & $\begin{array}{l}\text { w1 } \\
\text { (in.) }\end{array}$ & Rotation \\
\hline 501 & & 22 & 34 & 2.25 & 2.25 & 1.5 & & 1 \\
\hline 502 & & 22 & 28 & 1.69 & 1.69 & 1.5 & & 0 \\
\hline 503 & & 22 & 28 & 1.63 & 1.63 & 1.5 & & 0 \\
\hline 504 & & 22 & 28 & 1.31 & 1.31 & 1.5 & & 0 \\
\hline 505 & & 18 & 28 & 1.38 & 1.38 & 1.5 & & 0 \\
\hline 506 & & 22 & 28 & 1.81 & 1.81 & 1.5 & & 0 \\
\hline 507 & & 22 & 28 & 1.63 & 1.63 & 1.5 & & 0 \\
\hline 508 & & 22 & 34 & 2.25 & 2.25 & 1.5 & & 1 \\
\hline 601 & & 14 & 36 & 0.81 & 0.81 & 1.5 & & 0 \\
\hline 602 & & 16 & 36 & 0.94 & 0.88 & 1.5 & & 0 \\
\hline 603 & & 16 & 36 & 0.81 & 0.81 & 1.5 & & 0 \\
\hline 604 & & 14 & 36 & 0.81 & 0.81 & 1.5 & & 0 \\
\hline 605 & & 14 & 36 & 0.81 & 0.81 & 1.5 & & 0 \\
\hline 606 & & 16 & 36 & 0.88 & 0.81 & 1.5 & & 0 \\
\hline 607 & & 16 & 36 & 0.88 & 0.88 & 1.5 & & 0 \\
\hline 608 & & 14 & 36 & 0.81 & 0.81 & 1.5 & & 0 \\
\hline 701 & & 15 & 14 & 1.88 & 1.81 & 1 & & 0 \\
\hline 702 & 14WF314 & & & & & & & 1 \\
\hline 703 & 14WF193 & & & & & & & 1 \\
\hline 704 & 14WF84 & & & & & & & 0 \\
\hline 705 & 14WF68 & & & & & & & 1 \\
\hline 706 & 14WF184 & & & & & & & 1 \\
\hline 707 & 14WF287 & & & & & & & 1 \\
\hline 708 & & 15 & 14 & 1.75 & 1.69 & 1 & & 0 \\
\hline 801 & & 15 & 16 & 1.44 & 1.44 & 1 & & 0 \\
\hline 802 & 14WF370 & & & & & & & 1 \\
\hline 803 & & 15 & 17 & 1 & 1 & 1 & & 0 \\
\hline 804 & 12WF161 & & & & & & & 1 \\
\hline 805 & 14WF158 & & & & & & & 1 \\
\hline
\end{tabular}




\begin{tabular}{|c|c|c|c|c|c|c|c|c|}
\hline Column no. & Shape & $\begin{array}{c}\mathrm{B} \\
\text { (width in.) }\end{array}$ & $\begin{array}{c}D \\
\text { (Depth in.) } \\
\end{array}$ & $\begin{array}{c}\mathrm{t} 1 \\
\text { (in.) } \\
\end{array}$ & $\begin{array}{c}12 \\
\text { (in.) } \\
\end{array}$ & $\begin{array}{c}\text { t3 } \\
\text { (in.) } \\
\end{array}$ & $\begin{array}{l}1 \\
\text { (in.) }\end{array}$ & Rotation \\
\hline 806 & 14WF287 & & & & & & & 1 \\
\hline 807 & & 15 & 16 & 1.50 & 1.50 & 1 & & 0 \\
\hline 901 & 12 WF190 & & & 0.31 & & & 14 & 1 \\
\hline 902 & 14WF287 & & & & & & & 1 \\
\hline 903 & & 16 & 21 & 1.19 & 1.19 & 1.5 & & 0 \\
\hline 904 & 12 WF190 & & & & & & & 1 \\
\hline 905 & & 14 & 14 & 1 & 1 & 1 & & 0 \\
\hline 906 & 14WF237 & & & & & & & 1 \\
\hline 907 & 14WF287 & & & & & & & 1 \\
\hline 908 & 12WF190 & & & 0.31 & & & 14 & 1 \\
\hline 1001 & & 22 & 22 & 3 & 2.94 & 1.5 & & 1 \\
\hline 1002 & 14WF500 & & & & & & & 1 \\
\hline 1003 & 14WF665 & & & & & & & 1 \\
\hline 1004 & & 18 & 31 & 1.19 & 1.19 & 1.5 & & 0 \\
\hline 1005 & & 22 & 28 & 1.06 & 1.06 & 1.5 & & 0 \\
\hline 1006 & 14WF605 & & & & & & & 1 \\
\hline 1007 & 14WF500 & & & & & & & 1 \\
\hline 1008 & & 22 & 22 & 3 & 2.94 & 1.5 & & 1 \\
\hline
\end{tabular}

0 . Indicates that the column web is oriented in an east-west direction.

1. Indicates that the column is oriented in a north-south direction. 
Table B-8. WTC 2 Core Column Schedule for floor 81-83.

\begin{tabular}{|c|c|c|c|c|c|c|c|c|}
\hline Column no. & Shape & $\begin{array}{c}\mathrm{B} \\
\text { (width in.) }\end{array}$ & $\begin{array}{c}D \\
\text { (Depth in.) }\end{array}$ & $\begin{array}{c}\mathrm{t} 1 \\
\text { (in.) }\end{array}$ & $\begin{array}{c}\mathrm{t} 2 \\
\text { (in.) }\end{array}$ & $\begin{array}{c}3 \\
\text { (in.) }\end{array}$ & $\begin{array}{l}\text { w1 } \\
\text { (in.) }\end{array}$ & Rotation \\
\hline 501 & & 22 & 28 & 2.50 & 2.50 & 1.5 & & 1 \\
\hline 502 & & 22 & 25 & 1.69 & 1.63 & 1.5 & & 0 \\
\hline 503 & & 22 & 25 & 1.69 & 1.63 & 1.5 & & 0 \\
\hline 504 & & 22 & 25 & 1.38 & 1.31 & 1.5 & & 0 \\
\hline 505 & & 18 & 25 & 1.44 & 1.38 & 1.5 & & 0 \\
\hline 506 & & 22 & 25 & 1.81 & 1.75 & 1.5 & & 0 \\
\hline 507 & & 22 & 25 & 1.63 & 1.56 & 1.5 & & 0 \\
\hline 508 & & 22 & 28 & 2.50 & 2.50 & 1.5 & & 1 \\
\hline 601 & 12WF190 & & & 0.31 & & & 14 & 1 \\
\hline 602 & 14WF264 & & & & & & & 1 \\
\hline 603 & 14WF264 & & & & & & & 1 \\
\hline 604 & 12WF190 & & & & & & & 1 \\
\hline 605 & 12WF190 & & & 0.31 & & & 14 & 1 \\
\hline 606 & $14 W F 287$ & & & & & & & 1 \\
\hline 607 & 14WF246 & & & & & & & 1 \\
\hline 608 & 12WF190 & & & 0.31 & & & 14 & 1 \\
\hline 701 & & 15 & 14 & 1.63 & 1.63 & 1 & & 0 \\
\hline 702 & 14 WF314 & & & & & & & 1 \\
\hline 703 & 14WF193 & & & & & & & 1 \\
\hline 704 & 14WF84 & & & & & & & 0 \\
\hline 705 & 14WF68 & & & & & & & 1 \\
\hline 706 & 14WF184 & & & & & & & 1 \\
\hline 707 & 14 WF314 & & & & & & & 1 \\
\hline 708 & & 15 & 14 & 1.75 & 1.75 & 1 & & 0 \\
\hline 801 & & 15 & 16 & 1.50 & 1.50 & 1 & & 0 \\
\hline 802 & 14WF314 & & & & & & & 1 \\
\hline 803 & & 15 & 17 & 1.06 & 1.00 & 1 & & 0 \\
\hline 804 & 12WF161 & & & & & & & 1 \\
\hline 805 & 14WF158 & & & & & & & 1 \\
\hline 806 & 14WF287 & & & & & & & 1 \\
\hline
\end{tabular}




\begin{tabular}{|c|c|c|c|c|c|c|c|c|}
\hline Column no. & Shape & $\begin{array}{c}B \\
\text { (width in.) }\end{array}$ & $\begin{array}{c}D \\
\text { (Depth in.) }\end{array}$ & $\begin{array}{c}\mathrm{t1} \\
\text { (in.) }\end{array}$ & $\begin{array}{c}\mathrm{t} 2 \\
\text { (in.) }\end{array}$ & $\begin{array}{c}\mathrm{t} 3 \\
\text { (in.) }\end{array}$ & $\begin{array}{l}w 1 \\
\text { (in.) }\end{array}$ & Rotation \\
\hline 807 & & 15 & 16 & 1.50 & 1.50 & 1 & & 0 \\
\hline 901 & $12 \mathrm{WF} 190$ & & & 0.31 & & & 14 & 1 \\
\hline 902 & 14WF287 & & & & & & & 1 \\
\hline 903 & 14 WF314 & & & & & & & 1 \\
\hline 904 & 12WF190 & & & & & & & 1 \\
\hline 905 & & 14 & 14 & 1 & 1 & 1 & & 0 \\
\hline 906 & 14WF237 & & & & & & & 1 \\
\hline 907 & 14WF287 & & & & & & & 1 \\
\hline 908 & 12WF190 & & & 0.31 & & & 14 & 1 \\
\hline 1001 & 14WF730 & & & & & & & 0 \\
\hline 1002 & $14 \mathrm{WF} 500$ & & & & & & & 1 \\
\hline 1003 & 14WF665 & & & & & & & 1 \\
\hline 1004 & & 18 & 28 & 1.31 & 1.25 & 1.5 & & 0 \\
\hline 1005 & & 22 & 25 & 1.19 & 1.19 & 1.5 & & 0 \\
\hline 1006 & 14WF605 & & & & & & & 1 \\
\hline 1007 & $14 \mathrm{WF} 500$ & & & & & & & 1 \\
\hline 1008 & 14WF730 & & & & & & & 0 \\
\hline
\end{tabular}

0 . Indicates that the column web is oriented in an east-west direction.

1. Indicates that the column is oriented in a north-south direction. 
Table B-9. Types and locations of sprayed fire-resistive material on focus floors.

\begin{tabular}{|c|c|c|c|c|}
\hline \multirow[b]{2}{*}{ Building Component } & \multirow[b]{2}{*}{ Material } & \multicolumn{3}{|c|}{ Thickness (in.) } \\
\hline & & Specified $^{\mathrm{a}}$ & Installed & $\begin{array}{c}\text { Used in } \\
\text { Analysis }^{\mathrm{b}}\end{array}$ \\
\hline \multicolumn{5}{|l|}{ FLOOR SYSTEM } \\
\hline \multicolumn{5}{|l|}{ Original } \\
\hline Main trusses and diagonal struts & BLAZE-SHIELD DC/F & 0.5 & 0.75 & 0.6 \\
\hline Bridging trusses (one-way zone) ${ }^{c}$ & BLAZE-SHIELD DC/F & 0.5 & $0.38^{\mathrm{d}}$ & 0.3 \\
\hline 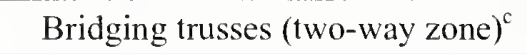 & BLAZE-SHIELD DC/F & 0.5 & $0.38^{\mathrm{d}}$ & 0.6 \\
\hline \multicolumn{5}{|l|}{ Upgraded } \\
\hline Main trusses & BLAZE-SHIELD II & 1.5 & 2.5 & 2.2 \\
\hline Main truss diagonal struts & BLAZE-SHIELD II & 1.5 & 2.5 & 2.2 \\
\hline Bridging trusses & BLAZE-SHIELD II & 1.5 & 2.5 & 2.2 \\
\hline \multicolumn{5}{|l|}{ EXTERIOR WALL PANEL } \\
\hline \multicolumn{5}{|l|}{ Box columns } \\
\hline Exterior face & BLAZE-SHIELD DC/F & $13 / 16$ & (e) & 1.2 \\
\hline Interior face & Vermiculite plaster & $7 / 8$ & (e) & 0.8 \\
\hline \multicolumn{5}{|l|}{ Spandrels } \\
\hline Exterior face & BLAZE-SHIELD DC/F & 0.5 & (e) & 0.5 \\
\hline Interior face & Vermiculite plaster & 0.5 & (e) & 0.5 \\
\hline \multicolumn{5}{|l|}{ CORE COLUMNS } \\
\hline \multicolumn{5}{|l|}{ Wide flange columns } \\
\hline Light & BLAZE-SHIELD DC/F & $23 / 16$ & (e) & 2.2 \\
\hline Heavy & BLAZE-SHIELD DC/F & $13 / 16$ & (e) & 1.2 \\
\hline \multicolumn{5}{|l|}{ Box columns } \\
\hline Light & BLAZE-SHIELD DC/F & $(\mathrm{f})$ & (e) & $2.2^{(\mathrm{g})}$ \\
\hline Heavy & BLAZE-SHIELD DC/F & (f) & (e) & $1.2^{(\mathrm{g})}$ \\
\hline CORE BEAMS & BLAZE-SHIELD DC/F & 0.5 & (e) & 0.5 \\
\hline
\end{tabular}

a. "Specified" means material and thicknesses determined from correspondence among various parties.

b. The analysis is described in NIST NCSTAR 1-6A.

c. Not expressly specified. SFRM was required for the areas where the main trusses ran in both directions and, while not required, was also applied in the areas where they ran in one direction only.

d. Analysis of photographs indicated that the thickness was approximately one half that on the main trusses.

e. Not able to determine.

f. Not specified.

g. Thickness assumed equal to wide flange columns of comparable weight per foot. 
